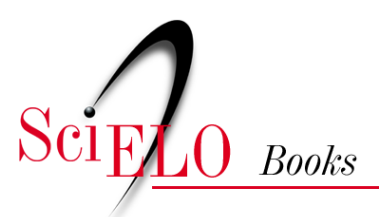

\title{
Política de saúde bucal no Brasil teoria e prática
}

\author{
Sônia Cristina Lima Chaves (org.)
}

CHAVES, S.C.L. Política de saúde bucal no Brasil: teoria e prática [online]. Salvador: EDUFBA, 2016, 376 p. ISBN 978-85-232-2029-7. https://doi.org/10.7476/9788523220297.

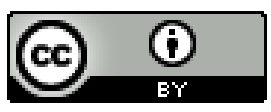

All the contents of this work, except where otherwise noted, is licensed under a Creative Commons Attribution 4.0 International license.

Todo o conteúdo deste trabalho, exceto quando houver ressalva, é publicado sob a licença Creative Commons Atribição 4.0. 
Política de saúde bucal no Brasil teoria e prática 


\section{UNIVERSIDADE FEDERAL DA BAHIA}

\section{REITOR}

João Carlos Salles Pires da Silva

VICE-REITOR

Paulo César Miguez de Oliveira

ASSESSOR DO REITOR

Paulo Costa Lima

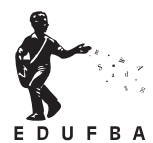

EDITORA DA UNIVERSIDADE FEDERAL DA BAHIA

DIRETORA

Flávia Goulart Mota Garcia Rosa

CONSELHO EDITORIAL

Alberto Brum Novaes

Angelo Szaniecki Perret Serpa

Caiuby Alves da Costa

Charbel Niño El Hani

Cleise Furtado Mendes

Dante Eustachio Lucchesi Ramacciotti

Evelina de Carvalho Sá Hoisel

José Teixeira Cavalcante Filho

Maria Vidal de Negreiros Camargo

Esta publicação contou com o apoio do CNPQ, Edital CNPq 41/2013, Processo n $405071 / 2013-2$.

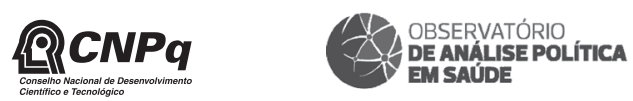


SÔNIA CRISTINA LIMA CHAVES

ORGANIZADORA

\section{Política de saúde bucal no Brasil teoria e prática}


2016, autores.

Direitos dessa edição cedidos à Edufba.

Feito o Depósito Legal.

Grafia atualizada conforme o Acordo Ortográfico da Língua Portuguesa de 1990, em vigor no Brasil desde 2009.

CAPA E PROJETO GRÁFICO

Leonardo Mota Lorenzo

REVISÃO E NORMALIZAÇÃO

Paulo Bruno Ferreira da Silva

Suzane Barros

SISTEMA DE BIBLIOTECAS - UFBA

Política de saúde bucal no Brasil: teoria e prática/Sônia Cristina Lima Chaves, organizadora. - Salvador : EDUFBA, 2016.

$377 \mathrm{p}$.

ISBN 978-85-232-1500-2

1. Saúde bucal - Brasil - Política governamental. 2. Saúde bucal - Estudo e ensino.

3. Odontologia - Bahia - Aspectos sociais. 4. Política pública. I. Chaves, Sônia Cristina Lima.

$C D D-362.19760981$

EDITORA AFILIADA À
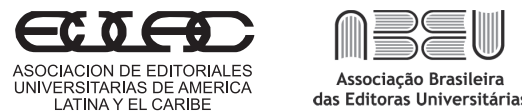

$\mathrm{CBaL}$

Associação Brasileira
das Editoras Universitárias

Editora da UFBA

Rua Barão de Jeremoabo

s/n - Campus de Ondina

40170-115 - Salvador - Bahia

Tel.: $+55713283-6164$

Fax: $+55713283-6160$

www.edufba.ufba.br

edufba@ufba.br 


\section{Agradecimentos}

Este livro reflete o encontro de muitas pessoas e suas trajetórias em torno da luta pelo direito à saúde bucal do povo brasileiro. A cada uma delas, meu agradecimento. Este livro também é uma afirmação da importância do lugar da saúde bucal no Sistema Único de Saúde (SUS), mas também é lugar de reafirmar o próprio SUS como parte de um projeto democrático do país, ainda que haja projetos conservadores em curso.

É necessário ressaltar também a excelência da produção científica e compromisso social do Instituto de Saúde Coletiva, lugar da crítica saudável, da busca incessante por reflexividade que mesmo nos seus antecedentes, já incluía a preocupação em torno da saúde bucal como tema de prática e pesquisa.

Este livro também resgata alguns antecedentes como dos professores Jairo Diniz e Aloysio Lopes Pontes, cujo pensamento em torno da construção social dos problemas bucais também colaborou para a reafirmação desse direito, somente posteriormente consolidado. Agradecimento essencial ao pensamento de Ligia Maria Vieira da Silva e Patrice Pinell, pelas contribuições na construção do pensamento sociológico na odontologia e na saúde bucal coletiva brasileira

Por fim, agradeço à Universidade Federal da Bahia, pública e de múltiplos saberes, e também à Faculdade de Odontologia, espaço de onde venho e onde sempre vou estar, porque a illusio que me alimenta é aquela que espera encontrar na expressão de cada um dos brasileiros a igualdade na sua forma de falar com bocas, dentes e saúde.

Por fim, a Carolina, Camila e Pedro Miguel, esses seres fantásticos que habitam em mim e são proprietários do meu amor incondicional.

\section{Sônia Chaves}




\section{Sumário}

9 Prefácio

JAIRNILSON SILVA PAIM

\section{Situando o debate}

13 Política e saúde: conceitos básicos e abordagens teórico-metodológicas para análise política em saúde bucal

SÔNIA CHAVES E SAMUEL MOYSÉS

47 Necessidades e problemas de saúde bucal no Brasil e tendências para as políticas de saúde

MARIA CRISTINA CANGUSSU, JOHELLE PASSOS-SOARES E MARIA BEATRIZ CABRAL

\section{Politics}

79 Estado e atenção à saúde bucal no Brasil no período pré-constituinte MARIA ISABEL VIANNA E JAIRNILSON PAIM

117 Políticas de saúde bucal no período pós-constituinte: governos FHC e Lula LUCÍLIA NUNES ASSIS, JAIRNILSON PAIM E CATHARINA LEITE MATOS SOARES

137 espaço da saúde bucal coletiva: contribuições para compreensão da formulação e implementação das políticas de saúde bucal no Brasil CATHARINA LEITE MATOS SOARES, JAIRNILSON PAIM, THAIS ARANHA ROSSI E SÔNIA CHAVES

\section{Policy}

173 Atenção primária e saúde bucal: as evidências de sua implementação no Brasil

SANDRA GARRIDO DE BARROS, MARIA GUADALUPE MEDINA, DANIELA LEMOS CARCERERI, DIANA CAROLINA RUIZ E ANA CAROLINA OLIVEIRA PERES 
203 A utilização dos serviços odontológicos: elementos teóricos e conceituais

DENISE NOGUEIRA, SÔNIA CHAVES E MARIA CRISTINA CANGUSSU

227 Implementação de serviços públicos odontológicos especializados no Brasil SÔNIA CHAVES, THAIS ARANHA ROSSI E ANA MARIA FREIRE

255 O dentista e o mercado de trabalho LANA BLEICHER

273 Educação em saúde bucal do trabalhador MARIÂNGELA SILVA DE MATOS, PATRÍCIA SUGURI CRISTINO E TATIANA FREDERICO DE ALMEIDA

297 A insuficiência da política pública para inclusão do técnico em saúde bucal na atenção primária à saúde no Brasil

DULCE MARIA DE LUCENA AGUIAR E PAULO FRAZÃO

319 Emergência da odontologia social na Bahia SÔNIA CHAVES, MONA LISA SOUZA

337 Avaliação da atenção à saúde bucal no Brasil: conceitos e abordagens SÔNIA CHAVES, ANA CARLA FREITAS FONSECA, STELLA MARIS MALPICI LUNA, ANA MARIA FREIRE

369 Posfácio

PAULO FRAZÃO

373 Sobre os autores 


\section{Prefácio}

Este livro é um convite ao olhar da odontologia para além da técnica. Ao considerar a sociedade e a ação sobre problemas de saúde bucal, os capítulos enfrentam-se, inevitavelmente, com as diversas leituras do social e com as disputas entre distintos projetos políticos de intervenção. Assim, aparecem a necessidade de investigar as políticas de saúde bucal e a possibilidade de analisar as respostas sociais, por ação ou omissão, via Estado, sobre problemas de saúde e seus determinantes, bem como sobre a organização, produção, distribuição e regulação de bens e serviços na área de odontologia.

Nesse sentido, a coletânea contempla um conjunto de textos diversificados cujo eixo central diz respeito às políticas de saúde bucal estabelecidas no Brasil, a partir do século XX. Ela inicia com uma sistematização de conceitos e abordagens acionados para a investigação das políticas de saúde, com indicações de estudos sobre políticas de saúde bucal no âmbito nacional. São examinados importantes problemas de saúde bucal nos últimos anos, assim como os resultados positivos obtidos mediante ações coletivas. É revisitada a intervenção do Estado brasileiro na atenção odontológica durante as décadas de 1970 e 1980, bem como seus antecedentes, com ênfase na transição democrática que permitiu o aparecimento de políticas racionalizadoras, a realização da $1^{\text {a }}$ Conferência Nacional de Saúde Bucal, em 1986, e a emergência de políticas democráticas inspiradas no projeto da Reforma Sanitária Brasileira.

Os capítulos seguintes analisam as políticas de saúde bucal no período pós-Constituinte, com ênfase nos governos FHC e Lula, e a constituição da saúde bucal coletiva no Brasil. Essa área de conhecimento, por sua vez, tem possibilitado um conjunto de pesquisas ligadas à atenção básica e especializada e à educação em saúde bucal, à utilização de serviços odontológicos, ao mercado de trabalho 
para dentistas, à inclusão do técnico de saúde bucal na atenção primária, à avaliação de programas, inclusive estudos históricos como o referente ao surgimento da odontologia sanitária e da odontologia social. Esses temas abordados no presente livro poderão despertar novos interesses e motivações que, certamente, indicarão outros objetos a demandar novos estudos, assim como alguns caminhos para a garantia do direito à saúde numa perspectiva integral.

Esta coletânea, ao reunir textos produzidos numa área de conhecimento em construção, aponta para a possibilidade de amadurecimento da saúde coletiva no Brasil, reforçando feixes disciplinares para a análise de políticas de saúde e articulando a teoria e a prática na análise política em saúde. A oportunidade de tecer uma rede de pesquisa sobre políticas de saúde, sob a coordenação do Instituto de Saúde Coletiva da Universidade Federal da Bahia, através do Projeto Análise de Políticas de Saúde no Brasil (2013-2017), e com o apoio do Ministério da Saúde e do Conselho Nacional de Desenvolvimento Científico e Tecnológico (Edital 41/2013), proporcionou a implementação do Observatório de Análise Política em Saúde e a publicação deste livro, juntamente com outras iniciativas para socializar saberes e práticas em política de saúde no Brasil.

\section{Jairnilson Silva Paim}

MAIO DE 2016 



\section{Política e saúde}

CONCEITOS BÁSICOS E ABORDAGENS TEÓRICO-METODOLÓGICAS PARA ANÁLISE POLÍTICA EM SAÚDE BUCAL

Sônia Chaves e Samuel Moysés

\section{Apresentação}

O estudo de análise de políticas públicas de saúde bucal no Brasil é recente e com incipiente produção de conhecimento, ainda que haja um importante esforço teórico empreendido na primeira década e meia do século XXI. O que caracteriza essa incipiente produção de parte desse conjunto de publicações é a ausência de teorias de fundo do campo sociológico ou das ciências políticas, capazes de iluminar o percurso da política de saúde bucal com maior poder heurístico. Quanto a isso, é preciso reconhecer que a fortuna crítica, dessa ou de qualquer área de conhecimento, só avança para níveis de maior consistência quando incorpora fundamentos epistemológicos de maior envergadura. Nesse sentido, este capítulo buscou analisar, ainda que de forma não exaustiva, um conjunto de contribuições do marxismo, sociologia e ciência política para essa área temática em crescimento, focando nas categorias de Estado, poder, política pública, política social e de saúde e ciclo da política, buscando trazer a contribuição de alguns pensadores e pesquisadores dessa temática. Além disso, buscou mapear a produção científica nacional focando na fase da entrada na agenda e formulação do ciclo da política, na tentativa de elucidar os principais 
achados e lacunas ainda existentes que possam problematizar e orientar estudos futuros. É também um guia teórico-metodológico para aqueles que se iniciam na temática ou que necessitam de uma síntese sobre a mesma na área de saúde bucal. Cabe lembrar o sentido da produção de conhecimento, conforme aponta Bourdieu (2004, p. 65-66):

É possível pensar com um pensador contra esse pensador. Por exemplo, construí a noção de campo contra Weber e ao mesmo tempo com Weber. [...] Acho que é possível pensar com Marx e contra Marx ou com Durkheim contra Durkheim, e também, é claro, com Marx e Durkheim contra Weber, e vice-versa. É assim que funciona a ciência. [...] Por definição, a ciência é feita para ser superada [...] e Marx reivindicou suficientemente o título de cientista para que a homenagem a lhe ser feita seja a de se usar o que ele fez para superar o que ele acreditou ter feito.

\section{Política e Estado Moderno}

A política é dimensão essencial de toda atividade humana. Todos fazemos política e muitos intelectuais e pensadores se ocuparam de defini-la, ao longo do tempo, tais como: Platão e Aristóteles na Grécia Antiga; Maquiavel, no Renascimento, com o livro O Príncipe; Hobbes e Locke nos séculos XVI e XVII, até alcançar os séculos XVIII e XIX com Hegel, Augusto Comte, Alexis de Tocquevile, John Stuart Mill que são defensores e teóricos do liberalismo político; Karl Marx, que lançará as bases de toda a teorização de esquerda que adentrará pelo século XX e influenciará revoluções e pensadores como Hannah Arendt, Antonio Gramsci, Norberto Bobbio, os pensadores da Escola de Frankfurt, entre outros. No presente capítulo, será adotada a visão de Bobbio (1991), para quem política é "atividade humana ligada à obtenção e manutenção dos recursos necessários para o exercício do poder sobre o homem".

O termo grego "política" deriva da "politeia", já utilizada por Platão no livro de sua autoria que aborda a cidade, A República, caracterizando a organização do mundo grego em cidades-estado; e politikos, sendo a arte de governar tais cidades. (PLATÃO, 2006) Com o tempo, a luta pelo poder passou a ser uma das características mais marcantes da política, chegando mesmo em muitos casos a ser a única real motivação dos políticos. Pode-se falar do "homem político" como aquele que vive para a política, que lhe dá sentido de vida e alimenta seus projetos ideológicos, e também pode-se falar do homem que vive da política, 
como aquele que exerce a ação política no interior do Estado, dele tirando seu sustento material. (WEBER, 2014)

É preciso lembrar que, para Weber, um conceito fundante da teoria sociológica é a categoria "ação". A ação é um comportamento humano a que os indivíduos vinculam um significado subjetivo, sendo ação social quando está relacionada com outro indivíduo. A análise da teoria weberiana como ciência tem como ponto de partida a distinção entre quatro tipos de ação social: 1) a ação instrumental, com relação a um objetivo, é guiada para fins próprios racionalmente avaliados e perseguidos; é uma ação concreta que tem um fim especifico; 2) a ação racional, com relação a um valor, é aquela definida pela crença consciente no valor - ético, estético, religioso ou qualquer outro onde o ator age racionalmente aceitando todos os riscos, não para obter um resultado exterior, mas para permanecer fiel à sua honra; 3) a ação afetiva é aquela definida por uma reação emocional do ator em determinadas circunstâncias e não em relação a um objetivo ou a um sistema de valor; 4) a ação tradicional é aquela ditada pelos hábitos, costumes, crenças em que o ator não precisa conceber um objeto, ou um valor, nem ser impelido por uma emoção, mas obedece a reflexos adquiridos pela prática. (WEBER, 2004) Nesta última acepção, a ação lembra o conceito de habitus de Bourdieu. Certamente, por reconhecer a importância do conceito weberiano de ação, Jürgen Habermas (1984) concede a Weber um papel fundamental em sua "teoria da ação comunicativa", descrevendo a sociologia weberiana da racionalização.

Aqui, há outro aspecto importante, pois falar do conceito weberiano de homem político (e, obviamente, de sua ação na esfera pública) é, necessariamente, situá-lo em um processo histórico mais vasto: o de racionalização. Esse conceito significa a presença, na modernidade ocidental, de uma atitude de instrumentalização que os agentes sociais têm para com o mundo, para com os outros e para consigo, com vistas à consecução de determinados fins ou valores. Tal instrumentalização modernizadora diferencia essa época, quanto ao sistema político que então se desenvolve, em contraposição a outros períodos históricos nos quais os processos de dominação ou autoridade são de outra natureza (como a tradicional e a carismática). Aqui estamos diante da natureza burocrática.

O tipo de autoridade (burocrática ou racional-legal) é justificado pela técnica, pela justiça, pela lei e pela meritocracia. Max Weber foi o primeiro teórico que, em uma análise voltada para a estrutura, acreditava que a burocracia era a 
organização por excelência, suportada por uma elite que, para manter o poder e a legitimidade, desenvolveu um determinado aparelho administrativo para servir de suporte à sua autoridade. Autores como Robert Merton encontraram limitações na obra de Weber, partindo para uma análise crítica da realidade descrita por ele. Merton menciona as disfunções da burocracia frequentemente exageradas pelos leigos quando fazem "sociologia espontânea": internalização das regras e o apego aos regulamentos, o excesso de formalismo e de papelório, a resistência a mudanças, a dificuldade no atendimento a clientes e os conflitos com o público. Na administração burocrática, os procedimentos sobrepõem-se à eficiência. A orientação é que o procedimento seja rigorosamente cumprido, mesmo que o resultado adquira onerosidade ou deixe de surtir efeito. Hannah Arendt (2001) é outra que se distancia de Weber, pois, enquanto na visão weberiana, o poder é uma ação estratégica em que o ator visa utilizar, da forma mais eficaz possível, os meios à sua disposição para atingir um fim previamente definido (isto é, submeter a vontade do outro à sua), para Arendt, o poder (e a ação política) é um fim em si mesmo e, dessa forma, não pode ser instrumentalizado em nome de qualquer outro fim. Sendo uma ação política, cujo sentido último é sempre a interação entre os homens, o poder não pode ser avaliado pelo seu resultado final, mas valorizado por si mesmo.

A política pode ser compreendida, no seu sentido amplo, como as relações de poder e dominação entre os agentes sociais. Contudo, neste capítulo, trataremos do conceito de política como ação diretiva do Estado. Precisamos então compreender o Estado, conforme visto por Pierre Bourdieu (2014), como um objeto impensável, pela sua imensa influência sobre todas as nossas categorias de percepção do mundo social do qual todos nós fazemos parte, desde o conceito de calendário até a classificação das profissões, por exemplo, que, em última instância, são categorias produzidas pelo próprio Estado.

O Estado moderno, como o compreendemos hoje, já foi problematizado por importantes pensadores e sociólogos - Antonio Gramsci, Max Weber, Karl Marx e Pierre Bourdieu - e pode ser entendido de diferentes maneiras. Bourdieu parte da definição dada por Weber (2014), para quem o Estado moderno ou contemporâneo é aquele onde se situa uma comunidade humana que reivindica para si o monopólio do uso da violência física legítima. É o lugar da posse do monopólio da violência legítima. E a política é a forma de participação no poder ou a luta para se incluir nessa distribuição de poder entre os grupos ao interior do Estado. Por outro lado, Bourdieu (2014) complementa afirmando 
que o Estado, além de monopolizar o uso da força física, é também aquele que exerce a violência simbólica legítima. É o lugar do monopólio da violência física e simbólica legítima. (BOURDIEU, 2014) Ou seja, é aquele que produz o discurso universal aceito e reconhecido como legítimo entre os dominados, mesmo em sociedades democráticas. Essa legitimação ocorre pelos Atos do Estado, como expressão da alquimia social infinitamente poderosa, onde repousa o consentimento. Portanto, é importante ficar sempre alerta quando pensamos ou escrevemos ou estudamos o Estado.

O Estado é essa ilusão bem fundamentada, esse lugar que existe essencialmente porque se acredita que ele existe. Essa realidade ilusória, mas coletivamente validada pelo consenso, é o lugar para o qual somos remetidos quando regredimos a partir de certo número de fenômenos diplomas escolares, títulos profissionais ou calendário. De regressão em regressão, chegamos a um lugar que é fundador de tudo isso. (BOURDIEU, 2014, p. 38)

Já foi compreendido como lugar neutro destinado a servir ao bem comum e ao governo, o bem do povo, segundo Thomas Hobbes e John Locke. Mas também como aparelho de coerção, de manutenção da ordem pública em proveito dos dominantes, "balcão de negócios" da burguesia. (MARX; ANGELS, 1999)

O principal alerta é que o Estado não é sujeito. É importante fugir dessa armadilha, substituindo o Estado pelos seus Atos. Os atos políticos têm pretensão de provocar efeitos no mundo social (território físico e imaterial). E a política (pública), portanto, será um tipo de Ato do Estado, reconhecida como legítima pela crença na existência do princípio que a fundamenta (o ato), numa espécie de cadeia de delegações infinita que faz com que o aparelho do Estado funcione.

Assim, a política é o resultado desse processo de delegação. Envolve politics - referente à existência e ao exercício do poder como a sua natureza, estrutura, distribuição e lutas -, mas também policy - que diz respeito ao estabelecimento de diretrizes, planos e programas. Em português, a palavra "política" envolve tanto as dimensões do poder quanto das diretrizes. Política pública refere-se ao exercício do poder (politics) e às intervenções planificadas (policy) na esfera pública, mas com repercussões na esfera privada. A política pública pode ter 
um caráter social, no sentido de enfrentamento de problemas sociais identificados pelos grupos interessados. Nesse caso, será uma política social.

\section{As questões relativas ao poder}

Falar de poder enquanto categoria não é tarefa fácil. Em capítulo dedicado à análise desse atributo, François Chazel (1995) define o poder como a capacidade de um determinado agente alcançar os resultados visados, de realizar as ações com êxito. Na vida social e política (ou seja, aquela que envolve o ponto de nosso interesse que é o Estado), o poder se reveste normalmente da forma de um poder sobre outros homens.

Empiricamente, atribuir poder a um determinado agente ou grupo de agentes seria analisar a produção dos efeitos pretendidos. Para Thomas Hobbes, reconhecendo o caráter mais filosófico de sua obra, o poder de um homem consiste na possibilidade de obtenção de um bem aparente no futuro (Leviatã, “Capítulo X"). Contudo, não podemos reduzir o poder ao seu exercício. Ele pode ser visto como uma capacidade, uma potencialidade duradoura. A concepção de poder como uma propriedade defende que este é detido por alguns agentes ou grupo de agentes, logo é substância. Contudo, o pensamento do poder numa concepção relacional é mais adequado, já que: 1) permite pensar que sua influência será variável em função dos agentes no tempo, ou seja, ainda que a sua propriedade se modifique; 2) permite também observar os processos da dinâmica subjacente às relações. Logo, é preciso considerar que o poder é exercício em relações de dominação.

Para Weber, o poder significa fazer triunfar em uma relação social a sua própria vontade, mesmo contra resistências. (WEBER, 2004) Ao apresentar o poder, Weber deixa clara a relação entre poder e dominação, poder e conflito. Há, portanto, que reconhecer nos três tipos de dominação legítima (tradicional, carismática e legal), a possibilidade do exercício do poder físico. Nesse sentido, tanto Max Weber (2004) como Pierre Bourdieu (2014) nos ajudam a compreender melhor as especificidades do poder político que é um componente essencial de qualquer sociedade, não sendo mero produto da dominação econômica. O poder político se distingue das demais formas de poder por três aspectos: 1) pelo seu caráter territorial; 2) tem à sua disposição toda uma série de sanções punitivas, coercitivas a que recorre ocasionalmente, constituindo-se na sua vertente coercitiva, de violência física; e 3) é resultado da alquimia 
do estado, de universalização dos discursos oficiais, constituindo-se na sua vertente simbólica.

Para Hannah Arendt, o poder não é atributo de um agente, mas o resultado da capacidade do agir em conjunto de um grupo, que produz consentimento ao seu interior e que leva à formação de uma vontade comum. Sua análise envolve o foco em grupos sociais e não em agentes específicos. (ARENDT, 2001) Essa análise foi útil no estudo das relações de poder na Política Nacional de Saúde Bucal (PNSB), no seu período de entrada na agenda e formulação, em 2003, que apontou a construção de um poder importante de um grupo militante que influenciou sua formulação. (ANDRADE, 2009)

Para Mário Testa (1992), um dos que pensaram o poder no setor saúde, este pode ser de três tipos: administrativo, técnico e político. Antes de tudo, é a capacidade de um em relação aos outros. O primeiro tipo seria essa capacidade de deter informações e manejo de recursos e processos. O segundo seria daqueles que manejam conhecimento técnico específico. O poder político seria o manejo ideológico de outros sujeitos. Para Testa, é bom destacar, a política pressupõe distribuição do poder entre os grupos sociais. (TESTA, 1992)

\section{Política pública e saúde}

Há farta literatura sobre políticas públicas e algumas falsas controvérsias. Um exemplo é a controvérsia em torno da diferença entre a abordagem estadista (state-centered policy-making), que considera que somente deve ser denominada como política pública aquela que emana dos agentes do Estado, e a abordagem multicêntrica (policy networks), que defende a ideia de que o importante é se o problema é de interesse público, em que, tanto os agentes no interior do aparelho governamental do Estado como os não governamentais, influenciam sua formulação e implementação. Essa controvérsia pode estar relacionada à origem disciplinar americana dos estudos sobre políticas públicas.

A política pública enquanto área de conhecimento e disciplina acadêmica nasce nos Estados Unidos, em contraposição à tradição europeia, que se concentrava mais na análise sobre o Estado e suas instituições do que na produção dos governos. Assim, na Europa, a área de política pública vai surgir como um desdobramento dos trabalhos baseados em teorias explicativas sobre o papel do Estado e de uma das mais importantes instituições do Estado - o governo -, produtor, por excelência, de políticas públicas. Nos Estados Unidos, ao contrário, a área surge no mundo acadêmico sem estabelecer relações com as bases 
teóricas sobre o papel do Estado, passando direto para a ênfase nos estudos sobre a ação dos governos, compreensível pelo seu nascimento ocorrer como subárea da ciência política.

Assim, a política pública nos Estados Unidos está focada na análise sobre a ação do governo e não do Estado. Devemos aqui diferenciar governo de Estado. Governo é um grupo que ganha uma eleição e fica por tempo determinado no poder. Já Estado é a estrutura, a instituição a qual o governo representa; é a nação politicamente organizada. Assim, tanto ações (o fazer) quanto inações (o não fazer) dos governos são passíveis de serem formuladas cientificamente e de serem analisadas por pesquisadores independentes.

E afinal, o que são políticas públicas? São conjunto de intervenções organizadas pelo Estado através de diferentes governos com a participação de agentes e instituições governamentais e não governamentais que visam enfrentar situações socialmente problemáticas, identificadas como necessidades sociais por diferentes grupos. Já a análise de políticas públicas é, resumidamente, o "campo do conhecimento que busca desvendar o 'governo em ação' e propor mudanças no rumo ou curso dessas ações". (SOUZA, 2007, p. 69) Logo, “a formulação de políticas públicas constitui-se no estágio em que governos democráticos traduzem seus propósitos e plataformas eleitorais em programas e ações, que produzirão resultados ou mudanças no mundo real". Ou seja, é o estudo do processo (do porquê e do como) e não das consequências.

Vale ressaltar que não devemos escolher primeiro a teoria e depois tentar encaixar o problema nela. A teoria deve ser apenas uma lente para nos auxiliar a compreender melhor a realidade. Esta necessita ser escolhida de acordo com o problema que queremos analisar. Nessa perspectiva, os elementos principais das políticas públicas são:

- A distinção entre o que o Governo pretende fazer e o que de fato faz;

- O envolvimento de diversos agentes e instituições (governamentais e não governamentais);

- A abrangência - não se limita a leis e regras;

- A ação intencional, planejada e de longo prazo;

- Os processos: entrada na agenda - decisão - proposição - implementação - execução - avaliação;

- É diferente de política social, que está focada nas consequências, os problemas sociais - a política social é um tipo de política pública e não o contrário. 
Portanto, esse espaço do conhecimento busca integrar quatro elementos: a política pública (policy); a dimensão do poder na política (politics); a sociedade política (polity); e as instituições que as regem. Tem como foco analítico a identificação do problema que a política visa corrigir; a chegada do problema ao sistema político (politics) e à sociedade política; o processo percorrido; e as instituições e regras que modelarão a decisão e a implementação da política pública.

No entanto, definições de políticas públicas, mesmo as minimalistas, guiam o nosso olhar para o lócus, onde os embates em torno de interesses, preferências e ideias se desenvolvem, isto é, os governos. As políticas públicas repercutem na economia e na sociedade, daí por que qualquer teoria da política pública precisa também explicar as inter-relações entre Estado, política, economia e sociedade.

De fato, a construção social do problema visto como de todos e seu enfrentamento é resultado da inter-relação entre os diferentes agentes situados nos distintos espaços sociais. Mas cabe ao Estado, lócus de dominação e construção do discurso universal, o papel importante na tomada de decisão em torno dos problemas sociais. (BOURDIEU, 2012)

\section{Política de saúde: conceitos básicos e seus instrumentos}

Política de saúde, um tipo de política pública e social, nesse capítulo é compreendida em acordo com a proposta de Paim (2003, p. 587):

[...] a ação ou omissão do Estado, através de uma resposta social diante de problemas de saúde e seus determinantes, materializada através de práticas ou ações de saúde voltadas para problemas e/ou necessidades na produção, distribuição e regulação de bens, serviços e ambientes que afetam a saúde de indivíduos e coletivos.

Essa política pode atender a demandas de grupos sociais interessados, mas é mais complexo que apenas responder a um grupo dominante específico. Possui uma dimensão do poder e outra da ação diretiva do Estado. Entre os instrumentos das políticas, como Atos do Estado, destacam-se os documentos institucionais que materializam decisões políticas, como leis, normas, decretos, portarias, planos, programas e projetos. Esses instrumentos visam produzir um efeito de legitimação simbólica. Políticas públicas (de saúde, como de 
qualquer outra área), após desenhadas e formuladas, desdobram-se em planos, programas, projetos, bases de dados e sistema de informação para pesquisas.

Não se defende aqui que o Estado (ou os governos que decidem e implementam políticas públicas ou outras instituições que participam do processo decisório) reflete tão somente as pressões dos grupos de interesse, como diria a versão mais simplificada do pluralismo. Também não se defende que o Estado opta sempre por políticas definidas exclusivamente por aqueles que estão no poder, como nas versões também simplificadas do elitismo, nem que servem apenas aos interesses de determinadas classes sociais, como diriam as concepções estruturalistas e funcionalistas do Estado. No processo de definição de políticas públicas, sociedade e Estado complexos como os constituídos no mundo moderno estão mais próximos da perspectiva teórica daqueles que defendem que existe uma "autonomia relativa do Estado", o que faz com que ele tenha um espaço próprio de atuação, embora permeável a influências externas e internas.

Apesar do reconhecimento de que outros segmentos que não os governos se envolvem na formulação de políticas públicas, tais como os grupos de interesse e os movimentos sociais, cada qual com maior ou menor influência a depender do tipo de política formulada e das coalizões que integram o governo, e apesar de certa literatura argumentar que o papel dos governos tem sido encolhido por fenômenos como a globalização, a diminuição da capacidade dos governos de intervir, formular políticas públicas e de governar não está empiricamente comprovada.

As políticas de saúde representam uma das principais parcelas dos investimentos sociais, juntamente com políticas de seguridade social e previdência, afetando todo o ciclo de vida. Porém, não deveriam ser vistas simplesmente como "gasto" social improdutivo. Sobre os sistemas de saúde contemporâneos, projetam-se tensões e pressões semelhantes às que encontramos noutras áreas sociais, quando se trata de lidar com reformas estruturais: aumento continuado da despesa, pressões demográficas, arrefecimento do crescimento econômico e constrangimentos fiscais. Na área da saúde, a complexidade econômico-financeira que decorre em grande parte da inovação tecnológica e terapêutica e a centralidade do poder dos profissionais de saúde, revertido em "autonomia", tornam-se fatores cruciais. Dessas especificidades, resulta um conjunto de desafios à mudança nas políticas. 


\section{Possíveis abordagens teóricas e metodológicas de políticas públicas de saúde}

O estudo desse processo político da política tem sido objeto de investigação da ciência política e também da sociologia. A análise do processo político para o enfrentamento de um determinado problema de saúde, por exemplo, na perspectiva da ciência política (considerada uma das três áreas das ciências sociais juntamente com a sociologia e antropologia), tem sido apresentada comumente em quatro ou cinco etapas, ainda que haja mais variações: 1) construção social do problema; 2) definição ou entrada na agenda; 3) formulação; 4) implementação; e 5) avaliação. Essas etapas fazem parte do ciclo da política pública, considerada uma abordagem metodológica consolidada para análise política (Figura 1).

Figura 1 - Ciclo da política em cinco momentos principais

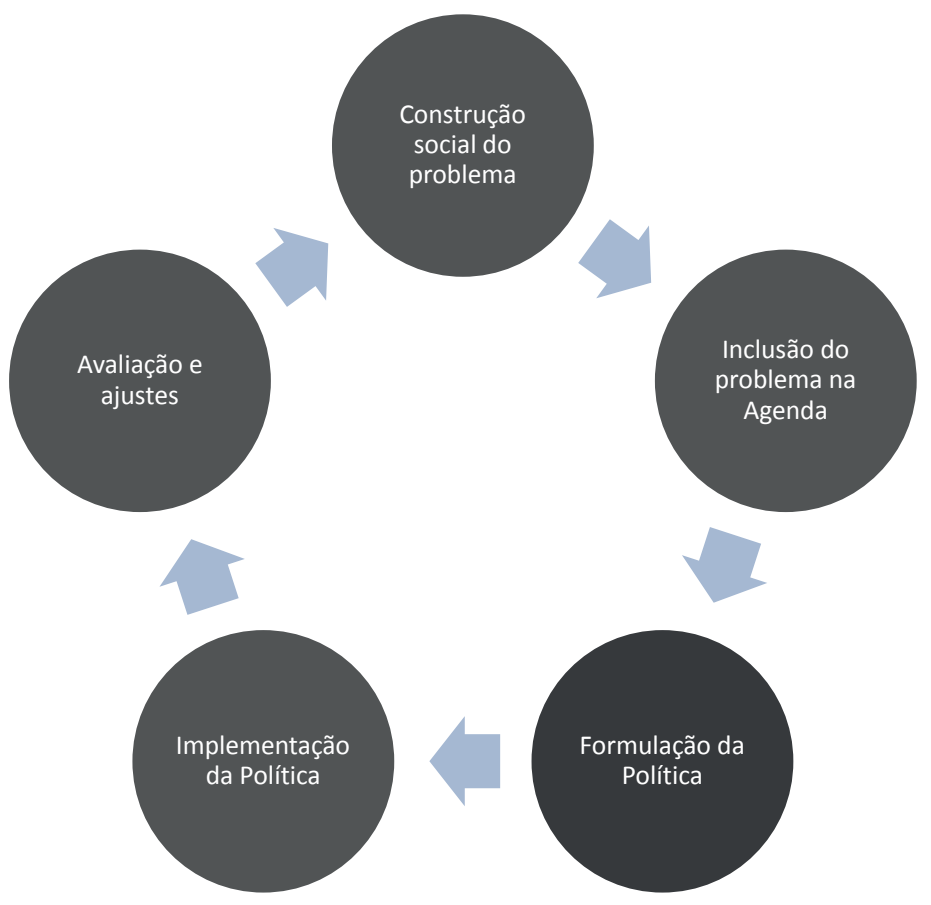

Fonte: elaboração dos autores. 


\section{Ciclo da política}

O ciclo da política pública é considerado um processo dinâmico e histórico. A principal contribuição dessa abordagem foi permitir ver que o curso da política não é um processo linear. Cada etapa tem dinâmica própria com diferentes influências dos agentes governamentais e não governamentais, das instituições envolvidas, bem como da conjuntura política e econômica. Ainda, fornece um quadro de referência para a análise processual ao atribuir funções específicas às diversas fases do processo político-administrativo.

Nesse sentido, teorias influentes na ciência política incluem a análise de múltiplos fluxos (multiple-streamstheory) de Kingdon (1995), cujo foco é a definição da agenda, em que há processos e fluxos independentes na priorização de problemas, na seleção de alternativas de políticas e na decisão sobre qual alternativa será eleita para a formulação. Esses momentos seriam, portanto, independentes e determinados por múltiplos processos.

A construção da agenda, ou seja, sua definição refere-se ao momento da entrada do problema como prioridade na agenda governamental. Cabe lembrar a existência de três tipos de agenda: a) agenda sistêmica ou não governamental, ou seja, aquela das prioridades dos atores fora do governo; b) agenda institucional ou governamental, ou seja, daqueles temas e problemas importantes para os agentes governamentais; e 3) agenda decisória ou política, aquela que realmente permanece, sendo ou do governo ou de fora dele.

Para Kingdon (1995), na primeira etapa da definição da agenda, o problema, entre muitos presentes, disputa a atenção da equipe dirigente e é então priorizado, numa provável janela de oportunidade. Ou seja, a agenda decisória corresponderá à definição de um conjunto de problemas que serão priorizados pelas autoridades governamentais, constituindo objeto de decisão política. A estatística e a epidemiologia, por exemplo, são ferramentas colocadas para enfatizar determinado problema, sendo instrumento de legitimação da agenda decisória, podendo aumentar o poder dos especialistas, dos empreendedores de política, já que reforçam a construção social do problema a ser enfrentado no período de governo.

Já na etapa de formulação da política, ao interior do governo, formulam-se tipos de soluções para os problemas, consistindo na investigação do problema e na busca de opções e alternativas para sua resolução. O estudo das diferentes alternativas é muito comum ao interior do legislativo e executivo, por exemplo. Nesse caso, a formulação terá forte influência dos especialistas de vários tipos 
que estudam o tema. No caso da saúde, o papel desempenhado pelos estudos de saúde pública, medicina ou odontologia, "baseado em evidências científicas" na formulação e avaliação dos resultados da política merece aprofundamento em estudos futuros. Críticas ao "centramento dentário" estão presentes no estudo de Pires e Botazzo (2015), onde, na análise histórica das políticas de saúde bucal no Brasil, mostrou que, desde os anos 1950, o setor público reproduz acriticamente a odontologia biologicamente centrada como modus operandi, mas com insuficiente resposta às necessidades. Esse estudo, a partir da perspectiva da teoria de Michel Foucault na obra Arqueologia do saber, também revelou o foco da política na redução de índices epidemiológicos de doenças com um modelo tecnológico e arranjos tecnológicos no processo de trabalho muitas vezes exitoso, mas não tem produzido suporte social para a autonomia dos sujeitos. Cabe refletir se a retórica das palavras na formulação é traduzida em ações concretas.

A etapa da implementação é uma das mais problemáticas, independente da abordagem teórica. (FISHER; MILLER; SIDNEY, 2007; PINELL, 2011) É, na verdade, o momento de colocar uma determinada solução em prática e envolve uma série de sistemas ou atividades da administração pública como os sistemas gerenciais, operacionais, de informação, entre outros. Nesse momento, uma diretriz pode ser rejeitada, modificada e alterar o argumento central da política, gerando novas negociações e formulações, reiniciando o ciclo. Para Paim (2002, p. 150), a implementação da política (sua institucionalização e mudança) “depende não apenas da correlação de forças políticas que dirigem ou pressionam o Estado e seus aparelhos, mas também da distribuição do poder ao interior do aparato estatal e das formas concretas de organização do processo de trabalho nas instituições”. Logo, estudar que tipo de Estado é o Estado brasileiro, sua história e sua determinação sobre as organizações é tarefa importante. Os estudos de Vianna (1988) e Assis (2006) são bons exemplos concretos de análises da implementação da atenção à saúde bucal no Brasil e as características do Estado brasileiro. As categorias desenvolvidas por Antonio Gramsci de revolução passiva e transformismo têm sido lembradas para explicar a natureza do Estado brasileiro no sentido das típicas revoluções burguesas de cima para baixo, sem participação popular onde se mantém a hegemonia a partir do "mudando sem transformar", transformando para não mudar. Já o transformismo se refere à absorção de indivíduos ou grupos ativos que pareciam irreconciliavelmente inimigos pelos grupos dominantes, manifestando-se em transformações das 
ideias e práticas dos grupos e intelectuais de esquerda em direção as ideias hegemônicas. (GRAMSCI, 1978)

A implementação de uma política dependeria de muitos fatores como transferência do projeto formulado para equipes de governo capazes de implementá-la, sua formulação clara e alocação de recursos associada à boa coordenação pelos burocratas (atores governamentais) na sua execução (FISHER; MILLER; SIDNEY, 2007), bem como de uma boa articulação entre o projeto, a capacidade de governo e sua governabilidade no nível local. (MATUS, 1996) A policy arena, ou seja, os diferentes agentes envolvidos com sua implementação, o grau de participação dos implementadores e grupos interessados poderiam significar maior êxito da mesma.

Quanto maior a mudança/transformação proposta pela política, provavelmente maiores serão as dificuldades de implementação. Ou seja, caso o propósito de governo seja de transformação (TESTA, 1995), sua capacidade de governo (MATUS,1996), sua organização e método deverão ser mais mobilizados. Sabatier (2007), também propõe uma análise considerando a implementação de cima para baixo ou debaixo para cima (top-down e bottom-up implementation), ou uma síntese dos dois. Há indícios de que a implementação ocorreria mais "de cima para baixo" do que o contrário, refletindo valores e interesses das burocracias estatais, dos especialistas no governo. (WALT et al., 2008)

Na etapa da avaliação, Sabatier (2007) sugere que "uma década ou mais" é a duração mínima da maioria dos ciclos de política, de emergência de um problema a seu enfrentamento com a implementação para uma "avaliação razoavelmente justa" de impacto. As avaliações são muito desejadas, mas nem sempre são realizadas. E mesmo quando realizadas, suas evidências são um elemento apenas para a tomada de decisão no processo político. Avaliação consiste sempre num julgamento de valor a respeito de uma intervenção ou qualquer dos seus componentes, visando à tomada de decisão. Contudo, ajustes são realizados pelos agentes envolvidos em sua implementação, independente das avaliações. A avaliação tem sido considerada um dos tipos possíveis de julgamento que se faz sobre as práticas sociais (VIEIRA-DA-SILVA, 2014), sendo que a política, como um conjunto de práticas articuladas, é objeto de julgamento do mérito em responder às necessidades sociais pretendidas.

Não existe uma proposta ou modelo único ou consensual para o processo de produção e análise do curso de uma determinada política, e sim variadas correntes de pensamento ou abordagens teóricas. Aqui, centraremos brevemente 
em três delas: o neoinstitucionalismo, a abordagem sociológica de análise de políticas públicas de saúde e as correntes marxistas e neomarxistas.

\section{O neoinstitucionalismo e as políticas de saúde}

O neoinstitucionalismo tem como foco o papel das instituições, que são consideradas como estruturas intermediárias que realizam a mediação da relação entre Estado e sociedade. (LIMA; MACHADO; GERASSI, 2011) Nesse sentido, é preciso elucidar o papel das instituições na determinação de resultados sociais e políticos decorrentes da formulação, implementação e avaliação da política pública. Ou seja, as instituições importam, podem ser fortes.

O conceito de instituição, no entanto, vai além de um lugar físico. As regras de conduta, as formas de constrangimento, a ordem social que rege o funcionamento de uma sociedade, leis fundamentais por que se rege um país, são instituições. Seria, portanto, um conceito mais amplo que organizações, que se referem aos grupos políticos (partidos, governos), econômicos (sindicatos, cooperativas), sociais (igrejas, associações profissionais, clubes) e educacionais (colégios, universidades), por exemplo. (LIMA; MACHADO; GERASSI, 2011) Cabe destacar que, sob o rótulo de neoinstitucionalismo, há uma diversidade de correntes e abordagens. São estudos que geralmente se concentram na análise de organizações.

O tema central é a relação entre estrutura e agente, e qual desses polos é o dominante. Ou seja, seria possível apontar que uma instituição estrutura a ação humana, num sentido mais ou menos determinista, de modo a produzir um modelo normalizado de comportamento? Ou, ao contrário, elas mesmas são produto dos modelos de comportamento e disposição dos agentes? (GUIDDENS, 1978) Veremos mais adiante que Pierre Bourdieu (2014) e Patrice Pinell (2011) podem nos ajudar a elucidar essa dualidade estrutura e agente.

\section{Abordagem sociológica de políticas de saúde}

As teorias de análise sociológica de políticas públicas de saúde têm sugerido outras abordagens para a compreensão e explicação do desenvolvimento da política. A sociologia reflexiva de Pierre Bourdieu tem contribuído com a conciliação entre a importância, tanto das estruturas quanto da posição dos agentes na explicação sociológica dos fenômenos. (BOURDIEU, 2003) Agente, segundo Pierre Bourdieu, rompe com a negação do sujeito, já que na filosofia 
do sujeito, este é concebido como ser estático, fora do jogo de interesses do campo. O agente é o ser que age e luta dentro do campo de interesses. Nessa perspectiva, a mudança das estruturas sociais passa pela ação social dos agentes ao interior de cada espaço social ou campo, sendo o habitus, essa mediação entre o agente e o campo.

No conceito de espaço social ou campo, aquilo que comumente se denomina sociedade, na verdade, é constituído de diversos microcosmos denominados "espaços sociais", no interior dos quais os agentes ocupam posições distintas relacionadas aos capitais acumulados do tipo cultural, político, econômico, social, entre outros. O campo é um tipo específico de espaço social com autonomia relativa em relação aos demais campos, com leis próprias e onde os agentes compartilham habitus comuns, constituindo uma illusio específica. O habitus é "um sistema de disposições duráveis e transponíveis socialmente incorporadas que, integrando todas as experiências passadas, funciona a cada momento como uma matriz de percepções, de apreciações e de ações". (BOURDIEU, 2003, p. 63)

O illusio, palavra originada de ludus (jogo), significa estar no jogo, estar envolvido no jogo, levar o jogo a sério, estar preso ao jogo que vale à pena jogar, dar importância a um jogo social, perceber que o que se passa aí é importante para os envolvidos, para os que estão nele, é reconhecer o jogo e reconhecer os alvos. (BOURDIEU, 1996) Ao desenvolver o conceito de illusio, Bourdieu afirma que os jogos sociais são jogos que se fazem esquecer como jogos. Illusio é, portanto, essa relação de encantamento com o próprio jogo, resultado da relação entre as estruturas mentais, as disposições incorporadas e as estruturas objetivas do espaço social. (BOURDIEU, 1996)

O espaço social é o espaço onde se joga o jogo e é expressão da estrutura de relações geradas pela distribuição de diferentes espécies de capital dos agentes. Nesse caso, o espaço social é aquele considerado como espaço de relações de poder entre agentes e instituições envolvidas em torno de um objetivo comum em lutas concorrentes. (PINELL, 2011) Nesse sentido, dentre os diferentes tipos de capital dos agentes, o capital social é considerado um capital de relações, de ganhos associados à existência de uma rede conectada atual e potencial, de pertencimento e associação a um grupo. Cabe destacar que o capital é a energia social do acúmulo histórico do agente ou instituição que garante posições distintas no espaço social de luta. (BOURDIEU, 1996) 
O capital simbólico, por outro lado, é uma forma de capital que nasce da relação entre uma espécie qualquer de capital e os agentes socializados de maneira a conhecer e reconhecer essa espécie de capital. (BARROS, 2013) O capital político seria essa capacidade de mobilização de um agente ou instituição/organização, como espécie de capital social e simbólico, obtido a título pessoal ou institucional. É também, portanto, de uma organização detentora desse tipo de capital, como ministérios específicos, partidos, associações ou sindicatos, conforme proposto por Barros (2013).

Para Bourdieu (2014), o Estado é esse espaço onde a política é legitimada e lugar dos dominantes dos diferentes campos sociais. O Estado é o lugar onde os atos políticos com pretensões de efeito no mundo social são dotados de uma autoridade que, gradualmente, por uma série de delegações em cadeia, remete a um lugar último, o próprio Estado, produzindo um discurso universal, de legitimação, lugar do monopólio da violência física e simbólica. (BOURDIEU, 2014)

Assim, Patrice Pinell (2011), numa abordagem sociológica do espaço de luta contra flagelos sociais como o câncer, a aids e o abuso de drogas, analisou a intervenção do Estado como resposta social contra esses flagelos, utilizando categorias para explicar a gênese das políticas, vinculando-a às preocupações sociais, ao espaço e à entrada de novos agentes especializados e instituições. $\mathrm{O}$ autor fundamentou sua análise em oito proposições explicitadas na gênese e na evolução ou implementação de políticas de saúde.

A construção social de um problema como problema é um processo cuja evolução é determinada pela dinâmica de alianças entre grupos sociais que têm todos eles, interesse em que esse problema seja reconhecido sem que tenham exatamente o mesmo ponto de vista nem sobre o que ele é, nem sobre as medidas a tomar e que, portanto, para se aliar devem negociar sua definição. (PINELL, 2011, p. 239)

Para esse autor, a evolução e a implementação de uma política de saúde é produto da dinâmica de um jogo social complexo, que escapa aos seus formuladores. Sua análise considera quatro fatores interdependentes: 1) as evoluções do front da luta de ordem médica e científica como novos dados sobre a incidência da doença, novos conhecimentos médicos e tratamentos, inovações técnicas e novos tratamentos; 2) as mudanças sociais, de mobilização contra a doença; 3) os efeitos concretos da implementação da política, como a criação 
de novas instituições, grupos profissionais, emergência de novas estruturas associativas; e 4) as mudanças de governo, de manutenção ou mudança da maioria política e mudanças independentes da política em questão, como reformas na saúde, educação e justiça, entre outros.

\section{A grande contribuição de Mário Testa e Carlos Matus}

Entre as correntes marxistas, destaca-se a contribuição teórica de Antonio Gramsci, considerado um neomarxista. Na saúde coletiva latino-americana, destacam-se as contribuições teóricas de Carlos Matus e Mário Testa, que também serão brevemente apresentadas.

O pensamento de Mário Testa e Carlos Matus tem influenciado a reflexão sobre as políticas públicas de saúde no Brasil, especialmente entre aqueles que se debruçam sobre as questões relacionadas ao planejamento em saúde. (PAIM, TEIXEIRA, 2006; VILLASBOAS, PAIM, 2008) Segundo Testa (1992), os desafios da prática impõem aos sujeitos, individuais e coletivos, não só perícia técnica-científica, mas, sobretudo militância sociopolítica, como sujeitos implicados.

Mário Testa centrou seu foco na problemática do poder no setor saúde, o que ele denominou "estrutura de poder no setor saúde". A compreensão do poder é útil para mapeamento dos agentes e análise de suas posições políticas. Para análise do processo político na saúde, o postulado da coerência é uma das suas maiores contribuições. Esta prevê que os propósitos de uma instituição, sua organização e os métodos que utiliza devem apresentar coerência.

Os propósitos de um governo, ocupantes do Estado, podem ser definidos enquanto legitimação, crescimento ou transformação. A legitimação é um propósito permanente dos governos. O crescimento é outro propósito, mas com foco na expansão do governo, sua produtividade. Já o propósito de transformação é o mais desafiador, já que se move na mudança da estrutura social e está relacionado à visão heterogênea do Estado. Os propósitos de legitimação e crescimento estão relacionados à visão de Estado como homogêneo, isto é, a articulação de grupos sociais similares no Estado. Os métodos de governo representam a formalização de uma boa prática, baseada implícita ou explicitamente em uma teoria eficaz. Quanto à organização, esta se constitui como "uma cristalização da história" e está determinada pelo propósito de governo e pelo método. A análise de organização em um dado momento reflete as determinações advindas do passado, juntamente com as atuais onde os outros dois 
elementos (propósito e método) são determinados também pela história, pelo Estado e pela teoria. (TESTA, 1992)

Como principal contribuição de Carlos Matus (1996), podemos situar a proposição da análise permanente do "triângulo de governo" que se conforma em vértices de um triângulo: o projeto de governo, a capacidade de governo e a governabilidade. Para esse importante pensador chileno, a capacidade de governo seria constituída por habilidades, perícia técnica e política, experiências de um ator e sua equipe dirigente para conduzir o processo social, quanto ao seu projeto. O projeto pode ser sinônimo de propósito, no sentido de Mário Testa, representando uma proposição ou conjunto de propostas de ações realizadas por um ator para alcançar metas, de legitimação ou transformação. O terceiro vértice do triângulo de governo, que, somado ao projeto de governo e à capacidade de governo, representam variáveis que se entrelaçam e condicionam-se mutuamente, é a governabilidade.

A governabilidade do sistema é uma relação entre o peso das variáveis que o ator controla e não controla no processo de governo. Quanto mais variáveis o ator controla, maior é sua liberdade de ação e maior é, para ele, a governabilidade do sistema. A governabilidade de um sistema expressa o poder que determinado ator tem para realizar seu projeto. É uma categoria relativa a um determinado ator, às demandas e exigências que o projeto de governo impõe a ele, e à sua capacidade de governo.

Cabe destacar que "ator social" é compreendido por Matus e Testa como pessoa, grupo de pessoas, instituições, organizações sociais ou partidos políticos que se constituem como centros de acumulação e (des-)acumulação de poder com capacidade de produzir fatos sociais e políticos.

Rossi (2015) analisou a configuração da PNSB em dois municípios baianos, a partir da articulação do pensamento de Carlos Matus e Mário Testa. A autora observou observou a existência de projeto de implementação em consonância com as diretrizes do governo local, com propósito de crescimento, alta capacidade de governo e métodos coerentes, além de uma organização favorável à implementação do projeto no municípios com implementação exitosa. Contudo, em outro município, a debilidade do método e um propósito de governo de conservação, aliados às ausências de articulação das variáveis que compõem o triângulo de governo, influenciaram o insucesso na implementação, onde a governabilidade foi ainda menor quando o ator possuía baixa capacidade de governo, sofrendo influências pela fragilidade no projeto de governo que expres- 
sava “conservação” ou legitimação. Esse estudo reforçou o potencial de análise de implementação de política de saúde a partir da contribuição desses autores, também revelado por Chaves e Vieira-da-Silva (2007) e Soares e Paim (2012).

\section{A contribuição Gramsciana}

O conceito de hegemonia foi elaborado por Antônio Gramsci para o estudo dos processos políticos e compreensão das relações de dominação em sociedades capitalistas. Para o autor, o desenvolvimento de um processo hegemônico compreende a constituição inicialmente de um Estado ampliado, cujo estudo das relações entre estrutura e superestrutura se faz necessário. A estrutura é a base econômica da sociedade e a superestrutura se refere à base político ideológica que assegura as condições não materiais, as condições simbólicas para a reprodução da estrutura social, através da ideologia de classe ou frações das classes dominantes. (GRAMSCI, 1978) Nesse sistema, uma determinada classe social detém hegemonia caso ela possua a direção política e ideológica na sociedade civil, utilize da dominação por meio do Estado, caso necessite e, ao mesmo tempo, controle os núcleos centrais da economia. Nos casos em que tal situação se concretize, significa a constituição de um bloco histórico ou um bloco de poder. A distinção realizada por Gramsci entre sociedade civil e política auxilia a compreensão dos fatos e a análise do bloco histórico, que pode facilitar a compreensão dos processos políticos, já que a sociedade política é a arena das instituições políticas de legitimação legal e a sociedade civil é o lugar do "não estatal", organizações cuja função é difundir pensamento hegemônico através de todos os meios de comunicação e instrumentos que permitem influenciar a opinião pública e que inclui a economia. A primeira é a dominação pela força e a segunda, pelo consentimento. Pode-se falar de hegemonia aplicando-a ao campo das relações entre Estados Nacionais, nas relações entre grupos sociais e partidos políticos, em diferentes políticas públicas, como a da saúde bucal, porexemplo.

A constituição de um bloco histórico compreende uma articulação hegemônica onde há interesses de classe, força política coercitiva, e que por sua vez são condicionados pela estrutura que condiciona uma determinada ação política. (GRAMSCI, 2000) A hegemonia é portanto, a concretização da direção que uma classe ou fração de classe exerce sobre a totalidade da sociedade mediante

a coerção ou o consenso. É possível nos jogos de luta, a construção de uma contra-hegemonia, que é organização da própria direção política e ideológica das classes subordinadas para alcançar um novo sistema hegemônico, um novo 
bloco histórico. Essa análise pode ser útil em estudos de políticas públicas setoriais, como a da saúde bucal.

Segundo Bobbio, Mateucci e Pasquino (1991), pode-se encontrar hegemonia fundamentalmente em duas acepções. A primeira associada à ideia de domínio acentuando o uso da força e, portanto da sociedade política, e uma segunda relacionada à direção, acentuando a dimensão intelectual e moral, o consenso, a dimensão cultural; e, por conseguinte a sociedade civil. (BOBBIO, 1991)

Estudo de Vianna (1988) sobre as políticas de saúde bucal no Brasil, nos anos 1970 e 1980, já aponta as dificuldades na implementação de propostas contra-hegemônicas à odontologia dominante, haja vista a dominação simbólica da prática odontológica liberal entre as entidades de classe, em formação naquele período. Burawoy (2010), ao buscar um diálogo entre Gramsci e Bourdieu, aponta grandes semelhanças entre ambos na medida em que estes se preocuparam com a dominação simbólica, além da econômica, através do conceito de superestrutura político-ideológica em Gramsci (a chamada superestrutura no marxismo clássico) e de violência simbólica em Pierre Bourdieu. A sociedade civil em Gramsci se assemelha ao conceito do campo do poder em Bourdieu, como espaço dos dominantes dos diversos espaços sociais, que disputam a ocupação do Estado.

\section{Os estudos de análise das políticas de saúde bucal no Brasil}

No Brasil, muito recentemente, o tema da análise política em saúde bucal tem sido objeto de interesse de alguns pesquisadores. O Quadro 1 sistematiza a produção científica recente em análise política sobre a atual PNSB no âmbito nacional. Não foram aqui incluídos estudos de análise de resultados ou do processo, com os estudos quantitativos. Apenas foram incluídos estudos que buscaram produzir análise política, na política de saúde bucal, ou seja, que se debruçaram sobre as relações e processos de acumulação e (des-)acumulação de poder e outros capitais que resultaram em caminhos: na entrada na agenda, na apresentação de alternativas, na sua formulação ou implementação, compreendido, nesse contexto, como etapas do ciclo da política.

Aqui, consideramos que o espaço "da saúde bucal” ou "da política de saúde bucal" é um espaço social onde as diversas instituições e agentes engajados pertencem a diferentes campos, com distintos interesses em jogo que podem ter efeitos nos resultados dessa implementação. O Quadro 1 apenas reflete o campo científico, espaço de relações entre agentes interessados na produção e legitima- 
ção do conhecimento da política. Neste, não foi objeto de análise os diferentes pontos de vista do campo burocrático, ou seja, do espaço onde se situa os funcionários dos governos que formulam e implementam a política pública.

Os dois primeiros estudos foram duas dissertações de mestrado defendidas no Instituto de Medicina Social da Universidade Estadual do Rio de Janeiro. (BARTOLE, 2006; GARCIA, 2013) Esta última publicou parte desse trabalho em 2013. (GARCIA, 2013) O principal referencial de análise política em ambos os trabalhos foi o neoinstitucionalismo em que as autoras identificaram dois processos de formulação de políticas distintos: a entrada da saúde bucal no Programa de Saúde da Família, em 2000, e a PNSB Brasil Sorridente, em 2004. A principal contribuição de Bartole (2006) foi identificar esses momentos como "janela de oportunidade", compreendida como situações que favorecem a convergência da construção social do problema da saúde bucal, das alternativas para seu enfrentamento num clima político favorável para a tomada de decisão, formando a agenda governamental e posteriormente decisória. Também houve a atuação de atores dos movimentos políticos, incluindo o movimento sanitário, compromissados com a saúde bucal e reconhecidos como um grupo com forte matiz político-partidária fora do espaço institucional do governo e posteriormente, dentro dele. (GARCIA, 2013) Andrade (2009) e Rendeiro (2011) também chegam às mesmas conclusões, ainda que com referenciais de análise política distintos. O primeiro (ANDRADE, 2009), em uma dissertação de mestrado, publicada posteriormente em formato de livro pela editora da Universidade Federal de Goiás, reafirma a força desse grupo a partir da categoria poder em Hannah Arendt, como atributo central de grupos que constroem vontade comum. A conclusão é que foi um processo envolvendo agentes sociais engajados na militância política que construíram a proposta, com poucas alternativas. O grupo inicial produziu vontade comum, ou poder no sentido arendtiano (ANDRADE, 2009), mas também foi considerado como uma comunidade epistêmica. (RENDEIRO, 2011) Este último trabalho foi uma tese de doutorado defendida na Escola Nacional de Saúde Pública, de referencial neoinstitucionalista.

Em síntese, os estudos sobre a entrada na agenda apresentam duas vertentes, não excludentes entre si: a oficial, que aponta que os dados dos inquéritos epidemiológicos, como o alto percentual de perda dental entre adultos e a 
baixa percentagem de procedimentos odontológicos especializados no sistema público, subsidiaram de forma relevante a construção da PNSB; e outra que defende que a entrada na agenda e a formulação de algumas alternativas políticas resultou da atuação de distintos grupos de interesse, com participação ativa da comunidade epistêmica (RENDEIRO, 2011), os militantes de esquerda e pesquisadores (BARTOLE, 2006; GARCIA, 2013), bem como do "poder emanado de um grupo de pessoas que age em comum acordo, com legitimidade da reunião inicial" (ARENDT, 1985, p. 28), por referência ao encontro inicial que foi a reunião de São Paulo, em 2002, quando um grupo de militantes elaborou um documento a ser entregue ao presidente Lula, recém-eleito.

A produção de conhecimento sobre os processos políticos envolvidos na implementação e avaliação da política no Brasil, tanto no nível estadual e municipal, não foi foco deste capítulo em particular. Pouco se sabe a esse respeito. Esforços devem ser empreendidos pelos pesquisadores e gestores no sentido da incorporação da melhor teoria possível para produzir o êxito em todo o ciclo da política pública. Reconhecer e compreender as relações de poder e dominação em jogo entre os agentes sociais interessados já é um grande primeiro passo para a transformação das relações de dominação simbólica.

\section{Referências}

ANDRADE, F. R. Relações de poder na Política Nacional de Saúde Bucal. Goiania: Editora UFG, 2009. (Coleção Expressão Acadêmica).

ARENDT, H. Da violência. Brasília: Editora Universidade de Brasília, 1985.

ARENDT, H. Poder e violência. Rio de Janeiro, Relume Dumará, 2001. p. 81-94.

AROUCA, S. O dilema preventivista: contribuição para a compreensão e crítica da medicina preventiva. Rio de Janeiro: Fiocruz/Unesp, 2007.

ASSIS, L. N. de. Politicas de saude bucal no periodo pos-constituinte (1988-2004). 2006. 392 f. Dissertação (Mestrado em Saúde Coletiva) - Instituto de Saude Coletiva, Universidade Federal da Bahia, Salvador, 2006.

BARROS, S. G. A política nacional de luta contra a aids e o espaço aids no Brasil. 2013. $274 \mathrm{f}$. Tese (Doutorado em Saúde Coletiva) - Instituto de Saúde Coletiva, Universidade Federal da Bahia, Salvador, 2013.

BARTOLE, M. C. S. A construção da política Nacional de Saúde Bucal: percorrendo os bastidores do processo de formulação 2000-2004. 2006. 104 f. Dissertação (Mestrado em Saúde Coletiva) - Instituto de Medicina Social, Universidade do Estado do Rio de Janeiro, Rio de Janeiro, 2006 
BOBBIO, N.; MATEUCCI, N.; PASQUINO, G. Dicionário de Política. 3. ed. Brasília: Editora UNB, 1991. p. 579-581. v. 1.

BOURDIEU, P. Razões práticas: sobre a teoria da ação. 6. ed. Campinas, SP: Papirus; 1996 BOURDIEU, P. Pontos de referências. In: BOURDIEU, P. Coisas ditas. Tradução Cássia Silveira e Denise Pegorim. São Paulo: Brasiliense, 2004. p. 49-73.

BOURDIEU, P. Questões de sociologia. Lisboa: Fim de Século, 2003.

BOURDIEU, P. Sobre o estado. São Paulo: Companhia das Letras, 2014.

BURAWOY, M. O marxismo encontra Bourdieu. Tradução Fernando Rogério Jardim. Campinas: Editora da Unicamp, 2010. 183p.

CARVALHO, L. A. C et al. Procedimentos coletivos de saúde bucal: gênese, apogeu e ocaso. Saúde e Sociedade, São Paulo, v. 18, n. 3, p. 490-499, 2009. Disponível em: <http:// www.scielo.br/scielo.php?script=sci_arttext\&pid=So104-12902009000300013>. Acesso em: 14 jun. 2016.

CHAVES, S. C. L.; VIEIRA-DA-SILVA, L. M. As práticas profissionais no campo público de atenção à saúde bucal: o caso de dois municípios da Bahia.Ciênia \& saúde coletiva, Rio de Janeiro, v. 12, n. 6, p. 1697-1710, dez. 2007.

CHAZEL, F. Poder. Tratado de Sociologia. Org. Raymond Boudon. Rio de Janeiro: Jorge Zahar Editor. 1995 .

FISHER, F.; MILLER, G. J.; SIDNEY, M. S. Handbook of public cpolicy analysis: theory, politics, and methods. Part II policyprocess. Boca Raton: CRC Press, 2007.

GARCIA, D. V. Sobre os bastidores do processo de formulação de políticas públicas: considerações acerca da saúde bucal no Brasil. Revista de Políticas Públicas. São Luis, v. 17, n. 1, p. 203-209, jan./jun., 2013.

GIDDENS, A. Central Problems in Social Theory. London: Macmillan, 1978.

GRAMSCI, A. Cadernos do cárcere. Rio de Janeiro: Civilização Brasileira, 1978. v. 2.

GRAMSCI, A. Cadernos do cárcere. Tradução Carlos Nelson Coutinho. Rio de Janeiro: Civilização Brasileira, 2000. v. 3.

HABERMAS, J. The theory of communicative action. Reason and the rationalizalion of society. Boston: Beacon Press, 1984. v. 1.

KINGDON, J. Agendas, alternatives, and public policies. New York: Logman, 1995.

LIMA, L. D.; MACHADO, C. V.; GERASSI, C. D. O neo-institucionalismo e a análise de políticas de saúde: contribuições para uma reflexão crítica. In: MATTOS, R. A.; BAPTISTA, T. W. (Org.). Caminhos para análise das políticas de saúde, 2011. Disponível em: <www.ims. uerj.br>. Acesso em: 16 maio 2016.

LIMA, W. G. Política pública: discussão de conceitos. Interface, Porto Nacional, n. 5, p. 4954, out. 2012.

MARX, K.; ENGELS, F. Manifesto do Partido Comunista. 9. ed. Petrópolis, RJ: Vozes, 1999. 
MATUS, C. Política, planejamento e governo. 2. ed. Brasília, DF: Instituto de Pesquisa Econômica Aplicada, 1996.

MOYSÉS S. J et al. Avanços e desafios à política de vigilância à saúde bucal no Brasil. Revista de Saúde Pública, São Paulo, v. 47, suppl. 3, p. 161-167, 2013, Disponível em: <http:// www.scielo.br/pdf/rsp/v47s3/0034-8910-rsp-47-supl3-00161.pdf>. Acesso em: 16 maio 2016.

PAIM, J. S. Políticas de saúde no Brasil. In: ROUQUAYROL, M. Z.; ALMEIDA FILHO, N. Epidemiologia e saúde. 6. ed. Rio de Janeiro: MEDSI, 2003. p. 587-603.

PAIM, J. S.; TEIXEIRA, C. F. Política, planejamento e gestão em saúde: balanço do estado da arte. Revista de Saúde Pública, São Paulo, v. 40, n. Esp., p. 73-78, agosto 2006.

PAIM, J. S. Saúde política e reforma sanitária. Salvador: ISC-CEPS, 2002. v. 1.

PINELL, P. Algumas reflexões sobre as políticas de luta contra os flagelos sociais. In: PINELL, P. Análise sociológica das políticas de saúde. Rio de Janeiro: Editora Fiocruz, 2011. p. 229-250.

PIRES, F. S.; BOTAZZO, C. Organização tecnológica do trabalho em saúde bucal no SUS: uma arqueologia da política nacional de saúde bucal. Saúde e Sociedade, São Paulo, v. 24, n. 1, p. 273-284, mar. 2015 .

PLATÃO. A República. Tradução Anna Lia Amaral de Almeida Prado. São Paulo: Martins Fontes, 2006.

RENDEIRO, M. M. P. O ciclo da Política de Saúde Bucal no Sistema Público Brasileiro: atores, idéias e instituições. 2011. 188 f. Tese (Doutorado em Saúde Coletiva) - Escola Nacional de Saúde Pública Sergio Arouca, Rio de Janeiro, 2011.

ROSSI, T. R. A; CHAVES, S. C. L. A política de saúde bucal na atenção especializada em dois municípios da Bahia: da entrada na agenda à sua implementação. Revista Saúde em Debate, Rio de Janeiro, v. 39, n. spe, p. 196-206, dez. 2015

SABATIER, P. A.Theories of the policy process. Boulder, CO: West view Press. 2007.

SOARES, C. L. M. Constructing public oral health policies in Brazil: issues for reflection. Brazilian Oral Research, São Paulo, v. 26, n. spe1, p. 94-102. 2012. Disponível em: $<$ http://www.scielo.br/scielo.php?script=sci_arttext\&pid=S1806-83242012000700014>. Acesso em: 16 maio 2016.

SOARES, C. L. M. ; PAIM, J. S. Aspectos críticos para a implementação da política de saúde bucal no Município de Salvador, Bahia, Brasil. Cadernos de Saúd Pública, Rio de Janeiro, v. 27, n. 5, p. 966-974, maio, 2011.

SOUZA, C. Estado da arte da pesquisa em políticas públicas. In: HOCHMAN, G.; ARRETCHE, M.; MARQUES, E. Políticas públicas no Brasil. Rio de Janeiro: Editora FioCruz, 2007.

TESTA, M. Pensamento estratégico e lógica da programação. Rio de Janeiro: São Paulo: HUCITEC, 1995.

TESTA, M. Pensar em saúde. Porto Alegre: Artes Médicas: ABRASCO, 1992. 
VIANNA, M. I. P. Estado e atenção odontológica no Brasil: um estudo sobre as políticas de saúde bucal na conjuntura pós-74. 211 f. (Mestrado em Saúde Comunitária) - Instituto de Saúde Coletiva, Universidade Federal da Bahia, Salvador, 1988.

VIEIRA-DA-SILVA, L. M. Avaliação de políticas e programas de saúde. Rio de Janeiro: Editora Fiocruz; 2014. (Temas em Saúde Coletiva)

VILASBOAS, A. L. Q.; PAIM, J. S. Práticas de planejamento e implementação de políticas no âmbito municipal. Cadernos de Saúde Pública, Rio de Janeiro, v. 24, n. 6, p. 12391250, jun. 2008.

WALT, G. et al. Doing' health policy analysis: methodological and conceptual reflections and challenges. Health Policy and Planning, Oxford, v. 23, p. 308-317, 2008.

WEBER, M. Economia e sociedade. Brasília: Editora UNB, 2004. v. 2.

WEBER, M. Ciência e política: duas vocações. 21. ed. São Paulo: Editora Cultrix, 2014. 


\section{Quadro 1 - Estudos de análise política em saúde bucal no Brasil, no século XXI, no âmbito nacional, a partir do momento do ciclo da política, abordagem teórico-metodológica e principais conclusões \\ (continua)}

\begin{tabular}{|c|c|c|}
\hline Autor, ano & $\begin{array}{l}\text { Garcia, D. do V. 2006. A construção da política nacional de saúde } \\
\text { bucal percorrendo os bastidores do processo de formulação. } \\
(2000-2004) \\
\text { IMS-UERJ }\end{array}$ & $\begin{array}{c}\text { Bartole, M. C. S. 2006. [dissertação de mestrado]. Da } \\
\text { boca cheia de dentes ao Brasil Sorridente: uma análise } \\
\text { retórica da formulação da política nacional de saúde } \\
\text { bucal. } \\
\text { IMS-UERJ }\end{array}$ \\
\hline $\begin{array}{l}\text { Ciclo da política/ } \\
\text { período }\end{array}$ & $\begin{array}{l}\text { Entrada na agenda } \\
\text { Formulação } \\
\text { 2000-2004 }\end{array}$ & $\begin{array}{l}\text { Entrada na agenda } \\
\text { Formulação } \\
\text { 2000-2004 }\end{array}$ \\
\hline $\begin{array}{l}\text { Abordagem teórico- } \\
\text { metodológica e } \\
\text { conceitos-chave }\end{array}$ & $\begin{array}{l}\text { Neoinstitucionalismo. Análise do ator institucional, Ministério da } \\
\text { Saúde, análise de documentos oficiais e entrevistas com atores } \\
\text { privilegiados. } \\
\text { Ator institucional, a coordenação nacional de saúde bucal, janela } \\
\text { de oportunidade. Agenda. }\end{array}$ & $\begin{array}{l}\text { Análise dos discursos que compuseram a processo de } \\
\text { formulação. Análise da retórica dos documentos para } \\
\text { observar o processo político. }\end{array}$ \\
\hline Principais conclusões & $\begin{array}{c}\text { Dois processos de formulação de políticas distintos: a entrada da } \\
\text { saúde bucal no PSF em } 2000 \text { e a PNSB Brasil Sorridente, em } 2004 . \\
\text { No primeiro, aproveitamento de uma janela de oportunidades } \\
\text { por técnicos ligados à saúde bucal. No segundo, um processo } \\
\text { de construção de um projeto por um grupo com forte matiz } \\
\text { político-partidária, fora do espaço institucional do governo e } \\
\text { posteriormente, dentro dele. }\end{array}$ & $\begin{array}{l}\text { Destacaram-se a existência de dois processos de } \\
\text { formulação de políticas distintos que foram: a entrada } \\
\text { da saúde bucal no PSF e a PNSB Brasil Sorridente. }\end{array}$ \\
\hline
\end{tabular}


Quadro 1 - Estudos de análise política em saúde bucal no Brasil, no século XXI, no âmbito nacional, a partir do momento do ciclo da política, abordagem teórico-metodológica e principais conclusões

(continuação)

\begin{tabular}{|c|c|}
\hline Autor, ano & $\begin{array}{l}\text { Andrade, F. R. de.2009. [dissertação de mestrado]. } \\
\text { Relações de poder na política nacional de saúde bucal. UFG }\end{array}$ \\
\hline Ciclo da política/período & $\begin{array}{l}\text { Entrada na agenda } \\
\text { Formulação } \\
\text { 2002-2004 }\end{array}$ \\
\hline $\begin{array}{l}\text { Abordagem teórico- } \\
\text { metodológica e } \\
\text { conceitos-chave }\end{array}$ & $\begin{array}{l}\text { Estudo com abordagem qualitativa que analisou as relações de poder na elaboração da PNSB. Foram conduzidas } \\
\text { entrevistas semiestruturadas com } 15 \text { atores. Conceitos ou categorias chave: atores participantes, tipo de participação, } \\
\text { início da elaboração, arenas de discussão, contexto político, impasses atuais e perspectivas. Poder na concepção } \\
\text { arendtiana, como atributo de grupos que constroem vontade comum, foi central. }\end{array}$ \\
\hline Principais conclusões & $\begin{array}{l}\text { Os atores participantes encontram-se divididos em dois grupos: individuais e coletivos. O primeiro deles, coeso, é } \\
\text { formado por indivíduos identificados com o projeto político vitorioso nas eleições presidenciais de } 2002 \text { e que possuem } \\
\text { um passado de militância na construção do Sistema Único de Saúde (SUS). A PNSB foi resultado de reflexões desde } \\
\text { o Movimento da Reforma Sanitária, com destaque para um encontro realizado no município de São Paulo logo após o } \\
\text { resultado do pleito eleitoral referente à candidatura à presidência da República de Lula em 2002. Essa reunião definiu a } \\
\text { proposta que foi apresentada aos membros da Comissão de Transição Governamental. }\end{array}$ \\
\hline
\end{tabular}




\section{Quadro 1 - Estudos de análise política em saúde bucal no Brasil, no século XXI, no âmbito nacional, a partir do momento do ciclo da política, abordagem teórico-metodológica e principais conclusões \\ (continuação)}

\begin{tabular}{|c|c|}
\hline Autor, ano & $\begin{array}{l}\text { Rendeiro, M., 2011. [tese de doutorado]. } \\
\text { O ciclo da política de saúde bucal no sistema de saúde brasileiro: atores, ideias e Instituições. } \\
\text { ENSP-FIOCRUZ }\end{array}$ \\
\hline $\begin{array}{l}\text { Ciclo da política/ } \\
\text { período }\end{array}$ & $\begin{array}{l}\text { Entrada na agenda } \\
\text { Formulação } \\
\text { 2000-2010 }\end{array}$ \\
\hline $\begin{array}{l}\text { Abordagem teórico- } \\
\text { metodológica e } \\
\text { conceitos-chave }\end{array}$ & $\begin{array}{l}\text { Neoinstitucionalismo, com foco nos atores, ideias e instituições, verificando as características do processo, as ideias, } \\
\text { atores e instituições. Entrevistas com } 12 \text { informantes-chave e dados secundários, por meio da pesquisa documental } \\
\text { e acesso aos bancos de dados do DATASUS, além da pesquisa documental. Empreendedor de políticas. Comunidade } \\
\text { epistêmica (acadêmicos, pesquisadores, consultores, sindicalistas, profissionais das SES e SMS), construída ao longo } \\
\text { de um processo histórico, que envolveu a militância político-partidária e setorial. Grupos de Interesse. Conceitos-chave: } \\
\text { Inovação como a provisão em larga escala de novos serviços na área da odontologia. Governo. Ator social. }\end{array}$ \\
\hline Principais conclusões & $\begin{array}{l}\text { Identificou três ciclos de inovação: saúde bucal no PACS, saúde bucal no PSF, em 2000, e a publicação das diretrizes da } \\
\text { PNSB, em } 2003 \text {. A saúde bucal chegou à agenda decisória, como resultado de fato social e político da Pesquisa Nacional } \\
\text { por Amostra de Domicílios } 2008 \text { com continuidade de trajetória. Houve formação incremental do ciclo da PNSB por meio } \\
\text { de inovações progressivamente inseridas, com influência dos partidos hegemônicos das coligações presidenciais e com } \\
\text { a participação de atores associados aos interesses da classe odontológica. Houve um empreendedor de políticas que } \\
\text { articulou a comunidade epistêmica com o chefe do executivo no terceiro ciclo. Sem elementos do controle social. }\end{array}$ \\
\hline
\end{tabular}




\section{Quadro 1 - Estudos de análise política em saúde bucal no Brasil, no século XXI, no âmbito nacional, a partir do momento do} ciclo da política, abordagem teórico-metodológica e principais conclusões

(continuação)

\begin{tabular}{|c|c|}
\hline Autor, ano & $\begin{array}{l}\text { Carvalho, L. A. C. et al. 2009. [artigo]. } \\
\text { Procedimentos coletivos de saúde bucal: gênese, apogeu e o caso. } \\
\text { FSP-USP }\end{array}$ \\
\hline $\begin{array}{l}\text { Ciclo da política/ } \\
\text { período }\end{array}$ & $\begin{array}{l}\text { Formulação } \\
\text { Implementação } \\
\text { 1994-2006 }\end{array}$ \\
\hline $\begin{array}{l}\text { Abordagem teórico- } \\
\text { metodológica e } \\
\text { conceitos-chave }\end{array}$ & $\begin{array}{l}\text { Não explicita o referencial teórico. Estudo de natureza descritiva com revelação dos principais agentes envolvidos com sua } \\
\text { gênese e implementação. Fonte de dados: pesquisa bibliográfica e análise documental, abrangendo o período de } 1991 \text { a } \\
2006 .\end{array}$ \\
\hline Principais conclusões & $\begin{array}{l}\text { O procedimento coletivo foi criado no governo Collor (1990-1992), no pós Lei no 8080/90, na gestão Sérgio Weyne. } \\
\text { Pagamento por procedimento de ações de promoção e prevenção em saúde bucal em todos municípios brasileiros. A } \\
\text { coincidência com um período de intensificação do processo de municipalização das ações e dos serviços de saúde por } \\
\text { certo potencializou esse efeito. Contribuiu para diversificar o modelo de prática odontológica predominante no setor } \\
\text { público, redirecionando-o para ações preventivas e de promoção da saúde. }\end{array}$ \\
\hline
\end{tabular}




\section{Quadro 1 - Estudos de análise política em saúde bucal no Brasil, no século XXI, no âmbito nacional, a partir do momento do}

ciclo da política, abordagem teórico-metodológica e principais conclusões

(continuação)

\begin{tabular}{|c|c|}
\hline Autor, ano & $\begin{array}{l}\text { Assis, L. N. 2006. [dissertação de mestrado]. } \\
\text { Politicas de saúde bucal no período pós-constituinte (1988-2004). } \\
\text { ISC-UFBA }\end{array}$ \\
\hline $\begin{array}{l}\text { Ciclo da política/ } \\
\text { período }\end{array}$ & $\begin{array}{c}\text { Implementação } \\
\text { 1999-2004 }\end{array}$ \\
\hline $\begin{array}{l}\text { Abordagem teórico- } \\
\text { metodológica e } \\
\text { conceitos-chave }\end{array}$ & $\begin{array}{l}\text { Identifica os principais fatos políticos em saúde bucal produzidos no âmbito dos governos dos presidentes Fernando } \\
\text { Henrique Cardoso (1999-2002) e Luís Inácio Lula da Silva (2003-2004), a partir dos componentes do sistema de saúde } \\
\text { como gestão, financiamento, organização, infraestrutura e modelo de atenção estudo de caso, de base documental. Fonte } \\
\text { de dados: leis, projetos de lei, normas, portarias, decretos, medidas provisórias, manuais, relatórios, referentes à atenção à } \\
\text { saúde bucal. }\end{array}$ \\
\hline Principais conclusões & $\begin{array}{l}\text { Evolução das políticas de saúde bucal formuladas e implementadas nos governos FHC e Lula, porém, pode-se inferir que } \\
\text { a viabilidade a longo prazo da odontologia no SUS apresenta a mesma limitação tratada por Vianna diante do caráter } \\
\text { secundário dessas políticas, que concorrem com políticas de maior gravidade da saúde. Dentre os componentes do sistema } \\
\text { de saúde, o modelo de atenção continua sendo o mais problemático. }\end{array}$ \\
\hline
\end{tabular}




\section{Quadro 1 - Estudos de análise política em saúde bucal no Brasil, no século XXI, no âmbito nacional, a partir do momento do} ciclo da política, abordagem teórico-metodológica e principais conclusões

(continuação)

\begin{tabular}{|c|c|}
\hline Autor, ano & $\begin{array}{c}\text { Pires F. S., Botazzo C. 2015. [artigo]. Organização tecnológica do trabalho em saúde bucal no SUS: uma arqueologia da } \\
\text { política nacional de saúde bucal. Saúde Sociedade, USP-SP }\end{array}$ \\
\hline $\begin{array}{l}\text { Ciclo da política/ } \\
\text { período }\end{array}$ & $\begin{array}{l}\text { Implementação } \\
\text { nacional } \\
\text { 2000-2012 }\end{array}$ \\
\hline $\begin{array}{l}\text { Abordagem teórico- } \\
\text { metodológica e } \\
\text { conceitos-chave }\end{array}$ & $\begin{array}{l}\text { Discute a organização tecnológica dos modelos de atenção à saúde bucal à luz da PNSB. O referencial teórico-- } \\
\text { metodológico estruturou-se em um histórico das políticas de saúde bucal no Brasil, buscando apreender o saber operante } \\
\text { que norteou a prática neste campo. A abordagem das políticas de saúde foi realizada sob a teoria de Michel Foucault na } \\
\text { obra Arqueologia do Saber. Utilizou-se de revisão de documentos normativos do SUS e de publicações do período de } 2000 \\
\text { a } 2012 .\end{array}$ \\
\hline Principais conclusões & $\begin{array}{l}\text { O levantamento de artigos sobre a atual PNSB destacou nos serviços um modus operandi calcado na pragmática prática } \\
\text { odontológica, plena de conflitos e contradições. Para que as diretrizes da PNSB transformem a prática em saúde bucal com } \\
\text { novos arranjos tecnológicos no processo de trabalho, outras formas de vínculo e comprometimento devem ser almejadas. } \\
\text { A pesquisa conclui que é necessário repensar a tecnologia do cuidado em saúde bucal como possibilidade da atenção com } \\
\text { integralidade e de sua legitimação como um dos componentes da saúde em uma expressão ampliada: a da qualidade de vida. }\end{array}$ \\
\hline
\end{tabular}




\section{Quadro 1 - Estudos de análise política em saúde bucal no Brasil, no século XXI, no âmbito nacional, a partir do momento do}

ciclo da política, abordagem teórico-metodológica e principais conclusões

(continuação)

\begin{tabular}{|c|c|}
\hline Autor, ano & Moysés S. J et al. 2013. Avanços e desafios à política de vigilância à saúde bucal no Brasil. PUC-PR. \\
\hline $\begin{array}{l}\text { Ciclo da política/ } \\
\text { período }\end{array}$ & $\begin{array}{l}\text { Implementação vigilância à saúde bucal } \\
2009-2010\end{array}$ \\
\hline $\begin{array}{l}\text { Abordagem teórico- } \\
\text { metodológica e } \\
\text { conceitos-chave }\end{array}$ & $\begin{array}{c}\text { Pesquisa participante. Revisão crítica e integrativa, de caráter descritivo-discursivo, dedicada à explanação da política de } \\
\text { vigilância à saúde bucal vigente no Brasil. Com base em uma apreciação crítica dos trabalhos nacionais e internacionais, } \\
\text { examina-se a formulação de uma agenda política e científica em vigilância à saúde bucal, ancorada na institucionalidade do } \\
\text { SUS. }\end{array}$ \\
\hline Principais conclusões & $\begin{array}{l}\text { A efetivação da referida agenda é exemplificada com a apresentação da Pesquisa Nacional de Saúde Bucal (SBBrasil 2010), } \\
\text { que evidenciou que é possível construir política e operacionalmente maior integração entre a academia e os serviços de } \\
\text { saúde. A implementação da vigilância à saúde bucal, integrada estrategicamente ao SNVS, traduz-se em um elemento } \\
\text { essencial para a sustentabilidade da PNSB e para o progressivo reconhecimento das boas práticas do SUS pela população. }\end{array}$ \\
\hline
\end{tabular}




\section{Quadro 1 - Estudos de análise política em saúde bucal no Brasil, no século XXI, no âmbito nacional, a partir do momento do ciclo da política, abordagem teórico-metodológica e principais conclusões \\ (conclusão)}

\begin{tabular}{|c|c|}
\hline Autor, ano & $\begin{array}{l}\text { Soares, C. L. M. 2012. Constructing public oral health policies in Brazil: issues for reflection. Braz. oral res., } \\
\text { ISC-UFBA }\end{array}$ \\
\hline $\begin{array}{l}\text { Ciclo da política/ } \\
\text { período }\end{array}$ & $\begin{array}{l}\text { Implementação } \\
\text { histórico das políticas }\end{array}$ \\
\hline $\begin{array}{l}\text { Abordagem teórico- } \\
\text { metodológica e } \\
\text { conceitos-chave }\end{array}$ & $\begin{array}{l}\text { Análise documental, buscando identificar os principais movimentos ideológicos em saúde bucal no mundo que tiveram } \\
\text { influência no Brasil, relacionando com as respostas estatais em saúde bucal no Brasil ao longo do século XX e no início XXI, } \\
\text { destacando-se a PNSB formulada em 2004. Conceito de movimentos ideológicos como um conjunto de atividades visando } \\
\text { transformar a "visão de mundo" em uma “nova visão de mundo" com um corpo coerente de ideias (Arouca, 2007), e de } \\
\text { hegemonia (Gramsci, 1996). }\end{array}$ \\
\hline Principais conclusões & $\begin{array}{l}\text { O estudo identificou quatro movimentos ideológicos relacionados às políticas públicas de saúde bucal no Brasil, mas } \\
\text { revelou a hegemonia das ideias em torno da odontologia de mercado, ou odontologia privada mesmo ao interior dos } \\
\text { serviços públicos. Dentre os movimentos ao interior do serviço público, identificou-se a odontologia sanitária ou social. } \\
\text { A odontologia simplificada, a odontologia preventiva e social e o movimento da saúde bucal coletiva. Ainda que haja } \\
\text { progressiva expansão da intervenção do Estado nas políticas de saúde bucal, é observado que continua hegemônica a } \\
\text { prática da odontologia privada no setor público e na estratégia de saúde da família. }\end{array}$ \\
\hline
\end{tabular}

Fonte: bases de dados Lilacs e Scielo. 


\section{Necessidades e problemas de saúde bucal no Brasil e tendências para as políticas de saúde}

Maria Cristina Cangussu

Johelle Passos-Soares

Maria Beatriz Cabral

\section{Introdução}

O presente capítulo propõe revisitar alguns problemas considerados importantes na saúde coletiva, bem como as ações desenvolvidas na atual Política Nacional de Saúde Bucal (PNSB) para o enfrentamento desses problemas na população. Na odontologia, utiliza-se como critérios de seleção e priorização dos problemas em saúde coletiva a magnitude, gravidade e vulnerabilidade do dano à saúde, bem como o impacto potencial das medidas de controle disponíveis para o seu enfrentamento. Outro aspecto muito importante é a transcendência social do problema e o grau de interferência na qualidade de vida dos indivíduos. (PINTO, 1994)

Nesse sentido, serão discutidos os aspectos epidemiológicos atuais dos seguintes problemas de saúde bucal: cárie dentária, doença periodontal, câncer bucal e fluorose, sendo também introduzidos outros problemas cuja relevância epidemiológica tem aumentado, seja em função das causas gerais de morbi-mortalidade, como os traumas dentários e de face, seja em função da mudança 
do perfil epidemiológico da população brasileira e importância social do problema, como as alterações de oclusão.

\section{Cárie dentária}

A cárie dentária é, ainda, um problema de saúde pública persistente na população brasileira. Estudos sistemáticos no país com o objetivo de mensurar a sua magnitude e severidade só ocorreram após 1950, no âmbito dos programas incrementais, seja para avaliar as estratégias adotadas à época pela Fundação Serviço de Saúde Pública, seja para justificar a intervenção em saúde bucal. (NARVAI, 2006)

Inquéritos de abrangência nacional que levaram em consideração amostras representativas, assim como estudos locais de cunho científico, tornaram-se mais frequentes a partir de 1980. (RONCALLI et al., 2012) Também nesse período, inúmeras iniciativas de organização dos serviços e mudanças na prática da saúde bucal, no contexto da Reforma Sanitária Brasileira puderam ser registradas. Na última década do século XX, e primeira do século XXI (já na vigência da atual PNSB), foram implantadas e expandidas importantes intervenções em saúde bucal em todo o país, tendo como referência o princípio constitucional da universalização das ações e serviços de saúde, a exemplo da fluoretação das águas de abastecimento público, do atendimento odontológico da rede pública do Sistema Único de Saúde (SUS) e da adição de compostos fluorados aos dentifrícios. (ANTUNES; NARVAI, 2010)

Destaca-se, nesse contexto, a partir de 2004, a PNSB, que também apresenta foco na saúde da família enquanto estratégia para a reorganização das práticas, ampliação e qualificação da atenção secundária e terciária através dos Centros de Especialidades Odontológicas (CEO) e Laboratórios Regionais de Prótese Dentária e a ampliação da fluoretação das águas de abastecimento público. (BRASIL, 2004a)

É importante assim, refletir sobre a realidade epidemiológica brasileira visando a reorientação de futuras ações da PNSB. Observa-se, de forma clara, uma tendência de redução da prevalência e severidade da cárie dentária na população jovem, consistente também com o controle da doença em grande parte do mundo ocidental, a exemplo do Brasil (Quadros 1 e 2), especialmente nos últimos 30 anos. Essa tendência também está presente em adultos jovens, embora com menor intensidade. Já aos cinco anos, continua apresentando condição persistente desse agravo, assim como adultos e idosos (Quadro 1). 
Quadro 1 - Média do CPOD/ceod nas idades/faixas etárias índices, segundo ano do levantamento epidemiológico nacional

\begin{tabular}{|l|c|c|c|c|}
\hline \multirow{2}{*}{ Idade - Faixas etárias } & \multicolumn{4}{|c|}{ CPOD/ceod } \\
\cline { 2 - 5 } & 1986 & 1996 & $2002-2003$ & 2010 \\
\hline 5 anos* $^{*}$ & - & - & 2,89 & 2,43 \\
\hline 12 anos & 6,65 & 3,06 & 2,78 & 2,07 \\
\hline $15-19$ anos & 12,68 & - & 6,17 & 4,25 \\
\hline $35-44$ anos & 22,50 & - & 20,13 & 16,75 \\
\hline $65-74$ anos $^{* *}$ & 27,22 & - & 27,79 & 27,03 \\
\hline
\end{tabular}

*valores referem-se ao ceod

**no ano de 1986, esse grupo correspondia a faixa etária de 50-59 anos.

Fonte: Brasil (1988), Brasil (1996), Brasil (2004a), Brasil (2011).

Destaca-se também em pré-escolares e jovens, um alto percentual de doença não tratada, bem como uma alta participação do componente perdido em adultos e idosos (Quadro 2), com redução maior apenas nas faixas etárias de 15-19 anos e 35-44 anos, entre os anos de 2002- 2003 e 2010.

Quadro 2 - Percentual de cárie não tratadas por faixas etária de 5, 12 e 15-19 anos e percentual de participação do componente perdido $(P)$ nas faixas etárias de 35-44 e 6574 anos, nos levantamentos nacionais após o ano 2000

\begin{tabular}{|l|c|c|c|c|}
\hline $\begin{array}{c}\text { Idade - Faixa } \\
\text { etária }\end{array}$ & \multicolumn{2}{|c|}{$\begin{array}{c}\text { Percentual de cárie não tratada no } \\
\text { CPOD (\%) }\end{array}$} & $\begin{array}{c}\text { Percentual de dentes perdidos no } \\
\text { CPOD (\%) }\end{array}$ \\
\hline & $2002-2003$ & 2010 & $2002-2003$ & 2010 \\
\hline 5 anos & 82,1 & 80,2 & 2,9 & 2,5 \\
\hline 12 anos & 58,3 & 54,1 & 6,5 & 5,8 \\
\hline $15-19$ anos & 42,1 & 35,8 & 14,4 & 8,9 \\
\hline 35-44 anos & 11,6 & 8,8 & 65,7 & 44,7 \\
\hline $65-74$ anos & 4,2 & 1,9 & 92,9 & 91,9 \\
\hline
\end{tabular}

Fonte: Brasil (2004a), Brasil (2011). 
Embora a redução da gravidade da doença, mensurada pela proporção de cárie não tratada e dentes perdidos mostre-se de extrema importância para o controle da doença em si, implementações de outras medidas necessárias aos serviços de saúde que deêm conta de uma das piores sequelas cumulativas da cárie, a perda do elemento dentário, requerem investimentos políticos e financeiros de modo assegurar a reabilitação protética de milhões de indivíduos.

Um dos grandes avanços da PNSB é explicitar a necessidade de reabilitação através da organização, implantação e expansão da cobertura dos CEO e Laboratórios Regionais de Prótese Dentária. (BRASIL, 2008) Tal fato pode ser confirmado pelo financiamento dessas ações, cujo montante de recursos envolveu, apenas no âmbito do governo federal, investimentos anuais que passaram de 56,5 milhões de reais, em 2003, para 427 milhões de reais, em 2005, e atingiram cerca de 600 milhões, em 2008, totalizando aproximadamente $\mathrm{R} \$ 2,4$ bilhões no período. (FRAZÃO; NARVAI, 2009)

O impacto dessas ações já pode ser percebido nas faixas etárias mais jovens (15 a 19 anos) e no maior uso de prótese na faixa etária de 65-74 anos (Quadro 3). Entretanto, a necessidade de saúde da população adulta permanece como uma demanda histórica, envolvendo alto grau de complexidade e de cobertura, a exemplo das próteses fixas e removíveis, que são menos ofertadas pelos serviços de saúde. (MIOTTO et al., 2012) Na população jovem, a redução do CPOD implica menor carga de doença e tem sido acompanhada da sua concentração em grupos específicos, reforçando as iniquidades em saúde e o fenômeno da polarização. (BRASIL, 2004a; NARVAI et al. 2006; BRASIL, 2011) Esse grupo, considerado de alto risco, necessitaria de ações específicas (ROSE, 2010), colocadas de forma complementar no guia de utilização de fluoretos no Brasil (BRASIL, 2009) incluindo a escovação dental supervisionada, bochechos fluorados, uso do flúor gel, vernizes e materiais com flúor, sendo, todos esses métodos, dependentes do acesso e cobertura dos serviços de saúde. É claro que existe a necessidade de adequação de cada um desses métodos ao perfil epidemiológico da população-alvo. 
Quadro 3 - Percentual do uso e necessidade de prótese nas faixas etárias de 15-19 anos, 35-44 e 65-74 anos, nos levantamentos nacionais após o ano 2000.

\begin{tabular}{|l|c|c|c|c|c|c|}
\hline \multirow{2}{*}{ Faixa etária } & \multicolumn{2}{|c|}{$\begin{array}{c}\text { Percentual uso de } \\
\text { prótese superior }\end{array}$} & \multicolumn{2}{c|}{$\begin{array}{c}\text { Percentual uso de } \\
\text { prótese inferior }\end{array}$} & \multicolumn{2}{c|}{$\begin{array}{c}\text { \% necessidade de } \\
\text { prótese }\end{array}$} \\
\hline & $\mathbf{2 0 0 2 - 2 0 0 3}$ & $\mathbf{2 0 1 0}$ & $\mathbf{2 0 0 2 - 2 0 0 3}$ & $\mathbf{2 0 1 0}$ & $\mathbf{2 0 0 2 - 2 0 0 3}$ & $\mathbf{2 0 1 0}$ \\
\hline 15-19 anos & 1,9 & 3,7 & 0,2 & 0,6 & 20,2 & 13,7 \\
\hline 35-44 anos & 48,3 & 32,8 & 15,3 & 10,1 & 70,1 & 68,8 \\
\hline 65-74 anos & 66,5 & 76,5 & 42,7 & 53,9 & 54,5 & 92,7 \\
\hline
\end{tabular}

Fonte: Brasil (2004a), Brasil (2011).

Ressalta-se, nos últimos 10 anos, a importância e diversidade da participação dos pesquisadores brasileiros nos estudos etiológicos sobre a cárie dentária. O Brasil possui mais de 9.000 artigos publicados no ISI Web of Science (Instituto para Informação Científica), nesse período, sobre a epidemiologia dessa alteração em todas as faixas etárias, sendo a maioria deles envolvendo crianças e adolescentes.

Estes apontam que, apesar dos inegáveis avanços no controle da cárie dentária, ainda persiste um quadro de iniquidade na distribuição da doença, identificado também nos levantamentos nacionais de 2002-2003 e 2010. A cárie está mais presente entre aqueles de menor nível socioeconômico ou maior vulnerabilidade social (BRASIL,1988; CARDOSO, 2003; CANGUSSU, CASTELLANOS, 2004; SOUZA et al., 2006), condições expressas, na maior parte dos trabalhos, por piores condições de vida, escolaridade ou renda. (ANTUNES; JAHN; CAMARGO, 2005; PEREIRA et al., 2010) Nos levantamentos nacionais, são visíveis as diferenças dos indicadores em relação ao porte populacional, acesso à água fluoretada e macrorregião do país. (BRASIL, 2004a; BRASIL, 2011)

Assim, não restam dúvidas que medidas sociais e econômicas mais gerais, voltadas ao enfrentamento da exclusão social e intervenções de saúde pública complementares de proteção à saúde bucal, dirigidas aos grupos mais vulneráveis, são fundamentais para o controle da doença.

Dentre as medidas de cobertura populacional que contribuíram para a redução da doença temos a fluoretação das águas de abastecimento público. $\mathrm{O}$ uso dessa tecnologia se iniciou há mais de meio século no país, com determinação legal - Lei ${ }^{0}$ 6.050, de 24 de maio de 1974, regulamentada pelo Decreto $\mathrm{n}^{\mathrm{o}} 76.872$, de 22 de dezembro de 1975. Em 2006, adotavam essa medida 45,7\% 
dos municípios brasileiros, beneficiando mais de 100 milhões de pessoas, aproximadamente $54 \%$ da população brasileira.

Contudo, os dados disponíveis apontam para uma extrema desigualdade no país com uma cobertura muito maior da fluoretação nos estados do Sul e Sudeste, onde se concentra a maior parte da riqueza, e insuficiente ou pouco sistematizada nas regiões Norte e Nordeste, onde, apenas as capitais e municípios com mais de 100.00 habitantes, com melhor renda e maior Índice de Desenvolvimento Humano a adotam. Assim, conforme coloca Antunes e Narvai (2010), uma das principais medidas de saúde pública efetiva na redução de desigualdades é, ela própria, objeto de profundas desigualdades em sua implantação.

A efetividade da fluoretação da água de abastecimento depende da sua manutenção e estabilidade dos teores de flúor dentro dos níveis adequados. Assim, o monitoramento constante dos equipamentos, bem como da manutenção da concentração de flúor dentro dos padrões recomendados é um problema nos sistemas de abastecimento. (RAMIRES; BUZALAF, 2007) A constatação de que, em muitas localidades brasileiras, ocorriam oscilações nas concentrações do flúor adicionado à água de abastecimento público, motivou a formulação de uma proposta para implantação de sistemas de vigilância sanitária da fluoretação das águas de abastecimento público, baseados no princípio do heterocontrole, embora ainda sejam escassos os estudos sobre o tema e o próprio monitoramento institucional no Brasil. (PANIZZI; PERES, 2008)

Afirma-se que a ação da fluoretação das águas no controle da cárie dentária diminui na atualidade, provavelmente, pelo emprego disseminado do flúor. É inegável que houve um aumento no uso de fontes alternativas de flúor, especialmente a adição do flúor aos dentifrícios, que, a partir de 1988, passaram a ser uma fonte significativa de flúor. A partir de 1990, praticamente 100\% dos dentifrícios vendidos no Brasil passaram a conter flúor em sua composição (LIMA; CURY, 2001), o que hoje contribui de forma significativa para a redução da experiência global de cárie no âmbito populacional. (NARVAI, 2006)

Do ponto de vista assistencial, outro elemento importante é que, de modo geral, o declínio da prevalência e severidade da cárie dentária não vem sendo acompanhado pela modificação dos padrões de oferta dos serviços de saúde. (NARVAI, 2006) Observa-se, no período entre 2004 e 2010, um expressivo crescimento na oferta de serviços de saúde na atenção básica, com quase o dobro de equipes de saúde bucal. Isso implicaria, por consequência, uma maior redução de dentes cariados e crescimento do componente restaurado, com 
maior impacto da reabilitação quando necessária. Entretanto, conforme pode ser constatado nos Quadros 2 e 3, a implantação da Estratégia Saúde da Família (ESF) e dos CEO, e o seu impacto ou resultado na saúde bucal da população brasileira, ainda é motivo de dissenso.

Narvai (2006) já colocava que a ampliação da cobertura dos serviços odontológicos, decorrente da descentralização do sistema de saúde brasileiro e dos investimentos no setor, assim como da maior disponibilidade de recursos odontológicos privados para a sociedade, não foi suficiente para alterar, significativamente, o padrão de composição do índice CPOD. Não há mudanças nos padrões de acesso e efetividade dos serviços, nem ao tipo de cuidado ofertado.

Reforçam esse argumento análises do modelo de atenção dos municípios com mais de 100.000 habitantes da região Nordeste, que encontraram resultados similares entre o modelo tradicional e a ESF nos aspectos relativos a morbidade, dor, acesso aos serviços, cobertura das ações curativas e preventivas. (PEREIRA et al., 2012) Assim, a incorporação da saúde bucal pelo setor público é ainda uma questão importante, considerando a magnitude do investimento e a proposta de inversão do modelo de atenção. Outros elementos precisarão ser analisados de forma local, como contexto político, organização e padrão da oferta dos serviços, processos de capacitação e envolvimento da equipe na prestação do cuidado, de forma a melhor compreender os seus papéis na organização à atenção à saúde bucal da população brasileira.

Por outro lado, as medidas populacionais têm, em muito, contribuído para a redução dos indicadores globais de cárie dentária no Brasil, mas de alguma forma, elas não superam completamente as iniquidades em saúde, visto que não são acessíveis a grupos de maior vulnerabilidade. Entretanto, apesar do aumento da oferta de serviços e a proposição de mudança do modelo assistencial, ainda é tímido o impacto sobre o perfil epidemiológico da população brasileira. A expansão histórica da rede, embora ainda insuficiente para atender às demandas existentes, assim como o investimento destinado às ações de saúde bucal e à implantação das equipes de saúde bucal na atenção básica e especializada, pouco tem contribuído para a melhoria dos indicadores epidemiológicos e assistenciais.

Assim, estratégias direcionadas a grupos com maior vulnerabilidade à doença, pautadas em planejamento local pelas equipes de saúde envolvidas, devem ser adotadas a fim de viabilizar a qualidade dessa cobertura ampliada 
dos serviços de saúde e a consequente melhoria do quadro de saúde bucal da população brasileira, especificamente, no que se refere à cárie dentária.

\section{Doença periodontal}

A prevalência da doença (presença de bolsas rasas e profundas) nos indivíduos entre 35 a 44 anos e naqueles com 65 e 74 anos de idade foi, respectivamente, de $19,4 \%$ e 3,3\% (BRASIL, 2011), sendo os sextantes posteriores os mais acometidos. A redução da periodontite no grupo de idosos é justificada pela grande proporção de sextantes excluídos (90,5\%), devido a grande perda dental, conforme o critério adotado (CPI), o que ratifica a precariedade da condição bucal da população brasileira com o avançar da idade, constituindo-se em um desafio atual para as autoridades sanitárias. Por outro lado, em uma leitura mais crítica, esse comportamento descritivo da doença nos idosos tem seu viés, uma vez que grande parte dos sextantes não foi examinada, mesmo apresentando uma unidade dentária presente, inclusive com a condição periodontal em diferentes níveis de gravidade. (NARVAI; GOMES-FILHO, 2011) A constatação da ausência da doença nas idades mais avançadas revela ainda que as estratégias adotadas para tratamento e controle da doença periodontal se concentram nas exodontias.

Figura 1 - Percentual de examinados segundo a condição periodontal, medida pelo Índice Periodontal Comunitário (CPI), e faixa etária (2003, 2010)

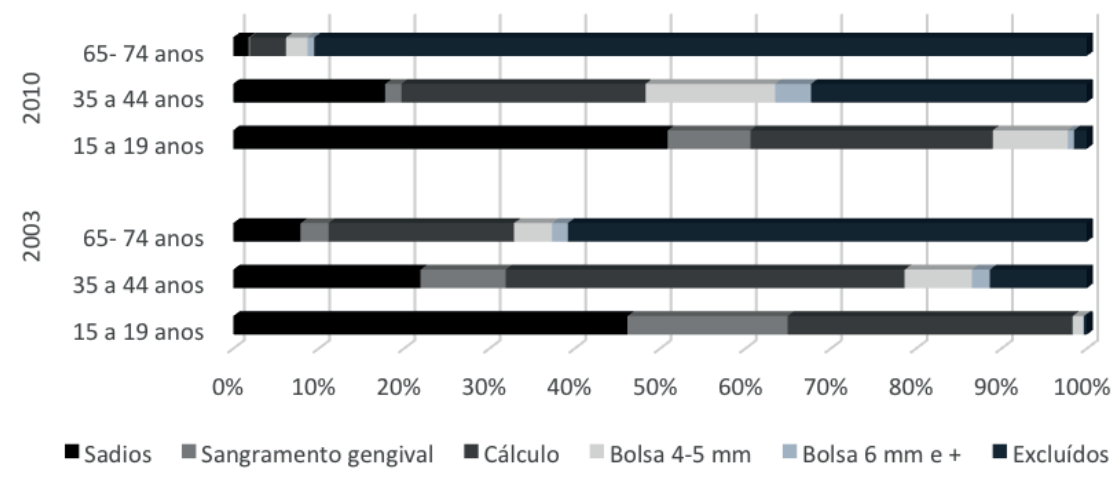

Fonte: Brasil (2004a, 2011). 
Nota-se que apesar da redução dos níveis de inflamação gengival na população entre os anos de 2003 e 2010, impulsionada pelas ações educativas para controle de biofilme, há necessidade de tratamento periodontal com acompanhamento contínuo para controle das medidas clínicas como profundidade de sondagem e nível de inserção clínica, as quais comprometem gravemente a estrutura de suporte do dente com o passar do tempo. A frequência de indivíduos com bolsas rasas (4-5 milímetros) e profundas (6 milímetros ou mais) têm aumentado, afetando, inclusive, as idades mais jovens.

Diversos fatores podem influenciar o desenvolvimento da doença periodontal como o hábito de fumar, gênero, algumas doenças sistêmicas como diabetes, uso de medicações, apinhamento dentário, nível socioeconômico, estresse e acesso aos serviços de saúde. (GENCO; BORGNAKKE, 2013; HAAS et al., 2014) Alguns estudos apontam também que esse agravo pode aumentar o risco de desenvolver condições sistêmicas como eventos cardiovasculares, doenças respiratórias, e nascimento de bebês de baixo peso. (SEYMOUR et al., 2007)

Explorar essas associações pode contribuir para melhor compreensão do processo saúde-doença periodontal e direcionar ações específicas no campo da saúde pública, de modo a intervir em fatores de risco comuns à doença e outros agravos sistêmicos. Porém, atuar sobre esses fatores, para alcance da qualidade de vida e nível ótimo de saúde, requer trabalho árduo, uma vez que não envolve somente a decisão do outro pela mudança de comportamento ou atitude frente à doença, mas uma abordagem interdisciplinar, integrada a diversos setores além da saúde, e pactuada com o indivíduo.

O forte gradiente social tem sido observado como determinante da doença periodontal. Estudos ecológicos mostram que indivíduos que vivem em áreas menos privilegiadas, com grande percentual de chefes de família sem instrução, apresentam piores condições gengivais. (PEREIRA et al., 2014) Esses espaços podem estar revelando que o nível de instrução e o poder aquisitivo vêm determinar as escolhas "impostas" por suas condições reais de vida, no que se refere, por exemplo, ao baixo consumo de produtos de higiene bucal nesse grupo. Dessa maneira, programas de saúde direcionados a essas áreas são essenciais para amenizar as iniquidades em saúde.

Diante desse cenário, do comportamento da doença periodontal nos grupos vulneráveis (gestantes, indivíduos com agravos sistêmicos, imunossuprimidos, e com precárias condições de vida), alguns desafios permanecem aos gestores da saúde. Apesar dos avanços com a expansão do número de equipes de saúde 
bucal no serviço público e oferta do serviço de periodontia no CEO, muitas dificuldades ainda são vivenciadas no controle da doença periodontal e tratamento das manifestações clínicas.

O incremento de periodontite na população, no período de 2003 a 2010, reforça o entendimento de que o aumento de 6 milhões de procedimentos especializados pelo SUS para 12,6 milhões, entre os anos de 2002-2012, e os R 48 milhões anuais destinados aos 1.037 CEO atuais, não têm sido suficientes para atender às necessidades periodontais da população. Em estudo que avaliou o desempenho dos CEO, no período de 2004 a 2009 (CORTELLAZZI et al., 2014), constatou-se que apenas 55,94\% dos CEO cumpriram as metas da periodontia, com percentuais inferiores para cirurgia $(33,07 \%)$ e endodontia $(22,61 \%)$. Isso nos leva a questionar sobre o efetivo papel do CEO no atendimento das necessidades acumuladas da população. Qual tem sido o seu desempenho frente em busca pelo serviço? Como tem sido utilizado os recursos investidos?

A realidade evidencia que, contrariamente ao proposto pela PNSB, a atenção básica não tem priorizado o encaminhamento ao serviço especializado dos casos complexos e com necessidade de terapia periodontal cirúrgica. Em alguns CEO, quase $100 \%$ dos procedimentos de periodontia estão relacionados à raspagem, alisamento e polimento sub e supragengival e raspagem coronoradicular, típicos da atenção primária. (CHAVES et al., 2011) Muitos desses encaminhamentos são determinados pela sobrecarga e falta de instrumentos e insumos adequados na atenção básica, bem como falta de clareza de suas atribuições no tratamento periodontal em relação aos demais níveis. A alta taxa de utilização dos serviços especializados de periodontia nos CEO, fruto principalmente desses encaminhamentos inadequados, tem resultado em longos tempos de espera para tratamento, em evasão e consequente impedimento de contrarreferência para atendimento na atenção básica.

Ainda no que se refere à organização dos serviços de saúde bucal, outra limitação observada refere-se à falta de integração e de planejamento interdisciplinar na atenção básica para assistência integral aos indivíduos suscetíveis a doença periodontal, como diabéticos e aqueles com outras doenças sistêmicas. As ações de saúde bucal têm se mantido fora do elenco das propostas do Ministério da Saúde voltadas ao controle da qualidade de vida de grupos de risco. (SILVA et al., 2010) No intuito de atender os princípios da integralidade, a equipe de saúde bucal necessita ser incluída nos grupos operativos de suporte e cuidado aos indivíduos com doenças crônicas, empregar na sua rotina as 
tecnologias para diagnóstico periodontal e compartilhar critérios pré-estabelecidos de tratamento e referenciamento. (SILVA et al., 2010)

Embora a literatura científica confirme o efeito de agravos sistêmicos na condição periodontal e vice-versa, é comum o encaminhamento desses indivíduos para consulta odontológica apenas em caso de "necessidade" ou determinada urgência. Um dos conflitos na interface entre atenção básica e especializada é percebido no modo de encaminhamento do paciente ao CEO, sem a realização devida de adequação do meio bucal e promoção de saúde bucal na atenção básica. (CHAVES et al., 2011) Com relação ao trabalho em equipe, observa-se a fraca incorporação do Técnico em Saúde Bucal na equipe odontológica, que tem como uma das atribuições a prática de higiene bucal supervisionada, orientação de higiene oral e remoção de cálculo dental. Apesar das resistências da categoria odontológica, essa inclusão aumentaria o escopo dos procedimentos e ampliaria o acesso às ações e serviços da rede.

Dessa forma, algumas ações estratégicas devem ser implementadas para minimizar os nós críticos na organização do serviço e diminuição das necessidades acumuladas. Dentre elas, destacam-se: a) busca ativa de indivíduos com problemas periodontais na comunidade, especialmente aqueles com sinais iniciais e que se enquadrem nos grupos de risco à doença; b) ajustes dos critérios predefinidos e do fluxo de referência e contrarreferência entre a atenção básica e especializada; e c) e manutenção periodontal pela atenção básica.

As ações estratégicas para prevenção e controle da doença periodontal (atividades de educação em saúde, remoção de fatores retentivos e raspagem supra e subgengival) devem ter como prioridade de atenção os grupos com idade mais jovem, no intuito de evitar a evolução para quadros mais graves. Para os indivíduos com alto risco de para desenvolverem a doença periodontal, as ações de planejamento em saúde devem envolver equipe multiprofissional e o estabelecimento de protocolo de atenção em saúde bucal, com definição dos procedimentos, inclusive aqueles a serem realizados exclusivamente nos CEO.

\section{Câncer bucal}

A mudança do perfil epidemiológico da população brasileira por conta do envelhecimento populacional e do padrão de consumo alimentar tem propiciado o crescimento das doenças crônicas, a exemplo, das neoplasias. O câncer bucal é uma das principais causas de morte por neoplasia que inclui cânceres com diversas localizações anatômicas e cujos valores de incidência têm aumen- 
tado no Brasil. Para o ano de 2014, o Instituto Nacional de Câncer José Alencar Gomes da Silva (INCA, 2014), estimou 11.280 casos novos de câncer bucal em homens e 4.010 em mulheres, sendo o quarto tipo de câncer mais frequente na região Sudeste (15,48/100 mil habitantes) e Nordeste (7,16/100 mil habitantes).

Dentre os variados tipos de câncer bucal, o carcinoma espinocelular ou epidermoide é o mais frequente ( $90 \%$ dos casos) e origina-se de lesões potencialmente malignas no epitélio de revestimento como leucoplasias, queilose actínica e eritroplasias. (SOUSA et al., 2014) Estudos nacionais têm identificado uma prevalência variando de $7 \%$ a $9 \%$ para as lesões potencialmente malignas (SOUSA et al., 2014), o que chama atenção para a identificação precoce dessas lesões e seu acompanhamento para prevenção do câncer bucal. Com relação às áreas anatômicas mais atingidas, o câncer de língua tem sido a categoria com mortalidade mais elevada. Os cânceres de lábio, área retromolar e gengiva têm sofrido queda nas taxas de mortalidade, ao contrário dos de orofaringe e áreas não especificadas da cavidade bucal. (SALOMÃO et al., 2013)

Quando se avalia o aumento na incidência de câncer bucal, acredita-se que a maior exposição aos fatores exógenos (ambientais e comportamentais) seja um fator influenciador do quadro, assim como o aumento dos exames diagnósticos, a busca ativa de casos suspeitos, e estímulo às notificações (SALOMÃO et al., 2013) com a política de saúde do governo.

Dentre os principais fatores de risco para o desenvolvimento de câncer bucal, destacam-se o tabagismo e o etilismo, sendo que a combinação desses dois hábitos tende a aumentar de forma multiplicativa a ocorrência da doença. (SOUSA et al., 2014) O incremento de mulheres fumantes têm favorecido a incidência nesse sexo. (LEITE et al., 2010) Outros fatores são apontados, como as infecções por HPV e a exposição à radiação UVA solar. Embora o câncer bucal acometa principalmente indivíduos com pelo menos 50 anos de idade, os jovens têm apresentado incidência de câncer bucal provocado pelo HPV, o que reforça a hipótese da influência da mudança de comportamento sexual na ocorrência dessas lesões.

O câncer bucal também apresenta uma forte relação com as iniquidades socioeconômicas, com maior incidência em indivíduos com piores condições de renda e instrução. (CONWAY et al., 2008) Essa distribuição desigual da doença na população reflete padrões diferenciais de acesso à informação e aos serviços de saúde. A dificuldade no acesso ao diagnóstico precoce e uso dos recursos 
terapêuticos, e o pior prognóstico do caso são mais evidentes nos indivíduos com maior privação social. (BIAZEVIC; ANTUNES, 2006)

Apesar da clareza sobre os potenciais fatores de risco à ocorrência da neoplasia bucal, a demora no diagnóstico, com identificação dos casos no último estágio, e a decisão clínica pelo tratamento mutilador como opção final, têm dado o tom das questões críticas a serem enfrentadas pela atual política de saúde bucal.

Estudos que têm avaliado a evolução das taxas de mortalidade por câncer na população evidenciam o aumento da mortalidade por câncer bucal ao longo dos anos, com maior frequência em homens do que em mulheres. (BOING et al., 2007, WÜNSCH FILHO; MONCAU, 2002; ) No período entre 1980 a 1995, as taxas de mortalidade exibiram um aumento de 2,9 a 3,3/100.000 homens e de 0,6 a, $8 / 100.000$ mulheres, influenciado pelos casos na faringe. Entre 2000 e 2004, constatou-se o contínuo incremento dessas taxas entre todas as regiões brasileiras, com o menor valor no Norte, fato provavelmente influenciado pelo baixo consumo de bebida alcoólica e tabagismo entre os indivíduos da região quando comparado às demais. (BOEING et al., 2006) Mesmo após a introdução da PNSB, que instituiu ações de recuperação (do diagnóstico ao tratamento) para controle da doença, esses números continuam a subir, alcançando a taxa ajustada de mortalidade de 4,54/100.000 homens e 0,97/100.000 mulheres no ano de 2013. (INCA, 2013)

A realização de exames periódicos em indivíduos de alto risco tem sido incentivada como estratégia populacional para redução dessa morbimortalidade. Entretanto, qual tem sido o impacto dessa medida no controle da doença? Pesquisas disponíveis sobre o impacto desses programas de rastreamento na redução das taxas de mortalidade são quase inexistentes. Em estudo nacional que avaliou os dados epidemiológicos da campanha "Abra a boca para a saúde", entre os anos de 2008 a 2013, concluiu-se que a população que procura a campanha não é o principal grupo de risco para a doença (NEOMOTO et al., 2015), o que leva a questionar sobre qual estratégia é mais eficaz para diagnóstico precoce da doença.

Sensibilizar os dentistas para a prevenção secundária do câncer bucal não é algo recente. Desde os anos 1930, essa preocupação era manifestada por meio de ações educativas junto aos profissionais dentistas. Entretanto, os primeiros sinais de envolvimento do governo com esse tópico se deram no ano de 1974, por meio da Divisão Nacional do Câncer (DNC) do Ministério da Saúde, ao 
promover, em vários estados, cursos de diagnóstico de câncer bucal. (SALTZ et al., 1998 apud TORRES-PEREIRA et al., 2012) Em 1976, a DNC, em parceria com a Sociedade Brasileira de Estomatologia, elaborou um documento com metas básicas para o Programa Nacional de Prevenção e Diagnóstico Precoce do Câncer da Boca (CABUL), propondo uma rede hierarquizada e permanente, ainda que vertical, e o treinamento de profissionais liberais até 1981. A realização de cursos de capacitação em câncer bucal foi realizada pelo Instituto Nacional de Assistência Médica da Previdência Social em vários estados nesse período, com criação de ambulatórios de controle da doença em Pernambuco e Bahia, posteriormente desativados. Nos anos 1980 e 1990, é criado o Programa de Expansão da Prevenção e Controle do Câncer da Boca, que vem enfatizar a importância da reabilitação pós-cirúrgica. Porém, até 2004, as ações de controle eram incipientes, sem difusão do conhecimento para coletividade ou adoção das medidas propostas.

Com o CEO na PNSB, cria-se um espaço para diagnóstico precoce de lesão bucal e acompanhamento dos casos junto às equipes de saúde bucal da atenção básica, a quem compete assumir responsabilidade pela detecção das necessidades, providenciar encaminhamentos e monitorar a evolução da reabilitação. (BRASIL, 2004) Porém, constata-se que algumas unidades de saúde não dispõem de referência regionalizada para encaminhamento necessário, dependendo de outras unidades para a realização de biópsia e de diagnóstico histopatológico, o que contribui para descontinuidade da atenção, agravando o quadro epidemiológico.

Para adequada ação diagnóstica, é dada ênfase no treinamento em estomatologia, por meio de cursos e acesso ao material instrucional, como condição essencial para ações de vigilância e prevenção secundária da doença. Apesar do reconhecimento do papel do dentista no diagnóstico precoce, alguns trabalhos revelam o despreparo dos profissionais na atenção básica para o diagnóstico de lesões bucais e realização de biópsias, criando mais uma barreira de acesso aos centros especializados para tratamento. (SOUSA et al., 2014) Outros autores ressaltam a necessidade de aproximar todas as categorias de profissionais de saúde envolvidas no conhecimento sobre câncer bucal, e de valorizar o trabalho multiprofissional com momentos de discussão, na medida em que muitas vezes os usuários tendem a procurar outros profissionais, que não o cirurgião-dentista, na ocorrência de uma lesão de boca. (LOMBARDO et al., 2014) 
Apesar dos esforços de mudança do modelo assistencial, a realidade atual do serviço demonstra ainda que os indivíduos com o câncer bucal ou lesão potencialmente maligna são acolhidos como demanda espontânea e em casos avançados. (TORRES-PEREIRA et al., 2012) Ampliar a possibilidade de detecção precoce com envolvimento dos agentes comunitários de saúde torna-se um caminho alternativo, com encaminhamento dos usuários de alto risco para exame clínico na unidade de saúde.

Quando se avalia o controle da doença nos serviços de média complexidade, constata-se que, do total de procedimentos de cirurgia oral menor, a realização de excisão e sutura de lesão de boca (passos primordiais para definição diagnóstica da lesão) tem variado entre $0,1 \%$ a $24,8 \%$, a depender do município. (CHAVES et al., 2011) Esse cenário conduz a uma reflexão sobre quais fatores podem estar interferindo nessa distribuição não equitativa de procedimentos especializados, e se a atenção básica tem conseguido desempenhar seu papel nas ações de encaminhamento e acompanhamento. Pesquisadores apontam ainda que a ausência de clareza sobre os padrões e metas propostas pelo serviço e mesmo a falta de pacientes podem ter reflexos na utilização dos procedimentos. (CHAVES et al., 2011)

Outro nó crítico em relação à rede de serviços, e que reflete nos números de mortalidade, é a dificuldade de acesso ao nível de alta complexidade (hospitais gerais de cirurgia oncológica e unidades e centros de alta complexidade oncológica). Segundo a Portaria n. ${ }^{\circ} 874 / 2013$, as unidades e centros de alta complexidade em oncologia que realizam o diagnóstico definitivo e o tratamento dos cânceres, têm como responsabilidade ofertar os serviços de cirurgia, radioterapia, quimioterapia, e cuidados paliativos. (BRASIL, 2013) Em 2010, a rede de atenção oncológica era composta por 276 hospitais aptos nos tratamentos dos diversos tipos de cânceres, sendo pelo menos um hospital em cada estado brasileiro habilitado para esse tratamento. No entanto, a articulação dos serviços de diagnóstico e de tratamento ainda é frágil e requer avanços importantes.

Ressalta-se a importância do diagnóstico dos principais problemas de lesão de boca mais prevalentes, uma vez que esse levantamento local norteará a elaboração de práticas integrais de saúde bucal específicas efetivas. Dessa forma, algumas estratégias gerais para controle da doença devem ser implementadas mais arduamente como: desenvolvimento de ações orientadas a indivíduos e grupos específicos, nos seus espaços cotidianos, como escolas e ambientes de trabalho, pelos profissionais de saúde; integração da equipe de saúde bucal aos 
programas de controle de tabagismo e etilismo; e estabelecimento e fortalecimento da rede de atenção oncológica, na qual a atenção básica possa se articular mais efetivamente com os serviços de média e alta complexidade.

\section{Fluorose dentária}

A fluorose dentária é um defeito de formação do esmalte, resultante da ingestão de flúor durante o desenvolvimento do dente, cujo comprometimento estético depende do efeito dose- resposta. A fluoretação das águas de abastecimento público consistia na única fonte de exposição sistêmica implantada enquanto ação pública coletiva de acesso ao flúor, antes dos anos 1970, no mundo, e, antes dos anos 1990, no Brasil. Na atualidade, o dentifrício fluoretado tem tido participação significativa na causalidade da fluorose (LIMA; CURY, 2001), principalmente em função da ingestão acidental em idades jovens.

Desde os primeiros registros sobre o efeito preventivo do flúor adicionado às águas de abastecimento, relatava-se uma prevalência esperada de 10\% a 15\% de fluorose muito leve. Na literatura nacional, revisões sistemáticas de trabalhos publicados, realizadas entre 1970 e 2006, identificaram grande diversidade de prevalências da alteração nas mais distintas regiões do país, variando de 1,7\% a 91,7\%, incluindo, entre eles, municípios com água fluoretada artificialmente, com proporções superiores ao valor esperado. (CANGUSSU et al., 2002; BARROS, TOMITA, 2010) Procurou-se atualizar essa sistematização com os artigos publicados nas bases de dados nacionais e internacionais, no período de 2005 a 2014. Incluíram-se os trabalhos sobre fluorose dentária que identificaram o município a que se referia a informação (com ou sem o ano de coleta de dados), o índice adotado, o tamanho da amostra e as idades contempladas, bem como a prevalência global da fluorose e dos casos moderados e severos (Quadro 4).

Apesar das grandes diferenças metodológicas e das prevalências obtidas da fluorose entre os estudos, é de fundamental importância ressaltar que os eles descrevem uma pequena proporção de casos moderados e severos (que provocam alterações estéticas e funcionais significativas), o que faz com que essa alteração não seja percebida como de relevância social para a comunidade e os pesquisadores não a identifiquem como um problema relevante de saúde pública. (PERES et al., 2007)

No Brasil, é recente a inclusão da fluorose dentária nos inquéritos nacionais. Sua ocorrência só foi investigada a partir do século XXI, tendo como resultado uma baixa prevalência e percentual insignificante das condições mais 
Quadro 4 - Estudos nacionais sobre a prevalência e severidade da fluorose dentária entre 2005 e 2014, segundo autor, ano de publicação, local, índice utilizado e presença de flúor na água de abastecimento público

(continua)

\begin{tabular}{|c|c|c|c|c|c|c|c|}
\hline Local (ano) & $\begin{array}{l}\text { Autor, ano de } \\
\text { publicação }\end{array}$ & Índice & $n$ & $\begin{array}{l}\text { Idade } \\
\text { (anos) }\end{array}$ & $\begin{array}{c}\text { Prevalência } \\
\text { (\%) }\end{array}$ & $\begin{array}{l}\text { Casos moderados e } \\
\text { severos (\%) }\end{array}$ & Água fluoretada \\
\hline Catalão, GO (2001) & $\begin{array}{l}\text { Bardal et al., } \\
\quad 2005\end{array}$ & Dean & 432 & $7-12$ & 5,56 & - & $\operatorname{sim}$ \\
\hline Santa Tereza, RS (-) & $\begin{array}{l}\text { Toassi e Abegg, } \\
2005\end{array}$ & Dean & 259 & 4- 18 & 63,7 & 0,4 & $\operatorname{sim}$ \\
\hline Bauru, SP (-) & $\begin{array}{l}\text { Ramires et al., } \\
2006\end{array}$ & TF & 52 & $7-15$ & 33,0 & - & $\operatorname{sim}$ \\
\hline Salvador, BA (2004) & $\begin{array}{l}\text { Oliveira Jr. et al., } \\
2006\end{array}$ & Dean & $\begin{array}{l}521 \\
511\end{array}$ & $\begin{array}{l}12 \\
15\end{array}$ & $\begin{array}{l}32,6 \\
16,8\end{array}$ & $\begin{array}{l}0,76 \\
0,59\end{array}$ & $\operatorname{sim}$ \\
\hline $\begin{array}{l}\text { João Pessoa, PB (2004- } \\
\text { 2005) }\end{array}$ & $\begin{array}{l}\text { Carvalho et al., } \\
2007\end{array}$ & TF & 1114 & $12-15$ & 29,2 & 2,2 & $\operatorname{sim}$ \\
\hline $\begin{array}{l}\text { Povoados rurais do Norte, } \\
\text { MG (2006) }\end{array}$ & $\begin{array}{l}\text { Costa et al., } \\
2006\end{array}$ & TF & $\begin{array}{l}227 \\
153\end{array}$ & $\begin{array}{c}7-9 \\
10-12\end{array}$ & $\begin{array}{l}99,1 \\
90,0\end{array}$ & $\begin{array}{l}19,8 \\
34,6\end{array}$ & $\begin{array}{c}\text { Área de fluorose } \\
\text { endêmica }\end{array}$ \\
\hline Passo Fundo, RS (-) & Rigo et al., 2010 & Dean & 633 & $\begin{array}{c}12 \\
15-19\end{array}$ & $\begin{array}{l}36,2 \\
26,8\end{array}$ & 1,9 & $\operatorname{sim}$ \\
\hline
\end{tabular}


Quadro 4 - Estudos nacionais sobre a prevalência e severidade da fluorose dentária entre 2005 e 2014, segundo autor, ano de publicação, local, índice utilizado e presença de flúor na água de abastecimento público

(conclusão)

\begin{tabular}{|l|c|c|c|c|c|c|c|}
\hline $\begin{array}{l}\text { São Francisco do Conde, } \\
\text { BA (2010) }\end{array}$ & $\begin{array}{c}\text { Soares et al., } \\
2010\end{array}$ & Dean & 1474 & $7-13$ & 39,8 & 0,81 & $\operatorname{sim}$ \\
\hline São Paulo, SP (2008) & $\begin{array}{c}\text { Narvai et al., } \\
2013\end{array}$ & Dean & 4085 & 12 & 40,3 & 2,3 & $\operatorname{sim}$ \\
\hline São Paulo, SP (2010) & $\begin{array}{c}\text { Narvai et al., } \\
2013\end{array}$ & Dean & 231 & 12 & 38,1 & 1,7 & $\operatorname{sim}$ \\
\hline Manaus, AM (2008) & $\begin{array}{c}\text { Régis-Aranha et } \\
\text { al., 2014 }\end{array}$ & TF & 826 & 12 & 15,6 & - \\
\hline
\end{tabular}

Fonte: Lilacs e Scielo. 
severas. Assim sendo, aos 12 anos, observaram-se prevalências de 8,56\% e $16,70 \%$ (2002-2003 e 2010 respectivamente), e, dos 15-19 anos, prevalência de 5,14\% em 2002-2003. (BRASIL, 2004a; BRASIL, 2011)

Entretanto, como destaca Freitas e colaboradores (2013), existem muitos limites na interpretação desses dados nacionais, os quais compreendem: o tamanho insuficiente da amostra para avaliar a fluorose no âmbito municipal, o grande número de examinadores e, consequentemente, a confiabilidade dos dados. A prevalência da fluorose dentária apresentou uma variação considerável, de $\%$ a 61\%, em 2003, e de ०\% a 59\%, em 2010. Assim, foram observadas inconsistências nos dados em termos individuais (por ano e por capitais e regiões). No comportamento da tendência entre os anos de 2003 e 2010, observaram-se casos extremos, a exemplo do município de Salvador, que apresentou variações da prevalência que foram de 7,6\% (2003) a 44,3\% (2010), valores distintos do encontrado em estudos locais desenvolvidos nesse período. (OLIVEIRA et al., 2006)

Assim, consideram-se os dados nacionais apenas como exploratórios, devendo ser mais valorizados os resultados de estudos locais sobre o tema (FREITAS et al., 2006), com planos amostrais específicos e os cuidados metodológicos necessários para seu diagnóstico clínico e epidemiológico, levando-se em consideração a subjetividade na natureza da classificação. Ressalta-se que os estudos ainda são escassos (CANGUSSU et al., 2002; BARROS; TOMITA, 2010), dada a grande extensão geográfica e as distintas realidades do país.

Quando se analisa a produção brasileira nos últimos 10 anos em bases internacionais (ISIs; Web of Science), incluindo as palavras chave fluorose e epidemiologia, observa-se em média, 45 publicações ao ano. A maior parte dessa produção se refere à ocorrência e severidade da alteração em grupos específicos, à sua associação em relação a diferentes concentrações de flúor nas águas de abastecimento público ou à associação com a cárie dentária. Em menor quantidade, os estudos têm como objetivo associar a ocorrência da doença com outros fatores, como nível socioeconômico (RÉGIS-ARANHA et al., 2014) ou outras fontes de fluoreto. (CATANI et al., 2007)

A fluorose parece estar associada com níveis mais altos e contínuos do flúor na água de abastecimento público, mesmo nos casos de menor severidade. Como o uso dessa tecnologia é imprescindível para o controle da cárie dentária, faz-se necessária a expansão da fluoretação das águas no Brasil, ainda que tal medida represente algum impacto na fluorose dentária. Entretanto, a 
efetividade preventiva da fluoretação da água (maior benefício associado ao menor risco) depende da adequação do teor de flúor e da continuidade do processo. A interrupção, temporária ou definitiva, faz cessar o efeito da medida, e o teor elevado do flúor adicionado à água de abastecimento pode provocar danos maiores do que os já esperados. É indispensável o seu controle, seja em termos operacionais nas estações de tratamento de água, seja na vigilância sanitária. No primeiro caso, são importantes os procedimentos rotineiros de controle operacional. $\mathrm{Na}$ área de vigilância em saúde, é imprescindível o heterocontrole.

Já em relação à vigilância sanitária do flúor em dentifrícios, está comprovadamente associado à menor incidência de cárie dentária quando contém cerca de $0,1 \%$ (1.000 ppm) de flúor - geralmente na forma de monofluorfosfato de sódio. (CHAVES; VIEIRA-DA-SILVA, 2002) Na norma brasileira (Portaria SNVS n. ${ }^{\circ} 22$, de 20 de dezembro de 1989), recomenda-se que a concentração de flúor, na sua forma ativa, adicionada aos dentifrícios seja de pelo menos 600 ppm após 12 meses da data de fabricação e pelo menos 450 ppm "no restante do seu prazo de validade". A concentração mínima inicial é 1.000 ppm e o teor máximo permitido é de 1.500 ppm.

É comum a ingestão de dentifrício por crianças. Estima-se que menores de cinco anos ingerem cerca de $30 \%$ da quantidade utilizada em cada escovação, e tal ingestão, em quantidade excessiva de dentifrício fluorado, tem sido fortemente relacionada ao surgimento da fluorose dentária. (LIMA; CURY, 2001) A dose provavelmente tóxica do íon flúor é $5 \mathrm{mg}$ por $\mathrm{kg}$ de peso corporal. Para uma criança de $10 \mathrm{~kg}$, isso corresponde à ingestão em única dose de aproximadamente metade do conteúdo de um tubo com 90 gramas de pasta. Por essa razão, os pais ou responsáveis devem supervisionar as escovações dentárias até os seis anos de idade para reduzir a ingestão. O Código de Defesa do Consumidor já obriga também a informação dos modos de uso, quantidades e danos potenciais provocados pelo uso inadequado.

Os fabricantes deveriam orientar o uso da técnica transversal (o,35 grama/ escovação) para colocar o creme dental na escova (o longo eixo da escova posicionado perpendicularmente ao longo eixo do tubo). Ao contrário, a propaganda invariavelmente mostra o produto sendo dispensado segundo a técnica longitudinal (o,65 grama/escovação), e o maior consumo do produto irá, certamente, acarretar o maior risco de fluorose em crianças. 


\section{Problemas emergentes para enfrentamento pela PNSB}

Além dos problemas tratados anteriormente, considerados como prioritários para a concepção e desenvolvimento da PNSB, surgem outras condições de saúde bucal, seja por sua relevância epidemiológica, seja por sua relevância social. Entre elas, colocam-se, por exemplo, as alterações oclusais.

Muitos métodos e índices já foram propostos e desenvolvidos para avaliar as oclusopatias na população brasileira e no mundo. Os principais são o Index of Orthodontic Treatment Need, o Dental Aesthetic Index (DAI) e a apresentação dos desvios morfológicos ou de função mais comuns. Entretanto, poucos estudos foram desenvolvidos no Brasil.

Nos levantamentos nacionais, as oclusopatias foram avaliadas nas idades de 5 a 12 anos e na faixa etária de 15 a 19 anos, em 2002-2003 e 2010, respectivamente. Apesar de índices diferentes serem utilizados, aos cinco anos de idade, observaram-se altas prevalências da doença - 38,49\% (BRASIL, 2004a) e 66,7\% (BRASIL, 2011). Em adolescentes, o DAI foi o índice de eleição. No ano de 2004, os resultados foram mais graves do que no ano de 2010, sendo eles respectivamente: 12 anos - 21,59\% de maloclusão definida, 15,79\% maloclusão severa e $20,76 \%$ muito severa. Esses mesmos valores, em 2010 , corresponderam a $20 \%$, $11,2 \%$ e 6,5\% para a mesma idade. Já na faixa etária de 15 a 19 anos de idade, destaca-se, em 2004, a maloclusão definida com 20,44\%, maloclusão severa, $14,04 \%$, e a muito severa com $18,75 \%$. Em 2010 , os dados foram semelhantes para a maloclusão definida (20,3\%) e apontaram menor severidade, 6,2\% e 9,1\% respectivamente, para os casos de maloclusão severa e muito severa. (BRASIL, 2004a; BRASIL, 2011)

Os resultados de estudos locais se aproximam muito aos dos inquéritos nacionais na população escolar - 65,6\% em Juiz de Fora (ALMEIDA; LEITE, 2013), 40,1\% em Goiânia. (JORDÃO et al., 2015) Em Salvador, relatam-se dois estudos importantes, com percentual de 45,1\% (THOMAZ et al., 2013) e 33,61\%. (LOPES; CANGUSSU, 2005) De modo geral existe redução da severidade das alterações oclusais entre a dentição decídua e a permanente tanto em estudo realizado no estado de São Paulo como em estudos locais. (FRAZÃO et al., 2002)

Peres, Frazão e Roncalli (2013) assinalam que, no inquérito nacional de 2010, as oclusopatias mais graves estavam mais presentes em indivíduos pretos e pardos, com maior perda dentária e menor renda. Assim, a distribuição das oclusopatias em adolescentes brasileiros segue o padrão de iniquidade social de outros agravos à saúde e é necessário repensar os critérios relacionados, 
tanto com a distribuição e provisão de recursos quanto com as prioridades de tratamento, incluindo o ortodôntico, fundamentados no princípio da equidade da atenção à saúde bucal.

Soma-se a isso inúmeros relatos de intervenções equivocadas em populações jovens com o uso de aparelhos ortodônticos falsos, realizados com materiais de uso comum como clipes, elásticos, cerdas de vassoura, como também de materiais de uso profissional (fios e elásticos ortodônticos), destacando a relevância social da questão. Embora ainda não existam estudos sobre a magnitude do problema, bem como os relativos aos seus danos, do ponto de vista populacional (clinicamente, já são descritos casos de movimentação dentária inadequada, perda óssea e outras lesões periodontais), esse é um tema que precisa ser incorporado em uma pauta conjunta de atividades de educação em saúde e intervenção sobre as necessidades e riscos à saúde bucal. (GUZZO et al., 2014)

Ainda no tema dos problemas emergentes para a PNSB, destaca-se o traumatismo maxilofacial impulsionado pelo crescimento de fatores predisponentes como os acidentes de trânsito e a violência interpessoal (agressões físicas, uso de armas de fogo ou branca) embora, outras causas também tenham sido apontadas como os acidentes de trabalho, domésticos e relacionados ao esporte.

Apesar da magnitude que esse problema tem adquirido no contexto nacional, a maioria dos estudos publicados são resultantes de dados baseados em prontuários hospitalares e outros serviços de saúde, e não de base populacional. Os escassos estudos nacionais que investigaram o perfil epidemiológico do evento mostram que os ferimentos e fraturas dento-faciais causados por acidentes de trânsito variam entre $4 \%$ a $32 \%$ e os por violência, entre $11 \%$ e $43 \%$. (BATISTA et al., 2012; CAVALCANTI et al., 2009; CAVALCANTI et al., 2012; CAVALCANTI; MELO, 2009; SILVA et al., 2011; SANTOS et al., 2012) A variação na prevalência é determinada por fatores como as características da amostra do estudo (inclusão somente de crianças) e o perfil de violência da cidade (estudos como em João Pessoa, Paraíba, quarta cidade mais violenta do país). De modo geral, esses traumas são mais frequentes em homens, na faixa etária de 20 a 30 anos, nas áreas urbanas, durante a noite e nos fins de semana. Associações com ingestão de bebida alcoólica, uso de drogas e velocidade excessiva no trânsito têm sido ainda apontadas, e fatores contextuais como desemprego e má distribuição de renda podem ainda agravar esse panorama crítico. 
Quanto ao local de ocorrência desses traumas, os poucos estudos que analisaram esse aspecto, particularmente em crianças, revelam que os conflitos familiares representam mais um contexto influente na sua etiologia. A desestruturação familiar e a fragilidade das relações internas e externas estabelecidas parecem determinar a ocorrência dessas injúrias, apontadas como não intencionais (HARRIS; KOTCH, 1994), requerendo das pesquisas sobre etiologia dos traumas investigações perceptivas da existência de negligência e maus-tratos nos domicílios.

$\mathrm{Na}$ ocorrência desse agravo, independente da causa, o atendimento de urgência e de alta complexidade é necessário, o que, por sua vez, tem representado parte importante dos gastos públicos com vítimas de acidentes e violência. Em 2014, os acidentes de transporte e agressões corresponderam a $22 \%$ e 6\%, respectivamente, do valor dos serviços hospitalares voltados a causas externas. O tratamento do trauma maxilofacial geralmente é bastante complexo, com envolvimento de equipe multiprofissional e posterior acompanhamento, após o atendimento de urgência, sendo necessários procedimentos especializados, como endodontia, cirurgia e prótese, para resolução de fraturas radiculares, avulsões, perdas ósseas, luxações, intrusões, e outros, que requerem tempo e podem deixar sequelas. (SILVA et al., 2011) Essas sequelas envolvem também a dimensão psicológica do indivíduo, seja pelo comprometimento da estética ou restrições ao bem-estar físico, impactando sua vida no nível social e comportamental, ou pela experiência traumática do próprio evento.

Dessa forma, nesse cenário de discussão do trauma maxilofacial e suas repercussões, percebe-se que alguns elementos são requeridos para avanços na saúde pública como: a) sustentação de políticas de prevenção do trauma direcionadas às principais causas locais, incluindo aumento de supervisão policial em locais onde a violência é mais frequente, e melhorias da circulação de pedestres e veículos nas vias públicas; b) capacitação contínua dos profissionais envolvidos no atendimento ao traumatizado, não somente no manejo do caso, mas também na identificação da origem do trauma, especialmente em casos de violência domiciliar, para atuação mais efetiva dos setores relacionados; e c) incentivo à elaboração de protocolos-padrão para monitoramento de futuras sequelas após o trauma como necrose pulpar, anquilose da ATM (Articulação Temporomandibular) e má-oclusão, de modo a serem incorporados na rotina dos profissionais. 
Dada atual intensidade das causas externas (violência e acidentes) no cenário brasileiro e perfil do atendimento desses traumas nos serviços, cada vez mais os gestores precisam se planejar para alocar adequadamente profissionais e tecnologias necessárias para a assistência no nível da emergência/urgência dos casos, com ampliação de vagas hospitalares para profissionais da área de cirurgia e trauma bucomaxilofacial, bem como de oferta de serviço odontológico nas unidades de pronto atendimento. Além disso, deve se organizar o serviço, de modo a concretizar o acompanhamento efetivo desses traumatizados na rede pelo município, com garantia à atenção na unidade básica e especialidades como o CEO, e adequar a oferta dos serviços especializados (procedimentos endodônticos e reabilitação protética, por exemplo) conforme o perfil local, visando a redução e controle das sequelas.

\section{Considerações finais}

Houve importantes avanços na condição de saúde bucal brasileira nos últimos 20 anos. É incontestável a redução significativa da prevalência e da gravidade da cárie dentária em adolescentes e adultos jovens. Esse declínio, entretanto, não foi tão marcante na primeira infância e em idosos. O que fortemente parece ter contribuído para essa redução foram as medidas de controle no âmbito populacional, incluindo a fluoretação das águas de abastecimento público, a adição do flúor aos dentifrícios e o incremento das ações de promoção e proteção à saúde, implantadas com o intuito de diminuir as desigualdades sociais no Brasil nesse período. Ainda há fragilidade no enfrentamento de outros problemas como a doença periodontal, câncer bucal, assim como novos problemas epidemiológicos emergentes. Destaca-se que a PNSB estimulou a expansão de medidas populacionais, embora ainda tenha grandes dificuldades em reduzir as iniquidades em saúde, compreendidas como desigualdades injustas e evitáveis, visto que muitas das ações de saúde são inacessíveis às populações mais vulneráveis.

Uma questão que também precisa ser enfrentada é a relação entre o crescimento do investimento, a oferta de serviços e o impacto e resultados produzidos na adequação às necessidades de saúde bucal da população brasileira, independente dos problemas de saúde considerados prioritários. Aqui, colocase não só a qualidade da oferta, mas também a sua efetividade e adequação à condição epidemiológica no nível local. É preciso fortalecer a descentralização da saúde e a avaliação dos sistemas locais para melhoria dos serviços. 


\section{Referências}

ALMEIDA, A. B.; LEITE, I. C. G. Orthodontic treatment need for Brazilian schoolchildren: a study using the Dental Aesthetic Index. Dental Press Journal of Orthodontics, Maringá, v. 18 , n. 1, p. 103-109, 2013.

AMERICAN ACADEMY OF PERIODONTOLOGY (AAP). Position paper: tobacco use and the periodontal patient. Research, science and therapy committee of the American Academy of Periodontology. Journal of periodontology, Chicago, v. 70, p. 1419-1427, 1999.

ANTUNES, J. L.; JAHN, G. M.; CAMARGO, M. A. Increasing inequalities in the distribution of dental caries in the Brazilian contexto in Finland. Community Dental Health, Sheffield, v. 22, n. 2, p. 94-100, 2005.

ANTUNES, J. L. F.; NARVAI, P. C. Políticas de saúde bucal no Brasil e seu impacto sobre as desigualdades em saúde. Revista de Saúde Pública, São Paulo, v. 44, n. 2, p. 360-365, 2010.

BARDAL, P. A. P.; et al. Dental caries and dental fluorosis in 7-12-year-old schoolchildren in Catalão, Goiás, Brazil. Journal of Applied Oral Science, Bauru, v. 13, n. 1, p. 35-40, 2005.

BARROS, B. S. de A.; TOMITA, N. E. Aspectos epidemiológicos da fluorose dentária no Brasil: pesquisas no período 1993-2006. Ciências \& Saúde Coletiva, Rio de Janeiro, v. 15, n. 1, p. 289-300, 2010.

BATISTA, A. M. et al. Urban-rural differences in oral and maxillofacial trauma. Brazilian Oral Research, São Paulo, v. 26, n. 2, p. 132-138, 2012.

BIAZEVIC, M. G. H.; ANTUNES, J. L. F. Câncer Bucal. In: ANTUNES, J. L. F; PERES, M. A. A. (Org.). Epidemiologia da Saúde Bucal. Rio de Janeiro: Guanabara-Koogan, 2006.

BOING, A. F.; VARGAS, S. A. L.; BOING, A. C. A carga das neoplasias no brasil: mortalidade e morbidade hospitalar entre 2002-2004. Revista da Associação Médica Brasileira, São Paulo, v. 53, n. 4, p. 317-222, 2007.

BOMFIM, M. de L. et al. Social determinants of health and periodontal disease in Brazilian adults: a cross-sectional study. BMC Oral Health, Londres, v. 20, p. 13- 22, 2013.

BRASIL. Ministério da Saúde. Cadernos de Atenção Básica. Brasília, DF, 2008. n. 17.

BRASIL. Ministério da Saúde, Secretaria de Atenção à Saúde, Departamento de Atenção Básica, Coordenação Nacional de Saúde Bucal. Condições de Saúde Bucal da População Brasileira 2002-2003. Resultados Principais. Brasília,DF, 2004a.

BRASIL. Ministério da Saúde. Diretrizes da política nacional de saúde bucal. Brasília, DF, , 2004b.

BRASIL. Ministério da Saúde, Secretaria de Atenção à Saúde, Departamento de Atenção Básica. Guia de recomendações para o uso de fluoretos no Brasil. Brasília, DF, 2009.

BRASIL. Ministério da Saúde, Secretaria de Políticas de Saúde, Área Técnica de Saúde Bucal. Levantamento epidemiológico de cárie dentária, 1996. DATASUS. Disponível em: < http://tabnet.datasus.gov.br/cgi/sbucal/sbdescr.htm>. Acesso em: 1 nov. 2012. 
BRASIL. Ministério da Saúde, Secretaria Nacional de Programas Especiais de Saúde, Divisão Nacional de Saúde Bucal. Levantamento epidemiológico em saúde bucal: Brasil, zona urbana, 1986. Brasília, DF, 1988.

BRASIL. Ministério da Saúde, Secretaria de Atenção à Saúde, Departamento de Atenção Básica, Coordenação Nacional de Saúde Bucal. SB Brasil 2010. Pesquisa Nacional de Saúde Bucal. Resultados Principais. Brasília, DF, 2011.

BRASIL. Ministério da Saúde. Portaria no 874, de 16 de maio de 2013. Disponível em: http:// bvsms.saude.gov.br/bvs/saudelegis/gm/2013/prto874_16_05_2013.html. Acesso em: 25 ago. 2015 .

CANGUSSU, M. C. T. et al. A fluorose dentária no Brasil: uma revisão crítica. Cadernos de Saúde Pública, Rio de Janeiro, v. 18, n. 1, p. 7-15, 2002.

CANGUSSU, M. C. T.; CASTELLANOS, R. A. F. Prevalência de cárie dentária em escolares de 12 e 15 anos de Salvador, Bahia, 2001. Revista Brasileira de Saúde Materno Infantil, Recife, v. 4 , n. 3, p. 287-97, 2004.

CARDOSO, A.C.C. A associação entre cárie e fluorose dentária com a fluoretação das águas em dois municípios do estado da Bahia. Revista Baiana de Saúde Pública, Salvador, v. 27, n. $1 / 2$, p. $7-18,2003$.

CARVALHO, R. W. F. et al. Estudo da prevalência de fluorose dentária em Aracaju. Ciência \& Saúde Coletiva, Rio de Janeiro, v. 15, p. 1875-80, 2010.

CARVALHO, T. S.; KEHRLE, H. M.; SAMPAIO, F. C. Prevalenceandseverityof dental fluorosisamongstudentsfrom João Pessoa, PB, Brazil. Brazilian Oral Research, São Paulo, V. 21, p. 198-203, 2007.

CATANI, D. B. et al. Relação entre níveis de fluoreto na água de abastecimento público e fluorose dental. Revista de Saúde Pública, São Paulo, v. 41, p. 732-9, 2007.

CAVALCANTI, A. L; LIMA, I. J. D DE; LEITE, R. B. Perfil dos pacientes com fraturas maxilo-faciais atendidos em um hospital de emergência e trauma, João Pessoa, PB, Brasil. Pesquisa Brasileira de Odontopediatria, João Pessoa, v. 9, n. 3, p. 339-345, 2009.

CAVALCANTI, A .L et al. Traumatismos maxilofaciais em crianças e adolescentes em Campina Grande, Paraíba, Brasil. Pesquisa Brasileira de Odontopediatria, João Pessoa, v. 12, n. 3, p. 439-445, 2012.

CAVALCANTI, A. L; MELO, T. R. N. B. Lesões faciais em pacientes pediátricos de 1 a 4 anos de idade: um estudo retrospectivo. RPG Revista de pós-graduação, v. 16, n. 1, p. 19-25, 2009.

CHAMBRONE, L. et al. Prevalência e severidade de gengivite em escolares de 7 a 14 anos: condições locais associadas ao sangramento à sondagem. Ciência \& Saúde Coletiva, Rio de Janeiro, v. 15, n. 2, p. 337-343, 2010.

CHAVES, S. C. L. et al. Avaliação da oferta e utilização de especialidades odontológicas em serviços públicos de atenção secundária na Bahia, Brasil. Caderno de Saúde Pública, Rio de Janeiro, v. 27, n. 1, p. 143-154, 2011. 
CHAVES, S. C. L.; VIEIRA-DA-SILVA, L. M. A efetividade do dentifrício fluoretado no controle da cárie dental: uma meta-análise. Revista de Saúde Pública, São Paulo, v. 36, n. 5, p. 598-606, 2002.

CHAVES, S.C. L. et al. Avaliação da oferta e utilização de especialidades odontológicas em serviços públicos de atenção secundária na Bahia, Brasil. Cadernos de Saúde Pública, Rio de Janeiro, v. 27, n. 1, p. 143-154, 2011.

CHIAPINOTTO, F. A. et al. Risk factors for gingivitis in a group of Brazilian schoolchildren. Journal of Public Health Dentistry, Malden, v. 73, n. 1, p. 9-17, 2013.

CONWAY, D.I. et al. Socioeconomic inequalities and oral cancer risk: a systematic review and meta-analysis of case-control studies. International Journal of Cancer, New York, v. 122, p. 2811-2819, 2008.

CORTELLAZZI, K. L. et al. Variáveis associadas ao desempenho de Centros de Especialidades Odontológicas no Brasil. Revista Brasileira de Epidemiologia, São Paulo,v.17, n.4, p. 978-988, 2014.

COSTA, S. M.; et al. Cárie dentária e fluorose endêmica em distritos rurais de Minas Gerais, Brasil. Revista Brasileira de Epidemiologia, São Paulo, v. 16, n. 4, p. 1021-1028, 2013.

EKE, P. I.; et al. Update on Prevalence of Periodontitis in Adults in the United States: NHANES 2009 to 2012. Journal of Periodontology, Chicago, v. 86, n. 5, p. 611-622, 2015.

FRAZAO, P. et al . Prevalência de oclusopatia na dentição decídua e permanente de crianças na cidade de São Paulo, Brasil, 1996. Caderno de Saúde Pública, Rio de Janeiro, v. 18, n. 5, p. 1197-1205, out. 2002.

FRAZÃO, P.; NARVAI, P. C. Saúde bucal no Sistema Único de Saúde: 20 anos de lutas por uma política pública. Saúde Debate, São Paulo, v. 33, n. 8, p. 164-71, 2009.

FREITAS, C. H. S. M. et al. Reflexões metodológicas sobre prevalência da fluorose dentária nos inquéritos de saúde bucal. Revista de Saúde Pública, São Paulo, v.47, Suppl 3, p. 138-147, 2013.

GENCO, R. J.; BORGNAKKE, W. S. Riskfactors for periodontal disease. Periodontology 2000, Copenhagen, v. 62, n. 1, p. 59-94, 2013.

GUZZO, S. C. et al. Ortodontia preventiva e interceptativa na rede de atenção básica do SUS: perspectiva dos cirurgiões-dentistas da Prefeitura Municipal de Florianópolis, Brasil. Ciência \& Saúde Coletiva, Rio de Janeiro, v. 19, n. 2, p. 449-460, 2014.

HAAS, A. N. et al. Risk factors for the progression of periodontal attachment loss: a 5-year population-based study in South Brazil. Journal of Clinical Periodontology, Copenhagan, v. 41, n. 3, p. 215-23, 2014.

HARRIS, M. J.; KOTCH, J. B.Unintentional infant injuries: sociodemographic and psychosocial factors. Public Health Nursing, Malden, v. 11, n. 2, p. 90-97, 1994.

INCA. Instituto Nacional de Câncer José Alencar Gomes da Silva. Coordenação de Prevenção e Vigilância. Estimativa 2014: incidência de câncer no Brasil. Rio de Janeiro: 
INCA, 2014. Disponível em: <http://www.inca.gov.br/estimativa/2014/estimativa-24042014. pdf>. Acesso em 28 set. 2015.

INCA. Instituto Nacional de Câncer. Atlas online de mortalidade. 2014. Disponível em: <https://mortalidade.inca.gov.br/MortalidadeWeb/pages/Modeloo3/consultar. xhtml\#panelResultado>. Acesso em: 28 set. 2015 .

JORDÃO, L. M. R. et al. Individual and contextual determinants of malocclusion in 12-year-old schoolchildren in a Brazilian city. Brazilian Oral Research, São Paulo, v. 29, n.1, p.1-8, 2015 .

LEITE, I.C.G. Mortalidade por Câncer de Boca e Faringe em Cidade de Médio Porte na Região Sudeste do Brasil, 1980-2005. Revista Brasileira de Cancerologia. Rio de Janeiro, v. 56, n. 1, p. 17-23, 2010.

LIMA, Y. B. DE O.; CURY, J. A. Ingestão de flúor por crianças pela água e dentifrício. Revista de Saúde Pública, São Paulo, v. 35, n. 6, p. 576-581, 2001.

LOMBARDO, E. M. et al. Atrasos nos encaminhamentos de pacientes com câncer bucal: avaliação qualitativa da percepção dos cirurgiões-dentistas. Ciência \& Saúde Coletiva, Rio de Janeiro, v. 19, n. 4, p. 1233-1232, 2014.

LOPES, L. S.; CANGUSSU, M. C. T. Prevalência e severidade das alterações oclusais em escolares de 12 a 15 anos de Salvador - Bahia, Brasil, 2004. Revista de Ciências Médicas e Biológicas, Salvador, v. 4, n. 2, p. 105-112, 2005.

MENEGHIM, M. DE C. et al. Classificação socioeconômica e sua discussão em relação à prevalência de cárie e fluorose dentária. Ciência \& Saúde Coletiva. Rio de Janeiro, v.12, n. 2, p. 523-529, 2007

MiOTTO, M. H. M. DE B.; BARCELLOS, L. A.; VELTEN, D. B. Avaliação do impacto na qualidade de vida causado por problemas bucais na população adulta e idosa em município da Região Sudeste. Ciência \& Saúde Coletiva, Rio de Janeiro, v. 17, n. 2 p. 397-405, 2012

NARVAI, P. C. Saúde bucal coletiva: caminhos da odontologia sanitária à bucalidade. Revista de Saúde Pública, São Paulo, v. 40, p.141-147, 2006.

NARVAI, P. C. et al. Cárie dentária no Brasil: declínio, iniqüidade e exclusão social. Revista Panamericana de Salud Pública, Washington, v. 19, n. 6, p. 385-393, 2006.

NARVAI, P. C.; GOMES-FILHO, I. S. Epidemiologia em saúde bucal. Em: Naomar de Almeida Filho; Maurício Lima Barreto. (Org.). Epidemiologia saúde: fundamentos, métodos, aplicações. Rio de Janeiro: Guanabara-Koogan. 2011.

NARVAI, P. C. et al. Fluorose dentária em crianças de São Paulo, SP, 1998-2010. Revista de Saúde Pública, São Paulo, v. 47, n. 3, p. 148-53, 2013.

NEMOTO, R. P. et al. Oral cancer preventive campaigns: are we reaching the real target? Brazilian Journal Otorhinolaryngol, São Paulo, v. 81, n. 1, p. 44-49, 2015. 
OLIVEIRA, A. G. R. C. Levantamentos epidemiológicos em saúde bucal no Brasil. In: ANTUNES, J.L.F.; PERES, M.A. (Org.). Fundamentos de odontologia. Epidemiologia da saúde bucal. Rio de Janeiro: Guanabara Koogan, 2006.

OLIVEIRA, J. S. R. de et al. Fluorose dentária em escolares de 12 e 15 anos de idade. Salvador, Bahia, Brasil, nos anos 2001 e 2004. Cadernos de Saúde Pública, Rio de Janeiro, v. 22, n.6, p. 1201-1206, 2006.

PANIZZI, M.;PERES, M. A. Dez anos de heterocontrole da fluoretação de águas em Chapecó, Estado de Santa Catarina, Brasil. Cadernos de Saúde Pública, São Paulo, v. 24, n. 9, p. 2021-2031, 2008.

PEREIRA S. M. et al. Geographicinformation system (GIS) in assessing dental health. International Journal of Environmental Research and Public Health, Basel, Suiça, v. 7, n. 5, p. 2423-2436, 2010.

PEREIRA, C. R. S. et al. Impacto da Estratégia de Saúde da Família sobre indicadores de saúde bucal: análise em municípios do Nordeste brasileiro com mais de 100 mil habitantes. Cadernos de Saúde Pública. São Paulo, v. 28, n. 3, p. 449-462, 2012.

PEREIRA, S. M. et al. Geographic information system and multilevel analysis: gingival status in 12-year-old schoolchildren. Revista Panamericana de Salud Pública, Washington, DC, v. 35, n. 2, p. 136-143, 2014.

PERES, K. G.; FRAZÃO, P.; RONCALLI, A. G. Padrão epidemiológico das oclusopatias muito graves em adolescentes brasileiros. Revista de Saúde Pública, São Paulo, v. 47, n. 3 , p. 109-117, 2013.

PETERSEN, P.E. The world oral health report 2003: continuous improvement of oral health in the 21st century-the approach of the who global oral health programme. Community Dentistry and Oral Epidemiology, v. 31, n.1, p. 3-23, 2003.

PINTO, V. G. Saúde bucal, odontologia preventiva e social. 4. ed. São Paulo: Editora Santos, 1994.

PINTO, R. DA S.; MATOS, D. L.; LOYOLA FILHO, A. I. DE. Características associadas ao uso de serviços odontológicos públicos pela população adulta brasileira. Ciência \& Saúde Coletiva, Rio de Janeiro, v. 17, n. 2 , p. 531-544, 2012.

RAMIRES, I.; BUZALAF, M. A. A fluoretação da água deabastecimento público e seus benefícios no controleda cárie dentária - cinquenta anos no Brasil. Ciência \& Saúde Coletiva, Rio de Janeiro, v. 12, n. 4, p. 1057-1065, 2007.

RÉGIS-ARANHA, L. DE A et al. L. Relation between oral health and socioeconomic variables among schoolchildren aged 12 in the City of Manaus - AM. Acta Amazonica, Manaus, v. 44, n. 3, p. 321-32, 2014.

RIGO, L. et al. Estudo sobre a fluorose dentária num município do Sul do Brasil. Ciência \& Saúde Coletiva, Rio de Janeiro, v. 15, p. 1439-48, 2010.

RONCALLI, A.G. et al. Aspectos metodológicos do Projeto SB Brasil 2010 de interesse para inquéritos nacionais de saúde. Cadernos de Saúde Pública, Rio de Janeiro, v. 28, p. 40-57, 2012. 
ROSE, G. Estratégias da medicina preventiva. Porto Alegre: Artmed; 2010.

SALOMÃO, F. G. D.; DIAS, A. A.; PEREIRA, A. C. Prevenção do câncer em saúde bucal. In: PEREIRA, A. C. Saúde Coletiva: métodos preventivos para doenças bucais. Porto Alegre: Artes médicas. 2013. (Série Abeno).

SANTOS, C. M. L.et al. Estudo epidemiológico dos traumas bucomaxilofaciais em um hospital público de Feira de Santana, Bahia de 2008 a 2009. Revista Bahiana de Saúde Pública, Salvador, v. 36, n. 2, p. 502-513, 2012.

SEYMOUR, G.J.; et al. Relationship between periodontal infections and systemic disease. Clinical Microbiology and Infection, Paris, v. 13, n. 4, p. 3-10, 2007.

SILVA, A. M. et al .A integralidade da atenção em diabéticos com doença periodontal. Ciência \& Saúde Coletiva, Rio de Janeiro, v. 15, n. 4, p. 2197-2206, 2010.

SILVA, H. R. DA et al. Perfil epidemiológico do trauma dentário e facial em Curitiba. Archives of Oral Sciences \& Research, Bangalore, India, v. 7, n. 3, p. 267-273, 2011.

SOARES, F. F. et al. Prevalência e severidade de fluorose em escolares do município de São Francisco do Conde-BA, 2010. Revista de Odontologia da UNESP, Marília, v. 41, n. 5, p. 318-323, 2012.

SOUSA, F. B. et al . Oral cancer from a health promotion perspective: experience of a diagnosis network in Ceará. Brazilian Oral Research, São Paulo, v. 28, p. 1-8, 2014 .

SOUZA, M. A. A; VIANNA, M. I. P.; CANGUSSU, M. C. T. Disfunção familiar referida pela presença de depressão materna e/ou alcoolismo na família e ocorrência de cárie dentária em crianças de dois e três anos de idade. Revista Brasileira de Saúde Materno Infantil, Recife, v. 6, n. 3, p. 309-17, 2006.

THOMAZ, E. B. A. F.; CANGUSSU, M. C. T; ASSIS, A. M. A. Malocclusion and deleterious oral habits among adolescents in a developing area in northeastern Brazil. Brazilian Oral Research, São Paulo, v. 27, n.1, p. 62-69; 2013.

TOASSI, R. F. C.; ABEGG, C. Fluorose dentária em escolares de um município da serra gaúcha, Rio Grande do Sul, Brasil. Cadernos de Saúde Pública, Rio de Janeiro, v. 21, n. 2, p. $625-655,2005$.

TORRES-PEREIRA, C. C. et al . Abordagem do câncer da boca: uma estratégia para os níveis primário e secundário de atenção em saúde. Cadernos de Saúde Pública, Rio de Janeiro, v. 28, p. s3o-s39, 2012.

WHO. The World Oral Health Report 2003. Continuous improvement of oral health in the 21st century - the approach of the WHO Global Oral Health Programme. Geneva: WHO, 2003 .

WÜNSCH FILHO, V.; MONCAU, J. E. Mortalidade por câncer no brasil 1980-1995: padrões regionais e tendências temporais. Revista da Associação Medica Brasileira, São Paulo, v. 48, n. 3, p. 250-257, 2008. 



\title{
Estado e atenção à saúde bucal no Brasil no período pré-constituinte
}

\author{
Maria Isabel Vianna \\ Jairnilson Paim
}

\section{Introdução}

A prática odontológica predominante no país nos anos 1970 tinha como base a ideologia liberal e mercantilista, privilegiando a atenção individual e reparadora em detrimento das ações preventivas de alcance coletivo. Além disso, a ampla utilização de tecnologia e a difusão acentuada da prática especializada, somadas a outros elementos, tinham promovido um alijamento histórico da grande maioria da população brasileira do acesso à atenção à saúde bucal. A falta de assistência e os problemas relativos às péssimas condições de vida da maioria da população geravam um quadro epidemiológico que, em relação à saúde bucal, situava-se entre os piores do mundo.

Em que pese o caráter hegemônico dessa modalidade de prática restritiva e elitista, foram realizados esforços na perspectiva de apreender as alterações que vinham se manifessando de forma cada vez mais evidente no sentido da progressiva substituição da atividade liberal por outras formas de organização do trabalho odontológico (PAIXÃO, 1979), incluindo a participação do Estado nesse processo.

Observava-se que, a despeito da crescente participação do Estado, essa questão não vinha sendo analisada na perspectiva da identificação de seus 
determinantes, das suas características peculiares, das suas contradições e limites. Estudos pioneiros restringiam-se a descrição do subsistema público de atenção à saúde bucal. (PINTO, 1977; VIANNA, 1977)

Com o propósito de ampliar o escopo da análise, foi realizado um estudo sobre as políticas de saúde bucal na conjuntura pós-74, defendida em 1988 (VIANNA, 1988), cuja síntese se apresenta neste capítulo. A investigação original examinou as políticas de saúde bucal empreendidas pelo Estado brasileiro naquela conjuntura, especialmente no âmbito da saúde pública, considerando a totalidade social em que se desenvolviam as políticas e, especialmente, a ampliação do papel do Estado na fase monopolista do modo de produção capitalista através das políticas sociais.

Buscando apreender o processo de emergência da participação do Estado na atenção à saúde bucal, foram resgatados os antecedentes mais relevantes do período compreendido entre 1923, ano em que foi aprovada a Lei Eloy Chaves, referente à Previdência Social, e 1974, quando teve início a distensão política do regime autoritário e certa ênfase nas políticas sociais a partir do II Plano Nacional de Desenvolvimento. (LUZ, 1979) Em seguida nesse estudo, dividiu-se a conjuntura em dois períodos (1974-1979 e 1980-1986), sendo apresentados certos desdobramentos no setor saúde e, especificamente, nas políticas de saúde bucal.

\section{Emergência das políticas de saúde bucal no Brasil}

No que pese o fato da odontologia ter se organizado historicamente enquanto prática liberal, prevalecendo o setor privado de prestação de serviços, pode-se identificar, nas origens da Previdência Social, o início do processo de participação estatal ao nível da prática odontológica no Brasil. O ano de 1923, quando se dá a promulgação da Lei Eloy Chaves, que cria, nas empresas de estrada de ferro existentes no país, uma Caixa de Aposentadoria e Pensões para os respectivos empregados, pode ser considerado como marco do surgimento efetivo da previdência no Brasil. Esse fato se insere num contexto mais amplo de mudanças, principalmente no que se refere à postura, até então marcadamente liberal do Estado frente à problemática trabalhista e social. (OLIVEIRA; TEIXEIRA, 1985)

Esse período é caracterizado pela intensificação das pressões operárias, por um lado, e também pela percepção, por parte das elites e governantes, da insuficiência de medidas repressoras, sendo necessária a ampliação das margens 
de consenso, através do atendimento de certas demandas aceitáveis que, obviamente não colocassem em cheque a própria dominação da oligarquia agrária. Teve início, então, o processo de ruptura do pacto informal que até então se mantivera entre essa fração e a burguesia industrial nascente, em torno da questão da intervenção estatal no âmbito das relações e condições do trabalho urbano. (OLIVEIRA; TEIXEIRA, 1985)

Amplia-se o processo de implantação das Caixas de Aposentadoria e Pensões (CAP), inaugurando a prestação de "assistência odontológica" aos seus segurados e beneficiários. No entanto, só a partir de 1933, com a criação dos Institutos de Aposentadorias e Pensões (IAP), esse tipo de serviço começa a crescer em termos reais. (LANA, 1984) Vale lembrar que esse período é marcado pela quebra do regime oligárquico (a partir de 1930) e pela presença, cada vez mais marcante, das classes assalariadas urbanas no cenário político e econômico do país. (COHN, 1980) Nesse contexto, vão sendo criados os institutos, numa sequência que evidencia o privilegiamento de certas categorias, mais organizadas e importantes economicamente.

No que tange à assistência odontológica, a ampliação ocorre sem que diretrizes e normas técnicas sejam fixadas, prevalecendo a prática de uma odontologia essencialmente "mutiladora" e emergencial, restrita "à remoção de focos”. (LANA, 1984) Embora essas características permeassem a quase totalidade das instituições, algumas diferenças podem ser identificadas em função de injunções políticas mais gerais, da capacidade de mobilização de cada categoria, da importância econômica de cada uma delas e das condições financeiras das instituições. (COHN, 1980)

Entretanto, mesmo considerando os avanços alcançados pela Previdência Social nos anos 1930, pode-se dizer que prevaleceu uma política de contenção de gastos públicos, condicionada pela crise econômica herdada do regime anterior pela Revolução de 1930. O desafio era conciliar as limitações financeiras do período com as necessidades políticas do regime.

A conjuntura inaugurada com a queda do Estado Novo, em 1945, é caracterizada por uma progressiva eliminação das medidas de cunho contencionista. Tal processo, contudo, não veio acompanhado de ações que buscassem equacionar os problemas que já vinham afetando a receita como, por exemplo, as dívidas e atrasos no pagamento dos encargos dos empregadores e da União. Era o prenúncio do que, mais tarde, aliado a outros fatores, viria a constituir a chamada "crise financeira" da Previdência Social. O novo contexto político interno, 
especialmente o processo de redemocratização, favorecia modificações nas organizações previdenciárias. (OLIVEIRA; TEIXEIRA, 1985) O governo Dutra (1946-1950) é marcado pela expansão do setor próprio de assistência médica previdenciária, de modo que a compra de serviços médicos e hospitalares do setor privado pelo Estado era considerada como meramente provisória. Oliveira e Teixeira (1985, p. 185) transcrevem um trecho da Mensagem presidencial de 1950, que versa sobre o tema aparecendo aqui menção à odontologia:

[...] nos locais em que a massa segurada, pela diluição, ainda não permite a instalação de ambulatórios, o Instituto manteve o sistema de credenciar ou contratar médicos, dentistas, serviços de enfermagem e hospitais, havendo, em 31 de dezembro último, 817 médicos, 50 dentistas e 133 hospitais trabalhando para os segurados da instituição, mediante esse regime.

Em 1954, é promulgado o Regulamento Geral dos Institutos de Aposentadorias e Pensões (Decreto n. ${ }^{\circ} 35.448$ de 10/05/54), onde é mantida a vinculação entre previdência e assistência, além do que se amplia a noção de serviços médicos. É o que demonstra o seguinte trecho do Decreto: “os serviços médicos proporcionarão assistência clínica, cirúrgica, farmacêutica ou odontológica aos beneficiários, em ambulatório, hospital ou domicílio, com a amplitude que os recursos financeiros e as condições locais permitirem”. (BRASIL, 1954)

No que tange à saúde pública, a odontologia dá seus primeiros passos no início da década de 1950. Em 1951, é instalada a Seção de Odontologia, do então denominado Serviços Especiais de Saúde Pública (SESP) (SINGER; CAMPOS; OLIVEIRA 1981, p. 131), 1981) e, logo no ano seguinte é implantado o serviço odontológico na cidade de Aimorés, Minas Gerais. Esse serviço incorporava, em seu programa de saúde bucal, equipamentos de baixa densidade tecnológica; utilização de pessoal auxiliar na prestação de cuidados dirigidos ao "grupo epidemiologicamente mais vulnerável” (crianças na faixa etária de 6 a 12 anos); e, de forma pioneira no Brasil, implantava o modelo de atenção baseado no Sistema Incremental de Atendimento (cobertura gradativa a partir das menores idades através de tratamento intensivo, realizado em poucas sessões). (BRASIL, 1983a)

Outro marco na atuação do SESP, nesse período, foi a implantação do primeiro sistema de fluoretação de água de abastecimento público do país, inaugurado em outubro de 1953, na cidade de Baixo Guandu, Espírito Santo. A expectativa dos técnicos era de que, passados os primeiros 14 anos de fluoretação 
ininterrupta, alcançasse-se uma redução da incidência de cárie dental, em torno de $66 \%$. (BRASIL, 1953)

Em 1960, é extinto o acordo entre Brasil e Estados Unidos, que dera origem ao SESP, o qual é transformado em Fundação (FSESP), vinculada ao Ministério da Saúde (MS):

[teve] redefinidas suas funções que passaram a ser de promover, nas áreas de expansão, programas de saúde, de saneamento, de treinamento de pessoal técnico e auxiliar, bem como realizar estudos, inquéritos e pesquisas necessárias ao desenvolvimento de suas atividades. (SINGER; CAMPOS; OLIVEIRA 1981, p. 131)

O primeiro manual impresso sobre Normas Técnicas de Odontologia Sanitária da FSESP foi elaborado, em 1961, numa reunião de supervisores realizada na cidade de Ilhéus, Bahia. (BRASIL, 1978) O atendimento prioritário a escolares, uso de consultórios semiportáteis e utilização de pessoal auxiliar constituem as características básicas do modelo estabelecido no manual. (BRASIL, 1963) Além disso, introduz alterações no sistema incremental até então adotado pelos serviços odontológicos da Fundação. (DINIZ, 1987)

Na Previdência Social, no início da década de 1960, ocorre a promulgação da Lei Orgânica da Previdência Social (LOPS) que uniformiza os planos de atribuições dos diferentes IAP. Segundo Oliveira e Teixeira (1985, p. 166), a promulgação da LOPS constitui “[...] o marco da derrota final do modelo contencionista, ao essender para o conjunto dos segurados da Previdência, um plano extremamente amplo de benefícios e serviços”. Embora seja dedicado todo um capítulo às "prestações", ampliando-se os serviços oferecidos, não são encontradas, no Artigo 45, que dispõe sobre a assistência médico-odontológica, diretrizes específicas relativas à odontologia (BRASIL, 1960)

Esse conturbado período (início dos anos 1960) é caracterizado, no plano político, pelo esgotamento do pacto populista entre o Estado e a classe trabalhadora. Nos marcos do modelo de acumulação capitalista adotado desde os anos 1950, baseado na associação ao capital estrangeiro, tornava-se cada vez mais difícil a incorporação das demandas trabalhistas e a manutenção do esquema de cooptação de setores da classe operária.

Diante das alternativas que se colocavam, relativas a quem confiar o desempenho do papel hegemônico no interior do bloco do poder: 
Se à coalizão nacional populista, via implementação das reformas de base e radicalização da luta anti-imperalista; ou à coalizão internacionalmodernizadora, via golpe de Estado e destruição do aparato nacionalpopulista. (FERNANDES, apud OLIVEIRA; TEIXEIRA, 1985, p. 195-6)

Prevaleceu a segunda alternativa, com amplo apoio das classes médias urbanas. Instala-se o regime militar, caracterizado pelo autoritarismo e fechamento dos canais de participação dos trabalhadores. No plano institucional, tem início, nas instituições existentes, um processo de "depuração" do seu caráter político, em nome de uma racionalidade técnica e administrativa. (OLIVEIRA; TEIXEIRA, 1985) Dadas as condições políticas necessárias, ocorre em 1966 a fusão dos IAP, exceto o Instituto de Previdência e Assistência dos Servidores do Estado (IPASE) e a criação do Instituto Nacional de Previdência Social (INPS).

Em 1969, por solicitação do MS, com vistas a servir de subsídio para a orientação das atividades de odontologia a serem por ele desenvolvidas, foi elaborado documento intitulado Atividades de odontologia (BORGES FILHO et al., 1969), que caracteriza sucintamente o problema das condições de saúde bucal da população brasileira, considerada pelo grupo como precária; faz uma apreciação do modelo de atenção adotado, destaca a inadequação e insuficiência dos recursos humanos e materiais, reconhece o mau emprego dos recursos financeiros no âmbito da atenção à saúde bucal e sistematiza um conjunto de recomendações.

A inalterabilidade das ações de odontologia no âmbito do MS, nos anos seguintes, indicam a não execução das recomendações do grupo. Enquanto isso, em 1969, pela primeira vez, são fixadas diretrizes específicas destinadas a orientar a prática odontológica no âmbito da Previdência Social, de acordo com recomendações do Conselho Diretor do Departamento Nacional de Previdência Social. (BRASIL, 1969a)

A Resolução n. ${ }^{\circ}$ CD/INPS-443/69 vem aprovar as diretrizes propostas por esse conselho, explicitadas em Ato Normativo de n. ${ }^{\circ}$ 48. (BRASIL, 1969b) Segundo essa norma, a assistência odontológica prestada pelo INPS, deveria, inicialmente, visar a remoção de focos, só incluindo a profilaxia da cárie dentária no tratamento odontopediátrico. Em segunda etapa, na medida em que os recursos orçamentários e financeiros permitissem, o INPS poderia estender a realização de tratamento conservador de "dentisteria" aos beneficiários adultos. Além disso, não incluía o acesso à prótese dentária, ortodontia e ortopedia dos maxilares (com exceção dos casos de complementação terapêutica de inter- 
venção cirúrgica reparadora de lesões congênitas). Finalmente, o Ato Normativo n. ${ }^{\circ} 48$ recomenda ao INPS que crie o código de custo específico para as despesas relacionadas com a assistência odontológica:

[...] devendo, até que seja criado código de custo próprio, o INPS reservar do montante dos recursos consignados para o custeio de assistência médica, uma parcela destinada à cobertura das despesas com os serviços odontológicos. (BRASIL, 1969b, p. 1-2)

\section{4-1979: início da crise, abertura e reformas}

A crise iniciada em 1962, e que atinge seu ápice nos primeiros meses de 1964, conduz o governo militar, durante os primeiros anos do novo regime, a optar pela adoção de uma política de estabilização, dentro dos moldes clássicos, que implicava o estabelecimento de medidas como: corte nos gastos públicos, aumento da carga tributária, contenção de crédito, arrocho salarial, além de buscar sanar questões de longo prazo, através do estimulo à poupança privada, reorganização do sistema financeiro, reformulação da lei de remessas de lucros e incentivo às exportações, entre outras. (BAER, 1978; DUPAS, 1987; NOGUEIRA, 1986).

Estavam assim determinados os rumos da recuperação e lançadas as bases para o acentuado crescimento que viria no período seguinte (1968/1974), cujo forte dinamismo seria calcado principalmente no desenvolvimento da indústria de bens duráveis e na indústria de bens de capital, aliado ao crescimento das importações e exportações, a maior abertura da economia ao financiamento externo, bem como a forte concentração de renda com aprofundamento das margens de diferenciação salarial.

Enquanto as camadas médias e altas, atraídas pelas facilidades de crédito ao consumo e beneficiadas pela concentração da renda, constituíam demanda garantida para o setor de duráveis, amplas parcelas de população, marginalizadas pelo modelo de desenvolvimento adotado, passavam a conviver com a persistente degradação das condições de vida, prenúncio de uma crise social que teria papel importante no período pós-74. As contradições inerentes ao processo de expansão desse período, aliada às questões relacionadas à conjuntura econômica internacional a partir de 1974, estariam na base da crise advinda em meados da década de 1970. 
Mello e Belluzzo (1985) buscavam as determinações mais profundas da crise, na dinâmica da acumulação empreendida no período pós-68. Dois fatores sobressaíam nessa análise: em primeiro lugar, está a defasagem entre os ritmos de acumulação verificados entre a indústria de bens duráveis, incapaz de manter um crescimento autogerado, e a indústria de bens de produção, cuja recuperação se manifesta posteriormente ao setor de duráveis. De outro lado, a expansão da indústria de bens de produção exigia uma brutal concentração de capital, além de financiamentos externos.

O início do governo Geisel (1974-1979), portanto, representa o final do ciclo de crescimento e começo de uma crise que, atingindo fortemente o setor econômico, tinha reflexos desastrosos sobre a área social e gerava insatisfação que teriam sua primeira manifestação política após o Golpe Militar, nas eleições de novembro de 1974. O choque do petróleo e a crise mundial vieram se somar aos problemas internos, com o peso relativamente importante numa economia marcadamente dependente do mercado internacional.

Diante desse quadro, o II Plano Nacional de Desenvolvimento vai tentar conciliar uma política de investimentos maciços em setores vitais, desencadeando um novo processo de substituição de importações via reciclagem energética (proálcool; Itaipu; acordo nuclear etc), com uma política social compensatória aos efeitos da concentração da renda, processo de urbanização acelerada e mudanças nas relações de produção no campo entre outros aspectos.

O período será marcado por um "vaivém" contínuo de medidas contencionistas e expansionistas, de modo que, entre 1974 e 1978, nas palavras de Coutinho e Belluzzo (1982), a política econômica estiolou-se na tentativa de conjugar objetivos irreconciliáveis.

Dessa forma, chega-se ao ano de 1979, fim do governo Geisel e início do governo Figueiredo (1979-1985), com um novo choque do petróleo, déficit na balança comercial (recuperada em 1977), aumento nas importações, enfrentando altas taxas de juros internacionais e uma dívida externa de proporções preocupantes; fatores esses aliados à súbita elevação nas taxas de juros internos, ao crescente processo de especulação e apropriação do excedente pelo setor financeiro (desencorajando os investimentos industriais), às pressões inflacionárias e ao desemprego. O Brasil caminhava, então, a passos largos, em direção à recessão. 


\section{A crise sanitária}

Os reflexos negativos, advindos da crise econômica iniciada em 1974, abateram-se mais drasticamente sobre aqueles que estiveram à margem do processo de crescimento experimentado no período anterior (1968-1973), gerando o que Cordeiro (1983) considerava uma verdadeira "crise sanitária".

A epidemia de meningite em 1974, o aumento da mortalidade infantil e desnutrição na cidade de São Paulo, maior centro do país, vêm desnudar as péssimas condições de vida de grandes parcelas da população. Por outro lado, não era mais possível manter o padrão de dominação adotado no período anterior. Teve início um processo de abertura política, aliado a um discurso que privilegiava a questão social, de sorte que a questão da saúde passa a adquirir relevo no bojo das políticas sociais.

Inaugurando uma série de medidas legais e de caráter administrativo, é criado o Ministério da Previdência e Assistência Social (MPAS), através da Lei n. ${ }^{0}$ 6.025, de 25 de junho de 1974. No mesmo ano, instituiu-se o Conselho de Desenvolvimento Social, formado pelos ministérios da área social (Saúde, Previdência, Interior, Educação e Trabalho), com atribuição de assessorar o presidente da República na formulação da política social e na coordenação dos ministérios envolvidos na implantação dessa política.

Quanto à legislação previdenciária, consolida-se a tendência à universalização da cobertura e ampliação da assistência médica. Medidas de cunho normalizador são adotadas nesse sentido, como é o caso do Plano de Pronta Ação, que deveria disciplinar e organizar as diversas modalidades de prática médica, vinculadas à Previdência Social, mas que na realidade acabou contribuindo para o aprofundamento do processo de privatização da assistência à saúde.

Em 1975, é aprovada a Lei n. ${ }^{0}$ 6.229, que cria o Sistema Nacional de Saúde, com o objetivo de definir atribuições e áreas de competência para as múltiplas instituições da saúde existentes. No entanto, não foram explicitados e, muito menos, colocados em prática os mecanismos efetivos de integração entre elas.

Nova ordenação no interior da Previdência Social ocorre em 1977, com a instituição do Sistema Nacional de Previdência e Assistência Social (SINPAS), subordinado ao MPAS. Integrando o SINPAS, têm-se as seguintes entidades: INPS, responsável pela concessão de benefícios; Instituto Nacional de Assistência Médica da Previdência Social (Inamps), encarregado de prestar assistência à saúde aos beneficiários do sistema; Instituto de Administração Financeira da Previdência Social, gestor de toda atividade financeira; e ainda a Fundação 
Legião Brasileira de Assistência; Fundação Nacional de Bem-Estar do Menor; e Empresa de Processamento de Dados da Previdência Social. Na categoria de órgão autônomo integra, ainda, o SINPAS, a Central de Medicamentos, a qual estava vinculada ao MPAS desde 1974.

No MS, “[...] as políticas dessa segunda metade da década assinalaram uma reativação do órgão". (CORDEIRO, 1983, p. 88) A cobertura é ampliada, além do que são elaborados alguns programas que, em linhas gerais, buscaram dar alguma resposta àqueles problemas sociais levantados anteriormente. É o caso, por exemplo, do Programa de Interiorização das Ações de Saúde e Saneamento do Nordesse (PIASS) e do Programa de Alimentação e Nutrição (Pronan), este vinculado ao Instituto Nacional de Alimentação e Nutrição.

\section{As políticas de saúde bucal no âmbito da saúde pública (1974-1979)}

Em maio de 1974, concretiza-se a antiga aspiração dos dentistas sanitaristas e é dado um importante passo do ponto de vista da saúde pública: é assinada a Lei n. ${ }^{0}$ 6.050, que dispõe sobre a fluoretação da água em sistemas de abastecimento quando existisse estação de tratamento. (BRASIL,1974)

Embora não explicite a obrigatoriedade da fluoretação, conforme reivindicavam as organizações de classe e conclaves científicos de odontologia, a Lei n. ${ }^{\circ}$ 6.050 constitui um considerável avanço nessa área. Contudo, a sua regulamentação só se efetivou mais de um ano depois, através do Decreto $\mathrm{n}^{\circ} 76.872$, de 22 de outubro de 1975. O Parágrafo Único do Art. $1^{\circ}$ abre novas perspectivas para o uso de métodos alternativos de utilização do flúor de modo que “[...] se aplica inclusive aos sistemas que não possuem estação de tratamento nos quais deverão ser utilizados métodos e processos de fluoretação apropriados...”. (BRASIL, 1975a) Com base no que dispõe a Lei n. ${ }^{0} 6.229$ do Sistema Nacional de Saúde, fica o MS responsável pelo estabelecimento de normas e padrões para fluoretação de água. (BRASIL, 1975b)

Como primeira medida de destaque, adotada após vigência da legislação apresentada, é firmado, em 1975, um convênio entre a FSESP e Instituto Nacional de Alimentação e Nutrição (INAN) que, através do Pronan havia incorporado a fluoretação entre os projetos destinados ao combate das carências nutricionais específicas (ARRUDA, 1975), no sentido da execução do Projeto de Fluoretação das Águas de Abastecimento Público (BRASIL, 1975c), com a colaboração os governos estaduais e municipais. Segundo dados do projeto, o Brasil, em 1972, contava com apenas 76 sistemas fluoretados, sendo que, em 41 
cidades, utilizando-se o fluoreto de cálcio (fluorita) e, em 35, o fluorsilicato de sódio. (BRASIL, 1975c) A população beneficiada somava um total de 3.280.467 habitantes, o que correspondia a 4,6\% da população brasileira (BRASIL, 1983a), estimada para o ano de 1972.

O objetivo do projeto era beneficiar, através da fluoretação, $80 \%$ da população de 132 cidades, com aproximadamente 33 milhões de habitantes, o que correspondia a 50\% da população brasileira estimada para o ano de 1980. Prevista sua execução em três fases, pretendia-se alcançar as metas estabelecidas, no último período, que deveria ir de 1978 a 1980. O custo do projeto foi estimado em cerca de 65 milhões de cruzeiros (cerca de U\$ 8,700,000, em $1^{\circ}$ de janeiro de 1975).

Os relatórios de acompanhamento do projeto demonstram claramente as dificuldades, lentidão e absoluta impossibilidade de serem alcançadas as metas diante do ritmo que foi imprimido à sua execução. (BRASIL, 1977a; BRASIL, 1979a; BRASIL, 1979b; BRASIL, 1980a) O último relatório disponível dava conta de que, até 1979, apenas $38 \%$ das metas previstas tinham sido alcançadas; que 50 cidades absorveram $53 \%$ dos recursos previstos para a fluoretação de 132 delas; e que, dos 26.043 .700 habitantes que deveriam ser beneficiados, apenas 4.394.000 efetivamente o foram, correspondendo a 16,9\%. (BRASIL, 1980b)

Outro programa de odontologia é elaborado pelo MS, em 1976. Dessa vez, relativo à prevenção e diagnóstico precoce do câncer bucal, sob a responsabilidade da Divisão Nacional do Câncer. Consta que chegaram a ser realizadas algumas reuniões entre técnicos do MS e entidades prestadoras de serviços, com vistas à sua implantação, no entanto, nenhuma medida concreta chegou a ser adotada nesse sentido.

A FSESP, único órgão prestador de serviços odontológicos pelo MS, passa, durante esse período (1974-1979), por um processo de revisão de alguns aspectos de sua política de saúde bucal, reafirmando, no entanto, os elementos básicos do modelo de prática adotado desde 1952, quando da instalação do primeiro serviço odontológico. Esse modelo esteve calcado na atenção odontológica ao escolar, com base em programas incrementais e no uso de métodos preventivos de caráter individual e coletivo para controle da cárie dental. Isso vinha sendo feito através da utilização de pessoal auxiliar e da adoção de equipamentos simplificados e padronizados, técnicas de planejamento, programação e critérios próprios de supervisão e avaliação. 
Após 25 anos de desenvolvimento dessa prática, realiza-se, em agosto de 1977, na cidade de Fortaleza, uma reunião de supervisores, visando promover a revisão e atualização das Normas Técnicas de Odontologia, adaptando-as às modificações introduzidas a partir de 1976 (normatização da assistência ao adulto) e aos novos conhecimentos técnicos e científicos, bem como analisar e avaliar as atividades de odontologia desenvolvidas pela Fundação, com o propósito de melhorar a qualidade da assistência prestada nas unidades de saúde. (BRASIL, 1977b) Como resultado dessa reunião, foi elaborado novo Manual de Instruções e de Orientação Técnica (BRASIL, 1978), que vigorou até 1984, quando novas alterações foram introduzidas ao modelo de prática da FSESP.

Vianna (1978), em Encontro de Odontologia Comunitária, realizado em fins de 1978, afirmava que outros organismos do MS, além da FSESP, desenvolviam atividades que incluíam algum componente relacionado com a saúde bucal sem que, no entanto, houvesse uma coordenação das ações de odontologia, no âmbito do Ministério. Considerava que, em consequência do Decreto n. ${ }^{\circ} 79.056$ de 30.12.76, que dispunha sobre a nova organização do MS não fazer qualquer referência à odontologia, a elaboração de programações de abrangência nacional e outras atribuições da área odontológica não estavam incluídas entre as competências da Secretaria Nacional de Ações Básicas de Saúde nem da Secretaria Nacional de Programas Especiais de Saúde, ficando, portanto, diluída entre vários órgãos e sujeita aos efeitos nocivos da descoordenação. Por fim, o autor destacava ainda o subfinanciamento das ações de odontologia no plano federal.

\section{0-1986: crise econômica e transição democrática}

O período ora analisado tem início no ano de 1980, quando o governo opta pela política econômica recessiva, que vai prevalecer até 1983. O ano seguinte congrega uma série de especificidades, tanto do ponto de vista econômico como principalmente do político - é o ano em que se consolidam as articulações em torno da transição democrática.

Numa breve recapitulação, vê-se que o regime militar, após a fase de adoção de uma política de estabilização (1964-1967), ruma no sentido da modernização da estrutura produtiva, conduzindo o país a um processo de crescimento acelerado (1968-1974), que se deu às custas de uma brutal concentração de renda e aprofundamento da dependência externa. Seguiu-se um período de desaceleração (1974-1979), onde se tentou, através de uma política de alternância 
de medidas contencionistas e expansionistas (stop and go), evitar o caminho da recessão.

Mas o novo salto nos preços do petróleo, acarretando aumento do gasto com importações e prejudicando a balança comercial, e a deterioração das relações de troca dos produtos brasileiros, conduzem ao crescimento da dívida externa em condições bastante desfavoráveis. Os juros internacionais começam a subir, em função da reciclagem dos créditos dos importadores de petróleo, implicando dificuldades de difícil superação para os países devedores, que passam a assumir duramente o ônus da política imposta pelo sistema financeiro internacional com base nos contratos com juros flutuantes.

O governo Figueiredo (79-84), ao tomar posse, tenta inicialmente manter as taxas de crescimento, o que resulta na perda de controle da inflação, mas logo em seguida, diante da desordem creditícia e fiscal e dos efeitos negativos sobre endividamento externo, ensaia os primeiros passos de uma política recessiva. As pressões contrárias atingem em cheio o então condutor da política econômica, ministro Simonsen, que acaba por se demitir do cargo. Assume a pasta, o ministro Delfim Neto que, durante os próximos quatro anos, teria nas mãos o poder absoluto no encaminhamento da economia do país.

O otimismo inicial, acompanhado do irrestrito apoio do empresariado, logo teria que enfrentar a dura realidade (inflação mensal recorde em setembro/1979 - 7,7\%; déficit financeiro do Tesouro da ordem de Cr\$280 bilhões - cerca de US\$ 13,4 bilhões a preço de $1^{\circ}$ de janeiro de 1979; preços do petróleo em alta; tudo isso reforçando a aceleração inflacionária e contribuindo para a deterioração da balança de pagamentos). (COUTINHO; BELLUZZO, 1982)

O ministro resolve administrar a crise de forma pragmática, e relativamente heterodoxa, evitando cair na recessão. Para isso, adota uma série de medidas no sentido do reforço da capacidade fiscal (aumento de impostos e eliminação de subsídios fiscais); recuperação dos níveis de autofinanciamento das empresas estatais (aumento de preços e tarifas administradas pelo setor público); e neutralização do ônus do crescente aumento do preço do petróleo através do repasse aos preços dos derivados (mais que proporcional no caso da gasolina).

Ao longo de 1980, a despeito das tentativas do ministro-chefe da Secretaria de Planejamento (SEPLAN), no sentido de convencer o país e os credores externos do acerto de sua política, a desconfiança é generalizada: 
incapaz de enfrentar essas pressões, assistindo a descontrolada evasão de reservas, e vitimado pelas mazelas de sua própria política de préfixação, o governo capitula finalmente e, em novembro de 80 , decide-se pela política recessiva. (COUTINHO; BELLUZZO, 1982, p. 183)

Seguindo o formulário ortodoxo ditado pelo Fundo Monetário Internacional (FMI), o governo adota uma série de medidas que, salvo algumas alterações, vão permear todo o período recessivo (final de 1980 a 1983). Implantadas com o objetivo de reduzir a inflação e viabilizar o pagamento dos serviços da dívida externa, através da obtenção de superávits comerciais, essas medidas se mostraram, no entanto, ineficazes e contraditórias. Em linhas gerais, foram promovidos cortes nos gastos públicos e nos orçamentos das estatais (REICHSTUL; COUTINHO, 1983); eliminação de subsídios (principalmente ligados a produtos agrícolas); liberação da taxa interna de juros (que subiu violentamente); controle rigoroso da expansão monetária; e incentivos para obtenção de saldos na balança comercial.

A inflação cai em 1981 para voltar a subir fortemente nos anos seguintes. Com a contenção dos gastos públicos e paralisação dos investimentos privados, cresce a taxa de desocupação, ampliando-se o recurso ao subemprego; além de decaírem as taxas de crescimento industrial. O Produto Interno Bruto (PIB) que, na fase áurea do crescimento, atingia uma média de 10\% ao ano, passa a 1,6\%, em 1981, e a -3,2\%, em 1983. (NOGUEIRA, 1986) Essa tendência atingiria, nesse período, toda a América Latina, subjugada ao comportamento do sistema financeiro internacional.

No bojo da crise econômica e das tensões sociais advindas da recessão, o regime militar começa a dar mostras de enfraquecimento político. $\mathrm{O}$ anseio pela volta do crescimento começa a se confundir com o desejo de que chegassem ao fim as restrições políticas contra os direitos individuais. O desgaste aumenta ao serem divulgados, pela imprensa, os primeiros escândalos financeiros que, por sua vez, viriam permear todo o ocaso do regime autoritário. A insatisfação atinge empresários, trabalhadores e todo o país.

Em novembro de 1982, ocorre a primeira eleição direta para governador, após 18 anos de Golpe, consagrando a vitória de um número considerável de governadores de partidos da oposição em estados importantes, política e economicamente. Esse foi um marco no desencadeamento do processo de mudança. (DUPAS, 1987) 
A crise atingia seu ápice no ano de 1983, assim configurada: um recorde negativo do PIB; momento crítico de estouro da inflação (que passa do patamar de 100 para 200\%); e agravamento da situação da população, face à pressão nos preços dos alimentos básicos. Atingia-se um nível de incerteza inédito na economia brasileira. No que tange à dívida externa, "toda a recessão provocada, para viabilizar um gigantesco superávit comercial não era suficiente sequer para honrar o serviço da dívida". (DUPAS, 1987, p.25) O Congresso dá os primeiros sinais de resistência, rejeitando decretos do executivo que aprofundavam o arrocho, através de políticas salariais cada vez mais restritivas.

Movimentos importantes mobilizam a área sindical. Escândalos financeiros continuam atingindo altos funcionários do governo, promovendo um esgotamento inevitável. São dados os primeiros passos, pela liderança da oposição, no sentido da articulação para a mudança na vida política da nação. Aquele ano de 1983 termina tendo "de positivo apenas o desempenho do setor externo e primeiras perspectivas de rompimento do regime autoritário”. (DUPAS, 1987, p.31)

A essa altura, a situação política já apontava para o irreversível esgotamento do regime militar. Persistiam as pressões internas, multiplicavam-se os movimentos grevistas, explodiam revoltas populares materializadas em depredações e saques. Ganhava força o movimento em defesa das eleições diretas, que vai às ruas com comícios históricos, resgatando o sentimento de cidadania há muito amordaçado no seio da população brasileira. Todavia, a despeito dos reclamos da nação e do desgaste político do regime, a emenda Dante de Oliveira (Diretas Já) é derrotada no Congresso, em meio à consternação geral.

Em junho, lideranças dissidentes do partido do governo constituem a Frente Liberal, que viria apoiar a candidatura de Tancredo Neves para a presidência da República, indicando o nome de José Sarney para o cargo de vice, compondo a chapa que concorreria no colégio eleitoral com Paulo Maluf, candidato do então Partido Democrático Social (PDS).

Por tudo isso, Singer (1986) considerava que, além dos fatores de ordem econômica, a situação política teria tido forte influência sobre a retomada do crescimento. Com a clara alteração no equilíbrio de forças políticas no país e previsível vitória de Tancredo Neves, o governo Figueiredo não teria condições de manter os ajustes de caráter recessivo, nos moldes até então adotados, mesmo considerando não apenas a inflação anual acima de $200 \%$ e a relativa desorganização das finanças públicas, como também as pressões do Fundo Monetário Internacional (FMI). 
Em meio, portanto, a toda sorte de dificuldades que o governo teria de enfrentar, um grande desafio econômico se colocava: retomar o crescimento de forma estável e sustentada e, ao mesmo tempo, controlar a inflação. Tudo isso convivendo com um grande dilema - a dívida externa. O plano de governo da chamada Nova República e as posições do presidente eleito deixavam antever certa ortodoxia no trato das questões econômicas, acompanhada de medidas avançadas na área social e redemocratizantes no plano institucional.

Chega o ano de 1985, cercado de esperanças e grande expectativa. No entanto, a fatalidade vem somar-se à complexidade dos problemas a enfrentar. Com a morte de Tancredo Neves, em abril, José Sarney que já havia tomado posse é definitivamente consagrado presidente da República. À paralisia dos primeiros dias, seguiram-se a hesitação e adoção de tímidas medidas.

A situação internacional continuava favorável, com juros baixos e a balança comercial apresentando os saldos animadores, permitindo vislumbrar perspectivas razoáveis para o novo governo. Durante o primeiro semestre, já se confirmavam as tendências do ano anterior de reaquecimento da economia, com firme crescimento e queda no nível de desemprego.

A despeito do clima favorável e da relativa estabilidade da inflação, os sintomas de elevação do seu patamar já eram preocupantes, somando-se a isso o nítido crescimento do déficit público. As demandas reprimidas durante 21 anos de autoritarismo desaguam sobre o governo de transição, cobrando os compromissos e exigindo ação. O dilema econômico se aprofunda, dificultando cada vez mais a solução da equação que envolvia a necessidade de manter o crescimento e atender às reivindicações trabalhistas, ao tempo em que cresciam o déficit, o público e a inflação.

Os impasses gerados nesse primeiro período conduzem a saída do ministro Dornelles, em agosto de 1985. Assume a condução da política econômica um novo grupo, identificado com o moderno empresariado nacional e preocupado basicamente como manutenção do crescimento econômico. Sob a direção do ministro Dilson Funaro, passam a atuar conjuntamente os ministérios da Fazenda e do Planejamento, e a nova diretoria do Banco Central, assessorados por economistas do Partido do Movimento Democrático Brasileiro (PMDB) (vindos da Universidade Estadual de Campinas e Pontifícia Universidade Católica do Rio de Janeiro). São rediscutidas e elaboradas opções alternativas de política econômica para o período de transição, mantendo-se nesse ínterim, o combate à inflação e buscando-se garantir o crescimento. 
Apesar das dificuldades, o desempenho da economia em 1985, fora satisfatório, apresentando um crescimento da ordem de $7 \%$ e havendo redução dos níveis de desemprego e ampliação da autosuficiência no setor energético. Além disso, o tratamento dado à dívida externa fugiu, de certa forma, aos modelos tradicionais, tendo o Brasil assumido uma posição mais independente em relação ao FMI, embora a inflação e o déficit público constituíssem problemas importantes.

Ainda em novembro de 1985 são realizadas as eleições para prefeitos das capitais, reafirmando a hegemonia do PMDB. O congresso convoca a Constituinte e promove uma reforma tributária de emergência, favorecendo estados e municípios. No final do mês, é anunciado um "pacote econômico", na tentativa de conter a inflação e déficit e manter o crescimento. O pacote procura aumentar a receita tributária global, diminuir a tributação na fonte para os salários menores e estimular o investimento (com o objetivo de aumentar a oferta e evitar o choque de demanda). (DUPAS, 1987) A alta inflação em 1986, pressão dos movimentos sindicais e do PMDB, além do esgotamento das soluções convencionais, impõem ao governo uma ação de emergência e a urgente adoção de medidas alternativas.

Em 28 de fevereiro de 1986, é anunciado o Plano Cruzado, estabelecendo em linhas gerais: nova moeda (o cruzado); tabela de conversão para pagamento das dívidas futuras; fixação, por um ano, das prestações do Banco Nacional de Habitação (BNH); congelamento dos preços de bens e serviços; inflação zero; estabilização do dólar; conversão de salários em cruzados pela média dos últimos seis meses; e instituição do gatilho salarial e do seguro desemprego; entre outras medidas. A despeito de alguns poucos opositores e da necessidade de alguns ajustes preliminares, a receptividade ao plano foi surpreendente. No decorrer do primeiro semestre daquele ano, apesar dos saldos positivos das medidas no tocante à melhoria das condições de consumo da população, acentuam-se algumas distorções consideráveis.

O empresariado passa a exercer uma oposição mais explícita ao plano, tendo como fortes aliados os pecuaristas. A elite conservadora se une na defesa de seus interesses recebendo para isso a colaboração da grande imprensa. Os credores internacionais acentuam as pressões a partir do segundo semestre, preocupados sobretudo com a tendência de queda das reservas cambiais provocada pelo aumento das importações e enfraquecimento das vendas externas, em função da volta do crescimento interno e do aquecimento da demanda. A 
despeito das dificuldades, os brasileiros vão às urnas em novembro e depositam seu voto de confiança e reconhecimento, consagrando o PMDB o vitorioso absoluto nas eleições. Mas, nesse momento, o cruzado já acumulara distorções que exigiam urgentes e profundas correções. Antes que terminasse a festa da vitória, o chamado "Plano Cruzado II" é anunciado, causando surpresa e indignação no eleitorado. As medidas tinham um "sabor de descongelamento de preços e contenção salarial”. (DUPAS, 1987, p. 160)

As perspectivas para 1987, ano da constituinte, apontavam para um quadro desalentador, em termos de economia, e complexo, quanto à consolidação da democracia brasileira.

\section{A crise do regime, a crise da saúde}

Importa, agora, observar os desdobramentos ao nível do setor saúde, nessa fase complexa da sociedade brasileira, que foi a primeira metade da década de 1980. A expansão da atenção à saúde, dentro dos moldes privatistas, alcançada através das medidas adotadas no período 1974-1979, encontra seus limites no aprofundamento da crise econômica que se verifica no início dos anos 1980. Por outro lado, essa mesma crise tornava a população de baixa renda cada vez mais vulnerável ao acometimento de doenças, ampliando assim a demanda por serviços de saúde.

Ao mesmo tempo, a crise de legitimidade do regime militar, aliada ao processo de abertura iniciado no governo Geisel, viabiliza o desencadeamento de um debate, onde as forças sociais, diretamente interessadas na questão da saúde, passam a explicitar os seus projetos e interesses. Esse embate perpassa todo o governo Figueiredo, e atinge a Nova República.

Em março de 1980, realiza-se a $7^{\text {a }}$ Conferência Nacional de Saúde (CNS), tendo como tema central a "Extensão das Ações de Saúde através de Serviços Básicos”, desdobrado em 11 subtemas. A estrutura temática da Conferência indica forte influência dos movimentos internacionais pela extensão da saúde, incorporados pelo governo, não só pela necessidade de buscar maior legitimidade, mas também pela premência em responder, de alguma maneira, ao flagelo a que estava sendo submetida a população de baixa renda. Tratava-se, pois, de buscar soluções alternativas, de cunho racionalizador e menor custo, que convivesse pacificamente com um modelo hegemônico, sem ferir radicalmente seus interesses. 
O debate se materializa, em torno do Programa Nacional de Serviços Básicos de Saúde (Prev-Saúde), anunciado durante a $7^{\mathrm{a}}$ CNS. Elaborado por técnicos do MS, com a participação do Ministério da Previdência e Assistência Social, o programa, ao tempo em que incorporava, em sua primeira versão, as propostas racionalizadoras defendidas pelos organismos internacionais e pelos críticos do modelo vigente, baseadas na atenção primária e participação comunitária, corporificava o caráter tecnocrático autoritário, próprios do regime militar.

As pressões dos empresários da saúde determinam sucessivas alterações no programa, até que, mutilado e carente de apoio político, foi abandonado sem que nenhuma medida tivesse sido tomada. Toda polarização se dá em cima do discurso, servindo para explicitar o posicionamento dos diferentes grupos. As relações de poder estavam agora claramente postas. (PAIM, 1984; OLIVEIRA; TEIXEIRA, 1985)

Embora colocadas de lado nesse momento, muitas das teses contidas no Prev-Saúde retornariam nos anos seguintes, diante da necessidade de se encontrar saídas para a crise que indubitavelmente atingira o setor. A Previdência Social, que acumulara distorções desde muitos anos, com a crescente ampliação dos planos de benefícios e extensão da cobertura, não acompanhadas de medidas eficazes no estabelecimento de uma base financeira sólida, tem sua situação agravada nos primeiros anos da década de 1980, em função principalmente da brutal recessão econômica e consequente redução da arrecadação previdenciária, constituída basicamente da contribuição dos assalariados. Outros fatores relacionados com a gestão dos recursos vêm contribuir para o agravamento da crise. Entre eles, destacam-se o conhecido sistema de "caixa dupla" que a Previdência mantinha com a rede bancária; os desvios de recursos para áreas de interesse político-econômico, promovendo a descapitalização das reservas e o privilegiamento do setor privado no tocante à assistência médica.

Após um período de hesitações, o governo anuncia o "pacote da Previdência”, que busca uma ampliação da receita, às custas mais uma vez dos assalariados, penalizando também os aposentados e criando mecanismos de controle, no tocante aos gastos com assistência médica. Nesse sentido, é fixado um teto para o ano de 1982, limitando a participação do Inamps em relação ao total de gastos do Simpas; além disso, através do Decreto n. ${ }^{\circ} 86.329$, é criado o Conselho Consultivo de Administração de Saúde Previdenciária (Conasp). As atribuições desse órgão colegiado, apesar do caráter autoritário da sua criação e composição, revelam, no entender de Paim (1984, p. 13), “uma preocupação 
com racionalização no uso dos recursos e com a operação e controle da assistência médica".

Durante o primeiro ano de existência, o Conasp enfrenta as resistências de algumas parcelas do setor privado da saúde, especialmente da Federação Brasileira de Hospitais, mas as alterações no âmbito do MPAS, como a troca de ministros (com a saída do Jair Soares e nomeação de Hélio Beltrão), e o prestígio do presidente do órgão, dr. Aloísio Salles, em certas áreas chave do poder aliados à premência de soluções a para crise financeira, fazem-no avançar no sentido das medidas racionalizadoras. É assim que, em agosto de 1982, é aprovado o Plano de Reorientação da Assistência à Saúde no Âmbito da Previdência Social (BRASIL, 1983a), também conhecido como o Plano do Conasp, através da Portaria $\mathrm{n}^{\mathrm{0}} 3.062$.

Dividido em três partes, o Plano apresentava inicialmente um diagnóstico do modelo de assistência médica da Previdência, caracterizando criticamente as 10 modalidades existentes, no que tange às formas de financiamento, distorções apresentadas e à cobertura. Noutra parte, propunha a reversão gradual de modelos através da adoção de uma série de medidas. E, finalmente, estabelecia uma estratégia de implantação, que tinha como base os princípios da gradualidade e da participação.

O processo de implantação tem início ainda em 1982-1983 através do então chamado Programa de Ações Integradas de Saúde (PAIS). As propostas alternativas iam aos poucos ganhando força no bojo da crise do autoritarismo. Em maio de 1984, a Comissão Interministerial de Planejamento e Coordenação (MS/MPAS/Ministério da Educação) designa as Ações Integradas de Saúde (AIS) (estratégia fundamental do plano do Conasp), como política oficial do setor saúde, integrando políticas e recursos do Ministério da Previdência, Saúde e Educação, aos das Secretarias Estaduais e Municipais de Saúde.

A questão da saúde esteve presente nesse debate nacional em torno das perspectivas que se avizinhavam com a posse do governo de Tancredo Neves. Ao nível da sociedade civil, são formuladas diversas propostas com vistas à definição de uma política de atenção à saúde para o governo de transição. (VIANNA, 1988) A criação do Parlamento Brasileiro da Saúde, congregando as Assembleias Legislativas, Câmara dos Deputados e Senado, vem ampliar o espaço político de luta pela democratização da saúde.

Em 1985, acirram-se as discussões sobre a construção do Sistema Único de Saúde (SUS). As posições favoráveis à imediata transferência do Inamps para o 
MS são suplantadas, consolidando-se a tendência em torno do aprofundamento da estratégia das AIS, como forma de garantir o pleno desenvolvimento das políticas de saúde do novo governo. Em julho do mesmo ano, por solicitação do então MS, o presidente da República convoca a $8^{\mathrm{a}}$ CNS. Marcada inicialmente para dezembro de 1985, é adiada para março do ano seguinte, em razão das reivindicações de diversos segmentos da sociedade, com vistas a possibilitar uma maior preparação e discussão ao nível da sociedade civil e instituições, viabilizando também que os estados e municípios realizassem o seu debate interno e público.

Realiza-se então em Brasília, entre os dias 17 e 21 de março de 1986, a 8 $8^{\text {a CNS, }}$ contando com a participação de mais de 4 mil pessoas (entre os quais mil delegados), tendo como pauta de discussão três temas básicos: 1. saúde como direito; 2. reformulação do Sistema Nacional de Saúde; e 3. financiamento do setor. Num processo participativo e democrático, nunca antes verificado entre as CNS, conseguiu-se um alto grau de consenso em torno das grandes questões, havendo algum nível de diversidade apenas quanto às formas de implementação.

Entretanto, as oposições, que iriam permear os anos 1986/1987, às teses defendidas na $8^{\text {a }}$ CNS já se fizeram sentir durante a sua realização, através da não participação dos empresários da saúde (que preferiram organizar sua própria conferência) e do boicote da grande imprensa no que tange à divulgação do evento.

Entre as proposições gerais contidas no Relatório Final (BRASIL, 1986b) aprovado em assembleia, destacam-se três pontos fundamentais que, por sua vez, comportam uma série de desdobramentos: amplia-se o conceito de saúde, vinculando-a a às condições gerais de vida e se estabelece que a saúde constitui um direito do cidadão, sendo o Estado responsável pelo pleno gozo desse direito; defende-se a criação de um Sistema Único de SaúdeSUS, através de uma ampla Reforma Sanitária; e propõe-se a constituição de um orçamento social que englobe os recursos destinados às políticas sociais dos diversos ministérios, devendo caber ao da Saúde uma parcela desses com vistas à constituição do Fundo Único Federal de Saúde.

A etapa seguinte, durante todo o ano de 1986, refere-se à realização das conferências por temas específicos - a $1^{\text {a }}$ Conferência Nacional de Saúde Bucal (CSNB) foi uma delas - como desdobramento da $8^{\text {a }}$ CNS. O embate entre o projeto conservador e o projeto democrático estava claramente posto, e as posições se explicitavam utilizando, cada segmento, as armas de que dispunham, 
tendo em vista não só influenciar os desdobramentos mais imediatos quanto à reestruturação do setor, mas principalmente, conquistar espaço na futura constituinte, através da eleição de representantes comprometidos com cada projeto. Naquele momento, a estratégia de implantação da Reforma Sanitária comportava dois planos: um a nível macro, baseado no reordenamento político através da constituinte; e outro ao nível micro, via construção ascendente com fortalecimento do processo de unificação dos serviços de saúde, no âmbito dos estados e municípios, através do estabelecimento dos Sistemas Unificados e Descentralizados de Saúde.

\section{As políticas de saúde bucal no âmbito da saúde pública (1980-1986)}

No início do período analisado, a atuação do MS restringia-se, basicamente, às atividades desenvolvidas pela FSESP, aos programas de fluoretação da água de abastecimento público e à formação de recursos humanos através da Fundação Oswaldo Cruz. Os municípios realizavam ações locais sem diretrizes nacionais e as Secretarias Estaduais de Saúde atuavam livre e independentemente de qualquer interferência do Ministério, já que ele não dispunha de mecanismos institucionais nem recursos que possibilitassem o estabelecimento de uma política de saúde bucal, nem dos meios necessários ao seu adequado acompanhamento.

Mesmo considerando essas limitações, vemos que, a partir de 1980, vinculada a todo o processo de discussão e rearticulação por que passa o setor saúde, a odontologia dá alguns passos importantes, tanto no sentido de uma avaliação mais crítica do seu modelo de prática, como no tocante à sua inserção do setor público de prestação de serviços de saúde.

Marca o início do segundo período da conjuntura sob análise a realização da $7^{\mathrm{a}}$ CNS (março de 1980) quando, pela primeira vez, a prática odontológica chega a constituir um dos temas de debate. Em conformidade com a temática central da conferência, o subtema relativo à saúde bucal teve por título a “Odontologia e os Serviços Básicos de Saúde”. (BRASIL, 198ob) Considerando que a odontologia teria um papel definido a cumprir dentro de um programa de atenção primária, o grupo chama atenção para o fato de que tal não deveria ocorrer, sob a forma de um subprograma de atenção odontológica primária, e sim, deveriam ser estabelecidas estratégias no sentido da plena integração das ações odontológicas ao programa geral de atenção à saúde. 
Com o objetivo de visualizar a natureza das dificuldades e contribuir para a orientação dos caminhos a percorrer, são ressaltadas as defasagens existentes entre o modelo de prática e assistência odontológicas e as características desejáveis e intrínsecas, em nível conceitual, estratégico e operacional, a um programa baseado em atenção primária. O referido modelo caracterizava-se em linhas gerais por: ineficácia; ineficiência; descoordenação; má distribuição; baixa cobertura; alta complexidade; enfoque curativo; caráter mercantilista e fortemente monopolista; e inadequação no preparo dos recursos humanos.

São feitas, ainda, as seguintes recomendações com vistas ao equacionamento das distorções apresentadas: que se realize a adequação dos recursos humanos de nível superior e se dê ênfase à preparação dos recursos humanos de nível auxiliar e técnico; que se adotem medidas administrativas que tornem impeditiva a utilização de equipamentos de alta densidade tecnológica por parte dos serviços públicos; que seja institucionalizado no MS um núcleo técnico dedicado ao equacionamento dos problemas da odontologia, ficando responsável pelo planejamento e normalização das ações odontológicas no país, a fim de suprir a falta de definição política existente na área e evitar a descoordenação das diversas instituições prestadoras de serviço; por fim, recomenda-se a inserção da odontologia na rede hierarquizada de serviços, criando-se as condições necessárias para que sejam contemplados os três níveis de atenção.

Ao concluir o relatório, o grupo afirma que:

[...] decisões firmes, corajosas e profundas deverão ser tomadas sob pena de se cair num superficialismo que nada mais representará do que a mudança de roupagem na participação da Odontologia nos programas de saúde [...] haverá de parte de segmentos mais conservadores da sociedade e da própria Odontologia sérias resistências ao processo de mudança, mas [...] se impõe uma nova forma de participação não só por razões técnicas, mas sobretudo, como resposta a uma população que quer e, felizmente no momento exige, um direito que legitimamente é seu: o direito de possuir saúde bucal. (BRASIL, 1980b, p. 178)

Estava aberto o debate que permearia todo o período. No entanto, as pressões que se seguiram à divulgação do Prev-Saúde na $7^{\mathrm{a}} \mathrm{CNS}$, fizeram com que, também ao nível da odontologia, fossem temporariamente abandonadas as propostas de mudança no modelo hegemônico de prestação de serviços. 
No âmbito da FSESP, ainda no ano de 1980, dá-se uma alteração importante no sentido da extensão da cobertura no que tange à prevenção da cárie dental. É implantado o Projeto de Prevenção da Cárie Dental (PRECAD), mediante a técnica de autoaplicação de bochechos fluorados (BRASIL, 1980a), empregando uma solução neutra de fluoreto de sódio a $0,2 \%$. O projeto, implantado inicialmente nas unidades de menor complexidade operacional e naquelas que não dispunham de qualquer ação odontológica, visava levar os benefícios da utilização do flúor, a um custo menor, com possibilidade de atingir maior número de crianças, além de comportar maiores facilidades operacionais se comparado às tradicionais aplicações tópicas a $2 \%$.

A antiga aspiração de considerável parcela da categoria odontológica, quanto à criação no MS de um núcleo técnico de odontologia, efetiva-se, ainda que parcialmente, em 1982, com a instituição do Grupo de Trabalho Unidade de Sistema de Odontologia (GT/Odonto), através da Portaria de $\mathrm{n}^{\circ}$ 191, de 27 de julho de 1982 (BRASIL, 1982a), cuja finalidade era a de definir e orientar as ações do MS no campo da odontologia e de integrar e coordenar as atividades de apoio das Secretarias Estaduais de Saúde. No entanto, não houve correspondência entre a magnitude das atribuições do grupo e a adoção de medidas concretas no sentido de viabilizar a plena execução dessas atribuições. É o que se percebe, não só através da análise de documentos como também por depoimento dos técnicos.

Ainda em 1982, a Unidade de Sistema de Odontologia elabora um documento buscando traçar algumas linhas de ação para o MS, no âmbito da atenção à saúde bucal. (BRASIL, 1982b). Inicialmente, são levantadas algumas questões relativas às condições de saúde bucal da população brasileira, constatando-se um acúmulo de necessidades de grande magnitude. Por outro lado, a modesta participação governamental na oferta de serviços odontológicos estaria limitando o atendimento dessas necessidades, conduzindo a um agravamento da situação ao longo dos anos.

Ciente das dificuldades, o GT/Odonto considera que todos os esforços devem ser concentrados na superação dos obstáculos que impedem o estabelecimento de uma política nacional de saúde bucal e a consequente execução de um programa que esteja prioritariamente dirigido para a atenção básica à população de baixa renda. São estabelecidas, então, cinco linhas programáticas no sentido de orientar a prestação de serviços odontológicos no Brasil: prevenção maciça (baseada na fluoretação da água de consumo); cuidados elementares 
(via agentes de saúde em comunidades sem atenção profissional); atividades de apoio (maximização da eficiência dos centros de saúde, postos de assistência médica e outros serviços públicos); atenção ao escolar de primeiro grau (via Sistema Incremental); e referências para casos complexos (racionalização do trabalho em unidades especializadas disponíveis). Em seguida, são explicitadas as medidas necessárias à efetivação da proposta, com a preocupação de torná-las viáveis através da redução dos custos operacionais. Finalmente, são sintetizadas as atribuições e diretrizes referentes à atuação do GT/Odonto, colocando-se que a criação da Unidade de Sistema “... constitui a resposta institucional dada pelo MS, no sentido de intervir com suficiente peso especifico, de forma a catalisar com maior rapidez as modificações que se fazem necessárias no setor". (BRASIL, 1982b, p.5)

No entanto, pelo que se pode apreender, a atuação do GT ao longo dos anos que se seguiram à sua criação, esteve fundamentalmente voltada para a questão da prevenção maciça, através da fluoretação. E a primeira iniciativa do grupo, nesse sentido, é levada a cabo em fins de 1982, através de sua participação, juntamente com o Instituto Nacional de Alimentação e Nutrição (INAN) e FSESP, na coordenação do Projeto de Fluoretação da Água em Sistemas de Abastecimento Público (BRASIL, 1982c), que contaria ainda com o apoio do Grupo de Trabalho Serviços Básicos de Saneamento, envolvendo também o BNH/Plano Nacional de Saneamento (Planasa), a o MS e Secretarias Estaduais de Saúde.

Adotando metas menos pretensiosas que o Projeto de Fluoretação - Convênio INAN/FSESP - (BRASIL, 1975c), esse novo Projeto visava reativar a operacionalização dos sistemas de fluoretação paralisados em 30 localidades e estender a implantação para novos sistemas de abastecimento público de água potável em 35 cidades. O que deveria beneficiar 7,8 milhões de habitantes, especialmente da região Nordesse.

Após tímidas realizações, no ano seguinte, em 1983, esse Projeto foi incorporado por um outro programa de maior abrangência. Tratava-se do Programa de Fluoretação da Água de Abastecimento Publico (VIANNA, 1988) - convênio Banco Nacional de Desenvolvimento Econômico e Social (BNDES)/BNH/MS. Esse programa deveria mais do que duplicar a cobertura da população servida com água fluoretada. Esperava-se beneficiar até 30 milhões de pessoas as quais, somadas aos 25 milhões já protegidos, corresponderiam a $46 \%$ da população brasileira (1981) e 85\% da população abastecida. Estando a população-alvo do 
programa distribuída em um total de 200 localidades (100 delas com até 50 mil habitantes, e 100 com mais de 50 mil). (VIANNA; PINTO, 1983)

A distribuição global dos recursos previa a alocação de 95\% para implantação, manutenção e reserva técnica; enquanto os $5 \%$ restantes seriam repassados ao MS, com vistas ao desenvolvimento de estudos epidemiológicos e atividades de vigilância sanitária devendo esse ministério, com recursos próprios, promover ainda, pesquisas de métodos alternativos de prevenção da cárie dental.

Quanto ao Levantamento Epidemiológico de Saúde Bucal, ficava estabelecido que este deveria incluir dois componentes básicos: a realização e inquérito referente à prevalência da cárie dental nas 200 localidades onde estava prevista a implantação da fluoretação da água de consumo, e um estudo mais abrangente sobre as condições de saúde no campo odontológico no país.

A pesquisa sobre métodos alternativos privilegiou estudos sobre o emprego do fluoreto de cálcio (fluorita) em localidades de maior porte, bem como a viabilidade do sal como veículo para a fluoretação. Segundo o documento, a existência de fartos depósitos de fluorita em pedra, no país, poderia permitir redução ainda maior dos custos do programa preventivo caso se conseguisse superar a restrição de seu uso tão somente em estações de tratamento de água em cidades com um máximo de 30 mil habitantes. As dificuldades de obtenção de insumos (ácido fluorsilícico e fluorsilicato de sódio), face à dependência do setor, são apontadas como mais um fator que reforçava a urgência na realização de pesquisas nessa área.

Após um ano de existência, em novembro de 1983, o GT/Odonto elabora seu primeiro Relatório de Atividades (BRASIL, 1983b), ressaltando as dificuldades enfrentadas e sistematizando as principais atividades desenvolvidas; cuja concentração de esforços, durante o ano de 1983, deu-se em ações de prevenção em massa e na busca da reorientação do modelo de assistência odontológica de saúde pública. Diz esse relatório que:

[...] sentindo que no elenco de prioridades do Ministério da Saúde não havia dessaque para as ações de Odontologia, o GT/ODONTO procurou desenvolver, e desenvolveu, ação conjunta com o Ministério da Previdência Social (INAMPS), que contemplou sua estrutura odontológica com forte apoio, e com o BNH e o BNDES que apesar de não serem órgãos específicos de saúde, lançaram através da política de fluoretação das águas de abastecimento público, um marco na saúde oral da população brasileira. (BRASIL, 1983b, p. 10.) 
Dentre os 15 itens que resumem as atividades desenvolvidas pelo grupo, oito se relacionam com a questão da fluoretação sob diferentes aspectos; e os sete restantes constam de ações várias realizadas em conjunto com a FSESP, secretarias estaduais e municipais de Saúde e Educação e com o Inamps. Quanto a este último, ressalta-se a participação do GT na elaboração do documento de reorientação da assistência odontológica ao nível do Inamps, como parte da estratégia do Conasp.

Durante o ano de 1984, são estabelecidas as bases institucionais e metodológicas com vistas à realização do levantamento epidemiológico em saúde bucal, novos recursos são alocados para o Programa de Fluoretação (BNH/BNDES/ MS), através da aprovação da Exposição de Motivos no 711/84, em 8 de outubro (BRASIL, 1984a), e, no mês de dezembro desse ano, realiza-se em Goiânia o I Encontro Nacional de Administradores e Técnicos dos Serviços Públicos Odontológicos (Enatespo), no sentido da elaboração de uma Proposta de Política Odontológica Nacional para um Governo Democrático. (ENCONTRO..., 1984)

A FSESP, ainda em 1984, publica novo Manual de Instruções e de Orientação Técnica (BRASIL, 1984b) em substituição ao de 1978. Em linhas gerais, mantem-se o modelo de prática odontológica tradicionalmente adotado pela Fundação, ressaltando-se, entretanto, duas alterações básicas: a primeira diz respeito à incorporação ao manual da técnica de autoaplicação de flúor através dos bochechos fluorados, implantada pela FSESP em 1980; e a segunda corresponde à expansão das funções delegadas ao auxiliar de higiene dental, quando acrescenta às 10 atribuições constantes no manual de 1978, a de condensar e esculpir amálgama de prata em cavidades dentárias previamente preparadas pelo dentista. O que não ocorreu sem certa resistência por parte de alguns técnicos da Fundação.

Em agosto, o GT/Odonto retoma antiga reivindicação dos técnicos da área, propondo, através de um documento (BRASIL, 1985a) a criação da Divisão Nacional de Odontologia Social, no âmbito do MS.

Nesse ínterim, a única medida adotada pelo MS com vistas à formulação de uma política de saúde bucal constituiu-se na criação de um grupo assessor de odontologia (Portaria n. ${ }^{\circ} 749$ de 14/11/85), que, no entanto, não chegou sequer a ser efetivamente composto. A primeira avaliação do Programa de Fluoretação da Água (BNDS/BNH/MS) (PINTO, 1985) ocorre nesse mesmo ano, com vistas a examinar seu andamento e definir as providências necessárias à sua continui- 
dade. Constatou-se que, da aplicação dos recursos referentes ao documento . 217/83 do FINSOCIAL foram beneficiados 186 sistemas, atingindo uma população urbana da ordem de 15,85 milhões de pessoas. Para o ano de 1985, teriam sido destinados à conta da fonte FINSOCIAL um total de Cr\$16,0.

Ainda em 1985, realiza-se o II Enatespo, em Curitiba, tendo como tema básico a odontologia e as AIS.

A FSESP, naquele momento, iniciava um processo de autoavaliação e discussão em torno das perspectivas de mudança. É o que deixa transparecer a introdução do Relatório Geral de 1985 (BRASIL, 1985b), quando afirma que, diante da instalação do novo governo e do prenúncio de alterações nas áreas econômica, política, e social, aliada à intensificação das discussões em torno das propostas de reorganização dos serviços de saúde, a FSESP, através da "nova administração", assume alguns princípios básicos consonantes com as AIS (participação, integração, regionalização, hierarquização e descentralização).

A partir de março de 1986, como um dos desdobramentos da $8^{a}$ CNS, teve início o processo de organização das conferências destinadas à discussão dos temas específicos. No que tange à saúde bucal, tendo sido constituída uma coordenação a nível nacional, com vistas à organização da $1^{\mathrm{a}} \mathrm{CSNB}$, foram formadas comissões organizadoras estaduais, no sentido de estimular o debate, $\mathrm{e}$ viabilizar a realização das pré-conferências nos estados. Durante esses eventos, foram eleitos os delegados que participariam da $1^{\text {a }} \mathrm{CNSB}$, e formuladas propostas, em cima dos temas discutidos: 1 . saúde como direito de todos e dever do Estado; 2. diagnóstico de saúde bucal no Brasil; 3. Reforma Sanitária - inserção da odontologia no SUS; e 4. financiamento do setor de saúde bucal. Vale salientar que o GT/Odonto, sentindo-se excluído do processo de composição da Coordenação Nacional, negou-se a participar da $1^{\text {a }}$ CNSB.

Realiza-se então, em Brasília, nos dias 10, 11 e 12 de outubro de 1986, a $1^{\mathrm{a}}$ CNSB. O embate entre as forças conservadoras e a parcela progressista da classe odontológica resulta num documento final (BRASIL, 1986b), votado em plenária, que deixa transparecer uma tendência no sentido do fortalecimento das propostas de mudança no que diz respeito à prática odontológica no Brasil.

Deve o Estado garantir ao cidadão o pleno exercício desse direito não apenas nos termos da lei, mas através de medida concretas, como, o estabelecimento de "uma política de saúde consequente integrada às demais políticas econômicas e sociais, garantindo os meios que permitam efetivá-las". (BRASIL, 1986b) 
A situação de saúde bucal da população brasileira foi considerada "caótica", reconhecendo-se que o modelo de prática odontológica cobria as necessidades de apenas $5 \%$ da população, caracterizando-se pela ineficácia, ineficiência, utilização de alta densidade tecnológica, caráter monopolizador, elitista, iatrogênico e mutilador, aliando-se a isso os altos custos dos serviços.

Defende-se que o Programa Nacional de Saúde Bucal, esteja inserido no SUS, universalizado, hierarquizado, regionalizado e descentralizado. Recomenda-se a criação, ao nível do SUS, de um órgão técnico-administrativo e de pesquisa encarregado de gerenciar os programas de saúde bucal, com desdobramento nas esferas estadual e municipal. A prática odontológica deveria pautar-se nos princípios da odontologia integral, baseada na simplificação, desmonopolização e prevenção.

E, finalmente, quanto, ao financiamento do setor, propunha-se que o Fundo Único Federal de Saúde destinasse um percentual do orçamento geral para o Programa e seus órgãos técnico-administrativos e de pesquisa; o que deveria ocorrer também nos estados e municípios. Outras medidas são levantadas como alternativas para a redução dos custos da atenção odontológica. Claro estava que a efetivação das propostas se encontrava na dependência direta dos desdobramentos das teses defendidas na $8^{\text {a }} \mathrm{CNS}$, o que, por sua vez, faziam parte de uma luta muito mais ampla entre as parcelas progressistas e os empresários do setor saúde.

\section{Considerações finais}

A intervenção do Estado brasileiro na atenção odontológica, iniciada de forma incipiente, em meados da década de 1920, e intensificada a partir da segunda metade dos anos 1970, caracterizou-se pela inexistência de coordenação claramente definida, revestindo-se as políticas de saúde bucal, de um caráter fragmentário, periférico e pouco sistematizado.

É o que sugere a análise das políticas desenvolvidas na conjuntura pós-74, no que tange especialmente às ações odontológicas de saúde pública. A intensificação da participação do Estado brasileiro na atenção à saúde bucal acompanha um processo mais amplo, verificado principalmente a partir de meados da década de 1970 quando, por uma série de fatores, as chamadas políticas sociais assumem maior destaque, com desdobramentos significativos no âmbito das políticas de saúde. A ampliação das funções do estado capitalista, especialmente na fase monopolista desse modo de produção, aliada aos elementos de 
ordem conjuntural, estariam por trás desse processo, dando-lhe os contornos e impondo-lhe os limites.

No que se refere ao primeiro período analisado (1974-79), observa-se que as dificuldades de ordem econômica, consequência do modelo de desenvolvimento concentrador e dependente adotado no pós-64, começam a adquirir contornos críticos a partir de 1973-1974, agravados pelo primeiro choque da crise do petróleo. Tornava-se patente o esgotamento do "milagre" e era essencial, para a legitimidade já enfraquecida do regime, a incorporação (ao nível do discurso oficial) de certas demandas, no sentido de amenizar as mazelas de grandes parcelas da população marginalizada nesse processo. O governo adota então, como estratégia: manter o crescimento (em patamares bem inferiores aos do período anterior), às custas de um progressivo aumento da dívida externa; distender os espaços de manipulação política, até então profundamente reprimidos, com a preocupação de reativar - de forma limitada e gradual - a sociedade civil, evitando a intensificação de conflitos; e propor medidas reformistas na área social e particularmente, na área de saúde, subordinadas, no entanto, aos interesses dos produtores privados, atuantes no setor.

Consolidam-se, então, ao longo do governo Geisel (1974-1979), as tendências em torno da universalização dos benefícios previdenciários e consequente expansão da assistência à saúde; ao mesmo tempo, promove-se uma certa reativação do MS e são implantados alguns programas de atenção coletiva (Programa de Interiorização de Ações de Saúde e Saneamento - PIASS, Pronan etc.). Esses, contudo, não alteram significativamente o modelo dominante, dicotômico e incapaz de responder de maneira satisfatória às necessidades básicas de saúde da população. Nesse contexto, verifica-se um notável fortalecimento dos técnicos dos órgãos centrais formuladores de políticas, a partir da progressiva incorporação dos princípios do planejamento, já difundidos em outras áreas de governo. (LUZ, 1979)

A extensão da assistência médica previdenciária, observada nesse período, teve como base o aprofundamento do processo de privatização do setor. Tratando-se da assistência odontológica, a opção pela compra de serviços e consequente beneficiamento dos produtores privados de bens e serviços foi ainda mais contundente, o que pode ser, em parte, atribuído não só à reduzida prioridade conferida à saúde bucal e à atenção odontológica no setor público, como também ao alto custo dos serviços, nos moldes do modelo tradicional de prática. Na saúde pública e atendendo a antigas pressões da categoria odonto- 
lógica, é promulgada a legislação referente à fluoretação das águas de abastecimento público, que teve, no estabelecimento do convênio entre FSESP e INAN, sua primeira consequência prática. Considerando-se as metas estabelecidas, os resultados não foram tão animadores sendo que, ao final do projeto, apenas $16,9 \%$ da população prevista havia sido efetivamente beneficiada. De certa forma, esses resultados reproduzem uma realidade verificada ao nível de grande parte dos programas de saúde pública, desenvolvidos nesse período, no âmbito do MS.

Quanto ao espaço institucional ocupado pela odontologia, nos níveis centrais do MPAS e MS, as alterações imprimidas entre os anos 1974-1979 refletem a primazia da prática individual e curativa, executada pela Previdência. Assim é que, em 1976, cria-se a Coordenadoria de Odontologia do INPS, enquanto o MS, tendo extinto o Serviço Nacional de Fiscalização da Odontologia, em 1975, sequer se refere à odontologia no Decreto . $^{\circ}$ 79.056, de 30.12.76, o qual dispunha sobre a nova organização do Ministério.

De um modo geral, o que se percebe é que a atenção odontológica, durante esse primeiro período analisado, acompanhou a ampliação verificada nas ações de saúde, mantendo, no entanto, uma certa independência enquanto prática e representando um papel secundário no conjunto das políticas de saúde. A dicotomia entre saúde pública e assistência individual, MS e Ministério da Previdência é reproduzida na saúde bucal de forma acentuada, como também a predominância da prática reparadora frente às ações preventivas de alcance coletivo.

O período seguinte (1979-1986) caracteriza-se por dois processos fundamentais: a crise econômica e a transição democrática. A década de 1980 tem início sob o espectro da recessão que perdura até 1983, implicando desastrosas consequências sociais. Nesse período, paulatinamente, ampliam-se os espaços de debate político. Nesse contexto, a questão da saúde assume um papel de destaque. A crise econômica, ao mesmo tempo que contribui para a deterioração das condições de vida da maioria da população, aumentando consequentemente a demanda por serviços de saúde, impõe limites à expansão da assistência, dentro dos moldes até então adotados. Prevalece a tendência no sentido da implantação de políticas racionalizadoras, enquanto as diferentes posições em torno da questão passaram a ser explicitadas, buscando cada setor garantir os seus interesses. Na odontologia pública, todo esse processo conduz à ampliação do debate em torno das principais distorções do modelo hegemônico 
de prática odontológica, e ao surgimento de propostas alternativas de corte racionalizador, que se mantiveram no plano do discurso.

No âmbito do MS, a criação da Unidade de Sistema de Odontologia (GT/ Odonto), em 1982, longe de significar a tomada de uma decisão política no sentido do Ministério intervir de forma mais contundente ao nível da saúde bucal, reflete muito mais o caráter fictício dessa intervenção, haja vista o descompasso entre as atribuições estabelecidas na Portaria de criação do grupo (BRASIL, 1982a) e as limitações da estrutura montada, principalmente no que tange à disponibilidade de recursos.

Dessa forma, a atuação do GT/odonto esteve predominantemente voltada para a questão da fluoretação, mesmo assim de forma tangencial e limitada. A fluoretação das águas de abastecimento público no Brasil, a despeito da sua comprovada eficácia e eficiência, esteve sempre, durante o período analisado, na dependência do estabelecimento de convênios entre diversas instituições. Isso decorre, principalmente, do processo lento e burocrático de liberação de recursos, baseado em geral numa sequência de elaboração, avaliação e aprovação de projetos. O Programa de Fluoretação da Água de Abastecimento Público - Convênio BNDES-FINSOCIAL/BNH-PLANASA/MS-GT-FSESP, constitui um bom exemplo desse tipo de administração por convênio e das restrições por ela impostas.

Em síntese, a análise das políticas de saúde bucal, na conjuntura 1974-1986, sugere a intensificação da participação do Estado brasileiro ao nível da atenção odontológica, mas indica também os limites desse processo. É também muito limitado o papel desempenhado pelas políticas de saúde bucal, na estratégia de hegemonia. Verifica-se, no que se refere especificamente à odontologia, que não havia, por parte das classes subalternas, em sua luta diária pela sobrevivência, uma maior preocupação e, consequentemente, uma pressão exercida sobre o Estado, no sentido do atendimento de suas necessidades odontológicas. É no terceiro aspecto levantado por Oliveira (1984) que vamos encontrar um elemento explicativo significativo para a questão da intensificação (apesar dos limites verificados) da participação do Estado ao nível da atenção odontológica. Trata-se do impacto das políticas sociais, enquanto gastos públicos, sobre a economia como um todo; e, em especial, sobre o mercado de determinados bens e serviços.

Dado o caráter restritivo do modelo hegemônico de prática odontológica, aliado à crescente perda do poder aquisitivo de amplas parcelas da população brasileira, o Estado passa a contribuir para a ampliação do mercado, viabilizando 
não só o consumo dos bens produzidos no setor, como também empregando, direta ou indiretamente, uma farta mão de obra profissional que dificilmente seria incorporada no livre jogo do mercado. Há que se ressaltar também a participação dos técnicos que, fortalecidos no âmbito do capitalismo monopolista de Estado, exerceram, no interior da burocracia estatal, forte influência na formulação das políticas oficiais, no período analisado. No caso da odontologia, essa participação foi significativa, apesar do caráter muitas vezes corporativista do discurso e da prática desses trabalhadores, condicionados por toda uma luta histórica em busca de maior valorização profissional. Mas, em linhas gerais, o que se observa é que a ampliação da atenção odontológica, mesmo considerando as suas especificidades, esteve fortemente atrelada à expansão da assistência médica.

Com a instalação da Assembleia Nacional Constituinte e posse dos novos governadores, procurou-se consolidar a estratégia delineada no final de 1986, no sentido de garantir, por um lado, que o Texto Constitucional incorporasse as teses aprovadas na 8 a CNS, e por outro, procurar, com o apoio do MPAS, promover a implantação ascendente da Reforma Sanitária, a partir dos Estados através do reforço à estratégia das AIS e de seu aprofundamento mediante a implantação dos Sistemas Unificados e Descentralizados de Saúde. Nesse processo, em todos os momentos esteve presente o embate entre o projeto conservador e o projeto democrático.

No âmbito da Constituinte, embora o texto aprovado tenha considerado as teses defendidas na $8^{\mathrm{a}} \mathrm{CNS}$, as mudanças imprimidas pelas forças conservadoras aglutinadas no chamado "centrão" possibilitaram retrocessos. Estava claro que a expansão da assistência pública à saúde e, particularmente, o desenvolvimento das políticas de saúde bucal se vinculava a uma luta muito mais ampla no sentido de garantir a efetiva democratização do país e viabilizar as necessárias transformações exigidas pela sociedade brasileira. Só assim, seria possível a concretização de políticas públicas que assegurassem o direito à saúde da população e a efetivação de mudanças sociais que apontassem para o direito a uma vida digna e ao pleno exercício da cidadania.

\section{Referências}

ARRUDA, B. K. G. de. Odontologia nutrição e saúde. (Pronunciamento na X Semana de Profilaxia Periodon tal do Recife). Recife, dezembro de 1975. Mimeo.

BAER, W. O crescimento brasileiro e a experiência do desenvolvimento: 1964-1975. In: ROETT, R. (Org.). O Brasil na década de 70. Rio de Janeiro: Zahar, 1978. 
BORGES FILHO, O. et al. Atividades de odontologia. Abril 1969. (Documento Técnico de trabalho elaborado por solicitação do Ministério da Saúde).

BRASIL. Ministério da Saúde. SESP. Inaugurando o Primeiro Serviço de Fluoretação D’água no Brasil. Boletim do SESP. n. 40, nov., 1953.

BRASIL. Decreto ${ }^{\circ} 35.448$, de $1^{\circ}$ de maio de 1954. Expede o Regulamento Geral dos Institutos de Aposentadoria e Pensões. Diário Oficial [da] República Federativa do Brasil, Rio de Janeiro, DF, 3 de maio de 1954.

BRASIL. Lei no $3807 / 60$ de 26 de agosto de 1960. Lei Orgânica da Previdência Social. Diário Oficial [da] República Federativa do Brasil, Brasília, DF, de 5 de setembto de 1960.

BRASIL. Instituto Nacional de Previdência Social. Resolução $n^{0}$ CD/DNPS-371, de 28 de agosto de 1969. Assunto: Assistência Odontológica (Seção I - BS/INPS 167, de 02.09.69), Brasília, DF, 1969a.

BRASIL. Instituto Nacional de Previdência Social. Resolução $n^{\circ}$ CD/DNPS-443, de 17 de outubro de 1969. Proc. MTPS - 145.413/69. Aprova Ato Normativo que fixa diretrizes gerais para prestação da assistência odontológica aos beneficiários da Previdência Social. Seção I/ BS/INPS 203, Brasília, DF, 1969b.

BRASIL. Lei n 6050 , de 24 de maio de 1974. Dispõe sobre a Fluoretação de Água em Sistemas de Abastecimento quando Existir Estação de Tratamento. Diário Oficial [da] República Federativa do Brasil, Poder Executivo, Brasília, DF, 27 maio 1974.

BRASIL. Decreto $\mathrm{n}^{0} 76.872$ de 22 de dezembro de 1975. Regulamenta a Lei $\mathrm{n}^{\circ} 6050$ de 24 de maio de 1974. Diário Oficial [da] República Federativa do Brasil, Poder Executivo, Brasília, DF, 23 dez. 1975a.

BRASIL. Ministério da Saúde. Portaria no 635/Bsb. de 26 de dezembro de 1975. Aprova normas e padrões sobre a fluoretação da água em si temas públicos de abastecimento, destinada ao consumo humano, Brasília, DF, 1975b.

BRASIL. Ministério da Saúde. Fundação Serviços Especiais de Saúde Pública. Normas técnicas de Odontologia Sanitária. Divisão de Orientação Técnica/Seção de Odontologia. Rio de Janeiro, 1963.

BRASIL. Ministério da Saúde. Fundação Serviços Especiais de Saúde Pública. Fluoretação das águas de abastecimento público. (Projeto a ser executado pelo MS, através da FSESP e do INAN, com a colaboração dos governos essaduais e municipais). 1975c. Mimeo.

BRASIL. Ministério da Saúde. Instituto Nacional de Alimentação e Nutrição. Projeto Fluoretação das Águas de Abastecimento Público. IV Relatório de Acompanhamento. Brasília, março de 1977a.

BRASIL. Ministério da Saúde. Fundação Serviços Especiais de Saúde Pública. Relatório da Reunião dos Supervisores Fortaleza, 15 a 19 de agosto de 1977b.

BRASIL. Ministério da Saúde. Fundação Serviços Especiais de Saúde Pública. Odontologia. Manual de instruções e de orientação técnica. Rio de Janeiro, 1978. 
BRASIL. Ministério da Saúde. Fundação Serviços Especiais de Saúde Pública. Relatório de Acompanhamento do Projeto Fluoretação das Águas de Abastecimento Público. Brasília, DF, março 1979a . Mimeo.

BRASIL. Ministério da Saúde. Fundação Serviços Especiais de Saúde Pública. Relatório de Acompanhamento do Projeto Fluoretação das Águas de Abastecimento Público. Brasília, DF, ago. 1979b. Mimeo.

BRASIL. Ministério da Saúde. Instituto Nacional de Alimentação e Nutrição. Projeto Fluoretação das Águas de Abastecimento Público. Relatório de Acompanhamento FísicoFinanceiro. [S. 1, s.d]. Mimeo.

BRASIL. Ministério da Saúde. Instituto Nacional de Alimentação e Nutrição. Relatório de Acompanhamento de Projeto Fluoretação das Águas de Abastecimento Público. Brasília, fevereiro de 1980a. 13p. Mimeo.

BRASIL. Ministério da Saúde. CNS, 7. Brasília, 1980 Anais da $7^{\circ}$ CNS. Brasília. Centro de Documentação do Ministério da Saúde, p .175-178, 1980b.

BRASIL. Ministério da Saúde. Fundação Serviços Especiais de Saúde Pública. Prevenção da carie dental pela aplicação de bochechos fluorados. Rio de Janeiro, 1980c.

BRASIL. Ministério da Saúde. Portaria MS/GM nº 191 de 27 de julho de 1982. Institui o Grupo de Trabalho sob a denominação de Unidade de Sistema de Odontologia (GT/ ODONTO) . Diário Oficial [da] República Federativa do Brasil, Poder Executivo, Brasília, DF, 28 jul. 1982a.

BRASIL. Ministério da Saúde. Instituto Nacional de Alimentação e Nutrição. Atividade prevenção a cárie dental. Projeto de Fluoretação da água em sistemas de abastecimento público. Brasília, novembro de 1982c. Mimeo.

BRASIL. Ministério da Saúde. SESP. Inaugurando o Primeiro Serviço de Fluoretação D’água no Brasil. Boletim do SESP. n. 4O, nov., 1953.

BRASIL. Ministério da Saúde. Secretária Nacional de Programas Especiais de Saúde. GT/ ODONTO. Linhas de ação em Odontologia. Brasília, DF, novembro de 1982b. Mimeo.

BRASIL. Ministério da Previdência e Assistência Social. Programa de reorientação da assistência odontológica. Rio de Janeiro, MPAS/CCS. 1983a.

198BRASIL. Ministério da Saúde. Secretária Nacional de Programas Especiais de Saúde. GT/ODONTO. Relatório de atividades 1983. Brasília, DF, 1983b. Mimeo.

BRASIL. Ministério da Saúde. Exposição de Motivos nº 711/84. Em o8 de outubro de 1984. Brasília, DF, 1984a. (Assinada pelo Ministro Antonio Delfim Netto. Autorizada em o8.10.84 pelo Presidente João Figueiredo.).

BRASIL. Ministério da Saúde. Fundação Serviços Especiais de Saúde Pública. Odontologia. Manual de instruções e de orientação técnica. Rio de Janeiro, 1984b.

BRASIL. Ministério da Saúde. Secretária Nacional de Programas Especiais de Saúde. GT/ODONTO. Odontologia Social. (Proposta para criação da Divisão Nacional de Odontologia Social). Brasília, DF, agosto de 1985a. 
BRASIL. Ministério da Saúde. Fundação Serviços Especiais de Saúde Pública. Relatório e Prestação de contas. Rio de Janeiro, 1985 b.

BRASIL. Ministério da Saúde. Universidade de Brasília. CNS Bucal, 1. Conclusões. Brasília, DF, 1986a. Mimeo.

BRASIL. Ministério da Saúde. CNS, 8. Relatório Final. Brasília, DF, 1986b. Mimeo.

COHN, A. Presidência social e processo político no Brasil. São Paulo: Ed. Moderna, 1980. p. 5-33.

CORDEIRO, H. de A. Políticas de saúde no Brasil (1970-1980). In: IBASE (Org.). Saúde e trabalho no Brasil. 2. ed. Petrópolis, RJ: Vozes. 1983. p .83-90.

COUTINHO, L. G.; BELLUZZO, L. G. M. Política econômica, inflexões e crise: 1974-1981. In: BEI.LUZZQ L .G. de M.; COUTINHO, R. (Org.). Desenvolvimento capitalista no Brasil. Ensaios sobre a crise. São Paulo: Brasiliense, 1982. p. 159-193. v. 1.

DINIZ, J. Contribuição ao estudo do sistema incremental de atendimento odontológico. Salvador, 1987. $144 \mathrm{f}$. Tese (Doutorado em Odontologia) - Faculdade de Odontologia, Universidade Federal da Bahia, 1987.

DUPAS, G. Crise econômica e transição democrática. 83/86. A delicada trajetória brasileira. São Paulo: Klaxon, 1987.

ENCONTRO NACIONAL DE ADMINISTRADORES E TÉCNICOS DOS SERVIÇOS PÚBLICOS ODONTOLÓGICOS, I (ENATESPO). Proposta de Política Odontológica Nacional para um governo Democrático. Goiânia, dez. 1984 . Mimeo.

FONSECA, A. S. Plano do Conasp: reflexões após dois anos de aplicação. Saúde em Debate, Belo Horizonte, v. 17, p. 25-27, jul., 1985.

LANA, F. A Odontologia na Previdência Social, história e evolução. Boletim dos Centros de Estudos, Belo Horizonte, v. 6, n. 18, .jan./jun. 1984. p. 7-16.

LUZ, M. T. As instituições médicas no Brasil. Instituição e estratégia de hegemonia. 2. ed. Rio de Janeiro: Graal, 1979. p. 60-65.

MELLO, J. M. C.; BELLUZZO, L. G. de M. Reflexões sobre a crise atual. In: BELLUZO, L. G. de M.; COUTINHO , R. (Org.). Desenvolvimento capitalista no Brasil. Ensaios sobre a crise. São Paulo: Brasiliense , 1982. p.141-158. v. 1.

NOGUEIRA, R. P. Dinâmica do mercado de trabalho em Saúde no Brasil - 1970-1983. Brasília: OPS - Acordo MS/ MPAS/MEC/MCT, 1986. p. 11-15

OLIVEIRA, J. A. de A. Política social, acumulação e legitimidade. Rev. Administração Pública. Rio de Janeiro, 18(2); 110-26, abril/junho, 1984.

OLIVEIRA, J. A.; TEIXEIRA, S. M. F. (IM) Previdência Social: 60 anos de história da Previdência no Brasil. Petrópolis, RJ: Vozes, 1985.

PAIM, J. S. As políticas de saúde e a conjuntura atual. Saúde em Debate, Rio de Janeiro, v. $15 / 16$, p. $8-15$, fev., 1984 . 
PAIM, J. S. Ações integradas de saúde (AIS): Porque não dois passos atrás e um adiante. In: CONGRESSO MÉDICO-SOCIAL DA BAHIA - ABM, 3., 1985, Salvador. Trabalho apresentado na Mesa- Redonda "Reorganização dos serviços de saúde e AIS". Salvador, 1985. Mimeo.

PAIXÃO, H. H. A Odontologia sob o capital: o mercado de trabalho e a formação universitariaprofissional cirurgião-dentista. Belo Horizonte, 1979. 167 f. Dissertação (Mestrado em Educação) - Faculdade de Educação, Universidade Federal de Minas Gerais, Belo Horizonte, 1979.

PINTO, V. G. Características do subsistema público federal de prestação de serviços em Odontologia. 1977. 188 p. Dissertação (Mestrado em Saúde Pública) - Faculdade de Saúde Pública, Universidade de São Paulo, São Paulo, 1977.

PINTO, V. G. Informe sobre o programa de fluoretação da água. Brasília, set. 1985. Não publicado.

REICHSTUL, H. P.; COUTINHO, L. G. Investimento estatal 1974-1980: ciclo e crise . In: BELLUZZO, L. G. de M.; COUTINHO, R. (Org.). Desenvolvimento capitalista no Brasil: ensaios sobre a crise. 2. ed . São Paulo: Brasiliense, 1983. p.38-58. v. 2.

SINGER, P. Os impasses econômicos da Nova República. In: KOUTZII, Flório (Org .). Nova República: um balanço. São Paulo: L\&PM Editores, 1986. p. 89-106.

SINGER, P.; CAMPOS, O.; OLIVEIRA, E. M. Prevenir e curar: o controle social através dos serviços de saúde. Rio de Janeiro: Forense-Universitária, 1981. p. 88-137.

VIANNA, S. M. A assistência odontológica no sistema nacional de saúde. 1977. Tese (Habilitação em Livre-Docência) - Instituto de Patologia Tropical, Universidade de Goiás, Brasília, DF. 1977. 178p.

VIANNA, S. M. Perspectivas da assistência odontológica no Brasil. Campinas-SP, nov. 1978. (Doc. apresentado no I Encontro Municipal de Odontologia Comunitária). Mimeo.

VIANNA, S. M.; PINTO, V. G. Programa de fluoretaçao água de abastecimento público. CNRH. Documento de trabalho $\mathrm{n}^{\circ}$ 28. IPEA/ IPLAN . Brasília , 1983. 18p.

VIANNA, M. I. P. Estado e atenção odontológica no Brasil: um estudo sobre as políticas de saúde bucal na conjuntura pós-74. 1988. 211 f. Dissertação (Mestrado em Saúde Comunitária) - Câmara de Ensino de Pós-Graduação e Pesquisa, Universidade Federal da Bahia, Salvador, 1988. 


\section{Políticas de saúde bucal no período pós-constituinte \\ GOVERNOS FHC E LULA}

Lucília Nunes Assis

Jairnilson Silva Paim

Catharina Leite Matos Soares

Após a Constituição de 1988, a formulação e implementação das políticas de saúde bucal representaram um desafio semelhante ao da saúde em geral, onde os serviços de saúde bucal eram meros reprodutores do sistema nacional de saúde que refletia uma atenção centrada na assistência curativa, com nítida separação das ações de saúde pública, além dos gastos insuficientes na área e de sua má utilização. (MENDES, 1986)

Diante do quadro, o Sistema Único de Saúde (SUS), legalizado, poderia ser visto como uma possibilidade de proporcionar à saúde bucal, além de uma base doutrinária, diretrizes políticas favoráveis à expansão dos serviços, bem como a reorientação do modelo de atenção em saúde bucal centrado até então na atenção a escolares. A introdução da saúde bucal no Programa de Saúde da Família (PSF), por exemplo, além de buscar viabilizar maior cobertura dessa atenção e modificar o espaço de produção do cirurgião-dentista, poderia contribuir para a reordenação de sua prática. (RONCALLI, 2000)

Anos depois de promulgada a Constituição, Córdon(1991) apontava que a implementação do SUS alcançava êxito em experiências onde se aliava a vonta- 
de política local e a participação popular. Porém, salientava haver necessidade de maior controle social em relação aos aspectos financeiros e na própria organização das práticas de saúde. Afirmava que as políticas de saúde bucal guardavam traços de centralismo, onde o monopólio do conhecimento refletia-se na tomada de decisões sobre o trabalho sem o envolvimento da comunidade, fato que comprometia a legitimidade dessas políticas e a manutenção dos serviços que se organizavam, ao haver mudança dos atores políticos locais.

A partir de 2000 , fatos importantes foram produzidos no cenário da saúde nacional na área da saúde bucal, tais como a entrada da saúde bucal na Estratégia de Saúde da Família e a formulação da Política Nacional de Saúde Bucal (PNSB). (BRASIL, 2000; 2004)

Dada a relevância de se compreender esse contexto, pretendeu-se assim, uma análise das políticas de saúde bucal, buscando reunir informações com a intenção de apreender a totalidade que a questão encerra (BRUYNE et al., 1997), tomando o período pós-constituinte como objeto de reflexão, por ser considerado um momento histórico significativo, rico em relações de forças estabelecidas entre diversos atores sociais que constituem o campo da Saúde Coletiva. Buscou-se realizar uma abordagem histórica e estrutural para o estudo de políticas de saúde bucal formuladas, na conjuntura pós-constituinte, particularmente nos governos de Fernando Henrique Cardoso (FHC) (19992002) e Luís Inácio Lula da Silva (2003-2004) a fim de identificar e analisar fatos políticos produzidos nesses governos no que tange a saúde bucal.

\section{Elementos teóricos}

Os fatos políticos a serem considerados tomam, de forma mais abrangente, a denominação de políticas públicas, de onde se esquadrinha os propósitos de governo em relação às políticas de saúde bucal. (TESTA, 1992) Assim, considerou-se um Estado capitalista periférico que produz políticas públicas, particularmente na área da saúde, respondendo a necessidades variadas, sendo as políticas de saúde respostas ou não a demandas diversas, tais como aquelas referentes aos problemas do estado de saúde e do sistema de saúde; relativas a determinantes econômicos (reprodução e manutenção da força de trabalho, produção de bens e serviços, entre outros) e, ainda, respostas a determinações de cunho político-ideológico para a coesão de todo o conjunto. (FERREIRA, 1990; PAIM, 2003) Coesão complexa, cujas respostas consentidas perpassam pelo aparelho do Estado, imbricado de interesses públicos legítimos e particu- 
lares, corporativos e partidários. Tal enfoque, acima descrito, permite a análise das políticas sociais em um plano estrutural, considerando as determinações oriundas do Estado capitalista. Essas políticas, portanto, no âmbito de um Estado ampliado, são respostas seletivas às demandas de múltiplos sujeitos coletivos. (COUTINHO, 1995) Ao se considerar a singularidade das políticas de saúde, pode-se, ainda, aperfeiçoar tal plano de análise, tomando como referência as instituições por onde se vocalizam os interesses dos grupos diversos. Nesse aspecto, além das demandas a serem consideradas, as respostas dadas são condizentes com estratégias políticas utilizadas pelas instituições para responder problemas de dominação, específicos do aparelho estatal, além de considerar questões administrativas, orçamentárias e os próprios conflitos sociais advindos das leis e regulamentos. (GERSCHMAN, 1995; OFFE, 1989)

No contexto descrito, faz-se necessária uma análise da conjuntura composta pelos distintos governos onde se formulam as políticas de saúde bucal. Conjuntura compreendida enquanto "um feixe de relações contraditórias (relações de força) que implica o conhecimento do desenvolvimento desigual dessas relações em cada um dos níveis que articuladamente compõem a totalidade social" (GRAMSCI, 1980, p. 48), estando, tais relações, refletidas no sistema de representação de interesses diversos e nas suas consequências sobre as políticas de saúde. (TEIXEIRA, 1995) Por fim, entende-se que as políticas de saúde bucal representam um recorte das políticas de saúde, de modo que o estudo toma como objeto a análise dessas políticas enquanto expressão dos propósitos de governo, considerando a conjuntura em que se dá a sua formulação. (TESTA, 1992)

Cabe também destaque a reflexão sobre o Estado, enquanto uma totalidade orgânica com a sociedade civil, onde a classe dirigente, através de um complexo de práticas e teorias, justifica seu domínio e obtém a reprodução social com o consentimento dos governados, representando uma condensação material de uma relação de forças contraditórias e caracterizando-se como um campo de influências das mesmas. (GRAMSCI, 1980; POULANTZAS, 1980) Esse agrupamento tem como destino criar condições de expansão, sendo as conquistas decorrentes vistas como universais, desenvolvendo-se através de equilíbrios instáveis entre os interesses dos grupos dominados e o dominante. Assim, Gramsci considera hegemonia como direção e controle que uma classe ou fração de classe exerce sobre a totalidade da sociedade mediante a coerção 
ou o consenso. A ideologia de classe ou fração de classe dominante passa a ser a de toda a sociedade. (GRAMSCI, 1980)

Para a produção desses fatos políticos, partiu-se basicamente da análise de textos oficiais, tais como leis, projetos de lei, normas, portarias, decretos, medidas provisórias, manuais e relatórios, alusivos à atenção à saúde bucal, tomando-se como referência os momentos do ciclo da política, particularmente a formação da agenda, a formulação e a implementação (CPPS/OPS, 1975), bem como os distintos componentes de um sistema de serviços de saúde: gestão, financiamento, organização da atenção, infraestrutura e modelo de atenção. (KLECZKOWSKI; ROEMER; WERFF, 1984; PAIM, 2003) Entre os componentes do sistema de saúde, entende-se por "infraestrutura" os recursos essenciais para o funcionamento do sistema de saúde, envolvendo os trabalhadores da saúde, estabelecimentos, medicamentos, equipamentos e outros insumos. Entende-se por "organização" a conformação dos variados recursos nos serviços de saúde, considerando aspectos relativos à estrutura física, a materiais, insumos e recursos humanos. A "gestão" se refere à prática político-administrativa que objetiva a implementação das políticas, fazendo uso de tecnologias desenvolvidas no campo da administração. O componente "modelo de atenção" refere-se especificamente à dimensão técnica das práticas de saúde, ou seja, à lógica que orienta como as combinações tecnológicas são aplicadas na intervenção de problemas e necessidades de saúde, individuais ou coletivas. O "financiamento" da saúde engloba as fontes das três esferas governamentais e suas respectivas aplicações em ações e serviços de saúde, recursos físicos e humanos. Caracteriza-se pela forma de ordenação, repasse dos incentivos, bem como, a prioridade de alocação, tendo-se em perspectiva o efeito produzido, nesse campo, pelas políticas macroeconômicas. (MUSGROVE, 2001)

\section{O governo FHC}

O governo FHC, no seu segundo mandato, desencadeou um conjunto de iniciativas no âmbito da saúde bucal, sob a liderança do ministro José Serra. A partir do ano 2000, o termo de compromisso pactuado entre gestores dos três níveis de governo, passou a incluir indicadores referentes às ações de odontologia na atenção básica. Também nesse ano, destacado pela vinculação das receitas das três esferas de governo com os gastos em saúde, segundo a Emenda Constitucional n. ${ }^{\circ}$ 29, definiram-se repasses próprios para a saúde bucal no SUS, com a implantação de incentivos no Piso da Atenção Básica, para muni- 
cípios que desenvolvessem ações de saúde bucal através das Equipes de Saúde Bucal (ESB) implantadas no PSF. (ASSIS, 2006)

A Portaria GM/MS n. ${ }^{\circ}$ 1.444/2000 estabeleceu que cada ESB deveria atender, no mínimo, 6.900 habitantes e, para cada ESB implantada, haveria a correspondência de duas Equipes de Saúde da Família (ESF), sendo que, nos municípios com menos de 6.900 habitantes, a relação poderia ser na proporção de uma ESB para uma ESF. Nessa portaria, ficou definido que o incentivo financeiro seria repassado aos municípios qualificados, fundo a fundo, em parcelas mensais (1/12), de acordo com a modalidade de ESB implantada. Além do incentivo para o custeio das ações e inserção dos profissionais, criou-se também, com essa legislação, o incentivo adicional por equipe implantada, para aquisição de instrumental e equipamentos odontológicos. Previa-se que a incorporação dessas equipes consideraria a adequação de espaços para a reestruturação dos serviços odontológicos, a partir das instalações já existentes e as iniciativas locais de organização dos serviços, cabendo ao gestor municipal garantir a infraestrutura e os equipamentos necessários para o desenvolvimento das ações específicas.

As orientações para a reorganização das ações e serviços de saúde bucal previstas na Portaria GM/MS n. ${ }^{\circ}$ 267/2001, após a criação do incentivo para a inserção da saúde bucal no PSF, também definia o papel a ser desempenhado pelos profissionais da área, cabendo-lhes a responsabilidade sanitária em relação à população adscrita, com o desenvolvimento de ações de prevenção de doenças e agravos, além de promoção e recuperação da saúde. Ampliava-se, assim, o campo de ação da ESB, atribuindo-se a todos os seus profissionais atividades de planejamento, monitoramento e avaliação das ações desenvolvidas pela ESF; identificação das necessidades de saúde bucal da população adscrita; estímulo e realização de atividades educativas, de promoção e proteção em saúde bucal; organização do processo de trabalho segundo diretrizes do PSF e Plano Municipal de Saúde; programação e realização de visitas domiciliares de acordo com as necessidades identificadas e desenvolvimento das ações intersetoriais para a promoção da saúde bucal. Detalharam-se, ainda, as atribuições específicas do Cirurgião-Dentista (CD), Técnico em Higiene Dental (THD), Atendente em Consultório Dentário (ACD) e do próprio Agente Comunitário de Saúde (ACS). No que tange às ações de prevenção de doenças e agravos, consta que a ESB também ficaria responsável pela realização de ações básicas de vigilância epidemiológica. Tal atividade podia se operacionalizar a partir de 
um registro no Sistema de Informação Ambulatorial (SIA) do SUS, que incluía a categoria do CD no desenvolvimento de ações educativas em grupo sobre vigilância da saúde.

No final da vigência da Norma Operacional Básica - SUS o1/96 (NOB-SUS 01/96), permanecia como desafio as limitações da capacidade de planejamento e coordenação das Secretarias Estaduais de Saúde, o que favoreceu o isolamento dos sistemas municipais e a incorporação tecnológica irracional, dificultando a estruturação de uma rede regionalizada, hierarquizada e resolutiva. (BRASIL, 1996) Frente a esses problemas, o desenvolvimento de ações especializadas na área passou a se associar à habilitação segundo Normas Operacionais da Assistência à Saúde, com a elaboração do Plano Diretor de Regionalização (PDR) e definição de microrregiões que deveriam desenvolver um conjunto de procedimentos de média complexidade, como primeiro nível de referência intermunicipal, organizados em um ou mais módulos assistenciais. (BRASIL, 2002a)

Concomitante à implementação das ESBs no PSF, definiram-se ações e estratégias mínimas como a prevenção de problemas odontológicos, realização de consultas e procedimentos clínicos ambulatoriais. Além das ações básicas, abordou-se a oferta de ações especializadas, identificando aquelas que deveriam estar incluídas no rol da atenção básica ampliada e definiu-se um elenco de procedimentos da média complexidade a serem ofertados por municípiossede. Dentre eles, citam-se tratamento e retratamento endodôntico de dentes permanentes e decíduos, radiografias periapical e interproximal. Quanto à oferta organizada das ações e procedimentos por nível de atenção, coube ao gestor municipal definir o fluxo de referência e contrarreferência para serviços de maior complexidade ou de apoio diagnóstico, considerando o PDR. Assim, a gestão estadual tinha como responsabilidade a inclusão das ações de saúde bucal em tal plano. (ASSIS, 2006)

A operacionalização dos serviços de referência odontológica pelos municípios habilitados, segundo Norma Operacional de Assistência à Saúde (NOAS), apoiou-se na discriminação disposta pelo Ministério da Saúde (MS) de cada equipamento necessário para a execução de tais procedimentos, incluindo a cobertura populacional prevista para o caso de aparelhos diagnósticos. (BRASIL, 2002a) O número de consultórios odontológicos e de CDs também passou a fazer parte dos critérios para a avaliação da atenção básica dos municípios que pleiteassem essa condição de gestão, bem como o registro de produção 
no SIA/SUS. Tal avaliação era feita através de marcadores específicos, como a cobertura de procedimentos coletivos e primeiras consultas odontológicas. (ASSIS, 2006)

Em 2002, o Encontro Nacional de Administradores e Técnicos do Serviço Público Odontológico (Enatespo) chamava a atenção para a difícil implementação dos serviços de média complexidade, discriminados nas NOAS, no que tange à saúde bucal, afirmando-se, que devido ao alto custo dos procedimentos de radiologia e endodontia, dificilmente eles seriam assimilados pelos municípios, mesmo porque a tabela do SIA/SUS não favorecia aos prestadores e, no caso dos municípios não habilitados em tal norma, a oferta de tais serviços à população dependia de sua inserção pelos gestores na programação físico-orçamentária da saúde, sem previsão de recursos federais.

Apesar do avanço do discurso institucional no que tange à área técnica em saúde bucal, as NOAS mantiveram a orientação de organização dos serviços em saúde bucal voltados para a faixa etária de $\circ$ a 14 anos em relação aos procedimentos preventivos e coletivos, além dos restauradores. Recomendava-se, também, a inclusão de consultas não agendadas para o cumprimento do atendimento das urgências odontológicas, sem especificar faixas etárias prioritárias. (BRASIL, 2002a) Por sua vez, o XVI Enatespo, na época, já apontava que a inserção da saúde bucal no PSF deveria prever uma abordagem universal de ações promotoras e preventivas, tendo como retaguarda o acesso irrestrito à atenção curativa. Tal evento propunha ainda que, nas regiões com infraestrutura relativa à rede de abastecimento público, fosse obrigatória a fluoretação das águas, como um pré-requisito para a implantação das ESBs. Em relação ao tema flúor, vale destacar que a $11^{\text {a }}$ Conferência Nacional de Saúde (CNS) e o XVII Enatespo reiteram dentre suas propostas a importância da fiscalização da água de abastecimento e das pastas de dente pela vigilância sanitária, por estas serem os produtos fluoretados de maior consumo no país, além de propor a definição de normas para aplicação tópica do flúor.

Esses dois últimos eventos citados reconheciam a existência no país de um modelo de atenção inadequado, com manutenção do caráter assistencialista, obsoleto, curativista, centrado na figura do médico, havendo necessidade, inclusive, de reconstrução das relações de poder nas equipes de saúde. Discutia-se a necessidade de uma maior interlocução entre usuários e profissionais da ESB, e propunha-se que a oferta de ações e serviços considerasse o espaço social e a necessidade percebida como ferramentas orientadoras da programação, além de 
construir um modelo integral de atenção que priorizasse grupos mais vulneráveis, ao invés da oferta de serviços segundo demanda livre. (ASSIS, 2006)

Dentre as propostas emanadas de eventos como conferências de saúde e Enatespo, no período do segundo mandato do governo FHC, no que tange ao controle social, tem-se reivindicações relativas à necessidade de participação popular mais efetiva através de conselhos de saúde mais representativos e deliberativos, bem como facilitação da mobilização social e educação pela comunicação entre setor saúde e população, incluindo o repasse de informações sobre dados relativos à situação de saúde, além daqueles pertinentes aos recursos financeiros e humanos disponíveis. (ASSIS, 2006)

Em se tratando dos Recursos Humanos (RH) em Saúde Bucal, tomando como referência proposições dos Enatespos posteriores a 1999, observa-se a similaridade do discurso em prol da garantia de inserção da ESB na equipe mínima do PSF, em uma referência direta à sua composição pelo médico, enfermeiro, auxiliar de enfermagem e ACS, desde 1997. Faz-se constar que, no XVII Enatespo, o tema é tratado com ressalvas, onde se ponderou que a inserção das ESBs no PSF de forma normativa e em rápida expansão, sem uma ampla discussão, principalmente sobre questões referentes ao modelo de atenção, poderia representar uma ameaça à própria proposta da saúde bucal no âmbito do programa. Daí, esse evento enfatizar a retomada do Movimento de Reforma Sanitária no âmbito da odontologia, através das entidades de categoria e estudantes da área. O tema da intersetorialidade permeia o conteúdo desses eventos de forma geral, sejam aqueles pertinentes especificamente à saúde bucal ou não, no que se refere à saúde e sua relação com os aspectos das políticas econômicas, educacionais, alimentares, do trabalhador, da população privada de liberdade, da criança e do adolescente, do índio, entre outras. (ASSIS, 2006)

No segundo mandato do governo FHC, fatos institucionais relativos a uma política específica de grupo apresentou maior correspondência com propostas da $11^{\mathrm{a}} \mathrm{CNS}$. Trata-se do programa do presidiário que se institui em 2002. (BRASIL, 2002b) Nesse plano, estabelecia-se que 70\% do custo das ações a serem desempenhadas ficariam a custo do MS e os $30 \%$ restantes caberiam ao Ministério da Justiça. Tal compromisso de incentivo ficou corroborado por termo de compromisso devidamente aprovado pelos dois ministérios, prevendo-se a contrapartida das Secretarias Estaduais de Saúde e de Justiça. O plano previa o atendimento por uma equipe mínima de saúde, incluindo médico, enfermeiro, auxiliar de enfermagem, odontólogo, ACD, assistente social e psicólogo. Assim, 
cada população de 500 presos teria a cobertura de uma equipe. No mesmo ano de instituição do plano, houve repasse de recursos para os estados habilitados desenvolverem o programa. (BRASIL, 2002b)

Ainda no que se refere a programas especiais, limitados a políticas setoriais voltadas para grupos específicos, tem-se ações relativas à saúde bucal no programa da saúde indígena. Destaca-se que, em 1999, a Fundação Nacional de Saúde (Funasa) reassumiu a responsabilidade pela assistência médico-sanitária aos índios, anteriormente fragmentada entre esta instituição, responsável apenas por ações de prevenção (imunização, saneamento, controle de endemias etc.), e a Fundação Nacional do Índio (Funai), então prestadora das ações curativas. Posteriormente, ressaltou-se a necessária articulação entre Funasa e Secretaria de Assistência à Saúde/MS para execução das ações de atenção à saúde dos povos indígenas, com observação dos princípios e diretrizes do SUS. $\mathrm{Na}$ atenção básica, esses recursos destinavam-se ao apoio da implantação de equipes multidisciplinares com inclusão do cirurgião-dentista. (ASSIS, 2006)

\section{O governo Lula}

Os primeiros anos do governo Lula apresentaram vários fatos institucionais que demonstraram um claro propósito de expansão da atenção à saúde bucal no SUS. Já em abril de 2003, o MS reajustou os valores dos incentivos financeiros relativos à atenção básica, incluindo aqueles pertinentes às ações de saúde bucal, no âmbito do PSF. Posteriormente, estabeleceu-se que se poderiam instalar nos municípios quantas ESB fossem necessárias, a critério do gestor municipal, desde que não ultrapassem o número existente de ESF, e se mantivesse em coerência com a lógica de organização da atenção básica. Reiterou-se, na mesma ocasião, a manutenção dos incentivos de custeio e implantação das ESBs, sendo requisitos para o recebimento dos recursos a qualificação dos municípios na Comissão Intergestora Bipartite e a alimentação mensal do Sistema de Informação Ambulatorial da Atenção Básica, com informação do número das ESBs em atuação, as ações desenvolvidas a as respectivas modalidades. Essas informações é que possibilitariam o cálculo dos incentivos a serem repassados na implantação de uma nova equipe. (ASSIS, 2006)

Seis meses após a viabilização da equiparação entre ESB e ESF, ocorreu novo reajuste dos incentivos da saúde bucal na atenção básica, orientando-se que, na compra dos materiais clínicos permanentes, deveriam estar incluídos aqueles utilizados para a confecção de próteses, fato que encontra correspon- 
dência com a inclusão de um procedimento no grupo das ações de atenção básica em odontologia do SIA, no subgrupo de reabilitação oral. (ASSIS, 2006)

Houve mudanças na forma de repasses de recursos para o financiamento da atenção básica, sendo incluídos como critérios a existência de desigualdades expressas nos indicadores epidemiológicos, nas dificuldades de retenção de profissionais e na dificuldade de acesso da população. Assim, proporcionou-se um aumento de 50\% aos incentivos do PSF e saúde bucal nos municípios com Índice de Desenvolvimento Humano (IDH) igual ou inferior a 0,7, com população de até 50 mil habitantes; nos estados da Amazônia Legal, incluindo, também, aqueles até 30 mil habitantes nos demais estados do país. Além disso, o mesmo se aplicou para os municípios com populações remanescentes de quilombos, residentes em assentamentos, com 70 ou mais pessoas. (ASSIS, 2006)

No segundo ano de governo do presidente Luiz Inácio Lula da Silva, foi lançado um programa nacional exclusivo para a saúde bucal, denominado Brasil Sorridente. Em documento que tratou das diretrizes políticas que englobam esse programa, referenciou-se que elas resultavam de um amplo processo de discussão, envolvendo coordenadores estaduais de saúde bucal, além de se fundamentar em proposições oriundas de conferências, encontros de odontologia e de saúde coletiva, fato amplamente verificado através dos relatórios divulgados por estes eventos mais recentes. (BRASIL, 2004a)

De forma geral, o documento apresentou pressupostos para a reorientação do modelo de atenção em saúde bucal, fundamentados nos princípios e diretrizes do SUS, segundo legislação vigente. Assumiu o PSF como grande oportunidade de reorientação do processo de trabalho na saúde bucal, destacando ações que tornariam a atenção básica mais resolutiva e para a operacionalização da assistência integral, determinou-se a implantação pelo MS de serviços de referência especializada em odontologia. Estes tiveram a sua institucionalização e implementação a partir de setembro de 2004, através dos Centros de Especialidades Odontológicas (CEO) e Laboratórios Regionais de Próteses Dentárias (LRPD). Dessa forma, a operacionalização desses serviços de referência associou-se a repasses federais na forma de incentivos de custeio e implantação, no caso dos CEOs, ou por pagamento segundo produção, no caso dos LRPDs. Assim, foram necessários acréscimos de procedimentos no SIA/SUS a serem realizados pelo Técnico em Prótese Dental (TPD), bem como, a inclusão da categoria profissional do CD patologista bucal e respectivos procedimentos. Recomendava-se que a organização desses serviços de referência, 
principalmente no que tange aos CEOs, considerasse para cobertura populacional o PDR. (ASSIS, 2006)

Segundo o MS, até 2003 , apenas 3,3\% dos atendimentos odontológicos feitos no SUS correspondiam a tratamentos especializados. O grande diferencial dessa política de saúde bucal, em relação às anteriores, portanto, centra-se no investimento para a organização de serviços públicos especializados em odontologia. Porém, em se tratando dessa recente implantação de serviços de referência, vale ressaltar que a $12^{\mathrm{a}}$ CNS e $3^{\mathrm{a}}$ Conferência Nacional de Saúde Bucal (CNSB) abordaram a importância da organização dos mesmos através de centrais de regulação. (BRASIL, 2003)

De forma geral, o conjunto de diretrizes apresentadas em eventos como a $12^{\mathrm{a}}$ CNS e $3^{\mathrm{a}} \mathrm{CNSB}$, referentes à orientação do modelo de atenção em saúde bucal, encontrou consonância nas Diretrizes da PNSB, em 2004. Assim, o conteúdo dessas proposições apresenta a recomendação da ampliação do acesso e a superação do modelo biomédico de atenção às doenças bucais, a partir de ações programáticas por linha de atenção, baseadas nas especificidades da faixa etária - criança, adolescente, adulto, idoso e por condição de vida -, saúde da mulher, saúde do trabalhador, saúde de portadores de necessidades especiais, hipertensos, diabéticos, entre outras. Rompe-se com o discurso de priorização da faixa etária de o a 14 anos para uma abordagem universal, sem fazer distinção entre grupos e respectivas ações a serem priorizadas. Essa universalidade da atenção, por sua vez, associa-se com a recomendação de que o deslocamento do CD, para o desenvolvimento das ações de saúde coletiva, seja criterioso, cabendo o exercício dessas atividades ao demais integrantes da ESB e ACS. Tal orientação pressupunha uma autonomia desses sujeitos e uma adequada programação dos serviços, incluindo processos de supervisão e avaliação, tendo no CD, o papel de coordenador. (ASSIS, 2006)

Essas diretrizes políticas estabelecidas no governo Lula, em 2004, também previam a realização de diagnóstico em saúde bucal o mais precocemente possível com o tratamento que priorizasse procedimentos conservadores, entendidos como todos aqueles executados para manutenção dos elementos dentários, invertendo a lógica que leva à mutilação, considerada então predominante nos serviços públicos. (BRASIL, 2004) Tais propostas relativas ao processo de trabalho em saúde bucal encontram correspondência com a situação encontrada em 2003 , onde os principais problemas da população brasileira em saúde bucal 
apresentaram-se como cáries não tratadas em crianças e jovens e perda dentária em adultos e idosos.

Cabe destacar que a $12^{\mathrm{a}}$ CNS reiterou todas as preconizações, disponibilizadas pelo MS em 2004, no que tange à dosagem adequada e monitoramento do flúor em águas de abastecimento, ressaltando que a questão era uma responsabilidade intersetorial do SUS. Por sua vez, essa conferência cobrou a garantia de implementação de uma Agenda Nacional de Prioridades de Pesquisa em Saúde que incluísse, dentre os seus temas, a fluorose, fazendo referência específica a estudos que abordassem a relação entre cremes dentais infantis e casos da doença. Já a $3^{\text {a }}$ CNSB, além da garantia da fluoretação das águas de abastecimento, propôs a criação de uma política de incentivo para a produção de insumos para higiene oral, materiais e produtos odontológicos, frente a uma ação reguladora da Agência Nacional de Vigilância Sanitária em relação a produtos que possam causar problemas de saúde bucal em geral, como chupetas, mamadeiras, escovas de cerdas duras etc. Esses temas, em geral, encontraram relação com as proposições da política Brasil Sorridente a partir da definição de critérios para a aplicação tópica de flúor de forma criteriosa pelos profissionais, além da expansão das águas de abastecimento fluoretadas com articulação entre Funasa, MS e Secretarias Estaduais de Saúde, bem como a previsão de distribuição de 1,9 milhões de kits de higiene oral, anualmente, entre 2004 e 2007. (ASSIS, 2006)

A proposta de definição de uma política de humanização pela $12^{a}$ CNS encontrou ressonância com o discurso da Política Nacional de Humanização do SUS, em janeiro de 2004 (BRASIL, 2004b) As diretrizes para sua operacionalização referiam-se ao direito do usuário de saber quais são os profissionais que o atendem, possibilitando o vínculo e corresponsabilidade; redução de fila com acolhimento, avaliação de risco e priorização para atendimento; além de ações voltadas para a maior participação dos usuários e profissionais na gestão dos serviços dessa saúde. (KLECZKOWSKI; ROEMER; WERFF, 1984) Assim, essa política recomenda a implementação dessas diretrizes nos planos de saúde dos diferentes níveis governamentais, visando articulação de recursos e compromissos com a humanização do SUS. (ASSIS, 2006)

Sobre questões relativas à formação dos recursos humanos em saúde bucal, a $3^{\text {a }}$ CNSB, em 2004, apontava o crescimento de $100 \%$ dos cursos de graduação de odontologia apenas em uma década, totalizando 161 cursos, em sua maioria, particulares e concentrados nas regiões mais desenvolvidas do país. Tal Conferência declarava que o sistema de ensino superior não estava cumprindo seu 
papel formador de RH comprometido com o SUS e com o controle social, nem considerando as reais necessidades de saúde bucal da população brasileira. Um dos entraves apontados referia-se à falta de articulação entre a saúde e a educação, com autonomização das universidades públicas e privadas. Por fim, abordou-se a permanência da pós-graduação com ênfase em especializações que confirmavam o caráter mercantilista e elitista da odontologia no Brasil, mantenedora do mesmo marco pedagógico conceitual da graduação. (ASSIS, 2006)

Ainda se tratando de RH em saúde bucal, tem-se a dificuldade de interiorização do profissional odontólogo, fato abordado na $3^{\mathrm{a}} \mathrm{CNSB}$, que fez referência à necessidade de incentivos para a fixação dos profissionais no interior através do Programa de Interiorização do Trabalho em Saúde, instituído em 2001, que, mesmo após a inclusão da ESB no PSF, permanece, no período analisado, incluindo somente as categorias de médicos e enfermeiros. Em relação à remuneração dos CDs, uma recomendação recorrente em eventos da área, é a isonomia salarial da categoria à dos médicos. (ASSIS, 2006)

No governo Lula, dentre as políticas relativas a programas voltados para grupos específicos que apresentaram maior correspondência com a saúde bucal, destaca-se a política para os privados de liberdade, através da reinstituição do Plano Nacional de Saúde do Sistema Presidiário em 2003. Manteve-se assim o financiamento intersetorial, aumentando-se a cobertura de 501 a 1.000 presidiários por duas equipes mínimas, com carga horária de 20 horas semanais por profissional, além da garantia da atenção à saúde bucal básica segundo cobertura disposta na NOAS-SUS 01/2002. Houve ainda a criação do cargo de agente promotor de saúde, um por equipe, a ser ocupado por presidiário selecionado. No caso de municípios com população prisional até 100 indivíduos, a rede local passa a assumir a responsabilidade pela oferta de ações e serviços da atenção primária, mediante repasse de incentivo específico ao município. (ASSIS, 2006)

\section{A política de saúde bucal e o acúmulo histórico dos fatos institucionais}

A análise dos dois governos revelou que houve avanço na formulação e implementação de ações para a área de saúde bucal, desde propostas na atenção primária com a inserção da atenção odontológica no PSF no governo FHC até a formulação de uma política específica para esse setor no governo Lula. O Quadro 1 sistematiza os principais fatos produzidos na atenção à saúde bucal nos dois governos (FHC e Lula I). Observou-se incorporação das principais proposições dos movimentos da área - Enatespo e CNSB - nas políticas formuladas, 
apontando para uma resposta social do Estado às necessidades de saúde de grupos organizados específicos, que, teoricamente, expressam o caráter coletivo dessas reinvindicações. Contudo, há evidências do caráter secundário dessa política, como também revelou Vianna (1988) em períodos anteriores.

Quanto aos componentes do sistema de saúde (gestão, financiamento, organização e infraestrutura, modelo de atenção), observou-se uma maior ênfase no aspecto organizacional e de infraestrutura, mas pouca clareza quanto ao modelo de atenção e financiamento do sistema, especialmente no governo FHC. (ASSIS, 2006)

\section{Quadro 1 - Principais fatos políticos produzidos no âmbito de saúde bucal nos governos FHC (1995-2002) e Lula (2003-2006) quanto aos cinco componentes dos sistemas de saúde \\ (continua)}

\begin{tabular}{|c|c|}
\hline Governos & Fatos políticos produzidos \\
\hline $\begin{array}{c}\text { FHC } \\
(1995-2002)\end{array}$ & $\begin{array}{l}\text { Financiamento } \\
\text { Criação de incentivos específicos para ESB no PSF. } \\
\text { Organização e infraestrutura } \\
\text { Orientaçães sobre a organização da atenção em saúde bucal (NOAS). } \\
\text { Definição de procedimentos de média complexidade em saúde bucal, segundo } \\
\text { habilitação (NOAS). } \\
\text { Gestão } \\
\text { NOB SUS 01/96 não se refere à saúde bucal. Manual da reorganização da } \\
\text { atenção básica referindo a ações em odontologia e cria indicador em saúde } \\
\text { bucal. Presença de consultórios odontológicos é condicional em unidades de } \\
\text { atenção básica e mista. Inserção da ESB no PSF. } \\
\text { Inclusão do indicador em saúde bucal no compromisso do pacto para a } \\
\text { atenção básica. } \\
\text { NOAS atrela o desenvolvimento de ações em saúde bucal como critério para } \\
\text { habilitação. } \\
\text { Presença de dentista, consultório odontológico e produção no SIA passam a } \\
\text { ser critérios para habilitação. } \\
\text { Modelo de Atenção } \\
\text { Realização de levantamento epidemiológico em escolares de capitais brasileiras. } \\
\text { Edição das Normas e Diretrizes da Saúde Bucal no PSF. Manual da Reorientação } \\
\text { da Saúde Bucal na atenção básica descreve atribuições e responsabilidades do } \\
\text { CD, THD, ACD e ACS. Ampliação do campo de ação da ESB no PSF. Programa } \\
\text { do Presidiário é lançado e instituído. }\end{array}$ \\
\hline
\end{tabular}


Quadro 1 - Principais fatos políticos produzidos no âmbito de saúde bucal nos governos FHC (1995-2002) e Lula (2003-2006) quanto aos cinco componentes dos sistemas de saúde

(conclusão)

\begin{tabular}{|c|c|}
\hline $\begin{array}{c}\text { Lula } \\
(2003-2006)\end{array}$ & $\begin{array}{l}\text { Financiamento } \\
\text { Ampliação de incentivo para implantação proporcional entre ESBs e ESFs. } \\
\text { Criação e manutenção de uma ação orçamentária específica para a saúde bucal } \\
\text { (2004); o reajuste de } 20 \% \text { no valor do incentivo de implantação repassado } \\
\text { para as ESB (2004); a determinação do financiamento para o CEO e próteses } \\
\text { dentárias (2004), segundo tetos, por produção. Aumento do incentivo em } \\
\text { saúde bucal para municípios com baixo IDH. } \\
\text { Organização e infraestrutura } \\
\text { Em 2006, o governo chegou a } 15.086 \text { ESBs (254,04\% de aumento em relação } \\
\text { a 2002). } \\
\text { Oferta de serviços especializados em } 2004 \text { com 100 centros especializados e } \\
\text { no final do governo chega a } 498 \text { centros (aumento de 398\%). } \\
\text { Gestão } \\
\text { Lançamento do Brasil Sorridente. Institucionalização de LRPDs. Implantação de } \\
\text { CEOs tipo I e tipo II. Inclusão de procedimentos do THD no SIA e da categoria } \\
\text { TPD e CD patologista bucal. Publicação da portaria que determina o valor } \\
\text { máximo permitido de fluoreto por mg/L de água (2004); a criação do Comitê } \\
\text { Técnico Assessor para estruturação (Comitê Tecnico Assessor - Vigilância em } \\
\text { Saúde Bucal - CTA-VSB e implantação da estratégia de vigilância em saúde } \\
\text { bucal dentro da PNSB); a determinação de critérios, normas e requisitos para } \\
\text { implantação e habilitação dos CEOs e LRPDs (2004). } \\
\text { Modelo de Atenção } \\
\text { Conclusão de levantamento epidemiológico em saúde bucal SB2000, em nível } \\
\text { nacional. } \\
\text { Diretrizes de Política Nacional com ações programáticas por linha de atenção. } \\
\text { Aumento do incentivo em saúde bucal para municípios com baixo IDH . } \\
\text { Definição do perfil de competências do THD e ACD. Definição de critérios para } \\
\text { a aplicação tópica de flúor. } \\
\text { Distribuição de kits de higiene oral. Ampliação da cobertura dos presidiários } \\
\text { por equipes de saúde. Definição do perfil de competências do THD e ACD. }\end{array}$ \\
\hline
\end{tabular}

Fonte: Documentos-Base do Ministério da Saúde e relatórios de gestão. Síntese da dissertação citado por Assis, (2006). 
As restrições orçamentárias à saúde no segundo mandato do governo FHC permaneceram principalmente pela manutenção da desvinculação da Receita da União (DRU $)^{1}$ com gastos sociais para a promoção de superávit fiscal primário, e que se mantém até 2015. Concomitante a essa limitação, os recursos assegurados para a saúde com a tentativa de instituição da Emenda Constitucional n. ${ }^{0} 29$ foram cerceados pelo entendimento do critério da "base fixa" do seu artigo 77, além de contingenciamento dos recursos da saúde pelas alterações do Poder Executivo à dotação orçamentária disposta na Lei das Diretrizes Orçamentárias. Foi a partir dessa conjuntura econômica, que se sucederam fatos relevantes nas políticas de saúde bucal no segundo mandato do governo FHC.

Um estudo sobre a municipalização no Brasil demonstrou que, no período de 1993 a 1998, a ampliação da oferta própria de serviços ambulatoriais pelos gestores locais não se associava à dinâmica político-partidária, nem com as relações entre o poder executivo e legislativo municipal, mas com a operacionalização dos incentivos descentralizados pelo governo federal. (CÓRDON, 1991) Assim, no que tange à saúde bucal, apesar das limitações dos propósitos do governo (TESTA, 1992) face à implantação dos serviços e respectiva organização, a criação de um incentivo específico no final do ano de 2000, na gestão do ministro José Serra, foi um fato importante para expansão dos serviços na atenção básica da política de saúde bucal (BRASIL, 2000). Por sua vez, a oferta das ações e serviços odontológicos especializados ficou comprometida pelas dificuldades inerentes à implementação das diretrizes dispostas na NOAS, bem como pelo financiamento limitado ao repasse de recursos de acordo com produção, nesse governo FHC.

A política macroeconômica do governo FHC foi mantida e aprofundada no mandato do governo Lula, com manutenção de todos os meios de restrição orçamentária aplicados pela gestão anterior. (MENDES; MARQUES, 2005) Contudo, a implementação da política de saúde bucal nunca havia merecido tanto destaque, sugerindo, nessa nova conjuntura política, a aglutinação de forças democráticas sensíveis à saúde bucal enquanto direito de cidadania. (OPS/ OMS, 2006) Faz-se constar que o conteúdo da política Brasil Sorridente se apresentou como proposta do programa de governo do então candidato, em

\footnotetext{
Desvinculação das Receitas da União é o controle realizado pelo governo brasileiro para facilitar a manutenção de receita em relação aos gastos públicos, ou seja, 20\% das vinculações constitucionais obrigatórias de toda a arrecadação tributária brasileira não tem sido cumpridas e foi renovada até dezembro de 2015.
} 
2002, onde se propunha a continuidade dos investimentos nas ESBs na ESF, bem como a oferta de procedimentos especializados. O governo Lula chegou a 15.086 ESBs em 2006 (254,04\% de aumento em relação a 2002) e a oferta serviços especializados passou de 100 centros especializados em 2004 para 498 centros em 2006 (aumento de 398\%).

Porém, há de se considerar que a integralidade das ações e serviços especializados em saúde bucal e a própria legitimidade do Brasil Sorridente são dependentes de uma rede de ESBs resolutiva e que se organize enquanto porta de entrada do sistema, a fim de que os centros de especialidade não se constituam em atenção à livre demanda, considerando a publicidade do programa em meios de comunicação de massa naquele período inicial e consequente pressão política sobre os gestores locais.

O caráter hegemônico da prática odontológica tradicional, compreendendo hegemonia como direção moral de fração da classe odontológica dominante sobre a totalidade, associado à expansão de cursos de graduação em odontologia e mudança do perfil epidemiológico de cárie dentária com tendência à maior redução nas classes médias e altas, levou o Estado a abrir mercado direta ou indiretamente para essa mão de obra profissional excedente, sendo que este Estado prosseguiu "reduzindo-se" à condição de Estado periférico, encontrando-se submetido à interferência do cenário externo na forma de ajustes aplicados em um contexto de globalização financeira e produtiva. (ORTIZ, 1996) É, portanto, resposta seletiva do Estado já que esses ajustes basearam-se na "desregulamentação dos mercados, na abertura comercial e financeira e na privatização do setor público”. (SOARES, 2001, p. 19) Por sua vez, um dos reflexos dessa configuração de Estado na saúde, além das restrições orçamentárias impostas pela área econômica, pode ser observada na precarização das relações de trabalho. As propostas de flexibilização dos vínculos empregatícios, segundo o disposto no Plano do Ministério da Administração e Reforma do Estado (BRASIL, 1995) seriam condizentes em uma administração estatal moderna, porém, inviáveis, principalmente, ao se tratarem do setor saúde, pela capacitação específica desses profissionais. Foi nessas condições adversas que, nos governos FHC e Lula, o PSF abriu-se enquanto mercado de trabalho para os profissionais de saúde bucal. (ASSIS, 2006)

Sem desconsiderar a importância de uma remuneração satisfatória dos profissionais de saúde, é equivocada a ideia de que a garantia de salários e valorização profissional reflitam em compromisso na resolução dos problemas dos 
usuários ou em atendimento acolhedor. O modo de assistir em saúde estaria mais dependente de uma determinada concepção em saúde que considere a construção de uma nova subjetividade em cada profissional e usuário, resultando em uma relação entre sujeitos, ambos produtores de saúde. Essa mudança dependeria da própria forma como o trabalhador de saúde relaciona-se "com o seu 'objeto de trabalho', com a vida e o sofrimento dos indivíduos e da comunidade". (MERHY, 1997, p. 123)

Essa percepção de uma nova prática em saúde (bucal) esteve presente nas diversas propostas emanadas das conferências e encontros ao longo das últimas décadas, bem como nas diretrizes políticas nacionais da área. Por sua vez, aspectos favoráveis à reorientação do modelo de atenção em saúde bucal, a nível municipal, encontram-se relacionados a projetos específicos de reorganização das práticas de saúde local, à capacidade técnica dos atores envolvidos e à respectiva governabilidade para implementação.

A partir das análises realizadas, constata-se a evolução das políticas de saúde bucal formuladas e implementadas nos governos FHC e Lula, porém, podese inferir que a viabilidade a longo prazo da odontologia no SUS apresenta a mesma limitação tratada por Vianna (1988), diante do caráter secundário dessas políticas mediante questões de maior gravidade da saúde. Mesmo quando tomadas como políticas prioritárias, estão em aberto as potencialidades do seu desenvolvimento e a perspectiva incerta do seu futuro. O modelo de atenção hegemônico em odontologia contribui para o afastamento da legitimação que essas políticas poderiam alcançar junto à população, permanecendo suscetível às conjunturas governamentais.

\section{Referências}

ASSIS, L. N. Políticas de Saúde Bucal Pós-Constituinte. 2006. 118 p. Dissertação de Mestrado (Mestrado em Saúde Comunitária) - Instituto de Saúde Coletiva, Universidade Federal da Bahia, Salvador, 2006.

BRASIL. Ministério da Administração e Reforma do Estado. Plano Diretor da Reforma do Aparelho do Estado do Ministério da Administração e Reforma do Estado (MARE), 1995.

BRASIL. Ministério da Saúde. $11^{a}$ Conferência Nacional de Saúde: o Brasil falando como quer ser tratado : Relatório Final. Brasília, DF, 2002b. Disponível em: <http://conselho.saude. gov.br/biblioteca/Relatorios/relatorio_11.pdf> Acesso em: 20 out. 2005.

BRASIL, Ministério da Saúde. Diretrizes da Política de Saúde Bucal, janeiro de 2004a. Disponível em: <ttp://bvsms.saude.gov.br/bvs/publicacoes/politica_nacional_brasil_ sorridente.pdf $>$. Acesso em: 15 out. 2005. 
BRASIL,. Ministério da Saúde. Política Nacional de Humanização do SUS, 2004b. Disponível em: <http://portal.saude.gov.br/portal/saude/cidadao/area.cfm?id_area=1342> Acesso em: 13 dez. 2005 .

BRASIL. Ministério da Saúde. Portaria $\mathrm{n}^{\circ}$ 2.215, de 5 de dezembro de 2001. Redefine os critérios para a avaliação da atenção básica segundo NOAS 01/2001. Brasília, DF, 6 dez. $2001 \mathrm{a}$.

BRASIL. Ministério da Saúde. Portaria $\mathrm{n}^{0}$ 267, de 6 de março de 2001. Aprova as normas e diretrizes de inclusão da saúde bucal no PSF. Diário Oficial [da] República Federativa do Brasil, Brasília, DF, 7 mar. 2001b.

BRASIL. Ministério da Saúde. Portaria $\mathrm{n}^{\circ} .373$, de 12 de janeiro de 2002. Aprova a Norma Operacional de Assistência à Saúde NOAS-SUS 01/2002. Diário Oficial [da] República Federativa do Brasil, Brasília, DF, 28 fev. 2002.

BRASIL. Ministério da Saúde. Portaria $\mathrm{n}^{0}$ 1.444, de, 28 de dezembro de 2000. Estabelece incentivo financeiro para reorganização da atenção à saúde bucal no PSF. Diário Oficial [da] República Federativa do Brasil, Brasília, DF, 29 dez. 2000.

BRASIL. Ministério da Saúde. Portaria $\mathrm{n}^{0} 74$, de 20 de janeiro de 2004. Reajusta valores de incentivos financeiros para ações de saúde bucal no PSF e inclui procedimentos de moldagem. Diário Oficial [da] República Federativa do Brasil, Brasília, DF, 22 jan. 2004.

BRASIL. Poder Legislativo. Lei Federal n ${ }^{\circ} 3.999$, de 15 de dezembro de 1961. Altera o salário-mínimo dos médicos e cirurgiões-dentistas. Diário Oficial [da] República Federativa do Brasil, Brasília, DF, 21 dez. 1961. Disponível em: <http://www.trto2.gov.br/geral/ tribunal2/Legis/Leis/3999_61.htm>. Acesso em: 10 nov. 2005.

BRUYNE, P. et al. Dinâmica da pesquisa em ciências sociais. Rio de Janeiro: Francisco Alves, 1997.

CENTRO PANAMERICANO DE PLANIFICACIÒN DE SALUD. Formulacion de Políticas de Salud. Caracas: CENDES, 1975.

CORDÓN, J. A. Saúde bucal e a municipalização da saúde. Divulgação em Saúde para Debate, Londrina, v. 32, p. 60-65, 1991.

COUTINHO, C. N. Representação de interesses, formulação de políticas e hegemonia. In: TEIXEIRA, Fleury S. Reforma Sanitária: em busca de uma teoria. Rio de Janeiro: Editora Cortez - ABRASCO, 1995.

FERREIRA, D. O. et al. Este Aparelho de Estado Pode não ser um Aparelho qualquer. Revista Divulgação em Saúde para Debate, Londrina, v. 28, p. 48-51, 1990.

GERSCHMAN, S. Sobre formulação de políticas sociais. In: TEIXEIRA. S. F. (Org.) Reforma Sanitária:em busca de uma teoria. Rio de Janeiro: Editora Cortez; ABRASCO, 1995 .

GRAMSCI, A. Maquiavel, a política e o Estado Moderno. 4. ed. Rio de Janeiro: Civilização Brasileira. 1980. p. 48-50. 
KLECZKOWSKI, B. M.; ROEMER M.; WERFF, A.V.D. Sistemas Nacionales de Salus y su reorientación hacia la salud para todos. Pautas para uma política. Cuadernos de Salud publica, OMS, 77, 134p, 1984.

MANSUR M. C. O. Financiamento federal da saúde no Brasil: tendências da década de 1990. 2001. 119 f. Dissertação (Mestrado em Saúde Pública) - Escola Nacional de Saúde Pública, Funadação Oswaldo Cruz, Rio de Janeiro, 2001. Disponível em: http://portalteses.cict. fiocruz.br/pdf/FIOCRUZ/2001/mansurmcm/capa.pdf. Acesso em: 2 mar. 2006.

MENDES, A. N.; MARQUES, R. M. O impacto da política econômica do governo Lula na Seguridade Social e no SUS. Divulgação em Saúde para Debate, Rio de Janeiro, v. 29, n. 71, p. $258-267,2005$.

MENDES, E. V. A reforma sanitária e a educação odontológica. Caderno de Saúde Pública, Rio de Janeiro, v. 2, n. 4, dec. 1986.

MERHY, E. E. Em Busca da Qualidade dos Serviços de Saúde: Os Serviços de Porta Aberta para a Saúde e o Modelo Tecno-Assistencial em Defesa da Vida. In: CECÍLIO, L. C. O.

(Org.) Inventando a mudança na saúde. São Paulo: Editora HUCITEC, 1997, 334p.

OFFE, C. Capitalismo desorganizado. São Paulo: Brasiliense, 1989.

OPAS/OMS. A política nacional de saúde bucal no Brasil: registro de uma conquista histórica. Brasília, DF, 2006. (Séria Técnica Desenvolvimento de Sistemas de Saúde, 11).

ORTIZ, A. R. et al. A proposta da reforma do aparelho de estado e suas possíveis implicações no SUS... São Paulo: Faculdade de Saúde Pública da Universidade de São Paulo, 1996. p. 8-16. (Série Monográfica n. 5 Eixo Políticas, Planejamento e Administração).

PAIM, S. J. Modelos de Atenção e Vigilância da Saúde. In: ROUQUAYROL, M. Z; ALMEIDA FILHO, N. F. Epidemiologia e saúde, Rio de Janeiro: Editora MEDSI Ltda., 2003.

PORTATIERO, J. C. Los usos de Gramsci. México: Folios Ediciones,1983.

POULANTZAS, N. O Estado, o poder e o socialismo. Rio de Janeiro, Graal, 1980.

RONCALLI, Â. G. A organização da demanda em serviços públicos de saúde bucal:

Universalidade, equidade e integralidade em Saúde Bucal Coletiva. 2000234 f. Tese

(Doutorado em Odontologia Preventiva e Social) - Faculdade de Odontologia, Universidade Estadual Paulista Júlio de Mesquita Filho, Araçatuba, 2000.

SOARES, R. T. L. Ajuste neoliberal e desajuste social na América Latina, Petrópolis, RJ: Editoras Vozes, 2001.

TEIXEIRA, S. F. Reflexões teóricas sobre democracia e reforma sanitária. In: TEIXEIRA, S. F. Reforma Sanitária:em busca de uma teoria. Rio de Janeiro: Editora Cortez; ABRASCO, 1995.

TESTA, M. Pensar em saúde. Porto Alegre: Artes Médicas, 1992.

VIANNA, M. I. P. Estado e Atenção Odontológica no Brasil: um estudo sobre as Políticas de Saúde Bucal na conjuntura Pós-74. 211p. Tese (Mestrado em Saúde Comunitária) -, Universidade Federal da Bahia, Salvador. 1988. 


\section{O espaço da saúde bucal coletiva CONTRIBUIÇÕES PARA COMPREENSÃO DA FORMULAÇÃO E IMPLEMENTAÇÃO DAS POLÍTICAS DE SAÚDE BUCAL NO BRASIL}

Catharina Leite Matos Soares

Jairnilson Paim

Thais Aranha Rossi

Sônia Chaves

No final dos anos 1980, começa a circular nos serviços de saúde e depois no âmbito acadêmico a expressão "Saúde Bucal Coletiva" (SBC). (SOARES, 2014) Essa expressão surgiu no estado de São Paulo, particularmente no Instituto de Saúde de São Paulo. (BOTAZZO et al., 1988; SOARES, 2014) Embora venha sendo usado com frequência a partir desse período, há alguns equívocos quanto ao seu emprego, pois muitos trabalhos encontrados na literatura mostram que a SBC representa a antiga Odontologia Preventiva e Social (OPS). (CELESTE, WAMERLING, 2012; DIAS, NARVAI; REGO, 2008; )

Pretende-se com o presente texto apresentar ao leitor o processo histórico de emergência da SBC, entendendo-o como um espaço social, um espaço de lutas (BOURDIEU, 1994), bem como o aporte teórico sobre o qual se assenta a SBC e seus aspectos de distinção em relação às correntes emanadas da odontologia no período da emergência da SBC. Pretende-se ainda apresentar uma discussão sobre o potencial da SBC para as políticas e as práticas de saúde bucal no Sistema Único de Saúde (SUS), entendendo o conceito de política de saúde no sentido que lhe é dado por Paim (2000) enquanto resposta social (ação ou 
omissão) de uma organização (como o Estado) diante das condições de saúde dos indivíduos e das populações e seus determinantes, bem como em relação à produção, distribuição, gestão e regulação de bens e serviços que afetam a saúde humana e o ambiente.

\section{Antecedentes}

A odontologia, desde as suas origens, articulou-se com a medicina, seus saberes e práticas, favorecendo a consolidação de uma prática odontológica centrada na doença e no doente, particularmente no processo curativo, na ação do cirurgião-dentista, especialista, cujas atividades eram desenvolvidas em ambiente clínico-cirúrgico individual. (BOTAZZO, 2000; NARVAI, 1994; WARMILING, 2009)

Essa forma de conceber o processo saúde doença bucal favoreceu uma prática privada da odontologia, que veio a se consolidar no serviço público brasileiro por meio da emergência e desenvolvimento da previdência social (SERRA, 1998), propiciando o aparecimento e desenvolvimento de uma "odontologia de mercado", expressão cunhada por Narvai em 1994. A odontologia de mercado caracteriza-se pela livre escolha e definição de preços com base no mercado, destacando-se a vinculação com os detentores do poder político-econômico. (NARVAI, 1994)

Em São Paulo, surge o Programa Dentário Escolar e o Departamento de Odontologia Sanitária desse mesmo estado, vinculado à Secretaria Estadual de Educação. Essa seção representou um importante setor de práticas de odontologia escolar e anos depois se transformou em Programa Estadual de Saúde do Escolar. (SOARES, 2014) Narvai (2006) aponta que a odontologia sanitária fracassou no rompimento com a odontologia de mercado, ou seja, a prática centrada no atendimento ao indivíduo doente e restrito ao ambiente clínico cirúrgico.

Nesses anos 1950, diversos movimentos ditos contra-hegemônicos apareceram no cenário brasileiro como a odontologia sanitária, odontologia preventiva, odontologia social, odontologia simplificada, odontologia comunitária e odontologia integral. (NARVAI, 1994)

A odontologia sanitária é entendida como uma disciplina de saúde pública, que tem como objeto a saúde oral da comunidade. (CHAVES, 1986) Suas ideias tomam por referência a saúde pública norte-americana, exercendo sua prática sobre os problemas de saúde das comunidades e considerando como agente 
principal o sanitarista, que teria como paciente a comunidade, a coletividade ou o corpo político. (CHAVES,1986) Caracterizou-se por introduzir duas práticas de saúde bucal fundamentais no Brasil: o sistema incremental e a utilização do flúor como medida populacional. (NARVAI, 1994)

O sistema incremental foi a principal ferramenta utilizada pela odontologia sanitária para diagnosticar os problemas de saúde oral nas comunidades e caracterizava-se por um método de trabalho que visava o completo atendimento dental de uma dada população, eliminando suas necessidades acumuladas e, posteriormente, mantendo-as sob controle, segundo critérios de prioridade quanto à idade e aos problemas. (NARVAI, 2006)

Em 1951, aqui no Brasil, incorporou-se ao Serviço Especial de Saúde Pública (SESP), a Secção de Odontologia Sanitária, que passa a desenvolver atividades complementares às atividades assistenciais da previdência social, enquanto práticas odontológicas voltadas para escolares. (NARVAI, 1994) Esses programas contavam com a participação de engenheiros e médicos sanitaristas que já utilizavam essa terminologia em saúde pública, oriundos de um programa de cooperação entre o Brasil e os Estados Unidos. Seus programas enfatizavam tratamento das crianças em idade escolar.

O primeiro manual impresso com Normas Técnicas de Odontologia Sanitária foi editado pela Fundação SESP (FSESP) em 1963, no Rio de Janeiro. A política de cunho nacional trazia o atendimento prioritário aos escolares, com possibilidade de considerar alguns casos especiais para atendimento a gestantes e outros, uso de consultórios semiportáteis, utilização de pessoal auxiliar e alterações no sistema incremental original. (FSESP, 1963) Deram origem também no Brasil na experiência piloto em Aymorés, Minas Gerais e depois outros programas com essa concepção.

A chamada odontologia escolar é um modelo de prática odontológica bastante conhecido no setor público, tendo sido iniciada no Brasil com o sistema incremental. (FRAZÃO; NARVAI, 2008) O Manual de odontologia sanitária publicado por Mário Chaves, em 1960, é obra de referência para o modelo escolar e sistematizou um conjunto de medidas para intervenção na saúde pública, especificamente na odontologia. (FRAZÃO; NARVAI, 2008)

Já a OPS, relaciona-se com a medicina preventiva, desenvolvida nas escolas médicas norte-americanas (GARCIA, 1972), cuja criação de disciplinas específicas influenciou em seguida a América Latina. Esse fenômeno, no âmbito odontológico, ocorre no Brasil na década de 1970, resultando na criação dos Departamentos 
de Odontologia Preventiva e Social nas universidades brasileiras, impulsionado por um conjunto de seminários promovidos pela Organização Pan-Americana de Saúde (OPAS) com o apoio da Fundação Kellogg. (CASOTTI, 2009; NARVAI, 1994; QUEIROZ E DOURADO, 2009) Embora a OPS tenha sido influenciada pela medicina preventiva norte-americana, particularmente no Brasil, encontra respaldo nos estudos da cariologia realizados nos países escandinavos e culminou com a fundação de entidade denominada Associação Brasileira de Odontologia Preventiva (ABOPREV), em 1981. (NARVAI, 2006) Introduziu um arsenal de tecnologias no serviço público, tais como: dentifrícios fluoretados, uso massivo do flúor gel, selantes, entre outros, encontrando legitimação no mercado de produtos odontológicos. (SOARES, 2014)

Paralelo ao desenvolvimento da OPS no Brasil, ganha corpo a odontologia simplificada, que compreende uma prática profissional, a qual através da padronização, da diminuição dos passos e elementos e eliminação dos supérfluos, visava tornar mais simples e barata a odontologia, sem haver alteração da qualidade dos trabalhos, como também mais produtiva (MENDES, 1985; NARVAI, 1994), de modo que pudesse utilizar-se em trabalhos comunitários, podendo encontrar-se na literatura como "odontologia comunitária”. (NARVAI, 1994) Seu desenvolvimento no Brasil relaciona-se com a modernização do ensino odontológico coordenado também pela OPAS, cujas experiências docente-assistenciais em curso na América Latina possibilitaram a reflexão e teorização da odontologia simplificada. (SOARES, 2014)

Ademais, a simplificação do equipamento e espaço físico e a racionalização do trabalho odontológico eram elementos importantes na busca pelo aumento da produtividade. (FERREIRA, 1985) Nesse sentido, a técnica previa "máxima" utilização de pessoal auxiliar, mudanças no equipamentos odontológicos e espaços mais compactos e eficientes para o tratamento. (FERREIRA, 1985)

A principal experiência brasileira na prática da odontologia simplificada foi desenvolvida em Brasília, por Sérgio Pereira, responsável pela constituição do Programa Integrado de Saúde Escolar (PISE) 1 do Distrito Federal. (SOARES, 2014) O PISE é citado como um programa de impacto da odontologia simplificada (UCHOA, 1985) e de importância histórica. (SILVEIRA et al., 2002) Ele foi implementado no final de 1970, com a proposta de clínicas móveis nas escolas, numa equipe composta por dois dentistas e quatro técnicos em higiene

1 Informação disponível em site da Secretaria de Educação do Distrito Federal. Disponível em: http:// www.se.df.gov.br/?page_id=434. Acesso em: 5 set. 2013. 
dental. O programa centrava sua atenção nos dentes permanentes, seguindo também fundamentos do sistema incremental, mas a posteriori passou a incluir os dentes decíduos. (SILVEIRA FILHO et al., 2002) O Pise promovia ações voltadas para a saúde dos alunos da educação infantil e do ensino fundamental da rede pública do Distrito Federal. Prestava assistência médica e odontológica aos estudantes, com vistas a contribuir para a melhoria de seu desempenho escolar. (SOARES,2014) Além do PISE, cita-se o Programa Integrada de Ações de Saúde e Saneamento, em todo território nacional, que revia fluoretação das águas, aplicação tópica de flúor via bochechos, adequação de recursos físicos e humanos com ênfase para o atendimento escolar e implementação de unidades elementares, através de pessoal técnico, em localidades sem acesso aos serviços odontológicos. (PINTO, 1993)

A simplificação do atendimento, que se originou da corrente teórica da odontologia simplificada, era apontada como uma das alternativas para solucionar os problemas crescentes que os dentistas vinham enfrentando de mercado de trabalho. Foram feitas muitas críticas ao modelo como extremamente limitado, pois erigia-se como apêndice à odontologia tradicional, destinada às classes sociais marginalizadas, além disso, tratava da importância da prevenção, mas priorizava a prática curativa. (MENDES; MARCOS, 1985; NARVAI, 2002)

A implementação da odontologia simplificada no Brasil gerou o dilema quantidade versus qualidade, além de ser acusada de "extremamente limitada" por não questionar o modelo científico ou flexneriano, e possibilitou, pela crítica a esse fato, a emergência de outra versão dessa corrente, denominada de “odontologia integral”. (MENDES; MARCOS, 1985) Essa corrente crítica nasceu como consequência da adesão do Departamento de Odontologia da Universidade Católica de Minas Gerais ao Programa de Inovações em Ensino e Serviços Odontológicos, viabilizado pela Fundação Kellog, no âmbito do movimento de reorientação do ensino odontológico, corrente essa que já surge sob a dupla influência do processo de simplificação e também do desenvolvimento da prevenção odontológica no Brasil. (SOARES,2014)

Segundo Mendes (1986), a odontologia integral seria então um marco conceitual alternativo às práticas oriundas da odontologia científica e estaria articulado ao projeto transformador da sociedade denominado de Reforma Sanitária Brasileira. Nega dialeticamente a odontologia simplificada à medida que a incorpora como essencial para a extensão de cobertura, dando à tecnologia o status necessário e assume a prevenção, em sua versão ampla, como elemento 
constitutivo da prática profissional, articulado à desmonopolização do saber odontológico, e introduzindo o repasse do conhecimento técnico e científico à sociedade. A odontologia integral propunha reverter a concepção dita flexneriana e considerava como preparo inicial o conjunto de atos cirúrgico-restauradores para restabelecer a integridade do sistema estomatognático e, a partir desse equilíbrio recomposto, dar sequência ao conjunto de procedimentos preventivos para manter a "saúde restaurada". (MENDES, 1985) Entendia que esse processo de modernização da prática começaria a incidir no ensino e refletiria, por conseguinte na prática odontológica. (MENDES, 1996)

Através do desenvolvimento desse projeto, a Pontifícia Universidade Católica de Minas Gerais, em 1983, celebra um convênio de experiência docente-assistencial com o Instituto Nacional de Assistência Médica da Previdência Social (Inamps), através do seu coordenador específico de odontologia, Paulo Freire. A experiência serviu de modelo para muitas faculdades de odontologia e reduziu a quantidade de extrações realizadas nesse modelo em comparação ao praticado nos serviços do Inamps.

A sua origem estaria vinculada ao processo de modernização odontológica viabilizado pela OPAS em parceria com a Fundação Kellogg e possibilitou o desenvolvimento no Brasil da odontologia simplificada e da sua versão mais crítica, a odontologia integral. A crítica a essas concepções e seu processo de implementação foi fundamental para o aparecimento da SBC no Brasil, embora toda uma tendência internacional para a incorporação da odontologia preventiva pela influência da medicina preventiva norte-americana tenha sido empreendida pela OPS e pela Fundação Kellogg, com a orientação inclusive de agentes brasileiros.

\section{O espaço de luta da saúde bucal e a constituição da SBC no Brasil: aspectos históricos da sua emergência}

A incorporação da OPS consolidou-se nos anos 1980, com aparecimento da Associação Brasileira de Odontologia Preventiva (Aboprev), que atualmente denomina-se de Associação Brasileira de Odontologia de Promoção da Saúde. A Aboprev incorpora a experiência e a produção científica dos países escandinavos no que tange à cárie e doença periodontal, bem como suas bases etiológicas, além das experiências de prevenção aplicada à saúde pública naqueles países, cujos níveis de cárie haviam reduzido com a introdução das tecnologias preventivas nos serviços de saúde. A disseminação desse conhecimento sobre 
a etiologia da cárie e da doença periodontal pela Aboprev ganha robustez à medida que se evidencia o uso das tecnologias preventivas também para o setor privado. (SOARES, 2014)

Membros da Aboprev à época, com capital científico e simbólico já acumulado, tiveram papel fundamental na produção crítica que a Aboprev desenvolveu acerca de produtos odontológicos e também na formulação de políticas de saúde bucal no âmbito da prevenção. Naquele momento, destacam-se duas ações fundamentais: o fortalecimento da ação de fluoretação das águas de abastecimento público e a vigilância dos cremes dentais. Sua fundação foi significativa para o espaço de luta da saúde bucal e possibilitou a emergência de um espaço social ao interior do campo odontológico, que vai agregar muitos agentes preocupados com a falência do modelo curativo da odontologia de mercado. (SOARES, 2014)

A análise da OPS mostra uma composição mista que agregava professores e pesquisadores, tanto da área básica como aqueles originalmente da saúde pública tradicional. As principais influências teóricas nesse espaço foram aquelas de origem escandinava e que tratavam da "nova cariologia" e as estratégias de prevenção para o controle da cárie e da doença periodontal. Ainda que agregasse na área à ideia da odontologia social, a visão escandinava desenvolveu-se como concepção dominante, assumindo inclusive a hegemonia no campo odontológico entre as concepções que eram disputadas no referido espaço, embora subalterna a odontologia de mercado. Como concepção dominante, exerceu influência nas políticas e práticas de saúde bucal, notadamente a normatização dos cremes dentais no Brasil e a definição dos argumentos que foram definitivos para a expansão da fluoretação das águas de abastecimento público. Alguns dirigentes da Aboprev compunham o comitê de assessoramento da Divisão Nacional de Saúde Bucal, em 1989, e influenciaram algumas respostas do Estado brasileiro quanto à fluoretação dos cremes dentais e posteriormente dos enxaguatórios bucais, através da Portaria n. ${ }^{\circ}$ 17, da Divisão Nacional de Vigilância Sanitária de Medicamento, de 25 de outubro de 1989, e da Portaria n. ${ }^{\circ}$ 22, da Secretaria Nacional de Vigilância Sanitária, de 20 de dezembro de 1989.

Entre as principais contribuições Aboprev para as políticas de saúde bucal no Brasil, é possível identificar alguns pontos fundamentais:

a. Auxiliou na fundação de uma concepção voltada para a prevenção das doenças bucais em detrimento da odontologia privada ou de mercado e distinta da visão americana que vinha sendo discutida no Brasil; 
b. Auxiliou na formulação de políticas, especialmente da fluoretação das águas de abastecimento público e a regulamentação das normas para a vigilância e comercialização dos cremes dentais no Brasil;

c. Atuou no rompimento do modelo dentário escolar sespiano, por meio da inserção de outra visão sobre a cárie dental, mas manteve a concepção de geração perdida;

d. Influenciou as políticas de saúde bucal de caráter preventivo;

e. Fomentou a crítica ao mercado odontológico, ainda que as contradições tenham possibilitado um fenômeno denominado preventivismo, fenômeno que corresponde ao "abuso" das tecnologias preventivas, com valor de mercado, em nome do qual as atividades assistenciais chegavam a se desestruturar.

f. Auxiliou a inserção de medidas preventivas no setor privado, ainda que essa incorporação se deva à transformação dessas em mercadoria.

g. Desenvolveu duas subáreas da odontologia: a cariologia e a periodontia no Brasil.

Nos anos 1990, com o avanço da Reforma Sanitária Brasileira (RSB) e a inclusão de novos temas no espaço social em questão, a Aboprev, como entidade coletiva, reduz a sua capacidade de influenciar as políticas e práticas de saúde bucal. Nesse particular, passa-se a discutir a democratização, a descentralização, a municipalização, a integração de recursos, a criação de um SUS entre outras questões que se tratavam de temas próprios da saúde coletiva e não do campo odontológico. Nesse espaço, que tinha como concepção dominante o controle e tratamento preventivo da cárie e da doença periodontal, conviveu de modo dominado, uma concepção que nasce nesse período atrelado a um grupo de agentes com prática de saúde pública mais orgânica e cuja aproximação com a RSB levou a problematizar certas questões desse espaço social híbrido e a pensar em fundar um espaço novo. Esse grupo, considerado dominado, que implementava as políticas de saúde bucal nos diversos estado e municípios do país, envolveu-se em vários movimentos no espaço social e vieram a disputar suas ideias com a concepção dominante até então, representada pela Aboprev. (SOARES, 2014)

O primeiro deles foi o Encontro Científico dos Estudantes de Odontologia (Eceo), retomado em 1979, pois fora suspenso pelo Golpe Militar de 1964. Sua 
origem remonta ao ano de 1954 e foi responsável pela conformação da União Nacional dos Estudantes, que envolviam diretórios acadêmicos dos quais participaram vários dos agentes engajados nas lutas pela saúde bucal pública. Tinha como propósito principal fomentar nos estudantes de odontologia a capacidade crítica acerca das questões fundamentais no campo odontológico, especialmente a prática odontológica hegemônica. (SERRA, 1998; SOARES, 2014)

No ano de 1984, surge o Movimento Brasileiro de Renovação Odontológica (MBRO). Correspondeu a um movimento social da categoria odontológica a fim de democratizar as entidades odontológicas e representava o movimento de Reforma Sanitária Brasileira ao interior da odontologia. Teve como precursor o MBROESP, movimento dos odontologistas do estado de São Paulo, que visava inserir-se nas entidades odontológicas, notadamente Conselho Regional de Odontologia de São Paulo (CROSP), Associação Paulista de Cirurgiões Dentistas (APCD) e Sindicato dos Odontologistas. (SOARES, 2014)

Suas principais pautas foram: a luta pelas liberdades políticas, a posição contrária à mercantilização da prestação de serviços odontológicos, a defesa da expansão desses serviços pela municipalização, o controle das instituições pela população organizada, aumento de recursos para a assistência odontológica com uso de tecnologia nacional, recursos humanos adequados à realidade socioeconômica e epidemiológica do país e sua justa remuneração, defesa do ensino público e gratuito em todos os níveis e campos do saber odontológico e a democratização das entidades odontológicas. Menciona ainda que, nas diretrizes do MBRO, divulgadas em 1985, constavam a luta permanente por liberdades políticas, a implantação de um SUS responsável pelos serviços odontológicos em todo o país, o repúdio frontal a qualquer tipo de mercantilização dos serviços odontológicos, ênfase na municipalização e no controle das instituições pela população organizada, a utilização de recursos humanos, materiais e financeiros para desenvolver uma odontologia adequada às necessidades socioeconômicas e epidemiológicas do país, a defesa de tecnologia nacional na pesquisa e produção de equipamentos, materiais e medicamentos de uso odontológico, a defesa do ensino público e gratuito em todos os campos do saber odontológico, a luta pelo fortalecimento e democratização das entidades odontológicas e o estímulo à promoção e participação das discussões acerca da prática odontológica brasileira. (SOARES, 2014)

O MBRO também representou um espaço de militância e formação política dos cirurgiões dentistas que vieram a se envolver nos serviços públicos de saú- 
de (Figura 1). No período das eleições diretas para governadores, esse movimento propiciou a ocupação de posições nas várias coordenações municipais e estaduais de saúde bucal por muitos dos seus militantes do movimento sanitário, cujas dificuldades com a implementação da Política de Saúde Bucal levaram à discussão coletiva dessas questões. A Política de Saúde Bucal representou o dispositivo para construir a crítica mais sistematizada ao campo odontológico, uma crítica de origem nos serviços de saúde. Sua influência cresce à medida que se articula com as questões mais gerais da Reforma Sanitária e, como consequência dessa articulação, em 1986, foi publicada a revista específica do Centro Brasileiro de Estudos em Saúde (Cebes) sobre as "questões odontológicas" (Figura 2).

Figura 1 - Boletim do MBRO de setembro de 1985

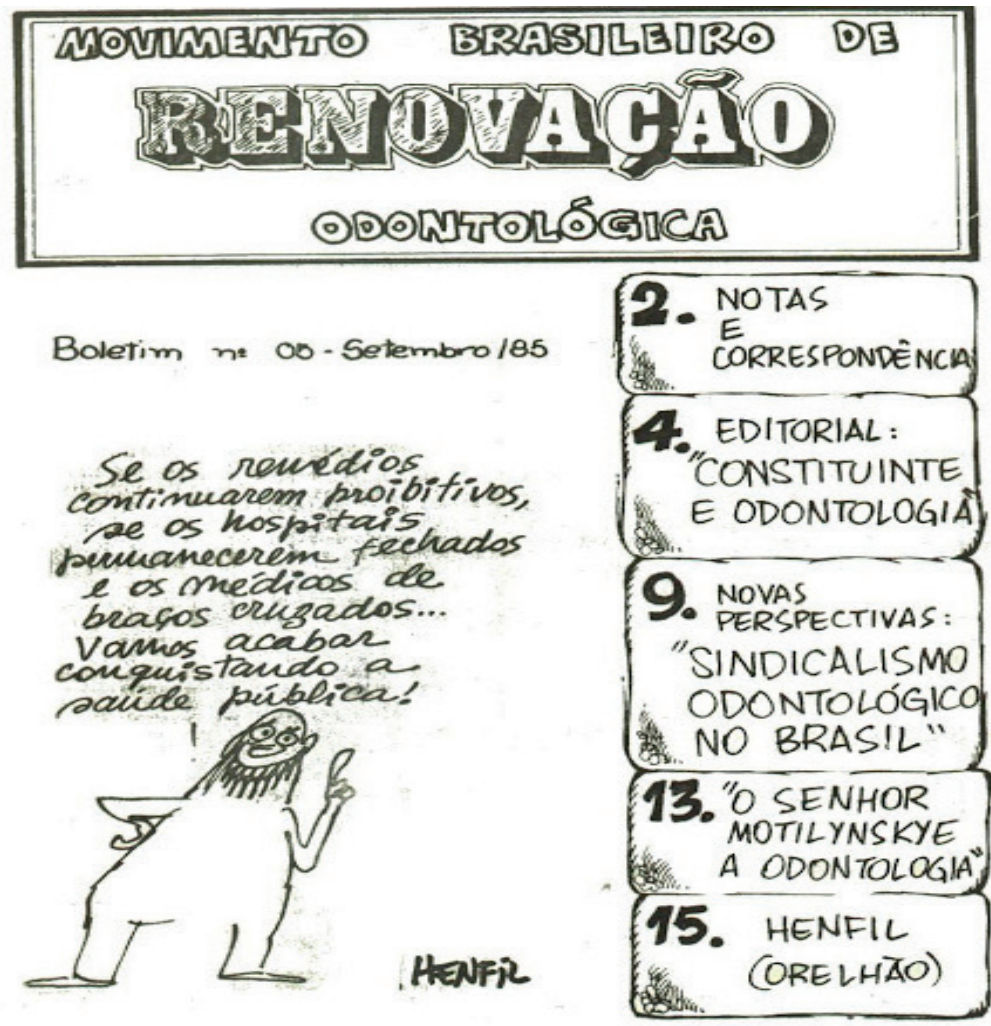

Fonte: (O) Dentista e o mundo do trabalho (2011). 
Figura 2 - Capa e expediente da revista Saúde em debate

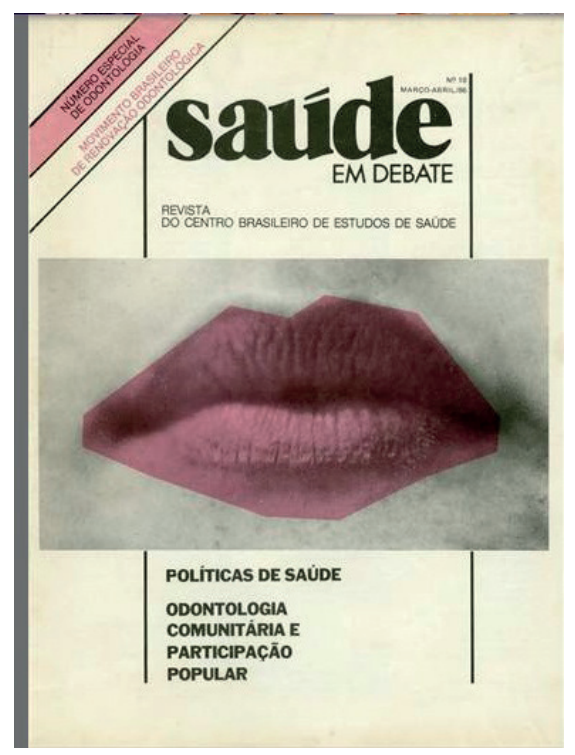

\section{Editorial}

O Centro Brasileiro de Estudos de Saúde e o Movimento Brasileiro de Renovação Odontológica colocam em circulação este número especial da REVISTA DO CEBES, dedicado à Odontologia.

A importância que, entre nós, o estudo das questões gerais da saúde tem merecido nos últimos anos, e a emergência de uma Sociologia vinculada à saúde bucal, justificam a necessidade desta edição.

Talvez para muitos colegas o conteúdo da Revista cause estranheza. As publicações especializadas que temos à nossa disposição são em geral publicações técnicas com forte inclinação para os aspectos biológicos - clínicos ou labororatoriais.

Julgamos existir uam lacuna entre a formação universitária - científica e técnica em sua essência - e a realidade social na qual estamos inseridos.

Faz-se, portanto, necessário que a investigação em saúde bucal se volte para essa realidade e que, incorporando as ciências sociais e sua metodologia de análise, busque equacionar os problemas de saúde oral da comunidade e analise as relações que a cirurgia-dentista com ela mantém.

É nosso desejo, sinceramente, que este número da Revista do CEBES ajude um pouco nesta tarefa.

Movimento Brasileiro de Renovação Odontológica

Dezembro de 1985.

Fonte: Saúde em Debate (1986). 
As dificuldades na implementação das políticas de saúde bucal nos níveis locais e estaduais levaram os agentes responsáveis por elas a criarem um fórum de debate onde as questões relativas ao contexto do sistema público de saúde fossem discutidas. Esse fórum foi denominado de Encontro Nacional dos Administradores e Técnicos dos Serviços Públicos Odontológicos (Enatespo), em 1986, e reunia lideranças envolvidas na luta pela saúde bucal pública e de qualidade. Os Enatespos acontecem até os dias de hoje e permanecem como um espaço de discussão das pautas dos serviços de saúde. Incorporou a partir da década de 1990 o Congresso de Saúde Bucal Coletiva, fora dos moldes acadêmicos tradicionais, embora possuam a contribuição de agentes do campo científico. (SOARES, 2014)

Em 1988, mais uma iniciativa para a politização do campo odontológico se concretiza na fundação de Federação Interestadual de Odontologistas (FIO). Essa entidade corresponde a uma entidade sindical para representação dos interesses da corporação odontológica, criada à época sob o argumento de que as demais entidades odontológicas eram mera formalidade. Agregaram vários dirigentes de sindicato odontológico, integrado aos demais trabalhadores de saúde e foi um importante veículo de formação política e técnica desses dirigentes. (SOARES, 2014) Sua fundação esteve relacionada a uma conjuntura nacional de grande mobilização política e social, vindo de uma ampla participação da sociedade civil e dos trabalhadores em especial, na Assembleia Nacional Constituinte. Sua fundação ocorre às vésperas das primeiras eleições diretas pós-Golpe Militar para presidente da República, que ocorreriam no ano seguinte (1989). Surgiu da necessidade de se construir uma entidade sindical que representasse os interesses mais legítimos da categoria odontológica, evoluindo de uma representação nacional meramente burocrática e formal, até então existente, distante das lutas da categoria. (SOARES, 2014)

Associaram-se, de imediato, a esse projeto vários sindicatos de odontologistas (Distrito Federal, Goiás, Espírito Santo, Minas Gerais, Mato Grosso do Sul, Mato Grosso, Rio de Janeiro, Rio Grande do Norte e Manaus) que tinham um compromisso político com a construção de um novo sindicalismo odontológico, integrado às lutas dos demais profissionais de saúde e trabalhadores brasileiros. Teve um papel importante em diversas ações na área de saúde, e no espaço social específico aqui discutido: atuou na luta pela aprovação das leis orgânicas da saúde e nas eleições diretas para presidente de 1989; na elaboração da tabela nacional de convênios e credenciamentos e em muitas mobilizações 
que culminaram em acordos salariais que envolveram sindicatos dos odontologistas. Também participou das Conferências Nacionais de Saúde e de Saúde Bucal e nas lutas pelo SUS. Destacou-se também nas lutas que culminaram com o impeachment do presidente Collor e outras conquistas para a categoria odontológica, tais como: duplo vínculo e equacionamento da jornada de trabalho. (SOARES, 2014)

Vale mencionar que, entre os papéis exercidos pela FIO, destacaram-se: a formação técnica e política de muitos coordenadores de saúde bucal no Brasil, bem como na influência das políticas de saúde bucal à época; a atuação no parlamento e nas negociações salariais com os setores público e privado; a articulação com as demais entidades odontológicas em todas as pautas que são do interesse dos cirurgiões-dentistas; a parceria com os demais profissionais de saúde e outras categorias dos trabalhadores brasileiros pela construção de uma sociedade em que todos tenham direito a condições dignas de saúde; além de possuir uma atuação na representação nos conselhos de saúde. (SOARES, 2014)

Às mobilizações oriundas do MBRO, Eceos, Enatespo e FIO agregaram-se professores universitários, coordenadores, técnicos de saúde bucal e estudantes de odontologia que foram se envolvendo nos processos políticos mais amplos, como a Reforma Sanitária Brasileira. A ampliação desse movimento constituiu importantes polos críticos da saúde bucal em vários locais do país a exemplo de Brasília, São Paulo, Belo Horizonte e Curitiba, embora outros estados com menor vulto também tenham participado desse processo. Esse processo de politização e a defesa de uma bandeira de luta comum articulada aos movimentos, culminaram com a realização da $1^{\text {a }}$ Conferência Nacional de Saúde Bucal, em 1986, e suas respectivas etapas estaduais que, na discussão local, abarcou diversos agentes que atuaram como delegados na Conferência Nacional. (SOARES, 2014) Ademais, possibilitou a emergência de críticas ao ensino e as práticas odontológicas em curso.

Nesse evento, houve a discussão da situação de saúde bucal e dos principais problemas inerentes ao campo odontológicos. Entretanto, a principal reivindicação dessa conferência consistia na entrada da odontologia no SUS e no Movimento de Reforma Sanitária Brasileira. Essa conferência foi o marco para o processo de politização do campo odontológico, dada à magnitude, extensão e visibilidade que adquiriu. (SOARES, 2014) 
Já no final dos anos 1990, as críticas continuam a se processar, porém concentrando-se no preventivismo, fenômeno decorrente da exacerbação dos usos da odontologia preventiva, e do crescimento da influência da OPS, consoante inclusive com o crescimento da atuação da Aboprev no cenário brasileiro; e da incorporação das práticas de odontologia preventiva, seja nos serviços públicos, seja nos serviços privados, num contexto de implementação do SUS.

Pode-se afirmar que a década de 1980 foi decisiva para o desenvolvimento da crítica à odontologia, seu campo e suas práticas tradicionais. Conformou-se, à época, espaços de militância, de crítica e de reflexão que vão contribuir, na década seguinte, para a origem da SBC no Brasil. Houve refluxo do MBRO no início dos anos 1990, quando muitos dentistas integrantes do movimento passaram a ocupar posições no âmbito do Estado e deixaram de participar mais efetivamente desses espaços de militância. Alguns agentes atribuem essa desmobilização à emergência da FIO, instância formal de intervenção nas políticas de saúde bucal, que passa a influenciá-las. (SOARES, 2014)

Com a aproximação dos agentes de saúde bucal da Reforma Sanitária Brasileira, particularmente por meio do envolvimento com a fundação ou participação no Cebes, houve, por conseguinte, a aproximação com a Saúde Coletiva Brasileira, entendida como um movimento crítico que estabelecia rupturas com a saúde pública tradicional. Esse movimento crítico trazia também algumas reinvindicações tais como: a conformação de um sistema universal de saúde, democratização da saúde, direito à saúde, entre outras questões. Dessa aproximação, emergiram também as críticas às práticas de saúde bucal desenvolvidas no sistema público de saúde e a discussão de integração das práticas de saúde bucal no âmbito do SUS.

Como produto dessa inserção, vários agentes do antigo espaço da OPS vão se aproximando dos referenciais teóricos da saúde coletiva, naquele momento, prioritariamente baseados no materialismo histórico de Karl Marx. Por sua vez, essa aproximação, constituiu uma rede de relações que deram origem à SBC no Brasil. Essa origem pode ser atribuída também a aproximação de agentes dos serviços de saúde no estado de São Paulo e às discussões e debates realizados ao interior do Instituto de Saúde de São Paulo.

No período em que ocorreram eleições democráticas para governador, assume o governo estadual de São Paulo o governador Franco Montoro, e a Secretaria Estadual de Saúde passa a ser conduzida por João Yunes, professor da Faculdade de Saúde Pública da Universidade de São Paulo, pediatra, sanitarista, que 
por sua vez convida Paulo Capel Narvai para assumir a Coordenação de Saúde Bucal do estado de São Paulo. Sua assunção ao cargo possibilitou a articulação com os coordenadores municipais de saúde bucal para o compartilhamento dos problemas acerca dos serviços públicos de saúde bucal do estado e a aproximação com o Núcleo de Dentistas dos Sindicatos de São Paulo. A tônica desse governo era a desconstrução da lógica da odontologia escolar que imperou no serviço de saúde de São Paulo até então. (SOARES, 2014)

Em 1985, Paulo Capel sai da referida coordenação e vai para o Instituto de Saúde de São Paulo, onde também encontra Carlos Botazzo e outros agentes que se envolviam em debates críticos acerca das políticas, práticas e correntes teóricas em saúde bucal em curso nos serviços de saúde pública. Ou seja, constitui-se um grupo de agentes que protagoniza um conjunto de discussões que tinha como objeto "as práticas de saúde bucal nos serviços de saúde”, notadamente o foco nos escolares, a odontologia de mercado e a simplificação e suas modificações. Nesse local, passou a funcionar encontros periódicos de discussão do andamento do curso das Políticas de Saúde Bucal e das principais experiências em andamento. Nesse particular, destacaram-se: a experiência de simplificação coordenada por Sérgio Pereira em Brasília, a experiência de Minas Gerais com a odontologia integral liderada por Eugênio Vilaça e Badeia Marcos e o próprio Programa Estadual de Odontologia Escolar de São Paulo. (SOARES, 2014)

Os encontros no Instituto de Saúde representaram um espaço de crítica e de reflexão acerca da odontologia na prática pública. O primeiro produto concreto dessas críticas surge em 1988, em um texto preparado por Marco Manfredini, Paulo Capel, Paulo Frazão e o Carlos Botazzo, que utiliza o termo SBC e traz uma reflexão teórica e crítica acerca das correntes alternativas em odontologia, em especial à odontologia integral. (BOTAZZO et al, 1988) Esse texto específico acerca da SBC foi produzido pelos agentes paulistas para um curso de formação de pessoal auxiliar em odontologia. Nesse manuscrito, os autores debruçam-se fundamentalmente sobre a construção do conceito de saúde, para apontar a necessidade de intervenção sobre os determinantes sociais e especialmente sobre a prática da odontologia integral. A crítica às demais práticas de saúde bucal vão sendo incorporadas por esses agentes em outros textos posteriores do Instituto de Saúde. (SOARES, 2014)

A negação dos referenciais com o campo odontológico (NARVAI, 1994) e a reflexão crítica das práticas em serviços de saúde, mais especialmente da odon- 
tologia integral, é que deram as bases conceituais para a SBC, já que as bases políticas foram construídas no Eceo, MBRO, Enatespo e FIO. (SOARES, 2014)

Contribuíram para a emergência da SBC: a conjuntura política da democratização do país, que possibilitou a realização de eleições diretas para governos estaduais e, por conseguinte, a criação de espaços democráticos em vários estados, incluindo São Paulo, que já possuía grupos de sanitaristas nos seus quadros. A democratização da saúde permitiu a criação de vários grupos de resistência e luta, incluindo nesse bojo grupos de saúde bucal para a politização da odontologia e seus agentes. Também a implantação dos governos democráticos favoreceu a ocupação de coordenações de saúde bucal por egressos desse processo político ocorrido no âmbito odontológico, e, de modo muito particular, as discussões sobre a prática odontológica nos serviços de saúde realizada no Instituto de Saúde de São Paulo. Acresce-se a essas questões a aproximação dos agentes da SBC com outros agentes da saúde coletiva e com a Reforma Sanitária Brasileira, o que potencializou a reflexão dos agentes da saúde bucal. (SOARES, 2014)

\section{Saúde bucal coletiva, o que é isso afinal?}

Pode-se afirmar que a SBC é produto de um processo histórico de construção de uma práxis política desencadeada ao longo da década de 1980, de uma crítica às correntes odontológicas em curso no mesmo período e também uma proposta de intervenção sobre os problemas de saúde bucal da sociedade.

A proposta de prática odontológica voltada para o tratamento dentário restrito a crianças em idade escolar para o enfrentamento da cárie dentária pode ser entendida como um dos primeiros objetos de crítica. Esse modelo de prática odontológica orientava-se pelas ideias de odontologia sanitária e durante muito tempo foi a principal influência para a organização dos serviços de saúde bucal no Brasil. (NIKEL, 2008)

Apesar da crítica à odontologia sanitária e à implantação de serviços nessa direção, a SBC toma como referência a odontologia integral e a odontologia simplificada.

A odontologia integral pode ser entendida como uma versão crítica da odontologia simplificada, experimentada e teorizada pelo grupo acadêmico de Minas Gerais. A crítica processava-se, de um lado, sobre a odontologia simplificada, especialmente sobre a "excessiva simplificação" que conformou um programa voltado para pobres, com tecnologia simples para gente simples; e, do 
outro, sobre a odontologia científica que se expressava no "espelho" da medicina e tendia a parcelar o corpo entendendo-o como máquinas. (MENDES, 1986)

No caso da simplificação, o ocasionamento de certo dilema pelo desenvolvimento de sua prática odontológica traduzido em uma prática para pobres, com baixa qualidade e utilização da prevenção como retórica, tornou-se "apêndice" da prática tradicional. Estaria então fomentando uma prática odontológica que expressava o exercício de uma política social excludente, discriminatória e que consolidava a desigualdade entre classes sociais. (MENDES, 1986)

E, no caso da odontologia científica, suas características coadunam com o mecanicismo entendendo o corpo como máquina, coerente com o modo de produção dominante, reconhecendo a natureza biológica das doenças e suas causas; o individualismo elegendo o indivíduo como objeto da prática profissional e como responsável pela própria doença; a especialização por meio da fragmentação do processo de trabalho, que estimula a acumulação do capital; a exclusão de práticas alternativas, bem como a tecnificação do ato odontológico, concentrando-se na odontologia curativa tal qual a odontologia de mercado (NARVAI, 1994) e a excessiva especialização. (MENDES, 1986)

Essas críticas assentavam-se nas ideias veiculadas no Movimento de Reforma Sanitária Brasileira que trazia um conjunto de proposições tendo em conta as transformações da sociedade e em particular um sistema de saúde universal e com princípios de justiça social. (ESCOREL, 1998; PAIM,2008) Daí que esse modelo de prática odontológica em curso torna-se incoerente com os seus princípios.

A proposta da odontologia integral (MENDES, 1986) apresentava-se como uma proposta consoante com os princípios da Reforma Sanitária Brasileira, entendendo-a como um projeto democrático para a saúde e alternativo ao projeto sanitário hegemônico. Este se expressava no Sistema Nacional de Saúde e nas práticas curativas de saúde derivadas desse sistema. Nesse particular, entende o conceito amplo de saúde evitando a sua redução às práticas médico-odontológicas preventivas, curativas ou reabilitadoras, ofertadas nos serviços de saúde, sendo, portanto, resultante da ação articulada dos diferentes setores como educação, alimentação e nutrição, lazer, esporte, terra, transporte entre outros.

A odontologia integral coloca-se como uma possibilidade teórica e prática substitutiva à odontologia científica, admitindo três pilares centrais: a) atitude preventiva; b) simplificação e adequação de atos e técnicas, equipamentos, materiais, métodos e sistemas de trabalho; e c) desmonopolização do saber e do 
fazer pela educação, instrução e repasse do conhecimento à sociedade. Cabe salientar que essa concepção busca inserir a questão da prevenção ${ }^{2}$ numa perspectiva ampliada, evitando a dicotomia curativo versus preventivo. (MENDES, 1986)

Ao apresentar esses elementos críticos, Mendes (1986) aponta os seguintes componentes estruturais e ideológicos para a odontologia integral:

- Coletivismo - consiste na integração das práticas promocionais, preventivas e curativas, recompondo a integralidade do ato odontológico, sob a hegemonia do preventivo e do promocional;

- Descentralização da atenção odontológica - substitui a concentração de recursos propostos pela odontologia científica pela ideia de níveis de atenção; pensa-se na universalização do acesso a todos os níveis e no deslocamento do poder decisório para a periferia do sistema;

- Inclusão de práticas odontológicas alternativas - capta no discurso popular as práticas odontológicas alternativas para integrá-las dialeticamente ao discurso oficial.

- Equipe de saúde - a equipe odontológica substitui o especialismo, onde se distribuirá as funções odontológicas por distintos recursos humanos, incluindo a comunidade.

- Tecnologia apropriada - a sofisticação é substituída pelo uso de tecnologia apropriada para os níveis de atenção a um custo mínimo;

- Participação comunitária - Participação ativa da comunidade nos processos educacionais e da prática odontológica, como condição básica para a sua democratização.

A odontologia integral seria então uma prática, ecologicamente orientada, alternativa à prática odontológica flexneriana, que tem como objetivo último a manutenção da saúde, e que é caracterizada pela natureza coletiva do seu objeto, pela ênfase na prevenção no seu significado mais amplo, pela simplificação dos elementos da prática profissional, com a utilização intensiva de tecnologia

\footnotetext{
2 Para Arouca (2003, p. 36), a atitude preventiva consistia em movimento ideológico que, partindo da crítica à prática médica, propõe uma mudança, baseada na transformação da atitude médica para com o paciente, sua família e a comunidade.
} 
apropriada e pela desmonopolização do saber odontológico. (MENES, 1986; p. 545)

De fato, a odontologia integral incorpora alguns elementos da Reforma Sanitária, especialmente a participação comunitária, integração de práticas de saúde promocionais, de prevenção das doenças bucais e de assistência, organizadas em níveis de atenção. Ela recompõe a integralidade do ato odontológico, porém sua construção epistemológica ancora-se no campo odontológico. Assim, a odontologia integral nasce como alternativa ao projeto conservador oriundo da odontologia científica, incorporando três diretrizes: a simplificação, sem, contudo, chegar à excessiva simplificação e a desmonopolização, incorporando o pessoal auxiliar. Nesse caso, o ponto de partida permanece situado no campo odontológico, e essa proposta apresenta-se como síntese às propostas e projetos em curso. Qual a distinção entre a odontologia integral e a SBC, então?

Em primeiro lugar, é importante destacar que a SBC propõe um processo de desodontologização. A SBC parte inicialmente do questionamento do que seria o social. O social, geralmente apresenta-se como "um conjunto de condições relativas apenas a ambiente e à família” e, em geral, ignora-se "as relações dinâmicas e contraditórias que os homens estabelecem entre si ao trabalharem" (BOTAZZO et al., 1988, p. 30), que engloba os grupos e classes sociais.

Assim, para a SBC, o social corresponderia ao cenário, o espaço ou local onde os homens, os grupos e as classes sociais estabelecem relações entre si, e no qual a cultura, a ciência, a moral e todos os demais valores humanos são produzidos. É por isso que cada sociedade humana (cada povo), em cada época específica, produz coisas diferentes umas das outras: literatura, arquitetura, música, vestuários, alimentação, ciência, moral, hábitos etc. (BOTAZZO et al., 1988, p.30)

Nessa perspectiva, a questão principal consiste na inserção da análise do social a partir da sociedade e suas contradições. Há que se reconhecer a sociedade em sua totalidade social, uma leitura de classe. (BOTAZZO, 1994) Em segundo lugar, aparece nessa construção a crítica da abordagem sobre os problemas de saúde bucal da população, especialmente a cárie dental. Para a SBC, esta fora analisada historicamente a partir de uma abordagem que versa da unicausalidade à visão ecológica que produz. Por conseguinte, um conjunto de práticas odontológicas que se utilizam da prevenção e que se expressam nas propostas da época, notadamente a odontologia simplificada e odontologia integral e 
também a OPS. O resultado é a integração de práticas educativas, preventivas e curativas e a racionalização do trabalho odontológico pela simplificação.

A SBC propõe uma visão não ecológica da cárie, apresentando a abordagem da determinação social como alternativa para a compreensão do processo saúde doença bucal. Reforça essa tese ao apontar que, para a Odontologia ser integral, seria cada vez menos odontologia. Na perspectiva da determinação social, as práticas de saúde bucal envolveriam atividades clínicas e não clínicas, e, por esse motivo, não poderiam estar no campo odontológico e sim na saúde coletiva. Envolveria ações sobre as causas das doenças e suas distintas naturezas, sejam elas biológicas, econômicas, políticas ou sociais. Não se trata, portanto, de assistência odontológica cujo compromisso é com o individual e envolveria práticas de atenção à saúde bucal, abarcando práticas de saúde em outros espaços para além da boca. (BOTAZZO, 1992; 1994; BOTAZZO et al., 1988)

Seus argumentos estariam ancorados também na crítica ao conceito de saúde como "completo bem-estar" (OMS, 1946), apresentando a impossibilidade dessa perspectiva já que a saúde não poderia ser universal, uma vez que nem todos os grupos e classes possuem as mesmas condições materiais de existência. Isso porque a inserção de classes sociais define condições materiais de existência, formas de consumo, de produção relacionada à saúde, cuja assunção ao bem-estar físico, mental e social. Sendo assim, a abordagem admite que essa condição estaria condicionada, por sua vez, ao pertencimento do grupo social, que também define o nível de escolaridade, a ocupação, o acesso à informação, a participação nas decisões políticas, entre outras questões. Não oculta, portanto, as contradições existentes entre grupos e classes sociais. (BOTAZZO et al., 1988)

Esses argumentos, introduzidos pela leitura do processo saúde doença bucal, a partir da determinação social, colocam a politização do agente etiológico como elemento central da SBC, que consiste em considerar que a boca, como parte do indivíduo, é social e historicamente determinada. Nesse caso, a abordagem das práticas odontológicas deve contemplar a questão das classes sociais para a leitura das necessidades de saúde. Sabe-se que a cárie acomete, em geral, o sorriso dos proletários e a ciência odontológica leva à mutilação e aponta a necessidade de se politizar também a leitura dos dados e indicadores, politizando, por sua vez, a relação entre os números e a realidade social, o que requer novas organizações de serviços públicos odontológicos. (BOTAZZO, 1994) 
Assim, as práticas de saúde bucal pautadas na SBC vinculam-se ao campo de práticas coletivas em saúde, requerendo interdisciplinaridade e o envolvimento em ações de natureza coletiva, entendendo-as como expressão das relações políticas entre os vários atores sociais e envolvendo uma equipe de saúde bucal. Dizem respeito a atividades grupais em interação nos espaços socialmente reconhecidos - organizações e instituições que são áreas por excelência da desmonopolização do saber, ou seja, democratização do conhecimento e também representam espaços privilegiados do exercício da cidadania. Trata-se, portanto, de aproximar as práticas de saúde bucal às demais práticas de saúde e de superar a clientela escolar e a prestação de serviços públicos apenas para pobres. (BOTAZZO, 1992)

Segundo Botazzo (1994), as práticas de SBC seriam então "práticas direcionadas ao social como local de produção social das doenças bucais e suas tecnologias que visam curar o paciente na diminuição e controle dos processos mórbidos na dimensão coletiva”. (BOTAZZO, 1994· p. 57)

A SBC teria como objeto os determinantes sociais do processo saúde doença bucal, cuja análise tomaria a cárie como produto das contradições da sociedade que ilustra as diferenças entre classes. Seria também uma prática que envolveria distintas naturezas: políticas, econômicas, sociais e técnicas. Abarcaria práticas de assistência odontológica propriamente dita e não odontológicas, políticas, técnicas e sociais realizadas em espaços coletivos que seriam práticas de atenção à saúde bucal desenvolvidas, fundamentalmente, por uma equipe de saúde bucal. (SOARES, 2014)

\section{Saúde bucal coletiva: possíveis contribuições para a formulação de políticas de saúde bucal no Brasil}

Após compreender o percurso sobre os antecedentes, as respostas do Estado brasileiro, os aspectos históricos da gênese e as principais propostas da saúde bucal coletiva, cabe aqui identificar a existência ou não de possíveis contribuições para políticas nacionais de saúde bucal. Para isso, tomar-se-á como ponto de partida a Política Nacional de Saúde Bucal (PNSB) de 1989 e o Programa Nacional de Controle da Cárie Dentária (Precad) do mesmo período, passando pelos Procedimentos Coletivos (PC), a entrada da saúde bucal no Programa de Saúde da Família (PSF) e por fim, a PNSB, de 2004.

A PNSB e o precad foram lançados em 1989, na gestão de Vitor Gomes Pinto, na Divisão Nacional de Saúde Bucal do Ministério da Saúde. 
O objetivo geral da Política aprovada pela Portaria n. ${ }^{\circ}$ 613/GM, de 13 de junho de 1989, foi "proporcionar melhores níveis de saúde bucal à população brasileira e ampliar o acesso aos serviços odontológicos disponíveis". (BRASIL, 1989a) Os objetivos específicos da política tratavam de: (i) reduzir em 50\% a prevalência de cárie dental em crianças e adolescentes no prazo de 10 anos; (ii) combater as doenças periodontais, aumentando os índices de higidez em todas as faixas etárias; (iii) reduzir significativamente os índices de edentulismo e o número de extrações na população jovem e adulta; (iv) democratizar o acesso aos serviços odontológicos por meio do aumento da oferta, da atenção a grupos prioritários e da ampla participação da comunidade; (iv) estruturar uma rede nacional de serviços básicos em saúde bucal; (v) promover ações continuada de educação para a saúde bucal, de forma a nortear todas as atividades do setor; (vi) apoiar a formação de recursos humanos de nível superior, técnico e auxiliar compatíveis com o quadro epidemiológico, com a situação econômico social e com os padrões de crescimento populacional do país. (BRASIL, 1989a)

Os serviços deveriam se organizar também por prioridades. Serviços emergenciais para todos e precederiam os demais; em segunda prioridade, as ações preventivas e de educação em saúde; em terceiro lugar, "serviços recuperadores básicos" como atenção à cárie e doença periodontal, ao grupo de 6 a 12 anos; em quarta escala, estariam as especialidades básicas para atenção endodôntica, periodontia, protética, cirúrgica e ortodôntica para os grupos de 6 a 12 anos e 13 a 19 anos participantes de um sistema organizado; e, na quinta posição, serviços especializados de maior complexidade. (BRASIL, 1989a)

O Programa de Prevenção da cárie dentária (Precad) foi um subprojeto da primeira política e traz planos mais detalhados de como combater a cárie dentária na década de 1980. O documento tinha como objetivo geral reduzir em 10 anos 50\% da cárie dentária na população brasileira. A proposta era atingir o máximo de pessoas possíveis. Os subprogramas eram: a) fluoretação de água de consumo público; b) uso tópico de fluoretos; c) opção pela adoção de géis fluoretados aplicados em moldeiras na época das campanhas de vacinação para atingir o máximo de pessoas; d) vigilância e controle - normas para controle e registro de produtos; e) formação de recursos humanos; f) estudos epidemiológicos e biológicos. (BRASIL, 1989b)

Tanto a PNSB quanto o Precad sofreram influências da odontologia sanitária, assim como da OPS, com influência escandinava. Citam-se também os métodos preventivos de fluoretação em massa por via tópica e sistêmica, foco nos recur- 
sos humanos auxiliares, priorização de grupos e de serviços. Observa-se relação com a OPS nos métodos de vigilância e controle da cárie dentária, assim como nas normas para controle e registro de produtos, além de um foco bastante voltado para dentro da odontologia e suas medidas de enfrentamento possíveis à época dos problemas de saúde bucal da população brasileira. A democratização do acesso era direcionada para grupos prioritários, apesar da política citar os princípios finalísticos do SUS.

Os PC foram criados a partir da Portaria n. ${ }^{\circ}$ 184, de 9 de outubro de 1991, na gestão de Sérgio de Carvalho Weyne, na Coordenação de Saúde Bucal, passando a entrar em vigor em janeiro de 1992. Os PC foram criados para substituir os Tratamento Completados (TC) no repasse de recursos federais para estados e municípios. (CARVALHO et al., 2009) Existiam três tipos de PC:

“a) Procedimentos Coletivos I (PC-I) - Conjunto de procedimentos de promoção e prevenção em saúde bucal, de baixa complexidade, dispensando equipamentos odontológicos, desenvolvidos integralmente em grupos populacionais previamente identificados. Componentes: 1) Exame Epidemiológico - Levantamento epidemiológico realizado anualmente com objetivo de medir modificações no quadro epidemiológico das doenças bucais no grupo atendido; 2) Educação em Saúde - Atividades educativas realizadas trimestralmente, enfatizando os cuidados com a saúde bucal (dieta, desenvolvimento orofacial, aleitamento materno etc.); 3) Bochechos Fluorados - Realizados semanalmente, com solução de fluoreto de sódio a 0,2\%, ao longo do ano (mínimo de 25 aplicações); 4) Higiene Bucal Supervisionada - Compreende evidenciação de placa bacteriana e escovação supervisionada com pasta fluoretada, realizadas, no mínimo, a cada três meses, ao longo do ano, fornecendo a cada participante uma escova de dentes e um tubo de pasta fluoretada de 100 ou 90 g a cada três meses. b) Procedimentos Coletivos II (PC-II) - Consiste no conjunto de procedimentos constantes no PC-I acrescidos de: 1) Exame Clínico para Diagnóstico; 2) Terapêutica Intensiva com Flúor. c) Procedimentos Coletivos III (PC-III) - Componentes: Consiste no conjunto de procedimentos constantes nos códigos anteriores (PC-I e PC-II) acrescidos de: 1) Remoção de Cálculo e Polimento Dentário; 2) Escariação e Selamento de Cavidade, com Cimento Provisório; 3) Aplicação de Selantes; 4) Remoção de Raízes Residuais; 5) Aplicação de cariostático. (BRASIL, 1991; CARVALHO et al., 2009) 
Os PC apresentam uma forte relação com a OPS. Destaca-se o modelo de educação em saúde não centrado apenas nas escolas, mas nos grupos de pessoas em comunidades ou até mesmo nos serviços, assim como as ações de controle da cárie dentária de influência escandinava, mas ainda um forte apelo para ações de prevenção voltadas para o público infanto-juvenil.

A partir de 2000, com a Portaria n. ${ }^{\circ}$ 1.444, de 28 de dezembro deste ano, estabeleceu-se inclusão da saúde bucal no PSF e criação de incentivo financeiro para suas ações. No ano seguinte, a Portaria n. ${ }^{0}$ 267, de 6 de março de 2001, regulamentou a anterior e apontou as diretrizes de inclusão da saúde bucal na Estratégia Saúde da Família (ESF). A Cirurgiã Dentista (CD) que ocupava a coordenação nacional à época era Sônia Dantas. A reorganização das ações no âmbito da atenção primária previstas tratava dos princípios finalísticos e das diretrizes organizativas do SUS, seguindo os pressupostos da atenção primária abrangente discutida em Alma-Ata. Destacam-se as observações para as ações interdisciplinares, as atribuições dos profissionais com centralidade nas famílias, no território e nas competências culturais. Inácio (2003) aponta que a saúde bucal só se insere com política pública no SUS tardiamente, através da sua inclusão na ESF. A operacionalização das suas propostas apresenta as contribuições da SBC como aproximação das práticas das demais profissões de saúde, orientação cultural, relevância do território e os diversos cenários onde habitam os sujeitos; integração de práticas educativas, compatibilização entre atividades clínicas e não clínicas. Entretanto, como a política era voltada para a atenção básica, havia necessidades dos usuários que não eram atendidas como aquelas que demandavam procedimentos especializados.

Em 2004, é lançada a Política Brasil Sorridente, na gestão de Gilberto Pucca Jr., que expressa o projeto de movimentos contra-hegemônicos iniciados na década de 1980, conforme já referidos, pela democratização da saúde e pela SBC. As diretrizes da política são consoantes com os princípios do SUS, atuando em diferentes perspectivas de promoção da saúde, prevenção, cura e reabilitação a todos os cidadãos brasileiros, no atendimento de suas necessidades de saúde. Pioneiramente, essa política prevê serviços de atenção especializada em saúde bucal e a atuação em diferentes níveis de complexidade. Os princípios norteadores baseiam-se na gestão participativa, ética, acesso, acolhimento, vínculo e responsabilidade profissional. O documento apresenta o conceito ampliado de saúde como norteador das mudanças progressivas nos serviços e enfatiza que as ações do CD não devem ser restritas à assistência odontológica. 
(BRASIL, 2004) Destaca-se ainda uma influência da OPS quando se trata das ações de controle da cárie dentária, apesar da defesa de que não devam existir programas isolados para as distintas faixas etárias.

Após analisar os documentos das principais políticas de saúde bucal no período pós 1988 e a relação com os diversos movimentos e propostas no decorrer dos anos, cumpre questionar como a SBC vem balizando a implementação dessas políticas na atualidade?

\section{A SBC e a implementação da Política de Saúde Bucal na atualidade}

A publicação do livro Saúde bucal coletiva, por Vitor Gomes Pinto (2000), que manteve as características da antiga obra Odontologia social, significaria, segundo o próprio autor, apenas uma solicitação da editora, uma vez que a especialidade havia mudado de nome (SOARES, 2014), porém mantendo-a fiel também aos pressupostos da OPS. Poder-se-ia indagar se o uso do termo nessa perspectiva não seria apenas nas origens do espaço da SBC. Porém, uma breve exploração na literatura atual aponta a permanência da "velha" OPS nas práticas de SBC. (DIAS, 2006; DIAS; NARVAI; REGO, 2008)

Corrobora para essa situação o fato do cenário internacional não favorecer a pesquisa em SBC no Brasil. (MOYSÉS, 2008) As áreas de fomento da Federação Dentária Internacional são: placa dental, sistemas adesivos, prevenção da doença periodontal, resinas compostas, anestesia local, antibióticos, regeneração tecidual, prevenção de cáries, não cabendo, portanto objetos localizados no âmbito da SBC ao tempo em que reforça a OPS.

Esse cenário pode ser observado na publicação Saúde bucal coletiva: metodologia de trabalho e práticas (DIAS, 2006), coletânea com trabalhos de professores e profissionais de saúde bucal que, embora tenha pontos positivos acerca da consolidação de um subespaço cientifico da SBC, revela traços de permanência das odontologias anteriores nos ensaios que se apresentam no interior do trabalho. Nunes (2006) discute que a SBC sofreria da síndrome da "grande família”, com núcleos, parentes próximos, de segundo grau, terceiro grau, e outros, comportando subcategorias disciplinares, temáticas que por vezes ficam fora das ciências sociais, ampliando o escopo da SBC e fugindo, de certa forma, aos seus pressupostos de origem. Acrescenta-se que essa produção científica não tem se refletido nas práticas odontológicas realizadas nos serviços de saúde. Esta permanece subalternizada pelas práticas odontológicas tradicionais, tanto no âmbito privado como nos serviços públicos. 
Estudo realizado com grupo de estudantes que participaram de projetos comunitários, buscando sensibilização para o desenvolvimento de outras práticas distintas da prática clínica, concluiu que permanece entre eles o interesse para o trabalho voltado para o mercado de trabalho, apontando permanência do conservadorismo do campo odontológico e da hegemonia das suas práticas clínicas. (GONTIJO et al., 2009) Essa evidência reitera as dificuldades da SBC em atuar na formação do estudante, que carrega na sua prática as disposições do campo odontológico.

Há também que se notar, a partir da produção científica acerca das práticas, políticas e serviços de saúde bucal certo reforço à OPS. Nesse caso, embora haja todo esforço do grupo de agentes mobilizados politicamente, articulados ao referencial teórico e metodológico da saúde coletiva, e a proposta de um espaço novo vinculado a ele, ainda não foi capaz de mudar a lógica interna dos espaços sociais que a precederam, permanecendo certos habitus ou disposições inconscientes (BOURDIEU, 2009), inerentes a esses espaços.

Desse modo, a análise das práticas de SBC aponta a manutenção das contradições do campo odontológico, isto é, avanços tecnológicos com práticas eminentemente restauradoras, dificuldades de rompimento com a clínica tradicional e de incorporação da Equipe de Saúde Bucal (ESB). (MORETTI-PIRES; LIMA; MACHADO, 2011) Também se mencionam a inadequação do perfil dos profissionais de saúde bucal para a prática em SBC. (CALADO, 2002) O fato dessa concepção não se encontrar consolidada no Brasil, nem tampouco no âmbito internacional, confere à SBC um problema a ser resolvido.

Nesse caso, o conhecimento dessa concepção por uma comunidade pequena de dentistas constitui-se em um dos principais problemas para a manutenção do espaço social, tal como nas origens. (SOARES, 2014) Outras pessoas reproduzem o termo, filiam-se a ele, mas de fato não reconhecem as distinções entre ele e as "velhas odontologias". Permanecem velhos habitus que permitem a reprodução da OPS no Brasil. O desconhecimento da vertente política que exige a SBC faz dela, de certa forma, a velha OPS com nova denominação.

Embora se reconheça a produção teórica sobre SBC, esta não se constitui ainda como subcampo nem da saúde coletiva e nem da odontologia. A mais recente reforma educacional viabilizada pelas Novas Diretrizes Curriculares - Programa Nacional de Reorientação da Formação Profissional em Saúde 
(Pro-Saúde) ${ }^{3}$-, que promoveu incentivos na mudança dos vários currículos de odontologia, propiciaram a inserção da SBC em pequena parte de currículos de odontologia e, em alguns casos, "odontologia em saúde coletiva” ou saúde coletiva. Essa problemática foi investigada por Rodrigues, Saliba e Mormaz (2006), envolvendo a análise dos currículos de 123 cursos de odontologia que tinham formado pelo menos uma turma até 2003. Os autores observaram, na sua investigação, que a nomenclatura mais recorrente para designar a área de saúde coletiva é OPS.

Desse modo, constata-se que as preocupações com as mudanças das práticas odontológicas não ficaram no passado. É uma questão que continua em jogo no cenário atual. Corresponde à luta cotidiana que encampa a disputa hegemônica pelas práticas de saúde bucal no serviço público odontológico, já que a SBC tem o compromisso com os serviços públicos de saúde, com a justiça social, redução das iniquidades e com a manutenção do direito à saúde.

Reconhecendo essa problemática, alguns fundadores permanecem tematizando a SBC (BOTAZZO, 2013; BOTAZZO; CHAVES, 2014; NARVAI, 2008; NARVAI, 2001; NARVAI, 2006; FRAZÃO), tendo a publicação Diálogos sobre a boca, em 2013, um esforço de recuperação conceitual e da trajetória da SBC (BOTAZZO; CHAVES, 2014), bem como o texto intitulado "Saúde Bucal Coletiva: antecedentes e estado da arte", em livro de saúde coletiva, no qual aparece novos agentes tematizando a SBC. (BOTAZZO; CHAVES, 2014)

Outros movimentos vêm ocorrendo no subespaço científico nas décadas que sucederam a emergência da SBC, na direção de construção de um arcabouço teórico e metodológico para a prática da SBC. Várias obras têm sido publicadas com essa intenção. Em 2008, Samuel Moisés, Leo Kriger e Simone Moysés publicam coletânea que mescla discussões teóricas e experiências práticas, envolvendo vários autores citados neste trabalho, bem como fundadores da SBC. E recentemente, esse mesmo autor, em parceria com Paulo Goes, apresentou nova obra denominada Planejamento, gestão e avaliação em saúde bucal, também com a participação de vários agentes citados ao longo deste trabalho, bem como de alguns dos fundadores. (MOYSÉS; GÓES, 2012)

A resposta a essa questão talvez esteja no fato de a SBC ser ainda um espaço social ainda dominado sem autonomia relativa, bastante influenciado por ou-

O objetivo do programa é a integração ensino-serviço, visando à reorientação da formação profissional, assegurando uma abordagem integral do processo saúde-doença com ênfase na atenção básica, promovendo transformações na prestação de serviços à população. 
tros espaços, especialmente pelo campo odontológico e, muito embora se filie aos pressupostos da saúde coletiva, seu processo de reprodução aproxima-o cada vez mais da "odontologia" e de suas práticas sociais, notadamente aquelas orientadas pela OPS e odontologia sanitária. Sendo assim, um dos principais desafios da SBC, seria constituir-se como campo, ou seja, um espaço social relativamente autônomo e com um habitus comum que, por sua vez, subsidie teoricamente a aplicação prática nos serviços de saúde.

A recuperação da sua face política também deve compreender a pauta dos agentes desse espaço social. A formação de dentistas comprometidos com a saúde pública e com a mudança das práticas odontológicas tem sido preocupação de alguns fundadores. A ampliação de quadros, conformação de visão crítica e o compromisso com a prática de saúde bucal, "não odontológica”, pode ser um caminho para assegurar novos movimentos contra-hegemônicos. Assim, outro desafio dessa área constitui a formação de agentes comprometidos com o projeto de transformação das práticas odontológicas hegemônicas e constituição de novos "intelectuais orgânicos" a esse projeto de transformação social. (GRAMSCI, 1978)

Para tal, cabe recuperar a análise crítica das origens da SBC e a matriz política que se perdeu ao longo do tempo histórico, no período pós-Constituinte. Significa então reinserir-se no "processo" da Reforma Sanitária Brasileira, definido por Paim (2008) como o conjunto de atos políticos que se processam nas distintas conjunturas pós criação do SUS e na (re)politização da saúde de modo geral. Ademais, a configuração atual do campo odontológico e as relações políticas, econômicas e sociais que refletem a hegemonia das práticas de saúde bucal e a permanência da odontologia de mercado encontram-se entre os principais problemas da área hoje, cujo reforço às odontologias "alternativas" das décadas anteriores preservam a autonomia do campo odontológico. Essa hegemonia acaba sendo reforçada pela PNSB. Mas vale reconhecer que a SBC corresponde a um caso sui generis, um fenômeno brasileiro, genuíno e distinto das odontologias anteriores. (NARVAI, 1994; SOARES, 2014)

A fundação do grupo de trabalho de saúde bucal, no âmbito da Associação Brasileira de Saúde Coletiva, estreita as relações com a saúde coletiva brasileira e reafirma um compromisso histórico com o deslocamento do solo epistemológico do campo “odontológico" para o espaço da "saúde coletiva”, assim como a Reforma Sanitária Brasileira. 
Avanços foram identificados com a introdução da saúde bucal na ESF (BRASIL, 2000) e, especialmente, com a formulação de uma política própria de saúde bucal em 2004 (BRASIL, 2004), que expressa a principal reivindicação da SBC no seu nascedouro que consistia na entrada da saúde bucal no SUS. Isso significa a possibilidade de aplicação da SBC nos serviços de saúde, muito embora consultas à literatura mostrem a permanência das práticas do campo odontológico hegemônico. (CALADO, 2002; MORETTI PIRES; LIMA; MACHADO, 2011; SOARES et al, 2011)

A mesma política pode estar favorecendo a contradição e nesse caso reforçando o habitus higienista da OPS e a manutenção da odontologia de mercado que mantém o campo odontológico. $\mathrm{O}$ apoio às velhas concepções de OPS e odontologia sanitária, pela implementação das políticas de saúde bucal persistem, mesmo no cenário atual. Sendo assim, a SBC permanece nos dias atuais na luta pela hegemonia das práticas odontológicas tal como nasceu, disputando os rumos das políticas de saúde bucal. A reivindicação das origens do espaço da SBC que dizia respeito à entrada da odontologia no SUS foi alcançada com desenvolvimento das políticas e das práticas de saúde bucal no âmbito público. Todavia, essa inserção não garante a implementação dos princípios da SBC e da Reforma Sanitária Brasileira nas mesmas. (SOARES, 2014)

Cabe então sistematizar novos e velhos problemas que permanecem no espaço social ainda hoje, para além dos previamente relatados. Esses problemas significam entraves à consolidação de um campo de saberes e práticas de saúde bucal compatível com os princípios eticopolíticos da saúde coletiva e da Reforma Sanitária Brasileira, quais sejam: a corporação odontológica que limita os avanços em relação à formação da equipe de saúde bucal, incluindo a atuação plena do técnico em saúde bucal; a insuficiência teórica no espaço odontológico capaz de entender a questão do adoecimento bucal a partir da abordagem sobre os determinantes sociais, os quais levam à simplificação da epidemiologia em saúde bucal na análise de um processo social complexo como a cárie e outros problemas; a permanência nas práticas dos serviços de saúde bucal de conceitos antigos da odontologia privada presente na Fundação Serviços de Saúde Pública como tratamento iniciado e tratamento concluído, que reduz o acesso; bem como a conservação de ideias higienistas de décadas anteriores, baseado em campanhas sanitárias de escovação dentária supervisionada. Podese relacionar ainda como elemento importante na consolidação desse espaço que o esvaziamento do processo político que iluminou o movimento no perí- 
odo da sua origem precisa ser revitalizado, visto que a incorporação de novos agentes comprometidos com o projeto político da SBC e da Reforma Sanitária corresponde a uma premissa fundamental. Essa incorporação de novos agentes com habitus comuns compartilhados representa o maior dos desafios, já que a SBC exige, além da dimensão técnico-científica, a militância sociopolítica.

\section{Referências}

AROUCA, A. S. S. O Dilema preventivista: contribuições para a compreensão e crítica da medicina preventiva. São Paulo: UNESP, 2003.

BOTAZZO, C. Saúde bucal coletiva: um conceito em permanente construção. Saúde Atual, São Paulo, v. 1, p. 14-23, 1992.

BOTAZZO, C. A saúde bucal nas práticas coletivas de saúde. São Paulo: Editora do Instituto de Saúde, 1994. v.1.

BOTAZZO, C. Da arte dentária: um estudo arqueológico sobre as práticas dos dentistas. 1998. Tese (Doutorado em Saúde Coletiva) - Faculdade de Ciências Médicas, Unicamp, Campinas, 1998.

BOTAZZO, C. Diálogos sobre a boca. São Paulo: Hucite, 2013.

BOTAZZO, C. et al. Saúde bucal coletiva. 1988. (Texto elaborado como material de apoio para formação do ACD e THD, no projeto Larga escala).

BOTAZZO, C. Sobre a bucalidade: notas para a pesquisa e contribuição ao debate. Ciência e Saúde Coletiva, v. 11, n. 1, p. 7-17, jan./mar. 2006.

BOTAZZO, C.; CHAVES, S. C. L. Saúde bucal coletiva: antecedentes e estado da arte. In: PAIM, J. S.; ALMEIDA FILHO, N. Saúde Coletiva: teoria e prática. Rio de Janeiro: Medbook, 2014. p. 639-48.

BOURDIEU, P. Algumas propriedades gerais dos campos de produção cultural. In: BOURDIEU, P. As regras da arte: gênese e estrutura do campo literário. São Paulo; Companhia das Letras, 1976. p. 243-311.

BOURDIEU, P. O campo científico. In: ORTIZ, R. Pierre Bourdieu - Sociologia. São Paulo: Ática, 1994. p. 122-155.

BOURDIEU, P. O senso prático. São Paulo: Vozes, 2009.

BOURDIEU, P. Razões práticas: sobre a teoria da ação. Campinas, SP: Papirus, 1996.

BRASIL. Ministério da Saúde, Coordenação Nacional de Saúde Bucal, Departamento de Atenção Básica, Secretaria de Atenção à Saúde. Diretrizes da Política Nacional de Saúde Bucal. Brasília, DF, 2004.

BRASIL. Ministério da Saúde. Portaria $n^{\circ}$ 1444, de 28 de dezembro de 2000 . Cria o incentivo de saúde bucal destinado ao financiamento de ações e da inserção de 
profissionais dessa área no Programa de Saúde da Família (PSF). Diário Oficial [da] República Federativa do Brasil, Brasília, DF, 29 dez. 2000.

BRASIL. Ministério da Saúde. Portaria no 184, de 09/10/1991. Aprova a nova tabela de procedimentos Odontológicos constantes no anexo I dessa Portaria e respectivos códigos e preços para utilização em clientela do Sistema Único de Saúde - SUS. Diário Oficial [da] República Federativa do Brasil, Brasília, DF, 9 out. 1991.

BRASIL. Ministério da Saúde. Portaria 267, de 06/03/2001. Aprova normas e diretrizes de inclusão da saúde bucal na estratégia do Programa de Saúde da Família. Diário Oficial [da] República Federativa do Brasil, Brasília, DF, 6 mar. 2001.

BRASIL. Ministério da Saúde. Secretaria de Atenção à Saúde. Departamento de Atenção Básica. Coordenação Nacional de Saúde Bucal. Diretrizes da Política Nacional de Saúde Bucal. Brasília-DF, 2004.

BRASIL. Ministério da Saúde. Política Nacional de Saúde Bucal: princípios, objetivos, prioridades. Brasília, DF, 1989a.

BRASIL. Ministério da Saúde. Programa Nacional de Prevenção da Cárie Dentária. Brasília: DF, 1989b.

CALADO, G. S. A inserção da Equipe de Saúde Bucal no Programa Saúde da Família: principais avanços e desafios. Dissertação (Mestrado em Planejamento e Gestão de Sistemas e Serviços de Saúde) - Escola Nacional de Saúde Pública, Fundação Oswaldo Cruz, Fiocruz, Rio de Janeiro, 2002.

CARVALHO, L. A. C. et al. Procedimentos coletivos de saúde bucal: gênese, apogeu e ocaso. Saúde e Sociedade, São Paulo, v. 18, n. 3, p. 490-499, set. 2009.

CASOTTI, E. Odontologia no Brasil: uma (breve) história do pensamento sobre o ensino. Rio de Janeiro, 2009. 108 f. Tese (Doutorado Educação em Ciências e Saúde) - Núcleo de Tecnologias Educacionais em Saúde - NUTES, Universidade Federal do Rio de Janeiro, Rio de Janeiro, 2009.

CELESSE, R. K.; WARMLING, C. M. Produção bibliográfica brasileira de saúde coletiva em periódicos de saúde coletiva e de odontologia. Ciência \& Saúde Coletiva, Rio de Janeiro, v. 19, n. 6, p. 1921-1932, 2012.

CHAVES, M. M. Odontologia social. 3. ed. Rio de Janeiro: Artes Médicas, 1986.

(O) DENTISTA E O MUNDO DO TRABALHO. Movimento Brasileiro de Renovação Odontológica-MBRO. 19 jul. 2011.

Disponível em: <http://odentistaeomundodotrabalho.blogspot.com.br/2011/o7/movimentobrasileiro-de-renovacao.html>. Acesso em: 23. Jun. 2016.

DIAS, A. A. et al. Saúde bucal coletiva: metodologia de trabalho e práticas. São Paulo: Editora Santos, 2007.

DIAS, A. A.; NARVAI, P. C.; RÊGO, D. M. Tendências da produção científica em odontologia no Brasil. Revista panamericana de salud pública, Washington, D.C., v. 24, n. 1, p. 54-60, jul. 2008. 
DUMMETT, C. O. Retrospective on community and public health at the university of Southern Califórnia (1966-1976). Journal of the National Medical Association, Washington, D.C., v. 90, n. 5, p. 309-316, May 1998.

FERREIRA, R. C. Sistemas simplificados de espaço físico. Belo Horizonte: PUC-MG/ FINEP, 1985 .

FRAZÃO, P. Saúde bucal coletiva: metodologia de trabalho e práticas. Cadernos de Saúde Pública, Rio de Janeiro, v. 22, n. 11, nov. 2006.

FRAZÃO, P.; NARVAI, P. C. Saúde bucal no Brasil: muito além do céu da boca. Rio de Janeiro: Fiocruz, 2008.

FSESP. Normas técnicas de Odontologia Sanitária. ODONTOLOGIA, D. D. O. T.-S. Rio de Janeiro: Fundação Serviço Especial de Saúde Pública - Ministério da Saúde: 66 p. 1963.

GARCIA, J. C. La educación médica en la América Latina. Washington, D.C.: OPS/OMS, 1972. (Publicacion Científica, n. 255).

GOES, P. S. A; MOYSÉS, S. J. (Org.). Planejamento, gestão e avaliação em saúde bucal. São Paulo: Artes Médicas, 2012.

GONTIJO, L. P. T. et al. A saúde bucal coletiva na visão do estudante de odontologia: análise de uma experiência. Ciência \& Saúde Coletiva, Rio de Janeiro, v. 14, n. 4, p. 1277-85, 2009.

GRAMSCI, A. Cadernos do Cárcere. volume 2: os intelectuais, o principio educativo, jornalismo. Rio de Janeiro: Civilização Brasileira, 1978.

GRAMSCI, A. Cadernos do Cárcere. volume 3: Maquiavel. Notas sobre o Estado e a política. Rio de Janeiro: Civilização Brasileira, 1978.

GRAMSCI, A. Cadernos do Cárcere, volume 5: O risorgimento, notas sobre a história da Itália. Rio de Janeiro: Civilização Brasileira, 1978.

INÁCIO, J. A atenção à Saúde Bucal e o Sistema de Informações no município do Rio de Janeiro.. Dissertação (Mestrado em Saúde Pública) - Escola Nacional de Saúde Pública, Fundação Osvaldo Cruz, Rio de Janiero 2003.

MEIRA, A. J. de. Modelo de atenção simplificado a Escolares. Belo Horizonte, PUC-MG/ FINEP, 1985.

MENDES, E. V. A Reforma Sanitária e a Educação Odontológica. Cadernos de Saúde Pública, Rio de Janeiro, v. 2, n. 4, p. 533-552, out./dez. 1986.

MENDES, E.V.; MARCOS, B. Odontologia integral: bases teóricas e suas implicações no ensino, no serviço e na pesquisa odontológicas. A experiência de Departamento de odontologia da Pontifícia Universidade Católica de Minas Gerais. Belo Horizonte: PUCMG/FINEP, 1984.

MENDES, E. V. A reforma sanitária e a educação odontológica. Cadernos de Saúde Pública, Rio de Janeiro , v. 2, n. 4, p. 533-552, dec.1986 
MENDES, E. V. Odontologia Integral. Belo Horizonte. Ed. Fundação Mariana Resende Costa, 1985 .

MOYSÉS, S. J. O contexto atual para a pesquisa em saúde bucal coletiva: editorial. Caderno de Saúde Pública, Rio de Janeiro, v. 24, n.4, p. 718, abr., 2008.

MORETTI-PIRES, R. O.; LIMA, L. A. M.; MACHADO, M. H. Sociologia das profissões e percepção de acadêmicos e odontologia sobre o Agente Comunitário de Saúde em Saúde Bucal. Interface - Comunicação, Saúde, Educação, Botucatu, v. 15, n. 39, p. 1085-95, 2011.

NARVAI, P. C. Caminhos da odontologia sanitária à bucalidade. Revista de saúde pública, São Paulo, v. 40, p. 141-7, 2006.

NARVAI, P. C. Odontologia e saúde bucal coletiva. Rio de Janeiro: Hucitec, 1994.

NARVAI, P. C. Saúde bucal coletiva, bucalidade e antropofagia. Ciência \& Saúde Coletiva, Rio de Janeiro, v. 11, n. 1, p. 18-21, 2006.

NARVAI, P. C. Saúde bucal coletiva: um conceito. Odont. \& Soc., v. 3, n. 1/2, p. 47-52, 2001.

NARVAI, P. C.; ALMEIDA, E. S de. O sistema de saúde e as políticas de saúde na produção científica odontológica brasileira no período 1986-1993. Cadernos de Saúde Pública, Rio de Janeiro, v. 14, n. 3, p. 513-21, 1998.

NARVAI, P. C.; ALMEIDA, E. S. The national health system and health policies in the Brazilian dentistry literature, 1986-1993. Cadernos de Saúde Pública, Rio de Janeiro,v. 14, n. 3, p. 513-22, jul./set. 1998.

NARVAI, P. C.; FRAZÃO, P. Saúde Bucal no Brasil: muito além do céu da boca. Rio de Janeiro: Editora FIOCRUZ, 2008.

NICKEL, D. A.; LIMA, F. G.; DA SILVA, B. B. Modelos assistenciais em saúde bucal no Brasil. Cadernos de Saúde Pública, Rio de Janeiro, v. 24, n. 2, p. 241-246, 2008.

NUNES, E. D. Saúde bucal coletiva: a busca de uma identidade. Ciências \& Saúde Coletiva, Rio de Janeiro, v. 11, n.1, p. 37-9, 2006.

PAIM, J. S. Políticas de saúde no Brasil. In: ROUQUAYROL M. Z.; ALMEIDA FILHO, N. Epidemiologia e saúde. 6. ed., Rio de Janeiro: MEDSI. 2003. p. 587-603.

PAIM, J. S. Reforma sanitária brasileira: contribuição para a compreensão e crítica. Salvador: EDUFBA; Rio de Janeiro: Fiocruz, 2008.

PINTO, V. G. Saúde bucal coletiva. 4. ed. São Paulo: Editora Santos, 2000. 541p.

PINTO, V. G. Serviços básicos de saúde: a experiência do PIASS. A Saúde no Brasil., Brasília, DF, 1983.

QUEIROZ, M. G.; DOURADO, L. F. O ensino da odontologia no Brasil: uma leitura com base nas recomendações e nos encontros internacionais da década de 1960. História, Ciência, Saúde - Manguinhos, Rio de Janeiro, v.16, n. 4, p. 1011-26, 2009.

REBELO, M. A. B. Saúde bucal coletiva: implementando ideias, concebendo integralidade. Cadernos de Saúde Pública, Rio de Janeiro, v. 25, n. 4, p. 943-4, 2009. 
RODRIGUES, R. P. C. B.; SALIBA, N. A.; MOIMAZ, S. A. S. Revista ABENO, Londrina, v. 6, n. 1, p. 81-87, jan.-jun. 2006.

SAÚDE EM DEBATE. Revista do Centro Brasileiro de Estudos de Saúde, Rio de Janeiro, n. 18, mar./abr. 1986. Disponível em: <http://docvirt.com/asp/acervo_cebes. asp?Bib=SAUDEDEBATE\&PASTA=N.17+-+jul\&pesq=\&x=82\&y=12>. Acesso em: 23 jun . 2016.

SERRA, C. G. A saúde bucal como política de saúde análise de três experiências recentes: Niterói, Campinas e Curitiba. Rio de Janeiro, 1998. 204 p. Dissertação (Mestrado em Saúde Coletiva) - Instituto de Medicina Social, Universidade do Estado do Rio de Janeiro, Rio de Janeiro, 1998.

SILVEIRA FILHO, A. D. et al. Os dizeres da boca em Curitiba: boca maldita, boqueirão, bocas saudáveis. Rio de Janeiro: Centro Brasileiro de Estudos de Saúde; Curitiba: Secretaria Municipal de Saúde de Curitiba, 2002.

SOARES, C. L. M. A Constituição da Saúde Bucal Coletiva no Brasil. 2014. 180 f. Tese (Doutorado Saúde Pública) - Instituto de Saúde Coletiva. Universidade Federal da Bahia, Salvador, 2014.

SOARES, F. F. et al. Atuação da equipe de saúde bucal na estratégia saúde da família: análise dos estudos publicados no período 2001-2008. Ciências \& Saúde Coletiva, Rio de Janeiro, v.16, n.7, p. 3169-80, 2011.

TEIXEIRA, C. F; VILAS BOAS, A. L. Modelos de Atenção à Saúde: conservação ou mudança? In: PAIM, ALMEIDA-FILHO (Org.). Saúde Coletiva: teoria e prática. Rio de Janeiro: Editora: Med Book. 2014. p. 121-137.

UCHOA, H. Assistência odontológica no país: perspectivas 2. Cadernos de Saúde Pública, Rio de Janeiro, v. 1, n. 2, p. 263-269, Jun. 1985

WARMLING, C. M. Da autonomia da boca: um estudo da constituição do ensino da odontologia no Brasil. Porto Alegre, 2009. Tese (Doutorado em Educação) - Faculdade de Educação, Universidade Federal do Rio Grande do Sul, 2009.

WARMLING, C. M. Dos práticos à institucionalização da odontologia: um estudo histórico de saúde bucal de Blumenau. 2002. 126 f. Dissertação (Mestrado em Ciências Sociais) Centro de Ciência da Saúde, Universidade Federal de Santa Catarina, 2002. 



\title{
Atenção primária e saúde bucal
} AS EVIDÊNCIAS DE SUA IMPLEMENTAÇÃO NO BRASIL

\author{
Sandra Garrido de Barros \\ Maria Guadalupe Medina \\ Daniela Lemos Carcereri \\ Diana Carolina Ruiz \\ Ana Carolina Oliveira Peres
}

\section{Introdução}

No Brasil, a atenção básica é definida como um conjunto de ações de saúde, individuais e coletivas, que incluem promoção e proteção da saúde, prevenção de doenças, diagnóstico, tratamento, reabilitação, redução de danos e manutenção da saúde. Por meio da implementação de tais ações por equipes de saúde responsáveis por populações adstritas, de modo articulado com os demais níveis e pontos de atenção do sistema de saúde, pretende-se desenvolver uma atenção integral que favoreça a autonomia dos sujeitos e estimule a participação comunitária, com efeitos positivos sobre os determinantes sociais e sobre a saúde das populações de forma global. (BRASIL, 2012a)

A Política Nacional de Atenção Básica (PNAB), desde 2006, vem sendo considerada como estratégia prioritária para expansão e consolidação desse nível do sistema de saúde brasileiro. (BRASIL, 2011) A principal estratégia para a reorganização e consolidação da atenção básica no Sistema Único de Saúde (SUS) e seguindo seus princípios tem sido a Estratégia Saúde da Família (ESF), a qual busca a reorientação do modelo assistencial, mediante o trabalho em equipes multiprofissionais de saúde. (BRASIL, 2012a) Apesar da importância conferida à atenção básica nos documentos normativos do SUS, existe uma 
série de tensões entre uma visão abrangente de Atenção Primária à Saúde (APS), afinada com os preceitos da Declaração de Alma-Ata, segundo a qual a APS deve ser reconhecida como coordenadora do cuidado, primeiro contato com o sistema, e responsável pela atenção integral dos indivíduos ao longo do tempo (IOM, 1978; STARFIELD,1979, 2002), e uma visão restrita, que entende APS apenas como um pacote mínimo de serviços para grupos sociais excluídos, focado nas doenças mais prevalentes, desenho induzido por agências financiadoras internacionais em diferentes países. (VILASBOAS et al., 2015)

Como forma de reorganizar a APS no Brasil, o Ministério da Saúde (MS) lançou, em 1994, o Programa Saúde da Família (PSF). Em um contexto de ajuste fiscal e reformas setoriais na saúde, o programa ganhou ampla aceitação nacional, com o objetivo de superar os limites do modelo vigente, particularmente na esfera municipal. (BRASIL, 1997a; VIANA; DAL POZ, 1998) A partir de 2006, o PSF configurou-se como estratégia prioritária para reorganização da APS no país, passando a ser denominado Estratégia de Saúde da Família (ESF).

Especificamente em relação à saúde bucal, às tensões relacionadas às diferentes visões da APS adicionam-se dificuldades oriundas do próprio modelo hegemônico de atenção à saúde bucal privatista (NARVAI; FRAZÃO, 2008). Junte-se a isso o escasso interesse do Estado nessa área durante muitas décadas (NARVAI; FRAZÃO, 2008) e a consequente inclusão tardia dos profissionais de saúde bucal no PSF, seis anos depois do início da implantação desse programa no país. (CHAVES et al., 2015)

Apenas em 2004, durante o governo do presidente Luíz Inácio Lula da Silva, as questões referentes à saúde bucal tomaram maior relevância, tendo sido lançada a Política Nacional de Saúde Bucal (PNSB) Brasil Sorridente. (BRASIL, 2004a; CHAVES et al., 2015) Criada para reorganizar o trabalho em saúde bucal nos três níveis de atenção, destacando "o cuidado como eixo de reorientação do modelo, a humanização do processo de trabalho, a corresponsabilização dos serviços e o desenvolvimento de ações voltadas para as linhas do cuidado e condições especiais de vida”. (BRASIL, 2004a, p. 3)

Foi inegável o aumento da oferta de serviços ocorrida com a inclusão das Equipes de Saúde Bucal (ESB) na ESF e com a implementação da PNSB, ainda que as mudanças no modelo de atenção à saúde bucal possam ser questionáveis. No que diz respeito ao quantitativo de equipes e municípios, de 2.200 ESB implantadas em 1.288 municípios em 2001, passou-se a 12.603 equipes em 3.897 (70\%) municípios brasileiros em 2005, com a existência de ESB em 51,3\% 
das Equipes de Saúde da Família (EqSF). (AQUINO et al., 2014) Já em agosto de 2015, contava-se com 22.296 ESB implantadas na modalidade I - CirurgiãoDentista (CD) e Auxiliar de Saúde Bucal (ASB) - e 2.252 na modalidade II - CD, ASB e Técnico de Saúde Bucal (TSB), em 5.025 (90.2\%) municípios brasileiros. (BRASIL, 2015a)

Segundo resultados do inquérito epidemiológico nacional das condições de saúde bucal da população brasileira, realizado em 2010 , 43,5\% das crianças de 12 anos de idade estavam livres de cárie na dentição permanente. O índice CPO-D aos 12 anos (média de dentes cariados, perdidos e restaurados) foi 2,07, o que representa uma redução de $26,2 \%$ quando se compara com esse índice para 2003. (BRASIL, 2004b; BRASIL, 2012b)

O CPO-D em adultos de 35-44 anos passou de 20,1 em 2003 para 16,7 em 2010, redução de 17\%. O componente "perdido" do índice caiu (de 13,23 para 7,48) enquanto o componente "restaurado" aumentou (de 4,22 para 7,33), o que significa que a população adulta dessa faixa de idade, nos últimos sete anos, experimentou menos perdas dentárias relacionadas à cárie e teve maior acesso aos serviços odontológicos para realização de procedimentos restauradores. (BRASIL, 2011)

Apesar dos resultados positivos assinalados, existem diferenças epidemiológicas e iniquidades ao interior do país. O CPO-D aos 12 anos, registrado nas regiões Norte $(3,16)$, Nordeste $(2,63)$ e Centro-Oeste $(2,63)$, foi pior do que aquele observado nas regiões Sudeste $(1,72)$ e Sul $(2,06)$. A participação de dentes restaurados na composição percentual do CPO-D nessa idade é menor na região Nordeste do que na região Sudeste, o que indica que existe um maior ataque da doença associado a menor acesso aos serviços nessa região. (BRASIL, 2012b)

Considerando esse panorama, pretende-se, neste capítulo, descrever o processo histórico de implementação da PNSB no Brasil, em sua interface com as políticas de atenção primária, discutir convergências e dissonâncias entre a política de atenção primária e a política de saúde bucal, sistematizar algumas experiências de implementação da política de saúde bucal no seu componente atenção básica no Brasil e apontar alguns desafios e questões para investigação sobre a política de saúde bucal na atenção básica na atualidade. 


\section{Política de saúde bucal e política de APS: convergências e dissonâncias}

A saúde bucal, tradicionalmente secundarizada pelo Estado brasileiro (CHAVES et al., 2015), apresenta importantes desafios, tanto na ampliação do acesso da população à atenção odontológica quanto na mudança das práticas de saúde bucal, centradas no atendimento clínico individual curativo. (NARVAI; FRAZÃO, 2008) O longo processo de discussões e lutas de poder em torno da temática de saúde bucal teve início em meados da década de 1970, na conjuntura da luta pela redemocratização do país, e no movimento da Reforma Sanitária Brasileira, do qual também fazia parte o Movimento Brasileiro de Renovação Odontológica (MBRO).

O MBRO, apesar de ter um período curto de mobilização (entre 1984-1990), representava ideais progressistas e de esquerda de um grupo de dentistas articulados ao Movimento da Reforma Sanitária Brasileira. Contribuiu para que o ideário da Reforma Sanitária alcançasse os grupos de ativistas da odontologia e os estudantes que se reuniam nos Encontros Científicos de Estudantes de Odontologia (espaços iniciais de politização das questões de saúde bucal). O MBRO foi um espaço de crítica contundente aos programas focalizados verticais vinculados ao Instituto Nacional de Assistência Médica e Previdência Social (Inamps) e ao processo de trabalho odontológico, propondo sua inovação, reorganização do espaço físico do consultório, e a utilização de pessoal auxiliar, questões que seriam incluídas na pauta da $1^{\text {a }}$ Conferência Nacional de Saúde Bucal (CNSB), realizada no mesmo ano na $8^{\text {a }}$ Conferência Nacional de Saúde (CNS). (ZANETTI, 1993)

Em 1986, a $8^{\text {a }}$ CNS reafirmou a saúde como direito dos cidadãos e delineou as bases fundamentais do que seria o SUS. (AQUINO et al, 2014; PAIM et al. 2011) Nesse ano, também o relatório final da $1^{a}$ CNSB criticava o modelo de prática odontológica, caracterizado como ineficaz, ineficiente, monopolizador, de alto custo, de tecnologia densa, iatrogênico, mutilador e elitista, e propunha a inserção do Programa Nacional de Saúde Bucal ao interior do SUS, a estatização dos serviços odontológicos, e a mudança da prática odontológica. (BRASIL, 1986)

De maneira contraditória às conclusões da $1^{\mathrm{a}}$ CNSB e com a Constituição Federal de 1988, no mesmo ano, o Departamento de Odontologia do Inamps criou um programa centralizado e vertical para o controle da cárie dental e o uso de selantes e flúor. (NARVAI, FRAZÃO, 2008; JUNIOR, 2013) De maneira 
similar, em 1989, o MS aprovou a PNSB (NARVAI; FRAZÃO, 2008), duramente criticada pelo MBRO por não seguir as propostas da $1^{\text {a }}$ CNSB e continuar priorizando quase exclusivamente os grupos populacionais em idade escolar. (PALUDETO JUNIOR, 2013) Nos anos seguintes, as ações de saúde bucal focaram-se principalmente na fluoretação da água, dentifrícios e bochechos. (NARVAI; FRAZÃO, 2008)

Em 1993, foi realizada a $9^{\text {a }}$ CNS, e, como parte desta, também realizou-se a $2^{\mathrm{a}} \mathrm{CNSB}$, que em seu relatório final descreve que:

O modelo de saúde bucal vigente no Brasil, caracteriza-se pela limitadíssima capacidade de resposta às necessidades da população brasileira. É ineficaz para intervir na prevalência das doenças bucais que assolam o país, elitista, descoordenado, difuso, individualista, mutilador, iatrogênico, de alto custo, baixo impacto social e desconectado da realidade epidemiológica e social da nação. (BRASIL, 1993, p. 6)

Também nesse relatório, ressaltava-se a necessidade do reconhecimento da saúde bucal como direito de cidadania e de um modelo de atenção à saúde bucal sob as bases da Reforma Sanitária Brasileira. Assim, a atenção primária em saúde bucal deveria ser realizada pela rede básica de saúde de cada município, com equipes de saúde bucal que incluiriam CD, auxiliar, técnico e Agentes Comunitários de Saúde (ACS). Profissionais que, preferencialmente, deveriam ser oriundos da comunidade onde iriam trabalhar e com formação em saúde pública. (BRASIL, 1993)

Novamente, de maneira contraditória às propostas da $2^{\mathrm{a}} \mathrm{CNSB}$, quando se iniciou o PSF, em 1994, os profissionais de saúde bucal não foram reconhecidos como parte deste. Os serviços de saúde bucal continuaram sendo priorizados para a população em idade escolar e atenção de urgência nos adultos. (JUNIOR, 2013; SILVESTRE et al., 2013) Apesar disso, vários municípios brasileiros implementaram seus próprios modelos municipais ou locais de saúde bucal. (JUNIOR, 2013; SILVESTRE et al., 2013) Experiências desse tipo foram desenvolvidas em Curitiba (PR), Sobral (CE), Belo Horizonte (MG), Campinas (SP), Porto Alegre (RS), Santos (SP) e São Paulo (SP), Camaragibe (PE), Distrito Federal e Vitória da Conquista (BA). (MARTELLI, 2010; SILVA, 2011; CHAVES e CRUZ, 2012) Segundo Calado (2002), antes da criação do incentivo financeiro para inclusão das ESB na ESF, em todo Brasil conhecia-se somente 76 experiências de participação desse profissional nas EqSF. 
No ano 2000, houve a publicação dos resultados da Pesquisa Nacional por Amostra de Domicílios (PNAD) sobre acesso e utilização de serviços de saúde que indicou que, em 1998, cerca de 29,6 milhões de brasileiros, ou 19,5\% da população, nunca haviam ido ao dentista. (IBGE,2000) Diante da necessidade de ampliação do acesso da população brasileira às ações de saúde bucal, bem como, da necessidade de melhorar os índices epidemiológicos, no final desse ano, foi estabelecido um incentivo financeiro para reorganizar a atenção à saúde bucal e incluir ESB no PSF. (BALDANI, et al., 2005; RIANI, CHAGAS, SILVESTRE, 2006; SOARES et al., 2011; JUNIOR, 2013)

As ESB integraram-se à ESF a partir da Portaria GM/MS n. ${ }^{\circ} 1.444$, de 28 de dezembro de 2000. (BRASIL, 2000) A inclusão das ESB aconteceria em uma relação de processo de trabalho de duas EqSF para cada uma ESB, que ficaria responsável por aproximadamente 6.900 habitantes. Eram previstas duas modalidades de ESB: na modalidade I, integravam a ESB, um CD e um ASB; e, na modalidade II, incluía-se também o TSB. Em 2003, foram aumentados os incentivos financeiros e permitiu-se a vinculação de uma ESB para cada EqSF. (KORNIS; MAIA; FORTUNA, 2011)

Com o impulso do presidente Lula e o empenho de instituições acadêmicas focadas na saúde coletiva, secretarias de saúde, e outros atores individuais e coletivos, em 2004, foram formuladas as Diretrizes da PNSB Brasil Sorridente. (NARVAI; FRAZÃO, 2008) Essa política orienta-se para a reorganização da atenção a saúde bucal em todos os níveis de atenção, propõe a ampliação e qualificação da atenção básica em saúde bucal, implantação dos Centros de Especialidades Odontológicas (CEO) e Laboratórios Regionais de Próteses Dentárias, fluoretação das águas de abastecimento público, e vigilância em saúde bucal. (BRASIL, 2004a; CHAVES et al., 2015)

O Quadro 1 apresenta uma síntese do processo de implantação da PNSB e o desenvolvimento do modelo de atenção à saúde adotado no Brasil.

Diversos estudos têm evidenciado o impacto da ESF na saúde da população, seja na redução da mortalidade infantil ou das internações hospitalares por causas sensíveis à atenção primária. No caso específico da saúde bucal, ainda que diversos estudos apontem para a ampliação da oferta e utilização de serviços de saúde bucal relacionados à inclusão da ESB na ESF (ANTUNES; NARVAI, 2010; BALDANI et al., 2009; MUNKEVITZ, PELICIONI, 2010), e a PNAD demonstre a redução do percentual de indivíduos que nunca tiveram acesso ao dentista (de $15,9 \%$ em 2003 para $11,7 \%$ em 2008), apenas cerca de $20,3 \%$ das pessoas que 


\begin{tabular}{|c|c|c|c|c|}
\hline Período & $\begin{array}{l}\text { Conjuntura político- } \\
\text { administrativa }\end{array}$ & $\begin{array}{c}\text { Práticas } \\
\text { odontológicas }\end{array}$ & Aspectos chave & $\begin{array}{c}\text { Modelos de atenção à saúde } \\
\text { no Brasil }\end{array}$ \\
\hline 1990 & $\begin{array}{l}\text { Crise política, “impeachment” } \\
\text { do presidente Collor. } \\
\text { Neoliberalismo. } \\
\text { Regulamentação do SUS: Lei } \\
\text { Orgânica da Saúde. } \\
\text { Operacionalização do SUS: } \\
\text { NOB. Descentralização. }\end{array}$ & $\begin{array}{l}\text { Procedimentos } \\
\text { Coletivos (PC) de } \\
\text { saúde bucal. } \\
\text { Implantação do PSF } \\
\text { (1994). }\end{array}$ & $\begin{array}{l}\text { Financiamento de PC pelo MS. } \\
\text { Experiências de inclusão da saúde bucal na } \\
\text { ESF em municípios. }\end{array}$ & $\begin{array}{l}\text { Retrocesso na implementação } \\
\text { do novo modelo, o Modelo } \\
\text { Assistencial. Privatista ganha } \\
\text { força. } \\
\text { O movimento da reforma } \\
\text { sanitária esforça-se em } \\
\text { operacionalizar o SUS. }\end{array}$ \\
\hline $\begin{array}{c}2000- \\
2006\end{array}$ & $\begin{array}{l}\text { Fim do governo Fernando } \\
\text { Henrique Cardoso (2002). } \\
\text { Início do primeiro mandato } \\
\text { governo Lula (2003-2006) }\end{array}$ & $\begin{array}{c}\text { Inclusão da saúde } \\
\text { bucal na ESF } \\
(2000) . \\
\text { Lançamento } \\
\text { da PNSB Brasil } \\
\text { Sorridente (2004) }\end{array}$ & $\begin{array}{l}\text { Início do processo de inclusão por parte dos } \\
\text { municípios. } \\
\text { Expansão da saúde bucal na ESF. } \\
\text { Implantação da rede especializada através dos } \\
\text { CEO. }\end{array}$ & $\begin{array}{l}\text { O SUS busca consolidar- } \\
\text { se com a reorientação da } \\
\text { atenção básica através da ESF, } \\
\text { que se expande rapidamente } \\
\text { pelo país. }\end{array}$ \\
\hline
\end{tabular}




\begin{tabular}{|c|c|c|c|c|}
\hline Período & $\begin{array}{l}\text { Conjuntura político- } \\
\text { administrativa }\end{array}$ & $\begin{array}{c}\text { Práticas } \\
\text { odontológicas }\end{array}$ & Aspectos chave & $\begin{array}{l}\text { Modelos de atenção à saúde } \\
\text { no Brasil }\end{array}$ \\
\hline $\begin{array}{c}2006- \\
2011\end{array}$ & $\begin{array}{l}\text { Segundo mandato do } \\
\text { governo Lula (2007-2010). } \\
\text { Início do governo Dilma } \\
\text { Roussef (2011). }\end{array}$ & $\begin{array}{c}\text { Ampliação do } \\
\text { número de ESB na } \\
\text { proporção um para } \\
\text { um. } \\
\text { Continuidade do } \\
\text { Programa Brasil } \\
\text { Sorridente }\end{array}$ & $\begin{array}{l}\text { Fortalecimento do Brasil Sorridente com } \\
\text { a criação e expansão da rede de centros } \\
\text { especializados (CEO) } \\
\text { Início da qualificação do processo de trabalho } \\
\text { em saúde bucal na lógica da ESF. } \\
\text { Ampliação da fluoretação das águas de } \\
\text { abastecimento público. } \\
\text { Avanços na implantação e qualificação da rede } \\
\text { de saúde bucal do SUS? } \\
\text { IV Conferência Nacional de Saúde Bucal? }\end{array}$ & $\begin{array}{l}\text { ESF configura-se como } \\
\text { modelo assistencial } \\
\text { reorganizador da atenção } \\
\text { primária. } \\
\text { Fortalecimento do SUS. }\end{array}$ \\
\hline $\begin{array}{l}2012- \\
2015\end{array}$ & $\begin{array}{l}\text { Primeiro mandato Dilma } \\
\text { Roussef (2011-2014). } \\
\text { Segundo mandato Dilma } \\
\text { Roussef (2015). } \\
\text { Crise ética, política e } \\
\text { econômica. }\end{array}$ & $\begin{array}{l}\text { Redes de Atenção à } \\
\text { Saúde Bucal - Linhas } \\
\text { de Cuidado } \\
\text { - Rede Cegonha } \\
\text { - Rede de Cuidados } \\
\text { à Pessoa com } \\
\text { Deficiência. }\end{array}$ & $\begin{array}{c}\text { PMAQ - AB } \\
\text { PMAQ - CEO } \\
\text { e-SUS } \\
\text { GraduaCEO }\end{array}$ & $\begin{array}{l}\text { Fragilização da gestão do SUS: } \\
\text { concessão da administração e } \\
\text { gerenciamento do SUS desde } \\
\text { a atenção primária à terciária } \\
\text { às Organizações Sociais de } \\
\text { Saúde, à Empresa Brasileira de } \\
\text { Serviços Hospitalares, criando } \\
\text { um cenário de terceirização } \\
\text { da saúde. }\end{array}$ \\
\hline
\end{tabular}

Fonte: adaptado de Carcereri (2005); Narvai e Carcereri (2011). 
tiveram atendimento nas últimas duas semanas devido a problema odontológico foram atendidas na rede pública (unidade básica de saúde ou centro de saúde). (IBGE, 2008) Ou seja, esse aumento na oferta e utilização dos serviços não se deu necessariamente no setor público, nem implica necessariamente em efetivas mudanças de prática ou reversão do modelo de atenção.

Várias pesquisas têm apontado que as ESB na ESF apresentam dificuldades importantes em tornar efetiva a mudança do modelo de atenção em saúde bucal. (MARTELLI et al., 2008; PEREIRA et al, 2012; REIS; SCHERER; CARCERERI, 2015; SOUZA; RONCALLI, 2007)

Estudos empíricos verificaram que a organização do processo de trabalho da ESB é realizada à parte dos outros participantes da ESF, bem como a organização da oferta de serviços de saúde bucal acontece sem conexão com a saúde geral. (FACCIN; SEBOLD; CARCERERI, 2010; PIMENTEL et al, 2010; FARIAS; SAMPAIO, 2011; PADULA; AGUILAR-DA-SILVA; 2014) Existe uma reprodução das tradicionais atividades coletivas do CD nas escolas, e existem poucos espaços para o trabalho em equipe. (FACCIN; SEBOLD; CARCERERI; 2010; PIMENTEL et al, 2010; PADULA, AGUILAR-DA-SILVA, 2014) Dessa maneira, a ESB e a EqSF parecem funcionar de maneira diferenciada.

As pesquisas também apontam que somente se observa integração na disponibilidade para responder à demanda imediata, nos encaminhamentos internos (NASCIMENTO et al., 2009; FACCIN, SEBOLD, CARCERERI, 2010; FARIAS, SAMPAIO, 2011), ou em atividades pontuais de trabalho em conjunto durante campanhas de vacinação (PIMENTEL et al., 2010), atividades de educação e prevenção em saúde bucal nas escolas, atendimento a pacientes de grupos programáticos (MATTOS et al., 2014), e organização da oferta baseada nas linhas de cuidado, ainda que o atendimento baseado na demanda espontânea seja predominante. (TAVARES et al., 2013)

Atividades como as reuniões de equipe e a visita domiciliar em conjunto com a EqSF não fazem parte do processo de trabalho habitual do $\mathrm{CD}$, por isso sua participação nelas é mínima. As reuniões de equipe não têm a periodicidade esperada (uma semana). Em muitos casos, ocorrem mensalmente, sem periodicidade definida, ou não ocorrem. (BALDANI et al, 2005; COSTA, ARAUJO, 2013; FACCIN; SEBOLD; CARCERERI, 2010; FARIAS; SAMPAIO, 2011; MOURA et al., 2013) As visitas domiciliares têm periodicidade variada, dependente da importância que cada equipe considere, e da disponibilidade de meios de transporte. (COSTA e ARAUJO, 2013; MOURA et al., 2013) 
Algumas pesquisas têm identificado situações onde os CD referem que existe conexão entre a ESB e a ESF (BALDANI et al., 2005), que sempre participam das reuniões de equipe e que sempre desenvolvem ações com a equipe de saúde da família. (SOUZA; RONCALLI, 2007) Ainda assim, os CD apontaram que elaboram e desenvolvem os programas de ação em saúde bucal sozinhos, sem suporte técnico, administrativo ou financeiro, pelo que a realização dessas atividades fica dependente de cada $\mathrm{CD}$, da sua permanência na ESF, no município, e da vontade e estímulo que ele tenha para o desenvolvimento delas. (SOUZA; RONCALLI, 2007) Assim, observa-se que existe um bom relacionamento pessoal, mas não existe uma adequada articulação dos saberes e conhecimentos para gerar uma intervenção conjunta. (FACCIN; SEBOLD; CARCERERI, 2010)

Outros estudos que têm buscado avaliar a saúde bucal na ESF a partir da expansão e do desempenho das ESB/ESF no nível estadual, através da análise de dados provenientes dos sistemas de informação de saúde (BALDANI et al., 2005; SILVA et al., 2011 PALACIO et al., 2014; PIMENTEL et al., 2014); no âmbito municipal, buscam identificar os nós críticos relacionados à implementação da estratégia a partir do ponto de vista dos usuários (ANDRADE: FERREIRA, 2006; EMMI: BARROSO, 2008), gestores (MARTELLI et al., 2008), e gestores e trabalhadores. (LOURENÇO et al., 2009; MATTOS et al., 2014; SOUZA; RONCALLI, 2007) Além disso, os estudos contemplam aspectos relacionados ao acesso e/ou utilização dos serviços de saúde bucal em áreas cobertas pela ESF. (SANTOS et al., 2007; CHAVES et al., 2012; SOARES et al., 2013; OLIVEIRA et al., 2014)

Os estudos de base populacional (CHAVES et al., 2012; OLIVEIRA et al., 2014; PEREIRA et al., 2009; PEREIRA et al., 2012; ROCHA, GOES, 2008; SOARES et al., 2013) têm evidenciado diferentes resultados com relação à inclusão da ESB/ESF nos municípios.

Em municípios de 50 mil a 100 mil habitantes da Bahia, com 100\% de cobertura da ESF, a utilização de serviços públicos na APS variou entre 23,2\% e 30\%. (CHAVES et al., 2012; SOARES et al., 2013) Em áreas cobertas pela ESF no município de Olinda (PE), verificou-se que $18,9 \%$ da população acima de 18 anos havia utilizado os serviços de saúde bucal da ESF. (OLIVEIRA et al., 2014)

Apenas três estudos buscaram comparar o desempenho dos serviços de saúde bucal em áreas cobertas e não cobertas por ESB/ESF, a fim de identificar as diferenças relacionadas à implantação dessa estratégia. (ROCHA; GOES, 2008; PEREIRA et al., 2009; PEREIRA et al., 2012) Nestes, não foi observada dife- 
rença de acesso aos serviços de saúde bucal entre residentes de áreas cobertas por ESB/ESF ou não cobertas (ROCHA; GOES, 2008), ou observou-se maior acesso a assistência odontológica em residentes de áreas cobertas pelo Programa de Agentes Comunitários de Saúde (PACS) ou ESF sem ESB, mas com CD. (PEREIRA et al., 2009) Estudo envolvendo 12 municípios com mais de 100 mil habitantes do Nordeste do Brasil não confirmou diferenças no acesso aos serviços odontológicos entre áreas cobertas e não cobertas por ESB/ESF, indicando a necessidade de investigar os fatores que levaram a esses resultados. (PEREIRA et al., 2012) Nesse sentido, é fundamental analisar o desenvolvimento da política de saúde bucal nos municípios, compreendendo o contexto político, cultural e social de sua implementação em cada local. Destaca-se a importância de relativizar os resultados considerando a implantação do novo modelo em cada município estudado. O município segue os pressupostos da ESF? Pode ser considerado um caso, um exemplo de implantação da política?

Nessa perspectiva, apresentaremos a seguir resultados de três estudos de caso realizados, dois em municípios do estado da Bahia (Salvador e Vitória da Conquista), e o terceiro em Florianópolis, Santa Catarina, que analisaram a implantação de equipes de saúde bucal como parte da ESF. Apesar de partirem de abordagens metodológicas diferentes, os estudos de caso dessas três experiências municipais trazem elementos para a discussão dos nós críticos sobre a implementação da política de saúde bucal no âmbito da atençãoo primária à saúde.

\section{Inclusão das ESB/ESF em Salvador e Vitória da Conquista, Bahia}

O ensaio comunitário realizado por Pereira e colaboradores (2012) avaliou agravos de saúde bucal (morbidade dentária autorreferida e prevalência de dor de origem dentária), acesso a serviço odontológico (consulta ao dentista no último ano), cobertura de ações curativo-reparadoras (tratamento de dor de origem dentária, tratamento restaurador e exodontia) e cobertura de ações preventivas (acesso a ações preventivas individuais e acesso a ações preventivas coletivas) em áreas cobertas e não cobertas por ESB/ESF em 12 municípios com mais de 100 mil habitantes do Nordeste do Brasil. Em cada município, foram sorteados respectivamente 10 setores censitários de áreas cobertas por ESB/ESF, que foram intencionalmente pareados com setores censitários não cobertos, identificados por proximidade geográfica e condição socioeconômica, sendo excluídos setores censitários que se localizavam em áreas parcialmente cobertas. 
Os dois municípios do estado da Bahia incluídos nesse estudo (Pereira et al., 2012), Salvador e Vitória da Conquista, tiveram desempenhos divergentes com relação aos indicadores de saúde bucal selecionados, em 2007, ano de realização da pesquisa de campo. Compreende-se que essas diferenças relacionem-se aos diferentes processos históricos de implementação das ações e políticas de saúde bucal nos municípios, bem como as prioridades municipais, refletindo em diferentes resultados sobre o estado de saúde da população, o acesso aos serviços de saúde e em termos de conhecimento e comportamentos derivados das práticas desenvolvidas.

Desse modo, é importante analisar os resultados dos indicadores de saúde bucal, à luz do processo histórico ${ }^{1}$ de implementação e a reorganização das práticas das ações de saúde bucal em ambos os municípios.

\section{Salvador}

No período de 1997 a 2004, Salvador teve continuidade político-administrativa, com a permanência de um mesmo grupo político na gestão municipal, estabelecendo-se para o período de 2005 a 2012 a gestão por outro grupo político. A proposta inicial de implantação da ESF no município era alcançar 100\% de cobertura no distrito sanitário de maior vulnerabilidade socioeconômica, o Subúrbio Ferroviário. Essa estratégia foi abandonada ao longo do processo de implementação da ESF, com a implantação de unidades em outras áreas da cidade, formando ilhas de áreas adstritas, cercadas por um mar de grandes áreas não cobertas, dificultando a implementação da adstrição de clientela. A implantação da ESB/ESF iniciou-se em 2001, logo após a instituição do incentivo financeiro com essa finalidade pelo MS, com quatro ESB/ESF para 14 EqSF, quando a cobertura da ESF era de 1,94\% da população. Em 2007, a cobertura da ESF chegou a 14,62\%, com 83 ESB/ESF para 115 EqSF (Tabela 1).

Soares e Paim (2011) identificaram como barreiras à implementação da política de saúde bucal no município, no período de 2004 a 2007, o contexto de ausência de autonomia financeira da secretaria municipal de saúde, descompromisso do prefeito com a política de saúde e a precarização das relações de trabalho, bem como a ausência de um projeto consistente de saúde bucal.

\footnotetext{
$1 \quad$ Resultados parciais do projeto "A gênese da política de saúde bucal nos âmbitos nacional e municipal”, edital Fapesb n. 017/2013. Apoio a projetos de pesquisa para Jovem Cientista no Estado da Bahia, T.O. n. JCBOo4O/2013, coordenado pela profa. Sandra Garrido de Barros.
} 


\begin{tabular}{|c|c|c|c|c|c|c|c|c|}
\hline $\begin{array}{l}\text { Município } \\
\text { (ano de } \\
\text { implantação } \\
\text { ESF) }\end{array}$ & Indicadores & 2001 & 2002 & 2003 & 2004 & 2005 & 2006 & 2007 \\
\hline \multirow{5}{*}{$\begin{array}{l}\text { Salvador } \\
(2000)\end{array}$} & População & 2.485 .702 & 2.485 .702 & 2.520 .504 & 2.556 .429 & 2.556 .429 & 2.673 .560 & 2.714 .018 \\
\hline & EqSF impl. (n) & 14 & 20 & 31 & 81 & 110 & 115 & 115 \\
\hline & ESB impl. (n) & 4 & 7 & 11 & 62 & 78 & 85 & 83 \\
\hline & Cob. Est. ESF (\%) & 1,94 & 2,78 & 4,24 & 10,93 & 14,84 & 14,84 & 14,62 \\
\hline & Cob. Est. ACS (\%) & 20,77 & 22,65 & 24,30 & 29,85 & 35,45 & 35,77 & 31,61 \\
\hline \multirow{5}{*}{$\begin{array}{l}\text { Vitória da } \\
\text { Conquista } \\
(1998)\end{array}$} & População & 267.189 & 267.189 & 270.364 & 274.618 & 274.618 & 286.575 & 290.690 \\
\hline & EqSF impl. & 30 & 31 & 32 & 36 & 37 & 37 & 37 \\
\hline & ESB impl. & 15 & 15 & 15 & 26 & 27 & 27 & 27 \\
\hline & Cob. Est. ESF (\%) & 38,74 & 40,03 & 40,83 & 45,23 & 46,48 & 44,54 & 43,91 \\
\hline & Cob. Est. ACS (\%) & 81,56 & 93,61 & 95,92 & 97,78 & 96,11 & 87,88 & 85,45 \\
\hline
\end{tabular}

Fonte: Ministério da Saúde/Secretaria de Atenção à Saúde/Departamento de Atenção Básica, outubro, 2015

Em 2007, no estudo conduzido por Pereira e colaboradores (2012), a capital do estado não apresentou diferença significativa entre áreas cobertas e não cobertas com relação à necessidade percebida de assistência odontológica $(\mathrm{p}=0,34)$ e dor de origem dentária $(\mathrm{p}=0,74)$. Entretanto, foi o município com maior necessidade acumulada de tratamento $(74,7 \%$ dos indivíduos de áreas cobertas e $76,2 \%$ de áreas não cobertas referiram necessidade de tratamento odontológico) dentre os 12 municípios do Nordeste analisados (Tabela 2).

O município apresentou impacto positivo da implementação da ESB/ESF com relação a utilização de serviço odontológico, oito vezes maior em áreas cobertas ( $\mathrm{p}<0,01$; RP=0,43; IC 95\%: ०,43-0,50), cobertura de ações clínicas individuais, como procedimento restaurador ( $\mathrm{p}<0,01 ; \mathrm{RP}=0,0,51$; IC 95\%: ०,43-0,50) e tratamento de dor de origem dentária ( $\mathrm{p}<0,00$; $\mathrm{RP}=0,0,65$; IC 95\%: ०,59-0,72) e ações preventivas individuais ( $\mathrm{p}<0, \mathrm{O} 1 ; \mathrm{RP}=0,47$; IC 95\%: $\circ, 43-0,51)$ e coletivas ( $\mathrm{p}<0,01 ; \mathrm{RP}=0,59 ;$ IC 95\%: ०,56-0,62) (Tabela 2).

Pode-se inferir, portanto, que, no município de Salvador, a inclusão das ESB/ ESF proporcionou ampliação significativa da rede de serviços odontológicos na esfera pública, ainda que alcançando uma baixa cobertura populacional. 
A inclusão das ESB/ESF significou maior acesso a serviços de saúde bucal nas áreas cobertas, seja relacionado a ações clínicas individuais, seja com relação a procedimentos preventivos individuais e coletivos. Para todos os tipos de serviços analisados, a probabilidade de um morador de área coberta por ESB/ESF ser atendido na sua unidade de referência foi maior que em áreas não cobertas.

Tabela 2 - Agravos de saúde bucal, acesso a serviços odontológicos na unidade, cobertura de ações clínicas individuais e cobertura de ações preventivas em áreas cobertas e não cobertas por ESB/PSF em Salvador (SSA) e Vitória da Conquista (VdC), Bahia, 2007 (continua)

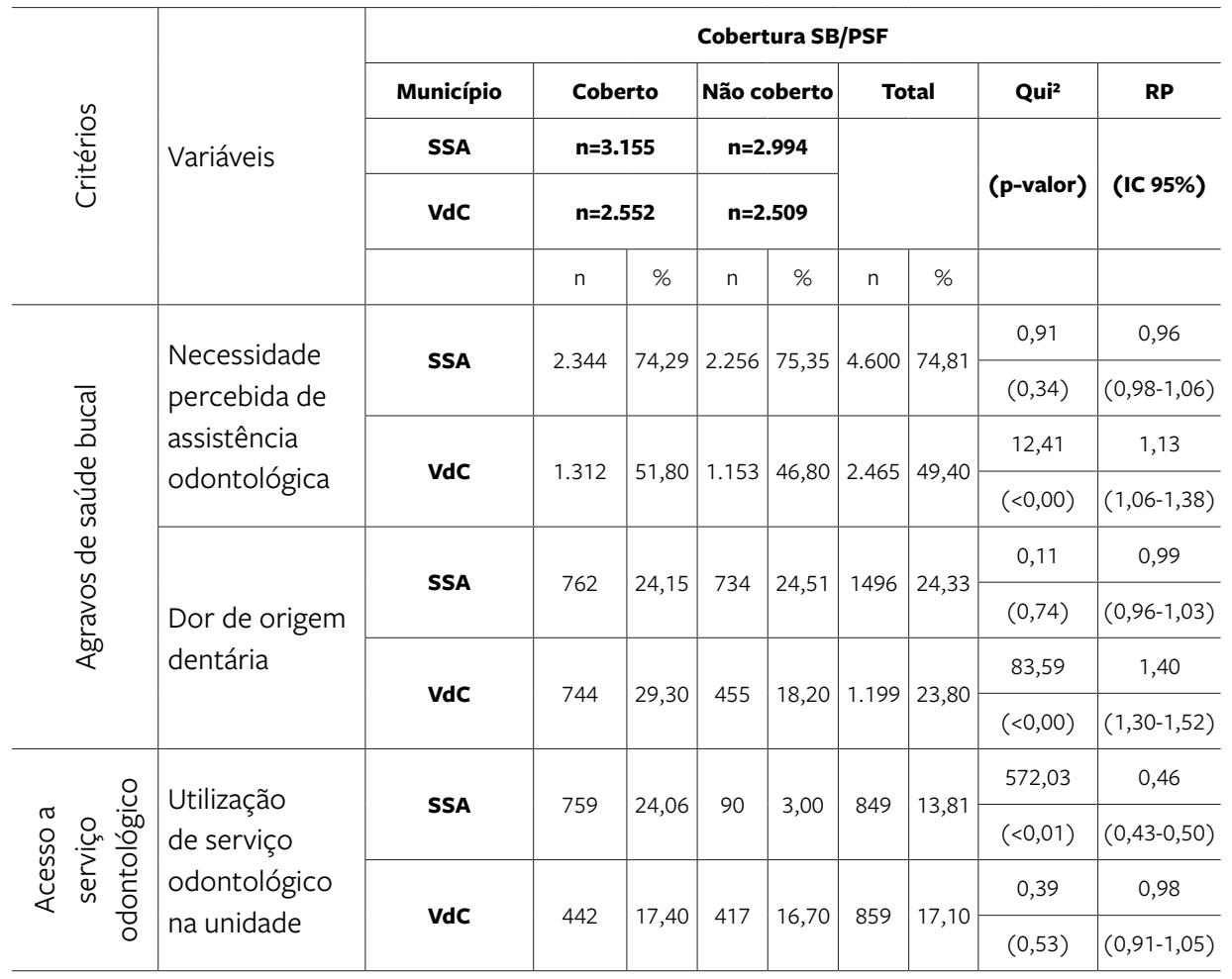


Tabela 2 - Agravos de saúde bucal, acesso a serviços odontológicos na unidade, cobertura de ações clínicas individuais e cobertura de ações preventivas em áreas cobertas e não cobertas por ESB/PSF em Salvador (SSA) e Vitória da Conquista (VdC), Bahia, 2007

\begin{tabular}{|c|c|c|c|c|c|c|c|c|c|c|}
\hline \multirow{5}{*}{ 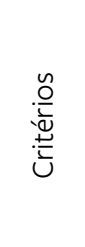 } & \multirow{5}{*}{ Variáveis } & \multicolumn{9}{|c|}{ Cobertura SB/PSF } \\
\hline & & Município & \multicolumn{2}{|c|}{ Coberto } & \multicolumn{2}{|c|}{ Não coberto } & \multicolumn{2}{|c|}{ Total } & Qui $^{2}$ & RP \\
\hline & & SSA & \multicolumn{2}{|c|}{$n=3.155$} & \multicolumn{2}{|c|}{$n=2.994$} & & & & \multirow[t]{2}{*}{ (IC 95\%) } \\
\hline & & VdC & \multicolumn{2}{|c|}{$\mathrm{n}=\mathbf{2 . 5 5 2}$} & \multicolumn{2}{|c|}{$n=2.509$} & & & & \\
\hline & & & $\mathrm{n}$ & $\%$ & $\mathrm{n}$ & $\%$ & $\mathrm{n}$ & $\%$ & & \\
\hline \multirow{8}{*}{ 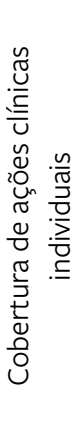 } & \multirow{4}{*}{$\begin{array}{l}\text { Realização de } \\
\text { procedimento } \\
\text { restaurador }\end{array}$} & \multirow{2}{*}{ SSA } & \multirow{2}{*}{271} & \multirow{2}{*}{8,59} & \multirow{2}{*}{37} & \multirow{2}{*}{1,24} & \multirow{2}{*}{308} & \multirow{2}{*}{5,01} & 174,57 & 0,51 \\
\hline & & & & & & & & & $(<0,01)$ & $(0,45-0,57)$ \\
\hline & & \multirow{2}{*}{ VdC } & \multirow{2}{*}{284} & \multirow{2}{*}{11,20} & \multirow{2}{*}{340} & \multirow{2}{*}{13,60} & \multirow{2}{*}{624} & \multirow{2}{*}{12,40} & 6,65 & 1,12 \\
\hline & & & & & & & & & $(0,01)$ & $(1,03-1,23)$ \\
\hline & \multirow{4}{*}{$\begin{array}{l}\text { Tratamento de } \\
\text { dor de origem } \\
\text { dentária }\end{array}$} & \multirow{2}{*}{ SSA } & \multirow{2}{*}{231} & \multirow{2}{*}{30,31} & \multirow{2}{*}{99} & \multirow{2}{*}{13,49} & & & 60,60 & 0,65 \\
\hline & & & & & & & (2) & $2<, 00$ & $(<0,00)$ & $(0,59-0,72)$ \\
\hline & & VdC & 189 & 2560 & 180 & 3960 & 369 & 3090 & 25,90 & 1,31 \\
\hline & & & 103 & 20,00 & 100 & $2 \pi, 00$ & & (2) & $(0,00)$ & $(1,17-1,46)$ \\
\hline$\tilde{0}$ & & $\csc$ & 626 & 1081 & 71 & & & & 459,37 & 0,47 \\
\hline 美 & Ações & הת הכת & $0<0$ & 1,04 & 74 & 2,47 & 100 & (11, & $(<0,01)$ & $(0,43-0,51)$ \\
\hline d & individuais & $\mathrm{VdC}$ & 277 & 1000 & 227 & 1230 & & & 6,54 & 1,12 \\
\hline थै & & vac & 271 & 10,90 & 332 & 13,30 & 609 & 12,10 & $(0,01)$ & $(1,03-1,23)$ \\
\hline $\begin{array}{l}\pi \\
0 \\
\end{array}$ & & $\operatorname{scs} \rightarrow$ & 701 & 2405 & 100 & 620 & רדי & & 398,06 & 0,59 \\
\hline$\frac{\pi}{5}$ & P. & ה מכת & 104 & $24,0]$ & 100 & 0,20 & 912 & $\mid 13,01$ & $(<0,01)$ & $(0,56-0,62)$ \\
\hline $\begin{array}{l}\frac{1}{d} \\
\text { Oे }\end{array}$ & arescias & Vdc & 277 & 10 (10 & 363 & 1450 & 640 & 1270 & 14,63 & 1,04 \\
\hline U & & ( & $2 \pi$ & 10,0 & (20) & 14,30 & 040 & 12,10 & $(<0,00)$ & $(1,02-1,06)$ \\
\hline
\end{tabular}

Fonte: (UFRN), financiado pelo edital MCT-CNPq / MS-DAB/SAS - No 49/2005.

\section{Vitória da Conquista}

Vitória da Conquista apresentava continuidade político-administrativa desde 1997, com manutenção do mesmo grupo político na gestão municipal até 2015. A reorganização da APS do município a partir da ESF foi uma decisão política dos gestores municipais. A ESF foi adotada como substitutiva, mas não como única estratégia no município, que manteve unidades básicas convencionais com equipes do PACS. Foram seguidas, contudo, algumas diretrizes para 
todas as unidades do município, a saber: mapeamento e territorialização; definição de áreas de abrangência e clientela adstrita; APS como porta de entrada do sistema de saúde.

O município tem um histórico de implantação de ESB iniciado em 1998, sendo um dos 76 municípios do país que incluiu a saúde bucal na ESF antes da criação do incentivo financeiro estabelecido no final de 2000. Já em 2001, tinha 14 ESB/ESF para 30 EqSF, com uma cobertura da ESF de 8,74\%. Em 2007, o município contava com 37 ESB/ESF para 37 EqSF, alcançando 43,91\% de cobertura da ESF. A cobertura estimada de ACS no município (áreas cobertas e não cobertas pela ESF) foi superior a $85 \%$ durante seis anos no período de 2001 a 2007 e a cobertura da ESF esteve acima de $40 \%$ durante todo o período (Tabela 1). O município adota a adstrição de clientela também nas unidades básicas convencionais, sendo que algumas dessas funcionavam em sistema de três turnos de atendimento, com funcionamento noturno, o que não ocorre nas unidades de saúde da família.

No estudo conduzido por Pereira e colaboradores (2012), Vitória da Conquista apresentou maior necessidade de assistência odontológica percebida e maior percentual de dor de origem dentária nos moradores de áreas cobertas por ESB/ESF. Não houve diferenças entre áreas cobertas e não cobertas com relação à utilização de serviços odontológicos, mas para a cobertura de ações clínicas individuais e ações preventivas individuais e coletivas, as maiores coberturas foram observadas nas áreas não cobertas (Tabela 2). Há que se destacar que o município apresentou os menores percentuais de necessidade de tratamento em ambos os modelos estudados entre os 12 municípios analisados por Pereira e colaboradores (2012).

No município de Vitória da Conquista, as áreas cobertas não apresentaram melhor desempenho que as áreas não cobertas, contudo, há que se destacar que todas as unidades básicas convencionais tinham área de abrangência definida, cadastramento familiar e clientela adstrita, sendo que algumas funcionavam em regime de três turnos. Ou seja, muito provavelmente o melhor resultado nos indicadores de acesso e utilização observados nas áreas não cobertas estão relacionados a esses fatos. Os resultados observados no município corroboram com os achados de Pereira e colaboradores (2009) no município de Natal, Rio Grande do Norte, onde também foi observado maior acesso a serviços odontológicos em áreas cobertas por ACS ou ESF sem ESB, mas com CD. 


\section{Implementação da política de saúde bucal no componente atenção básica em Florianópolis, Santa Catarina}

O caso de Florianópolis ocorre em um contexto de forte apoio da gestão estadual. No estado de Santa Catarina, a implantação do PSF iniciou-se em 1994 e ampliou-se por meio dos convênios firmados entre o MS e os municípios. Os primeiros dados do programa surgiram a partir da Portaria n. ${ }^{\circ}$ 1886/GM, de 18 de dezembro de 1997 (BRASIL, 1997b), que vinculou os recursos financeiros à alimentação do Sistema de Informação da Atenção Básica. (HENRIQUE; CAL$\mathrm{VO}, 2008)$

Com forte apoio da Secretaria de Estado de Saúde, as primeiras cidades catarinenses a contarem com as EqSF foram Ascurra, Chapecó e Blumenau. (SANTA CATARINA, 2009) Em 2009, 15 anos após a implantação, o estado de Santa Catarina tornou-se o primeiro estado do país a contar com a ESF em todos os municípios a partir do credenciamento, junto ao MS, de EqSF em Mirim Doce, única cidade que ainda não oferecia o serviço.

Mesmo tendo a PNAB como norteadora, as condições e características de implantação do novo modelo nos diferentes municípios foram heterogêneas, variabilidade que, na prática, configurou a expressão concreta dos contextos e momentos históricos específicos de cada experiência de implantação.

Na capital, Florianópolis, observou-se particularidades e um atraso relativo na implantação da ESF em comparação a outros municípios do estado de porte semelhante. As discussões iniciaram-se em 1994 e, em 1996, foram implantadas seis EqSF cobrindo quatro áreas de abrangência, aumentando esse número para 25 áreas no período de 1997/2000. (CONILL, 2002) As ESB/ESF foram instituídas no município a partir de agosto de 2004. Essa inserção tardia das ESB junto às EqSF, trouxe como consequência uma diferença significativa na cobertura populacional das equipes, ilustrada no Quadro 2. Além disso, o foco das ESB estava nas ações direcionadas aos escolares, nas demandas clínicas curativas dos usuários e também na integração desses profissionais às EqSF que já atuavam nas Unidades Básicas de Saúde (UBS). (FACCIN; SEBOLD, 2006)

Em 2006, dois anos após a inserção das ESB, observou-se que as práticas das ESB caracterizavam-se por realização de ações puramente clínicas, de cunho individual, sendo a inserção ao trabalho multiprofissional, pautado na integralidade do cuidado, o maior desafio. (FACCIN; SEBOLD, 2006) Questões como a falta de capacitação/formação para atuar na ESF, incompreensão do profissional como membro de uma equipe, manutenção das práticas tradicio- 
nais no trabalho preventivo com foco nos escolares, excesso de população na área adstrita, falta de adequação do ambiente de trabalho (vários dentistas em um mesmo espaço), escassez de recursos humanos - principalmente auxiliares, dificuldades de referenciamento ao nível secundário, foram relatados como pontos cruciais, os quais deveriam sofrer intervenções para que ocorresse a transformação das práticas (Quadro 2).

\section{Quadro 2 - Caracterização do processo de implantação ESF e ESB em Florianópolis, de 2002 a 2014}

\begin{tabular}{|c|c|c|c|c|c|c|c|c|}
\hline $\begin{array}{l}\text { Dados e } \\
\text { características }\end{array}$ & 2002 & 2005 & 2006 & 2007 & 2008 & 2010 & 2012 & 2014 \\
\hline $\begin{array}{l}\text { População } \\
\text { municipal }\end{array}$ & 360.603 & 396.778 & 406.564 & 416.267 & 402.346 & 402.346 & 427.298 & 433.158 \\
\hline $\begin{array}{l}\text { Cobertura } \\
\text { Populacional PSF/ } \\
\text { ESF }\end{array}$ & $41,1 \% \%$ & $61,7 \%$ & $67,8 \%$ & $71,3 \%$ & $77,6 \%$ & $84 \%$ & $92,04 \%$ & $94,78 \%$ \\
\hline $\begin{array}{l}\text { No de ESB } \\
\text { implantadas }\end{array}$ & 42 & 66 & 78 & 84 & 87 & 98 & 114 & 119 \\
\hline $\begin{array}{l}\text { NO ESB } \\
\text { implantadas }\end{array}$ & 0 & 10 & 9 & 25 & 29 & 39 & 59 & 65 \\
\hline $\begin{array}{l}\text { Cobertura } \\
\text { Populacional ESB }\end{array}$ & 0 & $9,2 \%$ & $7,8 \%$ & $21,13 \%$ & $25,66 \%$ & $33,41 \%$ & $47,66 \%$ & $51 \%$ \\
\hline $\begin{array}{l}\text { No de Centros de } \\
\text { Saúde }\end{array}$ & 47 & 48 & 48 & 48 & 48 & 48 & 49 & 49 \\
\hline \multirow{3}{*}{$\begin{array}{l}\text { Presença } \\
\text { de práticas } \\
\text { inovadoras na } \\
\text { Rede de Atenção } \\
\text { à Saúde (RAS) }\end{array}$} & \multicolumn{8}{|c|}{$\begin{array}{l}\text { Centro de Saúde (CS) campo de prática para graduação e pós-graduação (Residência em Saúde } \\
\qquad \text { da Família) }\end{array}$} \\
\hline & & & & \multicolumn{5}{|c|}{ Informatização Sistema } \\
\hline & & & & & & \multicolumn{3}{|c|}{$\begin{array}{l}\text { Núcleo de Apoio à Saúde da } \\
\text { Família } \\
\text { Complexo regulador }\end{array}$} \\
\hline $\begin{array}{l}\text { Habilitação em } \\
\text { gestão }\end{array}$ & $\begin{array}{r}\text { Gestão } \\
\text { pela } N \\
\text { Assi }\end{array}$ & $\begin{array}{l}\text { na da ater } \\
\text { ma Opera } \\
\text { ência à Sa }\end{array}$ & $\begin{array}{l}\text { o básica } \\
\text { nal da } \\
02\end{array}$ & & Termo de & to pela Sai & de Gestão & \\
\hline $\begin{array}{l}\text { Índice de } \\
\text { Desenvolvimento } \\
\text { Humano***}\end{array}$ & 0,881 & - & 0,875 & 0,875 & 0,875 & 0,847 & 0,847 & 0,847 \\
\hline
\end{tabular}

Fonte: adaptado de Sisson e colaboradores (2011) 
Tal pesquisa registrou insuficiente processo de discussão sobre as mudanças no processo de trabalho em saúde bucal carreadas pelo então PSF. Embora se tratando da introdução de um novo modelo de atenção, o espaço de discussão limitou-se ao treinamento introdutório para atuação no Programa. Assim, a inserção da ESB findou representando, naquele momento, simplesmente uma mudança contratual.

Em 2007, três anos após a implantação das ESB, seguindo os moldes Política Nacioanl da Atenção Básica (PNAB), foi aprovada a Política Municipal de Atenção Básica (PMAB) (Portaria/SS/GAB/ n. ${ }^{\circ}$ 283), que estabeleceu diretrizes e normas para a organização da atenção básica baseada na ESF.

Observou-se, então, uma nova postura da gestão municipal com relação à atenção básica, estabelecendo normativas que possibilitaram operacionalizar a ESF no município. Questões como definição de área adstrita com população de até 4 mil habitantes por EqSF, podendo essa ser reduzida em caso de áreas com interesse social; incentivo ao planejamento ascendente; definição do processo de trabalho pautado na territorialização, no acolhimento, no cadastramento domiciliar, além de proposição de atividades mínimas a serem oferecidas pelas UBS. Vale destacar ainda que o município adotou a integração ensino-serviço como eixo norteador, incluindo a supervisão de alunos de graduação como parte do processo de trabalho dos profissionais.

A partir dessa Portaria, foram regulamentadas as reuniões de área e as reuniões de planejamento das UBS como um todo, com normatização de carga horária e periodicidade. Dessa forma, foram ofertados aos profissionais momentos de encontro semanais e mensais.

Uma das características do processo de trabalho apontada pelo MS é o trabalho interdisciplinar e em equipe, promovendo a integração de profissionais com diferentes formações. (BRASIL, 2011)

Segundo Paim (2002), se o enfoque interdisciplinar for incorporado na formulação de políticas públicas e na organização de serviços de saúde, pode contribuir para mudar sua formação, desde a graduação. Destaca-se que o trabalho interdisciplinar multiprofissional e em equipe pode propiciar a retroalimentação no cuidado dos usuários e pode contribuir assim estrategicamente com a integralidade da atenção. Porém, é necessário manter as discussões em torno da interdisciplinaridade, vinculando a atual política de saúde, norteada pelo princípio da integralidade, com o exercício profissional, cujos modelos ainda permanecem conectados às práticas que, pendularmente, oscilam entre 
o uni e o multidisciplinar, indicando uma execução de disciplinas desprovidas de objetivos comuns sem aproximação ou cooperação. (MENDES; LEWGOY; SILVEIRA, 2008)

Após a publicação das políticas, uma nova pesquisa realizada no município por Ferreira (2010) teve como foco a integralidade do cuidado. Essa pesquisa evidenciou uma apropriação pelas EqSF e ESB do processo de trabalho como apontado na PMAB, principalmente pela introdução de novas práticas, denominadas pelo autor de "práticas sociais no cuidado da saúde". Foram consideradas práticas sociais o levantamento das necessidades da comunidade e posterior priorização gerada a partir de discussões entre a equipe, a realização de visita domiciliar, vinculação com comunidade e usuários, acolhimento e humanização do trabalho com foco na promoção da saúde.

Essa incorporação não foi homogênea mesmo dentro de uma mesma equipe, o que constituiu entraves, tanto para mudanças no processo de trabalho quanto para a implementação de um novo modelo de atenção. Parte dos entraves deve-se à formação, fragmentada e centrada nas especialidades, às dificuldades no acesso, à assistência pelos usuários, à carência de recursos materiais e de pessoal para atividades extramuros, ao conflito de poderes na indefinição do papel de cada profissional nas equipes, o que poderia influenciar na eficiência da equipe, à resistência em querer aprender o "algo mais", ir além "do céu da boca". (FERREIRA, 2009)

Em 2015, Florianópolis atingiu 100\% de cobertura, conquistando nacionalmente o título de melhor capital em cobertura da ESF. Para a saúde bucal, no entanto, a cobertura é de $54 \%$, demonstrando o descompasso entre a PNAB e a PNSB no município. (BRASIL, 2015b) Apesar do contexto de defasagem de cobertura de ESB em relação às EqSF, a capital destaca-se em outros quesitos, como, por exemplo, a priorização de contratação de profissionais por concurso, a carga horária de trabalho de 40 horas e a estrutura das UBS. Tal desempenho lhe valeu, em 2015, o quarto lugar no Prêmio Brasil Sorridente de Boas Práticas em Saúde Bucal. (CONSELHO REGIONAL de ODONTOLOGIA DE SANTA CATARINA, 2015)

O estágio de implementação e a atual estrutura e solidificação das práticas sociais no cuidado da saúde foi objeto de pesquisa realizada por Peres (2015). A análise da pesquisa permitiu categorizar o processo de trabalho das equipes em três vertentes. A primeira, com foco no usuário - acolhimento, vínculo, ampliação do acesso, priorização, corresponsabilização. As EqSF e ESB, ao or- 
ganizarem seu trabalho, utilizavam o acolhimento como o principal dispositivo para ampliar o acesso aos serviços e demonstraram compreensão do modelo assistencial proposto pela ESF. O tempo de experiência na atenção básica e o engajamento do profissional favoreceram a criação do vínculo. Profissionais engajados no sentido de qualificação para a saúde da população mostraram-se mais vinculados aos usuários e com maior envolvimento nas ações de saúde.

Na segunda vertente, dentre as ações de reorientação dos serviços com foco no processo de trabalho, foram identificadas reuniões de equipe, atividades compartilhadas, planejamento e avaliação de ações de saúde como principais estratégias na medida em que espaços coletivos próprios da equipe favoreceram a integração, a organização para sua área de abrangência e, principalmente, o planejamento das atividades grupais. Essa relação estabelecida nesses momentos contribuiu para a superação das relações hierarquizadas.

Na terceira vertente, foi possível identificar, como principais ações facilitadoras do trabalho da equipe, a existência de sistemas informatizados para a regulação, o prontuário eletrônico, presença de computadores com acesso a rede de dados, telefone, protocolos de atenção à saúde e fluxos de acesso definidos, além do conhecimento da norma para trabalhar com esses sistemas. Tais mecanismos promoveram para a equipe maior qualidade no desenvolvimento do trabalho e, para o usuário, uma maior equidade na oferta dos serviços.

Os estudos realizados em Florianópolis, em 2006, 2009 e 2014, sugerem que a política nacional de saúde bucal vem se consolidando ao longo dos anos no município. Por serem estudos qualitativos, cuja metodologia envolveu entrevistas e observações de campo, evidenciaram o contexto histórico e a compreensão dos participantes em cada período: a pesquisa realizada em 2006 permitiu compreender o início do processo de inserção da Saúde Bucal (SB) na ESF, em Florianópolis. O estudo de 2009 descreveu o período relativo aos cinco anos dessa inserção, e a pesquisa realizada em 2014 objetivou compreender as potencialidades e dificuldades de inserção da SB na ESF após 10 anos de adesão ao então PSF.

Como aspectos chaves para implementação da PNSB, em Florianópolis, destacam-se as mudanças ocorridas no processo de trabalho da ESB e a qualidade da APS desenvolvida no município, ao longo desses 10 anos. Destaca-se também a mudança do perfil dos profissionais, advinda da implementação das Novas Diretrizes Curriculares e de todas as políticas indutoras da formação em saúde que se sucederam promovendo a integração dos cursos da área da saúde 
da Universidade Federal de Santa Catarina com a Secretaria Municipal de Saúde. (CARCERERI et al., 2015; SOUZA; CARCERERI, 2O11)

O estudo de Conill (2002), ao analisar a implantação do PSF em Florianópolis, no período de 1994 a 2000, concluiu que parecem ter maior influência no processo o tempo de implantação, o tipo de movimento social existente na comunidade e as características dos profissionais.

Ainda que o município seja referência em APS no país, há muitos pontos a serem superados em prol da consolidação da PNSB bem como da ESF como modelo de atenção proposto para o SUS.

\section{Considerações finais}

Este capítulo buscou apresentar como tem se dado a implementação da política nacional de saúde bucal no seu componente atenção básica, a partir de revisão da literatura sobre o tema e da análise de três experiências municipais.

A partir de 1994, a ESF constituiu-se no país como principal estratégia de reorganização da atenção básica no SUS. O incentivo financeiro para a inclusão da ESB/ESF, estabelecido no final de 2000, configurou-se como principal elemento indutor desse processo no âmbito da saúde bucal. Ademais, o desenvolvimento da PNSB no âmbito municipal apresentou diferentes configurações a depender do contexto sócio-histórico, cultural, político-administrativo e do modelo de atenção à saúde adotado pelo município.

A inclusão tardia da saúde bucal na ESF, a formação dos profissionais de saúde bucal, em especial do CD, voltada para a prática clínica individual, centrada no modelo de atenção à saúde bucal privatista, bem como a tradição liberal da profissão, têm contribuído para uma integração ainda pequena da ESB no desenvolvimento de atividades da ESF e efetiva reversão do modelo de atenção à saúde. A prática dos profissionais de saúde bucal em grande parte continua centrada no atendimento curativo-restaurador individual e na priorização da população escolar para a realização de atividades de promoção da saúde e prevenção dos principais agravos de saúde bucal.

Mais de 90\% dos municípios do país já possuem ESB/ESF, mas ainda há um número reduzido de ESB modalidade II implantadas, e não parece haver interesse ou mesmo uma política de ampliação de cobertura nessa modalidade. Entretanto, considerando-se a relação custo-benefício do uso de pessoal auxiliar em odontologia, a escassez de recursos financeiros no setor público e 
a necessidade de tratamento acumulada da população, essa estratégia torna-se fundamental para a expansão da cobertura dos serviços de saúde bucal.

Há que se destacar que houve uma ampliação da oferta e utilização de serviços odontológicos, contudo ela ainda é insuficiente. Estudos que comparam o desempenho de indicadores de saúde bucal de áreas cobertas e não cobertas por ESB/ESF não evidenciaram necessariamente melhor desempenho em áreas cobertas pela ESF. É necessário, então, refletir que fatores estariam influenciando esses resultados.

A simples adesão ao incentivo financeiro não implica em decisão política de reversão do modelo de atenção à saúde. Bem como a não adesão não implica em manutenção do modelo hegemônico. Nesse sentido, a decisão política do nível local em organizar o sistema de saúde tendo como fundamento a APS com território de atuação definido, com população adstrita, acesso universal e contínuo aos serviços de saúde, com vínculo e corresponsabilização, participação da comunidade, é mais decisiva que a adesão a um incentivo financeiro. Ou seja, é possível um município adotar essas premissas sem aderir ao incentivo e obter bons resultados, mas a recíproca (aderir ao incentivo e não adotar essas diretrizes organizativas) não é verdadeira. Como no caso do município de Vitória da Conquista, que não apresentou melhores resultados em áreas cobertas por ESB/ESF, mas, comparado a 12 outros municípios, teve menor necessidade de tratamento em áreas cobertas e descobertas e maior percentual da população com acesso a serviços públicos de saúde bucal.

Por outro lado, o êxito de uma política pública está relacionada também às características dos trabalhadores que a implementam, bem como a articulação coerente entre um projeto de governo transformador, a alta capacidade de governo na condução do processo, e sua governabilidade. No caso da ESF, mudanças importantes na formação ainda estão em curso. Em que pese os esforços realizados pelos cursos de graduação na área da saúde para formar profissionais aptos ao trabalho em equipe interdisciplinar, ainda há um longo caminho a ser trilhado nessa direção. Faz-se necessário diminuir a carga horária de disciplinas, abrindo espaços para as interdisciplinas e estágios multiprofissionais. O Programa de Educação pelo Trabalho Saúde da Família configurou-se em alternativa relevante para que esse objetivo seja atingido. Assim como, em nível de pós-graduação, destacam-se os cursos de Residência Multiprofissional em Saúde da Família. 
Nesse sentido, visando à consolidação da PNSB, destaca-se também a importância do fortalecimento contínuo da integração ensino-serviço-comunidade como estratégia de formação inicial na área da saúde e, também de educação permanente dos trabalhadores da saúde, entendendo a saúde bucal como uma área de ação multiprofissional e interdisciplinar.

\section{Referências}

ANDRADE, K.; FERREIRA, E. Avaliação da inserção da odontologia no Programa Saúde da Família de Pompéu (MG): a satisfação do usuário. Ciência \& Saúde Coletiva, Rio de Janeiro, v.11, n. 1., p. 123-130. 2006.

ANTUNES J.; NARVAI P. Políticas de saúde bucal no Brasil e seu impacto sobre as desigualdades em saúde. Revista Saúde Pública, Rio de Janeiro, v. 44, n. 2, p. 360-5. 2010.

AQUINO, R. et al. Estratégia saúde da família e reordenamento do sistema de serviços de saúde. In: PAIM, J. S.; ALMEIDA-FILHO, N. Saúde Coletiva: teoria e prática. Rio de Janeiro: Medbook, 2014. Cap. 25 p. 353-371.

BALDANI, M. et al. A inclusão da odontologia no Programa Saúde da Família no Estado do Paraná, Brasil. Cadernos de Saúde Pública, Rio de Janeiro, v. 21, n. 4, p. 1026-1035. 2005.

BALDANI, M. et al. Serviços públicos odontológicos: provisão e equidade no Estado do Paraná, Brasil. Revista Saúde Pública, Rio de Janeiro, v. 43, n. 3, p. 446- 54. 2009

BRASIL. Ministério da Saúde. Relatório Final da $1^{a}$ Conferência Nacional de Saúde Bucal. Brasília, DF., 1986.

BRASIL. Ministério da Saúde. Relatório Final da $2^{a}$ Conferência Nacional de Saúde Bucal. Brasília, DF., 1993.

BRASIL. Ministério da Saúde. Secretaria da Assistência à Saúde. Coordenação da Saúde e Comunidade. Saúde da Família: uma estratégia de reorientação do modelo assistencial. Brasília, DF, 1997a.

BRASIL. Ministério da Saúde. Portaria no 1886 GM/MS, de 18 de dezembro de 1997. Aprova as normas e diretrizes do Programa de Agentes Comunitários de Saúde e do Programa de Saúde da Família. Diário Oficial [da] República Federaltiva do Brasil, Brasílis, DF, 22 dez. 1997, sec. 1, p. 11 (BRASIL, 1997b)

BRASIL. Ministério da Saúde. Portaria no 1.444 GM/MS, de 28 de dezembro de 2000. Estabelece incentivo financeiro para a reorganização da atenção à saúde bucal prestadas nos municípios por meio do programa de saúde da família. Diário Oficial [da] República Federativa do Brasil, Brasília, DF, 29 dez. 2000, sec. 1, p. 85

BRASIL. Ministério da Saúde. Secretaria de Atenção à Saúde. Departamento de Atenção Básica.Coordenação Nacional de Saúde Bucal. Diretrizes da Política Nacional de Saúde Bucal. Brasília, DF, 2004a. 
BRASIL. Ministério da Saúde. Secretaria de Atenção à Saúde. Departamento de Atenção Básica. Projeto SB Brasil 2003: condições de saúde bucal da população brasileira 2002-2003: resultados principais. Brasília, DF, 2004b.

BRASIL. Ministério da Saúde. Secretaria de Atenção Básica. Departamento deAtenção Básica. Política Nacional de Atenção Básica. Brasília: Ministério da Saúde; 2007.

BRASIL. Ministério da Saúde. Portaria no 2.488 GM/MS, de 21 de outubro de 2011. Aprova a Política Nacional de Atenção Básica, estabelecendo a revisão de diretrizes e normas para a organização da Atenção Básica, para a Estratégia Saúde da Família (ESF) e o Programa de Agentes Comunitários de Saúde (PACS). Diário Oficial [da] República Federativa do Brasil, Brasília, DF, 24 out. 2011, sec.1, p. 48.

BRASIL. Ministério da Saúde. Secretaria de Atenção à Saúde. Secretaria de Vigilância em Saúde.SB Brasil 2010: Pesquisa Nacional de Saúde Bucal: resultados principais. Brasília, DF, 2012a.

BRASIL. Ministério da Saúde. Secretaria de Atenção à Saúde. Departamento de Atenção Básica. Política Nacional de Atenção Básica. Brasília, DF, 2012b.

BRASIL. Ministério da Saúde. Secretaria de Atenção à Saúde. Departamento de Atenção Básica. Florianópolis atinge 100\% de cobertura da Atenção Básica com a Estratégia de Saúde da Família. Notícias. 1998. Disponível em: <http://dab.saude.gov.br/portaldab/ noticias.php?conteudo=_\&cod=1998>. Acesso em: 19 set. 2015

BRASIL. Ministério da Saúde. Secretaria de Atenção à Saúde. Departamento de Atenção Básica. Histórico de cobertura da Saúde da Família. 2015. Disponível em: <http//:dab.saude. gov.br/portaldab/histórico_cobertura_sf.php>. Acesso em: 5 out. 2015.

CALADO, G. S. A inserção da equipe de saúde bucal no Programa de Saúde da Família: principais avanços e desafios. 122 f. Dissertação (Mestrado em Saúde Pública) - Escola Nacional de Saúde Pública, Fundação Oswaldo Cruz, Rio de Janeiro, 2002.

CARCERERI, D. L. et. al. Formação em odontologia e interdisciplinaridade: o Pró-Saúde da UFSC. Revista da ABENO, Camaragibe, v. 11, n. 1, p. 62-70. 2011.

CARCERERI, D. L. et. al. Estudo Prospectivo sobre a gestão de competências na área de odontologia no contexto do Sistema Único de Saúde/SUS, no Estado de Santa Catarina. Tese (Doutorado em Engenharia de Produção) - Centro Tecnológico, Universidade Federal de Santa Catarina, 2005.

CHAVES, S. C. L.; CRUZ, D. N. Desafios contemporâneos à organização da atenção em saúde bucal na Bahia. Revista Baiana de Saúde Pública, Salvador, v. 36 n. 1, p.621-639, 2012.

CHAVES, S. et al. Características do acesso e utilização de serviços públicos odontológicos em municípios de médio porte. Ciência \& Saúde Coletiva, Rio de Janeiro, v. 17, p. 3119-3128, 2012.

CHAVES, S. et al. Análise de políticas de saúde bucal no Brasil. A política nacional de saúde bucal no período 2003 a 2013: breves considerações sobre cenário e implementação. PAIM, J. (Coord). Observatório de análise política em saúde. Relatório 
acompanhamento de políticas. Marco zero antecedentes da política Disponível em <http:// analisepoliticaemsaude.org/oaps/matriz/>. Acesso em: 23 ago. 2015.

CONILL, E. M. Políticas de atenção primária e reformas sanitárias: discutindo a avaliação a partir da análise do Programa Saúde da Família em Florianópolis, Santa Catarina, Brasil, 1994-2000. Cadernos de Saúde Pública, Rio de Janeiro, 18(Suplemento):191-202, 2002.

CONSELHO REGIONAL DE ODONTOLOGIA DE SANTA CATARINA - CROSC. Conselho Federal de Odontologia divulga municípios vencedores do Prêmio Brasil Sorridente. 2015. Disponível em: <http://www.crosc.org.br/2015/08/premio-brasilsorridente-3>. Acesso em: 19 set. 2015.

COSTA, S.; ARAUJO, F. Dental auxiliaries versus community health workers: similarities and contrasts. Revista de Odontologia, São Paulo, v. 42, n. 5, p. 350-356. 2013.

EMMI, D.; BARROSO, R. Avaliação das ações de saúde bucal no Programa Saúde da Família no distrito de Mosqueiro, Pará. Ciência \& Saúde Coletiva, Rio de Janeiro, v. 13, n. 1, p. 35-41, jan/fev. 2008.

FACCIN, D.; SEBOLD, R. Processo de trabalho em saúde bucal: em busca de diferentes olhares para compreender e transformar a realidade. 2006. $62 \mathrm{f}$. Trabalho de Conclusão de Curso (Especialização em Saúde da Família - Modalidade Residência) - Curso de Especialização Multiprofissional em Saúde da Família,Universidade Federal de Santa Catarina, Florianópolis, 2006.

FACCIN, D.; SEBOLD, R.; CARCERERI, D. Processo de trabalho em saúde bucal: em busca de diferentes olhares para compreender e transformar a realidade. Ciência \& Saúde Coletiva, Rio de Janeiro, v. 15, suppl.1, p. 1643-1652. 2010.

FARIAS, M.; SAMPAIO, J. Integração da equipe de saúde bucal na Estratégia Saúde daFamília: A percepção dos profissionais. Revista Baiana de Saúde Pública, Salvador, v. 34, n. 4, 2011.

FERREIRA, P. H. Integralidade da atenção nas relações de saúde geral/geral na estratégia saúde da família. 151 f. Dissertação (Mestrado em Odontologia em Saúde Coletiva) - Centro de Ciências da Saúde, Universidade Federal de Santa Catarina, Florianópolis, 2010.

HENRIQUE, F; CALVO, M. C. M. Avaliação do Programa Saúde da Família nosmunicípios do Estado de Santa Catarina, Brasil. Cadernos de Saúde Pública, Rio de Janeiro, v. 24, h.4, p. 809-819, abr, 2008.

IBGE. Pesquisa Nacional por Amostra de Domicílios 1998: Acesso y utilização de serviços de saúde. Rio de Janeiro, 2000.

IBGE. Pesquisa Nacional por Amostra de Domicílios 2008. Vol. 29. Rio de Janeiro, 2008.

IOM. Instituteof Medicine. A manpower policy for primary health care. IOM Publication 78-02. Washington DC. National Academy of Sciences, 1978.

JUNIOR, M. Avaliação de desempenho da política nacional de saúde bucal no período de 20042010. 2013. 89 f. Dissertação (Mestrado em Ciências da Saúde) - Faculdade de Ciências da Saúde, Universidade de Brasília. Brasília, DF, 2013. 
KORNIS, G.; MAIA, L. e FORTUNA, R. Evolução do financiamento da atenção à saúde bucal no SUS: uma análise do processo de reorganização assistencial frente aos incentivos federais. Physis, Rio de Janeiro, v. 21, n. 1, p. 197-215. 2011.

LOURENÇO, E. C. et al. A inserção das equipes de saúde bucal no programa de saúde no estado de MG. Ciência \& Saúde Coletiva, Rio de Janeiro, v. 14, suppl.1, p. 1367-1377. 2009.

MARTELLI, P. et al. Análise do modelo de atenção à saúde bucal em municípios do estado de Pernambuco. Ciência \& Saúde Coletiva, Rio de Janeiro, v. 13, n. 5, p. 1669-1674, 2008.

MARTELLI, P. Política Nacional de Saúde Bucal, da teoria a prática: Um estudo de caso acerca de sua implantação em Recife PE no período de 2000 a 2007. 2010. 235 f. Tese (Doutorado em Saúde Pública) - Centro de Pesquisas Aggeu Magalhães, Fundação Oswaldo Cruz, Recife, 2010.

MATTOS, G. et al. A inclusão da equipe de saúde bucal na Estratégia Saúde daFamília: entraves, avanços e desafios. Ciência \& Saúde Coletiva, Rio de Janeiro, v. 19, n. 2, p. 373-382, 2014.

MENDES, J. M. R; LEWGOY, A. M. B; SILVEIRA, E. C. Saúde e interdisciplinaridade: mundo vasto mundo. Revista Ciência \& Saúde, Porto Alegre, v. 1, n. 1, p. 24-32, jan./jun. 2008.

MOURA, M. et al. Saúde bucal na estratégia de saúde da família em um colegiado gestor regional do estado do Piauí. Ciência \& Saúde Coletiva, Rio de Janeiro, v. 18, n. 2, p. 471-48o, 2013.

MUNKEVITZ, M. E.; PELICIONI, M. Saúde bucal na Estratégia Saúde da Família no município de São Paulo: perspectiva do usuário. Revista brasileira de crescimento e desenvolvimento humano. São Pualo, v. 20, n. 3, 2010.

NASCIMENTO, A. et al. Oral health in the family health strategy: a change of practices or semantics diversionism. Revista de Saúde Pública, São Paulo, v. 43, n. 3, p. 455-462, Mar., 2009

NARVAI, P.C.; CARCERERI, D. L. Salud Bucal Colectivaen Brasil. In: Castaño-Séiquer A; Ribas-Pérez D. (Org.). Odontología preventiva y comunitaria: laodontología social. Undeber, una necesidad, um reto. Madrid: Fundación Odontología Social, 2012. p. 843-854.

NARVAI, P.; FRAZÃO, P. Saúde bucal no Brasil muito além do céu da boca. Rio de Janeiro: Editora Fiocruz, 2008. 148 p.

OLIVEIRA, R. S. et al. Use of dental services in areas covered by the Family Health Strategy in Olinda, Brazil. Cadernos de Saúde Coletiva, Rio de Janeiro, v. 22, n. 1, p. 40-45, 2014 .

OLIVEIRA, A. G. R. DA COSTA. Banco de dados do projeto "Impacto do Programa Saúde da Família no perfil de saúde bucal: análise em municípios do Nodeste com mais de 100.000 habitantes", Natal, [2005]. 
ORGANIZAÇÃO PANAMERICANA DE SAÚDE (OPAS). Discussão sobre o marco conceitual e referencial da atenção básica e saúde dafamília no Brasil. Brasília, DF, 2003. Disponível em: $<$ http//www.opas.org.br/serviço/arquivos/Sala5309.pdf>. Acesso em: 19 set. 2015.

PADULA, M.; AGUILAR-DA-SILVA, R. Professional profile of dentists who are members of the Family Health Strategy city of Marília, São Paulo: the challenge of interprofessional work. Revista de Odontologia, São Paulo, v. 43, n. 1, p. 52-60. 2014.

PAIM, J. S. et al. O sistema de saúde brasileiro: história, avanços e desafios. The Lancet, p. 11-31. 2011. Disponível em:

<http://www5.ensp.fiocruz.br/biblioteca/dados/txt_822103381.pdf> Acesso em : Acesso em: 23 ago. 2015

PAIM, J. S. O objeto e a prática da Saúde Coletiva: o campodemanda um novo profissional? Salvador: ISC/UFBA, 2002.

PALACIO, D. C. et al. Evolução de indicadores pós-implantação da saúde bucal na Estratégia Saúde da Família. Einstein, São Paulo, v. 12, n. 3, p. 274-281, 2014.

PEREIRA, C. R. et al. Impacto da Estratégia Saúde da Família com equipe de saúde bucal sobre a utilização de serviços odontológicos. Cadernos de Saúde Pública, Rio de Janeiro, v. 25 , n. 5, p. 985-996, 2009.

PEREIRA, C. R. et al. Impacto da Estratégia Saúde da Família sobre indicadores de saúde bucal: analise em municípios do nordeste brasileiro com mais de 100 mil habitantes. Cadernos de Saúde Pública, Rio de Janeiro, v. 28, n. 3, p. 449-62. 2012.

PERES, A. C. O., O trabalho interdisciplinar como inovação tecnológica na promoção da saúde: estudo qualitativo na atenção primária, em Florianópolis-SC. 2015. 80 f. Dissertação (Mestrado em Odontologia em Saúde Coletiva) - Centro de Ciências da Saúde, Universidade Federal de Santa Catarina, Florianópolis, 2015.

PIMENTEL, F. C. et al. Análise da atenção à saúde bucal na Estratégia de Saúde da Família do Distrito Sanitário VI, Recife (PE). Ciência \& Saúde Coletiva, Rio de Janeiro v.15, n. 4, p. 2189-2196, 2010.

PIMENTEL, F. C. et al. Análise dos indicadores de saúde bucal do estado de Pernambuco: desempenho dos municípios segundo porte populacional, população cadastrada no Sistema de Informação da Atenção Básica e proporção na Estratégia Saúde da Família. Cadernos Saúde Coletiva, Rio de Janeiro, v. 22, n. 1, p. 54-61, 2014.

REIS, W. G. ; SCHERER, M. D. A. ; CARCERERI, D.L. O trabalho do cirurgião-dentista na atenção primária de saúde: entre o prescrito e o real. Saúde em Debate, São Paulo, v. 39, p. 56-64, 2015 .

ROCHA, R. A. C. P.; GOES, P. S. A. Comparação do acesso aos serviços de saúde bucal em áreas cobertas e não cobertas pela Estratégia Saúde da Família em Campina Grande, Paraíba, Brasil. Cadernos de Saúde Pública, Rio de Janeiro, v. 24, n. 12, p. 2871-2880, 2008. 
SANTOS, A. et al. Linhas de tensões no processo de acolhimento das equipes de saúde bucal do Programa Saúde da Família: o caso de Alagoinhas, Bahia, Brasil. Cadernos de Saúde Pública, Rio de Janeiro, v. 23, n.1, p. 75-8, 2007.

SANTA CATARINA. SECRETARIA ESTADUAL DE SAÚDE. Estratégia Saúde da Família está presenteem todos os municípios do Estado. Revista Catarinense de Saúde da Família. Florianópolis, Ano I n. 1, p. 6-7, nov. 2009. Disponível em: <http://www.youblisher.com/ p/494381-1-Revista-Catarinense-de-Saude-da-Familia>. Acesso em: 19 set. 2015.

SILVA, S. et al. Análise do avanço das equipes de saúde bucal inseridas na Estratégia Saúde da Família em Pernambuco, região Nordeste, Brasil, 2002 a 2005. Ciência e saúde coletiva, v. 16, n.1, p. 211-220, 2011.

SILVESTRE, J.; DE AGUIAR, A.; TEIXEIRA, E. Do Brasil sem Dentes ao Brasil Sorridente: Um resgate histórico das políticas públicas de saúde bucal no Brasil. Cadernos ESP, Ceará, v. 7, n. 2, p. 28-39, jul./dez. 2013.

SISSON, M. C. et. al. Estratégia de Saúde da Família em Florianópolis: integração, coordenação e posição na rede assistencial. Saúde e Sociedade, São Paulo, v. 20, n. 4, p.9911004, 2011.

SOARES, F. et al. Atuação da equipe de saúde bucal na estratégia saúde da família: análise dos estudos publicados no período 2001-2008. Ciência \& Saúde Coletiva, Rio de Janeiro, v. 16, n. 7, p. 3169-3180, 2011.

SOARES, F., et al. Desigualdade na utilização de serviços de saúde bucal na atenção básica e fatores associados em dois municípios brasileiros.

Revista panamericana de salud pública, Washington, D.C., v. 34, n. 6, p. 401-6, 2013.

SOARES, C. L. M.; PAIM, J. S. Aspectos críticos para a implementação da política de saúde bucal no Município de Salvador, Bahia, Brasil. Cadernos de SaúdePública, Rio de Janeiro, v. 27, n. 5, p. 966-974, maio, 2011.

SOUZA, A. L; CARCERERI, D. L. Estudo qualitativo da integração ensino-serviço em um curso de graduação em Odontologia. Interface - Comunicação, Saúde, Educação, Botucatu, v. 15 , n. 39, p. 1071-84, out./dez. 2011.

SOUZA, T. M. S.; RONCALLI, A. G. Saúde bucal no Programa Saúde da Família: uma avaliação do modelo assistencial. Cadernos de Saúde Pública, Rio de Janeiro, v. 23, p. 27272739. 2007 .

STARFIELD, B. Measuring the attainment of primary care. Journal of Medical Education. V. 54, n. 5, p. 361-369. 1979.

STARFIELD, B. Atenção primária de saúde: equilíbrio entre necessidades de saúde, serviços e tecnologia. Brasília, DF: UNESCO; Ministério da Saúde, 2002.

TAVARES, R. et al. A organização do acesso aos serviços de saúde bucal na estratégia de saúde da família de um município da Bahia. Saúde em debate, São Paulo, v. .37, n. 99, p. 628635. 2013 . 
VIANA, A.; DAL POZ, M. R. A reforma sanitária do sistema de saúde no Brasil e Programa Saúde da Família. Physis, Rio de Janeiro, v. 2, p. 225-264, 1998.

VILASBOAS, A., et al. Estudos e pesquisa em Atenção primaria e promoção da saúde. Atenção primária e promoção da saúde no Brasil: origens e situação atual. In: PAIM, J. (Coord). Observatorio de análise política em saúde. Relatório acompanhamento de políticas.

Marco Zero antecedentes da política. Disponível em: <http://analisepoliticaemsaude.org/ oaps/matriz/>. Acesso em: 23 ago. 2015.

ZANETTI, C. As marcas de mal-estar social no sistema nacional de saúde tardio: o caso das políticas de saúde bucal no Brasil dos anos 80. 1993. 134 f. Dissertação (Mestrado em Saúde Pública) -Escuela Nacional de Saúde Pública, Fundação Oswaldo Cruz, Rio de Janeiro, 1993. 


\title{
A utilização dos serviços odontológicos \\ ELEMENTOS TEÓRICOS E CONCEITUAIS ${ }^{1}$
}

\author{
Denise Nogueira Cruz \\ Sônia Chaves \\ Maria Cristina Cangussu
}

Os diferentes sistemas universais de saúde buscam, por meio da implantação de políticas e mecanismos de organização e provimento das ações e serviços, melhorar o nível de saúde das populações. No Brasil, a proposição de um sistema universal, integral e equânime foi inscrito na Constituição de 1988 conformando assim o Sistema Único de Saúde (SUS).

Pensar no debate sobre a melhoria da saúde das populações, inevitavelmente, faz emergir dois aspectos centrais: o indivíduo e sua relação com o meio em que vive e os serviços de saúde.

Quando se analisa a dimensão da relação entre o indivíduo e a sociedade, vários elementos podem ser levantados, desde aqueles que tratam de características genéticas, comportamentais, sociodemográficas e culturais até aos aspectos relacionados com a percepção sobre a necessidade de saúde e a busca e utilização dos serviços de saúde. Em relação aos serviços de saúde, é preciso identificar a existência (ou ausência) deles e o modo como estão organizados para responder as necessidades individuais e coletivas.

O presente capítulo foi desenvolvido a partir do texto que compõe a tese de doutorado Desigualdades na utilização dos serviços odontológicos: posição e tomadas de posição no espaço social, defendida por Cruz (2015). 
Neste capítulo, pretendemos introduzir uma reflexão teórico-conceitual sobre utilização dos serviços de saúde de modo a compreender a interface entre organização dos serviços e as necessidades de saúde; apresentar evidências das desigualdades no uso dos serviços odontológicos no Brasil e, finalmente, fomentar um debate sobre perspectivas metodológicas para o desenvolvimento de estudos acerca da utilização dos serviços de saúde.

\section{Elementos teóricos e conceituais}

Qualquer estudo sobre o uso dos serviços de saúde aponta para os conceitos de "necessidade", em suas variadas dimensões, "oferta" e "acesso", bem como o conceito de "utilização", propriamente dito. A "necessidade de saúde" se dá por meio de uma percepção individual e, nesse sentido, Schraiber e MendesGonçalves (1996) apontam que a definição de necessidades é algo complexo, podendo ser representada pela procura (como "demanda") por cuidados de saúde cuja origem é o "carecimento" dos indivíduos. Isto é, as pessoas, ao identificarem alguma alteração no seu estado de saúde, e que, para si, seja percebida como algo que carece e precisa de reestabelecimento, desencadeiam a procura pelos serviços configurando, assim, uma demanda.

Tais necessidades não aparecem sem história ou sem razão social e, desse modo, esses autores discutem o termo "social" para necessidades sociais em saúde. Afirmam que os "carecimentos" ou faltas são criados e recriados na vida em sociedade e, consequentemente, podem envolver muitas pessoas. Essa característica do termo social pode resultar em manipulação ideológica e política fazendo parecer que uma determinada necessidade que não é de todos seja mostrada como tal e, muitas vezes, assumida como prioridade. É preciso ainda chamar a atenção para o fato de que "essa situação de bem comum, ocorre ignorando a efetiva desigualdade das necessidades sociais". (SCHRAIBER; MENDES-GONÇALVES, 1996, p. 31)

Heller (1986), ao analisar a teoria das necessidades em Marx, define-a como "desejo consciente, aspiração, intenção dirigida a todo o momento para certo objeto e que motiva a ação como tal". (HELLER, 1986, p. 170) A partir do arcabouço teórico utilizado, define três grupos de necessidades: naturais ou físicas, sociais e radicais. Acrescenta que necessidades radicais não são necessidades de reprodução social, como as duas primeiras; são aquelas que efetivam o enriquecimento humano e associam-se aos processos de criatividade e liberdade. Para a autora, as necessidades de saúde relacionam-se com os dois primeiros 
grupos de necessidades, pois são fundamentais para manutenção da vida e, por serem socialmente produzidas, exigem a conformação de instituições (de educação, saúde e cultura, por exemplo) para satisfazê-las.

Portanto, as necessidades de saúde podem gerar uma demanda pelos serviços de saúde por parte de indivíduos ou grupos populacionais que pretendem melhorar sua condição de saúde, tratar uma doença ou solucionar determinado infortúnio. Elas também podem ser construídas socialmente e, também, manejadas política e ideologicamente, não correspondendo à compreensão do bem comum.

Quando analisamos a demanda pelos serviços de saúde, geralmente o debate volta-se para os aspectos relacionados aos próprios serviços, sua existência e organização para responder às necessidades de saúde da população e, necessariamente, volta-se aos conceitos de "acesso" e "utilização".

Para Travassos e Martins (2004), os conceitos de acesso e utilização são complexos e muitas vezes empregados de maneira imprecisa e variam de acordo com o autor. Adota-se o sentido conferido por Donabedian (1998) que emprega o substantivo "acessibilidade" para referir-se às características dos serviços que facilitam ou dificultam a sua utilização por parte dos usuários e, ainda, aponta duas dimensões da acessibilidade: barreira geográfica e barreira sócio-organizacional.

A barreira geográfica relaciona-se, por exemplo, com a distância dos serviços de saúde para que o indivíduo possa acessá-lo, a topografia do terreno com a presença de aclives e declives, escadarias além do custo e o tempo de locomoção. A barreira sócio-organizacional abrange aspectos sobre o modo como os serviços de saúde se organizam e ofertam os serviços, incluindo, por exemplo, mecanismos de triagem, organização da porta de entrada, fluxo, entre outros.

Entende-se que uma das maneiras de se medir o acesso aos serviços de saúde é a partir da sua "utilização", ato do uso do serviço, que, por sua vez, está relacionada aos fatores de ingresso nos serviços de saúde. Andersen (1995) denominou a etapa de utilização dos serviços de saúde como acesso realizado.

A utilização dos serviços de saúde objetivada na forma de consumo de serviços de saúde é mediada pelas necessidades de saúde e pelo comportamento dos indivíduos; bem como pelas características da oferta desses serviços. (SCHRAIBER; MENDES-GONÇALVES, 1996; TRAVASSOS; MARTINS, 2004) Há, portanto, um forte imbrincamento entre os conceitos de "acessibilidade", "oferta" e "utilização". 
A organização dos serviços de saúde, na tentativa de responder às necessidades de saúde da população, também pode ser analisada em função do caráter das políticas de saúde e da extensão/tipos de cobertura dos sistemas de saúde (seguro saúde, cobertura universal, entre outros). Nesse sentido, é importante compreender que o Estado responde às necessidades de saúde da população e implementa diferentemente suas políticas de saúde compreendidas, aqui, como "ação ou omissão do Estado, enquanto resposta social, diante dos problemas de saúde e seus determinantes, bem como da produção, distribuição e regulação de bens, serviços e ambientes que afetam a saúde dos indivíduos e da coletividade humana". (PAIM, 2003, p. 588)

Assim, ao introduzir o componente da política nesse debate e estabelecer as necessidades em saúde como uma construção social, pode-se retomar algumas questões apresentadas. Tratou-se, anteriormente, que as necessidades sociais podem ser construídas como necessidades pelas camadas privilegiadas ou dominantes. Portanto, os mecanismos, as técnicas e processos para criação das instituições que satisfaçam necessidades sociais não são neutros. Desse modo, cabe questionar quais necessidades são priorizadas quando uma determinada política, um programa ou até mesmo um serviço de saúde é implantado e se ele atende, de fato, às "reais" necessidades de saúde de uma população.

Compreender o processo de implementação das políticas de saúde e quais necessidades serão respondidas pode revelar aspectos que confirmam a compensação ou o reforço das desigualdades de acesso e utilização dos serviços de saúde. Percebe-se, portanto, que a aplicação dos conceitos aqui apresentados possibilita a construção de estudos no âmbito da saúde com perspectivas de análise distintas.

\section{Evidências sobre a utilização dos serviços odontológicos e a Política Nacional de Saúde Bucal (2004)}

A utilização dos serviços odontológicos tem sido objeto de investigações nacionais e internacionais. Metodologicamente, destaca-se o predomínio da abordagem epidemiológica e a utilização de bases de dados provenientes de inquéritos populacionais nacionais (BARROS; BERTOLDI, 2002; MANHÃES; COSTA, 2008; MIRANDA; PERES, 2013; PERES et al., 2012a; SILVA et al., 2011) e internacionais (BAKER, 2009; GUARNIZO-HERREÑO et al., 2003; MATSUYAMA et al., 2014; PALÈNCIA et al., 2014). Há também estudos que utilizaram dados prove- 
nientes de coortes prospectivas (ASTROM et al., 2013; TCHICAYA, LORENTZ, 2014) e, inclusive, através do inquérito telefônico. (PERES et al., 2012b)

Os estudos sobre a utilização de serviços odontológicos no Brasil apontam desigualdades no padrão de utilização com associações, principalmente, entre: a) nível econômico, com maior acesso para aqueles de maior renda (ARAÚJO et al., 2009; BARROS; BERTOLDI, 2002; CAMARGO; DUMITH; BARROS, 2009; DAVOGLIO et al., 2009; MANHÃES; COSTA, 2008; PERES et al., 2012a); b) faixa etária, especialmente os adultos jovens e mulheres (ASTROM et al., 2013; BARROS; BERTOLDI, 2002; PERES et al., 2012a); e c) nível de escolaridade, com maior acesso aos mais escolarizados. (ARAÚJO et al., 2009; CAMARGO; DUMITH; BARROS, 2009; MANHÃES; COSTA, 2008; MIRANDA; PERES, 2013)

No Quadro 1, são apresentados os principais estudos nacionais publicados entre 2009-2015 e indexados com os descritores "utilização; assistência odontológica" e a síntese dos seus resultados mais relevantes (Quadro 1).

$\mathrm{Na}$ investigação de Araújo e colaboradores (2009), a maior utilização dos serviços odontológicos estava associada com o maior nível econômico e de escolaridade e com a melhor autopercepção de saúde. Outro estudo de base populacional, utilizando dados da Pesquisa Nacional por Amostra de Domicílios (PNAD), também verificou uma maior proporção de indivíduos que nunca consultou o dentista no grupo de indivíduos que representava o quintil mais pobre, sendo que, no grupo de indivíduos de 20-49 anos, a proporção de pessoas desse quintil que nunca foi ao dentista foi 16 vezes maior do que no quintil mais rico. (BARROS, BERTOLDI, 2002)

Estudo de Manhães e Costa (2008), que analisou o uso de serviços odontológicos em três grupos etários (15-19 anos, 35-44 anos e 65-74 anos), apontou que indivíduos menos escolarizados (jovens e adultos) e com menor renda per capita (jovens e idosos) têm limitações de acesso. Entre os adultos (35-44 anos), as chances dos homens utilizarem o serviço foi quase metade daquela observada entre as mulheres. Alguns fatores podem estar associados a esses resultados, como, por exemplo, a inadequação da oferta em relação à disponibilidade de horário do adulto produtivo brasileiro.

No Brasil, a PNAD, em 2003, verificou que $18,7 \%$ dos brasileiros nunca haviam consultado um dentista e apontou desigualdades na utilização dos serviços odontológicos, já que a proporção de pessoas que nunca consultaram um dentista era maior entre os brasileiros mais pobres. (IBGE, 2005) 
Entende-se que estudos sobre a utilização de serviços odontológicos e as desigualdades nessa utilização precisam também ser relacionados com o quadro epidemiológico da condição de saúde bucal da população brasileira. Dados epidemiológicos evidenciam a cárie dentária como o problema de saúde bucal mais prevalente no país. (BRASIL, 2004a) Esse agravo, associado à falta de acesso aos serviços de saúde bucal, resulta em uma alta prevalência de perda dental e grande necessidade de tratamentos especializados em adultos jovens e idosos. (FIGUEIREDO; GOES, 2009; FRAZÃO; NARVAI, 2010)

Os inquéritos epidemiológicos nacionais apontam um considerável aumento na média de dentes permanentes acometidos pela cárie com o aumento da idade; particularmente nas faixas etárias de 15 a 19 anos e 35 a 44 anos, resultando em um CPO-D2 de 2,8 aos 12 anos de idade e de 6,2 e 20,1 nos outros dois grupos etários respectivamente. (BRASIL, 2004b) Destaca-se, ainda, que o percentual do componente perdido no grupo de 35 a 44 anos corresponde a mais de $65 \%$ do CPO-D, o que é fortemente agravado na faixa etária de 65-74 anos. O levantamento realizado em 2010 (BRASIL, 2011) indica uma melhora na condição da saúde bucal de modo que o CPO-D nos grupos etários investigados alcançou a média de 2,07 nas crianças de 12 anos. Entretanto, permanece o aumento na média de dentes permanentes acometidos pela cárie com o aumento da idade resultando em um percentual de $68,8 \%$ dos indivíduos com idade entre 35 a 44 anos necessitando de alguma prótese dentária. (BRASIL, 2011)

A Política Nacional de Saúde Bucal (PNSB), lançada em 2004, apresenta estratégias para o enfrentamento dessas necessidades de saúde bucal da população brasileira. Essa política tem como principais propostas reorganizar os serviços públicos odontológicos com reorientação do modelo de atenção, qualificar e fortalecer a Estratégia Saúde Família (ESF) e ampliar o acesso aos procedimentos especializados, também, denominada atenção especializada. (BRASIL, 2004a)

A PNSB é considerada um importante avanço, visto que é uma política que procurou romper com as ações focalizadas pretendendo uma integralidade da atenção. No Brasil, o modelo de atenção à saúde bucal foi, historicamente, com ênfase curativo-restaurador e mutilador e elegeu, como público-alvo prioritário, a população escolar. A primeira oferta sistemática de serviços foi ao interior

2 O CPO-D é um índice que expressa a média de dentes permanentes cariados, perdidos e/ou obturados em virtude da doença cárie. É um indicador utilizado para avaliar o ataque da doença cárie numa determinada população. 
do Sistema Incremental de Atendimento, introduzido em 1952 pela Fundação SESP (Serviço Especial de Saúde Pública), em Aimorés, Minas Gerais, baseado na assistência odontológica para escolares de forma programada e sistemática, com o objetivo de aumentar ao máximo a produtividade, na forma de número de pacientes atendidos, e reduzir as necessidades de tratamento em crianças de 6 a 14 anos. Esse modelo de oferta programática também pressupunha a complementariedade de uma fase preventiva, com aplicações tópicas de flúor até o início da década de 1970 e, posteriormente, o uso de bochechos fluorados, além da recomendação da fluoretação das águas de abastecimento público. (DINIZ, 1987; MARTILDES, 1992) Para a população adulta, restava a demanda espontânea clássica, centrada basicamente na mutilação.

A possibilidade de uma estratégia racionalizadora na prestação da assistência odontológica fez com que o sistema incremental se transformasse num modelo de atendimento no Brasil, até a década de 1980, focalizando prioritariamente crianças de 7 a 12 anos de idade, especialmente nos programas de odontologia escolar. Entretanto, avaliações realizadas sobre o sistema, em municípios dos estados da Bahia e São Paulo, não identificaram impacto epidemiológico na redução dos índices de cárie dentária em relação às crianças que não possuíam nenhuma assistência odontológica sistemática, como relataram os estudos de Diniz (1987) e Martildes (1992).

A maior crítica ao sistema incremental foi de uma forma geral, a falta de eficácia da fase preventiva do programa, que não incorporou de forma significativa a educação sanitária e a evolução do conhecimento científico e técnico da odontologia preventiva, perpetuando uma assistência individual e curativa, de baixo impacto epidemiológico. (DINIZ, 1987; MARTILDES, 1992; NARVAI, 1994) Configurou, ainda, uma exclusão da maior parte da população, que dependia de políticas que privilegiavam a prática clínica privada, de alta tecnologia, cara e inacessível à população, já que, no setor público, predominava a assistência mutiladora e emergencial, restrita à remoção de focos infecciosos.

Na década de 1980, relatava-se o grave perfil epidemiológico da população brasileira, resultado de um modelo de atenção ineficaz e ineficiente, onde predominava a descoordenação, má distribuição da rede assistencial e dos recursos, baixa cobertura, enfoque curativo e o caráter mercantilista e monopolista do atendimento odontológico, aspectos descritos na I Conferência Nacional de Saúde Bucal (BRASIL, 1986), mesmo com o registro de algumas experiências 
municipais positivas, com ênfase nas necessidades de saúde da população e descentralização dos serviços.

O debate sobre os modelos de atenção e a consolidação de um novo referencial teórico-metodológico na determinação do processo saúde-doença bucal ganha amplitude com o movimento da Reforma Sanitária Brasileira, na busca por um modelo de prática que incluísse a saúde bucal no campo das demandas e necessidades de saúde da população e que tivesse resposta e respaldo no setor público. Assim, e somente após mais de uma década da conformação do SUS, a inserção da odontologia no então Programa de Saúde da Família (PSF) surge como uma iniciativa promissora para a inversão do modelo de atenção e como resposta às necessidades em saúde bucal no âmbito da atenção primária. A partir da PNSB de 2004, é que, além da atenção básica, priorizando a Equipes de Saúde da Família. (ESF) como forma de organização das práticas, também assume-se como política de saúde a necessidade de reabilitação do adulto e a sua inclusão em todos os níveis de atenção. (BRASIL, 2004b)

No que diz respeito às evidências sobre o efeito da ESF na utilização dos serviços odontológicos, identificam-se poucos estudos nacionais. Avaliações sobre a utilização de serviços odontológicos em áreas cobertas pela ESF foram realizadas em alguns municípios brasileiros. (BALDANI et al., 2010; BALDANI; ANTUNES, 2011; OLIVEIRA et al., 2014; PEREIRA et al., 2009; ROCHA; GOES, 2008) Em Ponta Grossa, no Paraná, a investigação sobre a existência de desigualdades no acesso e utilização de serviços odontológicos, para indivíduos residentes em áreas cobertas pela ESF, identificou que 15\% nunca tinham realizado consulta odontológica e esse percentual chegou a 50\% entre as crianças de o-6 anos. (BALDANI, ANTUNES, 2011) Nesse estudo, o fato de ser coberto por ESF não foi associado às recentes consultas ao dentista e melhor condição socioeconômica esteve positivamente associada à visita recente ao dentista. $\mathrm{Ou}$ seja, a implementação das Equipes de Saúde Bucal (ESB) na ESF não significou, enquanto política de saúde, maior utilização e as desigualdades persistiram.

Rocha e Goes (2008), ao compararem o acesso de serviços de saúde bucal em áreas cobertas e não cobertas pela ESF, identificaram que não há associação entre residir em uma ou outra área e que o percentual de indivíduos que procurou o dentista do serviço público $(34,5 \%)$ foi muito inferior ao daqueles que procuram serviços privados ou conveniados (64,3\%). Esses autores também identificaram que, entre aqueles que utilizaram o serviço público, apenas $6,8 \%$ tiveram acesso ao dentista da ESF. O estudo de Olinda, Pernambuco, obser- 
vou, da mesma forma, uma baixa utilização $(18,9 \%)$ dos serviços odontológicos prestados pela unidade de saúde da família por parte da população adscrita. (OLIVEIRA et al., 2014)

O ensaio comunitário realizado em Natal, Rio Grande do Norte, revelou que o impacto da saúde bucal no PSF na utilização de serviços odontológicos só é significativo quando se toma por análise áreas sem nenhuma cobertura ou quando cobertas por unidades tradicionais sem PSF ou Programa de Agentes Comunitários de Saúde. (PEREIRA et al., 2009) No Maranhão, foi observada uma baixa utilização dos serviços de saúde bucal por crianças e adultos incoerente com a cobertura da ESF no estado, que era de 74,29\% (GOMES et al., 2014), persistindo às iniquidades em saúde na população. No âmbito da atenção primária em odontologia, portanto, percebe-se que a política de uma crescente implantação de ESB, por si só, não tem sido capaz de garantir maior utilização dos serviços.

No que diz respeito à atenção especializada, a PNSB buscou viabilizar a oferta de procedimentos especializados através dos Centros de Especialidades Odontológicas (CEO) e Laboratórios Regionais de Próteses Dentárias. (BRASIL, 2004a) Os CEO são estabelecimentos de saúde que devem ofertar os serviços de diagnóstico bucal, com ênfase no diagnóstico e detecção do câncer de boca; periodontia especializada; cirurgia oral menor dos tecidos moles e duros; endodontia e atendimento a portadores de necessidades especiais. (BRASIL, 2004a)

Há de se conceber, entretanto, que, para garantir a integralidade, é necessário repensar a atenção primária e o estabelecimento de adequadas estratégias de referência e contrareferência, ainda frágeis. Do ponto de vista da sua cobertura, utilização e efetividade, também, foram encontrados poucos estudos com foco na atenção especializada em odontologia no Brasil.

Investigações que avaliaram a implementação da PNSB no âmbito da atenção especializada apontam que os resultados da utilização dos serviços desse nível de atenção não se distanciam daqueles que investigaram áreas cobertas pela ESF, visto que a atenção especializada depende, necessariamente, do funcionamento adequado da atenção primária.

O estudo de Chaves e colaboradores (2010), realizado na Bahia, identificou que os CEO realizavam atendimento à livre demanda e, predominantemente, procedimentos básicos. Portanto, não garantiam a integralidade da atenção, devendo ser implantados em município com uma atenção primária adequada- 
mente estruturada. Nesse mesmo estudo, os resultados apontaram que usuários com facilidade de acesso geográfico, moradores de municípios com elevada cobertura do PSF, menores de 35 anos de idade e com necessidade de serviço endodôntico tiveram mais chances de completar tratamento especializado.

Outros estudos, acerca da avaliação dos CEO, desenvolvidos numa perspectiva nacional (GOES et al., 2012), estadual (FIGUEIREDO; GOES, 2009) e municipal (CHAVES et al., 2011; CHAVES et al., 2012; SOUZA; CHAVES, 2010), apontam um desempenho ruim de alguns desses estabelecimentos bem como baixa ou inadequada utilização dos serviços.

As contribuições apresentadas acerca da utilização dos serviços odontológicos demonstram persistências das desigualdades na utilização desses serviços e apontam lacunas quanto aos aspectos que expliquem a utilização dos serviços no que diz respeito aos determinantes sociais da saúde. ${ }^{3}$

No Brasil, apesar da pretendida cobertura universal dos serviços odontológicos, há questões que merecem aprofundamento investigativo, como as diferenças na utilização dos serviços odontológicos em relação aos demais serviços de saúde. Um inquérito realizado por Barros e Bertoldi (2002) identificou que $52 \%$ dos atendimentos não odontológicos são realizados no SUS, enquanto apenas $24 \%$ dos atendimentos odontológicos são SUS. Nesse estudo, a maior parte dos atendimentos odontológicos (69\%) ocorreu em serviços particulares e de saúde suplementar.

Além disso, Silva e colaboradores (2011), ao investigarem a utilização de serviços de saúde no SUS, nos anos de 2003 e 2008, identificaram que, diferentemente das consultas médicas, os serviços odontológicos no SUS correspondem a apenas um terço das consultas realizadas. Ou seja, mesmo com cobertura universal e ampliação dos serviços odontológicos no SUS, os serviços privados e conveniados correspondem pela maior parte da assistência odontológica aos brasileiros, e observa-se, principalmente nos grandes centros urbanos, crescimento significativo da saúde suplementar.

3 Determinantes Sociais da Saúde (DSS) correspondem às "condições em que as pessoas nascem, crescem, vivem, trabalham e envelhecem, incluindo aquelas relacionadas ao sistema de saúde. Essas circunstâncias são influenciadas pela distribuição de dinheiro, poder e recursos nos níveis global, nacional e local, que, por sua vez, é moldada pelas políticas vigentes. As iniquidades em saúde são causadas, em sua maioria, pelos DSS. O termo é utilizado para resumir as forças sociais, políticas, econômicas, ambientais e culturais mais amplas que influenciam as condições de vida das pessoas". (OMS, 2011) 
Por fim, o estudo de Soares e colaboradores (2013) acrescenta mais um elemento a ser investigado: as desigualdades quanto ao tipo de serviço utilizado. Esses autores, ao investigarem as desigualdades na utilização dos serviços odontológicos, e assumindo a exodontia como tratamento mais resolutivo para população de baixa renda, observaram que a utilização desse procedimento foi associada a ser beneficiário de programa social, ter idade maior que 35 anos e menor nível de escolaridade. O estudo evidenciou que, mesmo entre grupos sociais relativamente homogêneos, há maior realização da exodontia entre os menos escolarizados e socialmente mais vulneráveis.

\section{Modelo explicativo de Ronald Andersen e perspectivas}

Para compreender a utilização dos serviços de saúde, modelos teóricos explicativos foram elaborados, a exemplo dos modelos de Andersen de 1968; Dutton de 1986 e Evans e Stoddart de 1990 (PAVÃO; COELI, 2008). Contudo, destaca-se que, na expressiva maioria dos estudos, nacionais e internacionais, que investigou a utilização de serviços odontológicos, predomina a aplicação do modelo elaborado por Andersen. (ADAY; ANDERSEN, 1974; ANDERSEN, NEWMAN, 1973; ANDERSEN, 1995)

No final da década de 1960, Andersen desenvolveu um modelo para compreender a utilização dos serviços de saúde. O autor revisitou o modelo inicial desenvolvendo mais outras três representações chegando àquele que denominou de fase emergente apresentado na Figura 1 adiante.

Inicialmente, o modelo comportamental era centrado na família e depois foi deslocado para o indivíduo. Na fase inicial, o desfecho era a utilização dos serviços (ANDERSEN, 1995) e o modelo sugeria que o uso dos serviços ocorria em função de determinantes individuais representados pelos seguintes fatores: propensão do indivíduo a utilizar os serviços (características ou fatores predisponentes), impedimentos ou facilidades para a utilização (fatores capacitantes) e as necessidades de saúde. (ANDERSEN; NEWMAN, 1973; ANDERSEN, 1995)

Os fatores predisponentes, no modelo da década de 1960 (ANDERSEN, 1995), estavam organizados em três grupos: características demográficas (idade, gênero, situação conjugal), estrutura/posição social (escolaridade, raça, religião, ocupação, tamanho da família) e crenças em relação aos serviços e cuidados de saúde (atitudes, valores e conhecimentos que afetam a percepção da necessidade e utilização). 
Os fatores capacitantes referiam-se aos meios disponíveis para utilizar o serviço, ou seja, àqueles fatores que irão capacitar ou facilitar a utilização dos serviços de saúde. São condições relacionadas ao indivíduo/família (como renda, cobertura de seguro) e à comunidade em que se vive (a natureza da fonte regular de cuidados de saúde, localização dessa fonte regular/rural-urbano, região do país, tempo de espera pelos cuidados de saúde).

As necessidades de saúde dizem respeito ao que ocasiona o imediato uso dos serviços de saúde. Podem ser necessidades percebidas pelo indivíduo (sintomas, estado geral) ou diagnosticadas, mediante avaliação profissional.

Na fase 2, do modelo o desfecho é a satisfação do usuário e não mais a utilização em si mesma. Nesse modelo, o sistema de saúde (com três dimensões: políticas em saúde, recursos financeiros, organização dos seviços) é incorporado como um outro determinante da utilização dos serviços. (ADAY; ANDERSEN, 1974; ANDERSEN, 1995) Portanto, nessa segunda representação, as características individuais (desenvolvidas na fase 1) e o sistema de saúde determinam o uso dos serviços que, por sua vez, podem resultar na satisfação do usuário.

$\mathrm{Na}$ fase 3, Andersen (1995), novamente repensa o desfecho do modelo que passa a ser mensurado pela satisfação do consumo e, também, pelo "acesso efetivo" (quando a utilização resulta em melhoria no estado de saúde ou satisfação com os serviços) e "acesso eficiente" (quando a melhoria no estado de saúde ou a satisfação com os serviços aumenta em relação ao volume de serviços utilizados). São introduzidos nessa terceira fase, o ambiente e as práticas individuais com a saúde. (ANDERSEN, 1995)

O modelo na fase 4 ou emergente (Figura 1) é aprimorado na tentativa de traduzir a complexidade de representar a utilização dos serviços de saúde. Nesse modelo, o ambiente é conformado pelo sistema de saúde e ambiente externo e são incorporadas algumas setas para demonstrar o quanto cada componente do modelo pode influenciar os demais (relações de feedback). 
Figura 1 - Modelo de utilização dos serviços de saúde elaborado por Andersen (fase 4 ou modelo emergente)

Ambiente Características da população Comportamento de saúde Desfechos

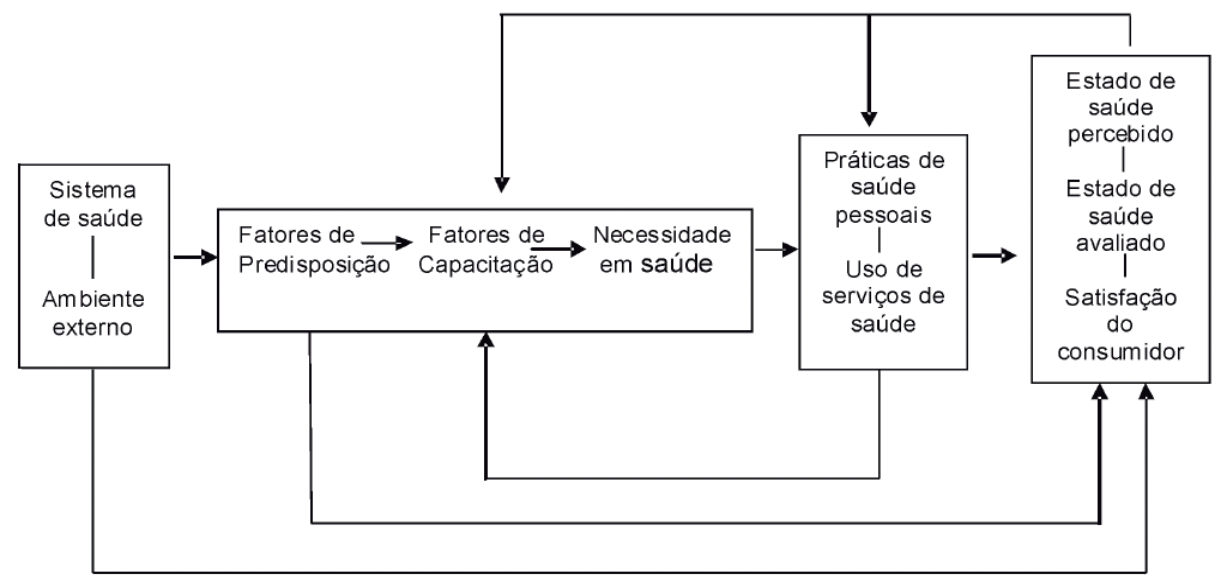

Fonte: Andersen (1995, p. 7, tradução nossa).

Entende-se que a utilização dos serviços de saúde pode ser explicada, em parte, pelo modelo proposto por Andersen, pela interação entre os determinantes individuais, do sistema de saúde e contexto social, além da experiência passada de utilização dos serviços, como apresentado em alguns estudos. (ASTROM et al., 2013; BAKER, 2009; BALDANI; ANTUNES, 2011; CAMARGO; DUMITH; BARROS, 2009; GOMES et al., 2014; MARSHMAN et al., 2012; MUIRHEAD, 2009; PINTO et al., 2012; ROCHA; GOES, 2008)

Essas investigações apontam importantes evidências sobre os fatores associados à utilização, entretanto, explicam parcialmente as razões das desigualdades na utilização dos serviços odontológicos. Nesse sentido, cabe ainda destacar que os estudos sobre utilização dos serviços odontológicos adotam, majoritariamente, uma abordagem epidemiológica, especialmente quando aplicam o modelo explicativo de Andersen. Outro elemento importante a ressaltar é a perspectiva teórico-marxista que fundamenta a explicação dos conceitos apresentados no início do texto por Heller (1986) e Schraiber e Mendes-Gonçalves (1996).

Propõe-se uma reflexão sobre como outras correntes sociológicas podem contribuir para futuras investigações sobre as desigualdades na utilização dos 
serviços de saúde a exemplo dos serviços odontológicos. Na direção desse debate, a teoria da ação social de Pierre Bourdieu pode revelar outras dimensões nos estudos do campo da saúde (VIEIRA-DA-SILVA, 2010) e, particularmente, sobre a utilização dos serviços de saúde e a relação entre a atenção à saúde bucal e a posição no espaço social dos agentes (CHAVES, VIEIRA-DA-SILVA, 2008; CRUZ, 2015), usuários desses serviços.

Os conceitos dos diferentes capitais (como o econômico, cultural e social), de habitus e campo (BOURDIEU, 2008, 2010) ajudam a explicar como a escolha pelo uso de determinados serviços de saúde podem ser a expressão de "disposições” social, histórica e inconscientemente incorporadas. Para Bourdieu, a posição ocupada pelo indivíduo no espaço social guarda relação com o modo com que o mundo é inscrito em seu corpo, ou seja, a maneira de andar, carregar o corpo, inclusive, a maneira de comer, revela um habitus, ou mais precisamente, uma hexis corporal. (BOURDIEU, 2007)

Estudos com tal abordagem teórica podem revelar como o uso dos serviços de saúde expressa, especialmente para as classes populares, um "gosto de necessidade" (necessidade econômica impõe a escolha pelo necessário) e como determinadas escolhas são a transformação de "necessidade em virtude". (BOURDIEU, 2008)

No estudo de Cruz (2015), o "gosto" pelo uso de determinados serviços odontológicos revelou-se diferente entre os indivíduos de estratos sociais mais elevados e aqueles das classes populares. O julgamento, por exemplo, do uso de dentes artificiais (prótese dentária) ao invés dos dentes naturais, como belo revelou-se como um gosto de classe que é reconhecido entre agentes com disposições e posições próximas no espaço social. (CRUZ, 2015) Esse estudo apontou, ainda, que a utilização de serviços odontológicos privados é uma prática distintiva e o encontro dos diferentes habitus (habitus do profissional e habitus do usuário) é importante para compreender as desigualdades no uso desses serviços.

Portanto, elementos da teoria social de Bourdieu apontam novas perspectivas de análise e revelam-se profícuas para outras explicações da persistência das desigualdades na utilização dos serviços odontológicos mesmo em condições de ampliação da rede de serviços públicos nessa área. 


\section{Referências}

ADAY, L. A.; ANDERSEN, R. A framework for the study of access to medical care. Health Services Research, v. 9, n. 3, p. 208-220, 1974.

ANDERSEN, R. Revisiting the behavioral model and access to medical care: does it matter?Journal of health \& social behavior, v. 36, March, p.1-10, 1995.

ANDERSEN, R.; NEWMAN, J. Societal and individual determinants of medical care utilization in the United States. Health an Society, v. 51, n. 1, p. 95-124, 1973.

ARAÚJO, C. S. et al. Utilização de serviços odontológicos e fatores associados: um estudo de base populacional no Sul do Brasil. Cadernos de Saúde Pública, Rio de Janeiro, v. 25, n. 5, p. 1063-1072, maio, 2009.

ASTROM, A. N. et al. Use of dental services throughout middle and early old ages: a prospective cohort study. Community dentistry and oral epidemiology, Copenhagen, v. 41, p. 30-39, 2013.

BAKER, S. R. Applying Andersen's behavioural model to oral health: what are the contextual factors shaping perceived oral health outcomes? Community dentistry and oral epidemiology, Copenhagen, v. 37, p. 485-494, 2009.

BALDANI, M. H.; ANTUNES, J. L. F. Inequalities in acess and utilization of dental services: a cross-sectional study in an area covered by the Family Health Strategy. Cadernos de Saúde Pública, Rio de Janeiro, v. 27, sup. 2, S272-S283, 2011.

BALDANI, M. H. et al. Determinantes individuais na utilização de serviços odontológicos por adultos e idosos de baixa renda. Revista brasileira de epidemiologia, São Paulo, v. 13, n. 1, p.150-162, 2010.

BARROS, A.J.D.; BERTOLDI, A.D. Desigualdades na utilização e no acesso a serviços odontológicos: uma avaliação em nível nacional. Ciência \& Saúde Coletiva, Rio de Janeiro, v. 7, n. 4, p.709-717, 2002.

BOURDIEU, P. Meditações Pascalianas. 2. ed. Rio de Janeiro: Bertrand Brasil, 2007.

BOURDIEU, P. A distinção: crítica social do julgamento. São Paulo: Edusp; Porto Alegre, RS: Zouk, 2008.

BOURDIEU, P. Razões práticas: sobre a teoria da ação. 10. ed. Campinas, SP: Papirus, 2010.

BRASIL. Ministério da Saúde. Conselho Federal de Odontologia. I Conferência Nacional de Saúde Bucal: relatório final. Brasília, DF, 1986.

BRASIL. Ministério da Saúde. Secretaria de Atenção à Saúde/ Secretaria de Vigilância em Saúde. Departamento de Atenção Básica. Coordenação Geral de Saúde Bucal. SB Brasil 2010: pesquisa nacional de saúde bucal: resultados principais. Brasília, DF, 2011. 
BRASIL. Ministério da Saúde. Departamento de Atenção Básica. Diretrizes da Política Nacional de Saúde Bucal. Brasília, DF, 2004a.

BRASIL. Ministério da Saúde. Secretaria de Atenção à Saúde. Projeto SB Brasil 2003: condições de saúde bucal da população brasileira 2002-2003: resultados principais. Brasília, DF: Ministério da Saúde, 2004b.

CAMARGO, M. B.; DUMITH, S. C.; BARROS, A. J. D. Uso regular de serviços odontológicos entre adultos: padrões de utilização e tipos de serviços. Cadernos de Saúde Pública, Rio de Janeiro, v. 25, n. 9, p. 1894-1906, set. 2009.

CAVALCANTI, R. P.; GASPAR, G. S.; GOES, P. S. A. Utilização e acesso aos serviços de saúde bucal do SUS - uma comparação entre populações rurais e urbanas. Pesquisa brasileira em odontopediatria e clínica integrada, João Pessoa, v. 12, n. 1, p. 121-26, jan./mar. 2012.

CHAVES, S.C.L. et al. Política Nacional de Saúde Bucal: fatores associados à integralidade do cuidado. Rev Saúde Pública, v. 44, n.6, p.1005-1013, 2010.

CHAVES, S.C.L. et al. Avaliação da oferta e utilização de especialidades odontológicas em serviços públicos de atenção secundária na Bahia, Brasil. Cadermos de Saúde Pública, Rio de Janeiro, v. 27, n.1, p.143-154, jan. 2011.

CHAVES, S.C.L. et al. Características do acesso e utilização de serviços odontológicos em municípios de médio porte. Ciência \& Saúde Coletiva, Rio de Janeiro, v. 17, n. 11, p. 3115-3124, 2012.

CHAVES, S.C.L; VIEIRA-DA-SILVA, L.M. Inequalities in oral health pratices and social space: an exploratory qualitativ estudy. Health Policy, v. 86, p. 119-128, 2008.

CRUZ, D.N. Desigualdades na utilização dos serviços odontológicos: posição e tomadas posição no espaço social. 2015. 156f. Tese (Doutorado em Saúde Pública) - Instituto de Saúde Coletiva, Universidade Federal da Bahia, Salvador, 2015.

DAVOGLIO, R.S. et al. Fatores associados a hábitos de saúde bucal e utilização de serviços odontológicos entre adolescentes. Cadernos de Saúde Pública, Rio de Janeiro, v. 25, n. 3, p. $655-667$, mar. 2009.

DINIZ, J. Contribuição ao estudo do sistema incremental de atendimento odontológico. 1987. Tese (Doutorado em Odontologia) - Faculdade de Odontologia, Universidade Federal da Bahia, Salvador, 1987.

DONABEDIAN, A. Los espacios de la salud: aspectos fundamentals de la organización de la atención médica. México, DF: Editora Biblioteca de la Salud: 1988.

FERREIRA, C. O.; ANTUNES, J. L. F.; ANDRADE, F.B. Fatores associados a utilização dos serviços odontológicos por idosos brasileiros. Revista de Saúde Pública, São Paulo, v. 47, supl.3, p. 90-97, dez.2013.

FIGUEIREDO, N.; GOES, P. S. A. Construção da atenção secundária em saúde bucal: um estudo sobre os Centros de Especialidades Odontológicas em Pernambuco, Brasil. Cadernos de Saúde Pública, Rio de Janeiro, v. 25, n. 2, p. 259-267, fev. 2009. 
FRAZÃO, P.; NARVAI, P. C. Saúde Bucal no Sistema Único de Saúde: 20 anos de luta por uma política pública. Saúde em Debate, Rio de Janeiro, v. 33, p. 64-71, 2010.

GOES, P. S. A. et al. Avaliação da atenção secundária nos Centros de Especialidades do Brasil. Cadernos de Saúde Pública, Rio de Janeiro, 28 sup., S81-S89, 2012.

GOMES, A. M. M. et al. Fatores associados ao uso de serviços de saúde bucal: estudo de base populacional em municípios do Maranhão, Brasil. Ciência \& Saúde Coletiva, v. 19, n. 2, p. 629-640, 2014.

GUARNIZO-HERREÑO, C. C. et al. Oral health and welfare estate regimes: a crossnational analysis of European countries. European Journal of Oral Sciences, v. 121, p. 169-175, 2013.

HELLER, A. Teoría de las necesidades en Marx. Barcelona: Ediciones Península, 1986.

IBGE. Acesso e utilização dos serviços de saúde - PNAD 2003. Rio de Janeiro, 2005.

LIMA, A. C. S.; CABRAL, E. D.; VASCONCELOS, M. M. V. B. Satisfação dos usuários assistidos nos Centros de Especialidades Odontológicas no município do Recife, Pernambuco, Brasil. Cadernos de Saúde Pública, Rio de Janeiro, v. 26, n. 5, p. 991-1002, 2010.

MANHÃES, A. L. D.; COSTA, A. J. L. Acesso e utilização de serviços odontológicos no Estado do Rio de Janeiro, Brasil, em 1998: um estudo exploratório a partir da Pesquisa Nacional por Amostra de Domicílios. Cadernos de Saúde Pública, Rio de Janeiro, v. 24, n. 1, p. 207-218, jan. 2008.

MARSHMAN, Z. et al. What influences the use of dental services by adults in the UK? Community Dentistry and Oral Epidemiology, Copenhagen,v. 40, p. 306-314, 2012.

MARTILDES, M. L. R. Avaliação do impacto de programas incrementais de atendimento odontológico sobre as condições de saúde bucal de escolares de 12 anos de idade em São José dos Campos- SP, 1991. 1992. Dissertação (Mestrado em Saúde Pública) - Faculdade de Saúde Pública, Universidade de São Paulo, São Paulo, 1992.

MATSUYAMA, Y. et al. Inequalities of dental prothesis use under universal health care insurance. Community Dentistry and Oral Epidemiology, Copenhagen, v. 42, p. 122-128, 2014.

MIRANDA, C. D. B. C.; PERES, M. A. Determinantes da utilização de serviços odontológicos entre adultos: um estudo de base populacional em Florianópolis, Santa Catarina, Brasil. Cadernos de Saúde Pública, Rio de Janeiro, v. 29, n. 11, p. 2319-2332, nov. 2013.

MUIRHEAD, V. E. et al. Predictors of dental care utilization among working poor Canadians. Community Dentistry and Oral Epidemiology, Copenhagen, v. 37, p. 199-208, 2009.

NARVAI, P. C. Odontologia e saúde bucal coletiva. São Paulo: Hucitec; 1994.

OLIVEIRA, R. S. et al. Use of dental services in áreas covered by the Family Health Strategy in Olinda, Brazil. Cadernos de Saúde Pública, Rio de Janeiro, v. 22, n. 1, p.40-5, 2014. 
OMS. Organização Mundial da Saúde. Diminuindo diferenças: a prática das políticas sobre determinantes sociais da saúde: documento de discussão. Conferência Mundial sobre Determinantes Sociais da Saúde. Rio de Janeiro, 2011.

PAIM, J. S. Políticas de Saúde no Brasil. In: ROUQUAYROL, M.Z; ALMEIDA FILHO, N. Epidemiologia \& Saúde, 6. ed. Rio de Janeiro: MEDSI, 2003. p. 587-603.

PALÈNCIA, L. et al. Socioeconomic inequalities in the use of dental care services in Europe: what is the role of public coverage? Community Dentistry and Oral Epidemiology, Copenhagen, v. 42, p. 97-105, 2014.

PAVÃO, A. L. B.; COELI, C. M. Modelos teóricos do uso de serviços de saúde: conceitos e revisão. Cadernos de Saúde Coletiva, Rio de Janeiro, v. 16, n. 3, p. 471-482, 2008.

PEREIRA, C. O. et al. Impacto da Estratégia Saúde da Família sobre indicadores de saúde bucal: análise em municípios do Nordeste brasileiro com mais de 100 mil habitantes. Cadernos de Saúde Pública, Rio de Janeiro, v. 28, n. 3, p. 449-462, mar. 2012.

PEREIRA, C. R. S. et al. Impacto da Estratégia Saúde da Família com equipe de saúde bucal sobre a utilização de serviços odontológicos. Cadernos de Saúde Pública, Rio de Janeiro, v. 25 , n. 5, p.985-996, maio 2009.

PERES, K. G. et al. Redução das desigualdades sociais na utilização de serviços odontológicos no Brasil entre 1998 e 2008. Revista Saúde Pública, Rio de Janeiro, v. 46, n. 2, p.250-8, 2012a.

PERES, M. A. et al. Desigualdades no acesso e na utilização de serviços odontológicos no Brasil: análise do Sistema de vigilância de fatores de risco e proteção para doenças crônicas por inquérito telefônico (VIGITEL 2009). Cadernos de Saúde Pública, Rio de Janeiro, 28 Sup., S9o-S100, 2012b.

PINTO, R. S.; MATOS, D. L.; LOYOLA FILHO, A. I. Características associadas ao uso de serviços odontológicos públicos pela população adulta brasileira. Ciência \& Saúde Coletiva, Rio de Janeiro, v. 17, n. 2, p. 531-544, 2012.

ROCHA, R. A. C. P.; GOES, P. S. A. Comparação de acesso aos serviços de saúde bucal em áreas cobertas e não cobertas pela Estratégia Saúde da Família em Campina Grande, Paraíba, Brasil. Cadernos de Saúde Pública, Rio de Janeiro, v. 24, n. 12, p. 2871-2880, dez. 2008.

RODRIGUES, L. A. M. et al. Uso de serviços odontológicos entre pré-escolares: estudo de base populacional. Ciência \& Saúde Coletiva, Rio de Janeiro, v. 19, n. 10, p. 4247-4256, 2014. SCHRAIBER, L. B.; MENDES-GONÇALVES, R. B. Necessidades de saúde e atenção primária. In: SCHRAIBER, L. B.; NEMES, M. I. B.; MENDES-GONÇALVES, R. B. Saúde do adulto: programas e ações na unidade básica. São Paulo: Hucitec, 1996. cap 1.

SILVA, Z. P. et al. Perfil sociodemográfico e padrão de utilização dos serviços de saúde do Sistema Único de Saúde (SUS), 2003-2008. Ciência \& Saúde Coletiva, Rio de Janeiro, n. 16, v.9, p.3807-3816, 2011. 
SOARES, F. F.; CHAVES, S. C. L.; CANGUSSU, M. C. T. Governo local e serviços odontológicos: análise da desigualdade na utilização. Cadernos de Saúde Pública, Rio de Janeiro, v. 31, n. 3, p. 586-596, 2015.

SOARES, F. F.; CHAVES, S. C. L.; CANGUSSU, M. C. T. Desigualdades na utilização de serviços de saúde bucal na atenção básica e fatores associados em dois municípios brasileiros. Revista panamericana de salud pública, Washington, D.C., v. 6 , n. 34, p. 401-406, 2013.

SOUZA, L. F.; CHAVES, S. C. L. Política Nacional de Saúde Bucal: acessibilidade e utilização de serviços odontológicos especializados em um município de médio porte na Bahia. Revista Baiana de Saúde Pública, Salvador, n. 34, v. 2, p. 371-378, abr./jun. 2010.

TCHICAYA, A.; LORENTZ, N. Socioeconomic inequalities in the non-use of dental care in Europe. International Journal for Equity in Health, n. 13, v. 7, p. 1-14, 2014.

TRAVASSOS, C.; MARTINS, M. Uma revisão sobre os conceitos de acesso e utilização de serviços de saúde. Cadernos de Saúde Pública, Rio de Janeiro, n. 20, supl. 2, S19o-S198, 2004.

VIEIRA-DA-SILVA, L. M. Saúde e Espaço Social. In: NOGUEIRA, R. P. (Org.). Determinação social da saúde e reforma sanitária. Rio de Janeiro: CEBES. 2010. p.180-200.(Coleção Pensar em Saúde). 


\begin{tabular}{|c|c|c|c|c|}
\hline Autor, ano & Local & População & Aspectos metodológicos & Resultados principais \\
\hline $\begin{array}{l}\text { Araújo et al., } \\
2009\end{array}$ & Pelotas-RS & $\begin{array}{c}\mathrm{n}=4.226 \text { indivíduos de } 10 \\
\text { anos ou mais. }\end{array}$ & $\begin{array}{l}\text { Estudo transversal de base } \\
\text { populacional com aplicação } \\
\text { de questionários. }\end{array}$ & $\begin{array}{l}\text { 50,9\% utilizaram serviço no último ano. Ter } \\
\text { escolaridade, sermaior de oito anos, maior } \\
\text { nível socioeconômico e maior percepção de } \\
\text { problemas aumentaram o uso. }\end{array}$ \\
\hline $\begin{array}{l}\text { Camargo; } \\
\text { Dumith; Barros, } \\
2009\end{array}$ & Pelotas-RS & $\mathrm{n}=2.961$ adultos. & $\begin{array}{l}\text { Estudo transversal com } \\
\text { aplicação de questionário. }\end{array}$ & $\begin{array}{l}\text { 32,8\% faziam uso regular. Esse uso foi maior } \\
\text { no sexo feminino, menor de } 60 \text { anos, de maior } \\
\text { escolaridade e nível socioeconômico e usuário de } \\
\text { serviços privados. }\end{array}$ \\
\hline $\begin{array}{l}\text { Davoglio et al., } \\
2009\end{array}$ & Gravataí-RS & $\mathrm{n}=1.170$ adolescentes. & $\begin{array}{c}\text { Estudo transversal com } \\
\text { aplicação de questionário } \\
\text { sobre hábitos de saúde bucal } \\
\text { e estilo de vida. }\end{array}$ & $\begin{array}{l}68,9 \% \text { utilizaram o serviço no último ano. Esse } \\
\text { foi maior no nível socioeconômico mais alto. }\end{array}$ \\
\hline $\begin{array}{l}\text { Figueiredo \& } \\
\text { Góes, } 2009\end{array}$ & $\begin{array}{l}\text { Estado de } \\
\text { Pernambuco }\end{array}$ & $\mathrm{n}=22$ CEO. & $\begin{array}{l}\text { Série histórica dos } \\
\text { procedimentos do Sistema } \\
\text { de Informação Ambulatorial } \\
\text { (SIA) do SUS, } 2006 \\
\text { (utilização de procedimentos } \\
\text { especializados). }\end{array}$ & $\begin{array}{l}\text { 40,9\% dos CEO com bom desempenho de } \\
\text { metas. Quanto menor o porte populacional } \\
\text { pior o desempenho. Quanto maior o Índice } \\
\text { de Desenvolvimento Humano, melhor o } \\
\text { desempenho. }\end{array}$ \\
\hline $\begin{array}{l}\text { Pereira et al., } \\
2009\end{array}$ & Natal-RN & $\begin{aligned} \mathrm{n}= & 4.604 \text { indivíduos de } \\
& \text { todas as idades. }\end{aligned}$ & $\begin{array}{l}\text { Comparação da percepção de } \\
\text { necessidade de tratamento } \\
\text { odontológico entre áreas } \\
\text { cobertas pela ESB, UBS } \\
\text { tradicional e sem serviços de } \\
\text { saúde bucal. }\end{array}$ & $\begin{array}{l}\text { Áreas cobertas pela ESB tem maior utilização } \\
\text { quando comparadas às áreas sem cobertura. } \\
\text { Utilização de } 1,32 \% \text { na ausência de serviço de } \\
\text { saúde; } 17,5 \% \text { nas UBS; e } 45,4 \% \text { na ESF. }\end{array}$ \\
\hline
\end{tabular}


Quadro 1 - Estudos nacionais publicados entre 2009-2015 sobre utilização dos serviços odontológicos no Brasil

\begin{tabular}{|c|c|c|c|c|}
\hline $\begin{array}{l}\text { Baldani et al., } \\
2010\end{array}$ & $\begin{array}{c}\text { Ponta Grossa- } \\
\text { PR }\end{array}$ & $\begin{array}{c}\mathrm{n}=246 \text { indivíduos de } 35 \\
\text { anos ou mais. }\end{array}$ & $\begin{array}{c}\text { Estudo transversal com } \\
\text { aplicação de questionário. }\end{array}$ & $\begin{array}{l}\text { 38,1\% adultos e } 19,5 \% \text { dos idosos foram no } \\
\text { dentista no último ano. Usar prótese total, não } \\
\text { residir em domicílio próprio e ter pior higiene } \\
\text { oral foram associadas como o maior uso. }\end{array}$ \\
\hline $\begin{array}{l}\text { Souza \& } \\
\text { Chaves, } 2010\end{array}$ & $\begin{array}{l}\text { Sem } \\
\text { identificação- } \\
\text { Bahia }\end{array}$ & $\mathrm{n}=148$ de 3 a 75 anos. & $\begin{array}{l}\text { Estudo transversal com } \\
\text { aplicação de questionário para } \\
\text { identificar acesso ao CEO. }\end{array}$ & $\begin{array}{l}\text { 61\% utilizou a atenção básica. Maior acesso } \\
\text { ao CEO por usuários que vinham da atenção } \\
\text { básica e para periodontia em relação a outras } \\
\text { especialidades. }\end{array}$ \\
\hline $\begin{array}{l}\text { Chaves et al., } \\
2011\end{array}$ & $\begin{array}{l}\text { Sem } \\
\text { identificação- } \\
\text { Bahia }\end{array}$ & $\mathrm{n}=4$ CEO. & $\begin{array}{l}\text { Produção ambulatorial, oferta } \\
\text { e utilização dos serviços } \\
\text { através do SIA/SUS, ano } 2008 \text {. }\end{array}$ & $\begin{array}{l}\text { Utilização de endodontias variaram de } 13 \% \text { a } \\
\text { 33,4\% e a maior utilização foi da periodontia } \\
\text {-100\%. Menor utilização quando existem } \\
\text { barreiras de acesso. }\end{array}$ \\
\hline Silva et al., 2011 & Brasil & $\begin{array}{l}\mathrm{n}=384.834 \text { indivíduos em } \\
2003 . \\
\mathrm{n}=391.868 \text { indivíduos em } \\
2008 .\end{array}$ & $\begin{array}{l}\text { Dados da PNAD } 2003 \text { e } 2008 \\
\text { sobre utilização de serviços de } \\
\text { saúde bucal. }\end{array}$ & $\begin{array}{c}\text { Utilização dos serviços odontológicos de } \\
\text { 8,6\% em } 2003 \text { e 14,3\% em 2008. As consultas } \\
\text { aconteceram de forma predominante nos } \\
\text { serviços não SUS, com menor proporção na } \\
\text { região Nordeste. }\end{array}$ \\
\hline $\begin{array}{l}\text { Cavalcanti; } \\
\text { Gaspar; Góes, } \\
2012\end{array}$ & $\begin{array}{l}\text { Sem } \\
\text { idenfiticação- } \\
\text { Bahia }\end{array}$ & $\begin{array}{l}\text { n=949 município A e } \\
\text { n=1.049 município B } \\
\text { Idade/Faixa índice OMS }\end{array}$ & $\begin{array}{l}\text { Estudo transversal com } \\
\text { aplicação de questionário. }\end{array}$ & $\begin{array}{c}\text { Utilização de } 80 \% \text { no município A e } 67,6 \% \text { no } \\
\text { município B. Maior utilização na zona urbana e } \\
\text { em idades maiores. }\end{array}$ \\
\hline $\begin{array}{l}\text { Chaves et al., } \\
2012\end{array}$ & $\begin{array}{l}\text { Não } \\
\text { identificado- } \\
\text { Bahia }\end{array}$ & $\begin{array}{c}\mathrm{n}=2.539 \text { indivíduos de } 15 \\
\text { anos oumais. }\end{array}$ & $\begin{array}{c}\text { Estudo transversal com } \\
\text { aplicação de questionário. }\end{array}$ & $\begin{array}{c}\text { Utilização na atenção básica foi } 26 \% \text { e } \\
\text { especializada } 11,7 \% \text {. Pouca articulação entre os } \\
\text { dois níveis de atenção. }\end{array}$ \\
\hline
\end{tabular}




\begin{tabular}{|c|c|c|c|c|}
\hline Góes et al., 2012 & Brasil & $n=613$ CEO. & $\begin{array}{l}\text { Série histórica dos } \\
\text { procedimentos SIA/SUS, } 2007 \\
\text { (utilização de procedimentos } \\
\text { especializados) - } \\
\text { cumprimento das metas. }\end{array}$ & $\begin{array}{l}\text { Melhor cumprimento das metas (utilização) em } \\
\text { cidades com maior porte populacional e maior } \\
\text { cobertura da ESF. }\end{array}$ \\
\hline $\begin{array}{l}\text { Pereira et al., } \\
2012\end{array}$ & $\begin{array}{l}12 \text { municípios } \\
\text { com mais } \\
\text { de } 100 \text { mil } \\
\text { habitantes - } \\
\text { Nordeste }\end{array}$ & $\mathrm{n}=59.221$ indivíduos. & $\begin{array}{c}\text { Utilização dos serviços entre } \\
\text { áreas cobertas pela ESB, UBS } \\
\text { tradicional e sem serviços de } \\
\text { saúde bucal. }\end{array}$ & $\begin{array}{l}\text { Maior acesso e utilização de serviços preventivos } \\
\text { em áreas cobertas pela ESB. Ações curativas } \\
\text { foram mais utilizadas no modelo tradicional. }\end{array}$ \\
\hline $\begin{array}{l}\text { Peres et al., } \\
2012 a\end{array}$ & Brasil & $\begin{array}{l}\mathrm{n}=384.834 \text { indivíduos em } \\
2003 . \\
\mathrm{n}=391.868 \text { indivíduos em } \\
2008 .\end{array}$ & $\begin{array}{c}\text { Dados da PNAD } 2003 \text { e } 2008 \\
\text { sobre utilização de serviços de } \\
\text { saúde bucal. Amostra dividida } \\
\text { em quintis. }\end{array}$ & $\begin{array}{l}\text { Aumento do uso de serviços entre } 2003 \text { e } 2008 . \\
\text { Menor utilização em idade inferior a seis anos e } \\
\text { entre os mais pobres. }\end{array}$ \\
\hline $\begin{array}{l}\text { Peres et al., } \\
2012 b\end{array}$ & $\begin{array}{l}\text { Capitais } \\
\text { brasileiras }\end{array}$ & $\mathrm{n}=54.367$ & Inquérito telefônico. & $\begin{array}{l}\text { Utilização do SUS de } 6,2 \% \text { (no DF) a } 35,2 \% \text { (Boa } \\
\text { Vista). Serviços privados foram utilizados por } \\
61,1 \% \text { da amostra. Maior uso em mulheres, meia } \\
\text { idade e mais escolarizados. }\end{array}$ \\
\hline $\begin{array}{l}\text { Pinto; Matos; } \\
\text { Loyola Filho, } \\
2012\end{array}$ & Brasil & $\begin{array}{c}\mathrm{n}=12.425 \text { adultos de } 35- \\
44 \text { anos. }\end{array}$ & Dados do SB Brasil '²003. & $\begin{array}{l}51,8 \% \text { fizeram uso de serviços públicos. O uso } \\
\text { do serviço público foi associado à menor renda, } \\
\text { municípios de menor porte, moradores de zona } \\
\text { rural e menor escolaridade quando comparado } \\
\text { ao serviço privado. }\end{array}$ \\
\hline
\end{tabular}


Quadro 1 - Estudos nacionais publicados entre 2009-2015 sobre utilização dos serviços odontológicos no Brasil

(conclusão)

\begin{tabular}{|c|c|c|c|c|}
\hline $\begin{array}{l}\text { Ferreira; } \\
\text { Antunes; } \\
\text { Andrade, } 2013\end{array}$ & Brasil & $\begin{array}{c}\mathrm{n}=6.702 \text { idosos de 65-74 } \\
\text { anos. }\end{array}$ & Dados do SB Brasil 2010. & $\begin{array}{l}\text { 46,5\% fizeram uso nos últimos dois anos. Maior } \\
\text { uso entre aqueles com maior escolaridade e } \\
\text { renda e não usuários de prótese. }\end{array}$ \\
\hline $\begin{array}{l}\text { Soares; Chaves; } \\
\text { Cangussu, } 2013\end{array}$ & $\begin{array}{l}\text { Sem } \\
\text { identificação } \\
\text {-Bahia }\end{array}$ & $\begin{array}{c}\mathrm{n}=2.539 \text { indivíduos acima } \\
\text { de } 15 \text { anos. }\end{array}$ & $\begin{array}{l}\text { Estudo transversal com } \\
\text { aplicação de questionário. }\end{array}$ & $\begin{array}{l}26,86 \% \text { utilizaram o serviço SUS no último } \\
\text { ano. A exodontia foi mais utilizada em usuário } \\
\text { beneficiado por programa social, acima de } 35 \\
\text { anos e de menor escolaridade. }\end{array}$ \\
\hline $\begin{array}{l}\text { Miranda \& } \\
\text { Peres, } 2013\end{array}$ & $\begin{array}{l}\text { Florianópoli- } \\
\text { SC }\end{array}$ & $\mathrm{n}=1.729$ adultos & $\begin{array}{l}\text { Estudo transversal com } \\
\text { aplicação de questionário. }\end{array}$ & $\begin{array}{c}\text { 66\% fizeram uso de serviços. Uso maior entre as } \\
\text { mulheres, nos mais escolarizados e portadores } \\
\text { de planos privados. }\end{array}$ \\
\hline $\begin{array}{l}\text { Gomes et al., } \\
2014\end{array}$ & $\begin{array}{l}\text { Municípios } \\
\text { com mais } \\
\text { de } 100 \text { mil } \\
\text { habitantes - } \\
\text { Maranhão }\end{array}$ & $\begin{array}{c}\mathrm{n}=1.214 \text { crianças; } \mathrm{n}= \\
1.059 \text { adultos. }\end{array}$ & $\begin{array}{l}\text { Estudo transversal com } \\
\text { aplicação de questionário. }\end{array}$ & $\begin{array}{l}\text { Uso por } 9 \% \text { crianças e } 28,1 \% \text { adultos. Uso foi } \\
\text { associado com maior idade, maior escolaridade e } \\
\text { o fato de referir necessidade de tratamento. }\end{array}$ \\
\hline $\begin{array}{l}\text { Rodrigues et al., } \\
2014\end{array}$ & $\begin{array}{l}\text { Montes } \\
\text { Claros-MG }\end{array}$ & $\begin{array}{c}\mathrm{n}=809 \text { crianças de 18-36 } \\
\text { meses. }\end{array}$ & $\begin{array}{l}\text { Estudo transversal com } \\
\text { aplicação de questionário. }\end{array}$ & $\begin{array}{l}\text { 15,5\% utilizaram serviço no último ano. O uso foi } \\
\text { maior em crianças mais velhas, de maior renda, } \\
\text { em famílias com moradia própria e com maior } \\
\text { acesso à informação em saúde. }\end{array}$ \\
\hline $\begin{array}{l}\text { Soares; Chaves; } \\
\text { Cangussu, } 2015\end{array}$ & $\begin{array}{l}\text { Sem } \\
\text { identificação- } \\
\text { Bahia }\end{array}$ & $\begin{array}{c}\mathrm{n}=2.539 \text { indivíduos acima } \\
\text { de } 15 \text { anos. }\end{array}$ & $\begin{array}{l}\text { Estudo transversal com } \\
\text { aplicação de questionário. }\end{array}$ & $\begin{array}{c}\text { No último ano, } 38,76 \% \text { utilizaram o serviço } \\
\text { privado, } 33,80 \% \text { a atenção básica no SUS e } \\
17,29 \% \text { a atenção básica e a especializada. } \\
\text { A menor escolaridade implicou maior uso do } \\
\text { serviço público. }\end{array}$ \\
\hline
\end{tabular}

${ }^{1}$ Inquéritos epidemiológicos em saúde bucal, realizados nacionalmente em 2003 e 2010 conhecidos por SB Brasil. 


\section{Implementação de serviços públicos odontológicos especializados no Brasil}

Sônia Chaves

Thais Aranha Rossi

Ana Maria Freire

\section{Atenção especializada e atenção secundária: diferenças e proximidades na política}

Há uma década no Brasil, jamais seria foco de reflexão ou pesquisa o tema referente à análise da implementação ou avaliação de serviços odontológicos especializados. Essa afirmação é prudente já que isso nos coloca em alerta por estarmos impregnados das categorias estatais sobre a própria concepção dessa política ou serviço no Brasil. Ou seja, corremos o risco, ao pensar a política de atenção especializada, ou secundária, com as categorias produzidas pelos agentes do Estado que a formularam. (BOURDIEU, 2014) Por isso, todo cuidado é fundamental para não refletir cientificamente sobre a política a partir das categorias produzidas pelos seus próprios produtores.

Cabe aqui também um alerta sobre a opção desse texto do uso do termo atenção "especializada" e não atenção "secundária". Esses termos são, na verdade, sinônimos, têm o mesmo sentido de tratar sobre práticas odontológicas especializadas, que são aquelas situadas fora do escopo das ações da atenção básica. Falar de atenção especializada nesse caso não é falar de especialista, é se reportar a maior densidade de tecnologia que determinada prática exige. Ainda 
que a compreensão do fenômeno da especialização na medicina e, também na odontologia, mundial seja questão fundamental, a entrada na agenda e ação governamental voltada para a oferta de especialidades odontológicas no serviço público pode estar relacionada à construção social dessa política no Brasil, desde os anos 1940, com a fluoretação das águas de abastecimento público, por exemplo, e formação de um corpo de agentes interessados e engajados no tema da odontologia pública, e também daqueles que participaram do movimento pela democracia e da Reforma Sanitária Brasileira. Atenção secundária remete ao preconizado para os sistemas universais de saúde no modelo piramidal e hierarquizado, baseado nas diferenças de incorporação tecnológica, mas não necessariamente em complexidade. Nesse modelo, a atenção básica está na base da pirâmide, e a atenção secundária e terciária (média e alta complexidade) estariam num nível superior. Isso pode reportar a uma ideia equivocada de maior valoração do trabalho nos degraus superiores, o que deve ser desconstruído.

O termo "atenção especializada" remete ao sentido da maior densidade tecnológica, por um lado, e, por outro, à ideia de redes de atenção, como uma relação menos hierárquica entre os pontos do sistema de saúde, podendo permitir um perspectiva menos rígida para as trajetórias dos usuários no sistema de saúde.

No caso brasileiro, o primeiro artigo publicado sobre a atenção especializada foi aquele de Figueiredo e Góes (2009), com forte influência de autores do sistema nacional de saúde do Reino Unido, onde o termo "secondary care, specialist secondary care" é a principal referência. (FAULKNER et al., 2003; MORRIS; BURKE, 2001) Esse uso influenciou uma série de publicações posteriores.

Cabe lembrar que na carta de intenção da política Brasil Sorridente, publicada em 2004, está explicitado o uso sinônimos dos termos "especializada" e "secundária", bem como argumento para sua implementação e os objetivos desse eixo da política como atenção complementar ou integral, a saber:

Os serviços odontológicos especializados correspondem a não mais do que $3,5 \%$ do total de procedimentos clínicos odontológicos. É evidente a baixa capacidade de oferta dos serviços de atenção secundária e terciária. (BRASIL, 2004a, p. 14)

Os CREO serão unidades de referência para as equipes de Saúde Bucal da atenção básica e, sempre integrados ao processo de planejamento locoregional, ofertarão, de acordo com a realidade epidemiológica de cada 
região e município, procedimentos clínicos odontológicos complementares aos realizados na atenção básica. (BRASIL, 2004a, p. 15)

Ampliação do atendimento [...] nos níveis secundário e terciário de modo a buscar a integralidade da atenção. (BRASIL, 2004a, p. 4, grifo nosso)

\section{Divisão social do trabalho odontológico e os caminhos para a especialidade}

O processo de especialização do trabalho é infinito e irreversível, como já afirmava Max Weber (2014) e Durkheim (livro publicado em 1893, edição nacional de 1989), resultado da divisão social do trabalho a partir da incorporação de novos saberes e desenvolvimento da ciência. Um especialista é aquele que se aprofunda e domina determinado subcampo do saber. O surgimento de novas áreas especializadas é produto do crescimento geométrico do conhecimento científico nos diversos campos sociais. Essas novas áreas especializadas têm demandado para si o domínio do monopólio da aplicação desse conhecimento através do reconhecimento entre os pares de seu domínio. A pressão exercida por esses especialistas é grande junto às autarquias, como os conselhos profissionais para a regulação e normatização. Essa é sempre questão em disputa.

Por outro lado, as novas necessidades sociais e técnicas requeridas pelo perfil epidemiológico da população nem sempre são objeto de reflexão para a compreensão desse fenômeno. No campo médico, os médicos foram aqueles que mais avançaram. Com grande reconhecimento simbólico, a atividade médica requer confiança, sigilo e credibilidade no seu exercício, assim como a atividade odontológica. (MACHADO, 1997)

Mesmo sendo o Cirurgião-Dentista (CD) um dominante incontestável no campo odontológico, outros agentes integram o processo de trabalho também na atenção especializada, o Auxiliar em Saúde Bucal (ASB) e o Técnico em Saúde Bucal (TSB). Objeto de discussões e conflitos durante muitos anos ao interior do campo odontológico, em 24 de dezembro de 2008 , é sancionada a Lei n. ${ }^{0}$ 11.889/2008, que regulamenta o exercício das profissões de TSB e ASB. A lei teve seu processo legislativo desencadeado pelo deputado Rubens Otoni, do Partido dos Trabalhadores de Goiás, e, à época, ainda utilizava os termos "técnico de higiene dental" e "atendente de consultório dentário". A proposta estabelecia regras para o registro nos Conselhos de Odontologia, enumerava as competências desses profissionais e passou por muitas discussões até ser pro- 
mulgada. (ANDRADE, 2008) Entretanto, seguindo o proposto para o presente texto, cumpre questionar como se dá o processo de trabalho em saúde bucal na atenção especializada. Qual o papel desempenhado pelo pessoal auxiliar?

Nos anais da VII Conferência Nacional de Saúde, em 1980, já constava a preparação dos recursos humanos de nível auxiliar e técnico, além de uma recomendação em caráter urgente acerca da formação de um "técnico dental operador". Ainda que o documento trate da odontologia nos serviços básicos de saúde, evidencia a luta em torno da legalização do pessoal auxiliar em um período de tentativas malsucedidas na legalização dos dentistas práticos. (CARVALHO, 2003) Ressalta-se que a introdução do pessoal auxiliar no Brasil não é recente, pois vem sendo experimentada desde 1950 com os Serviços Especiais de Saúde Pública. (FAQUIM; CARNUT, 2012) A partir dos anos 1980, o processo de muitas disputas ao interior do campo odontológico seguiu pelas atividades a serem desempenhadas no processo de trabalho, destacando-se as tomadas de posição das associações de classe que assumiam posição mais conservadora afirmando que o técnico poderia assumir o lugar do CD ou que um CD ficaria responsável por supervisionar uma quantidade muito grande de pessoal auxiliar, o que impactaria no mercado de trabalho para o CD.

Contraditoriamente, o processo contínuo de especialização foi um impulsionador para incorporação e expansão do pessoal auxiliar no Brasil, pois o CD se liberava de funções mais simples, transferindo-as para o seu auxiliar (FAQUIM; CARNUT, 2012) e obtendo consequente aumento da produtividade. (SILVA et al., 2006) Um estudo que investigou o processo de trabalho dos auxiliares na ortodontia na esfera privada concluiu que a maioria dos CD delegava procedimentos não permitidos pela legislação aos profissionais auxiliares. (SILVA et al., 2006) Rossi e Chaves (2015), que analisaram a implementação dos Centros de Especialidades Odontológicas (CEO) em municípios da Bahia, apontaram ASB também desempenhando atividades que não eram próprias de suas atribuições, mesmo após a Lei n. ${ }^{\circ}$ 11.889/2008 que regulamentou seu exercício. Outro trabalho que avaliou o perfil dos técnicos em higiene dental na Grande Vitória encontrou que a maioria dos entrevistados trabalhava no setor público. (AQUINO; MIOTTO, 2005) Em se tratando de setor público, destaca-se a Portaria GM/MS n. ${ }^{\circ} 1.570$, de 29 de julho de 2004 , que estabeleceu a exigência de um auxiliar de consultório dentário por cada equipe odontológica presente no CEO. Investigando um CEO em São Luís, Maranhão, Feitosa e colaboradores (2009) observaram o descumprimento à portaria e ausência de pessoal auxiliar 
odontológico. Nesse mesmo ano, um estudo avaliou 56 CEO implantados no Brasil, em seis estados, e encontrou uma média de 9,07 CD, 5,5 ASB e 0,9 TSB. A maioria dos auxiliares não recebia gratificação por trabalhar com especialidades. (DEITOS, 2009) Destaca-se a necessidade de estudos empíricos e revisões sistemáticas que avaliem o papel e ações desenvolvidas pelo pessoal auxiliar na atenção especializada pública e privada.

\section{Características sociológicas da profissão odontológica no Brasil}

Uma profissão é uma prática autorregulada realizada por especialistas, que tiveram formação específica, com forte orientação para o ideal de servir à coletividade, norteada por princípios ético-profissionais definidos por ela mesma. (STARR, 1991) Sobre a autorregulação, há controvérsias. É necessário relativizar essa premissa já que a profissão é também fruto de outorga do Estado, efeito de título que somente o Estado pode legitimar. Os conselhos profissionais no Brasil, como autarquias do estado, fazem esse papel. Cabe destacar que aqui vamos considerar a profissão ao interior de um campo social, no sentido de Bourdieu (2014), ou seja, os profissionais odontólogos são distintos e também estão em luta, e sofrem forte influência dos outros campos como o campo econômico e do Estado. Pode-se dizer que a prática odontológica no mundo contemporâneo é um tipo de dominação, no sentido de dominação legal de Max Weber (2014), em que o paciente obedece ao dominante profissional que possui tal autoridade legitimada pela outorga do Estado através do diploma profissional. Portanto, os dentistas possuem autonomia relativa em relação aos demais agentes, exercendo dominação legal com grande poder técnico.

O processo de formação e desenvolvimento da divisão social do trabalho em saúde, historicamente, consolidou-se na especialização e monopólio do saber. (MORETTI-PIRES; LIMA; MACHADO, 2011) Para Machado (1997) os conhecimentos singulares e a concepção de que existe um trabalho próprio, impossibilitado de ser desempenhado por outro profissional, tornam a medicina e a odontologia profissões em termos sociológicos, havendo clientela específica para sua negociação profissional.

Podemos afirmar que a profissão odontológica, bem como a médica apresenta grande autonomia técnica, compreendida como capacidade de tomar decisões por conta própria pelo corpo de conhecimento científico e controle sobre o processo de trabalho que adquiriu ao longo da sua constituição como profissão. Nossa perspectiva de análise é aquela que considera a odontologia 
como um espaço social relativamente autônomo onde os profissionais cirurgiões-dentistas exercem grande dominação sobre os demais agentes como os técnicos e auxiliares, mas também, entre as diversas especialidades, há grande disputa pelo reconhecimento e domínio. A odontologia brasileira conta hoje com 23 especialidades reconhecidas pelo Conselho Federal de Odontologia (CFO). Por sinal, é o Estado brasileiro que regula seu exercício através da concessão de poder às autarquias, enquanto um tipo especial de corporação profissional que pode supostamente se autorregular. Machado (1997, p. 59) alertou com um olhar sociológico sobre as profissões ditas autônomas, liberais:

Os advogados, médicos, arquitetos, engenheiros, odontólogos etc. constituem uma parcela pequena do setor de serviços. Trata-se, contudo, de uma fração estratégica na qual se concentra [...] 'a criatividade humana sob a forma de expertise especializada', que inventa e instala tecnologia [...]. No segmento profissional encontra-se a divisão do trabalho elevado ao mais alto grau de perícia e inteligência aplicada. Por isso, Perkin chama de 'sociedades profissionais' as sociedades pós-industriais.

O Relatório Flexner e o Relatório Gies, publicados nos Estados Unidos, respectivamente em 1910 e 1926, normatizaram o ensino médico-odontológico. A redução da doença à sua dimensão biológica resultou na centralidade do processo curativo-reparador, e em uma prática de alto custo, baixa cobertura, com pouco impacto epidemiológico e desigualdades no acesso. (MOYSÉS, 2004) O acesso aos benefícios do tratamento e avanço tecnológico na odontologia historicamente ficou restrito à parcela da população que poderia pagar por ele, e isso refletiu no não reconhecimento do papel social do profissional da odontologia.

No início da década de 1990, havia pouca preocupação social da odontologia, foco na especialização e expectativa de bons ganhos econômicos, sem interesse no serviço público. (PINHEIRO et al., 2009)

Ainda que este capítulo não pretenda esgotar esse tema, a especialização do profissional na odontologia é aspecto relevante. Para Freitas (2007), a especialização constitui um dos argumentos em defesa da autonomia, e aparece como componente para diferenciação e qualificação, sendo um caminho para o profissional se estabelecer e competir no mercado. A expectativa dos profissionais é a de manter, para a profissão, a posição ou situação conquistada anteriormente. A autora faz um paralelo bastante pertinente com Bourdieu (1996), afirmando que 
o monopólio do saber e da prática confere benefícios sociais, e assim traduz-se em capital simbólico, conceito que engloba status, prestígio e poder.

Para Bourdieu (1996), em algumas categorias-chave de sua teoria sobre os campos sociais, está a concepção de distribuição de distintas formas de capital entre os agentes neles situados. O capital é um tipo de energia social acumulada pelos agentes na sua trajetória social e cujo tipo e propriedade definem diferentes disposições que se traduzem em tomadas de posição distintas. Os principais são o capital econômico, relacionado à renda, e o capital cultural, que envolve o adquirido na escola e aquele também incorporado pela origem familiar. Há outros capitais que se traduzem nos diferentes esquemas de percepção e apreciação ao interior dos campos, como, no caso do campo médico, o capital médico, de especialidades e experiência adquirida, convertidas em prestígio, que é na verdade, o reconhecimento pelos pares. No subcampo odontológico, a lógica particular que define as relações entre seus membros é aquela do prestígio pela prática clínica, liberal, especializada no setor privado. (CHAVES; VIEIRA-DA-SILVA, 2007)

Estudos dessa década evidenciam que o perfil e o pensamento do CD tradicional, centrado no consultório, entrou em crise com a transição epidemiológica da doença cárie associada a uma saturação do mercado de trabalho, que não mais confere o status profissional. (GOMES; RAMOS, 2015; PINHEIRO et al., 2009) Pinheiro e colaboradores (2009) mapearam estudos sobre a formação do CD no Brasil, entre os anos de 1992 a 2005, e os resultados apontaram que, no plano político-estrutural, há uma crise da odontologia, seja pelo número de faculdades, seja pelo esgotamento do modelo de atenção, individual e elitista.

E isso já vem ocorrendo há algum tempo. Em 2003, uma pesquisa encomendada pelas principais entidades odontológicas revelou que a maioria dos profissionais relatava a autopercepção de serem liberais autônomos, contudo as informações coletadas se aproximavam bastante de uma realidade mais típica das classes trabalhadoras assalariadas: mais de $40 \%$ deles declararam exercer uma jornada de trabalho igual ou maior de 44 horas semanais, 37\% admitiram duplo vínculo com emprego público ou privado, e mais de $48 \%$ tinham uma renda familiar máxima mensal de $\mathrm{R} \$ 3.600,00$. Outro dado foi um número importante dos profissionais que exerciam a prática privada reconhecerem-se como dependentes dos convênios, que poderiam ser configurados como um "assalariamento indireto" exercido no próprio consultório privado, dada a grande dependência dessa modalidade de vínculo na geração de "receita". (MOYSÉS, 2004) 
Os planos e convênios na odontologia tiveram um crescimento importante nos últimos anos no Brasil, como reforçam os dados da Pesquisa Nacional por Amostra de Domicílios de 2003, 2008, e da Pesquisa Nacional de Saúde de 2013, divulgada nesse ano. Segundo dados da Agencia Nacional de Saúde Suplementar, no período de 2003 a 2014, observou-se um grande crescimento no número de beneficiários de planos exclusivamente odontológicos em todas as regiões do país. Quando se considera a distribuição desses beneficiários por regiões com relação ao total no país, observa-se grande predomínio na região Sudeste, mas com discreto decréscimo ao longo do período. Esses eram 63,9\% de usuários em 2003, 63,6\% em 2007, 60,3\% em 2011 e 58,5\% em 2014. Ainda na comparação entre regiões e considerando o total de beneficiários no país, as outras regiões, com exceção da Sul, apresentam aumento no número de beneficiários ao longo dos três períodos de governo (2003-2014).

Mesmo em expansão, essa "terceirização" promovida pelos planos de saúde odontológicos não está direcionado ao atendimento das necessidades profissionais, mas sim às necessidades de mercado das empresas. Outra situação atual do mercado de trabalho é o assalariamento nas clínicas "populares", que busca acumulação de capital na odontologia sobre relações precarizadas de trabalho, ${ }^{1}$ com exigência de alta produtividade que desconsidera a autonomia profissional e preceitos éticos deontológicos. (GOMES; RAMOS, 2015)

Gomes e Ramos (2015) elencam alguns aspectos da reestruturação produtiva na odontologia que tem resultado em precarização no mercado de trabalho profissional: 1) ampliação de um mercado de planos e seguros de saúde privados; 2) formação de uma camada profissional assalariada, especialmente na nova modalidade de clínicas "populares"; e 3) incorporação de uma intersubjetividade individual-narcisista e concorrencial/competitiva na identidade profissional, que desperta ressentimentos entre os pares. Moysés (2004) destaca que são milhares de profissionais vivendo o efeito nocivo da precarização, que favorece uma crescente "canibalização" profissional, com graves desvios de ética corporativa.

Nessa perspectiva, como analisar a profissão e prática odontológica no Sistema Único de Saúde (SUS)? A lógica do trabalho odontológico autônomo, liberal, cada vez mais especializado, permeado pelas intenções de lucro (seja ele

\footnotetext{
1 Instabilidade e insegurança nas novas formas de organização do trabalho, onde a terceirização e subcontratação ocupa um lugar central, e no recuo do papel do Estado como regulador do mercado de trabalho e da proteção social. (THEBAUD-MONY; DRUCK, 2007)
} 
empresarial ou individual) vai em direção oposta às características do trabalho e princípios do SUS. A atenção desenvolvida no sistema público de saúde enfoca na promoção de saúde, através de equipes multiprofissionais que atuam em um território conforme preza a Estratégia Saúde da Família (ESF), e, além disso, o trabalho é assalariado, com carga horária fixa e muitas vezes sem vínculo empregatício e cumprimento de direitos trabalhistas.

Outra questão que permeia a inserção do dentista no serviço público é que a odontologia tradicional, caracterizada pelo isolamento da clínica em consultório permanece como desafio à saúde bucal coletiva, no sentido da necessidade de sua "des-reconstrução". (GOMES; RAMOS, 2015; MOYSÉS, 2004) Cabe destacar que os aspectos biológicos e clínicos envolvidos na prática profissional são indispensáveis, mas é cada vez mais necessário o desenvolvimento de competências relacionadas às dimensões ética, política e social do seu trabalho (MOYSÉS, 2004; PINHEIRO et al, 2009). Essa realidade não se aplica apenas à odontologia, mas a demais áreas da saúde, em especial a enfermagem e a medicina, ou seja, as três profissões de nível superior que fazem parte da equipe mínima da ESF, atualmente.

Paralelo a isso, há ainda na odontologia a construção de "personagens" do SUS, com um olhar pejorativo como destaca Moysés (2004, p. 35):

Portanto, quem seriam os trabalhadores ou gestores em serviços de
saúde coletiva, senão o 'esquerdista', o profissional 'que não deu certo'
no mercado, o 'sacerdote', o monge franciscano, o 'rebelde' sem causa. E,
assim, fechando o ciclo dos pré-conceitos, os usuários do SUS nada mais
são senão 'carentes'.

Nesse contexto, a existência de profissionais que atuam exclusivamente na saúde coletiva, ainda que minoritários, potencializa um movimento eticopolítico e epistemológico transformador: um espaço profissional da saúde bucal coletiva (GOMES; RAMOS, 2015) ou um sujeito eticopolítico. Essa tomada de posição reflete as disputas no espaço em torno dos ajustes necessários desse agente social no subespaço público em que se esperam recompensas em torno do interesse pelo desinteresse, onde a lei do ganho econômico como primordial está em suspenso. (BOURDIEU, 2014) O sentido do interesse pelo público exige dos agentes nele engajados uma disposição política que toma posição pelo social e não revela abertamente os interesses econômicos em jogo. (CHAVES; VIEIRA-DA-SILVA, 2007) 


\section{As especialidades odontológicas no Brasil}

O primeiro grupo de especialidades reconhecidas, em 1968, pelo extinto Serviço Nacional de Fiscalização Odontológica, foi: cirurgia buco-facial, endodontia, radiologia, odontopediatria, periodontia, prótese odontológica e odontologia sanitária. Em 1971, houve ampliação dessas especializadas reconhecidas, entre elas a dentística restauradora, odontologia legal, patologia bucal, prótese buco-maxilo-facial e prótese dentária. Em 1990, é incluída a implantodontia bucal e a patologia pucal é renomeada patologia bucal e estomatologia. Outras mudanças são feitas em 1992, na I Assembleia Nacional de Especialidades Odontológicas (ANEO), onde a estomatologia é separada da patologia bucal e é retirado o termo bucal da implantodontia. A ortodontia e a ortopedia facial alteram sua nomenclatura, em 1997, e, na II ANEO (2001), outras mudanças de nomenclaturas são realizadas. Mais recentemente, o CFO promoveu a III ANEO, onde foram legalizadas mais três especialidades, incluindo a odontologia do esporte e a acumpultura. (CFO, 2014)

$\mathrm{O}$ número de especialistas registrados no $\mathrm{CFO}$ em todo território nacional aumentou 174,1\% de 2003 a 2014. Em 2014, a região Sudeste registrou o maior número de especialistas (50.792), seguida pelas regiões Sul (20.502) e Centro-Oeste (13.072), enquanto que os menores números de especialistas são encontrados nas regiões Norte (4.110) e Nordeste (9257). Quando se analisa a proporção de profissionais com especialização segundo regiões, a maior concentração de profissionais localiza-se no Sudeste e Sul do país, ao longo dos 12 anos. As regiões Nordeste, Norte e Centro-Oeste detinham apenas aproximadamente $30 \%$ dos especialistas do Brasil em 2014 e 23\% em 2003. Entretanto, observa-se uma tendência à redução na região Sudeste e de aumento nas outras regiões (Figura 1). 
Figura 1 - Proporção de CD especialistas registrados no CFO por região do país no período entre 2003 e 2014, Brasil

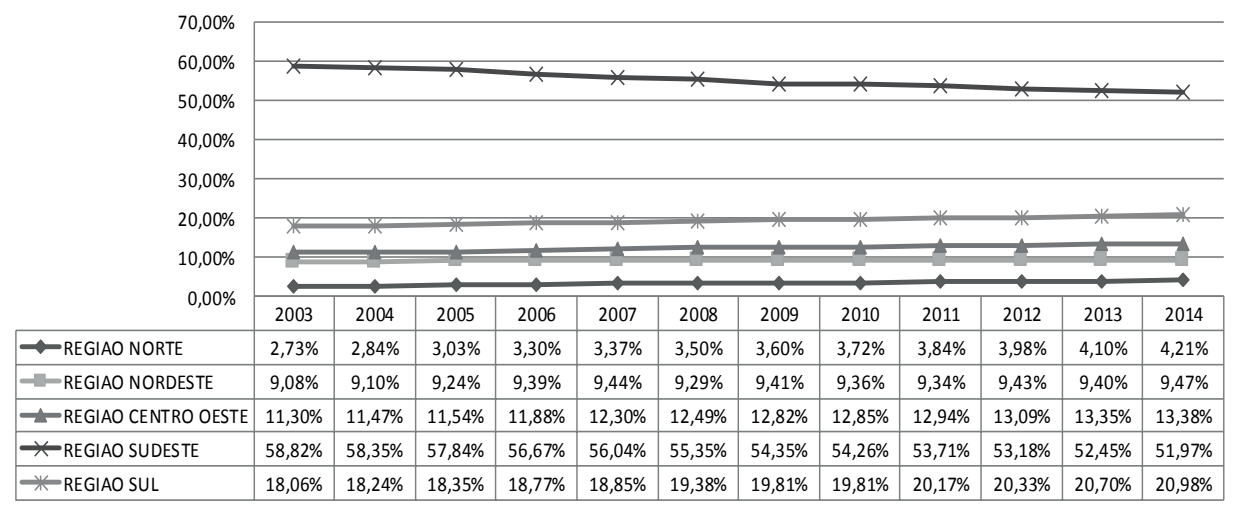

Fonte: CFO (2015).

A maioria dos especialistas atende na iniciativa privada, no período entre 2003 e 2010, segundo dados do Cadastro Nacional de Estabelecimentos de Saúde (CNES)/DataSUS, contudo ressalta-se que nem todos os especialistas são registrados no CNES. Os especialistas do Sudeste são os que mais atendem pelo SUS, seguidos pelos profissionais do Nordeste. As regiões Sul e Sudeste são aquelas que mais possuem especialistas atendendo na iniciativa privada. As regiões com menor número de especialistas na iniciativa privada, entre 2004 a 2014, são a Norte e a Centro-Oeste. As especialidades que possuem maior quantidade de profissionais atuando no SUS, quando comparado ao total de especialistas, são a endodontia e a cirurgia buco-maxilo-facial. Dentre os que mais atuam na iniciativa privada, estão os ortodontistas, endodontistas e protesistas. Entretanto, quando se analisa isoladamente cada especialidade e proporção de recursos humanos na iniciativa privada e no SUS, a cirurgia buco-maxilo-facial e a odontologia para pacientes com necessidades especiais são aquelas que apresentam maior proporção de profissionais no SUS dentro da sua especialidade. Já a implantodontia, ortodontia, odontopediatria, endodontia, prótese e periodontia possuem mais profissionais atuando na iniciativa privada. 


\section{As necessidades sociais que desafiam o campo odontológico no Brasil}

Entender o cenário epidemiológico da saúde bucal da população brasileira é requisito fundamental para a compreensão das necessidades de saúde bucal enquanto problema social e não apenas "problema dos dentistas" ou "da odontologia”. Esse entendimento é necessário também para o planejamento das estratégias de gestão de serviços de saúde de forma mais equitativa.

Para avançar na discussão sobre o incremento da atenção odontológica especializada no SUS, foi feita breve caracterização dos inquéritos epidemiológicos brasileiros de saúde bucal. O recorte empreendido foi baseado nos resultados diretamente relacionados aos serviços ofertados pelos CEO e Laboratórios Regionais de Próteses Dentárias (LRPD), a saber, perda dental (componente de dentes extraídos do Índice de Dentes Cariados, Perdidos e Obturados - CPO-D), edentulismo (perda dentária total em um dos maxilares) e doença periodontal (porcentagem de pessoas que não necessitavam de nenhum tratamento periodontal).

O primeiro inquérito nacional de saúde bucal realizado no Brasil foi em 1986. Realizou-se uma pesquisa em 16 capitais, as quais representaram as cinco regiões brasileiras (Norte, Nordeste, Sudeste, Sul e Centro-oeste). (RONCALLI; CÔRTES; PERES, 2012) Foram pesquisados grupos etários de 6 a 12 anos, 15 a 19 anos, 35 a 44 anos e 50 a 59 anos, totalizando 25.407 pessoas. Os resultados desse primeiro levantamento demonstraram que, nos adultos, o componente de dentes extraídos teve maior participação no índice CPO-D, com porcentagens de $15 \%$, 66\% e $86 \%$ para as faixas etárias de 15-19, 35-44 e 50-59 anos, respectivamente. Quanto ao edentulismo, $72 \%$ da população urbana analisada na faixa de 50-59 anos já haviam extraído todos os dentes de pelo menos um maxilar. Com relação à doença periodontal, a porcentagem de pessoas sadias, que não necessitavam de nenhum tratamento periodontal foi de $28,76 \%$ para a faixa de $15-19$ anos, caindo para 5,38\% para $35-44$ anos e $1,33 \%$ para 50-59 anos. Cabe destacar que a predominância de sextantes nulos, devido aos altos índices de edentulismo nos adultos e idosos brasileiros, influencia diretamente nessa informação.

O segundo inquérito, realizado 10 anos depois, em 1996, avaliou somente cárie dentária em escolares, o que pode representar uma estagnação do processo de aperfeiçoamento dos levantamentos em saúde bucal. (RONCALLI; CÔRTES; PERES, 2012) 
Em 2003, o Projeto SBBrasil do ponto de vista metodológico avançou, por abranger um número maior de municípios (250 no total, 50 em cada região do país), além de incluir a zona rural e municípios de pequeno porte. A composição de grupos etários foi de acordo com o ciclo da vida (bebês, 5 anos, 12 anos, 15 a 19 anos, 35 a 44 anos e 65 a 74 anos) e considerou variáveis qualitativas relacionadas à condição socioeconômica e acesso aos serviços odontológicos. (BRASIL, 2004b) Para Roncalli, Côrtes e Peres (2012), o Projeto SBBrasil se constituiu como principal estratégia de vigilância em saúde bucal no eixo da produção de dados primários sobre o tema, contribuindo para a construção de uma Política Nacional de Saúde Bucal pautada em modelos assistenciais de base epidemiológica.

Seus resultados demonstraram que a perda dental e edentulismo continuaram elevados em adultos e idosos. Nas faixas etárias de 35-44 anos e 65-74 anos, o componente de dentes perdidos representou respectivamente $65,7 \%$ e 92,9\% do índice CPO-D (Figura 2). As diferenças regionais permaneceram, e as regiões Norte e Nordeste apresentaram predomínio dos maiores índices de dentes perdidos em todas as faixas etárias. Dos idosos (65-74 anos), 57,91\% utilizavam prótese total superior e $34,18 \%$ utilizavam prótese total inferior. Sobre a necessidade de prótese nesse grupo, 16,15\% necessitam de prótese total superior e 23,81\% de prótese total inferior (Figura 3). Quanto à doença periodontal, a análise do Índice Periodontal Comunitário revelou que, nas faixas etárias de 15 a 19, 35 a 44 e 65 a 74 anos, a porcentagem de pessoas sem nenhum problema periodontal foi respectivamente de $46,2 \%, 21,9 \%$ e $7,9 \%$. O edentulismo elevado em adultos e idosos resultou na presença de muitos sextantes nulos.

E por fim, foi realizado o último levantamento epidemiológico de saúde bucal no Brasil no ano de 2010. O SBBrasil 2010 acrescentou aperfeiçoamentos importantes na metodologia, sobretudo com relação à pesquisa em domicílios. (RONCALLI; CÔRTES; PERES, 2012) Sobre a perda dental houve melhora, a exceção dos idosos (65-74 anos) que manteve uma porcentagem alta do componente perdido no índice CPO-D, 91,9\% (Figura 2). Com relação ao edentulismo em idosos (65 a 74 anos), 63,1\% utilizavam prótese total superior, e 37,5\% inferior (Figura 3), 23\% necessitam de prótese em pelo menos um maxilar e $15 \%$ necessitam de prótese total nos dois maxilares. Não foi possível comparar a necessidade de prótese com os dados dos levantamentos epidemiológicos anteriores, pois em 2010 houve modificação na apresentação dos dados, entretanto, de acordo com nota do Ministério da Saúde, esses números estão muito 
próximos dos encontrados em 2003 e representam um contingente de mais de 3 milhões de idosos que necessitam de prótese total em pelo menos um maxilar. (SB Brasil, 2010) No que diz respeito à doença periodontal, a porcentagem de pessoas sem nenhum problema periodontal nas faixas etárias de 15-19, 35-44 e 65-74 anos foi respectivamente de 50,9\%, 17,8\% e 1,8\%. Mais uma vez, cabe destacar que devido ao edentulismo ainda ser grave no Brasil, 90,5\% dos sextantes foram excluídos para os idosos e $32,3 \%$ para os adultos.

\section{Figura 2 - Proporção do componente perdido do Índice CPO-D no Brasil, entre adultos e idosos nos inquéritos epidemiológicos de 1986, 2003 e 2010, Brasil}

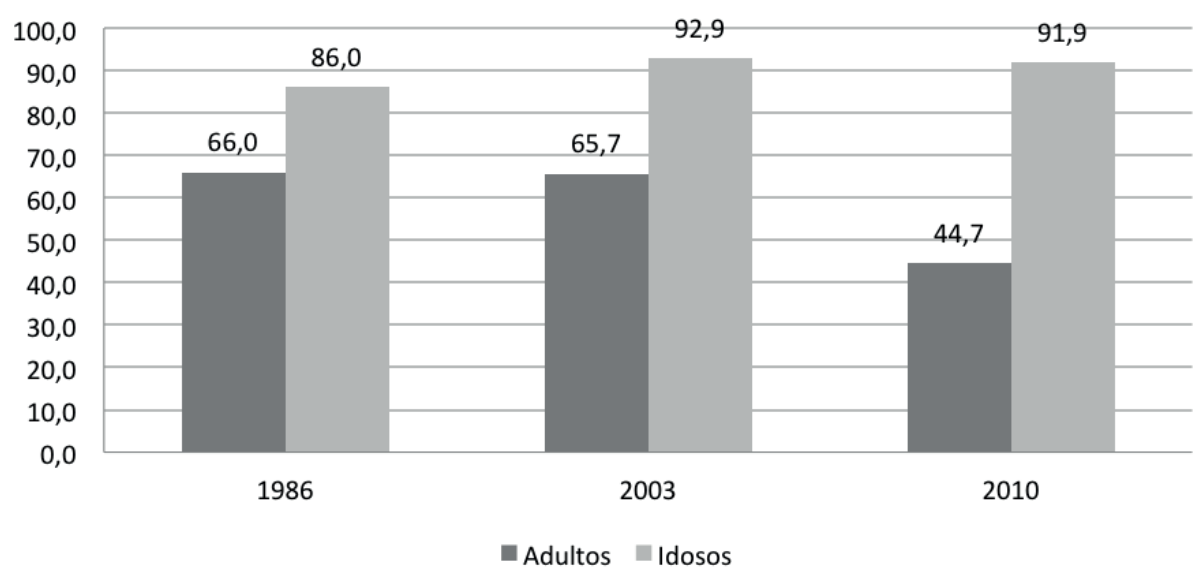

Fonte: BRASIL(1988); BRASIL (2004); BRASIL (2012)

Considerando o recorte aqui realizado dos resultados dos inquéritos epidemiológicos brasileiros em saúde bucal, verifica-se que houve melhora de alguns indicadores, como a cárie dental, contudo, a perda dental e o edentulismo ainda são elevados em adultos e idosos e há manutenção das desigualdades regionais e sociais. O nível de saúde dentária em adultos apresentou importante tendência de elevação em todas as regiões brasileiras no período de 1986 a 2003. Entre as hipóteses atribuídas a essa mudança, Nascimento e colaboradores (2013) destacam o impacto acumulado das políticas de prevenção da cárie (a adição de flúor à água de abastecimento público e ao creme dental), bem como o aumento de serviços restauradores e políticas públicas, que levaram à melhoria das condições de vida.

O cenário epidemiológico motiva algumas reflexões sobre os problemas de saúde bucal, como o enfrentamento das demandas de saúde bucal do brasileiro 
como um problema social e a existência da oferta e disponibilidade dos serviços odontológicos não significar necessariamente redução das necessidades e iniquidades de saúde bucal da população. Reflexão já presente nos primeiros escritos sobre o movimento da saúde bucal coletiva, conforme analisado no quinto capítulo, onde o retorno à compreensão dos determinantes sociais da saúde bucal é imperativo para o rumo das políticas.

Figura 3 - Proporção de idosos brasileiros que utilizavam Prótese Total Superior e Inferior entre nos Inquéritos Epidemiológicos de 1986 (50-59 anos), 2003 e 2010 (65-74 anos), Brasil

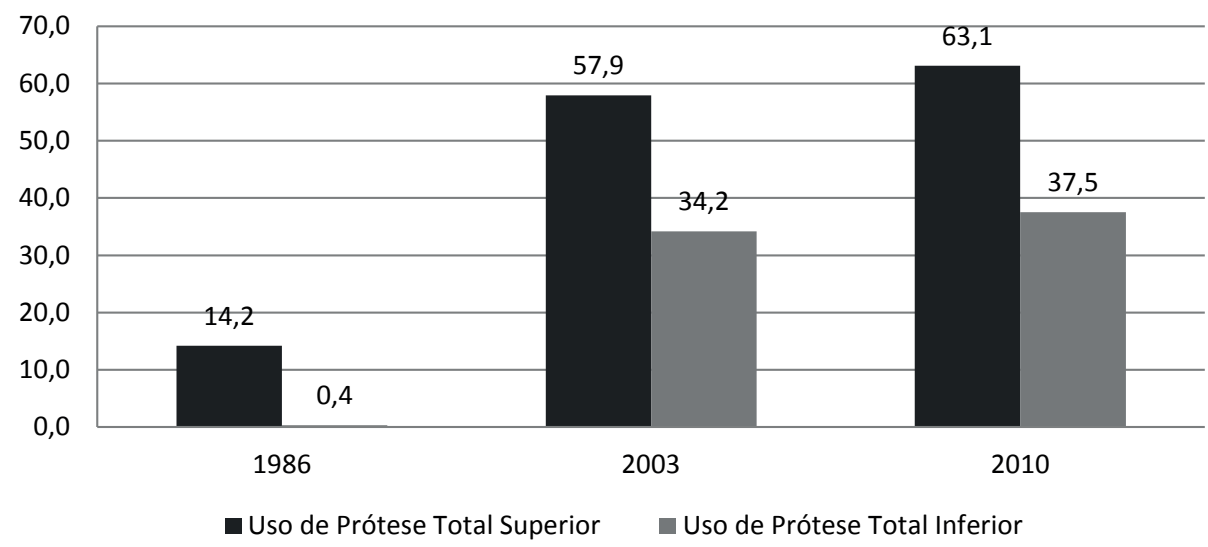

Fonte: BRASIL (1988); BRASIL (2004); BRASIL (2012)

\section{A evolução da implementação entre 2004 e 2014}

Após o lançamento da Política Brasil Sorridente, em 2004, os serviços públicos de referência para a atenção especializada são os CEO. O centro se constitui na principal estratégia de atenção odontológica especializada no sistema público brasileiro, e possibilitou aumento da oferta de especialidades que evitam a perda dental, como a endodontia e a periodontia. A criação do LRPD, por sua vez, abriu possibilidades de reparação da perda dental já instalada.

Este capítulo analisou também a evolução da política de oferta e produção de serviços especializados a partir do seu crescimento percentual nos três períodos de governo 2003-2006, Lula 2007-2010 e 2011-2014 - a partir de sua implemetação. Esses dados foram entendidos como indicadores de oferta (crescimento percetual dos CEO e LRPD) e utilização dos serviços odontológicos especializados (crescimento percentual de procedimentos nas três especialidades mínimas, a saber, cirurgia oral, endodontia e periodontia). O crescimento 
percentual foi calculado com base nas mudanças apresentadas entre os dois primeiros mandatos do presidente Lula (2003-2010), e entre o segundo mandato Lula e o primeiro de sua sucessora (2011-2014). As principais fontes de dados foram o site do DataSus e a sala de gestão estratégica do Ministério da Saúde. Cabe destacar que a oferta foi considerada como disponibilidade de recursos e a utilização representou a expressão do uso através da produção ambulatorial ou laboratorial desses serviços públicos odontológicos.

Para avaliar a produção ambulatorial da atenção especializada odontológica realizada pelos CEOs utilizou-se a lista de procedimentos constante no anexo da Portaria n. ${ }^{\circ}$ 1.464, de 24 de junho de 2011 , que dispõe sobre a produção a ser realizada nesses serviços. Devido à mudança na nomenclatura de muitos procedimentos nos Sistemas de Informação Ambulatorial (SIA/SUS) do Ministério da Saúde em 2008, nessa análise, somente foram incluídos procedimentos cujos códigos tinham correspondência com os códigos anteriores a 2008, para efeito de comparação entre os três períodos de governo (Quadro 1).

Dessa forma, puderam ser comparados os valores de 5 códigos de periodontia, 7 códigos de endodontia e 27 códigos de cirurgia oral (Quadro 1). Além disso, os procedimentos que, a partir de 2008 , passaram a ser contados por sextantes (e não mais por hemiarcada) tiveram seus valores divididos por 1,5, a fim de anular essa interferência no cálculo total de procedimentos. Através desses ajustes, foi possível diminuir os limites metodológicos impostos pela utilização desses dados secundários.

Quadro 1 - Procedimentos selecionados presentes na Portaria do MS n. ${ }^{\circ}$ 1.464, de 24 de junho de 2011, com códigos equivalentes no SIA/SUS (continua)

\begin{tabular}{|c|c|}
\hline Códigos SIA/SUS a partir de 2008 & Códigos SIA/SUS 1999 a 2007 \\
\hline \multicolumn{2}{|c|}{ Cirurgia Oral } \\
\hline $\begin{array}{l}\text { 0201010232; 0307010058; 0404020445; } \\
\text { 0404020615; 0404020623; 0404020674; } \\
\text { 0414010345; 0401010082; 0404020038; } \\
\text { 0404020054; 0404020089; 0404020097; } \\
\text { 0404020100; 0404020313; 0414010256; } \\
\text { 0414020022; 0414020030; } 0414020049 \\
\text { 0414020065; 0414020073; 0414020146 } \\
\text { 0414020170; 0414020243; 0414020278 } \\
\text { 0414020294; 0414020383; 0414020405 }\end{array}$ & $\begin{array}{c}0801135 ; 1005134 ; 1006101 ; 1005120 ; \\
\text { 1005127; 1005119; 1005110; } 0202102 ; \\
0813204 ; 0801120 ; 1005111 ; 0801110 \\
0801113 ; 1005123 ; 1005131 ; 1005101 ; \\
\text { 1005102; 1005105; 1005107; } 1005108 ; \\
\text { 1005114; 1005115; 1005121; } 1005124 \\
1005125 ; 0304105 ; 1005136\end{array}$ \\
\hline
\end{tabular}


Quadro 1 - Procedimentos selecionados presentes na Portaria do MS n. ${ }^{\circ}$ 1.464, de 24 de junho de 2011, com códigos equivalentes no SIA/SUS

\begin{tabular}{|c|c|}
\hline \multicolumn{2}{|c|}{ Endodontia } \\
\hline $\begin{array}{c}\text { 0307020061; 0307020045; 0307020053; } \\
\text { 0307020100; 0307020088; 0307020096; } \\
0307020118\end{array}$ & $\begin{array}{c}1004105 ; 1004202 ; 1004303 ; 1004102 ; \\
1004201 ; 1004301 ; 1004302\end{array}$ \\
\hline \multicolumn{2}{|c|}{ Periodontia } \\
$\begin{array}{c}\text { 0307030032; 0414020081; 0414020154; } \\
\text { 0414020162; 0414020375 }\end{array}$ & $1002106 ; 1002102 ; 1002103 ; 1002105 ;$ \\
\end{tabular}

Fonte: Brasil (2011).

Para os LRPD, como essa é uma política mais recente, iniciada em 2010, analisou-se apenas o crescimento percentual dessa oferta de laboratórios no período 2011-2014 e da produção laboratorial de próteses dentárias vinculadas a esse serviço.

\section{Os principais resultados}

Entre 2004 e 2014, ou seja, em 10 anos, foram implantados 1.030 CEO em todas as regiões do país. Esses serviços foram implantados, em sua maioria, inicialmente no Sudeste e no Nordeste. No primeiro ano, os municípios do Norte, Centro-Oeste e Sul foram aqueles que menos implantaram CEO. Ao final da primeira gestão do presidente Luís Inácio Lula da Silva, 498 serviços especializados e, ao final do segundo mandato, eram 853. Em 2006, é notória a concentração de CEO no Sudeste e Nordeste. Existe um discreto incremento de serviços no Sul. As regiões Norte e Centro-Oeste persistem como aquelas com uma quantidade menor, mesmo ao final de 2010 e 2014 (Tabela 1).

Entretanto, quando se faz a análise por municípios, os do Nordeste eram aqueles mais atendidos, ou seja, há maior distribuição entre cidades com uma quantidade menor de CEO. No Sudeste, ocorreu o oposto, uma quantidade maior de serviços numa quantidade menor de municípios. Ao final de 2010 e 2014, o Nordeste já superava discretamente o Sudeste em número de CEO. Houve baixa implantação da atenção especializada no Norte e Centro-Oeste do Brasil. 
Tabela 1 - Número de CEOs implantados e produção ambulatorial de procedimentos especializados de Cirurgia Oral Menor, Periodontia e Endodontia por região do país em três períodos de governo (2003-2006, 2007-2010 e 2011-2014). Brasil.

\begin{tabular}{|c|c|c|c|c|c|c|c|c|c|c|c|c|}
\hline $\begin{array}{c}\text { Oferta e utilização } \\
\text { Serviços Especializados }\end{array}$ & Norte & $\begin{array}{c}\text { Crescimento } \\
\% \text { Norte }\end{array}$ & Nordeste & $\begin{array}{l}\text { Crescimento } \\
\% \text { Nordeste }\end{array}$ & Sudeste & $\begin{array}{c}\text { Crescimento } \\
\% \text { Sudeste }\end{array}$ & Sul & $\begin{array}{c}\text { Crescimento } \\
\% \text { Sul }\end{array}$ & $\begin{array}{l}\text { Centro } \\
\text {-Oeste }\end{array}$ & $\begin{array}{c}\text { Crescimento } \\
\% \mathrm{CO}\end{array}$ & Brasil & $\begin{array}{c}\text { Crescimento } \\
\%\end{array}$ \\
\hline $\begin{array}{l}\text { Número CEOs } \\
\text { implantados }\end{array}$ & 25 & 316,7 & 176 & 604 & 190 & 387,2 & 71 & 373,3 & 36 & 140 & 498 & 398 \\
\hline Lula I (2003-2006) & 59 & 136 & 334 & 89,8 & 302 & 58,9 & 104 & 46,5 & 54 & 50 & 853 & 71,3 \\
\hline Dilma I (2011-2014) & 67 & 13,6 & 398 & 19,2 & 364 & 20,5 & 127 & 22,1 & 74 & 37 & 1030 & 20,8 \\
\hline \multicolumn{13}{|c|}{ Cirurgia Oral* } \\
\hline Lula I (2003-2006) & 535.628 & & 1.439 .921 & & 1.945 .637 & & 426.305 & & 335.463 & & 4.682 .954 & \\
\hline Lula II (2007-2010) & 1.259 .744 & 135,2 & 2.469 .074 & 71,5 & 3.277 .162 & 68,4 & 830.789 & 94,9 & 594.121 & 77,1 & 8.407 .612 & 79,5 \\
\hline Dilma I (2011-2014) & 1.943 .871 & 54,3 & 2.140 .259 & $-13,3$ & 4.536 .872 & 38,4 & 1.106 .982 & 33,2 & 580.020 & $-2,4$ & 10.308 .003 & 22,6 \\
\hline \multicolumn{13}{|c|}{ Endodontia* } \\
\hline Lula I (2003-2006) & 490.949 & & 428.139 & & 879.931 & & 156.516 & & 103.543 & & 2.059 .078 & \\
\hline Lula II (2007-2010) & 476.156 & $-3,0$ & 721.836 & 68,6 & 1.334 .129 & 51,6 & 272.272 & 74 & 193.565 & 86,9 & 2.997 .958 & 25,6 \\
\hline Dilma I (2011-2014) & 401.808 & $-15,6$ & 964.796 & 33,7 & 1.125 .118 & $-15,7$ & 337.126 & 23,8 & 314.538 & 62,5 & 3.143 .386 & 4,9 \\
\hline \multicolumn{13}{|c|}{ Periodontia* } \\
\hline Lula I (2003-2006) & 287.491 & & 889.253 & & 2.143 .438 & & 269.044 & & 187.037 & & 3.776 .263 & \\
\hline Lula II (2007-2010) & $596.307,90$ & 107,4 & 1.442 .718 & 62,2 & 2.825 .194 & 31,8 & 458.828 & 70,5 & 346.969 & 85,5 & 5.670 .017 & 50,1 \\
\hline Dilma I (2011-2014) & $837.671,70$ & 40,5 & 1.809 .136 & 25,4 & 3.279 .119 & 16,1 & 665.966 & 45,1 & 429.735 & 23,9 & 7.021 .628 & 23,8 \\
\hline
\end{tabular}

Fonte: MS/DATASUS/TABNET, 2015

*Procedimentos selecionados presentes na Portaria do MS no 1.464 de 24 de junho de 2011.

** Crescimento \% calculado com base na diferença de valores entre os períodos Lula I-Lula II e Lula II-Dilma I 
Distribuição semelhante ocorreu quanto aos LRPD. Nos períodos 20072010 e 2011-2014, as regiões Nordeste e Sudeste detinham o maior número de LRPD e apresentaram o maior número de próteses dentárias entregues. Destaca-se que, ao final de 2010, mesmo com uma quantidade menor de LRPD e CEO que a região Nordeste, o Sudeste entregou uma quantidade maior de próteses, o que não representou uma quantidade maior de repasse de recursos devido à maior forma de transferência fundo a fundo basear-se na modalidade do CEO e não diretamente na quantidade de procedimentos realizados.

Já no período 2011-2014, os serviços do Nordeste atingiam uma quantidade maior de municípios, entregaram a maior quantidade de próteses e receberam a maior parte dos recursos. Os municípios do Norte ainda persistem como aqueles que recebem uma parcela menor de recursos, apresentam uma quantidade menor de serviços implantados e consequentemente entregam poucas próteses, correspondendo a aproximadamente $8 \%$ do total de próteses entregues no Nordeste e 9,36\% no Sudeste.

Quanto à evolução do financiamento, em 2004, ano de implantação dos primeiros CEO no Brasil, o maior aporte financeiro foi realizado no Sudeste $(42,6 \%)$, no Nordeste $(26,3 \%)$ e no Sul (17,2\%). O Norte $(6,2 \%)$ e Centro-Oeste $(7,5 \%)$ receberam uma quantidade menor de recursos. Essas diferenças estão relacionadas ao número de $\mathrm{CEO}$ implementados em cada região.

Já ao final do primeiro mandato da presidente Dilma Rousseff, o maior repasse fundo a fundo realizado para atenção especializada foi para região Nordeste $(38,6 \%)$ e Sudeste $(33,8 \%)$. As regiões Norte $(6,9 \%)$, Centro-Oeste $(8,2 \%)$ e Sul (12,5\%) foram as que receberam uma quantidade menor de recursos. Destaca-se que o montante de recursos repassados apresenta aumento de aproximadamente 10 vezes de 2004 a 2006, após correção pelo índice IPCA (IBGE) para fins deflacionamento. Aumento que não se observa nos outros períodos. De 2007 a 2010, há incremento do montante total de 25,78\% e de 2011 a 2014, de 51,40\%. Quando se analisa o valor de recursos transferidos para atenção básica e especializada em saúde bucal, ao final de 2006, a Atenção Especializada (AE) representava 12,6\% do montante total, em 2010, 13,6\% e, no final de 2014, o mandato 2014 correspondeu a $17,9 \%$.

Observou-se que, entre o 2003-2006 e 2007-2010, houve um incremento na realização de procedimentos das três especialidades mínimas, com $80 \%$ de aumento de procedimentos de cirurgia oral, $45,6 \%$ de aumento de procedimentos de endodontia e 50,1\% de incremento nos procedimentos periodontais. Entre- 
tanto, quando analisadas as mudanças entre os períodos do segundo mandato de presidente Lula e o primeiro de Dilma Rousseff (2011-2014), esse crescimento foi bastante inferior, não passando de $20,5 \%$ para cirurgia oral, $23,8 \%$ para periodontia, e de apenas 4,9\% na endodontia (Tabela 1, Figura 4). Estudos da produção ambulatorial odontológica especializada, tanto no âmbito municipal (OLIVEIRA; QUEIRÓZ; OLIVEIRA, 2014) quanto estadual (SILVA et al., 2013), realizaram outros recortes temporais, e os seus achados corroboram com os dados aqui apresentados.

\section{Figura 4 - Crescimento \% de procedimentos de cirurgia oral menor, endodontia e periodontia na produção ambulatorial dos CEOs entre 2003-2010}

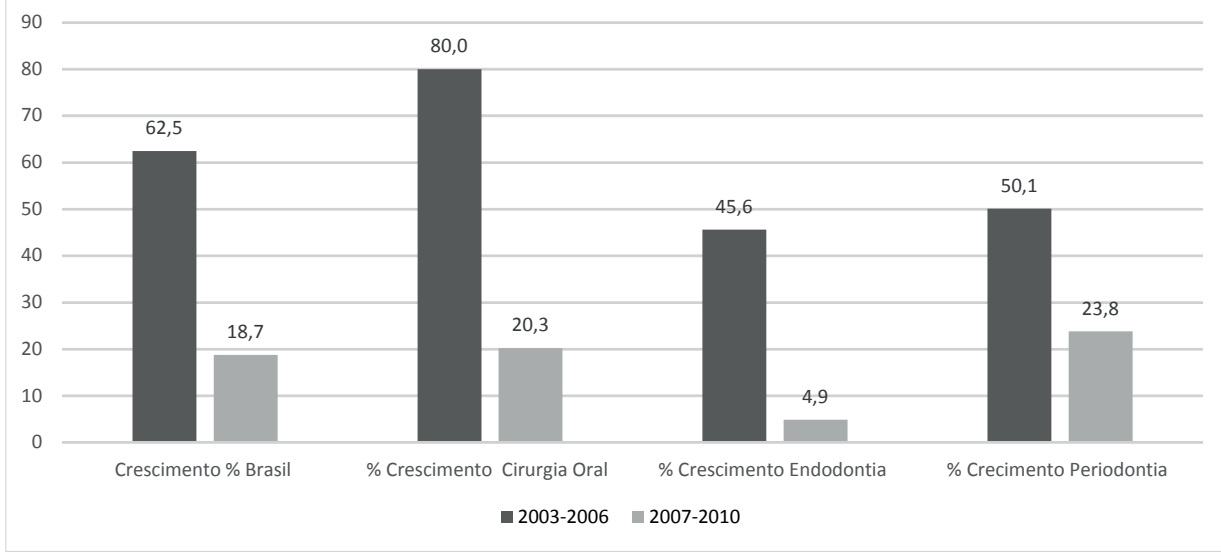

Sabe-se que não basta o aumento da oferta de serviços de saúde para que se tenha aumento na utilização desses serviços. Há inúmeras barreiras, como aquelas organizacionais (de marcação de consulta, disponibilidade de horários, gestão interna do serviço, entre outros), que podem dificultar sua utilização e uso. Há evidências de problemas na gestão interna do serviço, como apontaram Chaves e colaboradores (2011).

A partir da análise dos dados de produção ambulatorial, é possível observar que a atenção especializada foi priorizada a partir do primeiro governo Lula (2003-2006), teve avanço importante no período subsequente (2007-2010) e seguiu com redução no ritmo de crescimento no período de 2011-2014, o que pode apontar manutenção de certa institucionalidade, porém sem a mesma priorização na agenda federal.

Silva e colaboradores (2013) descreveram indicadores de atenção especializada em saúde bucal (endodontia, periodontia e cirurgia oral) na relação per 
capta em municípios do estado do Pará, no período de 2008-2010, e verificaram que houve elevação do número de procedimentos, entretanto, o número de procedimentos per capita demonstrou a baixa cobertura populacional e dificuldades de acesso aos procedimentos odontológicos especializados.

É fato que a Política Nacional de Saúde Bucal impulsionou o crescimento da atenção especializada no país, e ainda que os estudos indiquem os principais fatores que interferem no desempenho dos CEO (MACHADO; SILVA; FERREIRA, 2015), esse serviço tem potencial de se constituir em elemento que produza a integralidade da odontologia no SUS. Todavia, a redução do crescimento dos números da atenção especializada no período 2010-2014, poderá ter reflexos futuros na sua manutenção.

Entre os estados brasileiros, apenas cinco deles têm CEO em 100\% das suas regiões de saúde: Alagoas, Ceará, Mato Grosso do Sul, Rio Grande do Norte e Roraima. Tal situação é ainda mais alarmante quanto aos LRPD, visto que apenas Alagoas, Mato Grosso do Sul e Rio Grande do Norte têm LRPD em todas as regiões de saúde. (FORTUNA, 2011; MACHADO; SILVA; FERREIRA, 2015)

Na implementação dos LRPD, em 2010, iniciou-se essa política com 676 laboratórios implantados, 808 LRPD em 2011, chegando a 1.995 serviços em 2015. O crescimento percentual da oferta no governo 2011-2014 foi de $189,2 \%$.

Quanto à produção de próteses, essas foram 183.152 mil próteses em 2010, chegando a 600.196 mil em 2014. A entrega de próteses dentárias foi, portanto, de $227,7 \%$ no período $2011-2014$. Observou-se que, por ser um componente mais recente e sua retaguarda aos serviços especializados ser urgente, sua expansão foi expressiva nesse período. Necessário acompanhar e monitorar sua evolução nos próximos períodos de governo, bem como sua cobertura no território nacional.

O uso de indicadores de produção ambulatorial especializada a partir dos dados secundários dos sistemas de informação no SUS tem limitações inerentes a esses dados secundários, como o sub ou suprarregistro. Contudo, muitos estudos publicados com dados estaduais e municipais também os utilizam (LINO et al., 2014; OLIVEIRA; QUEIRÓZ; OLIVEIRA, 2014; SILVA et al., 2013; 
SILVA; PADILHA; BALDANI, 2013 ), e eles podem apontar tendências com relação ao efeito das políticas.

\section{As evidências dos estudos publicados de avaliação dos CEOs}

O estudo de Celeste e colaboradores (2014) sobre as taxas de utilização de procedimentos especializados odontológicos em cidades com CEO apontou inegavelmente que sua implementação significou melhoria na utilização desses serviços em relação a cidades sem CEO. Encontrou melhores resultados em relação aos procedimentos endodônticos e em relação ao número total de dentistas inscritos nesses serviços municipais. O desafio agora é avaliar o seu desempenho nas diversas dimensões como o da qualidade técnico-científica do cuidado, do cumprimento ao princípio da integralidade e sua equidade.

Os estudos no Reino Unido reforçam a ideia de que deve-se persistir num modelo de atenção especializada com interface com a atenção primária em que o acesso à primeira ocorra a todos os casos referenciados sem barreiras, que estas sejam de procedimentos pertinentes e que ocorram em tempo oportuno. Seria papel da atenção primária ou do CD clínico geral garantir a longitudinalidade do cuidado, como está descrito no sexto capítulo.

Um estudo de revisão da produção nacional sobre avaliação dos CEO, onde foram sistematizados os resultados de 13 trabalhos, revelou que o melhor desempenho está associado às formas de organização do processo de trabalho dos profissionais, como aquelas que reduzem o acesso via marcação de consultas por telefone, substituição de faltosos e publicização e monitoramento das metas mensais para os profissionais. A formação das redes regionais de atenção à saúde e às características contextuais e políticas locais, como a maior cobertura da ESF, desenvolvimento humano e capacidade de governo na sua implementação, também foram evidências importantes para o êxito. (MACHADO; SILVA; FERREIRA, 2015) O não cumprimento das metas mínimas de produção nas três especializadas básicas (endodontia, periodontia e cirurgia oral) tem sido uma preocupação. Góes e colaboradores (2012) verificaram que, na maioria das regiões brasileiras, houve dificuldade no cumprimento das metas relativas à quantidade de procedimentos a serem informados no SIA/SUS, sendo a Região Norte com menor percentual de serviços implantados. Estudos apontam para a necessidade de revisão no marco legal para a implantação dos CEO com modificações dos critérios e normas, como também definições de 
novos padrões e cumprimento de metas para avaliação e monitoramento desses serviços. (FIGUEIREDO; GOES, 2009; GOES et al., 2012)

Os motivos para a manutenção desse problema podem estar relacionados a não existência de rede de atenção ampla de referência que garante o cumprimento de metas, já que os pacientes referenciados são de fato atendidos em procedimentos pertinentes àquele nível de atenção. Isso pode explicar porque CEO estaduais, com plano diretor de regionalização bem estabelecido, geralmente cumprem as metas pactuadas. Além disso, a gestão interna do serviço é muito importante. Serviços que garantem substituição de faltosos, que compartilham o cumprimento de metas de produção entre os profissionais especialistas e fazem busca ativa de faltosos para conclusão do tratamento atingem mais facilmente as metas. Cabe destacar aqui que a meta é a produção mínima a ser alcançada pelo serviço, ou seja, é o objetivo do serviço quantificado. Algumas estratégias de triagem prévia e acompanhamento de casos deve ser estimulada, como aquelas desenvolvidas por Zaitter e colaboradores. (2009)

As diversas barreiras (geográficas, culturais, financeiras e funcionais) (BULGARELI et al., 2013) já enfrentadas pela população na atenção primária, permeiam o percurso dos indivíduos em busca da satisfação das suas necessidades de saúde no âmbito da atenção especializada.

Chaves e colaboradores (2010), a partir de estudo com quatro CEO na Bahia, revelaram alguns fatores relevantes para a garantia da integralidade na assistência à saúde bucal nos CEO. O principal deles se refere à maior cobertura da atenção primária no território em que o serviço especializado se situa. A ampliação dos serviços deve ser planejada, já que a instalação de CEO em cidades com atenção primária não estruturada pode levar ao atendimento da livre demanda e de procedimentos básicos nas clínicas de especialidades, impossibilitando a integralidade. (CHAVES et al., 2010)

O descumprimento da carga horária nos serviços públicos odontológicos pelos profissionais CD deve ser enfrentado pelos gestores desses serviços, já que este reduz enormemente sua possibilidade de produção e utilização pelos usuários potenciais, constituindo-se na principal barreira organizacional. Os profissionais geralmente têm vínculo no setor público e no setor privado. Nessa disputa em que há hegemonia da odontologia de mercado ou privada, o serviço público odontológico sempre será o mais prejudicado. Estudo de Chaves e Vieira-da-Silva (2007) já analisava, numa perspectiva sociológica, o fenômeno da dupla militância ou dupla inserção dos profissionais, alertando para a necessi- 
dade de qualificação em política, planejamento e gestão em saúde dos gestores desses serviços públicos odontológicos. A lógica dominante do campo privado odontológico está presente em diversos momentos e se revela, tanto nas práticas como nas aspirações dos profissionais da saúde bucal, e mais fortemente entre os especialistas. Essa evidência é reflexo do que ocorre nas disputas em torno da consolidação do sistema universal de saúde brasileiro entre o subsistema público, subfinanciado, e o subsistema privado, financiado pela renúncia fiscal do Estado, pela expansão de planos odontológicos de baixa remuneração e, em parte, pelo desembolso direto das famílias. Esse é forte espaço de luta e de disputas ideológicas em torno do que é mesmo o direito à saúde bucal no Brasil.

\section{Referências}

ANDRADE, F. R. Análise das relações de poder na Política Nacional de Saúde Bucal o dito e o visto. 2008. 169 f. Dissertação (Mestrado) - Faculdade de Odontologia, Universidade Federal de Goiás, Goiás, 2008.

AQUINO, V. R.; MIOTTO, M. H. M. B. Perfil do Técnico em Higiene Dental (THD) na região da Grande Vitória. UFES Revista de Odontologia, Vitória, v. 7, n. 3, p. 14-22, set./dez. 2005 .

BOURDIEU, P. Razões práticas: sobre a teoria da ação. São Paulo: Editora Papirus, 1996.

BOURDIEU, P. Sobre o Estado. São Paulo: Companhia das Letras, 2014.

BRASIL. Ministério da Saúde . Levantamento epidemiológico em saúde bucal: Brasil, zona urbana, 1986. Brasilia, 1988. 137p.

BRASIL. Ministério da Saúde. Coordenação Nacional de Saúde Bucal. Departamento de Atenção Básica. Secretaria de Atenção à Saúde. Diretrizes da Política Nacional de Saúde Bucal. Brasília: Ministério da Saúde, 2004a.

BRASIL. Ministério da Saúde. Secretaria de Atenção à Saúde. Departamento de Atenção Básica. Projeto SB Brasil 2003: condições de saúde bucal da população brasileira 20022003: resultados principais / Ministério da Saúde, Secretaria de Atenção à Saúde, Departamento de Atenção Básica. - Brasília: Ministério da Saúde, 2004b. 68 p.: il. color. (Série C. Projetos, Programas e Relatórios).

BRASIL. Ministério da Saúde. Secretaria de Atenção à Saúde. Secretaria de Vigilância em Saúde. SB Brasil 2010: Pesquisa Nacional de Saúde Bucal: resultados principais / Ministério da Saúde. Secretaria de Atenção à Saúde. Secretaria de Vigilância em Saúde. - Brasília : Ministério da Saúde, 2012. 116 p. : il.

BRASIL. Ministério da Saúde. Portaria n ${ }^{\circ}$ 1.464, de 24 de junho de 2011. Altera o Anexo da Portaria $n^{\circ} 600 / G M / M S$, de 23 de março de 2006, que institui o financiamento dos 
Centros de Especialidades Odontológicas (CEO). Diário Oficial da União, Seção 1, página 112. Brasília, DF, 2011.

BULGARELI, J. V. et al. Information from secondary care in dentistry for evaluation of models of health care. Revista de Odontologia da UNESP, Araraquara, v. 42, n. 4, p. 229-236, aug. 2013 .

CARVALHO, C. L. Dentistas práticos no Brasil: histórias de exclusão e resistência na profissionalização da odontologia brasileira. 2003. 266 f. Tese (Doutorado) - Escola Nacional de Saúde Pública da Fundação Oswaldo Cruz, Rio de Janeiro, 2003.

CELESTE, R. K. et al. Análise da produção ambulatorial em municípios com e sem centros de especialidades odontológicas no Brasil em 2010. Cadernos de Saúde Pública, Rio de Janeiro, v. 30, n. 3, p. 511-521, mar. 2014.

CHAVES, S. C. L.; VIEIRA-DA-SILVA, L. M. As práticas profissionais no campo público de atenção à saúde bucal: o caso de dois municípios da Bahia. Ciência \& Saúde Coletiva, Rio de Janeiro, v. 12, n. 6, p. 1697-1710, 2007.

CHAVES, S. C. L et al. Política Nacional de Saúde Bucal: fatores associados à integralidade do cuidado. Revista de Saúde Pública, São Paulo, v. 44, n. 6, p. 1005-1013, dez. 2010.

CHAVES, S. C. L et al. Avaliação da oferta e utilização de especialidades odontológicas em serviços públicos de atenção secundária na Bahia, Brasil. Cadernos de Saúde Pública, Rio de Janeiro, v. 27, n. 1, p. 143-154, jan. 2011.

CFO - Conselho Federal de Odontologia. Relatório da III Assembléia Nacional de Especialidade Odontológicas. Rio de Janeiro: Conselho Federal de Odontologia: Arquivo do CFO, 2014.

DEITOS, A. R. Avaliação na atenção especializada em saúde bucal. 2009. 168 f. Dissertação (Mestrado em Odontologia) - Faculdade de Odontologia, Universidade de São Paulo, São Paulo, 2009.

DURKHEIM, E. A divisão do trabalho social. Lisboa: Editorial Presença, 1989. v. 1.

FAULKNER, A. et al. A systematic rewiew of the effect of primary care-based service innovations on quality and patterns of referral to specalist secondary care. The British Journal of General Practice, v. 53, n. 496, p. 878-884, Nov. 2003.

FAQUIM, J. P. S.; CARNUT, L. Pessoal auxiliar em odontologia: a trajetóriaregulamentar da profissão de técnico em saúde bucal (1975-2008). Journal of Management and Primary Health Care, v. 3, n. 2, p. 202-207, 2012.

FEITOSA, D. M. Z. et al. Especialidades odontológicas: avaliação de um centro de assistência secundária na rede municipal em São Luís - MA. Revista do Hospital Universitário da UFMA, São Luís, v. 10, n. 2, p. 34-41, maio/ago. 2009.

FIGUEIREDO, N.; GOES, P. S. A. Construção da atenção secundária em saúde bucal: um estudo sobre os Centros de Especialidades Odontológicas em Pernambuco, Brasil. Cadernos de Saúde Pública, Rio de Janeiro, v. 25, n. 2, p. 259-67, Fev. 2009. 
FORTUNA, R. F. P. A média complexidade no quadro da Política Nacional de Saúde Bucal: uma abordagem do seu processo de desenvolvimento em uma perspectiva regional. 2011. 207f. Tese (Doutorado em Saúde) - Universidade do Estado do Rio de Janeiro, Rio de Janeiro, 2011.

FREITAS, C. H. S. M. Dilemas no exercício profissional da Odontologia: a autonomia em questão. Interface: Comunicação, Saúde, Educação, Botucatu, v. 11, n. 21, p. 25-38, abr. 2007.

GOES, P. S. A. et al. Avaliação da atenção secundária em saúde bucal: uma investigação nos centros de especialidades do Brasil. Cadernos de Saúde Pública, Rio de Janeiro, v. 28, supl., p. s81-s89, 2012.

GOMES, D, RAMOS F. R. S. O profissional da odontologia pós reestruturação produtiva: ética, mercado de trabalho e saúde bucal coletiva. Saúde e Sociedade, São Paulo, v. 24, n. 1, p. 285-297, 2015.

LINO, P. A. et al. Análise da atenção secundária em saúde bucal no estado de Minas Gerais, Brasil. Ciência \& Saúde Coletiva, Rio de Janeiro, v. 19, n. 9, p. 3879-3888, 2014.

MACHADO, F. C. A.; SILVA, J. V.; FERREIRA, M. A. F. Fatores relacionados ao desempenho de Centros de Especialidades Odontológicas. Ciência \& Saúde Coletiva, Rio de Janeiro, v. 20, n. 4, p. 1149-1163, abr. 2015.

MACHADO, M. H. (Coord.) Os médicos no Brasil: um retrato da realidade. Rio de Janeiro: FIOCRUZ, 1997.

MORETTI-PIRES, R. O.; LIMA, L. A. M.; MACHADO, M. H. Sociologia das profissões e percepção de acadêmicos de Odontologia sobre o Agente Comunitário de Saúde em Saúde Bucal. Interface: Comunicação, Saúde, Educação, Botucatu, v. 15, n. 39, p. 1085-1095, 2011.

MORRIS, A. J.; BURKE, F. J. T. Primary and secondary dental care: how ideal is the the interface? British Dental Journal, London, v. 191, p. 666-70, Dec. 2001.

MOYSÉS, S. J. Políticas de saúde e formação de recursos humanos em Odontologia. Revista da ABENO, Brasília, v. 4, n. 1, p. 30-37, jan./fev. 2004.

NASCIMENTO, S. et al. Condições dentárias entre adultos brasileiros de 1986 a 2010. Revista de Saúde Pública, São Paulo, v. 47, Supl 3, p. 69-77, 2013.

OLIVEIRA, E. R. S. B.; QUEIRÓZ, D. M.; OLIVEIRA, R. F. Avaliação da atenção odontológica no município de Montes Claros (MG) utilizando o Sistema de Informações Ambulatoriais do Sistema Único de Saúde. Revista Unimontes Científica, Montes Claros, v. 16, n.1, p.4-14, jan./jun. 2014. Disponível em: http://www.ruc.unimontes.br/index.php/ unicientifica/article/view/318/296. Acesso em: 24 set. 2015.

PINHEIRO, F. M. C. et al. A formação do cirurgião-dentista no Brasil: contribuições de estudos para a prática da profissão. RGO, Porto Alegre, v. 57, n. 1, p. 99-106, jan./mar. 2009.

RONCALLI, A. G.; DE SOUZA CÔRTES, M. I.; PERES, K. G. Perfis epidemiológicos de saúde bucal no Brasil e os modelos de vigilância. Cadernos de Saúde Pública, Rio de Janeiro, v. 28, Sup. p. S58-S68, 2012. 
ROSSI, T. R. A. A política de saúde bucal na atenção especializada em dois municípios da Bahia: da entrada na agenda à sua implementação. 2011. 100 f. Dissertação (Mestrado em Saúde Comunitária) - Instituto de Saúde Coletiva, Universidade Federal da Bahia, Salvador, 2011. ROSSI, T. R. A; CHAVES, S. C. L. A política de saúde bucal na atenção especializada em dois municípios da Bahia: da entrada na agenda à sua implementação. Revista Saúde em Debate 2015. No prelo.

SANCHEZ, H. F. et al. Integrality in everyday dental care: review of the literature. Trabalho Educação e Saúde. Rio de Janeiro, v. 13, n. 1, p. 201-214, apr. 2015.

SILVA, F. R.; PADILHA, E. Z.; BALDANI, M. H. Serviços odontológicos especializados nas cidades médias não metropolitanas do estado do Paraná, entre 2003 e 2010: estudo exploratório. Epidemiologia e Serviços de Saúde, Brasília, v. 22, n. 4, p. 641-650, dez. 2013.

SILVA, R. F. et al. Utilização de auxiliares odontológicos em Ortodontia: implicações éticas e legais. Revista Dental Press Ortodontia e Ortopedia Facial, Maringá, v. 11, n. 5, p. 121128, out. 2006.

SILVA L. S. et al. Indicadores de atenção básica e especializada em saúde bucal nos municípios do Estado do Pará, Brasil: estudo ecológico, 2001-2010. Epidemiologia e Serviços de Saúde, Brasília, v. 22, n. 2, p. 325-334, jun. 2013.

SOUZA, T.M.S.; RONCALLI, A.G. Saúde bucal no Programa Saúde da Família: uma avaliação do modelo assistencial. Cadernos de Saude Publica, Rio de Janeiro, v. 23, n. 11, p. 2727-39, 2007.

STARR, P. La transformación social de la medicina en los Estados Unidos de América. Trad. Agustín B. México: Fondo de Cultura Econômica, 1991.

WEBER, M. Ciência e política: duas vocações.21 ed. São Paulo: Editora Cultrix. , 2014.

ZAITTER W. M. et al. Avaliação da acessibilidade do paciente à clínica de especialidades de Endodontia em dois distritos de saúde do município de Curitiba (PR). RSBO, Joinville, v. 6, n. 4, p. 413-420, dez. 2009. 


\section{O dentista e o mercado de trabalho}

Lana Bleicher

\section{Apresentação}

Este capítulo cumpre dois objetivos: aproximar o estudante de graduação ao tema do mercado de trabalho do dentista e apresentar o cenário atual da odontologia suplementar. Dessa forma, é possível registrar que as duas partes em que se encontra dividido apresentam estrutura e linguagem diferentes. A primeira, por cumprir uma finalidade didática, retoma alguns clássicos da área, apresentando-os em linguagem acessível. A segunda atualiza dados do setor, percorre uma literatura mais atual e traz elementos para reflexão.

\section{O dentista}

É corrente na literatura, embora não consensual, a noção de que a odontologia no Brasil se origina a partir das práticas dos barbeiros. (MARTINO; BOTAZZO; ZILBOVICIUS, 2010) Até o século XIX, esses trabalhadores não se limitavam a cortar cabelo e fazer barba, mas também realizavam pequenas cirurgias, sangravam, aplicavam ventosas e sanguessugas e extraíam dentes. (FIGUEIREDO, 1999) Aos poucos, essa multiplicidade de atividades foi sendo abandonada, mas barbeiros coexistiram com médicos cirurgiões e dentistas ainda durante certo tempo.

Pimenta (2004) localiza que, no início do século XIX, as práticas de cura próprias das camadas sociais subalternas eram reconhecidas, pois o Estado 
expedia autorizações para médicos, cirurgiões e boticários, mas também emitia licenças para parteiras, sangradores e curandeiros. Médicos detinham mais prestígio que boticários e cirurgiões - estes sob o estigma do trabalho manual, em contato com o sangue. Parteiras e sangradores eram as ocupações mais subalternas. Embora essas diferentes categorias tenham partilhado um mesmo período histórico, em geral direcionavam suas práticas a setores diferentes da sociedade. As classes dominantes usufruíam da medicina praticada por médicos e cirurgiões formados e institucionalizados, enquanto as camadas subalternas recorriam aos barbeiros, sangradores, dentistas e curandeiros, em geral não formados e marginalizados. (MARTINO; BOTAZZO; ZILBOVICIUS, 2010) Não é à toa que Figueiredo (1999) aponta, ao estudar os barbeiros do século XIX, que todos eram homens pardos ou negros, alguns livres, outros escravos.

Com a instituição no Brasil do ensino superior de odontologia em 1884, ocorreu um processo de elitização da profissão, pois a exigência de exames, a frequência ao curso de dois anos, pagamento de taxas e mensalidades expulsou as camadas populares dessa prática. (MOTT et al., 2008) A partir daí, ocorre uma luta entre os profissionais formados para restringir o campo de atuação dos não outorgados. Tal fenômeno pode ser melhor compreendido a partir da Sociologia das Profissões, da qual Freidson (1996) é um dos teóricos mais conhecidos.

De acordo com Freidson (1996), profissões se distinguem das demais ocupações por serem um tipo específico de trabalho especializado. Freitas (2007) salienta que as profissões em geral detêm um conhecimento muito específico que não é acessível ao restante da sociedade, geralmente adquirido por uma formação longa. Isso dá a possibilidade àqueles que a exercem de deter o monopólio do conhecimento e dessa forma ter controle sobre seu próprio trabalho. Tipicamente, dentistas dominam o tratamento odontológico do diagnóstico à alta e não precisam submeter seu trabalho ao julgamento ou à autorização de outra profissão. Assim, no que se refere à prática clínica, o dentista em geral tem autonomia. Mas será que, nas suas relações de trabalho, também é possível constatar tal autonomia?

\section{Tipologias das inserções no mercado de trabalho}

Uma obra fundamental sobre o trabalho do médico foi escrita por Cecília Donnangelo em 1975. O livro Medicina e sociedade: o médico e seu mercado de trabalho influenciou gerações de pesquisadores e é referência também para estudiosos 
do mercado do trabalho dos dentistas. Uma grande contribuição deixada pela autora foi a tipologia pela qual ela classifica as modalidades de inserção no mercado de trabalho. Para fazer essa classificação, são utilizados três critérios.

O primeiro critério é o controle sobre a clientela. Em outras palavras, é a resposta à pergunta: esses pacientes, são pacientes de quem? É o médico (ou dentista) quem atrai e mantém a clientela? No caso dos profissionais que trabalham para empresas (hospitais e clínicas), o paciente é vinculado a estas e, se o profissional for trocado, muito provavelmente a relação entre profissional e usuário será desfeita. O segundo critério é a posse dos meios materiais de trabalho. Há profissionais que são proprietários dos seus equipamentos, insumos e espaço de trabalho. Em outros casos, esses meios pertencem a quem contrata os profissionais. Por fim, o terceiro critério é a liberdade na fixação do preço do trabalho. Profissionais que atendem diretamente sua clientela podem estabelecer o valor de seus honorários, em negociação direta com a pessoa que irá desembolsar o pagamento. Quando dentistas são empregados, o valor a ser cobrado é estipulado pela empresa e é ela quem recebe do usuário.

\section{Modalidades fundamentais}

Assim, a modalidade mais conhecida de inserção no mercado de trabalho para médicos e dentistas é a autônoma: aquela em que o profissional detém o controle sobre a clientela, os meios materiais de trabalho e a liberdade na fixação do preço do trabalho. Apesar dessa ser a forma tradicional pela qual médicos e dentistas se inseriram no mercado de trabalho durante gerações, ela não é a única. A forma autônoma ainda tem muita importância simbólica, pois é a maneira como em geral a sociedade e os profissionais se veem.

Outra modalidade existente é a do assalariado, aquele que vende a sua força de trabalho, sendo remunerado por quem detém os meios de trabalho. Enquanto o autônomo vende um serviço ao paciente (um tratamento completo, por exemplo), o assalariado vende horas de sua jornada para aquele que possui a clínica, equipamentos e insumos. Além de não deter os meios de produção, o assalariado também não pode dispor de sua clientela, que foi arregimentada pelo dono do estabelecimento. Caso seja demitido, será simplesmente substituído por outro que seguirá atendendo a clientela. Quanto cada paciente paga pelo atendimento também não é uma decisão do profissional: cabe-lhe apenas receber o salário. Assim, por mais que se conserve certa autonomia clínica em relação ao diagnóstico e liberdade de tratamento, ela nunca é completa. É o 
proprietário, na condição de comprador da força de trabalho, que estabelece as condições sob as quais o atendimento se processa: ritmo, duração, tipos de materiais.

Percebe-se, portanto, que para existir o assalariado, é preciso que exista o assalariador. A este, Donnangelo denomina empresário, mas poderíamos nominar proprietário. Tal como o autônomo, ele também detém o controle sobre a clientela, os meios materiais de trabalho e a liberdade na fixação do preço do trabalho, mas não o faz para si; ele contrata outros médicos ou dentistas. É comum que o profissional autônomo seja empregador de um ou mais auxiliares. Não é essa a condição que faz com que seja classificado como empresário nessa tipologia. Compreendemos por empresário aquele que tem a renda formada fundamentalmente pela diferença que consegue aferir entre aquilo que gasta remunerando os profissionais assalariados e o que arrecada pela cobrança aos pacientes. É o empresário que capta a clientela para a clínica, que estabelece as condições de trabalho.

Cabe evidenciar que essa tipologia apresenta modelos para interpretação sociológica da realidade e não está delimitada por critérios jurídicos ou contábeis. Donnangelo estabeleceu que estas três modalidades de inserção seriam as "puras" e que havia ainda outras duas "combinadas": autonomia atípica e cooperativa. Bleicher (2011) sugere uma atualização da classificação, conforme a Figura 1.

Figura 1 - Modalidades de inserção no mercado de trabalho, adaptado de Donnangelo (1975)

Modalidades fundamentais

Variações

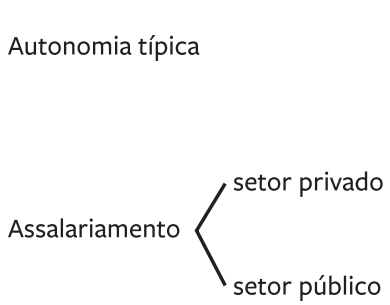

Proprietário
Aluguel de turno

Credenciamento a planos odontológicos

Cooperativa

Trabalho em porcentagem

Trabalhador pejotizado

Estatutário

Celetista

Temporário

Prestador de serviço

Prestador de serviço odontológico

Odontologia Suplementar 


\section{Variações}

O que rotineiramente se chama "aluguel de turno" se refere à situação em que o dentista firma contrato com uma clínica de uma quantidade de horas para fazer uso das instalações do estabelecimento. Muitas vezes, além das instalações, a clínica disponibiliza também o serviço de auxiliares, que, dessa forma, não são contratados diretamente pelo profissional. Assim, com os equipamentos e demais condições necessárias para fazer atendimento, o profissional deve captar a clientela por seus próprios mecanismos, tem liberdade de definir o método de trabalho e liberdade para fixar seus honorários.

Outra modalidade bastante comum é o credenciamento a planos odontológicos. Nesse caso, estamos nos referindo ao profissional que, detendo a posse do consultório, equipamentos e materiais, atende a uma clientela que não foi captada por ele, mas lhe chega a partir de uma operadora de plano de saúde. Ocorre uma sobreposição de características da autonomia típica e do assalariamento, pois o dentista não tem liberdade para fixar o preço de seu trabalho, que é definido pelas tabelas de remuneração das operadoras. Todavia, o fato de o consultório ser seu lhe dá a impressão de que permanece sendo autônomo.

Ainda dentro do espectro da autonomia, podemos localizar as cooperativas, que são sociedades de pessoas cujas forma e natureza jurídicas distinguem-nas de empresas. Não há a figura do dono da cooperativa, todos os cooperados são "donos" da mesma "empresa". A adesão é voluntária e cada associado deve contribuir com uma cota parte de capital para viabilizar a criação e funcionamento da cooperativa. Pessoas estranhas à cooperativa não entram como "investidores", investe quem trabalha nela. Após descontadas as despesas, o que sobra é dividido entre os cooperados. Por não haver um dono, as decisões importantes sobre a cooperativa são tomadas em assembleia onde cada cooperado tem direito a um voto.

Dentro do espectro do assalariamento, é possível encontrar muitas variações e talvez a tipologia apresentada não seja exaustiva. Há muitas formas atípicas de assalariamento. Uma é o trabalho em percentagem, na qual pode haver uma aparência de autonomia, pois o profissional não recebe exatamente um salário, mas uma percentagem do valor que o paciente paga. Há um dono da clínica, que controla a clientela, define em linhas gerais o processo de trabalho e fixa o preço do trabalho. Como o pagamento é vinculado à produtividade $\mathrm{e}$ muitas vezes não há um contrato formal de trabalho, pode parecer que não se trate de assalariamento, mas isso é apenas a aparência. 
Outra forma de assalariamento disfarçado é a pejotização, processo pelo qual o trabalhador é obrigado a se constituir como pessoa jurídica para conseguir vender sua força de trabalho. Como formalmente o profissional é considerado uma empresa, fica descoberto de todos os direitos trabalhistas, vivendo uma situação de muita insegurança. Isso acontece não apenas com dentistas, mas com várias categorias profissionais. Muitas vezes os trabalhadores são demitidos de uma empresa e avisados que, para continuarem desempenhando suas funções, terão que montar uma empresa, ou "abrir pessoa jurídica”, como se diz. O cotidiano do trabalhador segue a mesma rotina: ele continua cumprindo ordens de seu superior imediato, tem determinada carga horária semanal, recebe remuneração. Todavia, por formalmente não ser mais um empregado, mas supostamente o dono de uma empresa contratada, passa a não usufruir de direitos como férias, licença maternidade, $13^{\circ}$ salário etc. Apesar de essa situação contrariar a lei, infelizmente tem se tornado bastante comum.

Para aqueles que trabalham no setor público, há uma variedade extrema de formas de contratação. Infelizmente, os vínculos protegidos não são maioria para os profissionais que atuam no Sistema Único de Saúde (SUS). A pesquisa de Girardi e Carvalho (2008) revelou que, em 2006, 62,7\% dos dentistas brasileiros que trabalhavam no Programa de Saúde da Família tinham postos de trabalho desprotegidos, e 37,3\% tinham empregos protegidos. Os autores classificam como protegidos dois tipos de inserção: o estatutário, que é a relação de trabalho padrão entre servidores civis e a administração pública; e o celetista, aquele que é protegido pela Consolidação das Leis do Trabalho. Ambos têm suporte legal e proteção social, com garantia de direitos trabalhistas. Os postos de trabalho desprotegidos incluem os contratos temporários, contratos como autônomos e outas relações informais, vivenciando falta de direitos sociais e trabalhistas e instabilidade no emprego.

Sobre a modalidade proprietário, é importante destacar que nem sempre o empregador de dentista é um profissional formado em odontologia. Para nossa análise, isso não faz muita diferença, uma vez que nos importa mais entender a morfologia do capital que emprega a força de trabalho dos dentistas. Há basicamente dois tipos de empresas que empregam dentistas: aquelas que vendem diretamente aos usuários o serviço odontológico (prestadora de serviço odontológico) e as que operam planos odontológicos (odontologia suplementar), credenciando dentistas. Os detalhes sobre a chamada odontologia suplementar serão discutidos ao final do capítulo. 


\title{
Precarização social do trabalho
}

A partir do exposto acima, foi possível perceber que, em diversas situações, a inserção do dentista no mercado de trabalho se dá de forma vulnerável e privada de direitos. Para compreender tal fenômeno, é necessário recorrer ao conceito de precarização social do trabalho, que, segundo Thebaud-Mony e Druck (2007, p. 31, grifo nosso), é:

\begin{abstract}
Processo social constituído pela amplificação e institucionalização da instabilidade e da insegurança, expressas nas novas formas de organização do trabalho, onde a terceirização, subcontratação ocupa um lugar central e no recuo do papel do Estado como regulardor do mercado de trabalho e da proteção social através de inovação da legislação do trabalho e previdenciária. Um processo que atinge todos os trabalhadores, independentemente de seu estatuto e que tem levado a crescente degradação das condições de trabalho, saúde e vida dos trabalhadores e da vitalidade da ação sindical.
\end{abstract}

Queremos chamar atenção para o fato de que o fenômeno de precarização não se limita aos trabalhadores já historicamente fragilizados. Essa é uma característica que as autoras fazem questão de pôr em relevo: não se trata de imaginar uma sociedade dual, com incluídos e excluídos. É um fenômeno que, embora afete de maneira diferente grupos distintos de trabalhadores, não pode ser entendido como residual.

Sendo assim, Druck (2011) afirma que existem seis tipos de precarização:

- O primeiro diz respeito à vulnerabilidade das formas de inserção e desigualdades sociais. São formas de inserção precária no mercado de trabalho, sem proteção social, com baixos salários, informalidade e desemprego.

- O segundo se refere à intensificação do trabalho e terceirização. Compreende o prolongamento da jornada de trabalho, a determinação de metas inalcançáveis, o assédio moral no trabalho, a discriminação. Frequentemente a imposição do medo se torna um modelo de gestão. O processo de terceirização permite amplo uso desses "dispositivos gerenciais".

- O terceiro tipo consiste na insegurança e saúde no trabalho, a partir do não oferecimento de condições adequadas de trabalho e de treinamento adequado, resultando em amplo número de acidentes laborais. 
- O quarto tipo é a perda das identidades individual e coletiva, produzida pelo isolamento, perda de vínculos, desvalorização e exclusão. O trabalhador é tratado como descartável e é levado a crer que é o único responsável por sua empregabilidade.

- $\quad$ O quinto se expressa na fragilização da organização dos trabalhadores. 0 enfraquecimento dos sindicatos, a perseguição aos movimentos contestatórios e a judicialização das greves são alguns dos aspectos desse fenômeno.

- O sexto tipo fundamenta-se na condenação e descarte do Direito do TrabaIho através de mudanças na legislação retirando direitos trabalhistas ou na construção de situações em que tais leis se tornem inaplicáveis.

A partir do exposto, é possível perceber que a precarização social do trabalho também atinge os dentistas. É comum que esses profissionais estejam inseridos no mercado a partir de modalidades desprovidas de direitos, sem reconhecimento de vínculo trabalhista, submetidos a situações de alta produtividade, acumulando variadas doenças ocupacionais. A capacidade organizativa dos dentistas tem sido historicamente baixa, mas pode vir a aumentar em futuro próximo. É preocupante que muitas vezes tais situações sejam naturalizadas, como se fossem a obrigatória primeira etapa de toda profissão liberal.

\section{Aspectos quantitativos do mercado de trabalho dos dentistas}

A quantidade de dentistas no Brasil tem aumentado em uma proporção muito superior à taxa de crescimento populacional, um fenômeno que já ultrapassa cinco décadas de duração. Dessa forma, o índice de dentistas para cada 10 mil habitantes tem aumentado ou, inversamente, poderíamos dizer que a quantidade de habitantes por dentistas tem diminuído. Isso ocorre em meio a uma profunda desigualdade de distribuição desses profissionais, mais concentrados na região Sudeste e nos grandes centros urbanos.

Embora o trabalho com proporções (a exemplo de "habitantes por dentista”) seja útil para revelar tendências temporais e apontar desigualdades entre regiões, não é possível estabelecer qual seria a proporção ideal de dentista por população. Populações de tamanhos diferentes podem precisar de mais ou menos dentistas, a depender da prevalência de doenças bucais que apresentem, de diferenças sociodemográficas (tais como composição etária), do modelo de atenção (maior ou menor utilização de tecnologias preventivas) e do processo de trabalho utilizado (maior ou menor delegação de tarefas ao pessoal auxi- 
liar). Nesse sentido, a conhecida "meta da Organização Mundial da Saúde" para quantidade de dentistas não tem muito fundamento. (BLEICHER, 2011)

Ainda que não seja razoável o estabelecimento de metas de profissionais por população, os dados expressos na Tabela 1 parecem indicar que não há deficiência de profissionais no país em termos absolutos. A Tabela 2 revela a desigualdade na distribuição de dentistas pelas macrorregiões. É significativo que, no espaço de 26 anos, as proporções tenham se modificado tão pouco.

Tabela 1 - Número de Cirurgiões-Dentistas (CD), população, índice de CD por 10 mil habitantes e proporção habitante/CD, 1960-2015, Brasil

\begin{tabular}{c|c|c|c|c}
\hline Ano & CD & $\begin{array}{c}\text { População } \\
\text { (em mil) }\end{array}$ & $\begin{array}{c}\text { Índice } \\
\text { CD/10 mil hab. }\end{array}$ & Hab./CD \\
\hline 1960 & 23.000 & 70.191 & 3,28 & 3.052 \\
\hline 1970 & 34.000 & 93.139 & 3,65 & 2.739 \\
\hline 1980 & 61.067 & 119.071 & 5,13 & 1.950 \\
\hline 2000 & 146.677 & 169.799 & 8,64 & 1.158 \\
\hline 2010 & 224.745 & 192.399 & 11,68 & 856 \\
\hline 2015 & 269526 & 204.945 & 13,15 & 760 \\
\hline
\end{tabular}

Fonte: Bleicher (2011); CFO (2015).

Tabela 2 - Número e percentual de dentistas segundo macrorregiões, Brasil, 1982 e 2008

\begin{tabular}{c|c|c|c|c}
\hline \multirow{2}{*}{ Região } & \multicolumn{2}{|c|}{1982} & \multicolumn{2}{c}{2008} \\
\cline { 2 - 5 } & $\mathrm{n}$ & $\%$ & $\mathrm{n}$ & $\%$ \\
\hline Norte & 1.482 & 2,1 & 8.121 & 3,7 \\
\hline Nordeste & 10.057 & 14,3 & 29.714 & 13,5 \\
\hline Sudeste & 43.342 & 61,8 & 129.473 & 59,0 \\
\hline Sul & 11.409 & 16,3 & 34.561 & 15,7 \\
\hline Centrooeste & 3.855 & 5,5 & 17.706 & 8,1 \\
\hline Brasil & $\mathbf{7 0 . 1 4 5}$ & $\mathbf{1 0 0 , 0}$ & $\mathbf{2 1 9 . 5 7 5}$ & $\mathbf{1 0 0 , 0}$ \\
\hline
\end{tabular}

Fonte: Teles (1985); Morita, Haddad e Araujo (2010). 


\section{Odontologia suplementar}

O SUS apresenta três subsistemas: no setor público, há o SUS e, no setor privado, existem o Sistema de Desembolso Direto (SDD) e o Sistema de Atenção Médica Supletiva (SAMS). (CARTAXO; SANTOS, 2007) O SDD é caracterizado pelo atendimento direto aos pacientes, sem intermediação de um terceiro. É composto não apenas por profissionais que exercem a modalidade de autonomia típica, mas também por clínicas dos mais variados portes, qualquer que seja a forma de contratação de seus empregados. O SAMS é definido pela intermediação das operadoras de saúde, ou seja, o paciente não paga diretamente ao profissional que o atende, mas sim à operadora, sendo esta responsável pela remuneração do profissional. É importante salientar que, embora não sejam estatais, o SDD e o SAMS implicam em gastos para o governo, para os quais toda a sociedade contribui. A legislação permite que os gastos privados com saúde sejam deduzidos do imposto de renda, configurando um gasto tributário, uma vez que o Estado, ao não arrecadar, age como se pagasse. A estimativa de gastos tributários somente com planos de saúde relativos à renúncia decorrente do imposto sobre a renda da pessoa física no ano de 2011 foi de $\mathrm{R} \$ 4,8$ bilhões. Despesas que as pessoas fazem no SDD também estão sujeitas a abatimento no imposto de renda. (GARCIA, 2015)

O SAMS é regulado pela Agência Nacional de Saúde Suplementar (ANS), criada pela lei n. ${ }^{\circ} 9.961$ de 2000, mas a existência do setor é anterior a essa data. Já existiam companhias seguradoras e cooperativas odontológicas ao final dos anos 1979, por exemplo. (ANDREAZZI; KORNIS, 2003; VIEIRA; COSTA, 2008) A Lei n. ${ }^{\circ}$ 9.961/00 estabelece que a ANS é um “órgão de regulação, normatização, controle e fiscalização das atividades que garantam a assistência suplementar à saúde" que tem por finalidade “[...] promover a defesa do interesse público na assistência suplementar à saúde, regulando as operadoras setoriais, inclusive quanto às suas relações com prestadores e consumidores, contribuindo para o desenvolvimento das ações de saúde no País”. (BRASIL, 2000)

Alguns autores argumentam que a defesa do "interesse público" pode não ser exatamente o que se observa em vários aspectos da atuação dessa autarquia. Ocke-Reis (2007) considera que o estabelecimento pela ANS de barreiras de entrada a novas operadoras no setor aumenta o poder das empresas que já são líderes e que há quase uma autorregulação deste setor no mercado. Vilarinho (2010) admite que esse fenômeno leva a um abrandamento do rigor de aplicação das leis pela agência. Em pesquisa mais recente, Scheffer e Bahia 
(2015) fizeram um levantamento de doações oficiais de empresas de planos de saúde nas eleições de 2014 e descobriram que o valor de quase $\mathrm{R} \$ 55$ milhões repassados por 40 empresas a 131 candidatos foi quase cinco vezes superior ao investido no ano de 2010. A atuação da ANS não passa incólume a situações como essa. Os autores concluíram que tais doações podem ser consideradas como produtivos investimentos, uma vez que é comum que representantes das operadoras ocupem cargos diretivos na ANS, e que o Governo Federal e Congresso Nacional aprovem medidas que beneficiam economicamente tais empresas.

Os planos de saúde podem ser de contratação individual, caso em que o indivíduo assina contrato diretamente com a operadora, ou coletiva, situação em que o contrato é firmado entre uma pessoa jurídica e a operadora. (ALBUQUERQUE, 2008) Esse último caso abrange as situações em que uma empresa assina o plano de saúde para seus empregados (plano coletivo empresarial). Também existem as situações em que sindicatos e associações possibilitam que seus sindicalizados e associados optem pelos planos de saúde da operadora contratada (plano coletivo por adesão). Pelas normas atuais, o controle do reajuste das mensalidades feito pela ANS atinge somente os planos de contratação individual, que são franca minoria no setor. Para alguns autores, essa situação diminui a capacidade regulatória da agência.

As operadoras de planos de saúde podem ofertar planos médico hospitalares e planos odontológicos, conforme o Quadro 1.

$\begin{aligned} & \text { Quadro 1 - Modalidades de operadoras de planos de saúde segundo as Normas } \\
& \text { Nacionais, Brasil } \\
& \text { (continua) }\end{aligned}$
\begin{tabular}{|c|c|}
\hline Modalidade & Descrição \\
\hline Cooperativa médica & $\begin{array}{r}\text { Sociedades de pessoas sem fins lucrativos que operam planos } \\
\text { privados de assistência à saúde. }\end{array}$ \\
\hline Filantropia & $\begin{array}{r}\text { Entidades sem fins lucrativos que operam planos privados de } \\
\text { assistência à saúde e tenham obtido o certificado de entidade } \\
\text { beneficente de assistência social. }\end{array}$ \\
\hline Autogestão & $\begin{array}{r}\text { Pessoa jurídica de direito privado que opera plano privado } \\
\text { de assistência à saúde exclusivamente aos seguintes } \\
\text { beneficiários: empregados e ex-empregados, aposentados, } \\
\text { sócios, administradores e ex-administradores da entidade de } \\
\text { autogestão, bem como seus familiares e pensionistas. }\end{array}$ \\
\hline
\end{tabular}


Quadro 1 - Modalidades de operadoras de planos de saúde segundo as Normas Nacionais, Brasil

(conclusão)

\begin{tabular}{|c|c|}
\hline Modalidade & Descrição \\
\hline Medicina de grupo & $\begin{array}{r}\text { Empresas ou entidades que operam planos privados de } \\
\text { assistência à saúde, excetuando-se aquelas classificadas nas } \\
\text { modalidades anteriores. }\end{array}$ \\
\hline Cooperativa odontológica & $\begin{array}{r}\text { Sociedades de pessoas sem fins lucrativos, constituídas } \\
\text { conforme o disposto na lei que define a Política Nacional } \\
\text { de Cooperativismo, que operam exclusivamente planos } \\
\text { odontológicos. }\end{array}$ \\
\hline Odontologia de grupo & $\begin{array}{r}\text { Empresas ou entidades que operam exclusivamente planos } \\
\text { odontológicos, excetuando-se aquelas classificadas na } \\
\text { modalidade anterior. }\end{array}$ \\
\hline
\end{tabular}

Fonte: Adaptado de Agência Nacional de Saúde Suplementar (2000) e RN 137/2006.

Os usuários podem contratar planos médico hospitalares, com ou sem odontologia, ou se limitar a planos exclusivamente odontológicos. A distribuição do número de usuários de planos exclusivamente odontológicos entre as modalidades de operadoras pode ser vista na Tabela 3. A modalidade "odontologia de grupo", que tem como exemplo as operadoras Odontoprev e Odontosystem, tem sido, desde o início da Era ANS, a que detém mais beneficiários de planos odontológicos, com quase dois terços do universo. O segundo lugar, todavia, sofreu uma inversão: inicialmente ocupado pela modalidade "cooperativas odontológicas", de que fazem parte as Uniodontos, passou a abrigar a empresas de medicina de grupo, como Amil e Hapvida. Esse fenômeno deve ser melhor estudado e talvez signifique uma dificuldade maior das entidades que se guiam pelos princípios cooperativistas em concorrer com empresas e entidades com fins lucrativos (Tabela 3).

Tabela 3 - Número e percentual de beneficiários de planos exclusivamente odontológicos por modalidade. 2000 e 2015, Brasil

(continua)

\begin{tabular}{l|c|c|c|c}
\hline \multicolumn{1}{c|}{ Modalidade } & \multicolumn{2}{c|}{ Mar./2000 } & \multicolumn{2}{c}{ Jun./2015 } \\
\hline Autogestão & 37.268 & 1,73 & 94.030 & 0,44 \\
\hline Cooperativa médica & 7.759 & 0,36 & 372.596 & 1,73 \\
\hline Filantropia & 52 & 0,00 & 109.675 & 0,51 \\
\hline
\end{tabular}


Tabela 3 - Número e percentual de beneficiários de planos exclusivamente odontológicos por modalidade. 2000 e 2015, Brasil

(conclusão)

\begin{tabular}{l|c|c|c|c}
\hline \multicolumn{1}{c|}{ Modalidade } & \multicolumn{2}{c|}{ Mar./2000 } & \multicolumn{2}{c}{ Jun./2015 } \\
\hline Medicina de grupo & 75.362 & 3,50 & 3.554 .556 & 16,51 \\
\hline $\begin{array}{l}\text { Seguradora especializada em } \\
\text { saúde }\end{array}$ & 157.970 & 7,35 & 834.428 & 3,88 \\
\hline Cooperativa odontológica & 525.516 & 24,44 & 3.206 .085 & 14,89 \\
\hline Odontologia de grupo & 1.346 .616 & 62,62 & 13.355 .097 & 62,04 \\
\hline Total & $\mathbf{2 . 1 5 0 . 5 4 4}$ & $\mathbf{1 0 0 , 0 0}$ & $\mathbf{2 1 . 5 2 6 . 4 6 7}$ & $\mathbf{1 0 0 , 0 0}$ \\
\hline
\end{tabular}

Fonte: Agência Nacional de Saúde Suplementar (2015).

O setor de planos exclusivamente odontológicos tem apresentado extremo dinamismo, com taxas de crescimento superiores ao conjunto da saúde suplementar no período posterior à criação da ANS (Tabela 4). A expansão desse setor ocorreu em meio a um processo de progressiva concentração. Segundo o Caderno de informação da saúde suplementar da ANS, até dezembro de 1999, existiam 670 operadoras de planos exclusivamente odontológicos em atividade. Em junho de 2015, esse número foi reduzido a 377. (AGÊNCIA NACIONAL DE SAÚDE SUPLEMENTAR, 2015) São valores que contrastam vivamente com o exponencial aumento do número de beneficiários. Soma-se a isto o fato de que a maior operadora odontológica do país tem mais de 30\% dos beneficiários, tal como apontado pela publicação Foco saúde suplementar. (AGÊNCIA NACIONAL DE SAÚDE SUPLEMENTAR, 2014) As consequências dessa concentração de capital ainda não foram suficientemente estudadas. É possível que, mantendo-se essa tendência, os CD vinculados a essas empresas venham a se encontrar em maior desvantagem. 
Tabela 4 - Número de beneficiários e taxa de crescimento do número de beneficiários de planos médicos, com ou sem odontologia, e exclusivamente odontológicos, Brasil, 2003-2015

\begin{tabular}{|c|c|c|c|c|}
\hline \multirow{2}{*}{ Ano } & \multicolumn{2}{|c|}{$\begin{array}{c}\text { Número de beneficiários com } \\
\text { planos }\end{array}$} & $\begin{array}{c}\text { Taxa de crescimento (\%) do número } \\
\text { de beneficiários em relação a } \\
\text { dezembro do ano anterior }\end{array}$ \\
\cline { 2 - 5 } & $\begin{array}{c}\text { Médicos com ou } \\
\text { sem odontologia }\end{array}$ & $\begin{array}{c}\text { Exclusivamente } \\
\text { odontológicos }\end{array}$ & $\begin{array}{c}\text { Médicos com ou } \\
\text { sem odontologia }\end{array}$ & $\begin{array}{c}\text { Exclusivamente } \\
\text { odontológicos }\end{array}$ \\
\hline Jun./03 & 31.715 .480 & 3.877 .443 & 0,85 & 14,96 \\
\hline Jun./04 & 33.064 .858 & 4.744 .203 & 4,25 & 22,35 \\
\hline Jun./05 & 34.357 .440 & 5.815 .727 & 3,91 & 22,59 \\
\hline Jun./06 & 36.067 .336 & 6.690 .145 & 4,98 & 15,04 \\
\hline Jun./07 & 37.871 .485 & 7.860 .029 & 5,00 & 17,49 \\
\hline Jun./08 & 40.368 .599 & 9.904 .243 & 6,59 & 26,01 \\
\hline Jun./09 & 41.682 .920 & 11.926 .215 & 3,26 & 20,42 \\
\hline Jun./10 & 43.713 .704 & 13.943 .063 & 4,87 & 16,91 \\
\hline Jun./11 & 45.735 .629 & 15.842 .552 & 4,63 & 13,62 \\
\hline Jun./12 & 46.899 .715 & 18.003 .721 & 2,55 & 13,64 \\
\hline Jun./13 & 48.432 .584 & 19.068 .016 & 3,27 & 5,91 \\
\hline Jun./14 & 49.998 .277 & 20.514 .259 & 3,23 & 7,58 \\
\hline Jun./15 & 50.516 .992 & 21.526 .467 & 1,04 & 4,93 \\
\hline
\end{tabular}

Fonte: Agência Nacional de Saúde Suplementar (2015).

É comum a insatisfação de CD com as operadoras de planos odontológicos, em geral apontando para a perda da autonomia (FREITAS, 2007) e diminuição de rendimentos. (CARTAXO; SANTOS, 2007) Há denúncias de diminuição dos valores pagos por procedimentos e glosas indevidas. (BLEICHER, 2011) Nesse tema, cabe recorrer a uma publicação da ANS intitulada Guia prático da contratualização. (AGÊNCIA NACIONAL DE SAÚDE SUPLEMENTAR, 2013) O dentista que se credencia a uma operadora de plano de saúde deve formalizar a relação comercial por meio do contrato que especifique quais são as obrigações e os deveres das partes. É muito importante que os dentistas estejam protegidos por contratos. As operadoras que por ventura não formalizarem essa relação estarão sujeitas a sanções e multas. O descumprimento desse contrato por qualquer das partes gera a possibilidade de indenização. 
O critério de reajuste dos valores dos procedimentos a serem pagos aos dentistas credenciados deve estar expresso de forma objetiva no contrato, que deve especificar a periodicidade e a forma do reajuste (por exemplo, estabelecendo um índice inflacionário vigente que seja de conhecimento público). Não são permitidas fórmulas de cálculo de reajuste em que o valor contratado seja mantido ou reduzido. A ANS entende que não tem competência legal para definir os preços constantes na tabela remuneratória das operadoras de saúde nem de interferir em processos de glosa e falta de pagamento pelas operadoras aos prestadores. Fica evidente que a legislação pressupõe que a relação existente entre dentistas e operadoras é um assunto de natureza comercial. Nesse raciocínio, não haveria uma parte em desvantagem que mereceria de proteção à desigualdade de poder.

\section{Considerações finais}

O mercado de trabalho do dentista sofreu profundas alterações nas últimas décadas, que vão além do mero crescimento do número de profissionais. Houve uma complexificação desse mercado, com o surgimento de diversas modalidades de inserção. É usual o acúmulo de mais de uma modalidade de inserção no mercado, sobretudo entre dentistas jovens. Há um processo de assalariamento que se expressa nas formas mais precarizadas de contratação. Isso ocorre com a persistência de uma imagem de "profissão liberal" que dificulta uma resistência por parte daqueles que a exercem.

No outro polo desse processo, aquele que compra a força de trabalho do dentista, transformações importantes também ocorrem. Após a criação da ANS, houve um crescimento expressivo dos planos odontológicos, com o surgimento de operadoras de abrangência nacional. Esse mercado se tornou mais concentrado e apresenta problemas próprios de um modelo que toma a saúde como mercadoria, tal como a captura da agência reguladora.

\section{Referências}

AGÊNCIA NACIONAL DE SAÚDE SUPLEMENTAR. Dados Gerais. Disponível em: <http://www.ans.gov.br/perfil-do-setor/dados-gerais> Acesso em: 21 out. 2015.

AGÊNCIA NACIONAL DE SAÚDE SUPLEMENTAR. RDC $n^{0}$ 39, de 27 de outubro de 2000. Disponível em: < http://www.ans.gov.br/component/ legislacao/?view=legislacao\&task=TextoLei\&format=raw\&id=380> Acesso em: 19 out. 2015 . 
AGÊNCIA NACIONAL DE SAÚDE. RN n ${ }^{\circ}$ 137, de 14 de novembro de 2006. Disponível em: <http://www.ans.gov.br/component/ legislacao/?view=legislacao\&task=TextoLei\&format=raw\&id=MTExNw==>. Acesso em: 13 jun. 2016.

AGÊNCIA NACIONAL DE SAÚDE SUPLEMENTAR. Caderno de Informação da Saúde Suplementar: beneficiários, operadors e planos. Ano 9, n. 2, jun. 2015. Disponível em $<$ http://www.ans.gov.br/materiais-publicados/periodicos>. Acesso em: 21 out. 2015.

AGÊNCIA NACIONAL DE SAÚDE SUPLEMENTAR. Foco em saúde suplementar. 2014. Disponível em: <http://www.ans.gov.br/materiais-publicados/periodicos>. Acesso em: 21 out. 2015 .

AGÊNCIA NACIONAL DE SAÚDE SUPLEMENTAR. Reajuste de mensalidade: conceitos básicos, reajuste por variação de custos, reajuste por mudança de faixa etária. 2. ed. rev. ampl, 2005.

ALBUQUERQUE, C. et al . A situação atual do mercado da saúde suplementar no Brasil e apontamentos para o futuro. Ciência \& saúde coletiva, Rio de Janeiro, v. 13, n. 5, out. 2008.

ANDREAZZI, M. F. S.; KORNIS, G. E. M. Transformações e desafios da atenção privada em saúde no Brasil nos anos 90. Physis, v. 13, n. 1, p. 157-191, 2003.

BLEICHER, L. Autonomia ou assalariamento precário?: o trabalho dos cirurgiões- dentistas na cidade de Salvador. 2011. 289 f. Tese (Doutorado em Sociologia) - Universidade Federal da Bahia, Faculdade de Filosofia e Ciências Humanas, Salvador, 2011.

BRASIL. Lei n. 9961, de 28 de janeiro de 2000. Cria a Agência Nacional de Saúde Suplementar - ANS e dá outras providências. Disponível em: <http://www.planalto.gov.br/ ccivil_03/Leis/L9961.htm>. Acesso em: 17 out. 2015.

BRASIL. Lei n. 5.764, de 16 de dezembro de 1971. Define a Política Nacional de Cooperativismo, institui o regime jurídico das sociedades cooperativas, e dá outras providências. Disponível em: <http://www.planalto.gov.br/ccivil_03/LEIS/L5764.htm>. Acesso em: 17 out. 2015.

CARTAXO, J. L. S.; SANTOS, M. L. R. Estudo da satisfação do usuário de planos de saúde odontológicos em Salvador no ano de 2004. Revista Baiana de Saúde Pública, Salvador, v. 1, n. 31, p. 25-37, 2007

DONNANGELO, M. C. F. Medicina e sociedade: o médico e seu mercado de trabalho. São Paulo: Pioneira, 1975.

DRUCK, G. Trabalho, precarização e resistências: novos e velhos desafios? Caderno CRH, Salvador, v. 24, n. 1, p. 37-57, 2011.

FIGUEIREDO, B. G. Barbeiros e cirurgiões: atuação dos práticos ao longo do século XIX. Hist. cienc. saúde-Manguinhos, Rio de Janeiro, v. 6, n. 2, p. 277-291, out. 1999. 
FONSECA, F. Dimensões críticas das políticas públicas. Cad. EBAPE.BR, v. 11, n. 3, artigo 5, Rio de Janeiro, set./nov. 2013.

FREIDSON, E. Para uma análise comparada das profissões: a institucionalização do discurso e do conhecimento formais. Revista Brasileira de Ciências Sociais, São Paulo, ano 11, n. 31, jun. 1996.

FREITAS, C. H. S. de M. Dilemas no exercício profissional da Odontologia: a autonomia em questão. Interface: Comunicação, Educação e Saúde, Botucatu, v. 11, n. 21, p. 25-38, 2007.

GARCIA, L. P. et al. Gastos com planos de saúde das famílias brasileiras: estudo descritivo com dados das Pesquisas de Orçamentos Familiares 2002-2003 e 2008-2009. Ciência \& Saúde Coletiva, Rio de Janeiro, v. 20, n. 5, p. 1425-1434, maio, 2015.

GIRARDI, S. N.; CARVALHO, C. L. Trends in labor contracting in the Family Health Program in Brazil: a telephone survey. Cahiers de Sociologie et Démographie Médicales, v. 48, p. 271-288, 2008.

IBGE. Projeção da população brasileira. Disponível em: <http://www.ibge.gov.br/home/ popclock_home/iframe_popclock_p_home.html> Acesso em: 17 out. 2015.

MARTINO, L. V. S.; BOTAZZO, C.; ZILBOVICIUS, C. Os caminhos públicos da odontologia paulista no início do século XX. Cadernos de História da ciência. São Paulo, v. 6 n. 1, jan./jul. 2010.

MORITA, M. C.; HADDAD, A. E. ; ARAUJO, M. E. Perfil atual e tendências do cirurgiãodentista brasileiro. Dental Press International: Maringá, 2010. v. 1.

MOTT, M. L. et al .'Moças e senhoras dentistas': formação, titulação e mercado de trabalho nas primeiras décadas da República. Hist. cienc. saúde-Manguinhos, Rio de Janeiro, v. 15, supl., p. 97-116, 2008.

OCKE-REIS, C. O. Os desafios da ANS frente à concentração dos planos de saúde. Ciência \& Saúde Coletiva, v. 12, n. 4, p. 1041-1050, 2007.

PIMENTA, T. S. Transformações no exercício das artes de curar no Rio de Janeiro durante a primeira metade do Oitocentos, História, Ciências, Saúde-Manguinhos, Rio de Janeiro, v. 11, supl. 1, p. 67-92, 2004.

SCHEFFER, M.; BAHIA, L. Representação política e interesses particulares na saúde: a participação de empresas de planos de saúde no financiamento de campanhas eleitorais em 2014. 2015. Disponível em: <http://www.abrasco.org.br/site/wp-content/ uploads/2015/02/Planos-de-Saude-e-Eleicoes-FEV-2015-1.pdf>. Acesso em: 21 ago. 2015.

TELES, J. C. B. Assistência odontológica no país: perspectivas 1. Cadernos de Saúde Pública, Rio de Janeiro, v. 2, n. 1, p. 235-62, 1985.

THÉBAUD-MONY, A.; DRUCK, G. Terceirização: a erosão dos direitos nos trabalhadores na França e no Brasil. In: DRUCK, G.; FRANCO T. A perda da razão social do trabalho: terceirização e precarização. São Paulo: Boitempo, 2007. p. 23-58. Capítulo 2. 
VIEIRA, C.; COSTA, N. R. Estratégia profissional e mimetismo empresarial: os planos de saúde odontológicos no Brasil. Ciência \& Saúde Coletiva, Rio de Janeiro, v. 13, n. 5, p. 15791588, set./out. 2008.

VILARINHO, P. F. A percepção da captura política da saúde suplementar no Brasil. CADERNOS EBAPE.BR, Rio de Janeiro, v. 8, n. 4, p. 694-709, dez. 2010. 


\title{
Educação em saúde bucal do trabalhador
}

\author{
Mariangela Silva de Matos \\ Patrícia Suguri Cristino \\ Tatiana Frederico de Almeida
}

\section{Apresentação}

Este capítulo faz uma abordagem dos aspectos históricos, políticos e conceituais do campo da educação em saúde, contextualizando-o para a realidade das práticas da saúde bucal do trabalhador. A busca da integralidade da atenção à saúde, a compreensão atual da multicausalidade das doenças e o desenvolvimento teórico e prático da promoção da saúde, contribuíram para mudanças nos modelos de atenção à saúde, com destaque para o desenvolvimento da vigilância da saúde, em contraponto ao modelo biomédico, centralizado no profissional de saúde, na cura da doença e nas causas biológicas e comportamentalistas das doenças. A vigilância da saúde, ao contrário, aponta para a necessidade do controle mais efetivo das causas e riscos, e não somente sobre os danos das doenças e agravos que atingem as populações. O movimento da promoção da saúde preconiza diferentes campos de ação em busca da qualidade de vida e bem-estar das populações. Dentre esses, destacam-se a capacitação da comunidade e o desenvolvimento de habilidades individuais e coletivas, os quais requerem a incorporação de ações educativas, sejam elas voltadas para o autocuidado ou para a educação popular. No processo de educação em saúde, é cada vez mais valorizada a participação ativa do educando nas estratégias de ensino-aprendizagem, possibilitando um processo dialógico e mais efetivo. 
Nesse contexto, insere-se a saúde bucal do trabalhador, o qual reconhece a importância da íntima relação entre ambiente de trabalho e condições bucais. As consequências do trabalho para a saúde bucal são reconhecidas cientificamente e os agravos bucais geram problemas relativos à qualidade de vida das pessoas, dor, dificuldade de mastigação, comprometimento estético e psicológico. No ambiente do trabalho, esses impactos podem ser responsáveis pela perda de produtividade devido ao absenteísmo, seja pelo incômodo da dor de origem odontológica ou pela alta frequência às consultas odontológicas. Desse modo, os fundamentos da educação em saúde consolidam-se como uma ferramenta indispensável para a organização dos serviços na área de saúde bucal do trabalhador, principalmente no âmbito dos programas preventivos.

\section{Abrindo o debate}

Abordar o tema educação em saúde bucal remete a um processo complexo que articula, numa perspectiva interdisciplinar, dois campos de saberes: o da educação e o da saúde. Na saúde, as diferentes formas de interpretar o processo saúde-doença ao longo da história definemas formas de intervenção sobre ele, incluindo a percepção da necessidade de se adotar, ou não, práticas de educação em saúde. Na educação, ocorrem importantes mudanças nas abordagens educativas, de modo que elas passam a valorizar, cada vez mais, a participação ativa do educando no processo ensino-aprendizagem.

Tal concepção começa a partir da década de 1970, sob forte influência da proposta pedagógica de Paulo Freire, a pedagogia libertadora, subsidiando importantes referenciais para as práticas de educação em saúde, na direção de um maior empoderamento (empowerment) da população, tanto em nível individual como coletivo. (ALVES, 2005)

Em se tratando das formas de intervenção sobre o processo saúde-doença, as políticas de saúde no Brasil pautaram-se, tradicionalmente, pelo modelo biomédico, com foco na cura e controle das doenças. A partir da evolução do conhecimento científico, avançando-se na compreensão da multicausalidade do processo saúde-doença, dos movimentos internacionais para nortear as políticas de saúde, do movimento da Reforma Sanitária no Brasil e da promulgação da Constituição Brasileira, com a criação e a busca de consolidação do Sistema Único de Saúde (SUS), impõe-se importantes mudanças nos modelos de atenção. Nesse contexto, a atenção primária passa a ser prioritária, valorizando-se as ações de promoção de saúde. 
Essas ações, de acordo com Paim (2003), aplicam-se, essencialmente, à melhoria das condições e estilos de vida de grupos populacionais específicos, apoiando-se amplamente em atividades de educação e comunicação em saúde e na formulação de políticas públicas saudáveis.

Avançando-se na concepção de modelos de atenção mais integrais, que orientem as intervenções sobre a saúde, constrói-se o conceito de vigilância da saúde, apontando para a necessidade do controle mais efetivo das causas eriscos, e não somente sobre os danos das doenças e agravos que atingem as populações. Deriva daí, a implantação da vigilância na área de saúde do trabalhador, levando-se em conta os ambientes de trabalho e os riscos ocupacionais. (PAIM, 2003)

Em relação à saúde, o trabalho pode trazer inúmeras consequências: destrutivas, benéficas, ou ambas, podendo operar de modo distinto conforme o momento histórico e com a organização dos trabalhadores, sendo um importante determinante do processo saúde-doença. A lógica da saúde pública, de prevenção de riscos e de promoção da saúde com a participação dos trabalhadores, constituindo o que se chama "saúde do trabalhador", efetivou-se no Brasil a partir do SUS, em 1988 (SANTANA; SILVA, 2012), sendo o fundamento das suas ações pautado em uma articulação multiprofissional, interdisciplinar e intersetorial. (BRASIL, 2002a)

O campo da saúde do trabalhador busca compreender as relações entre o trabalho e o processo saúde-doença, considerando-se os diversos riscos ambientais e organizacionais aos quais os trabalhadores estão expostos em seus processos de trabalho. (BRASIL, 2002a)

Assim, as ações de saúde do trabalhador devem ser incluídas formalmente na agenda da rede básica de atenção à saúde. Dessa forma, amplia-se a assistência já ofertada aos trabalhadores, na medida em que passa a olhálos como sujeitos a um adoecimento específico que exige estratégias - também específicas - de promoção, proteção e recuperação da saúde. (BRASIL, 2002a, p. 9)

A área de especialidade de odontologia do trabalho regulamentada pelas Resoluções n. ${ }^{\circ} 22$, de 27 de dezembro de 2001 , e n. ${ }^{\circ} 25$, de 28 de maio de 2002 , objetiva a busca permanente da compatibilidade entre a atividade laboral e a preservação da saúde bucal do trabalhador; e uma das suas competências é o planejamento e implantação de campanhas e programas de duração permanente para educação 
dos trabalhadores quanto a acidentes de trabalho, doenças ocupacionais e educação em saúde. (MAZZILLI, 2003)

Essas novas propostas de intervenção sobre a saúde passam a exigir ações intersetoriais e uma atuação multiprofissional e interdisciplinar, com a mobilização de outros campos de saberes, destacando-se a sociologia, a antropologia, a psicologia e a educação.

No campo da saúde bucal do trabalhador, as estratégias de educação em saúde devem ser conduzidas em duas perspectivas:

- Fomentar o autocuidado com ações voltadasao aprimoramento das habilidades individuais para prevenção e controle de problemas bucais e para a busca de cuidados profissionais;

- Fortalecer uma postura política reivindicadorade direitosque vão desde o acesso às ações e serviços de saúde até a criação deambientes de trabalho que permitamatividadeslaborais com o mínimo de risco.

Inúmeras pesquisas têm ressaltado os impactos das más condições bucais sobre a qualidade de vida das pessoas, expondo-as a dor, dificuldade de alimentação, comprometimento estético, desconforto psicológico, dentre outros. (MATOS; FLORIANO, 2011) Em se tratando da saúde bucal do trabalhador, esses impactos podem ser responsáveis pela perda de produtividadedevido ao absenteísmo, seja pela dor oupela alta frequência às consultas odontológicas para o tratamento dos danos.

Nesse contexto, a educação em saúde consolida-se como uma ferramenta indispensável para a organização dos serviços na área de saúde bucal do trabalhador, sobretudo na elaboração de programas preventivos, tendo em vista a qualidade de vida e a força de trabalho.

Na condução desse processo, Matos e Floriano (2011) consideram necessário:

- Compreender a multidimensionalidade do processo saúde-doença, identificando os determinantes sociais das doenças,o comportamento humano, valores e atitudes relacionados à saúde bucal como saberes fundamentais para as ações de promoção de saúde;

- Aceitar outras fontes de saberes (crenças, mitos, religião, senso comum) como conhecimentos válidos para melhor compreender as atitudes das pessoas relacionadas à saúde bucal; 
- Desenvolver práticas de educação e atenção em saúde pautadas na salutogênese, ou seja, em motivar as pessoas a buscar comportamentos saudáveis, não apenas com a perspectiva de evitarem doenças, mas também de alcançarem qualidade de vida e sensação de bem-estar;

- Aprofundar as evidências científicas na compreensão dos determinantes psicossociais do processo saúde-doença bucal e do impacto das condições bucais sobre a qualidade de vida das pessoas/população;

- Fortalecer a voz da comunidade frente às forças estruturantes que afetam a sua saúde.

\section{Interseções entre o processo saúde-doença, os modelos de atenção em saúde e as práticas de educação em saúde}

Para se entender a construção histórica da necessidade de ações educativas no campo de saúde, bem como as diferentes concepções e estratégias de educação adotadas, será feita uma abordagem de alguns marcos históricos que refletem as diferentes concepções do processo saúde-doença e a evolução dos modelos de atenção em saúde, buscando-se compreender, no cenário atual, a emergência da educação em saúde como ação prioritária nas políticas públicas de saúde.

\section{Concepções acerca do processo saúde-doença}

As civilizações antigas conviveram com o processo saúde-doença, compreendendo-o como fenômeno mágico-religioso,de modo que as formas de intervenção eram pautadas nos rituais de magia e feitiçaria, no uso de plantas medicinais e nas práticas de massagens, banhos e sangrias. (CARVALHO; MARTINS, 1998; OLIVEIRA; EGRY, 2000) É preciso considerar que muitas dessas práticas persistem até os dias de hoje, e que muitas delas foram desenvolvidas e ainda se configuram como tentativas de sobrevivência diante da exclusão social aos cuidados médicos, e não somente como resultantes de manifestações culturais ou religiosas. Daí, a necessidade de uma imersão cotidiana nos "saberes populares" em saúde.

A partir dos avanços científicos, a medicina moderna se expandiu no século XIX, marcada pelo desenvolvimento das ciências básicas como a anatomia, a fisiologia, a patologia e a microbiologia, bem como, pelo desenvolvimento das 
vacinas. O corpo humano era comparado a uma "máquina" e importava conhecer o homem de perto e entender o funcionamento de cada parte do seu corpo. Com base nesses conhecimentos, nasce o conceito biomédico, a partir do qual a determinação das doenças está fundamentalmente pautada em fatores externos ao corpo (microorganismos) ou têm origem em mudanças internas involuntárias como os desequilíbrios químicos ea predisposição genética. (CARVALHO; MARTINS, 1998; OLIVEIRA; EGRY, 2000) Nesse contexto a doença é percebida como um mau funcionamento de partes do corpo humano e a saúde é considerada como a ausência de sinais e sintomas. (OGDEN, 2004)

Como o discurso biologicista reduz o processo saúde-doença à dimensão individual, ele propaga que grande parte dos problemas de saúde bucal é decorrente da falta de higiene e, sendo assim, é possível resolvê-los a partir da mudança de comportamentos individuais. Diante dessa perspectiva, as práticas de educação em saúde são pautadas em discurso autoritário de prescrição de regras de higiene. (ALVES, 2005)

Tradicionalmente, os estudos sobre as condições de saúde bucal das populações humanas, abordavam aspectos biológicos e comportamentais, enfatizando os fatores individuais como determinantes das principais doenças bucais. (MATOS; FLORIANO, 2011) Esse referencial biomédico passa, então, a nortear os modos de intervenção ou modelos de atenção em saúde no mundo ocidental. No Brasil, o modelo de atenção hegemônico passa a ser o médicoassistencial privatista, o qual valoriza a atenção individual, voltado para uma demanda espontânea e focado na doença.

A exclusão provocada por esse modelo, no setor público, deu-se pelo fato do direito à assistência ter sido concedido somente aos trabalhadores contribuintes da Previdência Social, deixando à margem desse sistema o restante (maioria) da população. No setor privado, essa exclusão é intrínseca à barreira socioeconômica imposta aos que não podem pagar pelos serviços de saúde. Mas, tanto no setor público como no privado, esse modelo contém um traço excludente em comum: não consegue alcançar os indivíduos ou grupos populacionais para prevenção e controle de doenças ou mesmo, para a manutenção da saúde. Por essas e outras razões, esse modelo não consegue alterar significativamente os níveis de saúde da população. (PAIM, 2003)

Cabe ressaltar que esse modelo ainda é hegemônico não apenas em função do olhar biomédico, reforçado na própria formação acadêmico-científica, como também pela mercantilização da saúde, uma vez que o setor privado da saúde 
ainda se fortalece a partir dos procedimentos curativos. Aliás, a existência desses dois modelos não é coincidência histórica, eles se complementam: quanto mais doenças, maior o gasto em saúde; daí, o foco sobre a doença e não propriamente na defesa da vida.

No modelo biomédico, o referencial para a prevenção de doenças e educação em saúde é permeado por um discurso focado apenas no autocuidado e na culpabilização dos sujeitos que não seguem as regras prescritas, já que o contexto de vida é subestimado, tanto em razão do olhar biomédico como pelos traços neoliberais de sociedade, que colocam apenas no indivíduo a responsabilidade "ou culpa" pelo seu estado de saúde.

Entretanto, estudos passam a contestar o impacto das ações médicas nos níveis de saúde da população. Dentre estes, o Relatório Lalonde é considerado um marco histórico para a mudança de perspectivas quanto à determinação das doenças e os modos para o seu enfrentamento. O conceito de "campo da saúde", proposto por Lalonde, marca o surgimento das primeiras propostas alternativas de modelos de intervenções estatais na saúde das coletividades.

O Relatório Lalonde é fruto de um estudo realizado na década de 1970, no Canadá, o qual fundamentou o esquema quadridimensional de Lalonde. Este considera o estilo de vida, a biologia humana, o ambiente e os serviços de saúde, como os quatro determinantes do nível de saúde do povo canadense. Concluiu-se, a partir desse estudo, que a melhoria dos níveis de saúde no Canadá, dependeria muito mais de ações sobre o estilo de vida e o meio ambiente e de novos conhecimentos sobre a biologia humana do que da melhoria e expansão da rede de hospitais e outros serviços de saúde. Na dimensão estilo de vida, compreende-se que o comportamento do indivíduo em seu cotidiano, nos seus microambientes, é dependente ou influenciado em grande parte por fatores sociais, culturais e psicológicos, representando dimensão fundamental para a análise da sua saúde. (CHAVES, 1998)

A partir do lançamento dessa proposta de promoção de saúde, têm sido organizadas as conferências internacionais de saúde, com a proposta de discutir e nortear as políticas públicas de saúde nos diferentes países do mundo.

A I Conferência Internacional sobre Promoção da Saúdetem sido referida como uma das mais importantes iniciativas que delineou discussões voltadas para um novo movimento mundial da saúde pública e, a despeito da importância das diretrizes contidas em todos os documentos das demais conferências, a 
Carta de Ottawa foi um marco importante no estabelecimento do conceito de promoção de saúde.

De acordo com esse documento, promoção de saúde é conceituada como “[...] processo de capacitação da comunidade para atuar na melhoria da sua qualidade de vida e saúde, incluindo uma maior participação no controle desse processo [...]”. Assim, a promoção de saúde não é responsabilidade exclusiva do setor saúde, e vai além de um estilo de vida saudável. Nesse sentido, são considerados pré-requisitos para a saúde: paz, habitação, educação, alimentação, renda, ecossistema estável, recursos sustentáveis, justiça social e equidade. (BRASIL, 1996)

Para muitas doenças que afetam as populações, o instrumental científicotecnológico, por si só, não é suficiente para responder a alta complexidade que as envolve. Assim, emerge o desafio de se pensar a saúde sob a ótica do desenvolvimento e da condição humana, porque evidências têm mostrado que a saúde está muito mais relacionada com o modo de viver das pessoas do que com os fatores biológicos e genéticos. O sedentarismo, a alimentação não saudável, o consumo de álcool, tabaco e outras drogas, o frenesi da vida cotidiana, a competitividade, e o isolamento do homem nas cidades são condicionantes diretamente relacionados à produção das doenças modernas. (BRASIL, 2010)

A saúde passa a ser compreendida não apenas como a mera ausência de doenças, mas como resultante de um conjunto de fatores individuais e coletivos, sociais, econômicos, étnicos, religiosos, culturais, psicológicos, laborais, biológicos e ambientais. Desse modo, o cuidado com a saúde na atualidade não é mais compreendido como uma ação exclusiva dos profissionais da área de saúde (BRASIL, 1996), ou tampouco focado na atenção individual.

No século XX, com o desenvolvimento da noção de multicausalidade nas abordagens teóricas e conceituais sobre causa em saúde, incorporaram-se aspectos psicossociais na explicação do fenômeno saúde-doença em odontologia. (FREIRE, 2001; LACERDA, 2005; VASCONCELOS, 1999) Dessa forma, acredita-se que a estrutura, o contexto social e o modo de vida, entendidos como qualidade de vida, influenciam diretamente o nível individual de saúde bucal. (MATOS; FLORIANO, 2011)

Essas novas abordagens, ao longo do século XX, fizeram emergir a medicina psicossomática, e mais recentemente, a psicologia da saúde. A medicina psicossomática desenvolveu-se a partir de observações e estudos de Freud, nos quais ele afirmava que experiências e sentimentos reprimidos eram expressos sob 
a forma de um problema físico. A psicologia da saúde se sustenta no modelo biopsicossocial, desenvolvido por Engel no final da década de 1970 e, diferente do modelo biomédico, esse modelo representa uma busca de interação entre os determinantes biológicos, psicológicos e sociais, sugerindo que os seres humanos devem ser vistos como sistemas complexos e que a doença é causada por uma multiplicidade de fatores. De acordo com a psicologia da saúde, se a saúde e a doença são vistas como uma associação de fatores, o individuo já não é compreendido como uma vítima passiva da doença. Reconhecer o papel do comportamento na sua origem, como por exemplo, o ato de fumar, significa que os indivíduos podem ser corresponsáveis pelo seu estado de saúde e suas doenças. (OGDEN, 2004)

Para assumir essa corresponsabilidade, entretanto, é imprescindível que os sujeitos tenham acesso à informação e educação em saúde, bem como às condições financeiras, políticas e ambientais para o exercício desse papel.

\section{Educação em saúde nas políticas públicas}

Um dos pressupostos das Diretrizes da Política Nacional de Saúde Bucal é centrar a atuação na vigilância à saúde, incorporando práticas contínuas de avaliação e acompanhamento dos danos, riscos e determinantes do processo saúde-doença. Assim, o modelo assistencial centrado na doença e baseado no atendimento a quem procura evolui para um modelo de atenção integral à saúde, onde haja a incorporação progressiva de ações programáticas de promoção, proteção e recuperação. (BRASIL, 2004a)

A Carta de Ottawa propõe cinco campos de ação para se intervir na perspectiva da promoção de saúde: (1) implementação de políticas públicas saudáveis; (2) criação de ambientes saudáveis; (3) capacitação da comunidade; (4) desenvolvimento de habilidades individuaise coletivas; e (5) reorientação dos serviços de saúde. (BRASIL, 1996)

Tratando-se da criação de ambientes saudáveis, advoga-se que existem elos indissolúveis entre a população e o seu meio, e esses constituem a base para uma abordagem socioecológica da saúde. Ressalta-se que a maneira como a sociedade organiza o trabalho deveria ajudar a criar uma sociedade saudável e que as ações de promoção da saúde devem gerar condições de vida e de trabalho seguros, estimulantes, satisfatórios e agradáveis. (BRASIL, 1996)

Observa-se que dentre os cinco campos de ação, a capacitação da comunidade e o desenvolvimento de habilidades individuais e coletivas requerem a in- 
corporação de ações educativas, sejam elas voltadas para o autocuidado ou para a educação popular, tendo em vista a melhoria da qualidade de vida e saúde.

Tais ações referem-se a processos educativos e políticos que visam, tanto o empoderamento (empowerment) das comunidades no estabelecimento de prioridades, tomada de decisões, planejamento e implementação de estratégias com o objetivo de atingir um melhor nível de saúde, como a capacitação dos sujeitos para o desenvolvimento pessoal que os habilite para uma vida saudável. (BRASIL, 1996)

Desse modo, além da compreensão de educação em saúde como instrumento de orientação e motivação individual voltado para o autocuidado, o Relatório Final da $3^{\text {a }}$ Conferência Nacional de Saúde Bucal (BRASIL, 2004b), aponta que a educação em saúde deve ser considerada: (1) como meio para o reconhecimento da população de que a "saúde é direito de todos e dever do Estado"; (2) como instrumento de transformação social; (3) como instrumento de formação para uma nova cultura política de participação popular e de exercício de cidadania, de forma individual ou coletiva; e (4) como meio de fortalecimento do controle social do SUS.

Essa abordagem exige a mobilização da educação como instrumento capaz de proporcionar a formação do homem como agente de mudança; crítico, criativo, reflexivo; e capaz de assumir no conjunto das lutas sociais a sua condição de agente ativo de transformação da sociedade e de si próprio, na conquista de direitos e justiça social e na adoção de novas práticas de interlocução, participação e articulação das ações para além dos espaços institucionais. (BRASIL, 2004b)

Na perspectiva do autocuidado, a educação em saúde bucal é compreendida como "ações que objetivam a apropriação do conhecimento sobre o processo saúde-doença incluindo fatores de risco e de proteção à saúde bucal, assim como a possibilitar ao usuário mudar hábitos apoiando-o na conquista de sua autonomia". (BRASIL, 2004a, p. 9) Assim:

A educação em saúde bucal deve fornecer instrumentos para fortalecer a autonomia dos usuários no controle do processo saúde-doença e na condução de seus hábitos. Sua finalidade é difundir elementos, respeitando a cultura local, que possam contribuir com o empoderamento dos sujeitos coletivos, tornando-os capazes de autogerirem seus processos de saúdedoença, sua vida, com vistas à melhoria da sua qualidade de vida.(BRASIL, 2006, p. 25) 
Ao trabalhar a educação em saúde com indivíduos ou grupos comunitários não se deve esquecer a leitura que cada pessoa faz sobre si mesmo e sobre o mundo. É como sinaliza Paulo Freire (1996): o desrespeito à leitura de mundo feita pelo educando revela um comportamento antidemocrático do educador porque evidencia um desrespeito à inteligência das pessoas, as quais se constroem social e culturalmente. Além disso, desconsidera que as pessoas só se motivam para aprender novos conhecimentos e adotar atitudes que julgam úteis para a sua vida quando ambos estão de acordo com o seu jeito de ser e estar no mundo. Essa compreensão coloca o diálogo como elemento estruturante do processo educativo, uma vez que é impossível educar sem exercitar a escuta do outro, sem estabelecer uma ação comunicativa entre educador e educando, na qual ambos são agentes que, simultaneamente, ensinam e aprendem.

Nesse sentido, alguns aspectos importantes são recomendados ao se planejar a educação em saúde bucal (BRASIL, 2006, p. 26):

- $\quad$ Respeito à individualidade;

- Contextualização nas diversas realidades, incluindo as possibilidades de mudança;

- Respeito à cultura local;

- Respeito à linguagem popular para encaminhar uma construção conjunta da prática;

- Ética;

- $\quad$ Autopercepção de saúde bucal;

- Reflexão sanitária: o processo de educação em saúde deve capacitar os usuários para participar das decisões relativas à saúde;

- Uso de metodologias adequadas a cada situação e a cada grupo etário.

A Figura 1 traz uma visão esquemática das diretrizes apontadas pelas políticas públicas de saúde, as quais podem nortear as ações de educação em saúde no âmbito do SUS. Entretanto, considerando-se que o modelo hegemônico de educação é apenas focado no autocuidado, com práticas educativas autoritárias e prescritivas (ALVES, 2005), torna-se evidente o tamanho do desafio a ser enfrentado pelo SUS no sentido de legitimar as práticas de educação baseadas nessas diretrizes. 
Figura 1 - Diretrizes das políticas públicas de educação em saúde segundo os documentos oficiais

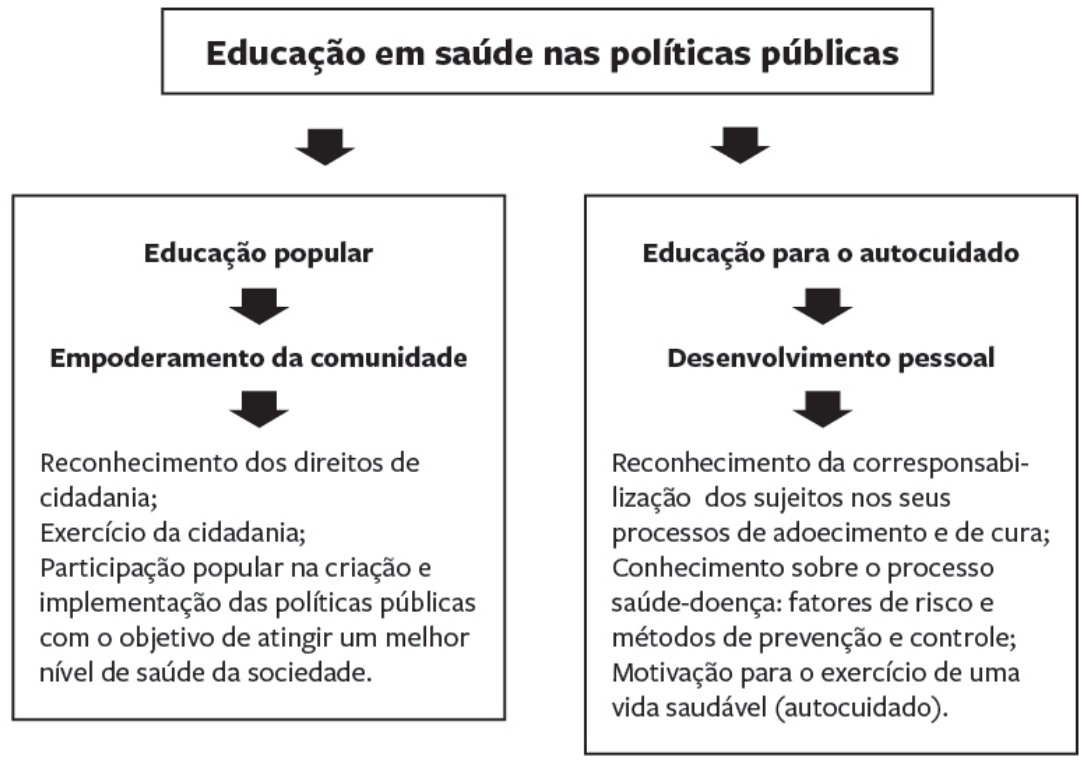

Fonte: Elaboração das autoras.

Observa-se que, no âmbito das políticas públicas, a educação em saúde vem sendo apontada como um importante instrumento para a consolidação do SUS. Os conceitos de educação incorporados no discurso oficial, bem como as diretrizes ou recomendações apontadas para nortear as práticas de educação em saúde, buscam superar o modelo tradicional de se pensar a educação e de se organizar as estratégias de intervenção, pautadas nas pedagogias tradicionais. A negação desse referencial vem dando lugar a propostas baseadas nas pedagogias críticas, as quais possibilitam o desenvolvimento de práticas educativas participativas que valorizam os saberes tácitos, a cultura e a autonomia dos sujeitos.

Entretanto, um dos grandes desafios para a consolidação dessa proposta se refere à compreensão que a grande maioria dos profissionais de saúde tem acerca do fazer educativo. Além da falta de valor atribuído a essa atividade, as concepções e práticas predominantes se baseiam nas pedagogias tradicionais. A educação permanente dos profissionais inseridos nos serviços de saúde e a ampla incorporação conceitual e prática dessa temática nos processos de 
formação profissional podem ser um caminho para a legitimação das políticas públicas de educação em saúde.

\section{Abordagens pedagógicas e práticas de educação em saúde}

Ainda que muitos de nós, ao realizar uma atividade educativa, não tenhamos consciência de que adotamos uma tendência pedagógica, para Bordernave (1983), todos os processos educativos têm por base uma determinada abordagem pedagógica. Ou seja, uma concepção de como se consegue fazer para que as pessoas aprendam alguma coisa e, a partir daí, possam fazer escolhas mais saudáveis, ainda que pese a força dos determinantes sociais em saúde.

Ao abordar os referenciais das práticas de educação em saúde para o Programa de Saúde da Família, Alves (2005), apesar de reconhecer a existência de modelos intermediários, apresenta dois modelos extremos: o tradicional e o hegemônico. O primeiro é focado na doença e no referencial biologicista, emprega estratégias educativas que valorizam as informações verticalizadas para ditar os comportamentos das pessoas, sendo o saber científico incorporado ao processo educativo com status de verdade. A autora argumenta que a principal crítica a esse modelo se refere à falta de consideração dos determinantes psicossociais e culturais dos comportamentos em saúde, perdendo-se de vista que as pessoas agem com as suas crenças, valores e representações do processo saúde-doença. Em oposição a esses referenciais, busca-se consolidar o modelo dialógico, no qual o usuário do serviço é reconhecido como um sujeito portador de um saber e que o papel da educação é reconhecer e transformar esses saberes, defendendo o protagonismo dos sujeitos e a sua responsabilidade no cuidado com a saúde. O diálogo é o instrumento pelo qual ocorre o intercâmbio entre os saberes técnico-científicos e os saberes populares, de modo a produzir-se um saber partilhado entre os profissionais de saúde e os usuários dos serviços, possibilitando a esses uma maior apropriação dos conhecimentos e a incorporação de novas atitudes favoráveis à saúde.

Assim, o planejamento de programas de educação em saúde requer uma discussão crítica dos referenciais pedagógicos tradicionais, buscando um modelo dialógico, no qual os educandos sejam abordados como sujeitos do processo educativo e não como meros receptores de conhecimentos. Para Freire (2005), o nosso papel não é falar ao povo sobre a nossa visão de mundo tentando impor a ele os nossos conteúdos que pouco têm a ver com os seus anseios, dúvidas, esperanças e temores. Conteúdos que, às vezes, aumentam os temores de uma 
consciência oprimida. O nosso papel é dialogar com ele sobre a sua e a nossa visão de mundo, entendendo que a ação educativa não pode prescindir do conhecimento crítico da realidade, da situação de mundo dos sujeitos porque, de outro modo, estaremos pregando no deserto.

Nessa perspectiva, estratégias que envolvem pedagogias críticas devem ser priorizadas, tais como: rodas de conversa, mesas demonstrativas interativas, oficinas de desenho, peças teatrais ou teatro de fantoches com textos produzidos a partir de um diagnóstico situacional dos grupos envolvidos, dentre outras. As rodas de conversa, inspiradas em Paulo Freire, permitem a horizontalidade na relação educador-educando e a circularidade da informação, de modo que, tanto os saberes populares quanto os saberes científicos, são importantes no processo de aprendizagem e na corresponsabilização com os cuidados necessários à saúde.

\section{Práticas de educação em saúde}

Os Cadernos de atenção básica apontam os conteúdos gerais a serem abordados nas ações coletivas de educação em saúde bucal. Destaca-se a seguir aqueles de interesse para os adultos: (1) conhecimento sobre as principais doenças bucais, como se manifestam e como se previnem; (2) a importância do autocuidado, da higiene bucal, da escovação com dentifrício fluoretado e o uso do fio dental; as orientações gerais sobre dieta; (4) a orientação para autoexame da boca; (5) a prevenção à exposição ao sol sem proteção; e, (6) a prevenção ao uso de álcool e fumo. (BRASIL, 2006)

Tais conteúdos devem ser pedagogicamente trabalhados, preferencialmente de forma integrada com outras áreas da saúde e podendo ser desenvolvidos na forma de debates, oficinas de saúde, vídeos, teatro, conversas em grupo, cartazes, folhetos e outros meios. (BRASIL, 2004a)

É importante compreender que, a despeito da importância de se trabalhar esses conteúdos, as ações de educação em saúde bucal não devem estar voltadas apenas para orientar as pessoas sobre as doenças e as diferentes formas de prevenção, mas também para estimulá-las a refletir sobre qual o valor que elas atribuem a sua saúde bucal, dentro do seu contexto de vida. Ajudá-las a refletir sobre os diferentes papéis que a boca exerce em suas vidas (alimentação, comunicação, estética facial, sexualidade, expressão de afetividade, por meio do beijo, e de felicidade, pelo sorriso) e que, em função disso, merece toda a nossa atenção e cuidado. 
As ações educativas não devem ser focadas apenas nas doenças, mas, também, nas possibilidades de prazer e bem-estar que uma boca saudável é capaz de nos proporcionar. Isso pode ser melhor compreendido a partir do pressuposto de que a motivação para o autocuidado é mais válida quando trabalhamos com estímulos que despertem pensamentos positivos (autoestima, bem-estar, prazer, aparência) do que quando optamos por despertar sentimentos negativos como o medo de contrair doenças e sofrer as suas sequelas. Segundo Martins (1998), os motivos que conduzem cada pessoa a cuidar dos seus dentes e da sua boca são internos ao indivíduo e dizem respeito ao seu desejo de ser socialmente aceito, de ser bonito e de cheirar bem.

Desse modo, para se planejar ações de educação em saúde bucal, é pertinente questionar: o que motiva as pessoas a viverem de modo mais saudável? Conhecer esses motivos pode apontar pistas importantes para o planejamento das ações educativas, uma vez que possibilita construir estratégias com base em motivações já explicitadas pelos educandos.

Sawazaki e Nakama (1997) buscaram identificar os motivos pelos quais a população procura o atendimento odontológico. Com essa finalidade, avaliaram 433 pais de crianças de o a 14 anos atendidos nas unidades básicas de saúde de Londrina, Santa Cantarina, os quais citaram como principais motivos: a estética (41\%), a saúde (29\%), evitar dor (15\%), preservar um hálito puro (9\%), higiene (4\%) e evitar gastos (2\%).

Ao pesquisar sobre as razões pelas quais 1.035 adolescentes de escolas públicas e privadas, na faixa etária de 10 a 19 anos, limpam os seus dentes, Matos e colaboradores (2009) registraram que 54,8\% das respostas estavam associadas à prevenção de cáries; 33,2\%, à intenção de ter um bom hálito; 19,7\%, de ter uma boa estética; e 3,3\%, para facilitar o convívio social.

Dessa forma, cada grupo com o qual se trabalha será sempre único, sendo necessário levantar suas crenças, demandas, valores, desejos, e não apenas as suas necessidades objetivas em saúde. Todas essas informações farão parte do substrato sobre o qual se planejará as ações educativas, uma vez que tais ações precisam ter/fazer sentido não apenas para o "educador”, mas sobretudo para os educandos. Para alguns grupos, "ter saúde bucal” pode estar mais atrelado aos fatores psicossociais das relações interpessoais, como ter um "hálito agradável" ou "sorriso bonito"; para outros; o "não ter dor" pode ser o mais impactante. Enfim, é preciso auscultar essas subjetividades, já que a educação não se dá apenas pela capacidade cognitiva, mas também pelos afetos, por aquilo que 
"nos afeta”. Há que se ressaltar aqui todo o cuidado ético que isso implica. A exploração do mundo das subjetividades como ponto de partida precisa ter assegurado o respeito aos sentimentos do outro, já que as perdas em saúde bucal têm muito a ver com vários tipos de perdas e barreiras interpostas pela vida. Em se tratando da população adulta, trabalhadora, muitas ausências podem se revelar na precariedade da saúde bucal.

Abordando os desafios da comunicação em saúde do trabalhador, Rangel (2004) questiona sobre como devemos fazer para que as informações trabalhadas ganhem para os educandos o sentido de compreensão que desejamos alcançar. De acordo com a autora, a comunicação é um fenômeno de expressão, interação e diálogo entre sujeitos, mediante a qual se produz os fenômenos da vida cotidiana. Desse modo, o primeiro passo é buscar compreender o sentido que o outro lhe deu, ou seja, como são interpretadas as orientações dadas aos trabalhadores em atividades educativas? Que significados eles atribuem à saúde, à doença, à prevenção, à promoção e às próprias ações educativas? Como eles reinterpretam e apreendem as orientações recebidas?

Compreender essa dinâmica da comunicação em saúde requer a avaliação continuada das ações educativas, buscando-se a melhoria dos resultados mediante uma maior proximidade entre as expectativas do educador e o que, de fato, os educandos conseguem atribuir em termos de significados e de valores, incorporando-os ao seu cotidiano.

Finalmente, é preciso considerar, ainda no universo das subjetividades, as raízes mais profundas da persistência dos fatores de risco. O fazer na educação em saúde, pensado numa dimensão mais humanizada, mais do que competente no sentido de esclarecer e informar, precisa adotar uma função de "apoio", para o qual se faz necessário o "vínculo". Nesse sentido, Campos (2003) defendeque o vínculo depende não somente da "disposição" dos profissionais de saúde, como também de conhecimentos sobre a inter-relação entre as pessoas, do modo como se dão os processos de "transferências", sendo também seu papel o "ajudar a se ajudar". E isso envolve identificar a rede de apoio possível em cada caso. No sentido da superação, comenta que "somente quando se sente apoiado é que se mostra seguro para arriscar alguns passos por conta própria". Depreende-se daí que educação em saúde seja um processo e não uma sucessão de "atividades educativas", na compreensão antiga das prescrições de bons comportamentos, que não chamam o "educador" para o enfrentamento, mas apenas o educando. 
No contexto da educação em saúde bucal do trabalhador, cabe perguntar: em que medida a equipe de saúde pode contar com (ou vir a construir) bases mais consistentes para se realizar essa função de "apoio" nas empresas? Será que nossos profissionais de saúde estão sensibilizados para esse papel? Ou seja, mais humanizado? Sem isso, talvez não faça muito sentido se pensar em educação em saúde no ambiente de trabalho, pois certamente uma série de condições emerge como necessária para a "criação dos ambientes saudáveis". Para muito além do universo das "informações", há que se pensar nas condições estruturais, físicas, mais tangíveis, até naquelas mais sutis, que passam mesmo pela qualidade do viver nesse ambiente onde o ser humano passa (ou gasta?) considerável parte da sua vida e onde talvez deposite sua maior parcela de energia.

\section{Proposições para educação em saúde}

Ao tratar a temática da educação em saúde, seja com grupos de graduação, de pós-graduação ou de educação permanente, é comum identificar-se como expectativa dos estudantes ou profissionais, o aprendizado de um modelo estruturado de prática, algo que seja facilmente reproduzido em suas atividades disciplinares ou em seus contextos de trabalho. Ainda que a apresentação de estratégias educativas ou relatos de experiências exitosas possam ser referências para o nosso "fazer educativo", cada contexto de prática tem as suas peculiaridades. Mesmo trabalhando com a abordagem por ciclo de vida, cada indivíduo ou cada grupo tem as suas particularidades (doenças mais prevalentes, fatores de risco específicos, crenças, valores, motivações). Além disso, cada um interpreta os seus problemas de saúde de forma diversa e os reinterpretam dando significados singulares às informações e orientações vinculadas às práticas educativas.

De acordo com Ferreira e colaboradores (2004), os programas de educação em saúde para adultos podem ser mais eficazes se forem considerados os seguintes aspectos:

- Envolvimento da equipe de saúde bucal no processo educativo;

- As atividades educativas devemconsiderar a determinação social dos problemas bucais e apresentar uma visão dinâmica do processo saúde-doença, buscando relacionar o autocuidado e a autonomia com a elevação da qualidade de vida; 
- Os educadores devem estar cientes da necessidade de motivação contínua dos educandos;

- As orientações para higiene bucal não devem ser pautadas na imposição de técnicas padronizadas, nem tampouco na prescrição de materiais dispendiosos para a higienebucal;

- O processo educativo deve ser continuado no decorrer do tratamento, e os profissionais podem conjugar a atenção individualizada às práticas em grupo;

- As metas a serem alcançadas devem ser realistas para que não causem frustração aos profissionais e sensação de incapacidade aos educandos;

- As atividades de educação para a saúde requerem do profissional a busca de estabelecimento de vínculo com os indivíduos, de modo a evitar a emergência de fatores que criem barreiras de comunicação;

- A linguagem deve ser clara e adequada a cada indivíduo ou grupo populacional.

Muito mais do que elaborar uma proposta padronizada para a organização de ações educativas na área de saúde, destaca-se a importância de educar os profissionais na perspectiva de que eles possam internalizar o processo educativo como um espaço de diálogo no qual os saberes científicos possam abrir espaços para os saberes da vida, uma vez que, no final das contas, são eles que ditam os comportamentos das pessoas em seu cotidiano.

Nesse sentido, o primeiro passo para o estabelecimento de programas de educação em saúde, numa perspectiva coletiva, é realizar um levantamento dos aspectos biopsicossociais e ambientais do grupo com o qual desejamos mediar o processo educativo. Segue-se a isso o planejamento das ações e a avaliação do processo, tendo em vista a sua melhoria, conforme demonstrado na Figura 2. 
Figura 2 - Planejamento de ações educativas

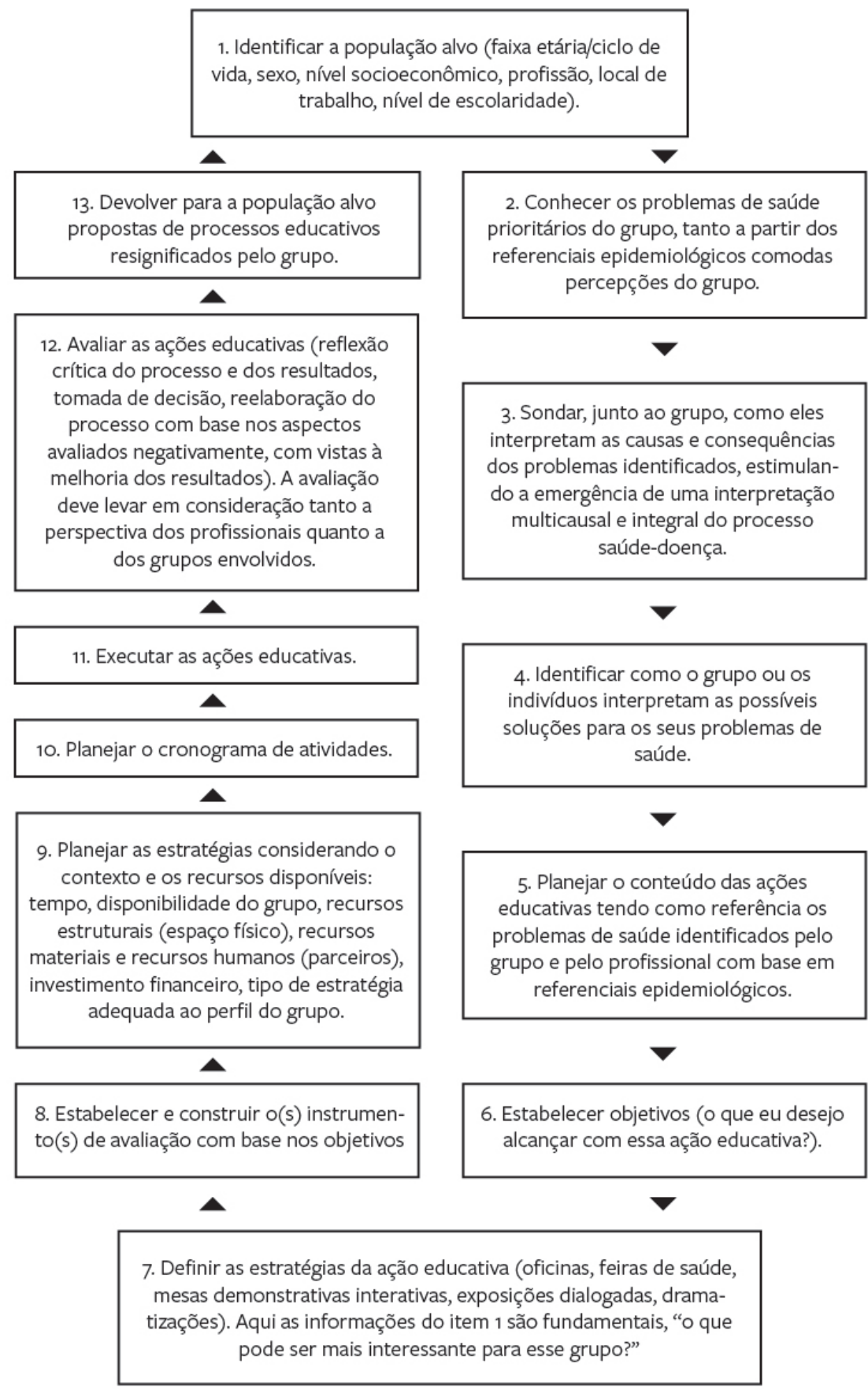

Fonte: Elaboração das autoras. 


\section{Estratégias de educação em saúde bucal do trabalhador}

$\mathrm{Na}$ área de saúde do trabalhador, busca-se avanços além da saúde do próprio trabalhador, visa-se integrá-lo com o ambiente, com o homem dignificado e satisfeito com a sua atividade, que tem vida dentro e fora do ambiente de trabalho e que almeja qualidade de vida. A partir desses pressupostos, as atividades de educação em saúde do trabalhador assumem fundamental relevância, devendo ir além dos programas de prevenção e campanhas para usos de equipamento de proteção individual com o intuito de atender a legislação vigente. Tornam-se essenciais as intervenções educativas que educam em um sentido mais amplo, que tenham um caráter humanitário, que colaborem para o empoderamento e autonomia em saúde, e em última instância produzam verdadeiramente bem-estar e valorização dos indivíduos. (OLIVEIRA, 2001) Vale lembrar que o desenvolvimento de programas de educação em saúde do trabalhador é atribuição de toda a equipe de saúde inserida nos serviços públicos da atenção básica no país. (BRASIL, 2002a)

As intervenções educativas em saúde bucal do trabalhador devem ser planejadas de acordo com os princípios da saúde do trabalhador. Ademais, deve-se considerar que o grupo populacional que exerce alguma atividade laboral, além de ser exposto aos fatores de risco comuns para os problemas bucais na população em geral, como a placa bacteriana e a higiene bucal inadequada, também está em contato direta ou indiretamente com outros fatores de risco ocupacionais, como a exposição a substâncias químicas, agentes físicos, mecânicos e radiações que aumentam ainda mais a probabilidade da ocorrência de lesões nos tecidos bucais. Assim, os trabalhadores devem ser olhados como indivíduos que estão sujeitos a um adoecimento específico e que exigem estratégias específicas de promoção, proteção e recuperação da saúde. (BRASIL, 2002a)

Essas estratégias devem ser planejadas e executadas com foco nos riscos ocupacionais específicos das atividades laborais. Assim em uma mostra de saúde cujo público alvo é constituído por salva-vidas, a abordagem do câncer de boca é pertinente, já que a radiação solar aos quais eles são expostos está associada com o surgimento de neoplasias, especialmente de lábio. Para essa intervenção, podem ser realizadas mesas demonstrativas, orientação sobre o autoexame bucal e também exames bucais a fim de se realizar uma triagem de indivíduos que possam apresentar esse problema bucal que pode levar à morte.

As estratégias de educação em saúde bucal, sempre que possível, devem possuir um caráter interdisciplinar, por meio das quais profissionais de dife- 
rentes áreas da saúde podem abordar os mais diversos temas, como: hipertensão, diabetes, acuidade visual, cárie dental, doença periodontal, câncer bucal, dentre outros.

\section{Considerações finais}

Os educadores em saúde devem considerar a realidade do indivíduo/comunidade, utilizando o diálogo como ponto de partida. Isso exige o abandono de posturas autoritárias, tanto profissionais como pessoais. Devem, ainda, considerar que, por trás de uma boca da qual ele está falando, existe uma pessoa, com uma história de vida, com um perfil psicológico e com uma inserção socioeconômico-cultural. Portanto, não basta informar e cobrar mudanças comportamentais apenas a partir das informações dadas.

O aprendizado é significativo quando o educando é respeitado em seus conhecimentos, percepções, crenças, valores, ideias, esperanças, expectativas e sentimentos. Por mais que consideremos os conhecimentos científicos importantes para a compreensão do processo saúde-doença e dos métodos de prevenção, as pessoas, em seu cotidiano, agem de acordo com as suas vivências, construídas individual e socialmente. Portanto, o grande desafio para os educadores em saúde é reconhecer no processo educativo a necessária associação entre os saberes científicos e os saberes e vivências populares.

\section{Referências}

ALVES, V. S. Um modelo de educação em saúde para o Programa Saúde da Família: pela integralidade da atenção e reorientação do modelo assistencial. Interface - Comuncação, Saúde, Educação, Botucatu, v. 1, n. 16, p. 39-52, set. 2004/fev. 2005.

ARAÚJO, M. E.; MARCUCCI, G. Estudo da prevalência das manifestações bucais decorrentes de agentes químicos no processo de galvanoplastia: sua importância para área de saúde bucal do trabalhador. Odontologia e Sociedade. v. 2, n. 1/2, p. 20-25, set./dez. 2000.

BORDENAVE, J. E. D. Alguns fatores pedagógicos. Revista Interamericana de Educação de Adultos, v. 3, n. 1-20, 1983. (Texto traduzido e adaptado do artigo 'La transferencia de tecnologia apropriada al pequeño agricultor’ por Maria Thereza Grandi, OPAS, Brasília, 1983)

BRASIL. Ministério da Saúde.Carta de Otawa, Declaração de Adelaide, Sundsvall e Santa Fé de Bogotá. Trad. por Luis Eduardo Fonseca. Brasília, 1996. 
BRASIL. Ministério da Saúde. Cadernos de Atenção Básica. Programa Saúde da Família. Saúde do Trabalhador. n. 5. Brasília, 2002. 63p. Disponível em: <www.saude.gov.br>. Acesso em: 14 set. 2011.

BRASIL. Ministério da Saúde. Diretrizes da Política Nacional de Saúde Bucal. Brasília, 2004a. Disponível em: < http://bvsms.saude.gov.br/bvs/publicacoes/politica_nacional_brasil_ sorridente.pdf >. Acesso em: 27 ago. 2004.

BRASIL. Ministério da Saúde. Relatório Final da $3^{a}$ Conferência Nacional de Saúde Bucal: acesso e qualidade superando a exclusão social. Brasilia, 29/07 a 01/08, 2004b. Disponível em: < http://bvsms.saude.gov.br/bvs/publicacoes/3_conferencia_nacional_saude_bucal_ relatorio_final.pdf >. Acesso em: 27 nov.2004.

BRASIL.Ministério da Saúde. Cadernos de Atenção Básica. Programa Saúde da Família. n.17. Brasília, 2006. 92p. Disponível em: <www.saude.gov.br>. Acesso em: 14 set. 2011.

BRASIL. Ministério da Saúde. Política Nacional de Promoção da Saúde.. Brasília, DF, 2010. Disponível em: <http://bvsms.saude.gov.br/bvs/publicacoes/politica_nacional_promocao_ saude_3ed.pdf $>$. Acesso em: 9 jun. 2016.

CAMPOS, G. W. S. Saúde paideia. São Paulo: HUCITEC, 2003.

CARVALHO, C. L.; MARTINS, E. M. O. O significado da saúde e da doença nas sociedades: guia curricular para formação do atendente de consultório dentário para atuar na Rede Básica do SUS: área I e II, Brasília: Ministério da Saúde, 1998. p. 91 - 102.

CHAVES, M. Complexidade e transdisciplinaridade: uma abordagem multidimensional do setor saúde. Maio, 1998. Disponível em: <http://www.uesc.br/cpa/artigos/ transdisciplinaridade.pdf $>$ Acesso em: 18 ago.2004.

FERREIRA, R. I. et al.Dental health education for adult patients: report of an experience. Revista de Odontologia da UNESP. Marília, v. 33, n. 3, p.149-56, 2004.

FREIRE, M.C.M. Fatores psicossociais, cárie dentária e comportamentos em saúde bucal. Revista ABOPREV, v. 4, n.1, p. 21-28, jan./jun, 2001.

FREIRE, P. Pedagogia da autonomia:saberes necessários à prática educativa. 25. ed. São Paulo: Paz e Terra 1996.

FREIRE, P. Pedagogia dooprimido. 41. ed. Rio de Janeiro: Paz e Terra, 2005.

LACERDA, J.T. Impacto da saúde bucal na qualidade de vida.2005. 173 f. Tese (Doutorado em Medicina Preventiva)- Universidade de São Paulo, São Paulo. 2005.

MARTINS, E. M. Educação em saúde bucal: o desafio de uma prática. Caderno de Odontologia, v. 1, n. 2, p. 30-40, jan./jun. 1998.

MATOS, M. S. et al. Hábitos de higiene bucal e dieta de adolescentes de escolas públicas e privadas em Salvador, Bahia. Revista Brasileira de Ciências da Saúde, João Pesso, v.13, n. 2, p. 7-14, 2009.

MATOS, M. S; FLORIANO, F. R. Saúde bucal e qualidade de vida. PRO-ODONTO. Prevenção. Ciclo 4, módulo 3, p. 45-92, Rio de Janeiro, 2011. 
MAZZILLI, L. E. N. Odontologia do trabalho. São Paulo: Ed. Santos, 2003.

OGDEN, J. Psicologia da saúde. 2. ed. Lisboa: Climepsi Editores, 2004.

OLIVEIRA, M. A. C.; EGRY, E. Y. A historicidade das teorias interpretativas do processo saúde-doença. Revista da Escola de Enfermagem da USP, São Paulo, v. 34, n. 1, p. 9-15, mar. 2000 .

OLIVEIRA, SG. Proteção jurídica à saúde do trabalhador. 3. ed. rev., ampl. e atual. São Paulo: LTr, 2001.

PAIM, J. S. Modelos de atenção e vigilância da Saúde. IN: ROUQUAYROL, M. Z.;

In: ALMEIDA FILHO, N. Epidemiologia e Saúde. 6. ed. Rio de Janeiro: MEDSI, 2003. p. 567586. Capítulo 19.

RANGEL, M. L. Educação e comunicação em segurança e saúde do trabalhador. Módulo 6. Curso de Especialização a Distância em Saúde e Segurança no Trabalho. Programa de Educação Continuada em Saúde e Segurança no Trabalho. ISC-UFBA/ UNISESI. 2005

SAWAZAKI, I; NAKAMA L. Educação para a saúde bucal: trabalho em equipe e aspectos psicossoaiais. Semina. v. 8, n. esp., p. 15-24, 1997.

SANTANA. V. S.; SILVA, J. M. Epidemiologia e saúde do trabalhador no Brasil. In: ALMEIDA FILHO, N.; BARRETO, M. L. Epidemiologia e saúde. Rio de Janeiro: Guanabara Koogan, 2012.

VASCONCELOS, E. M. A priorização da família nas políticas de saúde. Saúde em Debate. v. 23, n. 53, p. 6-19, 1999. 


\section{A insuficiência da política pública para inclusão do técnico em saúde bucal na atenção primária no Brasil}

Dulce Maria de Lucena Aguiar

Paulo Frazão

\section{Apresentação}

O conhecimento científico de que um Cirurgião-Dentista (CD) pode dar assistência a uma porcentagem maior de usuários dos serviços odontológicos, conforme o número e o preparo do pessoal de nível técnico que compõe a sua equipe, quando comparado a um CD que trabalha sozinho, foi produzido desde a primeira metade do século XX. No que pese a ampla documentação, abrangendo vários países, sobre a relevância da participação do pessoal auxiliar na equipe de saúde bucal, tanto do ponto de vista da cobertura quanto da qualidade dos serviços e da redução dos custos, muitos programas odontológicos em serviços de atenção primária à saúde permanecem centrados na figura do CD. Uma importante iniciativa de política de saúde bucal no Brasil foi a aprovação de dispositivos normativos visando incentivar a incorporação do Técnico em Saúde Bucal (TSB) na Estratégia de Saúde da Família (ESF). Neste capítulo, sumarizamos a literatura brasileira sobre o tema e descrevemos os dispositivos normativos da política. Frente aos modestos efeitos alcançados, argumentamos pela sua reformulação. 


\section{Contextualizando o debate}

A publicação do Relatório mundial da saúde de 2006 reafirmou a importância da força de trabalho para que os sistemas de saúde produzam uma resposta mais efetiva diante dos graves e persistentes problemas que afetam a saúde das populações. São amplas as evidências de que o número e a qualidade dos trabalhadores estão positivamente associados à cobertura vacinal, extensão de cuidados primários e sobrevivência perinatal, infantil e materna. A aplicação efetiva dos recursos de cada sistema de saúde depende dos trabalhadores e de processos de gestão que assegurem melhorias quantitativas e qualitativas nas dimensões institucional, organizacional e funcional. Melhor desempenho da força de trabalho pode ser alcançado através da aplicação de duas regras cardinais para o aumento da efetividade das intervenções: simplificação e delegação. Uma abordagem em equipe é necessária não somente na gestão de indivíduos com doenças crônicas, mas no tratamento mais geral desses desafios de saúde pública. Usualmente, a prestação de cuidados em casos de doenças crônicas é mais bem realizada em esforço colaborativo. Os gargalos que impedem o alcance de objetivos de saúde nacionais e globais não serão superados sem o desenvolvimento de trabalhadores de saúde capazes, motivados e apoiados. (ORGANIZAÇÃO MUNDIAL DA SAÚDE, 2007)

Essas considerações se aplicam aos trabalhadores dos serviços odontológicos mantidos pelos sistemas de saúde. Desde as primeiras experiências envolvendo a higienista dental nos Estados Unidos, em 1913 (DUNNING, 1958), e a enfermeira dentária escolar na Nova Zelândia, na década de 1920 (FULTON, 1951), surgiu ampla documentação, abrangendo vários países, sobre a relevância da participação desse tipo de pessoal auxiliar na equipe de saúde bucal, potencializando a atuação dessa equipe, tanto do ponto de vista da cobertura quanto do ponto de vista da qualidade dos serviços e da redução dos custos. (FRAZÃO; GONZÁLES; ROSA, 1995; JOHNSON, 1992) A relevância a esse tipo de profissional está associada ao fato de poder executar a prestação direta de serviços aos usuários dos sistemas de saúde, liberando o CD para atividades mais complexas, evitando a fragmentação do trabalho e aumentando o grau de autonomia do TSB, o que possivelmente resultaria em maior impacto epidemiológico na redução da cárie e da doença periodontal. (CARVALHO, 1999)

Um estudo longitudinal de âmbito internacional examinou as tendências e mudanças na participação de higienistas dentais por meio de cinco inquéritos realizados entre 1987 e 2006, nos quais o número de países com informação so- 
bre o tema aumentou de 13 para 25. Ao longo do período de 19 anos, observou-se um aumento significativo da formação, acompanhado pela crescente melhoria nas razões higienista/população e higienista/CD em vários países, mantendo-se notavelmente consistente, mundialmente, o seu âmbito de prática clínica. Japão e Estados Unidos são os países com maior número de higienistas dentais (aproximadamente $200 \mathrm{mil}$ cada), seguidos pela Coreia do Sul (30.782 mil) e Canadá (18.350 mil). Em geral, notou-se aumento no interesse pela participação do higienista dental nas atividades de prestação direta de serviços clínicos e uma maior diversificação em termos de tipos de serviços e locais de prática. No que pesem algumas mudanças observadas, a evolução vem resultando em uma homogeneidade contínua na profissão no mundo todo. As tendências descritas têm implicações para a acessibilidade e a eficiência técnica dos serviços odontológicos e devem continuar a ser monitoradas. (JOHNSON, 2009)

A formação do técnico em saúde bucal varia de um país para outro, mas geralmente consta de um curso de dois anos realizado após a conclusão do ensino médio, diferindo em alguns países, onde a formação de higienistas pode avançar para funções expandidas e alcançar um período de três anos letivos.

Historicamente, higienistas dentais têm sido empregados como cuidadores de crianças em instituições governamentais, usualmente em programas executados nas escolas, mas, diante de mudanças demográficas e epidemiológicas, em vários países, sua participação tem sido direcionada também para adultos e idosos. (HOPCRAFT et al., 2011)

Existem evidências de que higienistas dentais prestam serviços seguros, de qualidade e eficazes, sendo geralmente bem aceitos pelo público que atendem. (GALLOWAY et al., 2004)

No Brasil, a participação do pessoal auxiliar na prestação direta de serviços teve início nos anos 1950 em atividades odontológicas realizadas em escolas e unidades básicas de saúde do Serviço Especial de Saúde Pública (SESP), mais tarde denominada de Fundação Nacional de Saúde. A limpeza dos dentes, a aplicação tópica de fluoretos e a educação em saúde eram atribuições dos auxiliares àquela época. (FRAZÃO; NARVAI, 2012)

Os altos índices de cárie dentária e de doença periodontal, os movimentos por direitos sociais, entre eles o direito à saúde, o desequilíbrio entre a demanda e a oferta de serviços de assistência odontológica e o desenvolvimento científico-tecnológico contribuíram para a expansão do emprego de pessoal auxi- 
liar nos serviços públicos odontológicos nas décadas de 1970 e 1980. Conforme Frazão, Gonzáles e Rosa (1995, p. 22),

[...] a participação deixa de localizar-se apenas em algumas instituições, como por exemplo, SESP e Instituto Nacional da Assistência Médica da Previdência Social (INAMPS), para expandir-se em direção a outras organizações públicas dos setores de saúde e de educação do país.

O argumento principal compartilhado por vários analistas em seminários e publicações é que, para melhorar os níveis de saúde bucal, dois objetivos estratégicos devem ser perseguidos: aumentar as medidas de prevenção de doenças e de promoção da saúde e capacitar auxiliares e técnicos em saúde bucal nos serviços odontológicos. Dado que os recursos são limitados, do ponto de vista da saúde pública, busca-se alcançar um equilíbrio entre a cobertura da população beneficiada e os tipos de serviços prestados nos programas de saúde. Como consequência, a participação de auxiliares e técnicos deve ser orientada, de forma coordenada, tanto para as atividades de promoção da saúde, cuja finalidade é diminuir a magnitude e a gravidade das doenças bucais, como para as atividades de tratamento ou assistência individual, cuja finalidade é aliviar o sofrimento e recuperar o dano provocado pelas lesões. (FRAZÃO; CASTELLANOS, 1999)

Frazão, na década de 1990, realizou uma pesquisa em 10 Sistemas Locais de Saúde (Silos) de cinco municípios do estado de São Paulo, com a finalidade de descrever algumas características do Pessoal Auxiliar em Odontologia (PAO) que trabalhava nesses Silos e analisar sua participação em programas municipais de saúde bucal. Nessa pesquisa, a expressão PAO fazia referência ao Técnico em Higiene Dental (THD) e ao Auxiliar de Consultório Dentário (ACD). Um questionário foi respondido por $75 \%$ dos ACD e THD dos municípios participantes da pesquisa.

Os resultados indicaram participação desse pessoal, tanto em atividades de promoção da saúde bucal como de assistência odontológica individual, variando a ênfase conforme a programação das ações em cada município. Com base nos resultados desse estudo, Frazão e Castellanos (1999) encontraram que as atividades mais frequentes de promoção da saúde bucal foram os bochechos com flúor, a evidenciação de placa bacteriana dental seguida de escovação supervisionada; atividades educativas eram realizadas em escolas e unidades básicas de saúde. No nível individual, as atividades realizadas foram aplicação 
tópica de flúor, aplicação de selante, eliminação de placa bacteriana e polimento coronário, além da inserção de materiais restauradores provisórios e definitivos. Em todos os casos, a participação do pessoal auxiliar de odontologia nos Silos foi considerada importante por contribuir para a transformação das práticas da odontologia no âmbito da saúde coletiva e do sistema de saúde em construção no Brasil.

Sanglard-Oliveira e colaboradores (2013) analisaram o autorrelato das funções executadas pelos TSB, no estado de Minas Gerais, por meio de entrevista telefônica, com amostra representativa de 231 trabalhadores. Observou-se que 71,6\% (IC 95\%, 64,4-77,5) realizavam polimento coronário, 63,2\% (IC 95\%, 56,169,7 ) faziam raspagem de cálculo e 14,7\% (IC 95\%, 10,3-20,4) condensavam e inseriam materiais restauradores. Em relação às ações preventivo-coletivas, 100\% (IC 95\%, 97,6-100,0) participavam de ações educativas, 99,0\% (IC 95\%, 96,1-99,8) demonstravam técnicas de higiene bucal, 96,6\% (IC 95\%, 92,7-98,4) realizavam a aplicação tópica de flúor, 77,9\% (IC 95\%, 71,5-83,3) realizavam visitas domiciliares e 96,6\% (IC 95\%, 92,7-98,4) realizavam ações coletivas, principalmente em escolas.

Além de se constituir no estudo mais abrangente realizado no país, correspondendo a uma amostra representativa do estado de Minas Gerais - unidade federada que ocupa a primeira posição em número de Equipes de Saúde Bucal (ESB) da ESF com a participação do TSB -, cabe destacar que mais da metade deles realizavam ações diretas na assistência odontológica individual, um aspecto nunca antes documentado no país em um estudo de similar extensão.

Os primeiros instrumentos normativos relacionados ao PAO no Brasil, mais especificamente, ao TSB, surgiram na segunda metade do século XX em contextos específicos.

A partir da década de 1970, a população brasileira passou a pressionar pelo acesso aos serviços públicos odontológicos, levando o Estado brasileiro a ampliar a oferta desses serviços. Esse fato, somado ao grande contingente de pessoal auxiliar que vinha exercendo suas funções em clínicas privadas, favoreceu a aprovação do Parecer n. ${ }^{\circ} 460 / 75$ do Conselho Federal de Educação (CFE), o qual autorizava e estabelecia exigências para a formação do ACD e do THD. Compõe esse documento um conjunto de diretrizes com a finalidade de criar, disciplinar e regular o funcionamento de cursos para formação desse tipo de pessoal auxiliar no país. 
O THD, a partir de 1979, passa a ter destaque nacional, tornando-se alvo de intensa polêmica. A partir daí, em seus quase 30 anos de existência jurídica infralegal, as funções atribuídas a esse profissional foram alvo de diversos debates. Em seu apoio, manifestaram-se os sanitaristas reformistas, inicialmente pautados por princípios administrativos, como por exemplo, a eficiência produtiva, e alguns anos depois, impulsionados pelas ideias de Alma-Ata (saúde como direito de todos) e a reforma dos sistemas de saúde. (FRAZÃO; NARVAI, 2009) Contestando a presença desses trabalhadores nos serviços odontológicos, estavam lideranças profissionais da categoria odontológica, pautadas pelo princípio de defesa das competências consideradas exclusivas dos cirurgiões-dentistas sob a égide do modelo liberal-privatista. (AGUIAR et al., 2014)

Passados nove anos, o Conselho Federal de Odontologia (CFO), pressionado por ações e movimentos de defesa desses trabalhadores, disciplinou, através da Decisão 26/84, o exercício daquelas ocupações, reconhecendo-as como atividades no âmbito da profissão odontológica. (AGUIAR, 2010)

Com o passar dos anos, o CFO, com vistas à defesa de seus interesses, realizou modificações naquela Decisão. Com base nas recomendações contidas no relatório da I Conferência Nacional de Saúde Bucal, realizada em 1986, constituiu uma comissão especial para ponderar sobre alguns tópicos como o exercício das funções de ACD e THD sem habilitação legal e a ausência de regulamentação dessas ocupações pelo Ministério do Trabalho, com alteração dos capítulos IV e V da Decisão 26/84, aprovada pela Resolução 155/84, aliada à deliberação 157/87, que ampliava as funções do ACD com relação à prevenção e controle da carie dentária e à manutenção do equipamento odontológico.

As Resoluções 153, 185 e 195, aprovadas em 1993, visavam também adequar as atribuições do ACD e THD aos interesses do CFO. A Resolução 185 alterou o item "n" do capítulo IV, cuja redação era "polir restaurações", para "polir restaurações, vedando-se a escultura". A Resolução 14/2000 acrescentou à disposição relacionada ao ACD, atribuições referentes à "lavagem, desinfecção e esterilização do instrumental e do consultório”, referentes à biossegurança e que não estavam explicitadas na Resolução. 185/93 (CARVALHO, 1999)

Para a inscrição do THD nos conselhos regionais, a apresentação do diploma é exigida desde 1988. Antes disso, bastava uma carta de um CD comprovando a experiência de um ano desse profissional na função. Através da Decisão 47/2003 do CFO, a denominação "Atendente de Consultório Dentário" foi alterada para "Auxiliar de Consultório Dentário". A partir de junho de 2000, o 
CFO passou também a exigir, para inscrição do ACD nos conselhos regionais de odontologia, a apresentação de um certificado ou diploma conferido por curso de qualificação autorizado pelo Conselho Estadual de Educação. Com vistas à regulamentação das profissões de ACD e THD, em 1989 foi apresentado à Câmara dos Deputados o Projeto de Lei (PL) n. ${ }^{\circ}$ 2244/89 (BRASIL, 1989), de autoria do deputado Robson Marinho (PSDB/SP), no qual o próprio autor fez um substitutivo ao substitutivo, tendo sido reapresentado em 1991 (PL n. ${ }^{\circ}$ 284/91), pelo deputado Augusto Carvalho filiado ao Partido Comunista Brasileiro, pelo Distrito Federal (BRASIL, 1991). O PL n. ${ }^{\circ} 284 / 91$ foi aprovado pelas comissões da Câmara e encaminhado ao Senado Federal em 19/04/1993. Em nova legislatura, o Projeto de Lei da Câmara (PLC) recebeu o n. ${ }^{\circ}$ 53/93 (antigo 284/91), tramitou no Senado Federal e foi aprovado em 8/12/1993. Entretanto, após tramitar durante cerca de cinco anos no Congresso Nacional, o ex-presidente Itamar Franco vetou o PLC n. ${ }^{\circ} 53$ no penúltimo dia de 1993, sob os argumentos de que a regulamentação restringia o mercado de trabalho, delimitava o campo de ação, desmotivava o aperfeiçoamento profissional impedindo a plena liberdade contratual, para atender interesses específicos ainda desconhecidos, mas que poderiam estar ligados à influência do CFO, pois, como foi mencionado, o órgão disciplinador do exercício profissional pautou o assunto em diferentes ocasiões naquele ano.

Em 22/02/2000, o PL n. ${ }^{\circ} 2.487$ foi apresentado pelo deputado Agnelo Queiroz (PCdoB/DF) (BRASIL 2000). O PL tramitou na Comissão de Trabalho, de Administração e Serviço Público (CTASP), mas foi rejeitado pelo relator do projeto, o Deputado Freire Junior (PMDB/TO) sob os argumentos de que a proposta de regulamentação profissional não atendia as determinações da CTASP, segundo as quais, a atividade deveria exigir conhecimentos teóricos e científicos avançados; ser exercida por profissionais de curso superior; e se não regulamentada, poderia trazer riscos de dano social no tocante à saúde, ao bem-estar e à segurança da coletividade, além de outros aspectos que ensejaram o veto ao PLC 53/93 (BRASIL 2000). O PL n. ${ }^{\circ} 1140 / 2003$, de autoria do deputado Rubens Otoni (PT/GO), teve por finalidade regulamentar o exercício das profissões de THD e ACD, prevendo suas atribuições e direitos, seus deveres e vedações. (BRASIL 2003) Para justificá-lo, seu autor esclarece:

[...] o presente projeto de lei foi originalmente apresentado em 1989 pelo Deputado Robson Marinho (PL n. ${ }^{\circ}$ 2.244/89), tendo sido reapresentado pelo Deputado Augusto carvalho em 1991 (PL n. ${ }^{\circ}$ 284/91) e pelo Deputado 
Agnelo Queiroz em 2000 (PL n. ${ }^{\circ}$ 2.487/oo), em face do arquivamento da proposição, conforme o Regimento Interno desta Casa.

O referido projeto teve dois substitutivos, sendo um da Comissão de Seguridade Social e Família e outro da Comissão de Trabalho, Planejamento e Serviço Público, tendo sido aprovado pela Comissão de Constituição e Justiça e de Cidadania da Câmara dos Deputados em 2006 e encaminhado ao Senado Federal para análise em 27/12/2006. De acordo com o referido PL e seus substitutivos, as profissões de THD e ACD passariam a ser denominadas respectivamente, de TSB e Auxiliar de Saúde Bucal (ASB), podendo ser exercidas apenas por aqueles que possuíssem diploma ou certificado que atendessem às normas do CFE. A matéria também determinava que os TSB e ASB devessem ser registrados no CFO e no Conselho Regional de Odontologia e que seu trabalho deveria ser sempre supervisionado por um CD. Em 9/1/2007, o projeto foi apresentado ao Senado Federal (PLC 3/2007), tramitou pela Comissão de Assuntos Sociais e pela Comissão de Constituição, Justiça e Cidadania (BRASIL 2007) e foi aprovado em 4 de dezembro de 2008, dando origem à Lei 11.889 que regulamenta o exercício das profissões de de Técnico em Saúde Bucal e Auxiliar em Saúde Bucal (BRASIL 2008). Torna-se importante mencionar sob que cenários foram travadas tais lutas para que as referidas profissões fossem regulamentadas. Esse cenário não era neutro e por vezes mostrava-se desfavorável e profundamente adverso às mudanças desejadas. Nem sempre as autoridades representativas da categoria odontológica mantiveram-se a favor do pleito.

Narvai e colaboradores (1990) discutiram sobre a formação e incorporação do THD aos serviços de saúde, incluindo a aceitação desse profissional pelos dirigentes da categoria, compondo assim ESB, tanto no setor público quanto no privado. Os autores apontaram os seguintes motivos que levavam os dirigentes, na época, a rejeitarem o trabalho do THD: reserva de mercado; a incapacidade do THD de realizar trabalhos de qualidade comparada à do CD; e o risco que o $\mathrm{CD}$ assumiria ao trabalhar com o THD, pois, perante a justiça, o CD é o responsável pelo trabalho executado por aquele auxiliar.

Em uma publicação editada pela secretaria da Rede de Escolas Técnicas do Sistema Único de Saúde (RET-SUS), um membro da Associação Brasileira de Cirurgiões-Dentistas e da Federação Nacional dos Odontologistas posicionou-se contra a atuação do THD realizando raspagem gengival e inserção e con- 
densação de material restaurador, atividades para ele consideradas exclusivas de um CD.

Narvai e Frazão (1999) argumentaram que grande parte das críticas referentes às competências do THD e do ACD deve-se ao desconhecimento de dispositivos legais já existentes e considerados suficientes para disciplinar o trabalho das ESB sob a coordenação de um CD. Para esses autores, além do desconhecimento acerca dos dispositivos legais já existentes, a principal polêmica diz respeito à reserva de mercado por parte do CD.

Apesar de uma longa espera (mais de 20 anos), a Lei n. ${ }^{\circ} 11.889$, de 24 de dezembro de 2008, regulamentou o exercício das profissões de TSB e de ASB. Em seu artigo $5^{\circ}$, constam as competências do TSB, as quais devem ser realizadas sempre sob a supervisão do CD. No artigo $9^{\circ}$ da Lei, constam as atividades de competência do ASB, as quais deverão ser exercidas sob a supervisão do CD ou do TSB. Após a regulamentação, foram determinadas as seguintes atividades exclusivas para o TSB:

[...] participar de treinamento e capacitação de ASB e de agentes multiplicadores das ações de promoção à saúde; participar de ações educativas por meio de ações de promoção da saúde e da prevenção de doenças bucais; participar de levantamentos e estudos epidemiológicos, exceto na função de examinador; ensinar técnicas de higiene bucal e realizar prevenção de doenças bucais por meio da aplicação tópica de flúor, seguindo orientação do CD; fazer a remoção do biofilme, conforme indicação técnica definida pelo CD; supervisionar o trabalho do ASB quando delegado pelo $\mathrm{CD}$; realizar fotografias e tomadas de uso odontológico exclusivamente em consultórios ou clínicas odontológicas; inserir e distribuir no preparo cavitário materiais odontológicos na restauração dentária direta, vedado o uso de materiais e instrumentos não indicados pelo CD; proceder à limpeza e antissepsia do campo operatório, antes e após atos cirúrgicos, inclusive em ambientes hospitalares; remover suturas; aplicar medidas de biossegurança no armazenamento, manuseio e descarte de produtos e resíduos odontológicos; realizar isolamento do campo operatório; exercer todas as competências no âmbito hospitalar, bem como instrumentar O CD em ambientes clínicos e hospitalares. (BRASIL, 2008)

Embora estivesse estabelecida (normalizada) no campo da educação há mais de 30 anos, e há mais de 20 anos, em termos de exercício profissional, a regulamentação da profissão só veio a acontecer em 2008. 
O SUS exerceu papel importante no processo de regulamentação dessas profissões, na medida em que assumiu a prioridade de desenvolvimento de recursos humanos para a profissionalização do trabalhador da rede de atenção básica, com vistas a reorientar e qualificar a prática profissional.

Frazão e Narvai (2011) analisaram as competências do TSB, constantes na Lei n. ${ }^{\circ} 11.889 / 08$. Foram comparadas as competências definidas no referido instrumento legal com aquelas previstas no Parecer n. ${ }^{\circ} 460 / 75$ do CFE e na Resolução n. ${ }^{\circ}$ 63/2005 do CFO. Os autores concluíram que as competências aprovadas na Lei foram distribuídas em número menor de itens, em comparação aos dois outros documentos, do ponto de vista qualitativo, mas os resultados da análise permitiram retratar avanços obtidos com a regulamentação da profissão, nos termos aprovados, em todas as áreas de competência. Houve impacto positivo para o processo de trabalho em saúde, tanto com relação à cooperação interprofissional quanto à supervisão técnica das atividades, resultando em uma conquista relevante dos trabalhadores da área e também numa contribuição significativa para avançar na ampliação do acesso da população aos serviços odontológicos.

Em âmbito mundial e também no Brasil, a assistência odontológica é ofertada predominantemente no mercado de prestação de serviços de saúde sob os princípios do modelo liberal-privatista. (CHAVES, 2012; NARVAI; FRAZÃO, 2008)

No Brasil, a partir de 2000 , foi aprovado incentivo financeiro para impulsionar a inclusão das ESB na ESF. (BRASIL, 2000) A Política Nacional de Saúde Bucal, discutida no âmbito da $3^{\text {a }}$ Conferência Nacional de Saúde Bucal e aprovada na comissão de gestores das três esferas de governo do SUS, contribuiu para a ampliação da força de trabalho odontológica nos serviços públicos, propiciando uma nova perspectiva rumo à consolidação legal da profissionalização do TSB. (BRASIL, 2004) Os principais objetivos da implantação das ESB na ESF foram: melhorar as condições de saúde bucal da população, reorientar as práticas de atenção na área, observando os padrões de qualidade e o impacto das ações realizadas e ampliar o acesso da população às ações de promoção, prevenção e recuperação da saúde bucal, com consequente melhoria de seus indicadores.

Admite-se que para os profissionais da área, em especial para o dentista, a atuação na ESF traz alguns desafios, como por exemplo, abandonar o isolamento a que estava habituado, compartilhando com outro profissional a prá- 
tica antes restrita ao consultório odontológico; passar a trabalhar em equipe multiprofissional, onde é necessário desenvolver competências, inclusive de natureza relacional, para além de seu núcleo de competência saber, e de seus conhecimentos específicos; compreender a determinação social do processo saúde-doença mobilizando recursos do território, planejando, articulando e avaliando as ações de proteção à saúde bucal junto às demais ações de saúde. Em 2004, foi lançada a Política Nacional de Saúde Bucal, o Brasil Sorridente, tendo dentre seus pressupostos a qualificação da atenção básica e a incorporação da ESF como importante estratégia na reorganização da atenção básica. (BRASIL, 2004)

A ESF aparentou ser, à primeira vista, uma política nacional favorável à administração e à melhor composição da força de trabalho odontológica nos serviços públicos. Sua principal variável normativa fazia a distinção de ESB - modalidade I (sem TSB), e modalidade II (com TSB) -, condicionando as transferências federais aos municípios (piso de atenção básica variável da saúde bucal).

A ESB pode ser composta por um CD e um ASB (modalidade I). Acrescendo-se um TSB, a equipe passa a ser de modalidade II. A Portaria GM n. ${ }^{\circ} 267$, de 6 de março de 2001, estabelecia uma diferença de $23 \%$ por ano para custeio entre as duas modalidades (13 mil para 16 mil reais). No início, o incentivo federal aos municípios interessados foi limitado a uma ESB para cada duas ESF. Somente com a Portaria GM n. ${ }^{0}$ 673/2003 que o financiamento foi autorizado na proporção de uma para um considerando o teto máximo de transferência correspondente ao número de equipes de saúde da família.

Com a Portaria GM n. ${ }^{\circ}$ 74/2004, a equipe com TSB passou a receber do Ministério da Saúde um equipamento odontológico completo a ser utilizado pelo TSB, para a realização de atividades planejadas e supervisionadas pelo CD, e a diferença passou a $29,4 \%$ por ano para custeio (20,4 mil para 26,4 mil reais). Assim, os incentivos para essa área cresceram, criando condições para a reorientação das ações.

A Portaria n. ${ }^{0}$ 1.599, do Ministério da Saúde (BRASIL, 2011), definiu valores de financiamento do Piso da Atenção Básica Variável para as equipes de saúde da família, ESB e aos agentes comunitários de saúde, instituídos pela Política Nacional de Atenção Básica. No artigo $2^{\circ}$, são definidos valores do incentivo financeiro das ESB nas modalidades I e II, segundo critérios estabelecidos pela Política Nacional de Atenção Básica, da seguinte forma: para as ESB na moda- 
lidade I, serão transferidos R $2.100,00$ a cada mês, por equipe; e para as ESB na modalidade II, serão transferidos $\mathrm{R} \$ 2.800,00$ a cada mês, por equipe. $\mathrm{A}$ diferença alcançou $30 \%$.

A Portaria n..$^{\circ}$ 978, de maio de 2012 , reajustou esses valores, passando o incentivo da ESB modalidade I para R $\$ 2230,00$ por equipe, a cada mês; e o da modalidade II para $\mathrm{R} \$ 2.980,00$ - elevando a diferença para 33,6\%.

\section{A situação atual do TSB na atenção primária à saúde}

No que pesem todos os esforços para impulsionar a inclusão do TSB na atenção primária à saúde sob os princípios da ESF, nenhum estudo analisou detidamente a questão no Brasil, razão pela qual se justifica examinar o efeito dessa política de incentivo a fim de apreciar a extensão das mudanças que a medida vem produzindo e eventualmente as correções de rumo necessárias.

Para isso, foram consultados dados do portal do Departamento de Atenção Básica da Secretaria de Atenção à Saúde do Ministério da Saúde, relativos ao número de ESB implantadas nas modalidades I e II admitindo-se que eles expressam, de um lado, a força indutora da política para apoiar a estruturação de uma atenção primária mais abrangente, e de outro, o grau de aderência dos entes municipais à formulação e implementação da política pública. Além disso, foram recolhidos dados do CFO, referentes a setembro de 2015. No que pesem suas limitações - os dados podem conter profissionais inativos; que não exercem atividade na assistência odontológica e pode ser expressivo o subregistro dos que exercem atividades como auxiliar de saúde bucal -, registros sobre o exercício profissional podem ser úteis para caracterizar em linhas gerais a composição corrente da força de trabalho nos serviços odontológicos do país, refletindo em certo sentido o modelo de prática odontológica predominante. A magnitude dos desequilíbrios quantitativos na razão TSB/CD e razão ASB/CD foi apurada e os valores foram comparados, admitindo-se a hipótese de que as diferenças de valores entre as razões observadas podem ser indicativas do grau de alcance da política pública, ou seja, sua efetividade para induzir a reestruturação do modelo de prática odontológica na principal estratégia de atenção primária à saúde no país.

Na Tabela 1 é apresentada a distribuição do número de ESB segundo as modalidades I e II e, na Figura 1, a distribuição percentual. Pode-se observar que, apesar dos esforços descritos, persiste um desequilíbrio considerável entre as duas modalidades de ESB. A proporção de equipes modalidade II, em 2001, 
estava em 10\%; reduziu para 7,2\%, em 2005; em 2010, estava em 8,1\%; e, em setembro de 2015 , correspondia a 9,1\%, mostrando claramente a insuficiência da política pública para impulsionar a inclusão do TSB nas equipes multiprofissionais da atenção primária na ESF.

Tabela 1 - Número de equipes de saúde bucal (ESB) nas modalidades I e II nos anos de 2001, 2005, 2010 e 2015

\begin{tabular}{c|c|c|c}
\hline Ano & ESB & Modalidade I & Modalidade II \\
\hline 2001 & 171 & 154 & 17 \\
\hline 2005 & 11.751 & 10.898 & 853 \\
\hline 2010 & 20.103 & 18.457 & 1.646 \\
\hline 2015 & 24.566 & 22.309 & 2.257 \\
\hline
\end{tabular}

Fonte: Brasil (2016).

Nota: Modalidade I: inclui CD e ASB sem TSB; modalidade II: inclui CD, ASB e TSB; mês de referência: setembro 2015 .

Figura 1 - Percentual de equipes de saúde bucal (ESB) nas modalidades I e II nos anos de 2001, 2005, 2010 e 2015

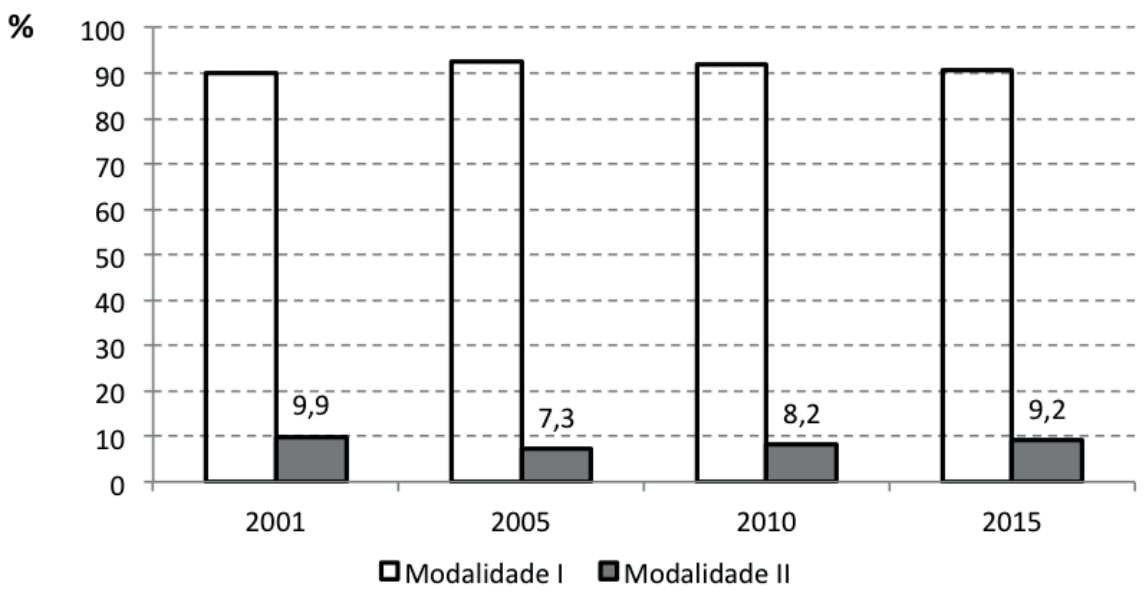

Fonte: Brasil (2016).

Nota: Modalidade I: inclui CD e ASB sem TSB; modalidade II: inclui CD, ASB e TSB; mês de referência: setembro 2015.

Em setembro de 2015, dentre as 24.566 ESB implantadas no Brasil, 2.257 eram equipes de modalidade II (9\%), sendo que 725 estavam concentradas no estado de Minas Gerais, seguido do Paraná (373) e São Paulo (243). Esses três 
estados juntos concentravam praticamente $60 \%$ do total de ESB de modalidade II implantadas no Brasil.

Prescindir da presença do TSB na ESB seria considerado aceitável somente no início do processo de implantação das ESB, tendo em vista sua importância para o aumento da cobertura e para a melhoria da qualidade da atenção à saúde bucal, criando condições mais favoráveis para a integralidade do cuidado e para a universalização do acesso da população a esse tipo de serviço de saúde.

No âmbito da prática odontológica como um todo, registros do exercício profissional indicavam uma força de trabalho composta predominantemente por CD. Na Tabela 2, é apresentada a distribuição absoluta e relativa da composição estimada da força de trabalho no Brasil. Em setembro de 2015, estavam registrados 276.711 CD, 21.539 TSB e 111.630 ASB no CFO (Tabela 2), resultando numa proporção de apenas $5 \%$ de TSB em relação ao total da força de trabalho. Isso equivalia a uma razão de sete TSB para cada 100 dentistas (Tabela 2). Mesmo se considerarmos a soma de ASB e TSB, a razão é bastante desfavorável (um para cada dois dentistas), correspondendo à mesma relação encontrada na década de 1950 em países com tradição desse tipo de profissional na força de trabalho. (DUNNING, 1958)

Tabela 2 - Força de trabalho odontológica brasileira nos serviços em geral e na ESF de
acordo com a categoria profissional

\begin{tabular}{c|c|c|c|c|c|c}
\hline $\begin{array}{c}\text { Categoria } \\
\text { profissional }\end{array}$ & $\begin{array}{c}\text { Serviços } \\
\text { odontológicos }\end{array}$ & $\%$ & $\begin{array}{c}\text { Razão } \\
\text { ASB/CD }\end{array}$ & ESF $^{2}$ & $\%$ & $\begin{array}{c}\text { Razão } \\
\text { ASB/CD }\end{array}$ \\
\hline CD & 276.711 & 68 & & 24.566 & 48 & \\
\hline TSB & 21.539 & 5 & $7 / 100$ & 2.257 & 4 & $8 / 100$ \\
\hline ASB & 111.630 & 27 & $40 / 100$ & 24.566 & 48 & $1 / 1$ \\
\hline
\end{tabular}

Fonte: CFO (2015), Brasil (2016).

Nota: Não foram incluídos técnicos de prótese dentária e auxiliares de prótese dentária.

A despeito da política pública implementada no âmbito do SUS, a relação entre o número de TSB e o número de CD correspondeu a uma razão praticamente igual no âmbito da ESF e nos serviços odontológicos em geral (7/100 para 8/100), notando-se uma diferença significativa apenas na relação entre o número de ASB e o número de CD. Mesmo que o subregistro de auxiliares ain- 
da seja expressivo nos serviços odontológicos, cabe destacar a efetividade da política para induzir a inclusão de auxiliares de saúde bucal na ESF.

Comparando a inclusão do TSB nas equipes da ESF e a composição da força de trabalho nos serviços odontológicos, os resultados sugerem que a política pública pode ter sido muito relevante para sinalizar a necessidade de inclusão do TSB na equipe, entretanto, não foi capaz de produzir uma modificação expressiva na composição da força de trabalho no âmbito da principal estratégia de atenção primária à saúde em curso no país.

Diante dos resultados observados, é lícito admitir que o quadro tende a permanecer estagnado se a política não sofrer modificações, significando baixo grau de reestruturação do modelo de prática odontológica na principal estratégia de atenção primária à saúde no país.

Por outro lado, havendo vontade para reformular a política pública de inclusão do TSB na equipe multiprofissional, um componente da política que não pode ser subestimado diz respeito aos valores financeiros transferidos aos entes municipais dispostos a implementá-la. Esse componente é ainda mais importante num contexto de subfinanciamento do subsistema público de saúde, do qual mais de $70 \%$ da população depende.

Frente aos modestos efeitos produzidos pela política, é razoável aceitar que os valores transferidos não foram suficientes para impulsionar sua inclusão na equipe multiprofissional. Mesmo considerando que, entre 2001 e 2012, a diferença percentual entre os valores transferidos para o custeio da modalidade II (com TSB) em relação à modalidade I (sem TSB) aumentou de $23 \%$ para $33,6 \%$, a resposta dos entes municipais à política não se modificou ao longo do período. Assim, é lícito admitir que, em havendo espaço para sua reformulação, é crucial discutir e pactuar com os gestores municipais e estaduais do SUS, valores que expressem uma participação mais adequada dos três níveis de gestão no financiamento da política.

Além disso, é imprescindível investigar os principais determinantes ligados a essa situação, e identificar aqueles que possam ser objeto de regulação e formulação de políticas a fim de suplantar as barreiras existentes. Para produzir os efeitos esperados, no que pese sua importância, é crucial reconhecer que a política não pode se apoiar apenas no componente financeiro. É preciso, numa futura reformulação, olhar para outras políticas e esforços que estão em curso, como por exemplo, as iniciativas envolvendo a gestão do trabalho e da educação na saúde; e as ações de melhoria do acesso e da qualidade da atenção básica. 
Nesse sentido, Aguiar e colaboradores (2014) realizaram um estudo em quatro pontos diferentes do país para produzir informações científicas sobre a participação do TSB na ESB da ESF. O propósito foi investigar como diferentes agentes sociais olhavam para a participação de técnicos em saúde bucal no desempenho de ações diretas, com o objetivo de compreender as disposições simbólicas associadas. Partiu-se do pressuposto de que a ESF em desenvolvimento no país é atravessada por diferentes interesses ideológicos e sanitários que refletem distintos projetos de sistema de saúde e modelos de atenção. De acordo com Campos (2007), existem dois grandes projetos sanitários para o país: um se refere às tradições dos sistemas nacionais de saúde e o outro à tradição liberal-privatista. Esses campos são considerados dois conceitos abstratos indicativos de projetos políticos articulados a partir de interesses e valores distintos. Segundo o autor, existe uma miríade de combinações entre eles. O modo liberal-privatista é apoiado pelos prestadores privados. Completam essa composição, partidos e políticos com tendência conservadora, além de profissionais que defendem o mercado como ordenador das relações sociais. Há nesse modelo, o estímulo econômico à produção de atos sanitários, onde a lógica da atenção à saúde é a individual, privilegiando os interesses privados, na medida em que estimula a prática prescritiva de exames e medicamentos. Por outro lado, a tradição dos modelos nacionais de saúde foi construída em articulação com a luta dos trabalhadores em prol de políticas públicas ou do socialismo, particularmente em países europeus no século passado. Nesse tipo de tradição foram propostos modos alternativos à tradição liberal para organizar o cuidado à saúde. Investiu-se na constituição de um sistema interligado de serviços, cuja organização baseia-se na integralidade da atenção, onde o planejamento e a programação devem ocorrer com base nas necessidades de saúde e nas possibilidades tecnológicas e financeiras para enfrentá-las e não na demanda de clientes por procedimentos e atos sanitários.

Essas diferentes visões se expressam na tradição liberal-privatista da profissão odontológica, e em valores que emergem a partir da aprovação da Constituição de 1988, no Brasil, que define a saúde, e por extensão a saúde bucal, como um direito humano. (NARVAI; FRAZAO, 2008)

Simultaneamente, num nível mais intermediário, Aguiar e colaboradores (2014) admitiram o pressuposto que essas diferentes visões sofrem relevantes mediações segundo os diversos focos de interesse e diferentes repertórios de habilidades e perspectivas que os agentes reconhecem no trabalho na atenção 
primária. Para transitar entre esses níveis, recorreu-se à contribuição de Pierre Bourdieu, em especial, o aporte teórico por ele utilizado para a superação da antinomia entre as interpretações internalistas e externalistas dos fenômenos sociais. De um lado, os que sustentam que, para compreender o significado das ações humanas, basta sistematizar o conteúdo das narrativas das pessoas, conectá-las aos ritos ou momentos de fruição coletiva; e de outro, outra tradição, representada por pesquisadores que procuram relacionar o conteúdo ao contexto, interpretando o significado das ações com base em estruturas mais gerais ligadas ao mundo social ou econômico. Para contrastar essas duas importantes tradições de explicação sociológica, onde se localizam o legado de várias perspectivas, cada qual com suas ferramentas de análise e características próprias, Bourdieu propôs a noção de campo simbólico como um microcosmo dotado de leis próprias que, ao mesmo tempo, que jamais escapa às determinações do macrocosmo, dispõe de uma autonomia parcial mais ou menos acentuada para mediar pressões externas mais gerais. (BOURDIEU, 1996)

Como uma cultura biomédico-centrada permanece orientando a organização do processo de trabalho das equipes, nas quais cada profissional tende a operar de forma isolada sob a lógica da produção de procedimentos (FRANCO; MERHY, 2007), para interpretação do material, foram empregados ainda conhecimentos relacionados aos determinantes de colaboração interprofissional (SAN MARTÍN-RODRÍGUEZ et al., 2005) considerados como um recorte temático útil para codificar as forças que orientam a interação profissional, seja para induzir o abandono de disposições competitivas entre os trabalhadores, seja para incentivar uma prática colaborativa.

Um pesquisador conduziu 24 entrevistas em profundidade com dentistas, TSB e gerentes de unidades de saúde. Com base no discurso dos agentes, foram identificadas disposições simbólicas associadas a determinantes interacionais, organizacionais e sistêmicos ligados à participação dos TSB nas ESB da ESF. Entre os primeiros, foram identificados aspectos interprofissionais, como, por exemplo, o sentimento de incompetência do CD para supervisionar as atividades do TSB, baixo grau de confiança e disposição para compartilhar o trabalho. Em nível organizacional, as disposições simbólicas denotaram aspectos ligados à falta de um projeto consistente de atenção primária ou à baixa capacidade para implementá-lo, dois vértices do conceito de triângulo do governo formulado por Matus (1997), ambos associados à falta de apoio e de atividades de educação permanente. Em nível sistêmico, os discursos remeteram a diferen- 
tes aspectos ligados ao sistema de profissões, à regulação do trabalho, entre outros aspectos normativos presentes nos sistemas de saúde e de educação. (AGUIAR, 2010)

Assim, ao olhar para outras políticas e esforços que estão em curso, como por exemplo, as iniciativas envolvendo a gestão do trabalho e da educação na saúde, e as ações de melhoria do acesso e da qualidade da atenção básica, descortinam-se diferentes possibilidades para formular propostas que possam dotar, de maior consistência, as iniciativas para impulsionar a inclusão do TSB na atenção primária.

Nesse aspecto, os especialistas, em encontros de administradores e técnicos do serviço público odontológico, têm recomendado que seja assegurada a presença do TSB em todas as ESB, extinguindo a distinção entre equipe modalidade I e modalidade II, de modo a que, por ESB, seja compreendido necessariamente a presença do CD, TSB e ASB. Ausência do TSB deveria ser considerada uma forma precária e transitória, devendo a gestão estadual e municipal assumir compromisso com sua implantação em um prazo pactuado. (ENATESPO, 2010) Zanetti (2012) postulou que a implantação das ESB deveria ser acompanhada de exigências de contrapartidas de estados e municípios, como, por exemplo, contrapartidas financeiras (cofinanciamento federativo), contrapartidas políticas (ações de apoio à política nacional, como a realização de cursos, treinamento, capacitação, oficinas, entre outras) e contrapartidas técnicas (necessidade de demonstração de viabilidade e eficiência estrutural e operacional dos sistemas locais de saúde bucal etc.).

Encontros de administradores e técnicos do serviço público odontológico realizados em Belo Horizonte (2012) e em Teresina (2014) também têm apontado para as limitações da política de inclusão, defendendo-se sua reformulação com a finalidade de fortalecer o processo de inclusão do TSB nas ESB da ESF, transformando as ESB tipo I para ESB tipo II; garantir "plena" competência e atribuição do TSB no exercício profissional; promover junto aos municípios a implantação de equipes modalidade II na ESF, otimizar os processos de trabalho; e afirmar o TSB como recurso estratégico para consolidação da política de saúde bucal coletiva brasileira. Tem sido ressaltada ainda a importância da atuação junto aos órgãos públicos, seja para impulsionar a criação de cargos de ASB e TSB, no Plano de Cargos, Carreiras e Salários; adequar as denominações de acordo com a Lei no ${ }^{0} 11.889 / 2008$; e também fomentar junto à gestão estadual incentivo às ESB com a participação do TSB. 
Assim, pode-se concluir que, apesar dos reajustes crescentes nos incentivos federais no âmbito da Política Nacional de Saúde Bucal, observa-se persistente desequilíbrio entre as ESB de modalidades I e II, justificando-se abertura de debate para a reformulação da política pública com a finalidade de expandir a inclusão do TSB nas ESF.

\section{Referências}

AGUIAR, D. M. L. A participação do técnico em saúde bucal na estratégia saúde da família:um olhar em municípios estruturados. 2010. 139 f. Tese (Doutorado em Serviços de Saúde Pública)-Universidade de São Paulo, São Paulo, 2010.

AGUIAR, D. M. L. et al. Oral health technicians in Brazilian primary health care: potentials and constraints. Cadernos de Saúde Pública, Rio de Janeiro, v. 30, n. 7, p.1560-1570, jul. 2014. BOURDIEU, P. Razões práticas: sobre a teoria da ação. Campinas, SP: Papirus, 1996.

BRASIL. Congresso Nacional. Câmara dos Deputados. Projeto de Lei n 2244, de 11/05/1989, que regulamenta o exercício das profissões de Técnico em Higiene Dental e de Atendente de Consultório Dentário. Disponível em: <http://www.camara.gov.br/proposicoesWeb/ fichadetramitacao?idProposicao=201383>. Acesso em: 5 nov. 2015 .

BRASIL. Congresso Nacional. Câmara dos Deputados. Projeto de Lei no 284, de 4/04/1991, que regulamenta o exercício das profissões de Técnico em Higiene Dental e de Atendente de Consultório Dentário. Disponível em: <http://www.camara.gov.br/proposicoesWeb/ fichadetramitacao?idProposicao $=201383>$. Acesso em: 8 jun. 2016

BRASIL. Congresso Nacional. Senado Federal. Projeto de Lei da Câmara nº 53, de 23/04/1993, que regulamenta o exercício das profissões de Técnico em Higiene Dental e de Atendente de Consultório Dentário. Disponível em: <http://www25.senado.leg.br/web/atividade/ materias/-/materia/20617/pdf>. Acesso em: 8 jun. 2016.

BRASIL. Congresso Nacional. Câmara dos Deputados. Projeto de Lei n 2487, de 22/02/2000, que regulamenta o exercício das profissões de Técnico em Higiene Dental e de Atendente de Consultório Dentário. Disponível em: <http://www.camara.gov.br/proposicoesWeb/ fichadetramitacao?idProposicao=18189>. Acesso em: 8 jun. 2016

BRASIL. Ministério da Saúde. Portaria nº 1.444, de 28 de dezembro de 2000. Estabelece incentivo financeiro para a reorganização da atenção básica à saúde bucal nos municípios por meio do Programa de Saúde da Família. Brasília, DF. 2000. Disponível em: <http:// www.camara.gov.br/sileg/integras/142359.pdf>. Acesso em: 8 jun. 2016.

BRASIL. Ministério da Saúde. Diretrizes da Política Nacional de Saúde Bucal. Brasília, DF, 2004.

Disponível em: <http://bvsms.saude.gov.br/bvs/publicacoes/politica_nacional_brasil_ sorridente.pdf $>$. Acesso em: 8 jun 2016 
BRASIL. Ministério da Saúde. Departamento de Atenção Básica. Histórico de Cobertura da Saúde da Família. Brasília, DF, 2016. Disponível em: <http://dab.saude.gov.br/portaldab/ historico_cobertura_sf.php> Acesso em: 19 nov. 2015.

BRASIL. Presidência da República. Casa Civil. Lei no 11.889, de 24 de dezembro de 2008. Regulamenta o exercício das profissões de Técnico em Saúde Bucal e Auxiliar em Saúde Bucal. Brasília, DF, 2008. Disponível em: <http://www.planalto.gov.br/ccivil_03/_Ato20072010/2008/Lei/L11889.htm>. Acesso em: 8 jun 2016.

BRASIL. Congresso Nacional. Câmara dos Deputados. Projeto de Lei no 1.140, de 28/05/2003, que regulamenta o exercício das profissões de Técnico em Higiene Dental e de Atendente de Consultório Dentário. Disponível em: <http://www.camara.gov.br/proposicoesWeb/ fichadetramitacao?idProposicao=117483>. Acesso em: 8 jun. 2016.

BRASIL. Congresso Nacional. Senado Federal. Projeto de Lei da Câmara nº 3, de 9/01/2007, que regulamenta o exercício das profissões de Técnico em Saude Bucal e Auxiliar em Saúde Bucal. Disponível em: http://www25.senado.leg.br/web/atividade/materias/-/materia/79741 Acesso em: 8 jun. 2016.

CAMPOS, G. W. S. O SUS entre a tradição dos Sistemas Nacionais e o modo liberalprivado para organizar o cuidado à saúde. Ciência \& Saúde Coletiva, Rio de Janeiro, v. 12, supl.

p. $1865-1874$, nov. 2007.

CARVALHO, C. L. Trabalho e profissionalização das categorias auxiliares em Odontologia. Revista Ação Coletiva. Brasília, DF, v. 2, n. 1, p. 25-33, 1999.

CHAVES, S. C. L. Oral health in Brazil: the challenges for dental health care models. Brazilian Oral Research, v. 26, n. supl 1, p.71-80, 2012.

CONSELHO FEDERAL DE EDUCAÇÃO (Brasil). Parecer no 460 de 06 de fev. de 1975. Dispõe sobre habilitação de Técnico em Higiene Dental e Atendente de Consultório Dentário. Brasília, DF, 1975. p. 20-24.

CONSELHO FEDERAL DE ODONTOLOGIA - CFO. (Brasil). Dados estatísticos. 2015. Disponível em: <http://www.cfo.org.br/servicos-e-consultas/dados-estatisticos/>. Acesso em: 29 nov. 2015.

DUNNING, J. M. Extending the field for dental auxiliary personnel in the United States. American Journal of Public Health, New York, v. 48, n. 8, p. 1059-1064, Aug. 1958.

FRAZÃO, P.; GONZÁLES, C. C.; ROSA, A. G. F. Ambiente de trabalho odontológico na perspectiva do Sistema Único de Saúde. Divulgação em Saúde para Debate, Londrina, n. 10, p. 21-28, jun. 1995 .

FRANCO, T. B.; MERHY, E. E. Programa Saúde da Família (PSF): contradições de um programa destinado à mudança do modelo tecnoassistencial. In: MERHY, E. E. et al. O trabalho em saúde: olhando e experienciando o SUS no cotidiano. São Paulo: Hucitec, 2007. Capítulo 3, p. 55-124. 
FRAZÃO, P.; CASTELLANOS, R. A. La participación del personal auxiliar de odontología en los sistemas locales de salud. Pan American Journal of Public Health, v. 5, n. 2, p. 106-115, feb. 1999.

FRAZÃO, P.; NARVAI, P. C. Lei n. 11.889/2008: avanço ou retrocesso nas competências do Técnico em Saúde Bucal? Trabalho, Educação e Saúde, Rio de Janeiro, v. 9, n. 1, p. 107-121, jun. 2011.

FRAZÃO, P.; NARVAI, P. C. Sistemas de trabalho em Odontologia: origens históricas e principais aplicações. In: PEREIRA, A. C. Tratado de Saúde Coletiva em Odontologia. São Paulo: Ed. Napoleão, 2009. p. 238-246.

FULTON, J. T. Experiment in dental care: results of New Zealand's use of school dental nurses. Geneva: World Health Organization, 1951.

GALLOWAY, J. et al. The Professionals Complementary to Dentistry: Systematic Review and Synthesis. York: Database of Abstracts of Reviews of Effects (DARE), 2004. Disponível em: <http://www.crd.york.ac.uk/CRDWeb/ShowRecord.asp?ID=12003008507> Acesso em: 19 nov. 2015.

HOPCRAFT, M. S. et al. Utilizing dental hygienists to undertake dental examination and referral in residential aged care facilities. Community Dentistry and Oral Epidemiology, Copenhagen, v. 39, n. 4, p. 378-384, Aug. 2011.

JOHNSON, Patricia M. Dental hygiene practice: international profile and future directions. International Dental Journal, London, v. 42, n. 6, p. 451-9, Dec. 1992.

JOHNSON, P. M. International profiles of dental hygiene 1987 to 2006: a 21-nation comparative study. International Dental Journal, London, v. 59, n. 2, p. 63-77, Apr. 2009.

Matus, C. Política, planejamento \& governo. 3. ed. São Paulo: IPEA, 1997. Tomo I.

NARVAI, P. C. et al Contra o técnico em higiene dental. Saúde em Debate, Londrina, v. 28, p. 59-65, mar. 1990.

NARVAI, P.C.; FRAZÃO, P. Saúde bucal no Brasil: muito além do céu da boca. Rio de Janeiro: Fiocruz, 2008. (Coleção Temas em Saúde).

NARVAI, P. C.; FRAZÃO, P. Técnico em higiene dental: hora de recuar? In: CONGRESSO DA FEDERAÇÃO INTERESTADUAL DOS ODONTOLOGISTAS, 5., 1999. Rio Quente. Anais... Rio quente: FSP/USP; FIO, 1999.

ORGANIZAÇÃO MUNDIAL DA SAÚDE. Trabalhando juntos pela saúde. Brasília: Ministério da Saúde, 2007. (Série B. Textos Básicos de Saúde).

SANGLARD-OLIVEIRA, C. A. et al. Atribuições dos Técnicos em Saúde Bucal na Estratégia Saúde da Família em Minas Gerais, Brasil. Ciência \& Saúde Coletiva, Rio de Janeiro, v. 18, n. 8, p. 2453-2460, 2013.

SAN MARTÍN-RODRÍGUEZ, L. et al. The determinants of successful collaboration: A review of theoretical and empirical studies. Journal of Interprofessional Care, v. 19, n. suppl. 1, p.132-147, May 2005. 
ZANETTI, C. H. G. Imputações ideológicas: derivações públicas e privadas do profissionalismo como crença na história da odontologia brasileira - um ensaio sobre o esvaziamento da ação. Brasília, DF: UnB/ObservaRH/Nesp, 2012. 


\section{Emergência da odontologia social na Bahia}

Sônia Chaves

Mona Lisa Souza

\section{A odontologia sanitária e social no Brasil e na Bahia}

Este estudo analisou os saberes e práticas de agentes sociais envolvidos com a emergência do espaço da odontologia social na Bahia, entre os anos 1940 e 1960. Foi um estudo sócio-histórico com recorte historiográfico baseado na perspectiva de análise sociológica de políticas de saúde de Pinell (2011), onde são analisados dois agentes, seus capitais e trajetórias nesse espaço de luta em torno do direito à saúde bucal. Foi reconstruída a biografia dos agentes do polo dominante desse período na Bahia, sua origem social, trajetória no campo burocrático e no campo científico, bem como as condições de possibilidade para emergência do espaço da odontologia social no estado.

Nos antecedentes históricos, cabe lembrar que a Faculdade de Medicina da Bahia foi a primeira da América Portuguesa, sendo instituída em 1808 com a chegada da corte portuguesa no Brasil. Nesse período, foi instituído o curso de cirurgia, porém a "arte de rancar dentes" continuou a ser realizada de maneira informal, com limitadas regulamentações, práticas que se perpetuaram até a segunda metade do século XIX. Somente em 1811, foi expedida a primeira carta de dentistas. Posteriormente, em 1820, veio para o Brasil diversos dentistas franceses o que muito influenciaram no ensino odontológico baiano. Outro fator importante para a saúde de maneira geral foi a criação da Junta de Higiene 
Pública, formada em 1850, objetivando o controle das epidemias, a exemplo da peste bubônica, febre amarela, dentre outros. (MACHADO et al., 1978)

Em 25 de outubro de 1884, data em que se comemora o dia do cirurgiãodentista no Brasil, pelo Decreto Imperial de n. ${ }^{\circ}$ 9311, conhecido como Reforma Saboia, é que a odontologia foi institucionalizada, passando a ter um curso regulamentado voltado para profissionalização da odontologia.

Os primeiros cursos de odontologia do Brasil foram criados a partir de 1884 nas Faculdades de Medicina do Rio de Janeiro e da Bahia. O provável motivo de esse curso ter sido criado na Bahia é exatamente porque aqui foi a primeira Faculdade de Medicina do Brasil, fundada nesse estado em 1808, conforme já ressaltado anteriormente, ainda que já houvesse um declínio de sua importância política desde a transferência da sede do governo imperial de Salvador para o Rio de Janeiro, ocorrida em 1762. Essa breve descrição histórica é reveladora do processo de esvaziamento da Bahia enquanto polo dominante no Brasil, com perda de poder, recursos e prestígio. Cabe destacar que essa nova conformação influenciou a consolidação das políticas de Estado, inclusive as de saúde, com a república instaurada em 1889, estendendo-se por todo o século XX. (JACOBINA; GALDINO, 2012)

Cabe destacar também que a emergência da odontologia social ocorre, diferentemente da medicina social (MACHADO et al., 1978), apenas no século XX, a partir dos trabalhos de Mário Chaves, cuja publicação Manual de odontologia sanitária, em três volumes, sistematiza essa disciplina "como aquela disciplina da saúde pública responsável pelo diagnóstico e tratamento dos problemas de saúde oral da comunidade”. (CHAVES, 1960, p. 24) Mário Chaves, juntamente com Alfredo Reis Viegas, inaugurou no Brasil o curso que confere a especialidade ao "Dentista de Saúde Pública" e as recomendações do Manual de odontologia sanitária orientaram as práticas, organização e docência da odontologia pública, cuja matriz foi influenciada principalmente pela saúde pública norteamericana. ${ }^{1}$

A reprodução desse curso formou gerações de dentistas sanitaristas brasileiros e latino-americanos. Dentre os sanitaristas formados, encontram-se

\footnotetext{
Na década de 1950, quando chega ao Brasil as ideias e práticas da odontologia sanitária, cujo agente principal no país foi o professor Mario Chaves. Em 1951, incorporou-se ao Serviço Especial de Saúde Pública (SESP), a Secção de odontologia sanitária, onde foi coordenador durante dois anos. Com a introdução da odontologia sanitária no SESP, iniciam-se atividades complementares às atividades assistenciais da previdência social, enquanto práticas odontológicas voltadas para escolares, influenciada pelas ideias da odontologia sanitária. (NARVAl, 1994)
} 
agentes importantes para a compreensão do espaço em estudo, como é o caso na Bahia de professor Jairo Diniz. Ademais, a tradução do Manual de odontologia sanitária para o espanhol, por ex-alunos do primeiro curso de saúde pública desenvolvido no Brasil, na Universidade de São Paulo (USP), vai possibilitar a disseminação desse conhecimento pela América Latina, Caribe e pelo mundo², expandindo a odontologia sanitária. (SOARES, 2011)

A odontologia social pode ser compreendida como sinônimo de odontologia sanitária, pois mantém suas mesmas bases conceituais como a ideia de "trabalho organizado na comunidade e para a comunidade, no sentido de obter as melhores condições possíveis de saúde bucal”. (CHAVES, 1986, p. 16) Reitera a relação desta com as disciplinas de saúde pública, sendo responsável pelo “[...] diagnóstico e tratamento dos problemas de saúde bucal da comunidade, entendendo a saúde bucal como aquela que abrange dentes e outras estruturas da cavidade bucal sob a responsabilidade do dentista." (CHAVES, 1986, p. 16)

Não foram encontrados estudos que analisem o surgimento do discurso e das práticas da odontologia social na Bahia. Nesse sentido, este capítulo analisou a emergência do espaço da odontologia social na Bahia nos anos 1940-1960, identificou e caracterizou alguns dos principais agentes do polo dominante, bem como suas trajetórias e inserção em distintos campos sociais, caracterizando também as condições históricas de possibilidade dessa emergência.

Para isso, foram revisados documentos históricos, incluindo o acervo da Faculdade de Medicina da Universidade Federal da Bahia (UFBA), no Terreiro de Jesus; foram localizadas as teses publicadas no período, bem como as matérias de jornais no período; foram entrevistados familiares e pessoas contemporâneas ao período analisado dos agentes investigados; foram reconstruídas as biografias dos agentes, buscando realizar um diálogo com a historiografia com respeito à emergência de práticas de odontologia social na conjuntura Vargas, na qual os agentes se situavam.

Do ponto de vista do referencial teórico, o conceito de espaço social se refere a um espaço de relações de força entre agentes engajados em lutas concorrentes em torno de um objetivo comum. Nesse caso específico, o "espaço da odontologia social" foi considerado um espaço onde há um conjunto de agentes que possuem diversas espécies de capital (econômico, cultural e social), como acúmulos, que são as principais formas de poder, onde as tomadas de posição são resultado da incorporação ou inculcação de princípios de visão 
de mundo, como disposições socialmente incorporadas ou habitus, resultado da conjunção da origem familiar, capital cultural e trajetória ao interior dos distintos campos sociais. (BOURDIEU, 1996) Não se buscou reconstruir toda a estrutura desse espaço social específico e datado, mas apenas revelar alguns dos fatos relacionados à trajetória dos agentes e das estruturas sociais naquele momento histórico.

\section{Condições de possibilidade na Era Vargas 1930-1954}

A análise das condições históricas de possibilidade do período de origem da odontologia social da Bahia é necessária para compreender as tomadas de posição e a disposições políticas dos principais agentes defensores da odontologia social.

É importante ressaltar que essa ampla conjuntura política (1930-1954) da chamada Era Vargas foi iniciada com a revolução de 1930, que representou o marco do início da Nova República do Brasil. Dessa maneira, chega ao fim a República Velha, representada pelas oligarquias dos estados de Minas Gerais e São Paulo. Assim, esse período da Nova República significou mudanças na forma de se pensar a saúde, economia e a política brasileira. Observa-se o nascimento de uma classe média que pressionava por mudanças no modo de se conduzir o país, que até então era dominado por uma pequena oligarquia ruralista e regionalista. Assim, a chegada de Getúlio Vargas ao poder marca um período de grande entusiasmo e construção da identidade nacional, com maior impulso à indústria nascente e criação também de diversas empresas estatais, a exemplo da Vale do Rio Doce e a Petrobras, em 1939.

Já os anos 1950 são considerados "os anos dourados", pois representaram o pós-guerra, com o fim do apogeu dos governos ditatoriais, do nazi-fascismo e o fim da ditadura Vargas. De outra forma, na Bahia, descobre-se o petróleo no bairro do Lobato. Porém, inicia-se a Guerra Fria com o mundo dividido em dois blocos: do capitalismo, liderado pelos Estados Unidos, e do socialismo, liderado pela União Soviética. Cria-se a Organização das Nações Unidades, polo de disputas do poder transnacional e o Estado de Israel. O Brasil, por outro lado, volta à democracia com as eleições presidenciais, pelas quais Gaspar Dutra é eleito presidente em 1946. O governo de Eurico Gaspar Dutra foi marcado pela promulgação da nova Constituição Brasileira de 1946, que, entre suas pautas importantes, estão: igualdade de todos perante a lei, liberdade de manifestação de pensamento, sem censura e separação dos três poderes. Em 1951, Getúlio 
Vargas volta ao poder, pois é eleito presidente pelo voto popular, sendo que seu governo continua marcado pela propaganda nacionalista e na promoção da industrialização. Em seu último mandato, Vargas cria as empresas estatais Petrobras, Eletrobrás e o Banco Nacional de Desenvolvimento, bem como os centros de profissionalização SENAI e SENAC e a siderúrgica de Volta Redonda.

No Brasil, no que tange à saúde pública, observa-se uma redução lenta da mortalidade por envelhecimento da população, há predomínio das doenças da pobreza e aparecimento da morbidade moderna (doenças do coração, neoplasias, acidentes e violências), com a industrialização, urbanização e mudanças nas condições de vida e saúde. A partir de 1930, inicia-se no país uma maior intervenção do Estado na saúde, além das ações de combate a epidemias com uma ação estatal de forma trifurcada (saúde pública, medicina previdenciária e saúde do trabalhador) através da institucionalização da saúde pública - Ministério da Educação e Saúde, e criação do Serviço Especial de Saúde Pública (SESP) - (CAMPOS, 2000) e da medicina previdenciária e saúde ocupacional - Ministério do Trabalho.

Apesar do período de grande avanço nas manifestações culturais e da perspectiva de progresso da nação nos anos 1950, uma grave crise econômica e política leva ao fim o governo Vargas, com seu suicídio em 1954, pondo fim ao Estado Novo. Em 1956, Juscelino Kubitschek ganha as eleições presidenciais e adota uma política desenvolvimentista com o famoso lema "cinquenta anos em cinco". Com a criação da cidade de Brasília, a capital do Brasil é transferida do Rio de janeiro. Na Bahia, em 1946, sobre o governo de Guilherme Carneiro da Rocha Marback, são criados, em 2 de julho desse ano, a UFBA e o Hospital das Clínicas da UFBA, tendo com reitor o médico Edgar Santos. Nessa conjuntura, cabe analisar a trajetória social dos dois agentes identificados (Aloysio Lopes-Pontes e Jairo Diniz).

\section{Aloysio Lopes Pontes: o pensamento higienista na odontologia social}

Aloysio Geraldo Souza Brito Lopes Pontes nasceu em 1918 na cidade de Salvador, Bahia, e faleceu em 1999, aos 81 anos. De família tradicional, com grande capital cultural e social, era irmão mais novo de irmã Dulce. Aloysio Lopes Pontes formou-se cirurgião-dentista pela Faculdade de Medicina da Bahia em 1941, sete anos depois de seu irmão mais velho, Augusto Raimundo Lopes Pontes. Seu pai, Augusto Lopes Pontes, também era cirurgião-dentista. Por essa formação, a família Lopes Pontes vivenciou as permanências e rupturas das 
práticas odontológicas realizadas na Bahia entre os períodos de 1920 a 1970, assim como os avanços científicos do conhecimento voltados para a melhoria da saúde bucal para a população brasileira e baiana.

Seu avô paterno, Manoel Lopes Pontes (1845-1899), era natural da cidade de Santo Amaro, foi deputado estadual, professor e fundador do colégio Santo Antônio. Seu avô materno, Manoel Joaquim de Souza Brito, foi médico, jornalista, escritor e professor. Sua mãe era professora, mas faleceu aos 26 anos de idade por complicações no parto do sexto filho. O pai de Aloysio, professor catedrático da Faculdade de Medicina da Universidade da Bahia, apoiava instituições filantrópicas pelo espírito de caridade com relações próximas a intelectuais baianos, a exemplo de Ruy Barbosa. Foi o fundador do Abrigo Filhos do Povo, que funcionava no bairro da Liberdade, ali criando o posto odontológico onde atendia a população pobre, gratuitamente. Era um católico filantrópico e social, que criou também os estatutos da Associação Obras Sociais Irmã Dulce (Figura 1).

Figura 1 - Aloysio Lopes Pontes (de óculos) ao lado de Irmã Dulce, sua irmã, e seu pai, Augusto Lopes Pontes e outros parentes

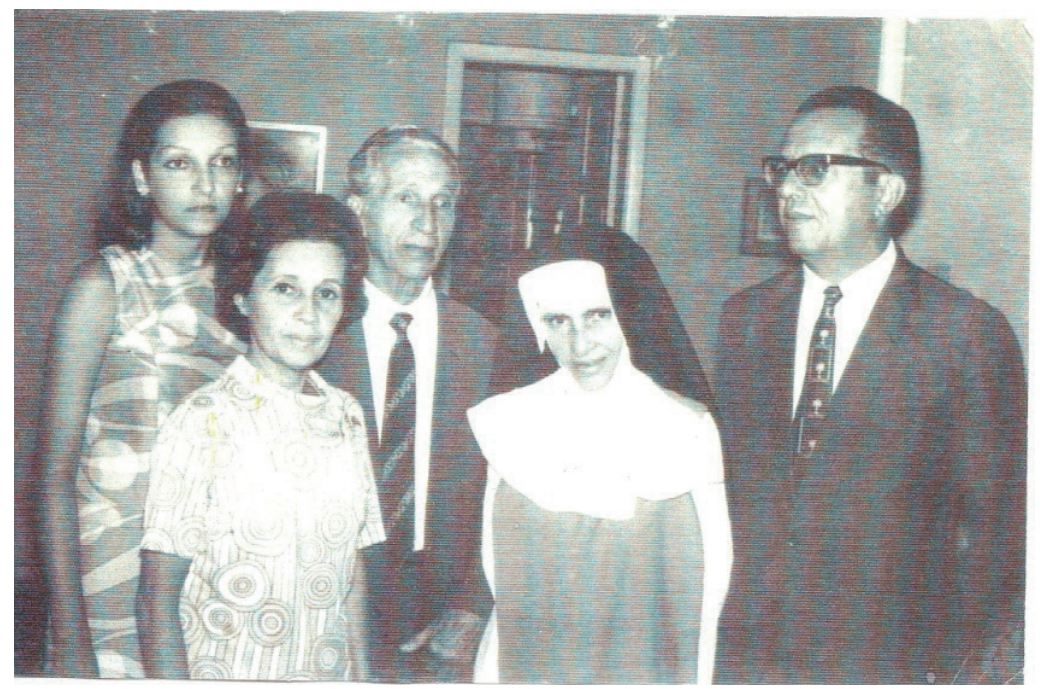

Fonte: acervo da família.

A trajetória no campo burocrático de Aloysio se inicia em paralelismo com sua carreira no incipiente campo científico odontológico baiano, sendo seu lócus principal a saúde do escolar ou assistência dentária escolar. Assumiu o 
cargo de cirurgião-dentista (classe G interino), em 1944, na Secretaria de Saúde Pública e Assistência Social da Bahia e, posteriormente, em 1950, prestou concurso para provimento do cargo efetivo de cirurgião-dentista, consolidando-se na classe J (1951), sendo logo promovido a chefe da Secção de Higiene da divisão médico-escolar do Departamento Estadual da Criança. Foi também dentista escolar do Colégio Central da Bahia e da Escola Maria Quitéria e, posteriormente, no consultório odontológico do $2^{\circ}$ Centro de Saúde Mário Andrea.

Tornou-se superintendente do Serviço Central de Higiene e Assistência Odontológica de Saúde Pública e Assistência Social, nomeado em 1967. É importante salientar que, desde 1935, na Bahia, a Secretaria de Saúde era conjunta com a de Educação, sendo intitulada Secretaria de Educação, Saúde e Assistência social. A separação dos órgãos ocorreu no governo do médico Luis Régis Pereira Pacheco (1951-1955).

Há relatos de dentista escolar na Bahia desde os anos 1920. Um processo movido por um dentista escolar para ganhos financeiros afirma

[...] Eu, cirurgião dentista Eneas Rocha, funcionário do ensino pertencente ao corpo administrativo da Escola Normal da Capital como encarregado do serviço dentário anexo à esta Escola [...] peço-vos o favor das competentes providencias concernentes à regularização na tabela anexa ao projeto de código da educação[...] "lei 1668 de 30 de agosto de 1923: fica criada a clínica dentária escolar anexa à Escola Normal da Capital. É também criada o lugar de zeladora do respectivo gabinete dentário". Essa lei também criou a clínica cirúrgica dentária na assistência pública [...] a lei 1846 de 14 de agosto de 1925 no art. 144: para educar praticamente os discentes do curso de professorado e os das escolas de aplicação, nos cuidados salutares de higiene profilática e de conservação dos dentes, haverá na escola normal da capital, um serviço de clínica odontológica provido do material indispensável e o cargo de cirurgiã-dentista nomeado por decreto do governador [...] o gabinete dentário anexo ao estabelecimento funcionará com o objetivo de educar praticamente os discentes nos cuidados salutares da higiene dos dentes. (BAHIA, 1937, p. 148)

No período em que Aloysio assumiu o cargo de cirurgião-dentista, o governador da Bahia, ainda na ditadura Vargas, foi o General Onofre Pinto Aleixo (1942-1945), que teve como secretário de Educação e Saúde o médico Aristides Novis. Dessa forma, é importante destacar que muitos profissionais da área de 
saúde estavam intimamente ligados a cargos políticos, constituindo uma rede de autoridades públicas envolvidas nas questões de higiene e saúde.

A trajetória na burocracia estatal se articula com sua carreira acadêmica na Faculdade de Odontologia da Bahia, onde foi docente-livre de Higiene e Odontologia Legal, com sua primeira tese defendida na Faculdade de Odontologia da Universidade da Bahia, intitulada Educação sanitária odontológica: aspectos e problemas, em 1954. Assim, acreditava que para o combate à cárie era necessária a educação sanitária do povo "prevenir para não curar eis o lema da odontologia preventiva", com grande influência da higiene que já havia sido disseminada no século XIX na Europa e mais tarde nos Estados-Unidos e que estava ganhando adeptos no Brasil. As práticas da odontologia social eram baseadas em campanhas e concursos do "mais belo sorriso" em escolas da rede pública (Figura 2).

Figura 2 - Grupo de dentistas na Escola Estadual Góes Calmon, nos anos 1953, em atividade da I Semana de Higiene Dentária do estado da Bahia com Aloysio segundo à direita. Presença do pai de Aloysio (primeiro à esquerda) como diretor da Faculdade de Odontologia

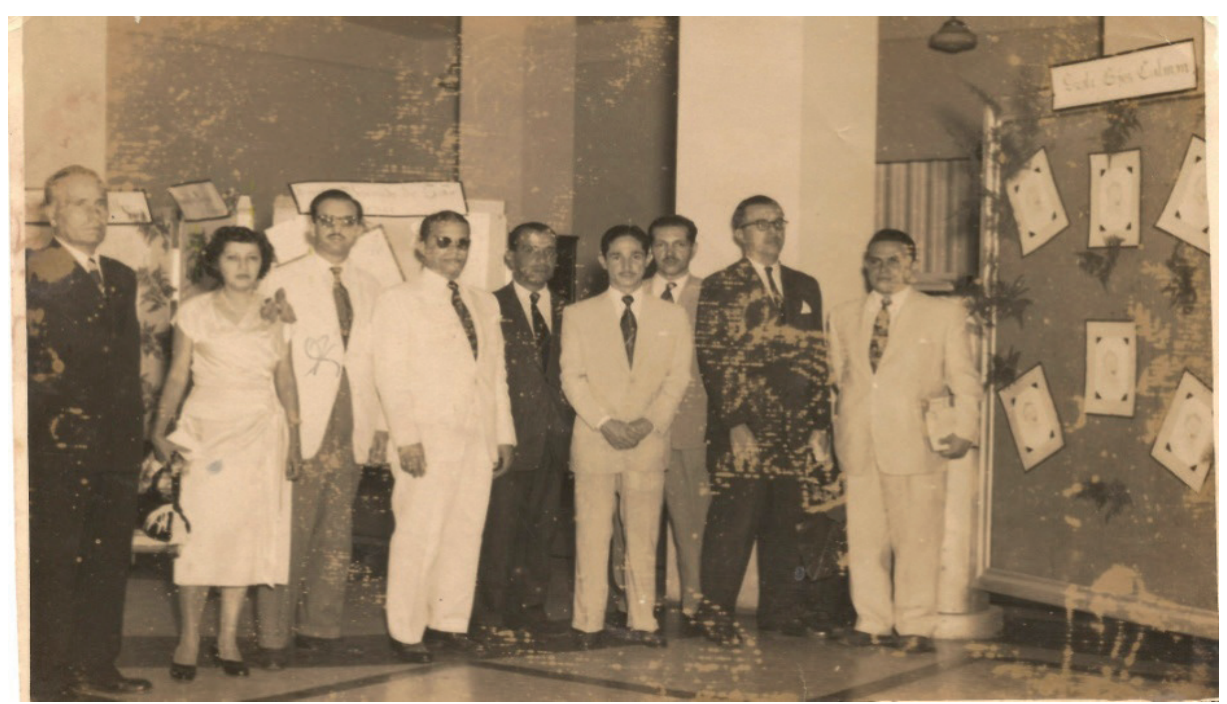

Fonte: acervo da família.

Nessa primeira tese, ele constrói um discurso em torno da cárie dentária que é importante destacar:

[...] desde os tempos mais recuados da vida no planeta que o homem sofre de cárie dentária, mas em tempo algum ela atingiu tão alto grau de incidência 
como atualmente, a ponto de ser chamada 'doença da civilização' e de ser incluída entre os flagelos da humanidade, [...] ela (a cárie dentária) constitui uma verdadeira praga [...] um dos mais sérios e devastadoras enfermidades da nossa época. (LOPES-PONTES, 1952 p. 3, 5, 6)

Há uma crítica à odontologia restauradora:

[...] o pior é que a função restauradora da odontologia não constitui, de todo, uma arma eficiente no combate à cárie. Por mais que obturemos as cavidades dentárias, não conseguiremos extinguir a 'praga' porquanto novos e novas cáries surgirão, de futuro. (LOPES-PONTES, 1952, p. 6)

A defesa da infância está em muitos trechos do seu trabalho:

Olhai as crianças e podereis avaliar o caráter de um povo. Elas são os indicadores do bem estar do nosso lar. A criança de uma democracia pode muito bem ser descrita como o barômetro da economia nacional [...] quantas crianças no Brasil nem sequer usam escovas de dentes! Tudo deve ser feito no Brasil em prol da higidez bucal, principalmente da criança porque como disse John Milton, poeta inglês: 'a infância mostra o homem assim como a manhã mostra o dia'. (LOPES-PONTES, 1952, p. 7, 11)

E propõe algumas intervenções baseadas em campanhas sanitária, do tipo "educação sanitária odontológica":

[...] ○ que se torna preciso, imperiosos, nessa campanha de educação sanitária odontológica é esclarecer por todos os meios possíveis, a importância dos dentes para a saúde, especialmente da criança. [...] execução de um programa de educação sanitária odontológica visando os pais, gestantes e crianças em idade pré-escolar e escolar e organização pelo estado da Bahia, à semelhança do outros estados do nosso país, de um completo, moderno e eficiente serviço de assistência odontológica à infância, visando principalmente o aspecto profilático e preventivo. (LOPESPONTES, 1952, p. 93)

Sua segunda tese, intitulada Das condições do primeiro molar permanente em 11.343 escolares baianos, trabalho de concurso para Cátedra de Higiene e Odontologia Legal da Faculdade de Odontologia da Universidade da Bahia, Aloysio 
manteve o seu discurso em defesa da disseminação da higiene. Entretanto, nesse trabalho, vai além do enfoque normativo e relato da experiência no Departamento Estadual da Criança do Estado da Bahia e produz o primeiro estudo epidemiológico sobre as condições de cárie dentária dos escolares baianos onde, segundo ele, os números, a eloquência dos dados estatísticos, seriam mais fortes do que palavras e conceitos. (LOPES-PONTES, 1962) A trajetória no campo burocrático e científico de ambos os agentes está sumarizada no Quadro 1.

\section{Quadro 1 - Trajetória nos campos científico e burocrático de dois agentes do polo dominante na origem da odontologia sanitária/Social na Bahia nos anos 1940-50}

\begin{tabular}{|c|c|c|}
\hline Agente & $\begin{array}{c}\text { Trajetória no campo burocrático } \\
\text { (Estado) }\end{array}$ & Trajetória no campo científico \\
\hline $\begin{array}{l}\text { Aloysio Lopes } \\
\text { Pontes }\end{array}$ & $\begin{array}{l}\text { Foi nomeado cirurgião dentista interino } \\
\text { do Serviço Público do Estado da } \\
\text { Bahia, em } 27 \text { de julho de 1944, por } \\
\text { Decreto Lei 12.076. Posteriormente, } \\
\text { foi dentista escolar, no Colégio } \\
\text { Estadual Central da Bahia (1944- } \\
\text { 1947). Depois, prestou concurso } \\
\text { para o Departamento do Serviço } \\
\text { Publico da Bahia, para provimento } \\
\text { efetivo do cargo de Cirurgião Dentista } \\
\text { da Secretaria de saúde Publica e } \\
\text { assistência Social (1950), passando } \\
\text { a Cirurgião dentista efetivo (1951). } \\
\text { Assumiu a chefia da Secção de Higiene } \\
\text { Assistência dentaria da Divisão Medico- } \\
\text { Escolar do Departamento Estadual da } \\
\text { Criança (1951-1962). Foi nomeado } \\
\text { Superintendente do Serviço Central } \\
\text { de Higiene e Assistência Odontológica, } \\
\text { da Secretaria de Saúde Publica e } \\
\text { Assistência Social. }\end{array}$ & $\begin{array}{l}\text { Assistente Honorário da Cadeira de } \\
\text { prótese da Faculdade de Odontologia da } \\
\text { Universidade da Bahia (1947-1954). } \\
\text { 1954, apresenta sua primeira tese } \\
\text { "Educação Sanitária Odontológica: } \\
\text { Aspectos e Problemas” para o cargo de } \\
\text { Docente Livre de Higiene e Odontologia } \\
\text { Legal da Faculdade de Odontologia da } \\
\text { Universidade da Bahia.Professor regente de } \\
\text { Higiene e Odontologia Legal da Faculdade } \\
\text { de Odontologia da Universidade da Bahia. } \\
\text { Catedrático Interino de Higiene e } \\
\text { Odontologia Legal, da Faculdade de } \\
\text { Odontologia da Universidade Federal da } \\
\text { Bahia (1961). } \\
\text { Enquadrado como Assistente de Ensino } \\
\text { superior (1964) e depois enquadrado } \\
\text { como professor adjunto (1967). } \\
\text { Enquadrado como professor catedrático da } \\
\text { cadeira de Higiene e Odontologia Legal pela } \\
\text { Universidade da Bahia (1967). Foi também } \\
\text { professor de odontologia sanitária da Escola } \\
\text { Bedicina e Saúde Pública. }\end{array}$ \\
\hline
\end{tabular}




\section{Quadro 1 - Trajetória nos campos científico e burocrático de dois agentes do polo dominante na origem da odontologia sanitária/Social na Bahia nos anos 1940-50}

\begin{tabular}{|c|c|c|}
\hline Agente & $\begin{array}{c}\text { Trajetória no campo burocrático } \\
\text { (Estado) }\end{array}$ & Trajetória no campo científico \\
\hline Jairo Diniz & 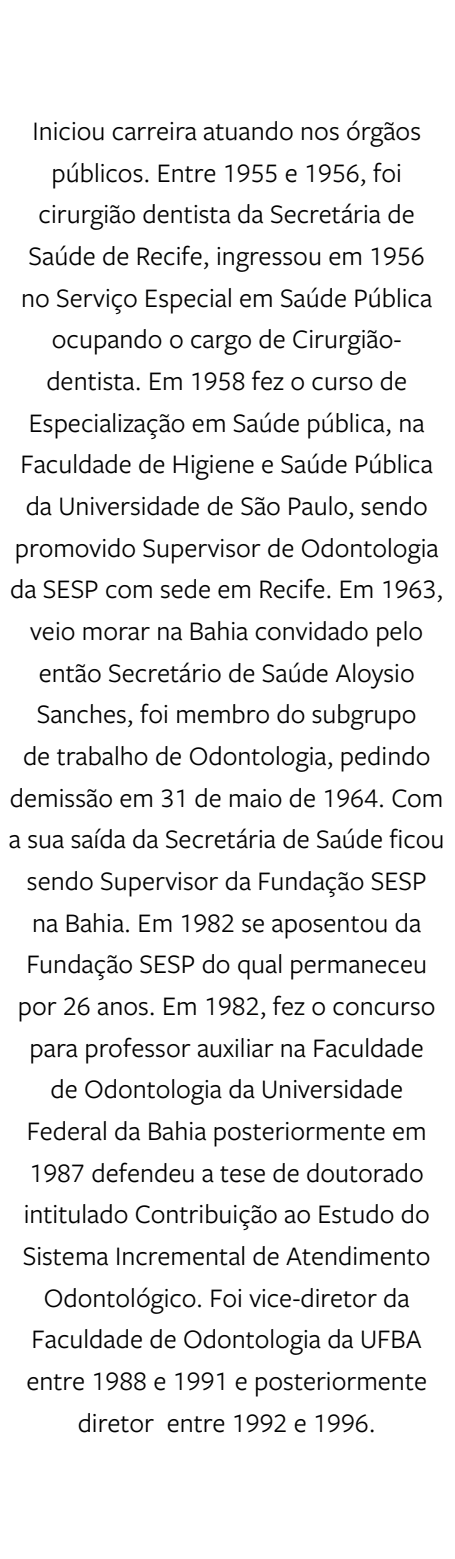 & 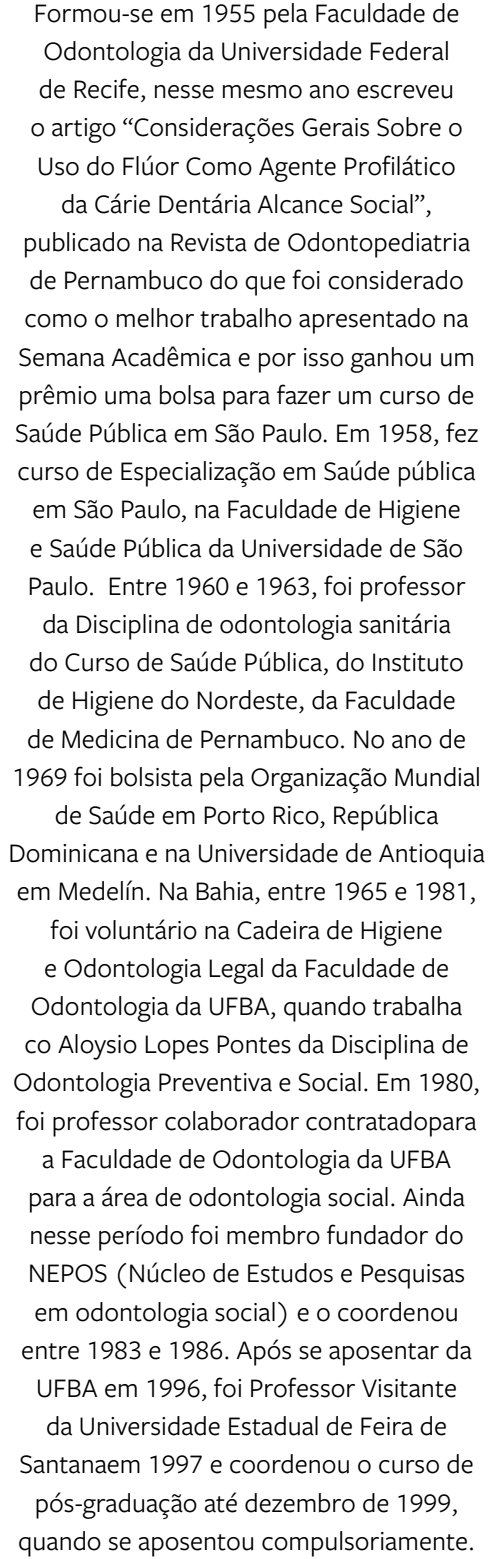 \\
\hline
\end{tabular}


Nesse sentido, percebe-se que Aloysio Lopes Pontes é de origem familiar com grande capital global acumulado com influência católica social, o que possivelmente o fez se envolver com as questões sociais e políticas de seu tempo. Interessou-se pela saúde pública quando assumiu o cargo de cirurgião-dentista da Secretaria de Saúde Pública e Assistência Social da Bahia, em 1944, e posteriormente foi promovido a chefe da secção de higiene da divisão médico-escolar do Departamento Estadual da Criança. Foi membro fundador da Associação Brasileira de Odontopediatria da Bahia.

Outra característica importante do seu capital social é sua influência na imprensa baiana. Exemplo disso são os artigos publicados em jornais, no qual todos estão relacionados ao tema odontológico e tendo como pedra angular a profilaxia. Foram cerca de 66 artigos publicados - sendo 20 em defesa da fluoretação das águas -, entre 1952 e 1970, nos principais jornais de circulação da Bahia, especialmente o jornal A tarde, um dos mais influentes em Salvador no período (Figura 3).

Dessa maneira, a grande maioria dos artigos publicados tiveram como tema central sempre a odontologia social, com objetivo de alertar o leitor para a importância de se cuidar dos dentes. Além disso, essas publicações tiveram também uma característica política, uma vez que vários artigos eram voltados para seu posicionamento a favor da fluoretação das águas, assunto de grandes discussões e posições opostas que se prolonga até a contemporaneidade.

Assim, além de trabalhos estritamente acadêmicos, Aloysio, fluente em francês e inglês, dialogava e se posicionava atento às transformações científicas odontológicas do período, com grande espaço na mídia impressa. As práticas comuns nesse período dos dentistas escolares eram as campanhas sanitárias em escolas na promoção de concursos em semanas de higiene dentária (Figura 4). 
Figura 3 - Matéria do jornal A Tarde, de Aloysio Lopes Pontes, em 23 de março de 1956, numa série de 20 publicações sobre os aspectos a favor e contra a fluoretação das águas

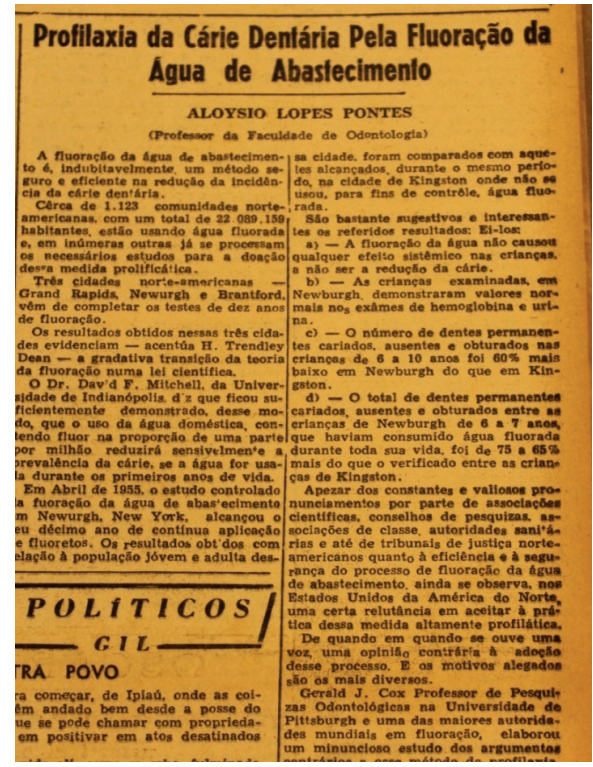

Fonte: acervo jornal A Tarde.

Figura 4 - Ações da Assistência Dentária Infantil de Pernambuco, em 1956, que presta assistência odontológica gratuita às crianças "pobres" do Recife

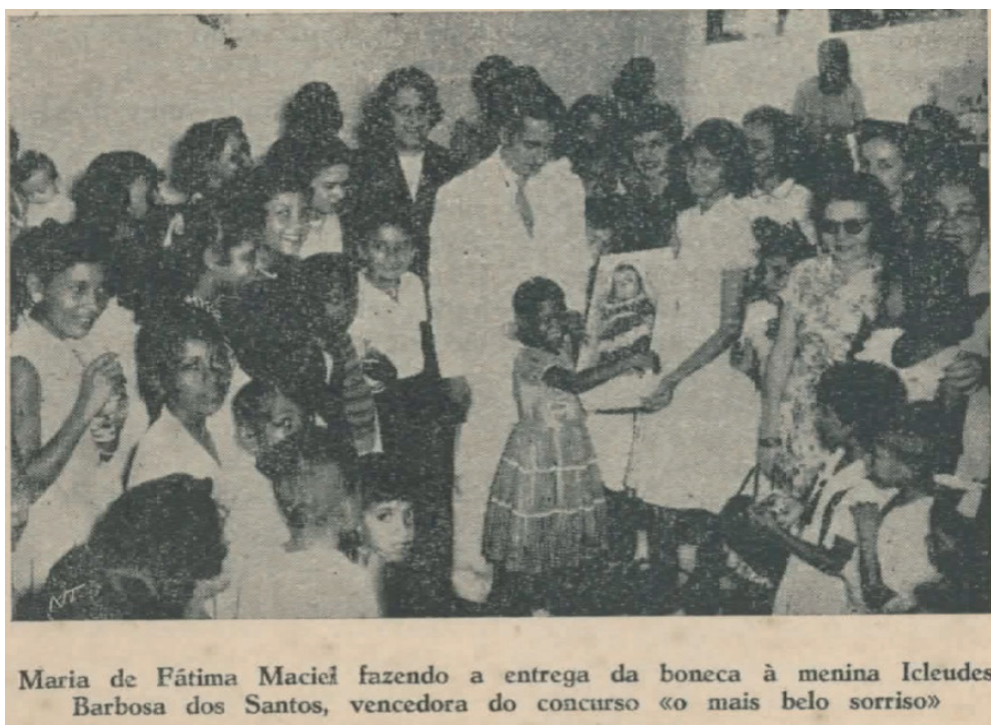

Fonte: Revista de Odontopediatria de Pernambuco (1956). 


\section{Jairo Diniz: a defesa da saúde como direito e o conhecimento sobre a ação do flúor}

Pernambucano, nasceu em Pedra, em 1929, e faleceu em Salvador, Bahia, em 2013, aos 84 anos. De família tradicional de interior, seu avô foi prefeito da sua cidade natal e seu pai e irmão foram coletores de impostos estaduais. Em 1955, forma-se cirurgião-dentista em Recife e, desde a graduação, é defensor da odontologia sanitária e social, tendo forte influência de Mário Chaves. Dessa forma, fez parte da equipe que implantou a odontologia sanitária no SESP, cujo pioneiro foi o professor Mario Chaves, que, em 1952, inaugurou o Sistema Incremental no Brasil na cidade de Aimorés, Minas Gerais, e implementou o primeiro sistema de fluoretação de águas de abastecimento público em Baixo Gandu, Espírito Santo, em 1953. Jairo Diniz defendia a saúde como um direito de todo o homem e que a odontologia prestava nobre colaboração à humanidade no setor da higiene e saúde pública além de atrelá-la ao "progresso", Como se observa no seu primeiro trabalho:

[...] A impossibilidade de dissociação da nossa ciência-arte com o progresso ascensional do mundo moderno. Caminhamos paralelamente com o seguimento das demais ciências contribuindo em igualdade de condições para a evidenciação e o alcance dos valores eugênicos e sociais, morais e espirituais da humanidade. (DINIZ, 1956, p. 24)

Saúde é uma das necessidades fundamentais da existência, é um direito do homem, sem distinção de raça, religião, ideologia política ou situação econômico-social. Basta meditarmos nas estatísticas de que nos países onde o poder estatal mais e melhor olha para os problemas de saúde da população. (DINIZ, 1956, p. 24)

Essa publicação, ainda como aluno de odontologia, marcará profundamente sua trajetória profissional, já que esse trabalho garantiu-lhe uma bolsa para fazer um curso de saúde pública em São Paulo pelo SESP, onde inicia uma rede de relações, que incluiu professor Mário Chaves, que posteriormente participará de sua banca de professor. Assim, ingressou em 1956 como cirurgião-dentista no Serviço Especial de Saúde Pública, trabalhando na cidade de Propriá, interior de Sergipe. O serviço dentário escolar do SESP foi implementado inicialmente em Aimorés, em 1952, mas também teve postos na Bahia. (NARVAI, 2006) Em 1958, finalmente fez o curso de Especialização em Saúde Pública, na 
Faculdade de Higiene e Saúde Pública da USP, sendo promovido supervisor de odontologia do SESP, em Recife. Em 1963, veio morar na Bahia, convidado pelo então secretário de saúde Aloysio Sanches, sendo membro do subgrupo de trabalho para elaborar um inventário dos recursos de odontologia do estado da Bahia. Foi assistente do secretário de saúde, nomeado por decreto pelo governador do estado da Bahia, pedindo demissão, em 31 de maio de 1964, com o Golpe Militar. Com a sua saída da Secretária de Saúde, ficou sendo supervisor da Fundação Serviços de Saúde Pública (FSESP), na Bahia (Figura 5). Em 1969, ainda como chefe da seção de odontologia da FSESP, foi contemplado com bolsa de estudos de quatro meses da Organização Mundial da Saúde e viajou para Colômbia, México, Estados Unidos e Porto Rico, para conhecer os diversos serviços de assistência odontológica integrados à saúde pública lá implantados. Em 1982, aposentou-se da FSESP, na qual permaneceu por 26 anos. Em 1982, fez o concurso para professor auxiliar na Faculdade de Odontologia da UFBA e posteriormente, em 1987, defendeu a tese de doutorado intitulada Contribuição ao estudo do sistema incremental de atendimento odontológico. Foi vice-diretor da Faculdade de Odontologia da UFBA, entre 1988 e 1991, e posteriormente diretor, entre 1992 e 1996. Foi também professor na Universidade Estadual de Feira de Santana (UEFS) até sua aposentadoria compulsória.

Figura 5 - Atividades de Assistência Dentária ao Escolar dos Serviços Especiais de Saúde Pública nos anos 1950. Jairo Diniz realizando exame epidemiológico em escolares no interior da Bahia e supervisão de aplicação tópica de Flúor em Pernambuco, 1957.
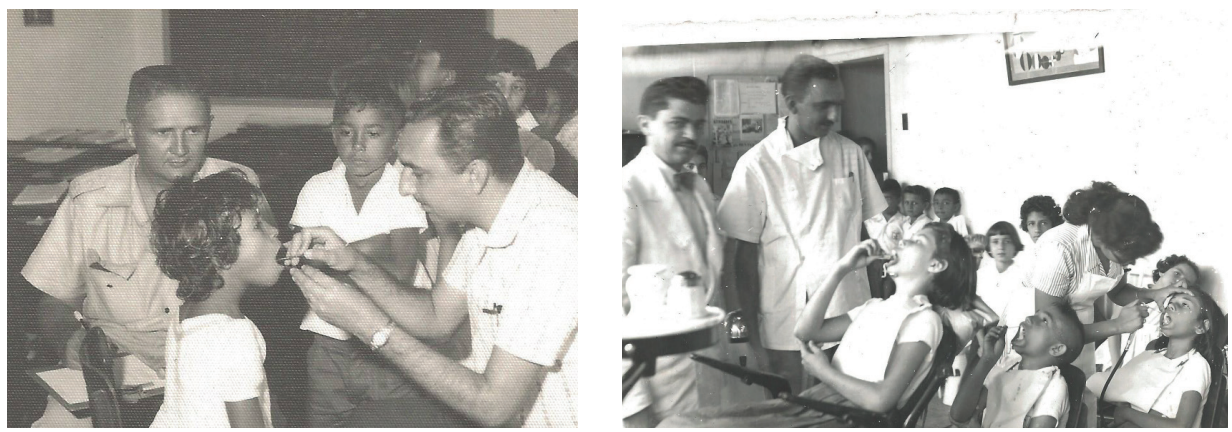

Fonte: Acervo familiar. 


\section{Considerações finais}

A emergência da odontologia social na Bahia esteve relacionada a condições de possibilidade concretas do avanço da intervenção estatal na saúde da Era Vargas, incluindo a oferta de serviços públicos odontológicos, ainda que limitados. Um exemplo disso foi a expansão do cargo de cirurgião-dentista escolar, ligado ao movimento de proteção da infância no Brasil, como o caso de São Paulo (MARTINO; BOTAZZO; ZILBOVICIUS, 2010) e da Bahia, com a puericultura e hospitais para crianças, já revelado em estudos anteriores (SOUZA; BARRETO, 2011) que o mesmo contexto foi observado na Europa e Estados Unidos, ao final do século XIX. (MARTINO; BOTAZZO; ZILBOVICIUS, 2010) A invenção do cargo de dentista escolar deve ser maior esclarecida em estudos posteriores, haja vista que sua inserção na Bahia data dos anos 1920, com trabalho em gabinete dentário na escola e com "o objetivo de educar os alunos nos cuidados salutares da higiene dos dentes". 3

Os principais agentes identificados na Bahia, nos anos 1950-1960, foram Aloysio Lopes Pontes, de família tradicional de alto capital cultural, e Jairo Diniz, com carreira consolidada no SESP. Ambos foram professores da Faculdade de Odontologia da UFBA, com trajetórias profissionais distintas, mas com disposições muito próximas. Aloysio Lopes Pontes teve inserção no campo burocrático como dentista da Secretaria de Assistência Social, em 1942, com posterior inserção no campo científico, nos anos 1950. Por outro lado, Jairo Diniz foi profissional de dedicação exclusiva do Serviço Especial de Saúde Pública, agência bilateral Brasil-Estados Unidos, fundada no período da Segunda Guerra Mundial, que só tardiamente na carreira, assume o cargo de professor.

As contribuições, nos anos 1940 e 1950, na Bahia, para a emergência desse espaço podem ser de dois tipos. A primeira foi a construção social do problema da cárie dentária como flagelo comparável às epidemias do período, ou como "flagelo moderno da humanidade", presente no pensamento higienista de Aloysio Lopes Pontes, através do qual a higiene é vista como a única intervenção possível pelos limites do conhecimento científico no campo médico desse período, no que se refere ao uso do flúor, cujo uso se consolida apenas no final dos anos 1950, com grande influência do SESP. A segunda contribuição foi 
a defesa do cirurgião-dentista escolar no estado da Bahia, com foco na proteção da infância.

Já em 1912, em São Paulo, iniciou-se a Assistência Dentária Escolar na atenção pública, de início, sob o viés da filantropia e, já em 1913, com auxílios públicos provindos da prefeitura da cidade. A presença do serviço dentário em São Paulo tem relação com a defesa da assistência à criança e, principalmente, da assistência ao escolar. Em 1925, o cargo de inspetor dentário na Inspetoria Médico Escolar é criada, também em São Paulo. A maior expansão nesse estado será nos anos 1950, quando já se observa mais de 1000 dentistas escolares em 732 clínicas odontológicas públicas. (DINIZ, 1955)

Nossa hipótese é que o pensamento social na odontologia inicia-se na recém-criada especialidade da odontopediatria, ainda em processo de consolidação no seu primeiro Congresso Nacional, em 1955, tendo como locus principal a escola, especialmente a partir dos avanços no conhecimento quanto ao uso do flúor tópico para prevenção da cárie dentária nos anos 1950. Jairo Diniz, ao utilizar os termos "odontopediatria estatal ou pública", aponta nessa direção. Essas evidências podem explicar em parte o predomínio atual do modelo centrado no escolar, comum ainda no século XXI, ainda a ser superado pelo movimento da saúde bucal coletiva. A luta em defesa de uma odontologia social iniciada por Aloysio Lopes Pontes e por Jairo Diniz, nos anos 1950, ainda é, portanto, um desafio na contemporaneidade.

\section{Referências}

BOURDIEU, P. Razões práticas: sobre a teoria da ação. 6. ed. Campinas, SP: Papirus; 1996. BOURDIEU, P. Sur l'État: Cours au Collège de France 1989-1992. Paris: Éditions Raisons D’agir ; Éditions Seuil, 2012.

CAMPOS, A. L. V. Políticas internacionais de saúde na era Vargas: o serviço especial de saúde pública. In: GOMES, A. C. (Org.) Capanema: o ministro e seu ministério. Rio de Janeiro: Fundação Getúlio Vargas, 2000.

CHAVES, M. M. Manual de odontologia sanitária. São Paulo: Ed. USP, 1960. Tomo I. CHAVES, M.M. Odontologia sanitária. Washington, DC: OPS, 1962. (Publicação Científica 63).

CHAVES, M. M. Odontologia social. 3. ed. Rio de Janeiro: Artes Médicas, 1986.

CHAVES, S. C. L.; CRUZ, D. N. Desafios contemporâneos à organização da atenção em saúde bucal na Bahia. Revista Baiana de Saúde Pública, Salvador, v. 36, n. 1, p. 621-639, jul./ set. 2012. 
CUNHA, E. S. História da odontologia no Brasil (1500-1900). 2. ed. Rio de Janeiro: Científica, 1952.

DINIZ, J. Contribuição ao estudo do sistema incremental de atendimento odontológico. 1987. 144 p. Tese (Doutorado em Odontologia) - Faculdade de Odontologia, Universidade Federal da Bahia, Salvador, 1987.

DINIZ, J. Considerações gerais sobre o uso do Flúor como agente profilático de cárie dentária: alcance social decorrente. Revista de Odontopediatria da Associação Pernambucana de Odontopediatria, Recife, Ano IV, n. 9 p. 23-34, jan./dez. 1956.

JACOBINA, T. A.; GALDINO, B. História e saúde na Bahia. 2012. Disponível em: <http:// www.isc.ufba.br/saudeehistoria/Artigo_Historia_e_Saude_na_Bahia>. Acesso: 20 jun. 2014.

MACHADO, R. et al. Danação da norma: a medicina social e constituição da psiquiatria no Brasil. Rio de Janeiro: Edições Graal, 1978.

MARTINO, L. V. S.; BOTAZZO, C.; ZILBOVICIUS, C. Os caminhos públicos da odontologia paulista no início do século XX. Cadernos de História das Ciências, São Paulo, v. 6, n. 1, p. 141-156, jan./jul. 2010.

MOLESINI, J. A. O. A Reforma Sanitária na Bahia: um lugar na história (1987 a 1989). 2011. 263 f. (Doutorado em Enfermagem) - Universidade Federal da Bahia, Salvador, 2011.

NARVAI, P. C. Odontologia e saúde bucal coletiva. Rio de Janeiro: Hucitec, 1994.

NARVAI, P. C. Saúde bucal coletiva: caminhos da odontologia sanitária à bucalidade. Revista de Saúde Pública, São Paulo , v. 40, n. esp., p. 141-147, 2006.

PINELL, P. Análise sociológica de políticas de saúde. Rio de Janeiro: Editora Fiocruz, 2011 PONTES, M. R. Irmã Dulce dos Pobres. 13. ed. Rio de Janeiro: Sindicato Nacional, 1991.

LOPES-PONTES, A. G. Das condições do primeiro molar em 11.343 escolares baianos. 1962. 123 f. Tese (Concurso à Cadeira de Higiene e Odontologia Legal) - Faculdade de Odontologia da Universidade Federal da Bahia, 1962.

LOPES-PONTES, A. G. Educação sanitária odontológica: aspectos e problemas. 1954. 107 f. Tese (Concurso à Cadeira de Higiene e Odontologia Legal) - Faculdade de Odontologia da Universidade Federal da Bahia, 1954.

\section{REVISTA DE ODONTOPEDIATRIA DA ASSOCIAÇÃO PERNAMBUCANA DE} ODONTOPEDIATRIA, Recife, Ano IV, n. 9 p. 23-34, jan./dez. 1956.

SOARES, C. L. M. A Constituição da saúde bucal coletiva no Brasil. 2014. 180 f. Tese (Doutorado em Saúde Pública) - Instituto de Saúde Coletiva, Universidade Federal da Bahia, Salvador, 2014.

SOUZA, C. M. C.; BARRETO, M. R. N. História da Saúde na Bahia: instituições e patrimônio arquitetônico (1808-1958). São Paulo: Manole, 2011. 


\title{
Avaliação da atenção à saúde bucal no Brasil
}

CONCEITOS E ABORDAGENS

\author{
Sônia Chaves \\ Ana Carla Freitas Fonseca \\ Stella Maris Malpici Luna \\ Ana Maria Freire
}

\section{A avaliação em saúde: situando o debate ao interior do ciclo da política pública}

Política pública é compreendida como conjunto de intervenções organizadas pelo Estado através de diferentes governos com a participação de agentes e instituições governamentais e não governamentais que visam enfrentar situações socialmente problemáticas e buscam a resolução ou melhor manejo delas. Por outro lado, a análise de políticas públicas é “[...] campo disciplinar do conhecimento que busca colocar o 'governo em ação' e/ou analisar essa ação e propor mudanças no rumo ou curso dessas ações”. (SOUZA, 2007, p. 69)

Na perspectiva do ciclo da política pública, a avaliação se refere ao momento de fim de um determinado decurso da política e também àquele em que se inicia ou não novo período da política em amadurecimento. As avaliações são sempre pretendidas e nem sempre realizadas, conforme os princípios da cientificidade exigidos. Certo é que ajustes são conduzidos pelos agentes envolvidos em sua implementação. Assim, a política pode ser reformulada, aprofundada, não implementada ou mesmo abandonada. 
O interesse do Estado na avaliação de políticas públicas depende dos agentes e do momento histórico haja vista a possibilidade de tais estudos legitimarem processos políticos ${ }^{1}$ em curso, bem como ser hoje aspecto fundamental da modernização da administração pública que está atenta à gestão por resultados ou na perspectiva do accountability. ${ }^{2}$ A realização de avaliações de políticas tem sido exigência comum dos organismos financiadores. Pode-se considerar que é prática e pesquisa em crescimento no Brasil, haja vista o aumento da produção acadêmica e a constituição dos grupos de pesquisa no Conselho Nacional de Desenvolvimento Científico e Tecnológico, ainda que em menor escala em relação a outros países. (FURTADO; VIEIRA-DA-SILVA, 2014)

Alerta se faz necessário ao debate na literatura da constatação de que o produto da pesquisa não é incorporado à gestão. A premissa de que as evidências científicas, produzidas por pesquisas avaliativas bem conduzidas acerca do sucesso ou fracasso de programas, seriam automaticamente utilizadas pelos tomadores de decisão, relacionando essas avaliações à implementação de ações para alcance dos resultados esperados, não é verdadeira. Somos mais cautelosos e há um entendimento de que variados e legítimos aspectos (interesses, valores, motivações, recursos) estão implicados nas decisões políticas e nos usos das avaliações para tomada de decisão. Logo, é importante lembrar que a avaliação é útil, mas é apenas mais uma entre várias dimensões que podem compor o conjunto de evidências para a tomada de decisão de gestores e stakeholders no rumo das políticas.

Por outro lado, é também a avaliação um dos componentes do Planejamento Estratégico Situacional (PES) (MATUS, 1994), onde ela é parte do momento tático-operacional, do fazer do plano, sendo a ferramenta que permite monitorar o avanço dos planos de ação em curso, permitindo sua manutenção em direção do "deve ser" ou a situação-objetivo traçada. Faz parte do quarto momento do PES, além dos momentos explicativo, normativo e estratégico. Tem, portanto, importância central na direcionalidade do plano, já que permite acompanhar

1 Refere-se a um conjunto de processos ao interior das organizações, geralmente conflituosos em torno do qual se define os rumos das respostas sociais do Estado que, muitas vezes, são frutos das relações de poder, sendo que é do interesse da ciência política explicar os prováveis déficits de implementação.

2 Refere-se à necessária prestação de contas de agentes do Estado em torno das políticas desenvolvidas em qualquer órgão da administração pública, mantida com recursos de toda a sociedade, tem como foco as instâncias controladoras ou a seus representados. 
seu desenrolar no processo político do jogo social. Os indicadores são instrumentos muito importantes nesse monitoramento.

\section{Os sentidos da avaliação em saúde: compartilhando conceitos}

A área de avaliação em saúde tem gradativamente se descolado das vertentes da política e do planejamento e gestão, tendo construído um saber e práticas próprias nos diferentes países. No caso brasileiro, a constituição desse subespaço no interior da saúde coletiva tem sido resultado da interação entre agentes dos campos burocrático e científico, respectivamente representados pelas instituições de gestão do Sistema Único de Saúde (SUS) e das universidades. (FURTADO; SILVA, 2014) Alerta é necessário ao pensar a avaliação em saúde no Brasil, já que esses autores apontam também que os agentes que atuam na área não se identificam como "avaliadores" ou, ao menos, como integrantes do espaço "da avaliação". A avaliação é mais uma atividade, um método utilizado, revelando a incipiência ou ambivalência desse espaço.

Importante destacar que a avaliação é um componente das práticas nos diversos âmbitos das políticas públicas em vários setores, o que gera uma grande polissemia conceitual e metodológica. (SILVA; FORMIGLI, 1994) A diversidade das definições sobre o que é avaliar e como fazê-lo é resultado dessa transversalidade da avaliação nos vários espaços ou microcosmos sociais, em que é ferramenta útil para a ação e também corresponde a pontos de vista diferentes, dependentes das posições ocupadas no espaço social. (SILVA, 2014)

Patton (1997) inclui na sua definição alguns aspectos como coleta de informações sobre as atividades, características e resultados dos programas para produzir julgamento sobre programas e subsidiar decisões sobre futuras programações. Weiss (1998) acrescenta uma concepção mais ampla, tratando-a como apreciação sistemática do funcionamento para além do acompanhamento dos objetivos traçados, mas analisando os processos para poder aprimorá-los.

Rossi e Freeman (1993, p. 5) definem a avaliação como “[...] a aplicação sistemática de procedimentos de pesquisa científica para verificar a conceitualização, design, implementação e utilidade dos programas de intervenção social". Esses autores consideram a avaliação como uma atividade complexa que envolve também decisões políticas e administrativas.

Autores como Guba e Lincoln (1989) ressaltam que a avaliação deve transcender a simples aplicação dos métodos de pesquisa científica, e incluir os diver- 
sos aspectos humanos, políticos, sociais, culturais e contextuais que envolvem todo o seu processo.

Entretanto, Champagne e colaboradores (2011, p. 44) apresentam uma definição que agrega mais elementos consensuais, adotada por este capítulo:

[...] avaliar consiste fundamentalmente em emitir um juízo de valor sobre uma intervenção, implementando um dispositivo capaz de fornecer informações cientificamente válidas e socialmente legítimas sobre essa intervenção ou sobre qualquer de um de seus componentes, com o objetivo de proceder de modo a que os diferentes atores envolvidos, cujos campos de julgamento são por vezes diferentes, estejam aptos a se posicionar sobre a intervenção para que possam construir individual ou coletivamente um julgamento que possa se traduzir em ações.

Adotamos esse conceito, onde avaliar, portanto, é antes de tudo fazer um julgamento de valor, julgamento do mérito de uma intervenção ou qualquer dos seus componentes com vistas ao auxílio na tomada de decisão por parte dos gestores, formuladores e implementadores de políticas (Figura 1). Esse julgamento de valor requer distintas abordagens. Ao refletir nas dificuldades enfrentadas de utilização dos resultados das avaliações, cada vez mais se reconhece que esse julgamento de valor sobre uma intervenção deve aportar conhecimento cientificamente válido e socialmente legítimo sobre ela, possibilitando que os diferentes agentes envolvidos, os quais geralmente ocupam posições distintas, estejam prontos a tomar posição sobre a intervenção e a construir individual e coletivamente um julgamento aproximado entre eles que possa se traduzir em ações de melhoria e transformação da intervenção. 
Figura 1 - A intervenção, seus principais componentes e principais características da intervenção (atributos) que podem ser avaliadas

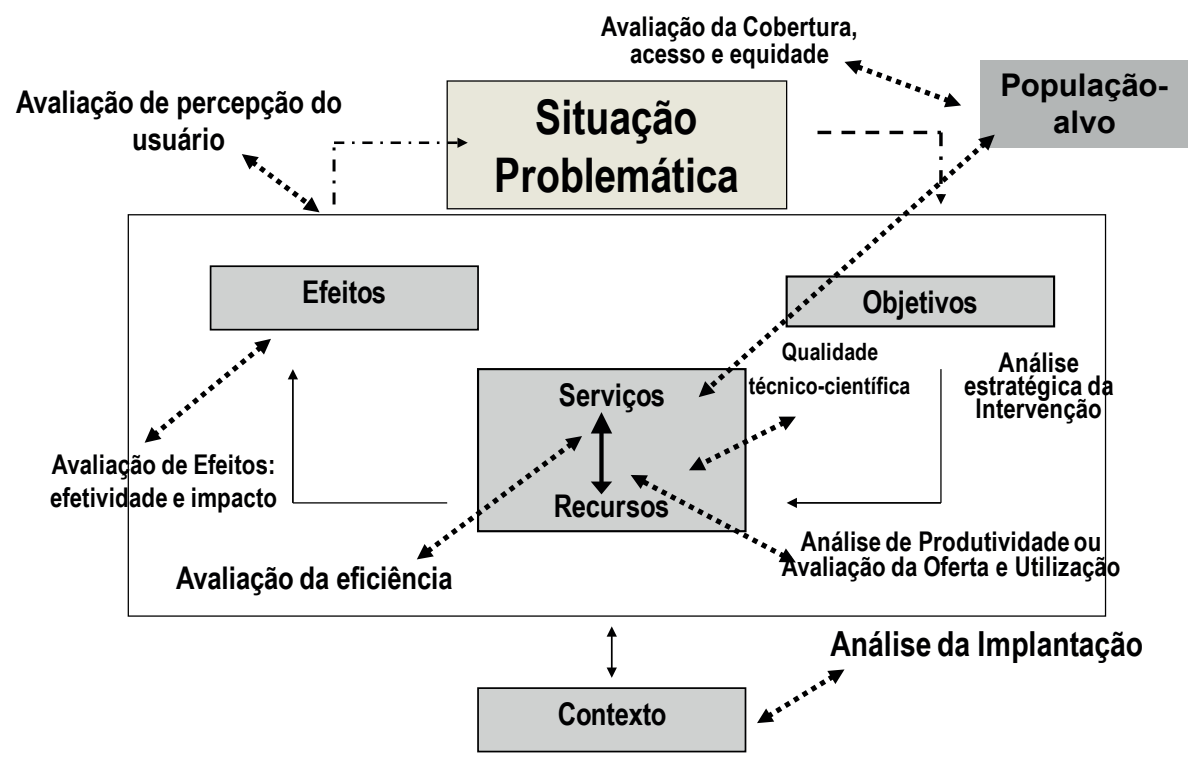

Fonte: adaptado de Contandriopoulos e colaboradores (1997).

Assim, é necessário perguntar: como devemos proceder para que todos os agentes envolvidos em uma intervenção possam conversar sobre ela, ter uma ideia em comum daquilo que ela é de maneira a poder fazer um julgamento sobre ela e agir?

É necessário também definir o que estamos denominando "intervenção", podendo ser sinônimo de programa. Intervenção é aqui compreendida como um sistema organizado de ação com seus componentes que, em um contexto e tempo determinado, podem modificar ou corrigir uma situação problemática, que são os agravos ou necessidades de saúde a serem enfrentados. Com isso, pode-se caracterizar diferentes tipos de intervenções. Desde programas e políticas, até intervenções técnicas como os protocolos clínicos (Figura 1). A intervenção compreendida como projetos, programas e planos pode ainda ser caracterizada como simples ou complexa ${ }^{3}$, e a abordagem e o método de avaliação dependerão do tipo e da complexidade dela.

Nas intervenção simples, os problemas podem ser resolvidos com solução única; nas complexas, procuram-se soluções que se apresentam de formas diversas, contraditórias ou opostas. (CHAMPAGNE et al., 2011) Será mais complexa quanto mais exigir ações de diferentes setores para resolver 
Segundo Cohen e Franco (1993, p. 85-86), os termos projeto, programa e plano designam modalidades de intervenção social que diferem em escopo e duração. Para esses autores:

[...] um plano é a soma dos programas que procuram objetivos comuns, ordena os objetivos gerais e os desagrega em objetivos específicos, que constituirão por sua vez os objetivos gerais dos programas. Ele determina o modelo de alocação de recursos resultante da decisão política e dispõe as ações programáticas em uma sequência temporal de acordo com a racionalidade técnica das mesmas e as prioridades de atendimento [...]. $\mathrm{O}$ plano inclui a estratégia, isto é, os meios estruturais e administrativos, assim como as formas de negociação, coordenação e direção.

Há conceitos diferentes para avaliação para a gestão ou avaliação normativa e pesquisa avaliativa. A avaliação normativa ou aquela para a gestão busca "apreciar cada um dos componentes da intervenção em função de critérios e normas. Ela se inscreve em um processo de verificação da conformidade dos componentes da intervenção em relação ao respeito às normas definidas". (BROUSSELLE et al., 2011, p. 44) Em outras palavras, avaliação normativa consiste em fazer um julgamento sobre uma intervenção, comparando os recursos empregados e sua organização (estrutura), os serviços ou bens produzidos (processo), e os efeitos obtidos (resultados), com critérios e normas, tendo como postulado que existe uma relação forte entre o respeito aos critérios e às normas escolhidas e os resultados do programa ou da intervenção. A tríade de Avedis Donabedian (estrutura, processo e resultado) é bastante utilizada em avaliações dessa natureza. A avaliação de uma intervenção voltada para a gestão é uma avaliação do tipo normativa, ou seja, relativa às normas estabelecidas. Esta deve ser estimulada como prática institucionalizada pelos serviços de saúde.

Por outro lado, a pesquisa avaliativa, como descrita por Contandriopoulos e colaboradores (1997), deve levar em consideração os fundamentos teóricos da intervenção, sua pertinência, sua produtividade e seus efeitos. Deve verificar o contexto que a gerou e buscar conhecer as relações entre contexto, processo e

a situação problemática. Um programa é uma intervenção, mas uma intervenção pode ser além do programa, uma política, uma ação organizada específica, por exemplo. 
resultados, de forma a ser capaz de produzir informações que permitam orientar efetivamente a tomada de decisões. Já Vieira-da-Silva (2014, p. 18) destaca:

A pesquisa avaliativa corresponde ao julgamento que se faz sobre as práticas sociais a partir de uma pergunta não respondida pela literatura especializada no tema a respeito das características dessas práticas em geral ou em um contexto particular mediante o recurso à metodologia científica. Já a pergunta que norteia a avaliação para a gestão decorre do desconhecimento sobre determinados aspectos da operacionalização de um programa ou intervenção específica. [...]

\section{Como conduzir uma avaliação}

O Quadro 1 sistematiza algumas possibilidades de avaliação a partir do estágio do programa. Tanto para avaliação de uma intervenção - do tipo avaliação normativa, por exemplo - quanto para uma pesquisa avaliativa, é desejável realizar uma importante etapa, geralmente exploratória, conhecida como estudo de avaliabilidade ou pré-avaliação, como um procedimento e método para determinar se a intervenção ou programa está minimamente implementado para ser objeto de uma avaliação sistemática. Essa, portanto, é uma característica importante de diferenciação de estudos avaliativos em relação a qualquer outro tipo. Somente podemos realizar uma avaliação se a intervenção já está em curso. É muito comum que haja o plano de ação como carta de intenções, mas não na prática, na concretude nas ações. Por isso, um estudo exploratório preliminar se a intervenção existe na prática é recomendado. 


\section{Quadro 1 - Os estágios de um programa, a proposta de avaliação e possíveis abordagens}

\begin{tabular}{|c|c|c|}
\hline $\begin{array}{l}\text { Estágio do } \\
\text { programa }\end{array}$ & Proposta de avaliação & Abordagem de avaliação \\
\hline $\begin{array}{c}\text { Planejamento do } \\
\text { Programa }\end{array}$ & $\begin{array}{c}\text { Produz informação pertinente } \\
\text { para ajudar os stakeholders no } \\
\text { desenvolvimento da racionalidade e } \\
\text { planejamento }\end{array}$ & $\begin{array}{c}\text { Avaliação formativa } \\
\text { Análise das necessidades }\end{array}$ \\
\hline $\begin{array}{l}\text { Implementação } \\
\text { inicial do } \\
\text { programa }\end{array}$ & $\begin{array}{l}\text { Produz informação a tempo sobre os } \\
\text { problemas de implementação para } \\
\text { auxiliar na sua estabilização }\end{array}$ & $\begin{array}{c}\text { Mapa conceitual (modelo } \\
\text { lógico) } \\
\text { Comentários ou advisory } \\
\text { Avaliabilidade } \\
\text { Avaliaçõesparticipativas }\end{array}$ \\
\hline $\begin{array}{l}\text { Estágio maduro } \\
\text { do programa }\end{array}$ & $\begin{array}{l}\text { Produz informação sobre os } \\
\text { problemas da implementação e as } \\
\text { fontes para melhor o seu processo } \\
\text { Monitorando o progresso da } \\
\text { implementação } \\
\text { Avaliação do processo de } \\
\text { implementação }\end{array}$ & $\begin{array}{c}\text { Avaliação formativa } \\
\text { Revisão do programa/reuniões } \\
\text { de desenvolvimento } \\
\text { Avaliação do processo guiada } \\
\text { pela teoria (teory-driven } \\
\text { process evaluation) }\end{array}$ \\
\hline $\begin{array}{l}\text { Resultados do } \\
\text { programa }\end{array}$ & $\begin{array}{l}\text { Avalia se um programa está pronto } \\
\text { para avaliação de resultados } \\
\text { Monitora o desempenho do programa } \\
\text { Avalia o desempenho do programa } \\
\text { segundo seus efeitos }\end{array}$ & $\begin{array}{c}\text { Evaluability assessment } \\
\text { Monitoramento do } \\
\text { desempenho } \\
\text { avaliação dos efeitos do } \\
\text { programa (efetividade e } \\
\text { impacto) } \\
\text { Avaliação dos resultados guiada } \\
\text { pela teoria (teory-driven } \\
\text { process evaluation) }\end{array}$ \\
\hline
\end{tabular}

Fonte: adaptado de Chen (2005).

Para merecer uma avaliação extensa, o programa deve satisfazer três critérios: 1) operar como previsto; 2) ser relativamente estável ao longo do tempo; e 3) indicar estar alcançando algum resultado positivo. Contudo, frequentemente, os objetivos do programa não estão bem definidos, ou não ficaram claros para os profissionais que atuam nos diversos níveis; a implantação não foi feita 
conforme previsto no plano e não há ainda tempo técnico suficiente para que os resultados esperados possam ter sido produzidos. Além disso, também é comum que os diversos gestores e profissionais responsáveis pela implementação do programa tenham concepções distintas acerca dos objetivos do programa, assim como sobre os aspectos mais frágeis que requerem avaliação bem como sobre os possíveis usos dos resultados obtidos. A análise exploratória dessas questões vem sendo denominada de "avaliabilidade" - Evaluability Assessment (EA). Trata-se de uma pré-avaliação realizada para identificar se um programa é bem concebido e consistentemente implementado de forma a poder se submeter a uma avaliação sistemática. (PATTON, 2002) Particularmente, antes de se realizar uma avaliação sobre a efetividade de um programa, é recomendada a realização de um estudo de avaliabilidade para evitar gastos desnecessários em termos de tempo e recursos humanos e materiais que envolvem uma avaliação desse porte. (CHEN, 2005)

Assim, a EA é o exame sistemático e preliminar de um programa, em sua teoria e em sua prática, para determinar se há justificativa para uma avaliação extensa e (ou) para melhor delimitar os objetivos do programa bem como identificar áreas críticas a serem priorizadas na avaliação. A EA pode ser considerada como um processo voltado para clarificar os desenhos dos programas, explorando sua realidade e, se necessário, ajudando a redesenhá-lo. Essa estratégia não somente nos mostra se o programa pode ser avaliado, mas também se a avaliação é capaz de contribuir para melhorar o seu desempenho. Dessa forma, seus objetivos podem ser os seguintes:

- Identificar se os objetivos do programa estão claramente formulados;

- Identificar se há concordância entre os diversos profissionais acerca dos objetivos, metas e população-alvo do programa;

- Discutir as relações entre problemas, objetivos e atividades verificando a plausibilidade das atividades como pertinentes para atingir os objetivos tendo em vista os seus determinantes e os objetivos e recursos (análise estratégica);

- Identificar se os formuladores de políticas ou gestores estão aptos ou dispostos para usar as informações da avaliação para mudar o programa.

A EA envolve diversas etapas: 1) clarificação dos objetivos da intervenção. Pode ser feita através de revisão da documentação do programa e entrevistas 
junto a gestores e profissionais envolvidos na sua execução (aqueles com interesse no programa ou em sua avaliação); 2) elaboração do modelo lógico 4 do programa, que é a modelização da intervenção com atenção especial para relações entre o problema, seus determinantes, o que o programa faz (a intervenção) e o que se espera que alcance (os resultados). Nessa vertente, faz-se uma análise da plausibilidade dessas relações, ou seja, uma análise lógica da teoria do programa. (MEDINA et al., 2005) A principal técnica nessa fase é a análise documental. Após a elaboração preliminar do modelo lógico a partir da consulta aos documentos, este deve ser apresentado aos gestores na busca de uma verificação se o "modelo no papel" corresponde àquele que está na representação dos profissionais; (3) descrição do funcionamento do programa na prática. Nessa etapa, pretende-se estimar de maneira aproximada qual o estágio de implantação do programa, como ele está funcionando na prática (o modelo da intervenção prático), o que se sabe e o que não se sabe sobre ele. (PATTON, 2002) Os dados para responder a essas questões devem ser obtidos através de entrevistas com informantes-chave e observação in loco. Essa etapa inclui comparação da realidade do programa com o modelo feito previamente, seguido pela apresentação subsequente aos gestores para novo feedback; 4) elaboração de recomendações. O objetivo final das etapas anteriores é reunir informações capazes de: identificar áreas para melhoria do programa, identificar componentes do programa sobre os quais não se tem informação (perguntas para avaliação) e identificar quais questões de avaliação são plausíveis e úteis para o mesmo. É imperativo a publicização dos resultados na medida em que, ao explicitar os resultados preliminares e finais do modelo lógico proposto, e as lacunas nos objetivos e atividades, por exemplo, essa estratégia se aproxime das correntes participativas da avaliaçao. A EA pode se constituir em uma avaliação para a gestão já que permite a reflexão sobre seu desenvolvimento em momentos de reunião conjunta entre gestores, executores, beneficiários e avaliadores.

$4 \quad$ O modelo lógico de um programa é definido como uma imagem da teoria e os pressupostos subjacentes ao programa. Um modelo lógico de um programa conecta resultados (tanto de curto quanto de longo prazo) às atividades/processos do programa e aos seus pressupostos teóricos, sendo uma maneira sistemática e visual de apresentar e compartilhar as relações entre os recursos para operar o programa, as atividades planejadas e as mudanças ou resultados a serem alcançados. 
As informações podem ser obtidas de diversas fontes tais como: análise de documentos (planos e relatórios), entrevistas com informantes-chave e observação in loco da intervenção.

Análise de documentos: os principais documentos relacionados com o programa devem ser analisados visando principalmente esclarecer os objetivos e metas, a situação atual do problema e seus determinantes e a relação entre os primeiros e os últimos. Ou seja, em que medida os objetivos e metas são adequados à atual situação do problema e suas causas?

Entrevistas com informantes-chave: informantes-chave são pessoas que conhecem em profundidade a situação, ou seus aspectos, que se quer investigar. Sua escolha é de fundamental importância para obter as informações desejadas. São as pessoas que coordenam e executam o programa nos seus diversos níveis. Os usuários são também informantes relevantes tendo em vista que grande parte do funcionamento real do programa pode ser apreendido através da sua satisfação. As entrevistas podem ser gravadas ou anotadas.

Observação: a observação é uma técnica das mais importantes, nessa etapa, pois frequentemente há uma distância entre o que está nos planos daquilo que os profissionais pensam do que está de fato acontecendo na prática. Ela deve focalizar o funcionamento do programa e indagar se as atividades previstas estão sendo realizadas e de que forma. Deve ser feita de forma sistemática a partir de um roteiro e ser registrada em um diário de campo.

Um exemplo de formulação de um modelo lógico de uma intervenção na saúde bucal é o modelo que expressa o esperado da implementação dos serviços odontológicos especializados (Figura 2).

Pode-se observar que esse modelo lógico proposto descreve sucintamente o ciclo da política desde a formulação, onde foram definidos seus objetivos principais pelo Ministério da Saúde, que seriam a oferta e acesso à atenção secundária e a busca da integralidade nas ações de saúde bucal. Para isso, o Governo Federal instituiu critérios, normas e requisitos para implantação e credenciamento dos Centros de Especialidades Odontológicas (CEO), bem como formas de financiamento, além de propor Protocolos Assistenciais específicos para a atenção especializada, que pudessem facilitar a etapa da implementação. No sentido da integralidade, o estabelecimento dos fluxos de referência e contrarreferência para diversas especialidades dos CEO são incentivados. Por outro lado, no nível local, esses objetivos seriam expressos nas práticas de gestão e assistenciais que incluem: a) oferta de serviços especializados de endodontia, 
Figura 2 - Modelo lógico da Atenção Especializada em saúde Bucal na Política Nacional de Saúde Bucal no nível local segundo seus objetivos, atividades e resultados esperados no ciclo da política, 2004-2014

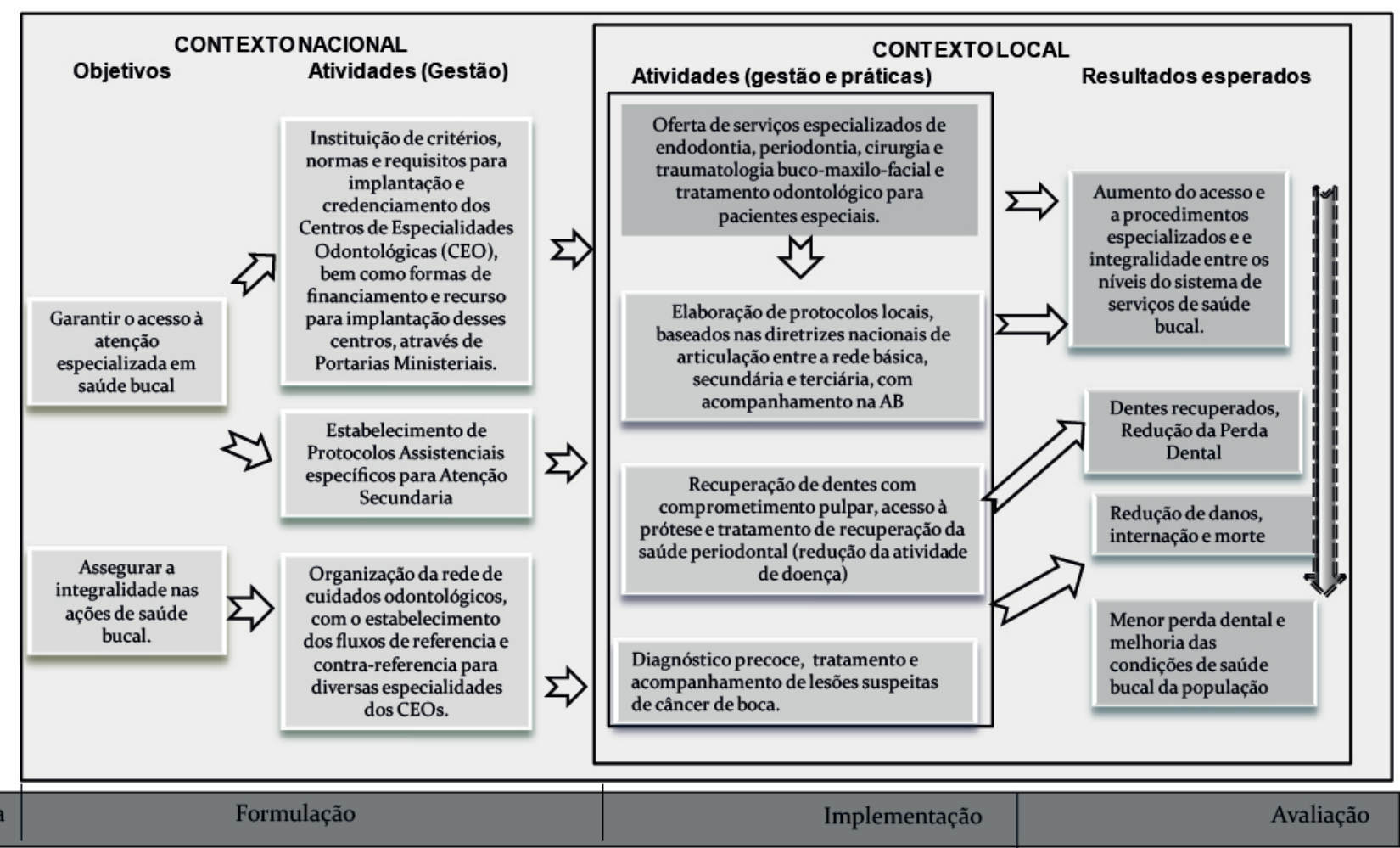

Fonte: Elaboração dos autores. 
periodontia, cirurgia e traumatologia buco-maxilo-facial e tratamento odontológico para pacientes especiais; b) elaboração de protocolos locais, baseados nas diretrizes nacionais de articulação entre a rede básica, secundária e terciária, com acompanhamento pela atenção básica; c) recuperação de dentes com comprometimento pulpar e recuperação da saúde periodontal (redução da atividade de doença); além do d) diagnóstico precoce, tratamento e acompanhamento de lesões suspeitas de câncer de boca. Os possíveis resultados esperados, ainda que não expressos explicitamente nos documentos oficiais, são: aumento do acesso da população aos procedimentos especializados, redução da perda dental e outros danos relacionados, maior integralidade entre os níveis do sistema de serviços de saúde bucal e, portanto, melhoria das condições de saúde bucal da população. Esses resultados esperados são objeto de análise no momento da avaliação do ciclo da política, podendo indicar novos rumos como o abandono, aprofundamento ou mudança. Desse modo, a partir desse modelo, foram derivadas as principais dimensões e critérios para avaliação preliminar (avaliabilidade), onde foram consideradas as seguintes categorias: a) os objetivos do CEO segundo os stakeholders; b) os principais resultados identificados pelos gestores e executores; c) a organização do serviço; d) a articulação com a atenção básica; e e) os principais aspectos para a melhoria do programa (Quadro 2).

Para Wholey (2004), o EA é uma importante ferramenta de gestão. O autor propõe como método para conduzir um EA a realização de entrevistas com gestores e formuladores de políticas, visitas ao local para observar o programa em operação e a análise dos seus documentos. 


\section{Quadro 2 - Principais dimensões e critérios para análise da implementação da atenção secundária na Política Nacional de Saúde Bucal (PNSB), 2009}

\begin{tabular}{|c|c|c|}
\hline Dimensão & Critério & Fonte de evidência \\
\hline Objetivos & $\begin{array}{l}\text { Os objetivos do } \\
\text { serviço }\end{array}$ & $\begin{array}{c}\text { Análise documental e entrevistas } \\
\text { Em sua opinião, quais são os principais objetivos } \\
\text { do CEO? } \\
\text { Da apresentação do Programa, o que você se } \\
\text { lembra do proposto nos documentos? }\end{array}$ \\
\hline \multirow[t]{2}{*}{$\begin{array}{c}\text { Atividades (gestão } \\
\text { e práticas) }\end{array}$} & $\begin{array}{c}\text { A organização do } \\
\text { serviço }\end{array}$ & $\begin{array}{c}\text { Entrevista: } \\
\text { Descreva as atividades que você desenvolve. Cite } \\
\text { exemplos. } \\
\text { Qual o número de atendimentos diários feitos } \\
\text { por você neste serviço? } \\
\text { Há um padrão proposto pelo serviço de } \\
\text { produção diária ou mensal? } \\
\text { Observação in loco: tempo de consulta, horário } \\
\text { de início e fim das atividades do turno de } \\
\text { trabalho. }\end{array}$ \\
\hline & $\begin{array}{l}\text { A articulação com } \\
\text { a atenção básica } \\
\text { e os protocolos } \\
\text { assistenciais }\end{array}$ & $\begin{array}{c}\text { Entrevista: } \\
\text { Como se organiza o acesso ao CEO no município } \\
\text { (a articulação com a rede básica)? }\end{array}$ \\
\hline Resultados & $\begin{array}{l}\text { Os principais } \\
\text { resultados } \\
\text { identificados }\end{array}$ & $\begin{array}{c}\text { Entrevista: } \\
\text { Na sua opinião, quais os principais resultados } \\
\text { observados por você aqui no serviço de saúde? }\end{array}$ \\
\hline Lacunas & $\begin{array}{l}\text { Os principais } \\
\text { aspectos para } \\
\text { melhoria }\end{array}$ & $\begin{array}{c}\text { Entrevista: } \\
\text { Quais seriam suas principais recomendações para } \\
\text { a melhoria do CEO } \\
\text { Quais são suas principais dificuldades que você } \\
\text { enfrenta na coordenação deste serviço? }\end{array}$ \\
\hline
\end{tabular}

Fonte: Rossi e Chaves (2015). 


\section{Outros atributos a serem avaliados}

Em seguida, ao constatar que a intervenção está operando como previsto e pode ser avaliada, pode-se conduzir uma pesquisa avaliativa a partir do estudo de mais características dessa intervenção como a análise estratégica ${ }^{5}$, a lógica, a produtividade, os efeitos, a eficiência, e a análise da implantação (BROUSSELLE et al., 2011), ainda que Vieira-da-Silva (2014) considere outros atributos como a acessibilidade, cobertura, qualidade técnico-científica, entre outros (Figura 1). Neste capítulo, focaremos mais especificamente na avaliação da cobertura e utilização como ferramentas da avaliação para a gestão, assim como a avaliação da implantação. As demais abordagens podem ser aprofundadas na literatura indicada, especialmente no livro introdutório de Vieira-da-Silva (2014).

A cobertura, acesso e utilização são características presentes em qualquer intervenção ou política e estão relacionadas à disponibilidade e distribuição social dos recursos dessa intervenção. A cobertura se refere à capacidade de uma intervenção em atingir os seus potenciais beneficiários. Na atenção à saúde bucal, há um indicador muito importante para avaliação da cobertura que é a Primeira Consulta Odontológica ${ }^{6}$ porque revela qual foi a proporção das pessoas moradoras em determinado território, município ou estado, por exemplo, que chegou a ser atendido em consulta odontológica programática, ou seja, com vistas a tratamento odontológico. Sua forma de cálculo é muito simples e deve ser um indicador fundamental de monitoramento da ampliação da atenção à saúde bucal pública no Brasil. Pode-se dizer que esse indicador mede a cobertura real do serviço odontológico, muito semelhante, portanto, ao conceito de utilização de serviços (cobertura real), entendida como uso e resultado da interação entre a necessidade percebida, a busca pelo serviço produtor de acesso ao interior de um sistema de saúde, que possui características próprias (políticas e organizacionais).

A acessibilidade é aqui compreendida como um dos aspectos da oferta de serviços relativo à capacidade de gerá-los e resolver as necessidades da população. Desse modo, refere-se às características dos serviços e seus recursos ca-

5 Uma análise estratégica pode ser apenas uma avaliação para a gestão que não responde a uma pergunta de pesquisa (lacuna no conhecimento).

6 A Cobertura da Primeira Consulta Odontológica é a porcentagem entre o total de indivíduos que foram ao dentista no setor público naquele ano e foram registrados como primeira consulta para tratamento em relação ao total da população daquele território, município ou estado. 
pazes de facilitar, limitar ou obstruir a utilização por seus potenciais usuários. (CUNHA; VIEIRA-DA-SILVA, 2010)

Estudos de acessibilidade a serviços de saúde bucal revelam o quanto um serviço está acessível e para que público, bem como explicitam fatores organizacionais como os relacionados aos processos gerenciais e de trabalho das equipes - modo de marcação de consulta, cumprimento de carga horária dos profissionais e clareza das metas - , e aspectos geográficos dos serviços de saúde que podem dificultar, obstruir ou facilitar o acesso a estes. Nesse sentido, persistem lacunas quanto à influência dos determinantes sociais, por um lado, e dos determinantes organizacionais e geográficos, por outro. Pode-se mesmo dizer que há uma acessibilidade social, acessibilidade organizacional e a acessibilidade geográfica.

\section{Análise e avaliação da implantação}

A implantação de uma intervenção é a transferência de uma intervenção no plano operacional, é a sua adequada operacionalização. Segundo Denis e Champagne (1997, p. 51, 54), a “[...] a análise da implantação consiste em especificar o conjunto dos fatores que influenciam os resultados obtidos após a introdução de uma intervenção". Faz uma relação entre a intervenção, seus componentes e o contexto, em comparação com a produção dos efeitos, e "[...] visa, principalmente, identificar os procedimentos implicados na produção dos efeitos de uma intervenção". Essa pode ser realizada quando a intervenção analisada é complexa e possui elementos sobre os quais o contexto pode interagir de várias formas. As possíveis teorias explicativas que influenciam a implantação de uma política podem ser aquelas de matriz sociológica de autores como Max Weber e Pierre Bourdieu, como também políticas, revelando a contribuição das relações de poder (Carlos Matus e Mário Testa). Teorias da cultura organizacional, de correntes neoinstitucionalistas também podem ser incorporadas.

A análise da implantação, ao buscar compreender os efeitos da interação, ou seja, o papel desempenhado por um conjunto de fenômenos que não a intervenção (como as concepções dos atores, da organização e outros) na determinação dos efeitos observados, aumenta a validade externa de uma avaliação. Além disso, ao discriminar a contribuição dos componentes realmente implantados do programa (grau de implantação) na produção dos efeitos, contribui também para aumentar a validade externa da pesquisa. (DENIS; CHAMPAGNE, 1997) 
Denis e Champagne (1997) apresentam três componentes para guiar a análise de implantação: a) o componente 1 propõe a análise dos determinantes contextuais do grau de implantação; b) o componente 2 que analisa a influência da variação na implantação sobre os efeitos observados; e c) o componente 3 que analisa a influência da interação entre o contexto de implantação e a intervenção sobre os efeitos observados. ${ }^{7}$

$\mathrm{Na}$ análise da implantação estes componentes trazem informações sobre os meios a serem beneficiados por uma intervenção (componente 1 e 3 ) e permitem também especificar como variações no grau de implantação agem no impacto de uma intervenção (componente 2).

\section{As avaliações participativas}

Numa perspectiva histórica, Guba e Lincoln (1989) propuseram uma classificação dos últimos cem anos do campo da avaliação em quatro gerações: a primeira geração da avaliação se caracterizaria pela mensuração, especialmente voltada para a avaliação do desempenho de escolares, no início do século XX. Nessa fase, o papel do avaliador é estencialmente técnico, cabendo ao mesmo construir e usar instrumentos de medição. A segunda geração caracterizava-se pela descrição dos processos, os padrões e pontos fortes e fracos em relação a certos objetivos declarados, considerando a necessidade de reconhecer como funcionavam os programas, como estes atingem seus resultados, diferente da geração anterior, que focalizava exclusivamente a medição de resultados. A terceira geração valorizava o julgamento, onde o avaliador continuou a exercer as funções de descrição e mensuração, sendo acrescida a função de estabelecer os méritos do programa avaliado considerando referenciais externos. Nessa pers-

Segundo Denis e Champagne (1997, p. 56-60): no componente do tipo 1, a análise desse tipo de implantação visa definir os fatores explicativos das diferenças observadas entre a intervenção planejada e a implantada, e é apropriada quando a intervenção é complexa e composta de elementos sequenciais; no componente do tipo 2 , a análise permite interpretar com mais exatidão os resultados de uma avaliação de impacto, contribuindo para distinguir os componentes de uma intervenção que facilitaram o alcance dos resultados, busca analisar a influência do grau de implantação de uma intervenção, sendo as variáveis dependentes os efeitos observados, após a sua introdução. Por ser a intervenção complexa e com pouca especificidade, o seu grau de implantação pode variar a depender do local. Então, nesse caso, pode ser possível analisar em que medida essas variações modificam os efeitos trazidos pela ação interventora; e, o componente do tipo 3 analisa a interação, sinérgica ou antagônica, entre o contexto e a intervenção em relação à produção de efeitos, tendo como objeto a generalização de uma intervenção em outros contextos. 
pectiva avaliativa, parte-se da premissa que os efeitos de um programa extrapolam os seus objetivos. (GUBA; LINCOLN, 1989)

Para esses autores, as três primeiras gerações apresentaram limitações no que se refere ao predomínio do aspecto gerencial, sem consideração à diversidade de grupos de interesse em torno do objeto avaliado; além de compromisso demasiado com o paradigma científico da investigação.

A predominância do aspecto gerencial refere-se à tendência em se atender às necessidades daqueles que encomendam ou financiam a avaliação, considerando padrões próprios e disseminação dos resultados que menosprezam ou pouco consideram outros interessados. O compromisso demasiado com o paradigma científico da investigação indica uma hegemonia de métodos quantitativos, com uma excessiva rigidez e por consequência, pouca relevância do contexto na análise das intervenções.

Em contraposição às gerações anteriores, desenvolve-se a denominada quarta geração, centrada em abordagens participativas. Estas têm como objetivo o envolvimento dos agentes no processo de avaliação, visando a capacitação e desenvolvimento dos mesmos para aprimoramento das práticas. Essa abordagem se concentra mais nas atividades meio do programa do que em seus resultados, apoiada no paradigma construtivista, em respeito à dinâmica da intervenção e dos envolvidos. Além disso, consideram uma diversidade de dados, objetivos e subjetivos, que representam múltiplas realidades e diferentes posicionamentos dos agentes envolvidos em consideração a diferentes interesses.

Nos últimos anos, a reflexão conceitual e metodológica tende a convergir sobre alguns denominadores comuns, identificando três aspectos-chave que permeiam as diversas definições: atenção pelas questões metodológicas, visualizando a avaliação como uma atividade de pesquisa; atenção com a finalidade e utilidade da avaliação, numa perspectiva de aumento do valor de uso no âmbito dos processos de tomada de decisões; reconhecimento do pluralismo de valores, que remonta à necessidade de valorização de diversos grupos de interesse.

Uma importante temática que também incorpora a discussão desses aspectos é a meta-avaliação, que se constitui como um processo de descrição, julgamento e síntese de um procedimento de avaliação, fundamentada em padrões e critérios propostos e validados pelas associações profissionais e outros organismos auditores, valorizando especialmente a qualidade e a utilidade da avaliação. (HARTZ; CONTANDRIOPOULOS, 2008) 
Uma das principais referências em termos de padrões de avaliação de programas públicos é fruto de um trabalho desenvolvido pelo Joint Committee on Standards for Educational Evaluation (JCEE). O Standards for evaluations of educational programs, projects and materials foi publicado em 1981 e revisado em 1994 para ser aplicado em outros espaços, incluindo a área da saúde. Trinta diretrizes são agrupadas em torno de quatro grandes princípios: 1) utilidade - responde às necessidades de informação dos usuários intencionais; 2) viabilidade - realista e moderada nos custos, de modo a justificar a sua realização; 3) propriedade - conduzida eticamente, respeitando o bem-estar das pessoas envolvidas na avaliação; e 4) precisão - produz informações sobre o valor dos programas e dos aspectos que determinam mérito e relevância do programa avaliado. (HARTZ; CONTANDRIOPOULOS, 2008)

A utilidade é reconhecida pelo JCEE como o atributo prioritário da avaliação. Na discussão sobre meta-avaliação, a "função da avaliação" é reconhecida como o foco prioritário, considerando os avanços no processo de institucionalização da avaliação e a necessidade desta ser valorizada e utilizada como ferramenta de governo. (HARTZ; CONTANDRIOPOULOS, 2008)

Os critérios de utilidade, conforme definido pelo JCEE (1994) são: identificação dos interessados, credibilidade do avaliador, escopo e seleção de informações, identificação de valores (perspectivas, procedimentos e justificativas usados para interpretar os resultados da avaliação devem ser cuidadosamente descritos), clareza dos relatórios de avaliação, entrega a tempo adequado e disseminação dos relatórios e impacto da avaliação.

A utilidade dos resultados da avaliação é amplamente valorizada por Patton (1997), o qual propõe uma abordagem avaliativa que tem como foco a utilização dos resultados (utilization-focused evaluation). A abordagem parte da premissa que as avaliações deveriam ser julgadas por sua utilidade, sendo que a avaliação deveria ser desenhada e desenvolvida considerando como as pessoas vivenciarão o processo de avaliação e a sua aplicação. O autor discute a avaliação como dispositivo de mudança, a partir da incorporação dos principais grupos de interesse e valorização das possibilidades de utilização dos resultados pelos envolvidos na reformulação de suas práticas. A avaliação com foco na utilização considera que existem maiores possibilidades que os participantes utilizem as avaliações se estes compreendem e se sentem donos do processo de avaliação e de seus resultados. Além disso, durante o processo de avaliação, é possível reforçar a utilidade pretendida e "preparar o terreno" para o uso. Segundo Pat- 
ton (1997), a avaliação com foco na utilização inicia-se com a premissa de que avaliações devem ser julgadas por sua verdadeira utilidade; para tanto, os avaliadores devem facilitar o planejamento e a implementação da avaliação com cuidadosa consideração não em abstrações, mas sim levando-se em conta as expectativas de pessoas reais no mundo real, consequentemente, a ênfase da avaliação com foco na utilização é na intenção de uso revelada pelos usuários intencionais.

\section{Estudos no Brasil de avaliação da atenção em saúde bucal}

Como subespaço ao interior da saúde coletiva, imagina-se que a produção de conhecimento em torno da avaliação em saúde bucal seja ainda mais incipiente que na sua subárea de origem que é o próprio subespaço da avaliação na saúde coletiva. Na área da saúde bucal, a avaliação em saúde pode subsidiar a tomada de decisão, o redirecionamento das políticas, programas e serviços, mas tem como desafio realizar contínuo monitoramento dos serviços através do uso de indicadores, tanto dos serviços de saúde como do estado de saúde da população. O monitoramento dos indicadores do estado de saúde bucal da população brasileira tem sido denominado por Goes e colaboradores (2012) de vigilância em saúde bucal. Entre eles, destacam-se os índices já aceitos internacionalmente como o CPO-D, a ceo-d para tendências da prevalência e severidade da cárie dental com diferentes análises quanto à participação da composição percentual dos seus componentes. Indicadores de doença periodontal como o IPC e o PIP, índice de Dean para fluorose. Para o câncer bucal, coeficientes de mortalidade por sexo e faixa etária podem ser monitorados. ${ }^{8}$

Colussi e Calvo (2012) publicaram revisão da literatura sobre avaliação da atenção em saúde bucal no Brasil. As autoras encontraram 23 estudos de avaliação do serviço ou da assistência em saúde bucal, sendo 15 artigos e 8 dissertações, até o ano de 2010, com grande diversidade metodológica.

$8 \quad \mathrm{O}$ CPO-D se refere à média de dentes permanentes cariados. perdidos e restaurados por grupo etário, bem como o ceo-d, como média de dentes decíduos cariados, perdidos por cárie e restaurados por grupo etário. Revelam a pevalência quando são apresentados em termos de proporção de indivíduos livres de cárie e também revelam a severidade, quando são apresentados em média por grupo etário. O IPC é um indicador que revela a proporção de indivíduos ou sextantes em determinado grupo com gengiva saudável, com sangramento gengival com bolsa periodontal leve ou severa. O índice de Dean revela a prevalência de fluorose dentária. Ele mede a proporção de indivíduos com fluorose muito leve, leve, moderada e severa. Para maior aprofundamento nos indicadores do estado de saúde bucal da população, ver capítulo 2. 
Com o objetivo de verificar a continuidade das publicações sobre avaliação em saúde bucal no período de 2011 a 2015, este capítulo complementou a busca de artigos na base de dados Scielo, com as palavras chaves "avaliação", "odontologia" e "saúde bucal". Nessa busca, foram encontrados 57 artigos, dos quais 9 foram considerados "estudos de avaliação", conforme critérios utilizados por Colussi e Calvo (2012), ou seja, aqueles que apresentavam a palavra "avaliação" no título do trabalho, nas palavras-chave, ou aqueles que utilizaram o verbo "avaliar" nos objetivos ou metodologia do trabalho - e tratavam da avaliação do serviço ou da assistência odontológica no país (Quadro 3). As autoras apontaram que a maioria dos trabalhos é do tipo avaliação externa, provenientes de pesquisas acadêmicas. Obviamente, a publicação de estudos de avaliação rotineira dos serviços não é simples em revistas indexadas, o que dificulta mensurar em que medida a avaliação nessa área tem sido institucionalizada. Outra questão problemática tem sido a não explicitação de juízo de valor referente ao objeto "avaliado", o que é contraditório com o conceito já compartilhado de formulação clara desse julgamento por qualquer estudo dessa natureza. $\mathrm{Na}$ revisão realizada por Colussi e Calvo (2012), chamou atenção também que, dentre os atributos mais avaliados, estavam a satisfação dos usuários em 8 dos 23 estudos (34,8\%), e o acesso em três estudos (13,1\%). Conforme foi ressaltado anteriormente, pesquisas avaliativas, produto da formação acadêmica, tem maior possibilidade de publicação em periódicos indexados. Provavelmente, estudos de avaliação de intervenções, realizadas rotineiramente nos serviços não foram captados pelas limitações da própria fonte de dados, que estão revistas com grande filtro nas publicações. Concordamos com a necessidade de mapear as práticas avaliativas rotineiras nos serviços odontológicos públicos, inclusive, pensando no processo desencadeado pelo Programa para Melhoria do Acesso e Qualidade da Atenção Básica (PMAQ-AB) e Programa para Melhoria do Acesso e Qualidade dos Centros de Especialidades Odontológicas (PMAQ-CEO), que possibilitaram essa capilaridade. Essa prática avaliativa como fenômeno social interno aos serviços de saúde é muito importante e precisa ser melhor estudada, tanto no sentido das avaliações desencadeadas a partir do monitoramento dos principais indicadores da atenção à saúde bucal quanto através das induções advindas das políticas do poder executivo, como foi o caso recente do PMAQ. Observa-se ainda pouca produção em saúde bucal no que se refere aos estudos de avaliação da qualidade da atenção odontológica. Há iniciativa com o PMAQ e os resultados do PMAQ-AB no país apontam que na 
maioria das subdimensões os desempenhos das ações de saúde bucal estão na mediana ou muito abaixo da média, são desafios importantes, tanto no acesso quanto na organização e qualidade do processo de trabalho.

\section{Quadro 3 - Estudos de avaliação do serviços de atenção à saúde bucal no Brasil até 2015, a partir dos estudos selecionados de Colussi e Calvo até 2010 (2012)}

(continua)

\begin{tabular}{|c|c|c|c|}
\hline $\begin{array}{l}\text { Autor(es) e } \\
\text { natureza da } \\
\text { publicação }\end{array}$ & Abordagem & $\begin{array}{l}\text { Natureza } \\
\text { dos } \\
\text { dados }\end{array}$ & Atributos da avaliação \\
\hline $\begin{array}{c}\text { Matos et al., } 2002 \\
\text { Centro de Pesquisas } \\
\text { René Rachou da } \\
\text { Fundação Oswaldo Cruz. } \\
\text { Minas Gerais }\end{array}$ & Quantitativa & Primários & $\begin{array}{l}\text { Avaliação da desigualdade na utilização de } \\
\text { procedimentos restauradores e preventivos em serviços } \\
\text { odontológicos privados, públicos e de sindicato. } \\
\text { Satisfação do usuário. }\end{array}$ \\
\hline $\begin{array}{l}\text { Barros, Bertoldi, } 2002 \\
\text { Universidade Federal } \\
\text { de Pelotas -Rio Grande } \\
\text { do Sul }\end{array}$ & Quantitativa & Secundários & $\begin{array}{l}\text { Utilização e acesso a serviços odontológicos } \\
\text { públicos e privados, e diferenciais entre os estratos } \\
\text { socioeconômicos. }\end{array}$ \\
\hline $\begin{array}{l}\text { Mialhe, Oliveira, Silva, } \\
\qquad 2006 \\
\text { UNICAMP - São Paulo }\end{array}$ & Quantitativa & Primários & $\begin{array}{c}\text { Acesso e satisfação dos usuários aos serviços } \\
\text { odontológicos públicos e privados em uma comunidade } \\
\text { rural. }\end{array}$ \\
\hline $\begin{array}{c}\text { Andrade, Ferreira, } 2006 \\
\text { UFMG- Minas Gerais }\end{array}$ & $\begin{array}{c}\text { Quantitativa e } \\
\text { qualitativa }\end{array}$ & Primários & $\begin{array}{l}\text { Satisfação do usuário sobre a atuação da equipe de } \\
\text { saúde da família em um município. }\end{array}$ \\
\hline $\begin{array}{c}\text { Souza, Roncalli, } 2007 \\
\text { UFRN - Natal }\end{array}$ & $\begin{array}{l}\text { Quantitativa } \\
\text { e qualitativa }\end{array}$ & Primários & $\begin{array}{c}\text { Implantação do modelo assistencial do PSF com foco no } \\
\text { acesso, organização do processo de trabalho e lógica de } \\
\text { programação. }\end{array}$ \\
\hline $\begin{array}{l}\text { Chaves, Silva, } 2007 \\
\text { ISC/ UFBA- Bahia }\end{array}$ & Quantitativa & $\begin{array}{l}\text { Primários e } \\
\text { secundários }\end{array}$ & $\begin{array}{l}\text { Grau de implantação da atenção à saúde bucal em dois } \\
\text { municípios a partir da imagem-objetivo da política. }\end{array}$ \\
\hline $\begin{array}{l}\text { Fadel, Sandrini, Zardo, } \\
\qquad 2007 \\
\text { UEPG- Paraná }\end{array}$ & $\begin{array}{l}\text { Quantitativa e } \\
\text { qualitativa }\end{array}$ & Primários & $\begin{array}{l}\text { Satisfação dos usuários dos serviços odontológicos na } \\
\qquad \text { ESF, incluindo acesso e relação com a equipe. }\end{array}$ \\
\hline $\begin{array}{l}\text { Emmi, Barroso, } 2008 \\
\text { Universidade Federal do } \\
\text { Pará. Pará. }\end{array}$ & Quantitativa & Primários & $\begin{array}{l}\text { Satisfação do usuário quanto às ações de saúde bucal } \\
\text { desenvolvidas. }\end{array}$ \\
\hline
\end{tabular}




\section{Quadro 3 - Estudos de avaliação do serviços de atenção à saúde bucal no Brasil até 2015, a partir dos estudos selecionados de Colussi e Calvo até 2010 (2012)}

(continuação)

\begin{tabular}{|c|c|c|c|}
\hline $\begin{array}{l}\text { Martelliet al., } 2008 \\
\text { Centro de Pesquisas } \\
\text { Aggeu Magalhães, } \\
\text { Fundação Oswaldo Cruz } \\
\text { - Pernambuco. }\end{array}$ & $\begin{array}{c}\text { Quantitativa e } \\
\text { qualitativa }\end{array}$ & Primários & $\begin{array}{l}\text { Implantação do modelo de atenção à saúde bucal, } \\
\text { incluindo a qualificação dos profissionais, mudança do } \\
\text { perfil assistencial e referência e contrarreferência. }\end{array}$ \\
\hline $\begin{array}{l}\text { Ribeiro-Sobrinho, Souza, } \\
\text { Chaves, } 2008 \\
\text { ISC/UFBA- Bahia }\end{array}$ & Quantitativa & Secundários & Cobertura de um serviço odontológico. \\
\hline $\begin{array}{l}\text { Nickel, Calvo, Caetano, } \\
\qquad 2009 \\
\text { UFSC - Santa Catarina }\end{array}$ & Quantitativa & $\begin{array}{l}\text { Primários e } \\
\text { secundários }\end{array}$ & $\begin{array}{l}\text { Atenção em saúde bucal na atenção básica municipal } \\
\text { com proposta de indicadores de avaliação para a gestão. }\end{array}$ \\
\hline $\begin{array}{l}\text { Figueiredo, Góes, } 2009 \\
\text { Universidade de } \\
\text { Pernambuco }\end{array}$ & Quantitativa & Secundários & Implantação/desempenho dos CEO. \\
\hline $\begin{array}{l}\text { Frazão, Marques, } 2009 \\
\text { Universidade Católica de } \\
\text { Santos -São Paulo }\end{array}$ & Quantitativa & Primários & $\begin{array}{l}\text { Efeito/impacto do Programa Agentes Comunitários de } \\
\text { Saúde na promoção da saúde bucal. }\end{array}$ \\
\hline $\begin{array}{l}\text { Reis et al., } 2009 \\
\text { FUNORTE -Minas Gerais; } \\
\text { UFBA -Bahia. }\end{array}$ & Qualitativa & Primários & $\begin{array}{l}\text { Satisfação dos usuários sobre o serviço de saúde bucal } \\
\qquad \text { municipal. }\end{array}$ \\
\hline $\begin{array}{l}\text { Lima, Cabral, } \\
\text { Vasconcelos, } 2010 \\
\text { UFPE- Pernambuco }\end{array}$ & Quantitativa & $\begin{array}{l}\text { Primários e } \\
\text { secundários }\end{array}$ & Satisfação dos usuários dos CEO. \\
\hline $\begin{array}{l}\text { Chaves et al., } 2011 \\
\text { ISC/ UFBA - Bahia. }\end{array}$ & $\begin{array}{l}\text { Qualitativa e } \\
\text { Quantitativa }\end{array}$ & $\begin{array}{l}\text { Primários e } \\
\text { Secundários }\end{array}$ & $\begin{array}{l}\text { Utilização dos serviços odontológicos especializados de } \\
\qquad \text { CEO e fatores relacionados. }\end{array}$ \\
\hline $\begin{array}{c}\text { Pereira et al., } 2012 \\
\text { PUC -Minas Gerais;UFRN- } \\
\text { Natal; } \\
\text { UFBA, Bahia; CRO- } \\
\text { Maranhão }\end{array}$ & Quantitativa & Primários & $\begin{array}{l}\text { Efeito da ESF sobre a saúde bucal na população do } \\
\text { Nordeste do Brasil de } 12 \text { municípios com mais de } 100 \\
\text { mil habitantes. (implantação e modelo assistencial?) }\end{array}$ \\
\hline $\begin{array}{l}\text { Góes et al., } 2012 \\
\text { UFPE- Pernambuco }\end{array}$ & Quantitativa & $\begin{array}{l}\text { Primários e } \\
\text { Secundários }\end{array}$ & $\begin{array}{l}\text { Implantação dos CEO com base na produção } \\
\text { ambulatorial e satisfação da equipe profissional. }\end{array}$ \\
\hline
\end{tabular}




\section{Quadro 3 - Estudos de avaliação do serviços de atenção à saúde bucal no Brasil até 2015, a partir dos estudos selecionados de Colussi e Calvo até 2010 (2012)}

(conclusão)

\begin{tabular}{|c|c|c|c|}
\hline $\begin{array}{l}\text { Bulgareliet al., } 2013 \\
\text { UNICAMP -São Paulo }\end{array}$ & Quantitativa & Secundários & $\begin{array}{c}\text { Efeito na integralidade dos diferentes modelos de } \\
\text { atenção básica em saúde bucal (ESF e UBS) em relação } \\
\text { à referência à atenção especializada. }\end{array}$ \\
\hline $\begin{array}{l}\text { Giudice, Pezzato e } \\
\text { Botazzo, } 2013 \\
\text { UNICAMP - São Paulo }\end{array}$ & Qualitativa & Primários & $\begin{array}{l}\text { Avaliação do processo de trabalho da ESF e reflexões a } \\
\text { partir do PMAQ-AB. }\end{array}$ \\
\hline $\begin{array}{l}\text { Bulgareliet al., } 2014 \\
\text { UNICAMP - São Paulo. }\end{array}$ & Quantitativa & Secundários & $\begin{array}{l}\text { Efeito dos modelos de atenção básica (ESF ou UBS) em } \\
\text { relação às necessidades de saúde bucal da população no } \\
\text { acesso e conclusão de tratamento odontológico. }\end{array}$ \\
\hline $\begin{array}{l}\text { Lino et al., } 2014 \\
\text { UFMG- Minas Gerais }\end{array}$ & Quantitativa & Secundários & $\begin{array}{c}\text { Implantação da atenção especializada com base na } \\
\text { produção ambulatorial municipal. }\end{array}$ \\
\hline $\begin{array}{c}\text { Pimentel et al., } 2014 \\
\text { Centro de Pesquisas } \\
\text { Aggeu Magalhães da } \\
\text { FIOCRUZ - Pernambuco }\end{array}$ & Quantitativa & Secundários & $\begin{array}{l}\text { Assistência à saúde bucal no âmbito estadual. Utilizou } \\
\text { indicadores de saúde bucal. }\end{array}$ \\
\hline $\begin{array}{l}\text { Magalhães et al., } 2015 \\
\text { UFPE - Pernambuco. }\end{array}$ & Quantitativa & Primários & $\begin{array}{l}\text { Qualidade dos serviços ofertados nos CEO na } \\
\text { perspectiva da satisfação dos usuários. }\end{array}$ \\
\hline
\end{tabular}

Fontes: adaptado de Colussi e Calvo (2012) e complementado com artigos do Scielo entre 2010 e 2015.

Na releitura desses trabalhos selecionados por Colussi e Calvo (2012), bem como nos trabalhos posteriores, destacou-se a diversidade e confusão conceitual quanto aos atributos da avaliação, bem como a não explicitação de conceitos. Exemplos disso foram o uso do termo qualidade, desempenho e eficiência. Há um número de estudos que poderiam ser classificados como estudos de avaliação de processo ou implantação, ainda que não tenha explicitado exatamente esse termo no método, já que estes estavam voltados para avaliar o quanto foi adequadamente operacionalizada a política ou atenção à saúde bucal. Desempenho como sinônimo de implantação foi muito comum, ou seja, a ideia de operacionalização adequada de uma intervenção vista como desempenho. Exemplos disso foram os estudos de Figueiredo e Goes (2009), Goes e colaboradores (2012), Lino e colaboradores (2014), Martelli e colaboradores (2008), Souza e Roncalli (2007). A avaliação da satisfação do usuário predominou, mas não se pode considerar a qualidade do serviço a partir dessa satisfação. Além disso, um mesmo estudo analisava mais de um atributo, como acesso e satisfa- 
ção. No Quadro 3, adaptado de Colussi e Calvo (2012), estão apresentados 24 artigos, dos quais 15 são aqueles já sistematizados por essas autoras e nove artigos novos publicados do período entre 2011 e 2015. Observou-se predominância de estudos quantitativos (60,9\%), seguidos pelos de abordagem mista quali-quanti $(30,4 \%)$. Chama a atenção a existência de apenas um estudo somente qualitativo nessa área. Há predomínio do uso de dados primários $(60,9 \%)$ e primários e secundários (21,7\%). É curioso notar grande esforço na coleta de dados (dados primários locais), com análise quantitativa apenas.

Giudice, Pezzato e Botazzo (2013), único estudo com abordagem participativa de quarta geração, avaliaram o processo de trabalho em uma Equipe de Saúde da Família de Campinas, São Paulo, através do uso da metodologia da pesquisa qualitativa (entrevistas semiestruturadas - com usuários - e grupos focais - com profissionais de saúde). Os autores destacam que este modelo de atenção conseguiu introduzir novos saberes nas práticas dos profissionais, contribuiu para um maior envolvimento intraequipe e com os usuários e incrementou o compromisso com a promoção de saúde das famílias. Entretanto, cabe destacar que esse estudo avaliou uma Equipe de Saúde da Família (ESF) diferenciada, com as equipes ampliadas - que incluem pediatra e ginecologista, além de contar com o matriciamento de outros profissionais, como psiquiatra, psicólogo, terapeuta ocupacional e nutricionista, dentre outros. Além disso, houve uma capacitação, seguindo os protocolos de implantação do Programa de Saúde da Família (PSF) para toda a rede municipal, com cerca de 180 horas-aula a partir do método paideia.

Bulgareli e colaboradores (2013) reforçam que o impacto das ações de saúde bucal na ESF tem evidente progresso em relação aos princípios de universalidade, equidade e integralidade, sendo esta análise importante na avaliação da resolutividade da atenção básica. Ainda que o modelo baseado na Estratégia Saúde da Família (ESF) possua dificuldade em prover atendimento integral, no acesso à endodontia (uma das maiores necessidades odontológicas em especialidade de forma geral), a saúde da família apresentou melhores resultados que a Unidade Básica de Saúde (UBS) tradicional. Os autores também verificaram que na UBS, a população adscrita na área de abrangência é bem superior à da ESF, o que dificulta desde o acesso geográfico dos pacientes para a unidade de saúde até o reconhecimento de toda a clientela do território, dessa maneira, o vínculo é menor e há pouca adesão ao tratamento. (BULGARELI et al., 2013). Bulgareli e colaboradores (2014) em outra publicação a partir do mesmo estu- 
do, avaliaram também a resolutividade das ações de saúde bucal desenvolvidas na atenção básica em modelos de atenção distintos (ESF ou UBS). Os autores concluíram que o modelo baseado na saúde da família apresentou melhor resultado no acesso e conclusão de tratamento odontológico.

Um estudo de avaliação da atenção secundária em saúde bucal, com caráter avaliativo normativo, utilizando dados da produção ambulatorial dos CEO do país registrados nos Sistemas de Informação Ambulatorial (SIA/SUS), em 2007, e dados primários, de 10\% dos serviços implantados, observou que, na maioria das regiões, houve dificuldade no cumprimento das metas relativas à quantidade de procedimentos por especialidade, sendo a região Norte com menor percentual de cumprimento de metas. Foi evidenciada a necessidade de revisão no marco legal para a implantação dos CEO e definições de novos padrões e cumprimento de metas para avaliação e monitoramento de tais serviços. (GOES et al., 2012) Outro estudo avaliou a atenção odontológica especializada no estado de Minas Gerais, também através da produção ambulatorial registrada no SIA/ SUS. (LIMA; CABRAL; VASCONCELOS, 2010) Todas as unidades de saúde que realizavam procedimentos considerados especializados nas áreas de endodontia, periodontia e cirurgia pela PNSB foram incluídas na análise. Apesar da maioria dos procedimentos ter sido realizada em UBS, os resultados do estudo indicaram que os CEO são mais eficientes na execução de procedimentos especializados em saúde bucal. Todavia, ainda que o desempenho dos CEO tenha sido mais favorável, grande parte desses serviços não atingiram as metas estabelecidas pelo Ministério da Saúde. (LINO et al., 2014)

Pimentel e colaboradores (2014) analisaram a assistência à saúde bucal no estado de Pernambuco, com base em seus indicadores (cobertura de primeira consulta odontológica programática; cobertura da ação coletiva Escovação Dental Supervisionada; média de procedimentos odontológicos básicos individuais e proporção de exodontias em relação às ações odontológicas básicas individuais) segundo as variáveis porte populacional, proporção da população cadastrada e relação entre as ESF e ESB. Os resultados mostraram que municípios de grande porte apresentaram menores valores para proporção de exodontias. Outro aspecto encontrado foi que, quanto maior a cobertura e quando a relação entre as equipes era um para um, mais favoráveis eram os indicadores.

Também no estado de Pernambuco, Magalhães e colaboradores (2015) realizaram estudo com o objetivo de avaliar os serviços ofertados nos CEO, na perspectiva da satisfação dos usuários. A análise dos dados revelou que os usuários 
estão satisfeitos com a qualidade dos serviços prestados nos CEO do estado. É importante destacar que, na dimensão da eficiência, os autores consideraram a relação custo-benefício no sentido de que "valeu a pena" a utilização dos serviços de saúde bucal, mesmo diante de todas as dificuldades/barreiras que eles possam ter enfrentado para acessar o serviço. Aqui, cabe uma ressalva do uso do termo "qualidade" no senso comum. A satisfação do usuário com serviço é uma dimensão distinta da dimensão da sua qualidade, considerando este ou no sentido amplo (sete pilares da qualidade de Donabedian) ou no sentido estrito como a qualidade técnico-científica, como o uso adequado da evidência técnica e científica para o cuidado.

Estudo de Chaves e colaboradores (2011) analisou a oferta e utilização de procedimentos em CEO na Bahia, tendo como foco a relação entre a oferta potencial como disponibilidade de recursos em horas de trabalho e a utilização real dessa oferta na produção ambulatória desses serviços no sistema de informação ambulatorial. Houve uma baixa taxa de utilização conforme os padrões propostos pela Portaria GM n. ${ }^{0} 1.101 / 2002$ e pela consulta aos especialistas, ou seja, a oferta disponível está, de fato, sendo subutilizada para um tipo de serviço estencial na garantia da integralidade da atenção à saúde bucal. Nesse sentido, a baixa taxa de utilização em algumas especialidades pode ser reveladora de problemas de gestão do serviço, como o não monitoramento de padrões e metas de produção por especialidade e a falta dos pacientes, que não são substituídos. Além disso, houve conflitos importantes na integração entre a atenção básica e atenção especializada, tanto na pertinência na indicação para esse nível de atenção, bem como na referência do paciente sem a devida promoção de saúde bucal e procedimentos básicos, funções da atenção primária.

\section{Considerações finais}

Avaliação da política, através do uso de indicadores de produção ambulatorial oriundos de base de dados secundárias, traz elementos de resultados e implantação desses serviços públicos odontológicos e são úteis para a gestão, sobretudo para organização da saúde bucal no âmbito municipal. Contudo, este não analisa outros atributos do serviço e da própria política, que devem ser avaliados a partir das demandas dos gestores e beneficiários, bem como dos interesses daqueles que produzem conhecimento na temática.

O espaço da avaliação em saúde bucal carece de estudos que contemplem análises com abordagens metodológicas mistas e que incluam teorias sociais 
explicativas dos fenômenos observados, e possam assim avançar na contribuição acadêmica sobre a implementação da PNSB e para a prática política cotidiana daqueles que militam na área. Outra questão importante é em que medida as avaliações serão utilizadas na tomada de decisão dos gestores e dos executores. Problemática também relevante no espaço da avaliação em saúde que merecerá estudos posteriores para seu acompanhamento. Nesse caso, a aposta em estratégias participativas com a devida cientificidade é um caminho possível.

\section{Referências}

ANDRADE K. L. C.; FERREIRA, E. F. Avaliação da inserção da odontologia no Programa de Saúde da Família de Pompeu (MG): a satisfação do usuário. Ciência \& Saúde Coletiva, Rio de Janeiro, v. 11, n. 1, p. 123-130, 2006.

BARROS, A. J. D.; BERTOLDI, A. D. Desigualdades na utilização e no acesso a serviços odontológicos: uma avaliação em nível nacional. Ciência \& Saúde Coletiva, Rio de Janeiro, v. 7, n. 4, p. 709-17, 2002.

BROUSSELlE, A. et al. (Org.). Avaliação, conceitos e métodos. Rio de Janeiro: Ed. Fiocruz, 2011.

BULGARELI, J. V. et al . Informações da atenção secundária em Odontologia para avaliação dos modelos de atenção à saúde. Revista de Odontologia da UNESP, v. 42, n. 4, p. 229-236, 2013 .

BULGARELI, J. et al. A resolutividade em saúde bucal na atenção básica como instrumento para avaliação dos modelos de atenção. Ciência \& Saúde Coletiva, Rio de Janeiro, v. 19, n. 2, p. 383-391, 2014

CHAMPAGNE, F. et al. A Avaliação no Campo da Saúde: conceitos e métodos. In: BROUSSELlE, A. et al (Org.) Avaliação, conceitos e métodos. Rio de Janeiro: Ed. FIOCRUZ, 2011. p. 41-60.

CHAVES, S. C. L. et al. Avaliação da oferta e utilização de Especialidades Odontológicas em Serviços Públicos de Atenção Secundária na Bahia, Brasil. Cadernos de Saúde Pública, Rio de Janeiro, v. 27, n. 1, p. 143-154, 2011.

CHAVES, S. C. L.; SILVA, L. M. V. da. Atenção à saúde bucal e a descentralização da saúde no Brasil: estudo de dois casos exemplares no Estado da Bahia. Cadernos de Saúde Pública, Rio de Janeiro, v. 23, n. 5, p. 1119-31, 2007.

CHEN, H. T. Practical Program Evaluation: assessing and improving planning, implementation, and effectiveness. Thousand Oaks, CA: Sage Publications, 2005.

COHEN, E.; FRANCO, R. Avaliação de projetos sociais. Petrópolis, RJ: Vozes, 1993. 
COLUSSI, C. F.; CALVO, M. C. M. Avaliação da atenção em Saúde Bucal no Brasil: uma revisão da literatura. Saúde e Transformação Social., Florianópolis, v. 3, p. 92-100, jan. 2012. CONTANDRIOPOULOS, A. P. et al. Avaliação na área da saúde: conceitos e métodos. In: HARTZ, Z. M. A. (Ed). Avaliação em saúde: dos modelos conceituais à prática na análise da implantação de programas. Rio de Janeiro: Ed. Fiocruz, 1997. p. 29-48.

CONTANDRIOPOULOS, A. P. et al. Avaliação na área da saúde: conceitos e métodos. In: HARTZ,Z. M. A. Avaliação em Saúde. Rio de Janeiro: Ed. Fiocruz, 1997.

CUNHA, A. B. O.; SILVA, L. M. V. Acessibilidade aos serviços de saúde em um município do Estado da Bahia, Brasil, em gestão plena do sistema. Cadernos de Saúde Pública, , Rio de Janeiro, v. 26, n. 4, p. 725-737, 2010.

DENIS, J. L.; CHAMPAGNE, F. Análise da implantação de programas. In: HARTZ, Z. M. A. (Ed). Avaliação em saúde: dos modelos conceituais à prática na análise da implantação de programas. Rio de Janeiro: Ed. FIOCRUZ, 1997. p. 49-88.

EMMI, D. T.; BARROSO, R. F. F. Avaliação das ações de saúde bucal no Programa Saúde da Família no distrito de Mosqueiro, Pará. Ciência \& Saúde Coletiva, Rio de Janeiro,, v. 13, n. 1, p. 35-41, 2008.

FADEL, C. B.; SANDRINI, J. C.; ZARDO, L. N. Avaliação do perfil e grau de satisfação dos usuários dos serviços odontológicos na Estratégia de Saúde da Família, na zona rural do município de Castro/PR. Publ. UEPG Ci. Biol. Saúde, Ponta Grossa, v. 13, n. 3/4, p. 59-66, 2007.

FIGUEIREDO, N.; GOES, P. S. A. Construção da atenção secundária em saúde bucal: um estudo sobre os Centros de Especialidades Odontológicas em Pernambuco, Brasil. Cadernos de Saúde Pública, , Rio de Janeiro, v. 25, n. 2, p. 259-267, 2009.

FRAZÃO, P.; MARQUES, D. Efetividade de programa de agentes comunitários na promoção da saúde bucal. Revista de Saúde Pública., v. 43, n. 3, p. 463-471, 2009.

FURTADO, J. P.; SILVA, L. M. V. da. A avaliação de programas e serviços de saúde no Brasil enquanto espaço de saberes e práticas. Cadernos de Saúde Pública, Rio de Janeiro, v. 30, n. 12, p. 2643-2655, 2014.

GIUDICE, A. M. P.; PEZZATO, L. M.; BOTAZZO, C. Práticas avaliativas: reflexões acerca da inserção da saúde bucal na Equipe de Saúde da Família. Saúde em Debate. Rio de Janeiro, v. 37, n. 96, p. 32-42, 2013.

GOES, P. S. A. de et al. Avaliação da atenção secundária em saúde bucal: uma investigação nos centros de especialidades do Brasil. Caderno de Saúde Pública, Rio de Janeiro, v. 28, supl., p. s81-s89, jan. 2012 .

GUBA, E.; LINCOLN, Y. Fourth generation evaluation. Newsbury Park: Sage, 1989.

HARTZ, Z. M. A. (Org.). Avaliação em saúde: dos modelos conceituais à prática na análise da implantação de programas. 20. ed. Rio de Janeiro: Ed. FIOCRUZ, 1997. 
HARTZ, Z. M. A.; CONTANDRIOPOULOS, A. P. Do quê ao para quê da meta- avaliação em saúde. In: HARTZ, Z. M. A.; FELIZBERTO, E.; SILVA, L. M. V. da. (Org.). Meta - Avaliação da Atenção Básica à Saúde: teoria e prática. Rio de Janeiro: Ed. FIOCRUZ, 2008.

LEVITON, L. C.; HUGHES, E. F. X. Research on the utilization of evaluations: a review and synthesis. Evaluation Review., v. 5, p. 525-547, 1981.

LIMA, A. C. S.; CABRAL, E. D.; VASCONCELOS, M. M. V. B. Satisfação dos usuários assistidos nos Centros de Especialidades Odontológicas do Município do Recife, Pernambuco, Brasil. Cadernos de Saúde Pública, Rio de Janeiro, v. 26, n. 5, p. 991-1002, 2010.

LINO, P. A. et al. Análise da atenção secundária em saúde bucal no estado de Minas Gerais, Brasil. Ciência \& Saúde Coletiva, Rio de Janeiro,, v. 19, n. 9, p. 3879-3888, 2014.

MAGALHÃES, B. G. et al. Avaliação da qualidade dos serviços prestados pelos Centros de Especialidades Odontológicas: visão dos usuários. Cadernos Saúde Coletiva, Rio de Janeiro, v. 23 , n. 1, p. 76-85, 2015 .

MARTELLI, P. J. de L. et al . Análise do modelo de atenção à saúde bucal em municípios do estado de Pernambuco. Ciência \& Saúde Coletiva, Rio de Janeiro, v. 13, n. 5, p. 1669-1674, 2008 .

MATOS, D. L. et al. Projeto Bambuí: avaliação de serviços odontológicos privados, públicos e de sindicato. Revista de Saúde Pública, São Paulo, , v. 36, n. 2, p. 237-243, abr. 2002.

MATUS, C. El PES en la practica. Caracas: Fundación Altadir, 1994.

MEDINA, M. G. et al.Uso de modelos teóricos na avaliação em saúde: aspectos conceituais e operacionais. In: HARTZ, Z. M. A.; SILVA, L. M. V. da. (Org.). Avaliação em saúde: dos modelos conceituais à prática na análise de programas e sistemas de saúde. Salvador: EDUFBA; Rio de Janeiro: Ed. FIOCRUZ. 2005. p. 41- 63.

MIALHE, F. L.; OLIVEIRA, C. S. R.; SILVA, D. D. Acesso e avaliação dos serviços de saúde bucal em uma localidade rural da região sul do Brasil. Arquivos de Ciências da Saúde da Unipar, v. 10, n. 3, p.145-149, set./dez. 2006.

NICKEL, D. A.; CALVO, M. C. M.; CAETANO, J. C. Modelo de avaliação da atenção em saúde bucal. Pesquisa Brasileira em Odontopediatria e Clínica Integrada, João Pessoa, . v. 9, n. 3, p. 373-379, 2009.

PEREIRA, C. R. S. et al. Impacto da Estratégia Saúde da Família sobre indicadores de saúde bucal: análise em municípios do Nordeste brasileiro com mais de 100 mil habitantes.

Cadernos de Saúde Pública, Rio de Janeiro, v. 28, n. 3, p. 449-462, 2012.

PIMENTEL, F. et al. Análise dos indicadores de saúde bucal do Estado de Pernambuco: desempenho dos municípios segundo porte populacional, população cadastrada no Sistema de Informação da Atenção Básica e proporção na Estratégia Saúde da Família. Cadernos Saúde Coletiva, Rio de Janeiro, v. 22, n. 1, p. 54-61, 2014.

PATTON, M. Q. Utilization-focused evaluation.The new century text.Thousands OaksLondon- New Delhi: SAGE Publications, 1997. 
PATTON, M. Q. Qualitative Research \& Evaluation Methods.Thousands Oaks: SAGE Publications, 2002.

REIS, C. et al. Avaliação do serviço de saúde bucal no município de Grão Mogol, Minas Gerais, Brasil: "a voz do usuário". Ciência \& Saúde Coletiva, Rio de Janeiro, , v. 14, n. 4, p. 1287-1295, 2009.

RIBEIRO-SOBRINHO, C.; SOUZA, L. E. P. F.; CHAVES, S. C. L. Avaliação da cobertura do Serviço Odontológico da Polícia Militar da Bahia em Salvador, Bahia, Brasil. Cadernos Saúde Coletiva, Rio de Janeiro, v. 24, n. 2, p. 295-302, 2008.

ROSSI, P. H.; FREEMAN, H. E. Evaluation: a systematic approach. 5th ed. Newbury Park: Sage, 1993.

ROSSI, T. R. A; CHAVES, S. C. L. Implementação da Atenção Especializada em Saúde Bucal em dois municípios na Bahia/Brasil. Saúde debate, Rio de Janeiro, v. 39, n. spe, p.196206, dez. 2015. Diponível em: <http://dx.doi.org/10.5935/0103-1104.2015So05186>. Acesso em: 16 jun. 2016.

SILVA, L. M. V. da.; FORMIGLI, V. L. A. Avaliação em saúde: limites e perspectivas. Cadernos de Saúde Pública, Rio de Janeiro, v. 10, n. 1, p. 80-91, 1994.

SILVA, L. M. V. da. Conceitos, Abordagens e Estratégias para Avaliação em Saúde. In: SILVA, L. M. V. da.; HARTZ, Z. M. A. Avaliação em saúde: dos modelos teóricos à prática na avaliação de programas e sistemas de saúde. Salvador: EDUFBA; Rio de Janeiro: Ed. FIOCRUZ, 2005. p. 15-39.

SOUZA, C. Estado da Arte da Pesquisa em Políticas Públicas. In: HOCHMAN, G.; ARRETCHE, M.; MARQUES, E. Políticas públicas no Brasil. Rio de Janeiro: Ed. FIOCRUZ, 2007.

SOUZA, T. M. S.; RONCALLI, A. G. Saúde bucal no Programa Saúde da Família: uma avaliação do modelo assistencial. Cadernos de Saúde Pública, Rio de Janeiro, v. 23, n. 11, p. 2727-2739, 2007.

VIEIRA-DA-SILVA, L. M.. Avaliação de Políticas e Programas de Saúde. Temas em Saúde Coletiva. Rio de Janeiro: Ed. FIOCRUZ; 2014.

WEISS, C. H. Evaluation: methods for studing programs and policies. 2. ed. UpperSaddle River, NJ: Prentice Hall, 1998.

WHOLEY, J. S. Evaluability assessment. $2^{\text {nd }}$ ed. San Francisco: Jossey-Bass, 2004. 


\section{Posfácio}

Foi com grande satisfação que recebi os originais para elaborar o posfácio da obra Política de saúde bucal no Brasil: teoria e prática, organizada por Sônia Cristina Lima Chaves, professora que combina admiravelmente bem as qualidades do trinômio docência-pesquisa-extensão, tão necessárias para a universidade pública comprometida com a inclusão e o exercício de direitos sociais, aspectos crescentemente desvalorizados pelos que reduzem a universidade a uma mera organização prestadora de serviços referenciados por metas que lhe assegurem uma posição favorável num ambiente competitivo.

Ao criar um observatório de análise política em saúde onde as políticas de saúde bucal figuram como um eixo temático, os pesquisadores do Instituto de Saúde Coletiva da Universidade Federal da Bahia (UFBA) respondem a uma reconhecida necessidade de proporcionar um espaço de reflexão e análise crítica das políticas de saúde no Brasil, através da articulação de uma rede de investigadores da área de Política, Planejamento e Gestão em Saúde (PPGS) proveniente de diversos centros de pesquisa. Além disso, oferecem um dispositivo de interação para todos os interessados em aprofundar a compreensão relativa às políticas de saúde bucal em curso nos diferentes territórios, considerando que estudos de áreas temáticas específicas contribuem dialeticamente para a renovação da teoria de subáreas e disciplinas afins do campo interdisciplinar da Saúde Coletiva.

A Saúde Bucal Coletiva (SBC) é um movimento teórico-político com origem na Reforma Sanitária brasileira que tem inspirado transformações relevantes nos processos de formação de profissionais e trabalhadores em diferentes níveis da educação, nas políticas de saúde bucal, incluindo os serviços odontológicos, e na 
produção de conhecimentos científicos. O conteúdo do livro percorrido pelo leitor confirma essa assertiva representando uma contribuição significativa para a renovação da teoria da SBC enquanto área temática pertencente ao campo interdisciplinar da Saúde Coletiva. A diversidade de temas e enfoques, e o rigor com que são abordados, oferecem aos leitores referentes teóricos fundamentais, tanto para aprofundar a formação crítica e científica dos profissionais e trabalhadores da saúde, quanto para subsidiar a reflexão sobre as limitações das políticas e dos serviços organizados para responder às necessidades de saúde bucal das populações.

Contando com 26 autores, o conteúdo do livro foi distribuído em 13 capítulos, sendo os dois primeiros de caráter introdutório e os demais abordando temas específicos de análise das políticas de saúde bucal. O leitor que decodificou cada página do livro foi recompensado com capítulos que sintetizaram parte importante da produção científica nacional analisando o grau de extensão e profundidade com que as políticas de saúde bucal se fazem presentes na agenda, na formulação, na implementação e na avaliação das políticas de saúde no Brasil (capítulos 1 e 13), abrangendo o discurso e as ações sob determinados governos em nível federal nos anos 1970 e 1980 (capítulo 3) e entre 1999 e 2006 (capítulo 4), e também políticas específicas de atenção primária e secundária implementadas na primeira década do século XXI (capítulos 6 e 7). Situando o debate, capítulo sobre abordagens teóricas de análise política em saúde é foco do capítulo 1. Além disso, um capítulo analisou condicionantes sociais e históricos relacionados à emergência do espaço da SBC nos anos 1980 no Brasil (capítulo 5) e à configuração do espaço da odontologia social na Bahia entre os anos 1940 e 1960 (capítulo 12). Complementam a publicação quatro capítulos sistematizando conhecimentos, identificando tendências e aspectos críticos sobre a distribuição das doenças e agravos em saúde bucal (capítulo 2), a utilização de serviços odontológicos (capítulo 7), a educação em saúde bucal do trabalhador (capítulo 10), a questão do TSB (capítulo 11). E o mercado de trabalho odontológico (capítulo 9).

Entretanto, a elaboração de um posfácio, é menos apresentar o seu conteúdo, tarefa presumivelmente cumprida pelo prefácio, e mais compartilhar com os autores e os leitores da obra um conjunto de considerações que emergiram após a leitura do seu corpo. Nesse sentido, um primeiro aspecto que salta aos olhos do leitor é a abrangência do objeto. As políticas públicas de saúde bucal não se restringem às proposições de ações específicas da área odontológica, usualmente voltadas aos serviços de assistência odontológica individual, mas envolvem sobretudo as ações intersetoriais, sendo o exemplo mais conhecido a política de fluore- 
tação da água de abastecimento público que mobiliza diferentes setores entre os quais o meio ambiente, saneamento, planejamento urbano. Além disso, abrangem também as ações que produzem efeitos, intencionais ou não, sobre a saúde bucal das populações, sendo a queda da cárie dentária em decorrência das políticas de racionamento do consumo do açúcar durante a Segunda Guerra Mundial um fenômeno que ilustra bem a questão.

O conhecimento científico acerca das conexões entre as condições sistêmicas e a saúde bucal, e de ambas com a qualidade de vida, tem aumentado nos últimos anos, levando a uma crescente convicção de que o manejo das condições crônicas sistêmicas não pode dispensar a assistência odontológica como parte da produção do cuidado se o objetivo é alcançar um nível de qualidade de atenção à saúde compatível com o volume de evidências científicas correntes. Assim, tanto nas ações de atenção primária quanto nas ações de atenção especializada e hospitalar, a participação da equipe de saúde bucal integrada à equipe multiprofissional pode ser tomada como um importante componente de qualificação da atenção à saúde proporcionada por sistemas de saúde bem estruturados.

Como parte da agenda política internacional de saúde pública, a fluoretação da água de consumo tem sido objeto de muitos estudos e pesquisas abordando diferentes aspectos a ela relacionados, por mobilizar diferentes setores, entre os quais, o meio ambiente, saneamento, planejamento urbano, e uma diversidade de agentes políticos, entre os quais, autoridades governamentais, parlamentares, lideranças comunitárias e representantes de empresas e organizações. Aspectos relacionados às fontes para obtenção da água, à cobertura da rede de abastecimento, à aceitação da população em consumi-la, e à repartição dos custos do seu tratamento e distribuição, tanto pelo Estado quanto pela sociedade, são temas geradores de intensas disputas e debates em torno das políticas públicas de saúde e saneamento.

Um segundo aspecto a destacar é o caráter multidisciplinar do campo das políticas públicas no qual se destacam, de forma mais nuclear, as disciplinas de Ciência Política, Sociologia e Administração Pública, em relação a outras que aportam conhecimentos relativamente mais específicos como as disciplinas de História, Economia, Geografia e Direito. Em decorrência, o avanço da produção teórica atinente às políticas de saúde, incluindo as de saúde bucal, dependerá em grande medida da capacidade dos centros de pesquisa em impulsionar a pesquisa interdisciplinar, o que significa ultrapassarmos a onipresença do discurso acerca da sua necessidade, identificando e superando em cada realidade concreta as barreiras 
existentes, como por exemplo, as dificuldades para compartilhar e reconhecer as diferenças de linguagens, métodos, e objetivos das várias disciplinas, bem como os constrangimentos institucionais e profissionais para a prática interdisciplinar.

A despeito do crescimento expressivo da literatura científica na área de PPGS, nota-se ainda um predomínio dos estudos voltados à análise das políticas que orientam a ação do Estado em detrimento da análise das relações de poder que dão sustentação a essas orientações nos diferentes espaços sociais. A busca de uma maior consistência acadêmico-científica nos trabalhos de investigação da área é importante para não limitar a produção de conhecimentos à agenda de pesquisa das agências governamentais.

A elevação do número de programas de pós-graduação em Saúde Coletiva ocorrida nas duas últimas décadas, combinado ao crescente ingresso nos programas de profissionais não médicos, entre os quais dentistas, tem propiciado condições para que temas de interesse da saúde bucal coletiva sejam abordados, tanto sob o enfoque das Ciências Sociais e Humanas em Saúde quanto sob o referencial da PPGS, ainda que haja o predomínio da epidemiologia no volume total da produção abrangendo as três subáreas do campo interdisciplinar da Saúde Coletiva.

Embora Política de saúde bucal no Brasil: teoria e prática tenha reunido conhecimentos produzidos principalmente no âmbito dos programas de pós-graduação da UFBA, por pesquisadores majoritariamente a eles vinculados, o exame da relação de referências ao final de cada capítulo oferece ao leitor uma amostra da vitalidade da literatura científica relacionada à área temática sob o enfoque da PPGS produzida no país nos últimos anos. A organização do livro oferece um panorama sucinto de como diferentes recortes teóricos, temáticos e empíricos podem ser articulados para a análise política em saúde bucal, contribuindo de forma relevante para adensar o conhecimento sobre as políticas públicas de saúde bucal junto aos estudantes, pesquisadores e demais profissionais interessados.

Paulo Frazão

MAIO DE 2016 


\section{Sobre os autores}

Ana Carla Freitas Fonseca - Mestre em Saúde Comunitária pelo Instituto de Saúde Coletiva da Universidade Federal da Bahia. Gestor da Secretaria Estadual de Saúde da Bahia.

Ana Carolina Oliveira Peres - Mestre em Odontologia, área de concentração em Saúde Coletiva, pela Universidade Federal de Santa Catarina (UFSC). Doutoranda em Odontologia, área de concentração em Odontologia em Saúde Coletiva, pela UFSC.

Ana Maria Freire de Lima Almeida - Dentista. Mestranda em Saúde Comunitária. Instituto de Saúde Coletiva da Universidade Federal da Bahia.

Catharina Matos Soares - Professora adjunta do Instituto de Saúde Coletiva da Universidade Federal da Bahia (ISC/UFBA). Doutora em Saúde Pública pelo ISC/ UFBA na área de concentração em Planificação e Gestão de Serviços e Sistemas de Saúde.

Daniela Carcereri - Professora associada da Faculdade de Odontologia da Universidade Federal de Santa Catarina (UFSC). Docente do Programa de Pós-graduação em Odontologia da UFSC e da Residência Multiprofissional em Saúde da Família.

Diana Carolina Ruiz - Formada em Odontologia na Universidade Nacional da Colômbia. Mestranda em Saúde Coletiva no Instituto de Saúde Coletiva da Universidade Federal da Bahia. 
Denise Nogueira Cruz - Dentista Sanitarista. Doutora em Saúde Pública pelo Instituto de Saúde Coletiva da Universidade Federal da Bahia (UFBA). Professora e pesquisadora do Departamento de Odontologia Social e Pediátrica da Faculdade de Odontologia da UFBA.

Dulce Maria de Lucena Aguiar - Doutora em Saúde Publica pela Universidade de São Paulo. Professora e assessora pedagógica do curso de Odontologiada da Universidade de Fortaleza.

Jairnilson Silva Paim - Professor titular de Política de Saúde do Instituto de Saúde Coletiva da Universidade Federal da Bahia. Pesquisador 1-B do Conselho Nacional de Desenvolvimento Científico e Tecnológico.

Johelle de Santana Passos Soares - Doutora em Saúde Pública pelo Instituto de Saúde Coletiva da Universidade Federal da Bahia (UFBA). Professora adjunta da Faculdade de Odontologia da UFBA.

Lana Bleicher - Doutora em Ciências Sociais pelo Programa de Pós-Graduação em Ciências Sociais da Universidade Federal da Bahia (UFBA). Professora adjunta da Faculdade de Odontologia da UFBA.

Lucília Nunes de Assis - Mestre em Medicina Comunitária pelo Instituto de Saúde Coletiva da Universidade Federal da Bahia. Analista em Educação e Pesquisa em Saúde da Escola de Saúde Pública de Minas Gerais. Doutoranda em Saúde Coletiva pelo Centro de Pesquisas René Rachou /Fundação Oswaldo Cruz.

Maria Beatriz Barreto de Sousa Cabral - Doutora em Saúde Pública pela Universidade Federal da Bahia, professora associada da Faculdade de Odontologia da Universidade Federal da Bahia.

Maria Cristina Teixeira Cangussu - Doutora em Saúde Pública pela Universidade de São Paulo, professora e pesquisadora do Departamento de Odontologia Social e Pediátrica da Faculdade de Odontologia da Universidade Federal da Bahia.

Maria Guadalupe Medina - Médica, mestre em Saúde Comunitária e doutora em Saúde Pública, docente do Programa de Pós-Graduação em Saúde Coletiva e 
da Residência Multiprofissional em Saúde da Família do Instituto de Saúde Coletiva da Universidade Federal da Bahia. Membro da Rede de Pesquisa em Atenção Primária e do grupo de trabalho de Avaliação da Associação Brasileira de Saúde Coletiva.

Maria Isabel Pereira Vianna - Doutora em Saúde Pública pela Universidade Federal da Bahia (UFBA). Professora associada da Faculdade de Odontologia da UFBA.

Mariangela Silva de Matos - Dentista. Doutora em Educação pela Faculdade de Educação da Universidade Federal da Bahia (UFBA). Professora associada da Faculdade de Odontologia da UFBA.

Mona Lisa Nunes de Souza - Graduada em História pela Faculdade de Ciências Humanas e Sociais da Universidade Federal da Bahia.

Patrícia Suguri Cristino - Professora assistente da Faculdade de Odontologia da Universidade Federal da Bahia. Mestre em Odontologia Restauradora pela Universidade de São Paulo.

Paulo Frazão - Doutor em Saúde Pública pela Universidade de São Paulo (USP). Livre docente pela USP. Professor titular da Faculdade de Saúde Pública da USP. Pesquisador 2 do Conselho Nacional de Desenvolvimento Científico e Tecnológico e consultor do Ministério da Saúde (MS). Coordenador de projetos do Centro Colaborador do MS em Vigilância em Saúde Bucal da Faculdade de Saúde Pública da USP.

Sandra Garrido de Barros - Doutora em Saúde Pública pelo Instituto de Saúde Coletiva da Universidade Federal da Bahia (UFBA). Professora adjunta da Faculdade de Odontologia da UFBA.

Samuel Jorge Moysés - Professor titular da Pontifícia Universidade Católica do Paraná. Professor adjunto da Universidade Federal do Paraná. Consultor do Ministério da Saúde em Vigilância em Saúde Bucal. Philosophiae Doctor (PhD) em Epidemiologia e Saúde Pública pela Universidade de Londres, Inglaterra. 
Sônia Cristina Lima Chaves - Doutora em Saúde Pública pelo Instituto de Saúde Coletiva da Universidade Federal da Bahia (ISC/UFBA). Professora associada da Faculdade de Odontologia da UFBA. Professora do Programa de Pós-Graduação em Saúde Coletiva do ISC/UFBA.

Stella Maris Malpici Luna - Nutricionista. Doutora em Saúde Pública pelo Instituto de Saúde Coletiva da Universidade Federal da Bahia. Secretaria Estadual de Saúde de Mato Grosso.

Tatiana Frederico de Almeida - Professora adjunta da Escola Bahiana de Medicina e Saúde Pública. Cirurgiã-Dentista da Secretaria Municipal de Saúde de Salvador-Ba. Doutora em Saúde Pública pelo Instituto de Saúde Coletiva da Universidade Federal da Bahia.

Thais Regis Aranha Rossi - Professora da Universidade do Estado da Bahia. Mestre em Saúde Comunitária pelo Instituto de Saúde Coletiva da Universidade Federal da Bahia. 


\begin{tabular}{r|l} 
& Colofão \\
Formato & $175 \times 240 \mathrm{~mm}$ \\
Tipografia & Freight \\
Papel & Alcalino $75 \mathrm{~g} / \mathrm{m}($ miolo) \\
& Cartão Supremo $300 \mathrm{~g} / \mathrm{m}$ (capa) \\
Impressão & Edufba \\
Acabamento & Cian Gráfica \\
Tiragem & 500 exemplares
\end{tabular}

